
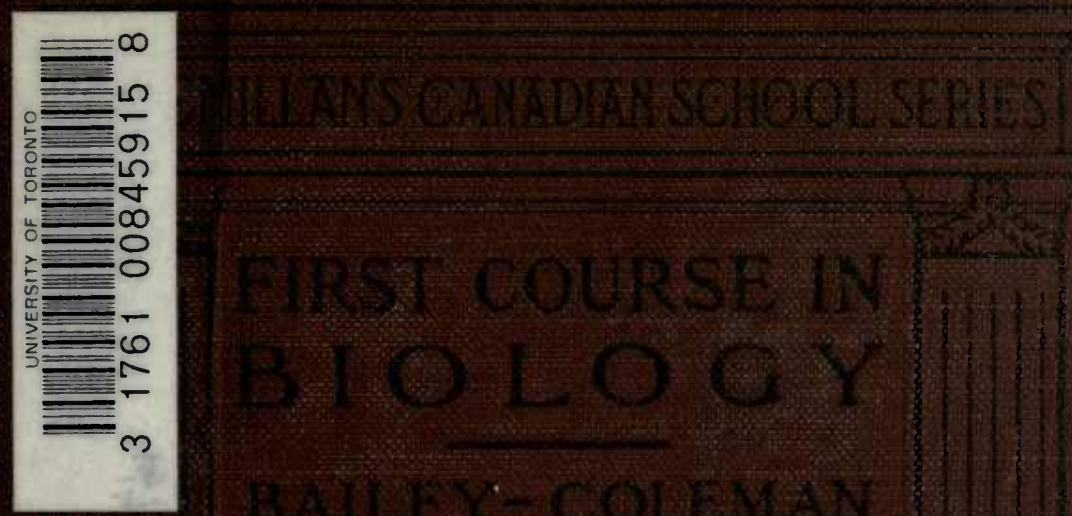


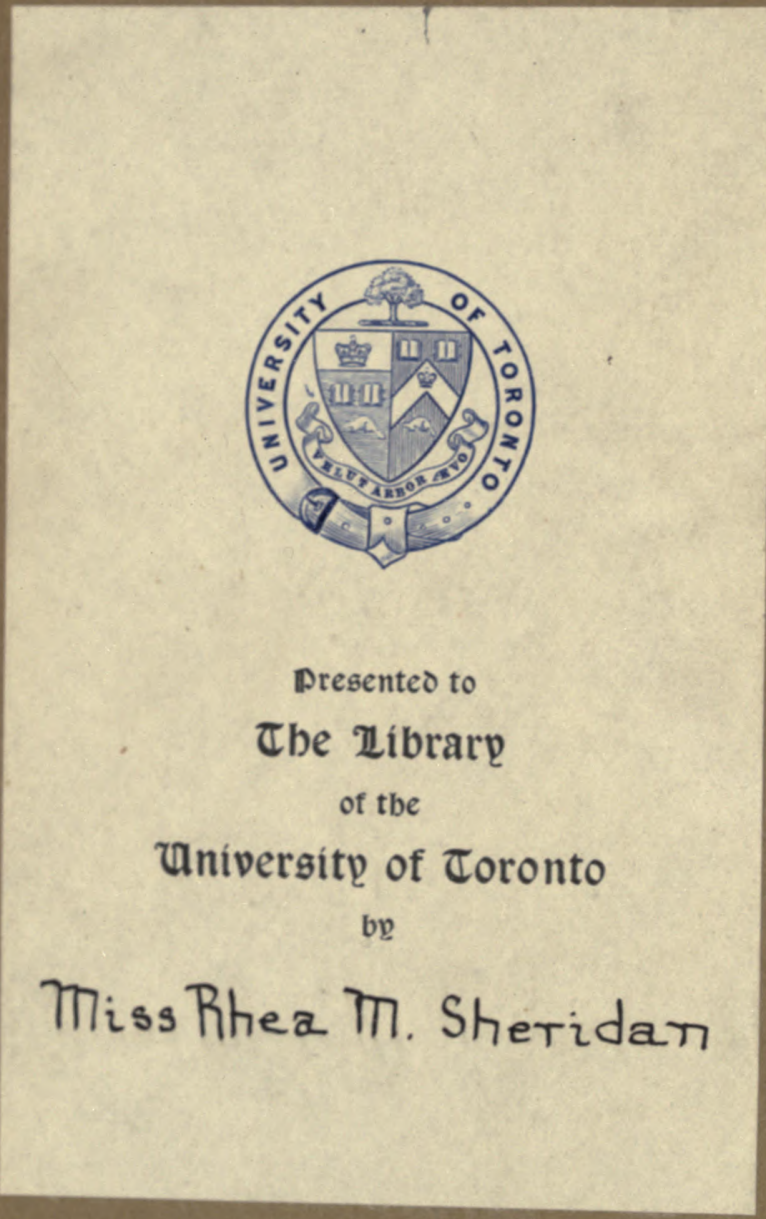




FIRST COURSE IN BIOLOGY 


$$
\begin{aligned}
& \because \because x=\text { The } \\
& \text { THE MACMILLAN COMPANY } \\
& \text { NEW YORK - BOSTON - CHICAGO } \\
& \text { ATLANTA - SAN FRANCISCO } \\
& \text { MACMILLAN \& CO., Limited } \\
& \text { LONDON - BOMBAY - CALCUTTA } \\
& \text { MELBOURNE }
\end{aligned}
$$


ophea ty eldred shend 


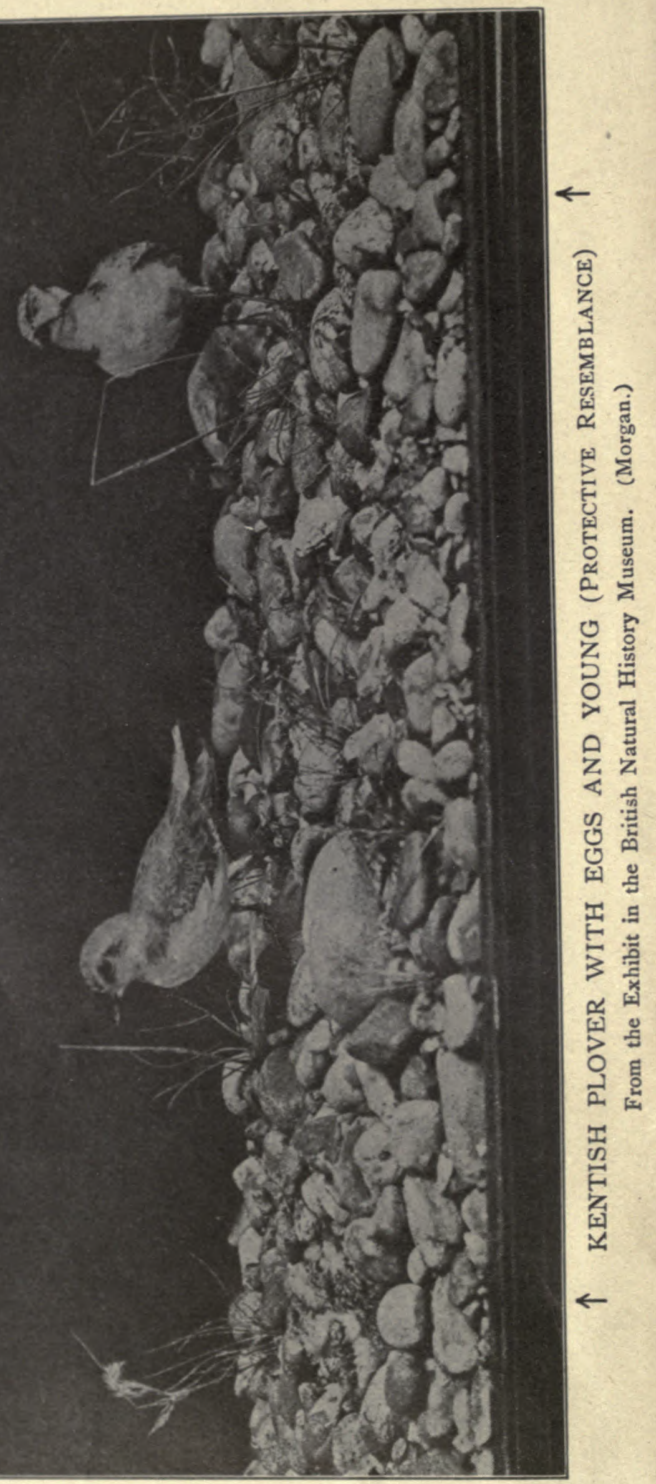




\title{
FIRST COURSE IN BIOLOGY
}

\author{
BY \\ L. H. BAILEY \\ PART I. PLANT BIOLOGY \\ P(D) \\ WALTER 'M. COLEMAN \\ PART II. ANIMAL BIOLOGY \\ PART III. HUMAN BIOLOGY
}

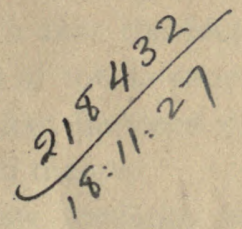

TORONTO

THE MACMILLAN CO. OF CANADA, LTD. 


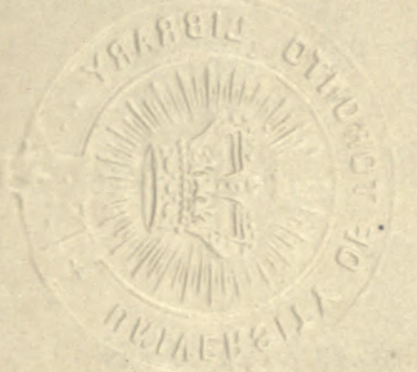

Copvright, rgo8,

By THE MACMILLAN COMPANY.

Set up and electrotyped. Published July, rgo8. Reprinted October, 1908: February, September, 1909 ; January, 1910; May, rgr3; May, 1914. 


\section{PREFACE}

THE present tendency in secondary education is away from the formal technical completion of separate subjects and toward the developing of a workable training in the activities that relate the pupil to his own life. In the natural science field, the tendency is to attach less importance to botany and zoology and physiology as such, and to lay greater stress on the processes and adaptations of life as expressed in plants and animals and men. This tendency is a revolt against the laboratory method and research method of the college as it has been impressed into the common schools, for it is not uncommon for the pupil to study botany without really knowing plants, or physiology without knowing himself. Education that is not applicable, that does not put the pupil into touch with the living knowledge and the affairs of his time, may be of less educative value than the learning of a trade in a shop. We are coming to learn that the ideals and the abilities should be developed out of the common surroundings and affairs of life rather than imposed on the pupil as a matter of abstract, unrelated theory.

One of the marks of this new tendency in education is the introduction of unit courses in biology in the secondary schools, in the place of the formal and often dry and nearly meaningless isolated courses in botany, zoology, and physiology. This result is one of the outcomes of the recent nature-study discussions.

The present volume is an effort to meet the need for 
a simple and untechnical text to cover this secondary biology in its elementary phases. The book stands between the unorganized nature-study of the intermediate grades and the formal science of the more advanced courses. It is a difficult space to bridge, partly because the subjects are so diverse, and partly because some teachers do not yet understand the importance of imparting to beginners a general rather than a special view point.

Still another difficulty is the lack of uniformity in the practice of different schools. It is not urged that it is desirable to have uniformity in all respects, but the lack of it makes it difficult to prepare a book that shall. equally meet all needs. It is hoped, however, that the present book is fairly adaptable to a variety of conditions, and with this thought in mind the following suggestions are made as to its use :

Being in three separate parts, the teacher may begin with plants, or with animals, or with human physiology.

If a one-year course is desired, the topics that are printed in large type in Parts II and III may be used, and a choice from the chapters in Part I.

For three half-year courses, all the parts may be covered in full.

If the course in biology begins in the fall (with the school year), it may be well to study plant biology two days in the week and animal biology three days until midwinter; when outdoor material becomes scarce, human biology may be followed five days in the week; in spring, plants may be studied three days and animals two days.

If the use of the book is begun at midyear, it will probably be better to follow the order in the book consecutively. 
If it is desired to take only a part of the plant biology, Chapters VI, XIV, XX, XXIII, XXIV may be omitted, and also perhaps parts of other chapters (as of X, XII, XIII) if the time is very short. The important point is to give the pupil a rational conception of what plants are and of their main activities; therefore, the parts that deal with the underlying life processes and the relation of the plant to its surroundings should not be omitted.

If more work is wanted it is best to provide the extra work by means of the study of a greater abundance of specimens rather than by the addition of more texts; but the teacher must be careful not to introduce too much detail until the general subject has first been covered.

The value of biology study lies in the work with the actual things themselves. It is not possible to provide specimens for every point in the work, nor is it always desirable to do so; for the beginning pupil may not be able to interest himself in the objects, and he may become immersed in details before he has arrived at any general view or reason of the subject. Great care must be exercised that the pupil is not swamped. Mere book work or memory stuffing is useless, and it may dwarf or divert the sympathies of active young minds.

Every effort should be made to apply the lessons to daily life. The very reason for knowing plants and animals is that one may live with them, and the reason for knowing oneself is that he may live his daily life with some degree of intelligence. The teacher should not be afraid to make all teaching useful and practical.

In many cases a state syllabus designates just what subjects shall be covered; the topics may be chosen easily from the text, and the order of them is usually left largely to the discretion of the teacher. 
Finally, let it be repeated that it is much better for the beginning pupil to acquire a real conception of a few central principles and points of view respecting common forms that will enable him to tie his knowledge together and organize it and apply it, than to familiarize himself with any number of mere facts about the lower forms of life which, at the best, he can know only indirectly and remotely. If the pupil wishes to go farther in later years, he may then take up special groups and phases. 


\section{CONTENTS}

General Introduction

PAGE
$\mathrm{xi}$

PART I. PLANT BIOLOGY

CHAPTER

I. No Two Plants or Parts are Alike.

II. The Struggle to Live • • • • • • 4

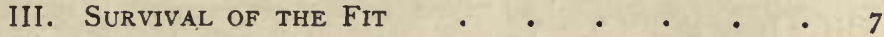

IV. Plant Societies • • • • • • • 9

V. The Plant Body • • . . . • . I5

Vi. Seeds and Germination . • • • • . 20

VII. The Root - The Forms of RoOTs • • . . 32

VIII. The Root-Function and Structure • • • 38

IX. The Stem - Kinds and Forms-Pruning • . 49

X. The Stem - Its General Structure - • 59

XI. Leaves - Form AND Position • • • • 73

XII. Leaves - Structure and Anatomy • • • 86

XIII. LEAVES - FUNCTION OR WORK • • • • $\quad 92$

XIV. Dependent Plants . . . . . . . 106

XV. Winter and Dormant Buds • . • . . III

XVI. BUd Propagation • . . • . • . III

XVII. How Plants Climb . . . . • . . I29

XVIII. The Flower - Its Parts and Forms • • . I33

XIX. The Flower-Fertilization and Pollination • 144

XX. Flower-Clusters • • • • • • • 155

XXI. FRUITS • • • • • • • • • I63

XXII. DisPersal OF SEEdS . . . • • . . I72

XXIII. Phenogams and CRyptogams . . . • 176

XXIV. Studies in CRyptogams . . . • • . I8z 


\section{PART II. ANIMAL BIOLOGY}

CHAPTER

I. INTRODUCTION

II. Protozons

III. SPONGES .

IV. POLYPS

V. ECHINODERMS

VI. WORMS .

ViI. Crustaceans .

VIII. INSECTS .

IX. Mollusks

X. Fishes • • • • • • • • • • 109

XI. Batrachians . • • • • • . 126

XII. Reptiles • • • • • • • • • 139

XIII. BIRDS . • • • • • • • •

XIV. Mammals . . . . . . . . . I84

\section{PART III. HUMAN BIOLOGY}

I. INTRODUCTION

II. The SKIn AND Kidneys • . • • • • 16

III. The Skeleton • • • • • • • . 29

IV. The Muscles • . • . • • • 39

V. The Circulation . . . . . . . . 51

Vi. The Respiration . . . . . . . . 70

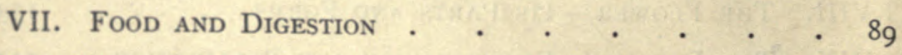

VIII. The Nervous System . . . . . . . 117

IX. The Senses . . . . . . . . . . . 142

X. Bacteria and Sanitation . . . . $15^{8}$ General Index 


\section{GENERAL INTRODUCTION}

\section{PRELIMINARY EXPERIMENTS}

These experiments are inserted for those pupils who have not had instruction in chemistry and physics, to give them a point of view on the subjects that follow. At least a general understanding of some of these subjects is necessary to a satisfactory elementary study of biology.

Elements and Compounds. - The material world is made up of elements and compounds. An element is a substance that cannot be separated into two or more substances. A compound is formed by the union of two or more elements. All the material or substance of which the earth and its inhabitants is composed is formed of the chemical elements; this substance taken all together is known as matter.

Carbon and iron are examples of elements. Compare a bit of charcoal, which is one form of carbon, with a new iron nail. Which is brighter? Heavier for its size? Tougher? More brittle? Harder? More readily combustible? Resistant to change when left exposed to air and dampness? There are two other forms of carbon: graphite or black lead (used in pencils and stove polish); and diamond, which occurs in crystals and is the hardest known substance. Iron does not have varied forms like carbon. Sulfur is another element. What is its color? Has it odor? Taste? Will it dissolve in water? Is it heavy or light? Will it burn? What is the color of the flame? Of the fumes? Phosphorus, another element, 
burns so readily that it ignites by friction and is used in matches. Rub the tip of a match with the finger. What is the odor of phosphorus? Phosphorus exists in nature only in combination with other elements. Lead, tin, silver, gold, copper, zinc, nickel, platinum, are elements.

There are less than eighty known elements ; but the compounds formed of them are innumerable. Carbon is found in all substances formed by the growth of living things. That there is carbon in sugar, for example, can easily be shown by charring it on a hot shovel or a stove until its water is driven off and only charcoal is left. Part of the starch in a biscuit remains as charcoal when it has been half burned.

Favorable and Unfavorable Conditions for Evaporation. - Pour the same quantity of water (half a glassful) into three saucers and two bottles. Place one saucer near a hot stove; place the other two in a cool place, having first covered one of them with a dish. Place one of the bottles by the stove and the other by the remaining saucers. After some hours, examine the saucers and bottles and compare and record the results. Explain. State three conditions that are favorable to evaporation. State three ways in which evaporation may be prevented or decreased.

Tests for Acid, Alkaline, and Neutral Substances. - For acid tests, use sour buttermilk (which contains lactic acid), or hydrochloric acid diluted in ten parts water, or strong vincgar (which contains acetic acid). Has the acid a characteristic ("sour") odor and taste (test it only when very dilute)? Rub dilute acid between the fingers; how does it feel? Is there any effect on the fingers? Obtain litmus paper at a druggist's. Dip a strip of red litmus and of blue litmus paper into the acid. What result?

For alkaline tests, dissolve in a glass of water a spoonful 
of baking soda or some laundry soap; or dissolve an inch stick of caustic soda in a glass of water. Test odor and "feel" of last solution as with the acid; likewise test effect of alkaline solution on red and blue litmus paper. Record results. Alkalies are strong examples of a more general class of substances called bases, which have the opposite effect from acids.

Test pure water. Has it odor? A taste? Test it with red and blue litmus paper. Water is a neutral substance; that is, it is neither an acid nor an alkali (or base).

After making appropriate tests, write $a c, a l$, or neu after each name in the following list (or write in three columns): vinegar, soda, saliva, sugar, juice of apple, lemon, and other fruits, milk, baking powder, buttermilk, ammonia, salt water.

Pour some of the alkaline solution into a dish, gradually add dilute acid (or sour buttermilk), stirring with glass rod and testing with litmus until the mixture does not turn red litmus blue nor blue litmus red. The acid and alkali are then said to have neutralized each other, and the resulting substance is called a salt. The salt may be obtained by evaporating the water of the solution. Most common minerals are salts. If the last experiment is tried with soda and sour buttermilk, the demonstration will show some of the facts involved in bread making with the use of these substances.

Tests for Starch. - Starch turns blue with iodine. The color may be driven away by heat, but will return again as the temperature lowers. Produce a few cents' worth of tincture of iodine and dilute it. Get a half dozen pieces of paper and cardboard, all different, and test each for starch by placing it over mouth of bottle and tipping the bottle up. If much starch is present, the spot will be blue-black 
or dark blue; if little starch, pale blue; if no starch, brown or yellowish.

Make pastes with wheat flour, potato starch, and corn starch. Treat a little of each with a solution of rather dilute tincture of iodine. Try grains from crushed rice with the same solution. Are they the same color? Cut a thin section from a potato, treat with iodine and examine under the microscope.

To study Starch Grains. - Mount in cold water a few grains of starch from each of the following: potato, wheat, arrowroot (buy at drug store), rice, oats, corn. Study under microscope the sizes, forms, layers, fissures, and location of nuclei, and make a drawing of a few grains of each.

Test for Grape Sugar. - Make a thick section of a bit of the edible part of a pear and place it in a bath of Fehling's solution. After a few moments boil the liquid containing the section for one or two minutes. It will turn to an orange color, showing a deposit of an oxid of copper and perhaps a little copper in the metallic form. A thin section treated in like manner may be examined under the microscope, and the fine particles, precipitated from the sugar of the pear, may be clearly seen. (Fehling's solution is made by taking one part each of these three solutions and two parts of water: (1) Copper sulfate, 9 grams in 250 cubic centimeters of water; (2) sodium hydroxid, 30 grams in 250 c.c. water; (3) Rochelle salts, 43 grams in 250 c.c. water.)

Test for Nitrogenous Substances, or Proteids. - Put a little white of egg into a test tube and heat slowly. What change takes place in the egg? Put another part of the white of egg into a test tube and add dilute nitric acid. Compare the results of the two experiments. White of egg is an example of a proteid; that is, it is the form of nitrogen most 
commonly found in plant and animal tissue, and it can be formed only by life processes. Do acid and heat harden or soften most substances? Either of the above tests reveals proteid, if present. Does cooking tend to soften or toughen lean meat?

Another test for proteid is nitric acid, which turns proteid (and hardly anything else) yellow. Proteid when burned has a characteristic odor; this will be noticed if lean meat or cheese is charred in a spoon. The offensive odor from decomposing proteid is also characteristic, whether it comes from stale beans, meat, mushrooms, or other things containing proteid.

Test for Fats and 0ils. - Place a little tallow from a candle on unglazed paper and warm. Hold the paper up to the light and examine it. What effect has the fat had on the paper? Place a little starch, sugar, powdered chalk, or white of egg on paper and repeat the experiment; is the effect the same? Place some of the tallow in a spoon, and heat. Compare the effect of heat on fat and proteid. Water also makes paper semi-transparent, but it soon evaporates: fat does not evaporate.

Another test for fats is to mount a thin section of the endosperm of castor-oil seed in water and examine with high power. Small drops of oil will be quite abundant. Treat the mount with alcanin (henna root in alcohol). The drops of oil will stain red. This is a standard test for fats and oils.

To make or liberate 0xygen. - If there is a chemistry class in school, one of its members will doubtless be glad to prepare some of the gas called oxygen, and furnish several glass jars filled with it to the biology class. If it is desired to make oxygen, the following method may be employed: Provide a dry glass flask of three to four 
ounces capacity. It should have a glass delivery tube, inserted through a one-holed rubber stopper, and so bent as to pass under the surface of water contained in a decp dish. Fill several pint fruit-jars with water, cover with pieces of stiff pasteboard, and turn mouth downwards in the dish of water. From one half to two thirds ounce of an equal mixture of potassium chlorate and manganese dioxid (procured at drug store) is put in the flask and heated by means of a gas or alcohol lamp. When the oxygen begins to form, collect some in jars by inserting the end of delivery tube under the jars as they stand in water. Caution: Remove delivery tube from water before cooling the flask, to prevent any water being drawn back.

Oxygen and the Air. - The great activity of pure oxygen in attacking other substances can be shown by passing into a fruit-jar a lighted splinter, a piece of lighted magnesium ribbon, an old watch spring (or a bit of picture wire), the end of which has been dipped in sulfur and lighted. About one fifth of the air is oxygen and about four fifths is nitrogen and other inactive gases. Pure nitrogen will quickly extinguish a lighted splinter thrust into it. It is the oxygen in the air that supports all forms of burning. Less than one half of one per cent of the air is an inactive gas called carbon dioxid, a compound of carbon and oxygen. It is formed not only when wood or coal is burned, but also by the life processes of animals and plants.

Oxidation. - That something besides wood or coal is necessary to a fire can be shown by shutting off entirely the draught of a stove. Fire and other forms of combustion depend on a process called oxidation. This consists in the uniting of oxygen with other substances. When 
wood decays, the carbon in it oxidizes (unites with oxygen) and carbon dioxid gas is formed. When wood burns, the oxidation is more rapid. When iron oxidizes, iron rust is formed. When hydrogen is oxidized, water is formed. Kerosene oil contains hydrogen, and water is formed when it is burned. Almost every one has noticed the cloud of moisture which collects on the chimney when the lamp is first lighted. By using a chimney which has been kept in a cold place, the moisture becomes apparent; soon the chimney becomes hot and the water no longer collects, but it continues to pass into the room as long as the lamp burns. Fats also contain hydrogen. Hold a piece of cold glass or an inverted tumbler above the flame of a tallow candle. Does water collect on it?

Oxidation may be said to be the basis of all life processes for this reason : oxidation gives rise to heat and sets free energy, and all living things need heat and energy in order to grow and live. The heat of animals is very noticeable. The oxidation in plants also forms a slight amount of heat. In both animals and plants oxidation is much slower than in ordinary fires. That heat is formed even in slow oxidation is shown by fires which arise spontaneously in masses of decaying material. The rotting of wood is not only accompanied by heat but sometimes by light, as when "fox fire" is emitted. Rub the end of a match on your finger in the dark. Explain the result. Strike a match and notice the white fumes which rise for an instant. These fumes are not ordinary smoke (particles of carbon), but they are oxid of phosphorus. Why will water (oxid of hydrogen) not burn? Sand is oxid of silicon. Explain how throwing sand on a fire puts it out. [See also experiments with candle and breath, in Introduction to Human Biology.] 
Inorganic and Organic Matter. - Test for Minerals. The earth was once in a molten condition, which would have destroyed any combustible material if any had then existed. Before plants and animals existed, the earth consisted mostly of incombustible minerals, known as inorganic matter. Substances formed by animals and plants are organic matter, so called because built up by organized or organ-bearing or living things; starch is an example, being formed in plants. Organic substances are composed chiefly of carbon, oxygen, hydrogen, and nitrogen. (See page I of "Animal Biology.") Coal-oil, and all combustible materials have their origin in life. Hence, burning to find whether there is an incombustible residue is also a test for mincrals. Meat, bread, oatmeal, bone, wood, may be tested for mineral matter by burning in a spoon held over a hot fire, or flame of gas or lamp. The substance being tested should be burned until all black material (which is organic carbon and not a mineral) has disappeared. Any residue will be mineral matter.

Protoplasm. - Inside the cells of plants and animals is the living substance, known as protoplasm. It is a structureless, nearly or quite colorless, transparent jelly-like substance of very complex and unstable composition. Eighty per cent or more is water; the remainder is proteid, fats, oils, sugars, and salts. Protoplasm has the power of growth and reproduction; it can make living substance from dead or lifeless substances. It has the pozver of movcment within the cell, and it is influenced (or is irritable) by heat, light, touch, and other stimuli. When protoplasm dies the organism dies.

Physics is the science that treats of the properties and phenomena (or behavior) of matter or of objects; as of such properties or phenomena or agencies as heat, light, 
force, electricity, sound, friction, density, weight, and the like.

Chemistry is the science that treats of the composition of matter. All matter is made up, as we have seen, of elements. Very few elements exist in nature in a free or uncombined form. The nitrogen and oxygen of the air are the leading uncombined elements.

In order to express the chemical combinations clearly, symbols are used to represent each element, and these symbols are then combined to represent the proportions of each in the compound. If $\mathrm{C}$ stands for carbon and $\mathrm{O}$ for oxygen, the carbon dioxid might be represented by the formula COO. In order to avoid the repetition of any letter, however, a number is used to denote how many times the element is taken: thus the formula always used for carbon dioxid is $\mathrm{CO}_{2}$. The formula for hydrogen oxid, or water, is $\mathrm{H}_{2} \mathrm{O}$; that for starch is $\mathrm{C}_{6} \mathrm{H}_{10} \mathrm{O}_{5}$. N stands for nitrogen; $\mathrm{P}$, for phosphorus; $\mathrm{K}$, potassium; Fe, iron; S, sulfur.

Biology is the science that treats of life; that is, of all knowledge of plants and animals of all kinds. (See page I, “Animal Biology.”)

\section{How a Candle Burns}

Some of the foregoing suggestions may be readily explained and illustrated by simple experiments with a burning candle. The following directions for such experiments are by G. W. Cavanaugh.

The materials needed for this exercise are: a piece of candle about two inches long, a lamp chimney (one with a plain top is best), a piece of white crockery or window glass, a piece of fine wire about six inches long, a bit of quicklime about half the size of an egg, and some matches. . All of these, with the possible exception of the quicklime, can be obtained in any household. 
If you perform the experiment requiring the lime, be sure that you start with a fresh piece of quick or stone lime, which can be had of any lime or cement dealer. During the performance of the following simple experiments, the pupil should describe what he sees at each step. The questions inserted in the text are offered merely as suggestions in the development of the desired ideas. The answers are those which it is desired the pupils shall reach or confirm by their own observation.

\section{Oxygen}

Light the candle and place it on a piece of blotting paper $(A)$. What do you see burning? Is anything burn-

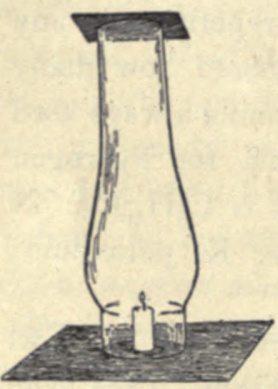

A. - THE BeginNing OF the Candle ExPERIMENT. ing besides the candle? The answer will probably be "no." Let us see.

Place the lamp chimney over the lighted candle, and partly cover the top by a piece of stiff paper, as in Fig. A. Ask the pupils to observe and describe how the flame goes out; i.e. that it is gradually extinguished and does not go out instantly. Why did the flame go out? The probable thought will be, "Because there was no air." (If there was no air within the chimney, some could have entered at the top.)

Place two pencils beside the relighted candle and on them the chimney $(B)$. What is the difference between the way in which the candle burns now and before the chimney was placed over it? It flickers, or dances about more. What makes

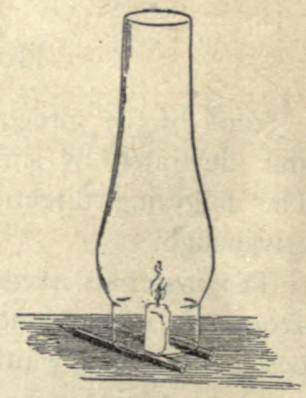

B. - SUPPLyING AIR UNDERNEATH THE CHIMNEY. 
boys and girls feel like dancing about when they go out from a warm schoolroom? What makes the flame dance or flicker when the chimney is raised by the pencils? Because it gets fresh air under the chimney.

Repeat the first experiment, in which the flame grows gradually smaller till it is extinguished. Why does the flame die out now? Is it really necessary to have fresh air in order to keep a flame burning?

To prove this further, let the candle be relighted. Place the chimney over it, now having the top completely closed by a piece of paper. Have ready a lighted splinter or match, and just as soon as the candle is extinguished remove the paper from the chimney top and thrust in the lighted splinter. Why does the light on the splinter go out? What became of the freshness that was in the air? It was destroyed by the burning candle.

Evidently there is some decided difference between unburned air and burned air, since a flame can continue to burn only in air that has the quality known as freshness. This quality of fresh air is due to oxygen, represented by $O$. Why was the splinter put out instantly, while the candle flame died out gradually? When the splinter was thrust in, the air had no freshness or oxygen at all, while when the candle was placed under the chimney, it had whatever oxygen was originally in the air within the chimney.

Endeavor to have this point clearly understood: that the candle did not go out as long as the air had any oxygen and that the splinter was extinguished immediately because there was no oxygen left.

Relight the candle. A former question may now be repeated: Is anything else burning besides the candle?

When the subject of the necessity of fresh air and consequently of oxygen for the burning of the candle seems 
to be understood, the following questions, together with any others which suggest themselves, may be asked: What is the reason that draughts are opened in stoves? Why is the bottom of a "burner" on a lamp always full of holes?

\section{Carbon}

Let us now observe the blackened end of a burned match or splinter. This black substance is usually known by the name of charcoal. If handled, it will blacken the fingers. Try this. The same substance is found on the bottoms of kettles which have been used over a wood fire, but it is there a fine powder.

Let us see what was burning when the candle was lighted, besides the oxygen in the air. Relight the candle

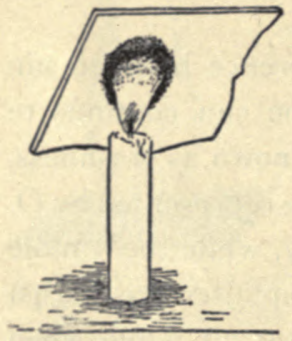

C.-THE Carbon (OR

SOOT) IS DEPOSITED ON THE GLASS.

and hold the porcelain or glass about an inch above the bright part of the flame. What happens to it there? Next, lower it directly into the flame $(C)$. What is the black stuff that gets on the glass? Look closely and see whether it is not deposited here also as a fine powder. Will this deposit from the candle blacken the fingers?

Instead of using the name charcoal for this black substance, let us call it carbon, the better name, because there are several kinds of carbon, and charcoal is only that kind which is rather light and easily blackens the hands.

The carbon from the candle flame came mostly from the wax or tallow; only a very small part came from the wick. It cannot be seen in the tallow, neither can it be seen in 
unburned wood, and yet it can be found when the wood is partly burned.

Why, now, is the glass blackened when held in the flame and not when held directly above it? It is because the carbon from the candle has not been completely burned at the middle of the flame; but it is burned beyond the bright part of the flame. When the glass is held in the flame, the carbon that is not yet completely burned is deposited on it, because it is cooler than that in the surrounding flame.

A fine deposit of carbon can be had from any of the luminous parts of the flame; and it is these thousands of little particles of carbon, getting white hot, which glow like coals in the stove and make the light. Just as soon as they are completely burned, there is no more light, as coals cease to glow when burned to ashes.

\section{Carbon dioxid}

Let us now inquire what becomes of the carbon that we find in the bright part of the flame and of the oxygen that was in the air in the lamp chimney. When the candle was extinguished within the chimney, there was no oxygen left, as shown by the lighted splinter, which was put out immediately. Neither could any of the particles of carbon be found except on the wick. Yet they both still exist within the chimney, but in an entirely different condition. While the candle was burning, the little particles of carbon that we find ascending in the flame are joining with the oxygen of the air and making an entirely new substance. This new substance is a gas and cannot be seen in the air.

Of what two substances is this new substance made? It is $\mathrm{CO}_{2}$. 
Place a bit of quicklime in about half a glass of water on the day previous to the experiment. When ready for use there will be a white sediment at the bottom and a thin

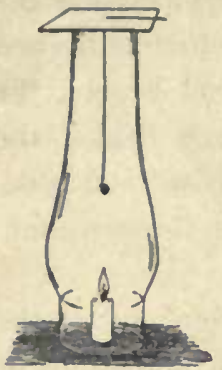

D. - ТиЕ TEST WITH THE SUSPENDED FILM OF LIMEWATER. white scum on the top of the clear limewater. The pupils should see this white scum, as a question about it will follow. Make a loop in the end of the piece of wire by turning it around the point of a lead pencil. Remove the scum from the limewater with a piece of paper and insert the loop into the clear water. When withdrawn, the loop ought to hold a film of clear water. Pass the wire through a piece of cardboard or stiff paper, and arrange as shown in $D$.

Place the chimney over the lighted candle. Lower the loop into the chimney and cover the top of the chimney with the paper. Withdraw the wire two minutes after the candle goes out. Note the cloudy appearance of the film of water on the wire. The cloudiness was caused by the carbon dioxid formed while the candle was burning.

Omitting the candle, hang the freshly wetted wire in the empty chimney. Let the film of limewater remain within the chimney for the same length of time as when the candle was used. It does not become cloudy now. The cloudiness in clear limewater is a test or indication that carbon dioxid is present.

What caused the white scum on the limewater which stood overnight?

How does the $\mathrm{CO}_{2}$ get into the air? It is formed whenever wood, coal, oil, or gas is burned.

The amount of $\mathrm{CO}_{2}$ in ordinary air is very small, being only three parts in ten thousand. If the limewater in the 
loop be left long enough in the air, it will become cloudy. The reason it clouds so quickly when the candle is being burned is that a large amount of $\mathrm{CO}_{2}$ is formed. Besides being made by real flames, $\mathrm{CO}_{2}$ is formed every time we breathe out air. Renew the film of water in the loop and breathe against it gently for two or three minutes.

The presence of $\mathrm{CO}_{2}$ in the breath may be shown better by pouring off some of the clear limewater into a clean glass and blowing into it through a straw.

Why does water put out a fire? The answer is, not alone because it wets and shuts off the supply of free oxygen, but because it cools the carbon, which must be hot in order to unite with the oxygen, and prevents the oxygen of the air from getting as near the carbon as before. 



\title{
PLANT BIOLOGY
}

\author{
CHAPTER I
}

NO TWO PLANTS OR PARTS ARE ALIKE

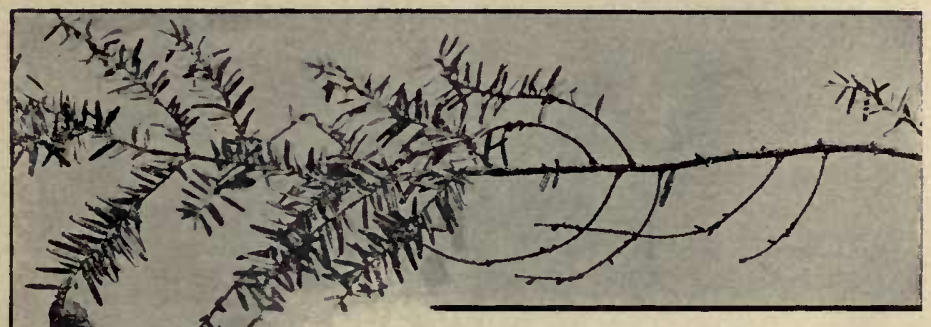

FIG. I. - No Two BRANChes ARE Al.IkE. (Hemlock.)

If one compares any two plants of the same kind ever so closely, it will be found that they differ from each other. The difference is apparent in size, form, color, mode of branching, number of leaves, number of flowers, vigor, season of maturity, and the like; or, in other words, all plants and animals z'ary from an assumed or standard type.

If one compares any two branches or twigs on a tree, it will be found that they differ in size, age, form, vigor, and in other ways (Fig. I).

If one compares any two leaves, it will be found that they are unlike in size, shape, color, veining, hairiness, markings, cut of the margins, or other small features. In some cases (as in Fig. 2) the differences are so great as to be readily seen in a small black-and-white drawing. 
If the pupil extends his observation to animals, he will still find the same truth; for probably no two living objects are exact duplicates. If any person finds two objects that he thinks to be exactly alike, let him set to work to

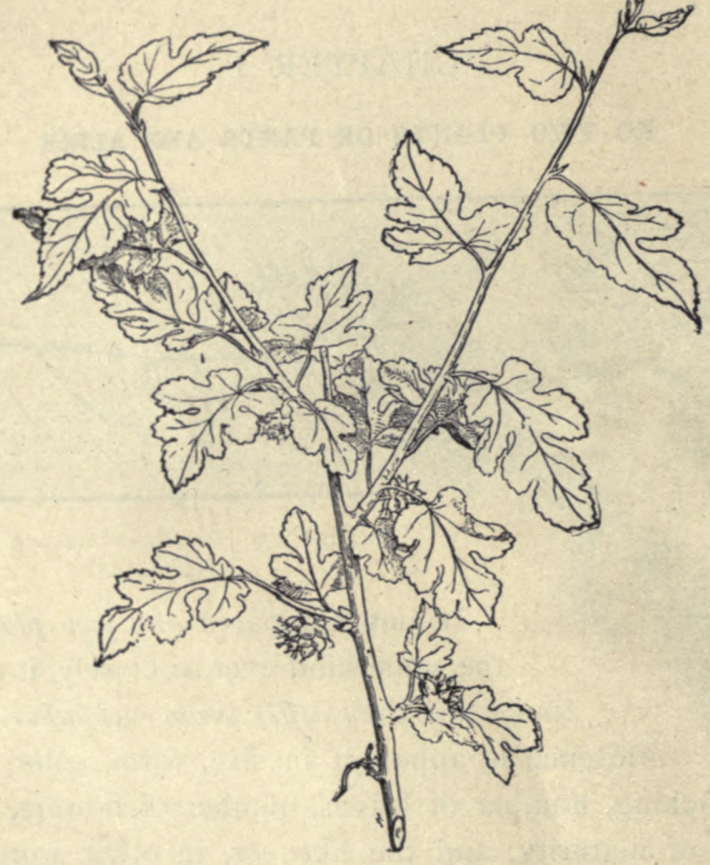

Fig, 2. - No Two Leaves ARE Alike.

discover the differences, remembering that nothing in nature is so small or apparently trivial as to be overlooked.

Variation, or differences between organs and also between organisms, is one of the most significant facts in nature.

SugGestions. - The first fact that the pupil should acquire about plants is that no two are alike. The way to apprehend this great fact is to see a plant accurately and then to compare it with 
another plant of the same species or kind. In order to direct and concentrate the observation, it is well to set a certain number of attributes or marks or qualities to be looked for. 1. Suppose any two or more plants of corn are compared in the following points, the pupil endeavoring to determine whether the parts exactly agree. See that the observation is close and accurate. Allow no guesswork. Instruct the pupil to measure the parts when size is involved:

(I) Height of the plant.

(2) Does it branch? How many secondary stems or "suckers" from one root?

(3) Shade or color.

(4) How many leaves?

(5) Arrangement of leaves on stem.

(6) Measure length and breadth of six main leaves.

(7) Number and position of ears; color of silks.

(8) Size of tassel, and number and size of its branches.

(9) Stage of maturity or ripeness of plant.

(Io) Has the plant grown symmetrically, or has it been crowded by other plants or been obliged to struggle for light or room?

(I I) Note all unusual or interesting marks or features.

(I2) Always make note of comparative vigor of the plants.

Note to Teacher. - The teacher should always insist on personal work by the pupil. Every pupil should handle and stuay the object by himself. Books and pictures are merely guides and helps. So far as possible, study the plant or animal just where it growes naturally.

Notebooks. - Insist that the pupils make full notes and preserve these notes in suitable books. Note-taking is a powerful aid in organizing the mental processes, and in insuring accuracy of observation and record. The pupil should draw what he sees, even though he is not expert with the pencil. The drawing should not be made for looks, but to aid the pupil in his orderly study of the object ; it should be a means of self-expression.

Laboratory. - Every school, however small, should have a laboratory or work-room. This work-room may be nothing more than a table at one side of the room where the light is good. Here the specimens may be ranged and studied. Often an aquarium and terrarium may be added. A cabinet or set of shelves should be provided for a museum and collection.

The laboratory may be in part out of doors, as a school garden ; or the garden may be at the pupil's home, and yet be under the general direction of the teacher. 


\section{CHAPTER II}

\section{THE STRUGGLE TO LIVE}

Every plant and animal is exposed to unfavorable conditions. It is obliged to contend with these conditions in order to live.

No two plants or parts of plants are identically exposed to the conditions in which they live. The large branches

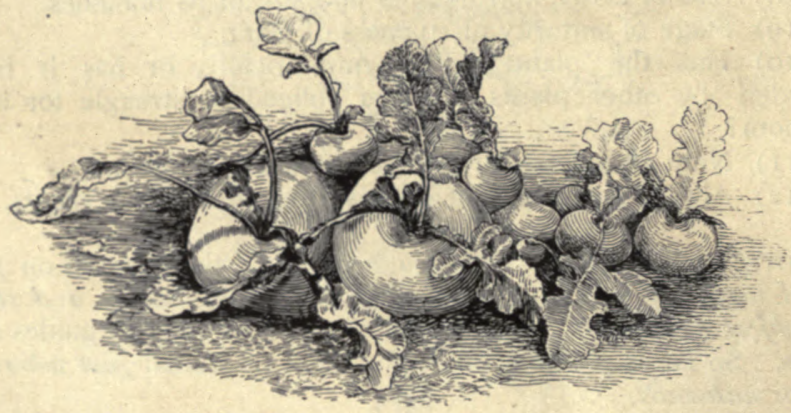

Fig. 3.-A BATtLe FOR Life.

in Fig. I probably had more room and a better exposure to light than the smaller ones. Probably no two of the leaves in Fig. 2 are equally exposed to light, or enjoy identical advantages in relation to the food that they receive from the tree.

Examine any tree to determine under what advantages or disadvantages any of the limbs may live. Examine similarly the different plants in a garden row (Fig. 3); or the different bushes in a thicket; or the different trees in a wood. 
The plant meets its conditions by succumbing to them (that is, by dying), or by adapting itself to them.

The tree meets the cold by ceasing its active growth, hardening its tissues, dropping its leaves. Many herbaceous or soft-stemmed plants meet the cold by dying to the ground and withdrawing all life into the root parts. Some plants meet the cold by dying outright and providing abundance of seeds to perpetuate the kind next season.

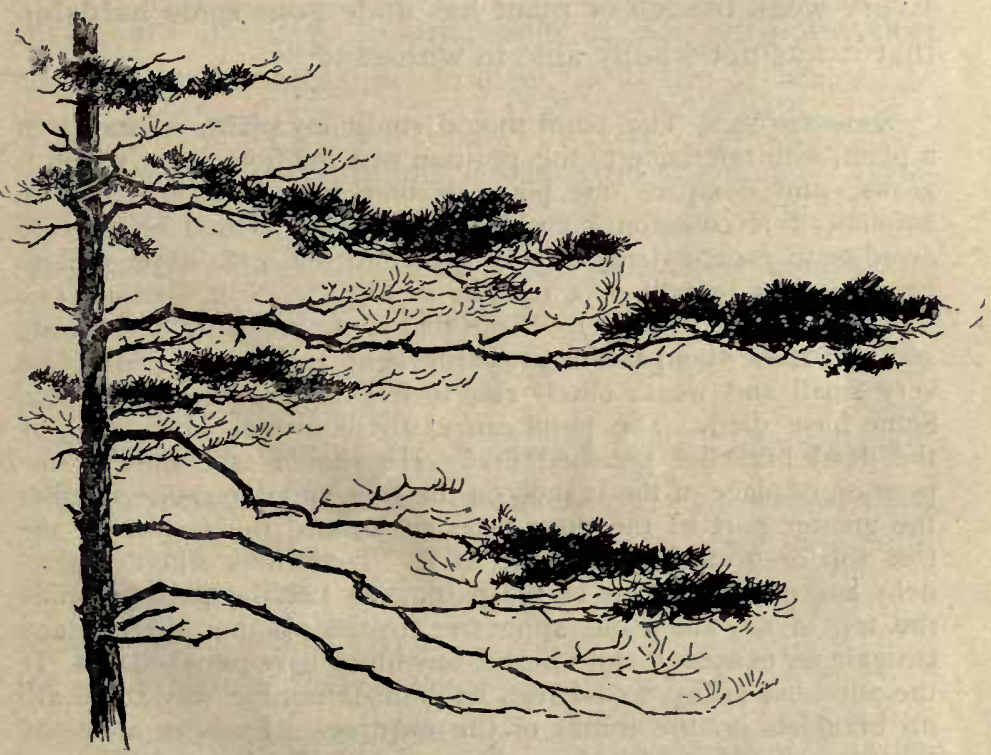

Fig. 4. - The Reacil For Light OF a TREe ON THE EdGe OF a WOOD.

Plants adapt themselies to light by growing toward it (Fig. 4); or by hanging their leaves in such position that they catch the light; or, in less sunny places, by expanding their leaf surface, or by greatly lengthening their stems so as to overtop their fellows, as do trees and vines.

The adaptations of plants will afford a fertile field of study as we proceed. 
Struggle for existence and adaptation to conditions are among the most significant facts in nature.

The sum of all the conditions in which a plant or an animal is placed is called its environment, that is, its surroundings. The environment comprises the conditions of climate, soil, moisture, exposure to light, relation to food supply, contention with other plants or animals. The organism adapts itself to its environment, or else it weakens or dies. Every weak branch or plant has undergone some hardship that it was not wholly able to withstand.

SugGestrons. - The pupil should study any plant, or branch of a plant, with reference to the position or condition under which it grows, and compare one plant or branch with another. With aninals, it is common knowledge that every animal is alert to avoid or to escape danger, or to protect itself. 2. It is well to begin with a branch of a tree, as in Fig. I. Note that no two parts are alike (Chap. I). Note that some are large and strong and that these stand farthest towards light and room. Some are very small and weak, barely able to live under the competition. Some have died. The pupil can easily determine which ones of the dead branches perished first. He should take note of the position or place of the branch on the tree, and determine whether the greater part of the dead twigs are toward the center of the tree top or toward the outside of it. Determine whether accident has overtaken any of the parts. 3. Let the pupil examine the top of any thick old apple tree, to see whether there is any struggle for existence and whether any limbs have perished. 4. If the pupil has access to a forest, let him determine why there are no branches on the trunks of the old trees. Examine a tree of the same kind growing in an open field. 5. A row of lettuce or other plants sown thick will soon show the competition between plants. Any fence row or weedy place will also show it. Why does the farmer destroy the weeds among the corn or potatoes? How does the florist reduce competition to its lowest terms? what is the result? 


\section{CHAPTER III}

\section{THE SURVIVAL OF THE FIT}

THE plants that most perfectly meet their conditions are able to persist. They perpetuate themselves. Their offspring are likely to inherit some of the attributes that enabled them successfully to meet the battle of life. The fit (those best adapted to their conditions) tend to survive.

Adaptation to conditions depends on the fact of variation; that is, if plants were perfectly rigid or invariable (all exactly alike) they could not meet new conditions. Conditions are necessarily new for every organism. It is impossible to picture a perfectly inflexible and stable succession of plants or animals.

Breeding. - Man is able to modify plants and animals. All our common domestic animals are very unlike their original ancestors. So all our common and long-cultivated plants have varied from their ancestors. Even in some plants that have been in cultivation less than a century the change is marked : compare the common black-cap raspberry with its common wild ancestor, or the cultivated black- Fig. 5.-Desirable and Undesirable berry with the wild form.

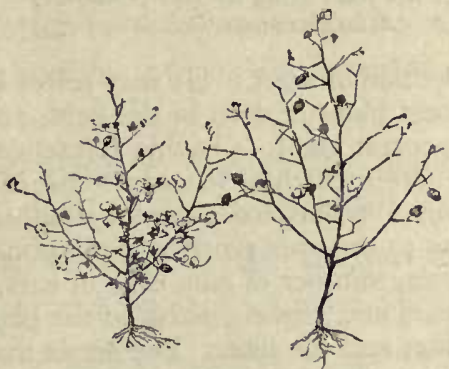

TyPES OF COTTON Plants. Why?

By choosing seeds from a plant that pleases him, the breeder may be able, under given conditions, to produce 


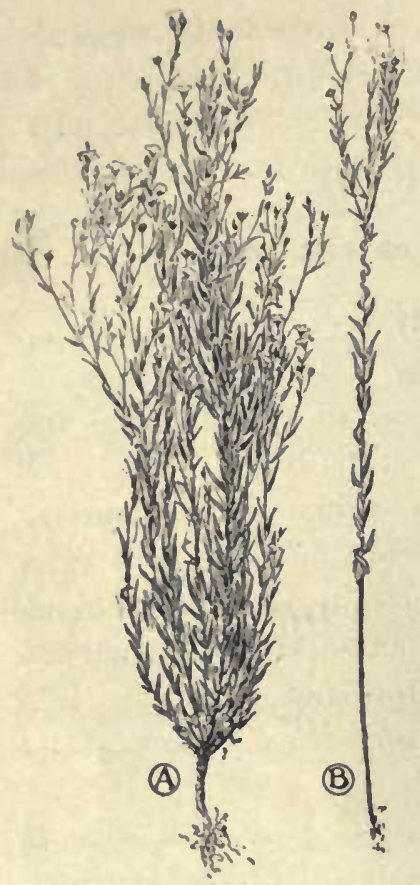

FiG. 6. - FlaA BREediNG.

$A$ is a plant grown for seed production; $B$, for fiber production. Why ? numbers of plants with more or less of the desired qualities; from the best of these, he may again choose; and so on until the race becomes greatly improved (Figs. 5, 6, 7). This process of continuously choosing the most suitable plants is known as selection. A somewhat similar process proceeds in wild nature, and it is then known as natural selection.

Suggestions. -6. Every pupil should undertake at least one simple experiment in selection of seed. He may select kernels from the best plant of corn in the field, and also from the poorest plant, - having reference not so much to mere incidental size and vigor of the plants that may be due to accidental conditions in the field, as to the apparently constitutional strength and size, number of ears, size of ears, perfectness of ears and kernels, habit of the plant as to suckering, and the like. The seeds may be saved and sown the next year. Every crop can no donbt be very greatly improved by a careful process of selection extending over a series of years. Crops are increased in yield or efficiency in three ways : better general care ; enriching the land in which they grow; attention to breeding.

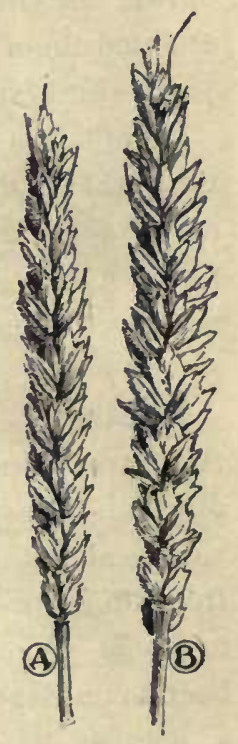

FIG. 7.- BREEDING.

$A$, effect from breeding from smallest grains (after four years), average head; $B$, result from breeding from the plumpest and heaviest grains (after four years), average head. 


\section{CHAPTER IV}

\section{PLANT SOCIETIES}

In the long course of time in which plants have been accommodating themselves to the varying conditions in which they are obliged to grow, they have become adapted to every different environment. Certain plants, therefore, may live together or near each other, all enjoying the same general conditions and surroundings. These aggregations of plants that are adapted to similar general conditions are known as plant societies.

Moisture and temperature are the leading factors in determining plant societies. The great geographical societies or aggregations of the plant world may conveniently be associated chiefly with the moisture. supply, as: wet-region societics, comprising aquatic and bog vegetation (Fig. 8); arid-region societies, comprising desert and most sand-region vegetation; mid-region societies, comprising the mixed vegetation in intermediate regions (Fig. 9), this being the commonest type. Much of the characteristic scenery of any place is due to its plant societies. Arid-region plants usually have small and hard leaves, apparently preventing too rapid loss of water. Usually, also, they are characterized by stiff growth, hairy covering, spines, or a much-contracted plant-body, and often by large underground parts for the storage of water.

Plant societies may also be distinguished with reference to latitude and temperature. There are tropical societies, temperate-region societies, borcal or cold-region societies. 
With reference to altitude, societies might be classified as lowland (which are chiefly wet-region), intermediate (chiefly mid-region), subalpine or mid-mountain (which are chiefly boreal), alpine or high-monntain.

The above classifications have reference chiefly to great geographical floras or societies. But there are societies within societies. There are small societies coming within the experience of every person who has ever seen plants

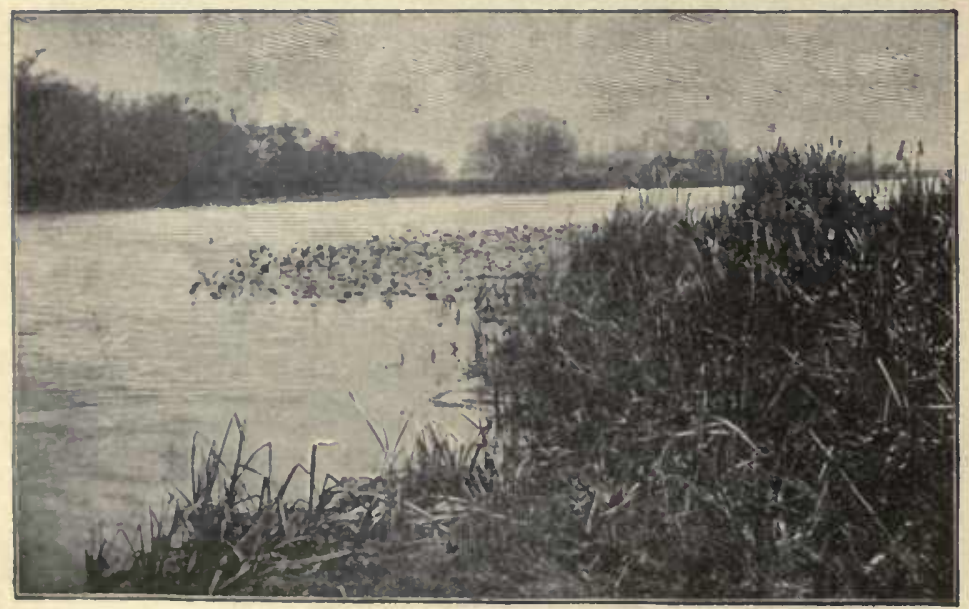

Fig. 8. - A WET-REgION SOCIETY.

growing in natural conditions. There are roadside, fencerow, lawn, thicket, pasture, dune, woods, cliff, barn-yard societies. Every different place has its characteristic vegetation. Note the smaller societies in Figs. 8 and 9. In the former is a water-lily society and a cat-tail society. In the latter there are grass and bush and woods societies.

Some Details of Plant Societies. - Societies may be composed of scattered and intermingled plants, or of dense clumps or groups of plants. Dense clumps or groups are usually made up of one kind of plant, and they are then 
called colonies. Colonies of most plants are transient: after a short time other plants gain a foothold amongst them, and an intermingled society is the outcome. Marked exceptions to this are grass colonies and forest colonies, in which one kind of plant may hold its own for years and centuries.

In a large newly cleared area, plants usually first establish themselves in dense colonies. Note the great patches

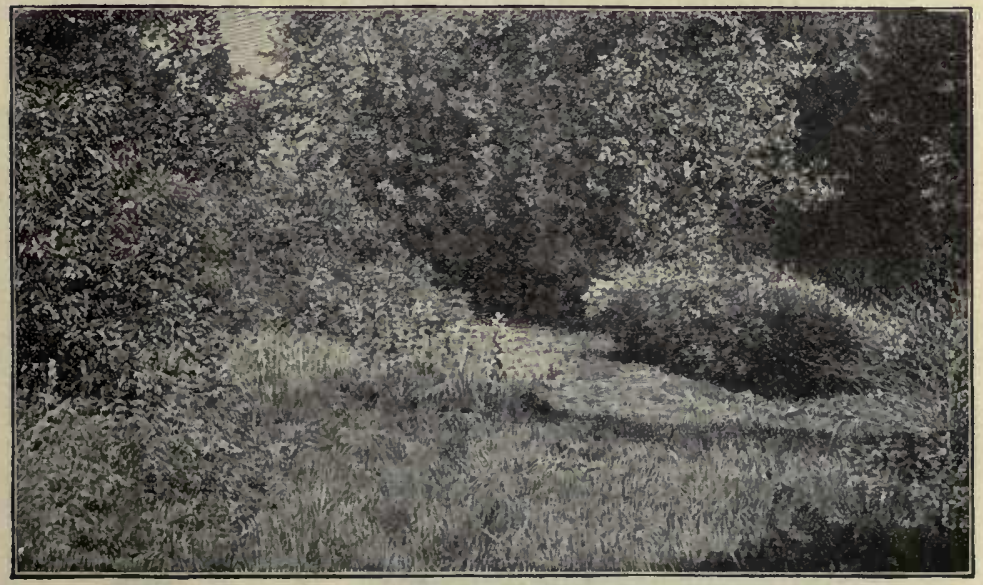

FIG. 9.-A MID-REGION SOCIETY.

of nettles, jewel-weeds, smart-weeds, clot-burs, fire-weeds in recently cleared but neglected swales, also the fire-weeds in recently burned areas, the rank weeds in the neglected garden, and the ragweeds and May-weeds along the recently worked highway. The competition amongst themselves and with their neighbors finally breaks up the colonies, and a mixed and intermingled flora is generally the result.

In many parts of the world the general tendency of neglected areas is to run into forest. All plants rush for the 
cleared area. Here and there bushes gain a foothold. Young trees come up; in time these shade the bushes and gain the mastery. Sometimes the area grows to poplars or birches, and people wonder why the original forest trees do not return; but these forest trees may be growing unobserved here and there in the tangle, and in the slow processes of time the poplars perish - for they are short-lived - and the original forest may be replaced. Whether one kind of forest or another returns will depend partly on the kinds that are most seedful in that vicinity and which, therefore, have sown themselves most profusely. Much depends, also, on the kind of undergrowth that first springs up, for some young trees can endure more or less shade than others.

Some plants associate. They grow together. This is possible largely because they diverge or differ in charac-

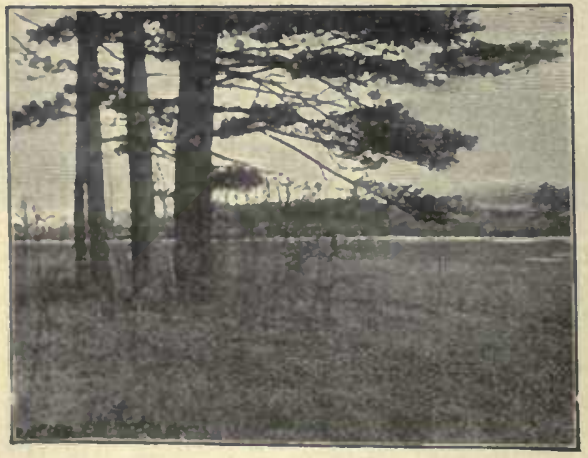

FIG. IO. - OVERGROWTH AND UNDERGROWTH IN THREE SERIFS, - trees, bushes, grass. ter. Plants associate in two ways: by growing side by side; by growing above or beneath. In sparsely populated societies, plants may grow alongside each other. In most cases, however, there is overgrowth and undergrowth:

one kind grows beneath another. Plants that have become adapted to shade are usually undergrowths. In a cattail swamp, grasses and other narrow-leaved plants grow in the bottom, but they are usvally unseen by the casual 
observer. Note the undergrowth in woods or under trees (Fig. IO). Observe that in pine and spruce forests there is almost no undergrowth, partly because there is very little light.

On the same area the societies may differ at different times of the year. There are spring, summer, and fall societies. The knoll which is cool with grass and strawberries in June may be aglow with goldenrod in September. If the bank is examined in May, look for the young plants that are to cover it in July and October; if in September, find the dead stalks of the flora of May. What succeeds the skunk cabbage, hepaticas, trilliums, phlox, violets, buttercups of spring? What precedes the wild sunflowers, ragweed, asters, and goldenrod of fall?

The Landscape. - To a large extent the color of the landscape is determined by the character of the plant societies. Evergreen societies remain green, but the shade of green varies from season to season; it is bright and soft in spring, becomes dull in midsummer and fall, and assumes a dull yellow-green or a black-green in winter. Deciduous societies vary remarkably in color - from the dull browns and grays of winter to the brown greens and olive-greens of spring, the staid greens of summer, and the brilliant colors of autumn.

The autumn colors are due to intermingled shades of green, yellow, and red. The coloration varies with the kind of plant, the special location, and the season. Even in the same species or kind, individual plants differ in color; and this individuality usually distinguishes the plant year by year. That is, an oak which is maroon red this autumn is likely to exhibit that range of color every year. The autumn color is associated with the natural maturity and death of the leaf, but it is most brilliant in long and open 
falls - largely because the foliage ripens more gradually and persists longer in such seasons. It is probable that the autumn tints are of no utility to the plant. Autumn colors are not caised by frost. Because of the long, dry falls and the great variety of plants, the autumnal color of the American landscape is phenomenal.

Ecology. - The study of the relationships of plants and animals to each other and to seasons and environments is known as ecology (still written $a c o l o g y$ in the dictionaries). It considers the habits, habitats, and modes of life of living things - the places in which they grow, how they migrate or are disseminated, means of collecting food, their times and seasons of flowering, producing young, and the like.

Suggestions. - One of the best of all subjects for school instruction in botany is the study of plant societies. It adds definiteness and zest to excursions. 7. Let each excursion be confined to one or two societies. Visit one day a swamp, another day a forest, another a pasture or meadow, another a roadside, another a weedy field, another a cliff or ravine. Visit shores whenever possible. Each pupil should be assigned a bit of ground - say 1o or $20 \mathrm{ft}$. square - for special study. He should make a list showing (I) how many kinds of plants it contains, (2) the relative abundance of each. The lists secured in different regions should be compared. It does not matter greatly if the pupil does not know all the plants. He may count the kinds without knowing the names. It is a good plan for the pupil to make a dried specimen of each kind for reference. The pupil should endeavor to discover why the plants grow as they do. Note what kinds of plants grow next each other; and which are undergrowth and which overgrowth; and which are erect and which wide-spreading. Challenge every plant society. 


\section{CHAPTER V}

\section{THE PLANT BODY}

The Parts of a Plant. - Our familiar plants are made up of several distinct parts. The most prominent of these parts are root, stem, leaf, flower, fruit, and seed. Familiar plants differ wonderfully in size and shape, - from fragile mushrooms, delicate waterweeds and pond-scums, to floating leaves, soft grasses, coarse weeds, tall bushes, slender climbers, gigantic trees, and hanging moss.

The Stem Part. - In most plants there is a main central part or shaft on which the other or secondary parts are borne. This main part is the plant axis. Above ground, in most plants, the main plant axis bears the branches, leaves, and flowers; below ground, it bears the roots.

The rigid part of the plant, which persists over winter and which is left after leaves and flowers are fallen, is the framework of the plant. The framework is composed of both root and stem. When the plant is dead, the framework remains for a time, but it slowly decays. The dry winter stems of weeds are the framework, or skeleton of the plant (Figs. I I and I2). The framework of trees is the most conspicuous part of the plant.

The Root Part. - The root bears the stem at its apex, but otherwise it normally bears only root-branches. The stem, however, bears leaves, flowers, and fruits. Those living surfaces of the plant which are most exposed to light are green or highly colored. The root tends to grow downzard, but the stem tends to grow upward toward light 
and air. The plant is anchored or fixed in the soil by the roots. Plants have been called "earth parasites."

The Foliage Part. - The leaves precede the flowers in point of time or life of the plant. The flowers always precede the fruits and seeds. Many plants die when the seeds have matured. The whole mass of leaves of any

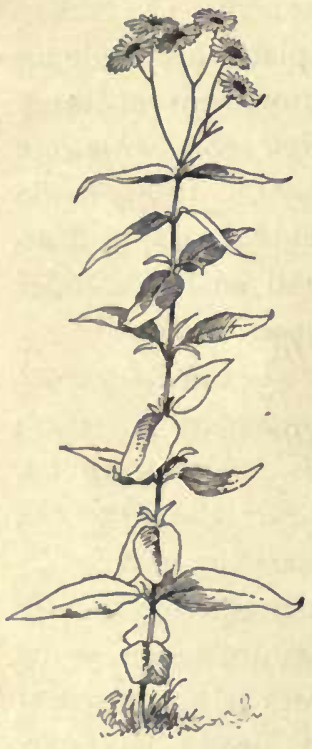

Fig. I1. - PLANT of A

WILD SUNFLOWER.

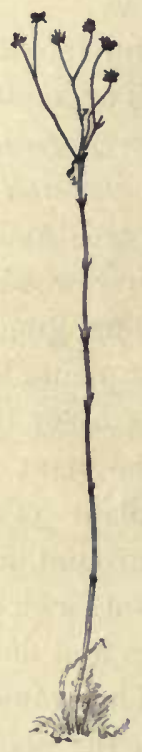
plant or any branch is known as its foliage. In some cases, as in crocuses, the flowers seem to precede the leaves; but the leaves that made the food for these flowers grew the preceding year.

The Plant Generation. - The course of a plant's life, with all the events through which the plant naturally passes, is known as the plant's life-history. The life-history emFIG. I2 - FRAME- braces various stages, WORK OF FIG. II. or epochs, as dormant sced, germination, growth, flowering, fruiting. Some plants run their course in a few weeks or months, and some live for centuries.

The entire life-period of a plant is called a generation. It is the whole period from birth to normal death, without reference to the various stages or events through which it passes.

A generation begins with the young seed, not with germi- 
nation. It ends with death - that is, when no life is left in any part of the plant, and only the seed or spore remains to perpetuate the kind. In a bulbous plant, as a lily or an onion, the generation does not end until the bulb dies, even though the top is dead.

When the generation is of only one season's duration, the plant is said to be annual. When it is of two seasons, it is biennial. Biennials usually bloom the second year. When of three or more seasons, the plant is perennial. Examples of annuals are pigweed, bean, pea, garden sunflower; of biennials, evening primrose, mullein, teasel; of perennials, dock, most meadow grasses, cat-tail, and all shrubs and trees.

Duration of the Plant Body. - Plant structures which are more or less soft and which die at the close of the season are said to be herbaceous, in contradistinction to being ligneous or woody. A plant which is herbaceous to the ground is called an herb; but an herb may have a woody or perennial root, in which case it is called an herbaceous perennial. Annual plants are classed as herbs. Examples of herbaceous perennials are buttercups, bleeding heart, violet, water lily, Bermuda grass, horse-radish, dock, dandelion, golden rod, asparagus, rhubarb, many wild sunflowers (Figs. I I, I2).

Many herbaceous perennials have short generations. They become weak with one or two seasons of flowering and gradually die out. Thus, red clover usually begins to fail after the second year. Gardeners know that the best bloom of hollyhock, larkspur, pink, and many other plants, is secured when the plants are only two or three years old.

Herbaceous perennials which die away each season to bulbs or tubers, are sometimes called pseud-annuals (that 
is, false annuals). Of such are lily, crocus, onion, potato, bull nettle, and false indigo of the Southern states.

True annuals reach old age the first year. Plants which are normally perennial may become ainual in a shorterseason climate by being killed by frost, rather than by dying naturally at the end of a season of growth. They are climatic annuals. Such plants are called plur-annuals in the short-season region. Many tropical perennials are plur-

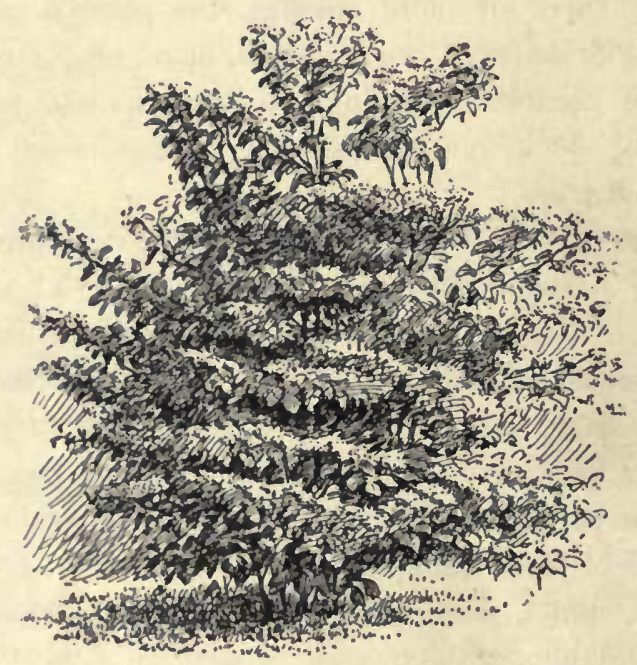

FIG. 13. - A SHRUi OR BUSH. Dogwood osier.

annuals when grown in the north, but they are treated as true annuals because they ripen sufficient of their crop the same season in which the seeds are sown to make them worth cultivating, as tomato, red pepper, castor bean, cotton. Name several vegetables that are planted in gardens with the expectation that they will bear till frost comes.

Woody or ligneous plants are usually longer lived than herhs. Those that remain low and produce several or 
many similar shoots from the base are called shrubs, as lilac, rose, elder, osier(Fig. I 3). Low and thick shrubs are bushes. Plants that produce one main trunk and more or less elevated head are trees (Fig. I4). All shrubs and trees are perennial.

Every plant makes an effort to propagate, or to perpetuate its kind; and, as far as we can see, this is the end for which the plant itself lives. The seed or spore is the final product of the plant.

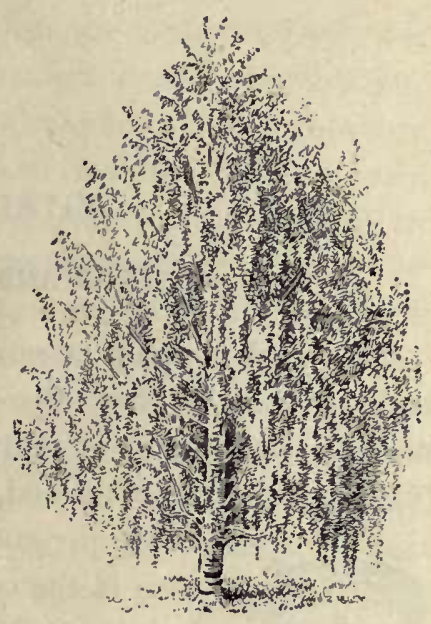

FIG. 14. - A TREE. The weeping birch.

Suggestions. - 8. The teacher may assign each pupil to one plant in the school yard, or field, or in a pot, and ask him to bring out the points in the lesson.' 9. The teacher may put on the board the names of many common plants and ask the pupils to classify into annuals, pseud-annuals, plur-annuals (or climatic annuals), biennials, perennials, herbaceous perennials, ligneous perennials, herbs, bushes, trees. Every plant grown on the farm should be so classified: wheat, oats, corn, buckwheat, timothy, strawberry, raspberry, currant, tobacco, alfalfa, flax, crimson clover, hops, cowpea, field bean, sweet potato, peanut, radish, sugar-cane, barley, cabbage, and others. Name all the kinds of trees you know. 


\section{CHAPTER VI}

\section{SEEDS AND GERMINATION}

THE seed contains a miniature plant, or embryo. The embryo usually has three parts that have received names: the stemlet, or caulicle; the seed-leaf, or cotyledon (usually I or 2); the bud, or plumule, lying between or above the cotyledons. These parts are well

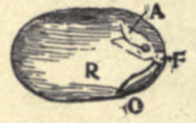

FIG. 15.-PAR'TS OF THE BEAN.

$R$, cotyledon; $O$, caulicle; $A$, plumule; $F$, first node. seen in the common bean (Fig. 15), particularly when the seed has been soaked for a few hours. One of the large cotyledons comprising half of the bean - is shown at $R$. The caulicle is at $O$. The plumule is shown at $A$. The cotyledons are attached to the caulicle at $F$ : this point may be taken as the first node or joint.

The Number of Seed-leaves. - All plants having two seed-leaves belong to the group called dicotyledons. Such seeds in many cases split readily in halves, e.g. a bean. Some plants have only one seed-leaf in a seed. They form a group of plants called monocotyledons. Indian corn is an example of a plant with only one seed-leaf : a grain of corn does not split into halves as a bean does. Seeds of the pine family contain more than two cotyledons, but for our purposes they may be associated with the dicotyledons, although really forming a different group.

These two groups - the dicotyledons and the monocotyledons - represent two great natural divisions of the vegetable kingdom. The dicotyledons contain the woody 
bark-bearing trees and bushes (except conifers), and most of the herbs of temperate climates except the grasses, sedges, rushes, lily tribes, and orchids. The flower-parts are usually in fives or multiples of five, the leaves mostly netted-veined, the bark or rind distinct, and the stem often bearing a pith at the center. The monocotyledons usually have the flower-parts in threes or multiples of three, the leaves long and parallel-veined, the bark not separable, and the stem without a central pith.

Every seed is provided with food to support the germinating plant. Commonly this food is starch. The food may be stored in the cotyledons, as in bean, pea, squash ; or outside the cotyledons, as in castor bean, pine, Indian corn. When the food is outside or around the embryo, it is usually called endosperm.

Seed-coats; Markings on Seed. - The embryo and endosperm are inclosed within a covering made of two or more layers and known as the seed-coats.

Over the point of the caulicle is a minute hole or a thin place in the coats known as the micropyle. This is the point at which the pollen-tube entered the forming ovule and through which the caulicle breaks in

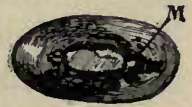

FIG. 16.- - EXTERNAL PARIS OF BEAN. germination. The micropyle is shown at $M$ in Fig. 16. The scar where the seed broke from its funiculus (or stalk that attached it to its pod) is named the hilum. It occupies a third of the length of the bean in Fig. 16. The hilum and micropyle are always present in seeds, but they are not always close together. In many cases it is difficult to identify the micropyle in the dormant seed, but its location is at once shown by the protruding caulicle as germination begins. Opposite the micropyle in the bean (at the other end of the hilum) is an elevation known as the raphe. 
This is formed by a union of the funiculus, or seed-stalk, with the seed-coats, and through it food was transferred for the development of the seed, but it is now functionless.

Seeds differ wonderfully in size, shape, color, and other characteristics. They also vary in longevity. These characteristics are peculiar to the species or kind. Some seeds maintain life only a few weeks or even days, whereas others will "keep" for ten or twenty years. In special cases, seeds have retained vitality longer than this limit, but the stories that live seeds, several thousand years old, have been taken from the wrappings of mummies are unfounded.

Germination. - The embryo is not dead; it is only dormant. When supplied with moisture, warmth, and oxygen (air), it awakes and grows: this growth is germination. The embryo lives for a time on the stored food, but gradually the plantlet secures a foothold in the soil and gathers food for itself. When the plantlet is finally able to shift for itself, germination is complete.

Early Stages of Seedling. - The germinating seed first absorbs water, and swells. The starchy matters gradually become soluble. The seed-coats are ruptured, the caulicle and plumule emerge. During this process the seed respires freely, throwing off carbon dioxid $\left(\mathrm{CO}_{2}\right)$.

The caulicle usually elongates, and from its lower end roots are emitted. The elongating caulicle is known as the hypocotyl ("below the cotyledons"). That is, the hypocotyl is that part of the stem of the plantlet lying between the roots and the cotyledon. The general direction of the young hypocotyl, or emerging caulicle, is downwards. As soon as roots form, it becomes fixed and its subsequent growth tends to raise the cotyledons above the ground, as in the bean. When cotyledons rise into the 
air, germination is said to be epigeal ("above the earth"). Bean and pumpkin are examples. When the hypocotyl does not elongate greatly and the cotyledons remain under ground, the germination is hypogeal ("beneath the earth"). Pea and scarlet runner bean are examples (Fig. 48). When the germinating seed lies on a hard surface, as on closely compacted soil, the hypocoty!

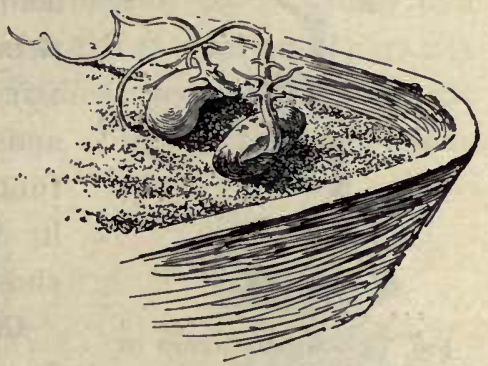

FIG. 17.-PEA. Grotesque forms assumed when the roots cannot gain entrance to the soil. and rootlets may not be able to secure a foothold and they assume grotesque forms. (Fig. 17.) Try this with peas and beans.

The first internode ("between nodes") above the cotyledons is the epicotyl. It elevates the plumule into the air, and the plumule-leaves expand into the first true leaves of the plant. These first true leaves, however, may be very unlike the later leaves in shape.

Germination of Bean. - The common bean, as we have seen (Fig. 15), has cotyledons that occupy all the space

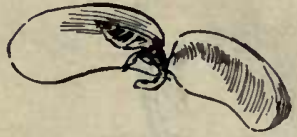

Fig. 18. - COTYLEDONS

OF GERMINATING

BEAN SPREAD APART

TO SHOW ELONGAT-

ING CAULICLE AND Plumule. inside the seed-coats. When the hypocotyl, or elongated caulicle, emerges, the plumule-leaves have begun to enlarge, and to unfold (Fig. I 8). The hypocotyl elongates rapidly. One end of it is held by the roots. The other is held by the seed-coats in the soil. It therefore takes the form of a loop, and the central part of the loop "comes up" first ( $a$, Fig. 19). Presently the cotyledons come out of the seed-coats, 


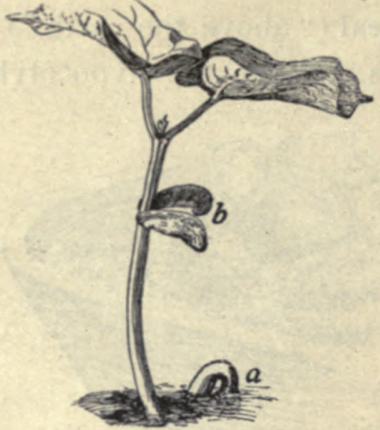

Fig. 19. - Germination OF BEAN. and the plant straightens and the cotyledons expand. These cotyledons, or " halves of the bean," persist for some time ( $b$, Fig. 19). They often become green and probably perform some function of foliage. Because of its large size, the Lima bean shows all these parts well.

Germination of Castor Bean. In the castor bean the hilum and micropyle are at the smaller end (Fig. 20). The bean "comes up" with a loop, which indicates that the hypocotyl greatly elongates. On examining germinating seed, however, it will be found FIG, 20, - SPROUT, ING OF CASTOR BEAN. that the cotyledons are contained inside a fleshy body, or sac ( $a$, Fig. 2I). This sac is the endosperm. Against its inner surface the thin, veiny cotyledons are very closely pressed, ab-

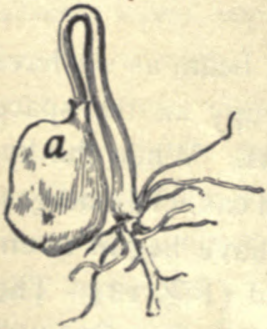

Fig, 21. - GerminaTION OF CASTOR BEAN.

Endosperm at $a$.

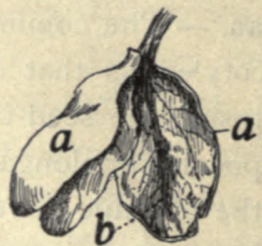

Fig. 22, - CASTOR BEAN.

Endosperm at $a, a$; cotyledons at $b$.

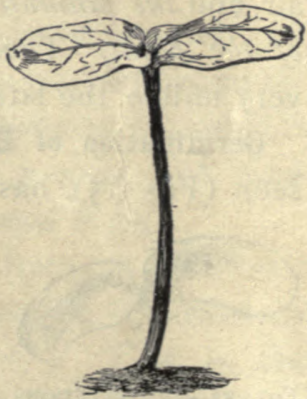

Fig. 23. - Germination COMPLETE IN CASTOR BEAN.

sorbing its substance (Fig. 22). The cotyledons increase in size as they reach the air (Fig. 23), and become func. tional leaves. 
Germination of Monocotyledons - Thus far we have studied dicotyledonous seeds; we may now consider the monocotyledonous group. Soak kernels of corn. Note that the micropyle and hilum are at the smaller end (Fig. 24).

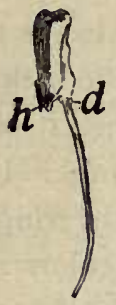

FIG. 24.-SPROUTING INDIAN CORN.

Hilum at $h$; micropyle at $d$. Make a longitudinal section through the narrow diameter; Fig. 25 shows it. The

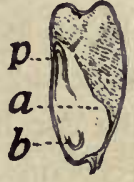

FIG. 25.-KF.RNEL OF INDIAN CORN.

Caulicle at $b$; cotyledon at $a$; plumule at $p$.

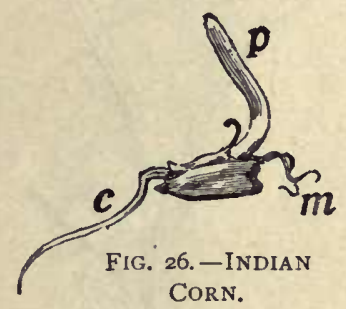

Caulicle at $c_{i}$, roots emerging at m; plumule at $p$.

single cotyledon is at $a$, the caulicle at $b$, the plumule at $p$. The cotyledon remains in the seed. The food is stored both in the cotyledon and as endosperm, chiefly the latter. The emerging shoot is the plumule, with a sheathing leaf ( $p$, Fig. 26). The root is emitted from the tip of

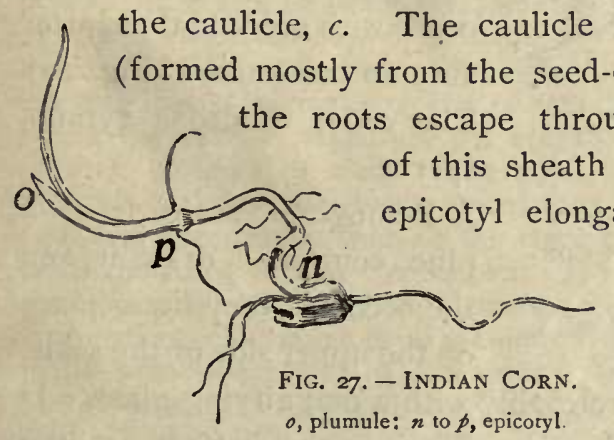

is held in a sheath 
sheath, $c, m$; the epicotyl has grown to $p$; the first plumule-leaf is at $o$.

In studying corn or other fruits or seeds, the pupil should note how the seeds are arranged, as on the cob. Count the

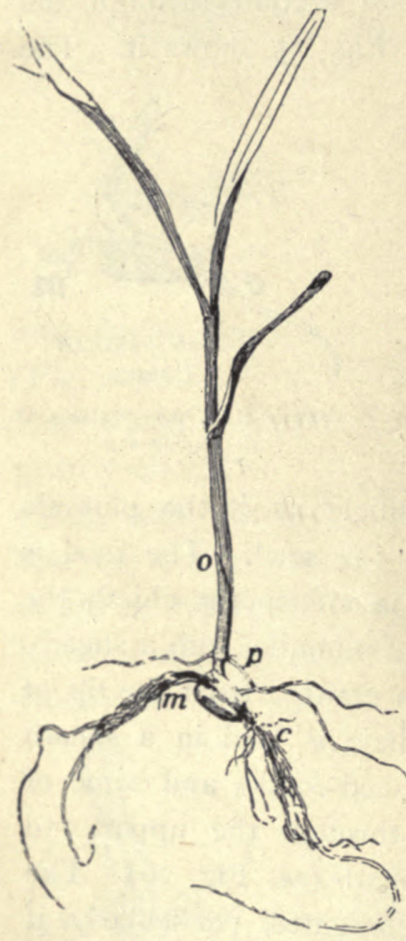

Fig. 28.-Germination is ComPLETE.

A, top of epicotyl; $o$, plumule-leaf; $m$, roots; $c$, lower roots. rows on a corn cob. Odd or even in number? Always the same number? The silk is the style: find where it was attached to the kernel. Did the ear have any coverings? Explain. Describe colors and markings of kernels of corn; and of peas, beans, castor bean.

Gymnosperms. - The seeds in the pine cone, not being inclosed in a seed-vessel, readily fall out when the cone dries and the scales separate. Hence it is difficult to find cones with seeds in them after autumn has passed (Fig. 29). The cedar is also a gymnosperm.

Remove a scale from a pine cone and draw it and the seeds as they lie in place on the upper side of the scale. Examine the seed, preferably with a magnifying glass. Is there a hilum? The micropyle is at the bottom or little end of the seed. Toss a seed upward into the air. Why does it fall so slowly? Can you explain the peculiar whirling motion by the shape of the wing? Repeat the ex- 
periment in the wind. Remove the wing from a seed and toss it and an uninjured seed into the air together. What do you infer from these experiments?

SugGeStions. - Few subjects connected with the study of plant-life are so useful in schoolroom demonstrations as germination. The pupil should prepare the soil, plant the seeds, water them, and care for the plants. 10. Plant seeds in pots or shallow boxes. The box should not be very wide or long, and not over four inches deep. Holes may be bored in the bottom so it will not hold water. Plant a number of squash, bean, corn, pine, or other seeds about an inch deep in damp sand or pine sawdust in this box. The depth of planting should be two to four times the diameter of the seeds. Keep the sand or sawdust moist but not wet. If the class is large, use several boxes, that the supply of specimens may be ample. Cigar boxes and chalk boxes are excellent for individual pupils. It is well to begin the planting of seeds at least ten days in advance of the lesson, and to make four or five different plantings at intervals. A day or two before the study is taken up, put seeds to soak in moss or cloth. The pupil then has a series from swollen seeds to
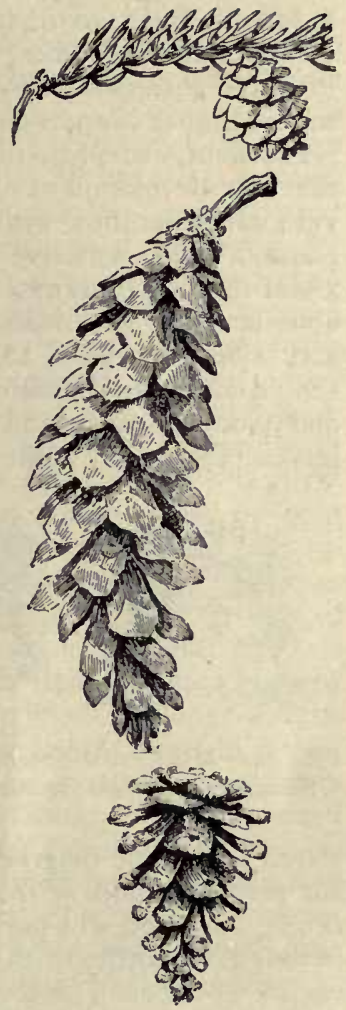

FIG. 29. - CONES OF HEMLOCK (ABOVE), WHITE Pine, Pitch Pine.

complete germination, and all the steps can be made out. Dry seeds should be had for comparison. If there is no special room for laboratory, nor duplicate apparatus for every pupil, each experiment may be assigned to a committee of two pupils to watch in the schoolroom. 11. Good seeds for study are those detailed in the lesson, and buckwheat, pumpkin, cotton, morning glory, radish, four o'clock, oats, wheat. It is best to use familiar seeds of farm and garden. Make drawings and notes of all the events in the germination. Note the effects of unusual conditions, as planting too deep and too shallow and different sides up. For hypogeal germination, use the garden pea, scarlet runner or Dutch 
case-knife bean, acorn, horse-chestnut. Squash seeds are excellent for germination studies, because the cotyledons become green and leafy and germination is rapid. Its germination, as also that of the scarlet runner bean, is explained in "Lessons with Plants." Onion is excellent, except that it germinates too slowly. In order to study the root development of germinating plantlets, it is well to provide a deeper box with a glass side against which the seeds are planted. 12. Observe the germination of any common seed about the house premises. When elms, oaks, pines, or maples are abundant, the germination of their seeds may be studied in lawns and along fences. 13. When studying germination, the pupil should note the differences in shape and size between cotyledons and plumule-leaves, and between plumule-leaves and the normal leaves (Fig. 30). Make drawings. 14. Make the tests described

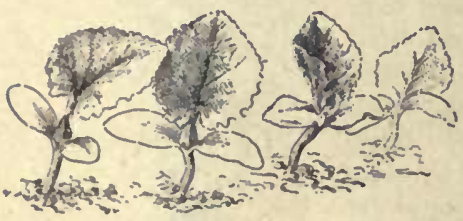

FiG. 3o. - MUSKMELON SEEDlings, with the unlike seed-leaves and true leaves. in the introductory experiments with bean, corn, the castor bean, and other seed for starch and proteids. Test flour, oatmeal, rice, sunflower, four o'clock, various nuts, and any other seeds obtainable. Record your results by arranging the seeds in three classes, 1. Much starch (color blackish or purple), 2. Little starch (pale blue or greenish), 3. No starch (brown or yellow). 15. Rate of growth of seedlings as affected by differences in temperature. Pack soft wet paper to the depth of an inch in the bottom of four glass botiles or tumblers. Put ten soaked peas or beans into each. Cover each securely and set them in places having different temperatures that vary little. (A furnace room, a room with a stove, a room without stove but reached by sunshine, an unheated room not reached by the sun.) Take the temperatures occasionally with a thermometer to find difference in tempera:ure. The tumblers in warm places should be covered very tightly to prevent the germination from being retarded by drying out. Record the number of seeds which sprout in each tumbler within I day; 2 days ; 3 days; 4 days, etc. 16. Is air necessary for the germination and groweth of seedlings? Place damp blotting paper in the botton of a bottle and fill it three fourths full of soaked seeds, and close it tightly with a rubber stopper or oiled cork. Prepare a "check experiment" by having another bottle with all conditions the same except that it is covered loosely that air may have access to it, and set the bottles side by side (why keep the bottles together?). Record results as in the preceding experiment. 17. What is the 
nature of the gas given off by germinating seeds? Fill a tin box or large-necked bottle with dry beans or peas, then add water; note how much they swell. Secure two fruit-jars. Fill one of them a third full of beans and keep them moist. Allow the other to remain empty. In a day or two insert a lighted splinter or taper into each. In the empty jar the taper burns: it contains oxygen. In the seed jar the taper goes out: the air has been replaced by carbon dioxid. The air in the bottle may be tested for carbon dioxid by removing some of it with a rubber bulb attached to a glass tube (or a fountain-pen filler) and bubbling it through lime water. 18. Temperature. Usually there is a perceptible rise in temperature in a mass of germinating seeds. This rise may be tested with a thermometer. 19. Interior of seeds. Soak seeds for twenty-four hours and remove the coat. Distinguish the embryo from the endosperm. Test with iodine. 20. Of what utility is the food in seeds? Soak some grains of corn overnight and remove the endosperm, being careful not to injure the fleshy cotyledon. Plant the incomplete and also some complete grains in moist sawdust and measure their growth at intervals. (Boiling the sawdust will destroy molds and bacteria which might interfere with experiment.) Peas or beans may be sprouted on damp blotting paper; the cotyledons of one may be removed, and this with a normal seed equally advanced in germination may be placed on a perforated cork floating in water in a jar so that the roots extend into the water. Their growth may be observed for several weeks. 21. Effect of darkness on seeds and seedlings. A box may be placed mouth downward over a smaller box in which seedlings are growing. The empty box should. rest on half-inch blocks to allow air to reach the seedlings. Note any effects on the seedlings of this cutting off of the light. Another box of seedlings not so covered may be used for a check. Lay a plank on green grass and after a week note the change that takes place beneath it. 22. Seedling of pine. Plant pine seeds. Notice how they emerge. Do the rotyledons stay in the ground? How many cotyledons have they? When do the cotyledons get free from the seed-coat? What is the last part of the cotyledon to become free ? Where is the growing point or plumule? How many leaves appear at once? Does the new pine cone grow on old wood or on wood formed the same spring with the cone? Can you always find partly grown cones on pine trees in winter? Are pine cones when mature on two-year-old wood? How long do cones stay on a tree after the seeds have fallen out ? What is the advantage of the seeds falling before the cones? 23. Home experiments. If desired, nearly all of the foregoing experiments may be 
tried at home. The pupil can thus make the drawings for the notebook at home. A daily record of measurements of the change in size of the various parts of the seedling should also be made. 24. Seed-testing. - It is important that one know before planting whether seeds are good, or able to grow. A simple seed-tester may be made of two plates, one inverted over the other (Fig. 3I). The lower plate is nearly filled with clean

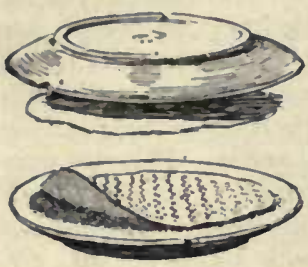

FIG. 3I. - A HOME-MADE SEED-TESTER. sand, which is covered with cheese cloth or blotting paper on which the seeds are placed. Canton flannel is sometimes used in place of sand and blotting paper. The seeds are then covered with another blotter or piece of cloth, and water is applied until the sand and papers are saturated. Cover with the second plate. Set the plates where they will have about the temperature that the given seeds would require out of doors, or perhaps a slightly higher temperature. Place roo or more grains of clover, corn, wheat, oats, rye, rice, buckwheat, or other seeds in the tester, and keep record of the number that sprout. The result will give a percentage measure of the ability of the seeds to grow. Note whether all the seeds sprout with equal vigor and rapidity. Most seeds will sprout in a week or less. Usually such a tester must have fresh sand and paper after every test, for mold fungi are likely to breed in it. If canton flannel is used, it may be boiled. If possible, the seeds should not touch each other.

Note to TEACHER. - With the study of germination, the pupil will need to begin dissecting.

For dissecting, one needs a lens for the examination of the smaller parts of plants and animals. It is best to have the lens mounted on a frame, so that the pupil has both hands free for pulling the part in pieces. An ordinary pocket lens may be mounted on a wire in a block, as in Fig. A. A cork is slipped on the top of the wire to avoid injury to the face. The pupil should be provided with two dissecting needles (Fig. B), made by securing an ordinary needle in a pencil-like stick. Another convenient arrangement is shown in Fig. C. A small tin dish is used for the base. Into this a stiff wire standard is soldered. The dish is filled with solder, to make it heavy and firm. Into a cork slipped on the standard, a cross wire is inserted, holding on the end a jeweler's glass. The lens can be moved up and down and sidewise. This outfit can be made for about seventy-five cents. Fig. D shows a convenient hand-rest or dissecting-stand to be 
used under this lens. It may be 16 in. long, 4 in. high, and 4 or 5 in. broad.

Various kinds of dissecting microscopes are on the market, and these are to be recommended when they can be afforded.

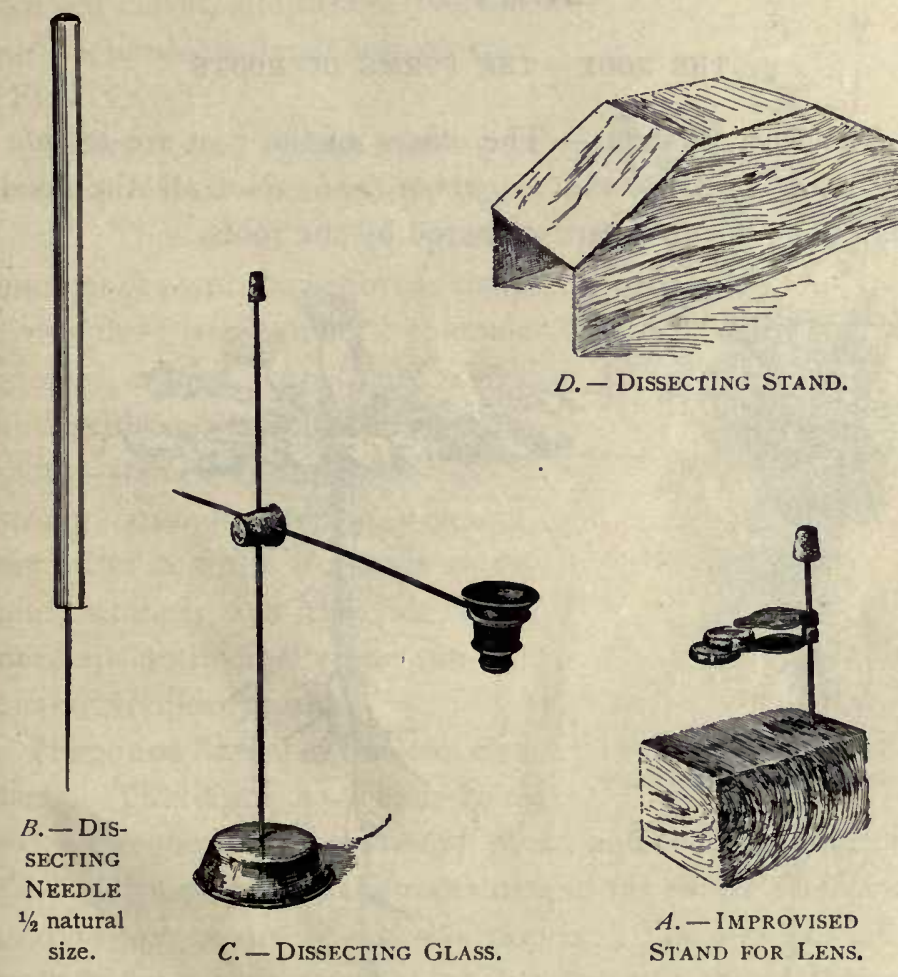

Instructions for the use of the compound microscope, with which some schools may be equipped, cannot be given in a brief space; the technique requires careful training. Such microscopes are not needed unless the pupil studies cells and tissues. 


\section{CHAPTER VII}

\section{THE ROOT - THE FORMS OF ROOTS}

The Root System. - The offices of the root are to hola the plant in place, and to gather food. Not all the food materials, however, are gathered by the roots.

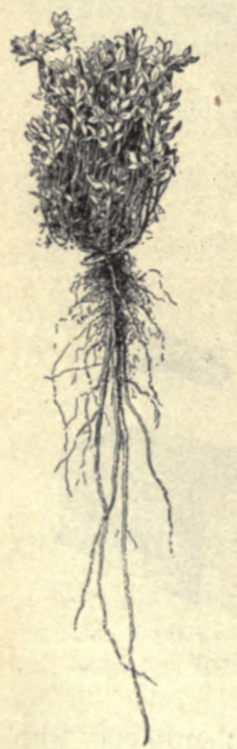

FiG. 32, - TAP-ROOT SYSTEM OF ALFALFA.

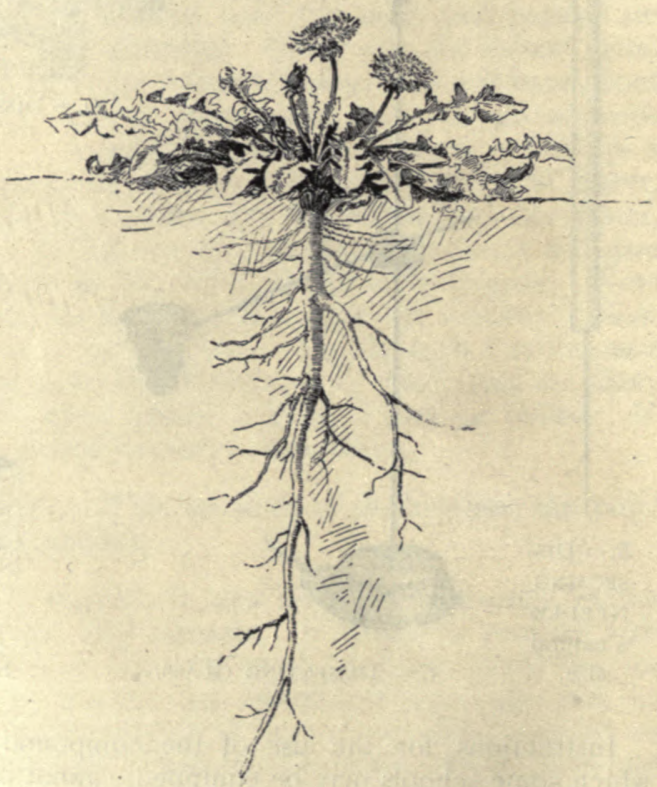

FIG. 33. - TAP-ROOT OF THE DANDELION.

The entire mass of roots of any plant is calied its root system. The root system may be annual, biennial or perennial, herbaceous or woody, deep or shallow, large or small.

Kinds of Roots. - A strong leading central root, which runs directly downwards, is a tap-root. The tap-root forms 
an axis from which the side roots may branch. The side or spreading roots are usually smaller. Plants that have such a root system are said to be tap-rooted. Examples are red clover, alfalfa, beet, turnip, radish, burdock, dandelion, hickory (Figs. 32, 33).

A fibrous root system is one that is composed of many nearly equal slender branches. The greater number of plants have fibrous roots. Examples are many common grasses, wheat, oats, corn. The buttercup in Fig. 34 has a fibrous root system. Many trees have a strong tap-root when very young, but after a while it ceases to extend strongly and the side roots develop until finally the tap-root character disappears.

Shape and Extent of the Root System. - The depth to which roots

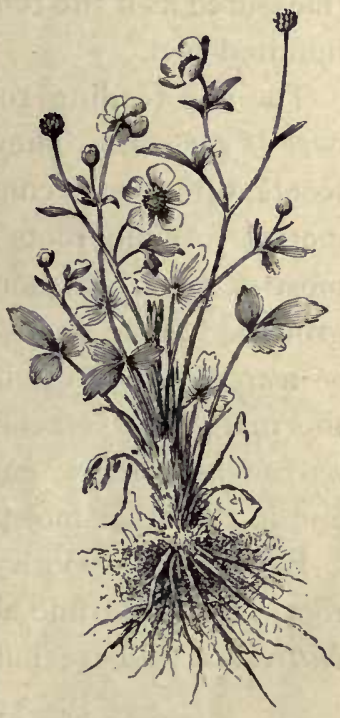

FIG. 34. - A BUTTERCUP PLANT, with fibrous roots. extend depends on the kind of plant, and the nature of the soil. Of most plants the roots extend far in all directions and lie comparatively near the surface. The roots usually radiate from a common point just beneath the surface of the ground.

The roots grow here and there in search of food, often extending much farther in all directions than the spread of the top of the plant. Roots tend to spread farther in poor soil than in rich soil, for the same size of plant. The root has no such definite form as the stem has. Roots are usually very crooked, because they are constantly turned aside by obstacles. Examine roots in stony soil. 
The extcnt of root surface is usually very large, for the feeding roots are fine and very numerous. An ordinary plant of Indian corn may have a total length of root (measured as if the roots were placed end to end) of several hundred feet.

The fine feeding roots are most abundant in the richest part of the soil. They are attracted by the food materials. Roots often will completely surround a bone or other morsel. When roots of trees are exposed, observe that most of them are horizontal and lie near the top of the ground. Some roots, as of willows, extend far in search of water. They often run into wells and drains, and into the margins of creeks and ponds. Grow plants in a long narrow box, in one end of which the soil is kept very dry and in the other moist: observe where the roots grow.

Buttresses. - With the increase in diameter, the upper roots often protrude above the ground and become bracing buttresses. These buttresses are usually largest in trees

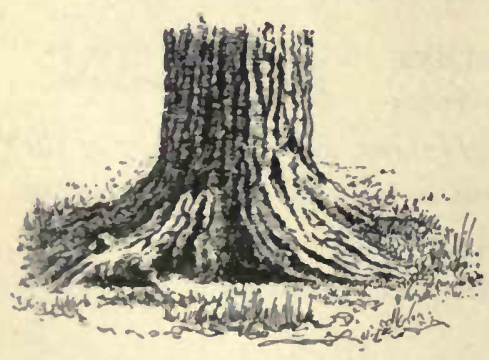

Fig. 35.-THE. BRAcing Basf. of a FIELD PINE. which always have been exposed to strong winds (Fig. 35). Because of growth and thickening, the roots elevate part of their diameter, and the washing away of the soil makes them to appear as if having risen out of the ground.

Aërial Roots. - Although roots usually grow underground, there are some that naturally grow above ground. These usually occur on climbing plants, the roots becoming supports or fulfilling the office of tendrils. These aërial roots usually turn away from the light, and therefore enter the 
crevices and dark places of the wall or tree over which the plant a. climbs. The trumpet creeper (Fig. 36), true or

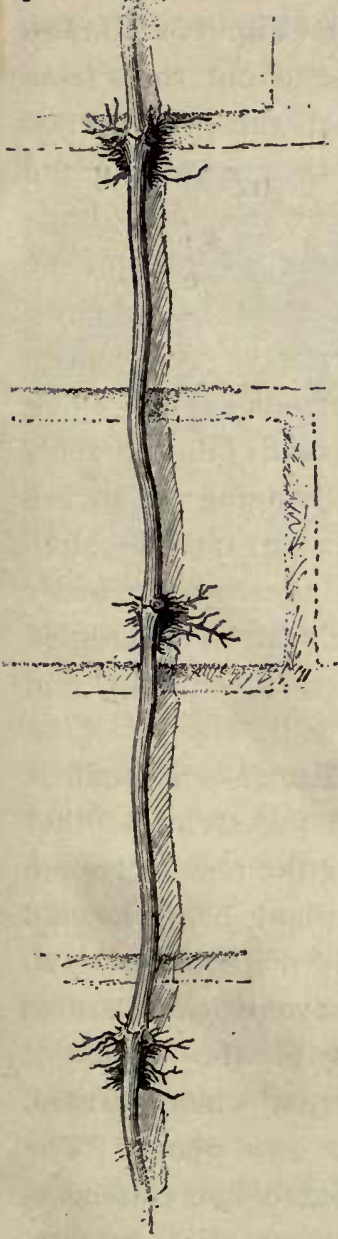

FIG. 36. - AËRIAL ROOTS OF TRUMPET CREEPER OR TECOMA.
English ivy, and poison ivy climb by means of roots.

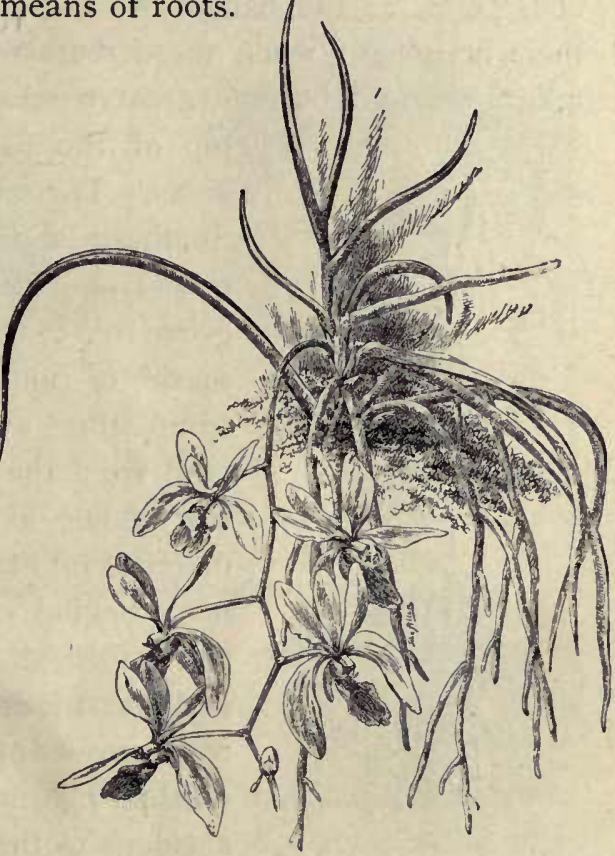

FIG. 37. - AËRIAL ROOTS OF AN ORCHID.

In some plants all the roots are aërial; that is, the plant grows above ground, and the roots gather food from the air. Such plants usually grow on trees. They are known as epiphytes or air-plants. The most familiar examples are some of the tropical orchids, which are grown in glasshouses (Fig. 37). Rootlike organs of dodder and other parasites are discussed in a future chapter. 
Some plants bear aërial roots, that may propagate the plant or may act as braces. They are often called prop-roots. The roots of Indian corn are familiar (Fig. 38). Many ficus trees, as the banyan of India, send out roots from their branches; when these roots reach the ground they take hold and become great trunks, thus spreading the

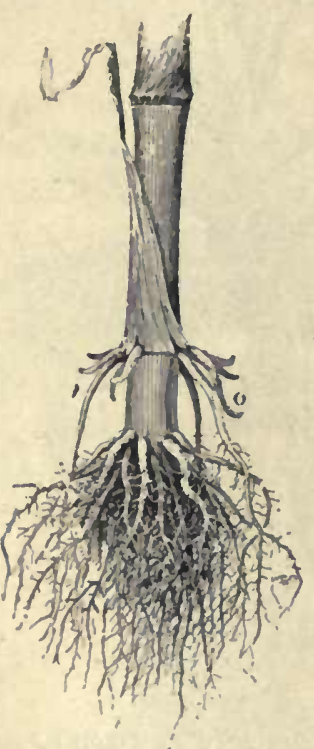

FIG. 38. - INDIAN CORN, showing the brace roots at 00 . top of the parent tree over large areas. The muscadine grape of the Southern states often sends down roots from its stems. The mangrove tree of the tropics grows along seashores and sends down roots from the overhanging branches (and from the fruits) into the shallow water, and thereby gradually marches into the sea. The tangled mass behind catches the drift, and soil is formed.

Adventitious Roots. - Sometimes roots grow from the stem or other unusual places as the result of some accident to the plant, being located without known method or law. They are called adventitious (chance) roots. Cuttings of the stems of roses, figs, geraniums, and other plants, when planted, send out adventitious roots and form new plants. The ordinary roots, or soil roots, are of course not classed as adventitious roots. The adventitious roots arise on occasion, and not as a normal or regular course in the growth of the plant.

No two roots are alike; that is, they vary among themselves as stems and leaves do. Each kind of plant has its 
zwn form or habit of root (Fig. 39). Carefully wash away the soil from the roots of any two related plants, as oats and wheat, and note the differences in size, depth, direction, mode of branching, number of fibrils, color, and other
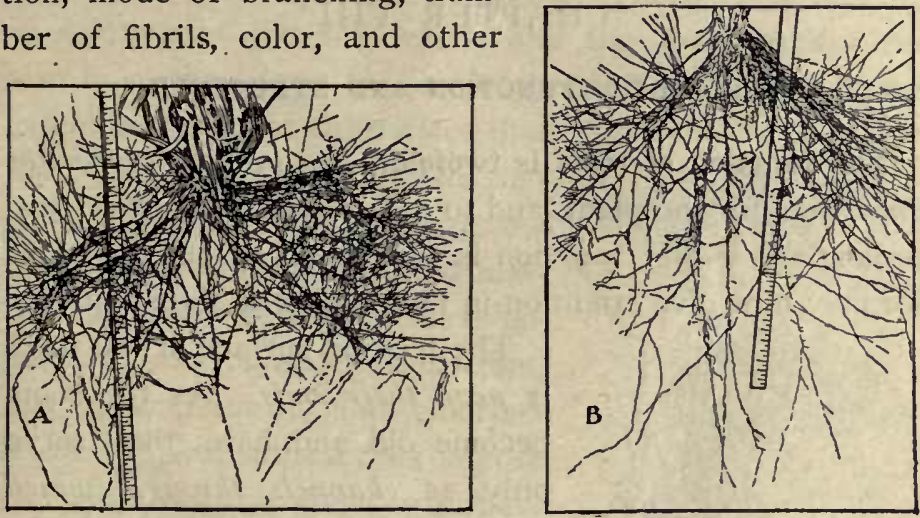

Fig. 39.- ROOTS OF BARLEY AT $A$ AND CORN AT $B$. Carefully trace the differences.

features. The character of the root system often governs the treatment that the farmer should give the soil in which the plant or crop grows.

Roots differ not only in their form and habit, but also in color of tissue, character of bark or rind, and other features. It is excellent practice to try to identify different plants by means of their roots. Let each pupil bring to school two plants with the roots very carefully dug up, as cotton, corn, potato, bean, wheat, rye, timothy, pumpkin, clover, sweet pea, raspberry, strawberry, or other common plants.

Root Systems of Weeds. - Some weeds are pestiferous because they seed abundantly, and others because their underground parts run deep or far and are persistent. Make out the root systems in the six worst weeds in your locality. 


\section{CHAPTER VIII}

\section{THE ROOT. - FUNCTION AND STRUCTURE}

The function of roots is twofold, - to provide support or anchorage for the plant, and to collect and convey food materials. The first function is considered in Chapter VII; we may now give attention in more detail to the second.

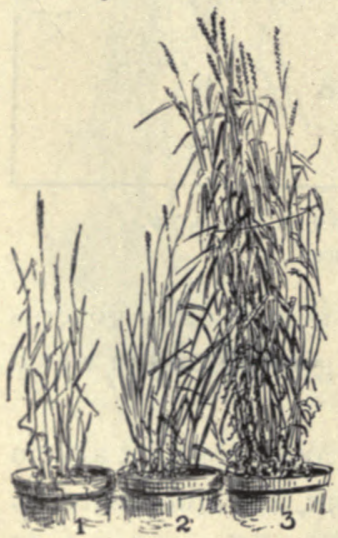

FIG. 40,- WHEAT GROWING UNDER DIFFERENT SOIL Treatments, Soil deficient in nitrogen; commercial nitrogen applied to pot 3 (on right).

The feeding surface of the roots is near their ends. As the roots become old and hard, they serve only as channels through which food passes and as hold-fasts or supports for the plant. The roothold of a plant is very strong. Slowly pull upwards on some plant, and note how firmly it is anchored in the soil.

Roots have power to choose their food; that is, they do not absorb all substances with which they come in contact. They do not take up great quantities of useless or harmful materials, even though these materials may be abundant in the soil; but they may take up a greater quantity of some of the plant-foods than the plant can use to advantage. Plants respond very quickly to liberal feeding, - that is, to the application of plant-food to the soil (Fig 40). The poorer the soil, the more marked are the results, as a rule, of the application 
of fertilizers. Certain substances, as common salt, will kill the roots.

Roots absorb Substances only in Solution. - Substances cannot be taken in solid particles. These materials are in solution in the soil water, and the roots themselves also have the power to dissolve the soil materials to some extent by means of substances that they excrete. The materials that come into the plant through the roots are water and mostly the mineral substances, as compounds of potassium, iron, phosphorus, calcium, magnesium, sulfur, and chlorine. These mineral substances compose the ash when the plant is burned. The carbon is derived from the air through the green parts. Oxygen is derived from the air and the soil water.

Nitrogen enters through the Roots. - All plants must have nitrogen;

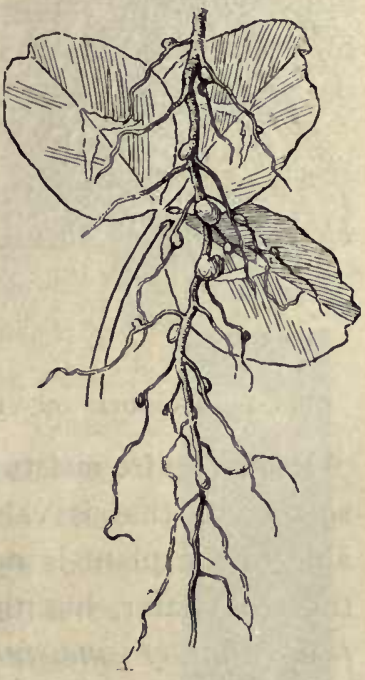
yet, although about four fifths of the air is nitrogen, plants are not Fig. 4I. - NODULES ON ROOTS OF RED CLOVER. able, so far as we know, to take it in through their leaves. It enters through the roots in combination with other elements, chiefly in the form of nitrates (certain combinations with oxygen and a mineral base). The great family of leguminous plants, however (as peas, beans, cowpea, clover, alfalfa, vetch), use the nitrogen contained in the air in the soil. They are able to utilize it through the agency of nodules on their roots (Figs. 41, 42). These nodules contain bacteria, which appropriate the free or uncombined nitrogen and pass it on to the plant. The nitrogen 
becomes incorporated in the plant tissue, so that these crops are high in their nitrogen content. Inasmuch as

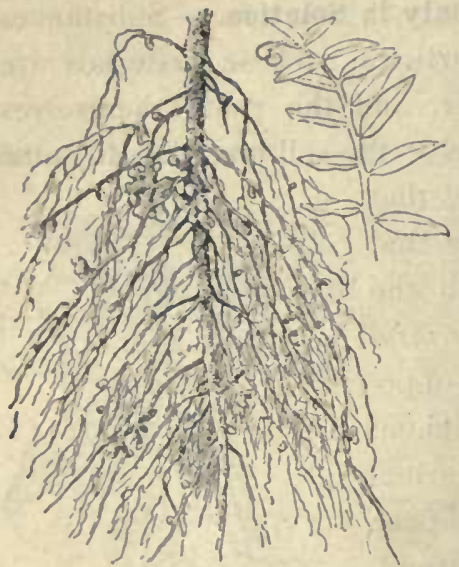

Fig. 42. - Nodules ON VETCH. nitrogen in any form is expensive to purchase in fertilizers, the use of leguminous crops to plow under is a very important agricultural practice in preparing the land for other crops. In order that leguminous crops may acquire atmospheric nitrogen more freely and thereby thrive better, the land is sometimes sown or inoculated with the nodule-forming bacteria.

Roots require moisture in order to serve the plant. The soil water that is valuable to the plant is not the free water, but the thin film of moisture which adheres to each little particle of soil. The finer the soil, the greater the number of particles, and therefore the greater is the quantity of film moisture that it can hold. This moisture surrounding the grains may not be perceptible, yet the

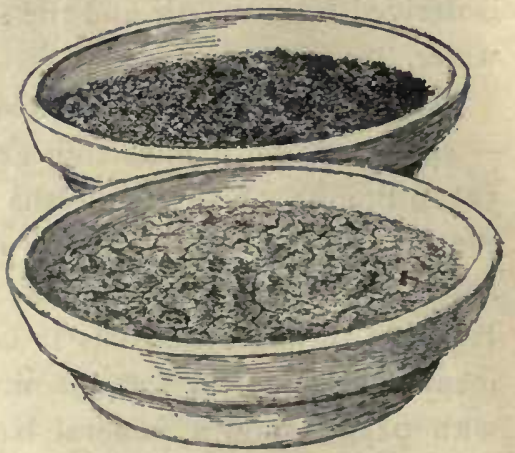

Fig. 43. - Two Kinds OF Soll. That have BEEN WET AND THEN DRIED. The loamy soil above remains loose and capable of growing plants; the clay soil below has baked and cracked. plant can use it. Root absorption may continue in a soil which secms to be dust dry. Soils that are very hard and 
"baked". (Fig. 43) contain very little moisture or air, not so much as similar soils that are granular or mellow.

- Proper Temperature for Root Action. - The root must be warm in order to perform its functions. Should the soil of fields or greenhouses be much colder than the air, the plant suffers. When in a warm atmosphere, or in a dry atmosphere, plants need to absorb much water from the soil, and the roots must be warm if the root-hairs are to supply the water as rapidly as it is needed. If the roots are chilled, the plant may wilt or die.

Roots need Air. - Corn on land that has been flooded by heavy rains loses its green color and turns yellow. Besides diluting plant-food, the water drives the air from the soil, and this suffocation of the roots is very soon apparent in the general ill health of the plant. Stirring or tilling the soil aërates it. Water plants and bog plants have adapted themselves to their particular conditions. They get their air either by special surface roots, or from the water through stems and leaves.

Rootlets. - Roots divide into the thinnest and finest fibrils: there are roots and there are rootlets. The smallest rootlets are so slender and delicate that they break off even when the plant is very carefully lifted from the soil.

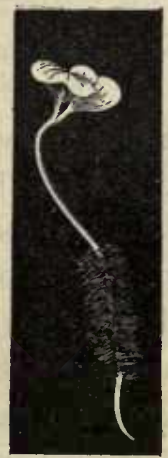

FIG. $44 .-$ ROOTHAIRS OF THE RADISH.

The rootlets, or fine divisions, are clothed with the root: hairs (Figs. 44, 45, 46). These root-hairs attach to the soil particles, and a great amount of soil is thus bronght into actual contact with the plant. These are very delicate prolonged surface cells of the roots. They are borne for a short distance just back of the tip of the root.

Rootlet and root-hair differ. The rootlet is a compact 
cellular structure. The root-hair is a delicate tubular cell (Fig. 45), within which is contained living matter (protoplasm); and the protoplasmic lining membrane of the

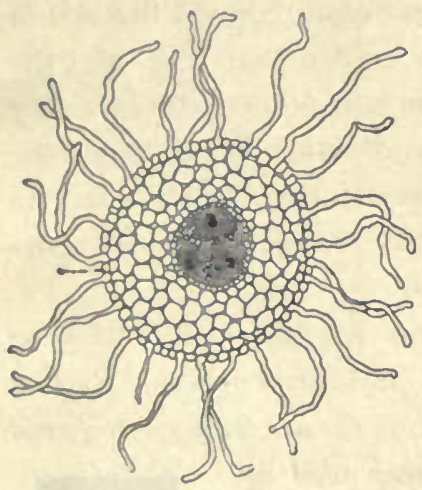

FiG. 45. - Cross-section of ROOT, enlarged, showing root-hairs.

wall governs the entrance of water and substances in solution. Being long and tubelike, these root-hairs are especially adapted for taking in the largest quantity of solutions; and they are the principal means by which plant-food is absorbed from the soil, although the surfaces of the rootlets themselves do their part. Water plants do not produce an abundant system of root-hairs, and such plants depend largely on their rootlets.

The root-hairs are very small, often invisible. They, with the young roots, are usually broken off when the plant is pulled up. They are best seen when seeds are germinated between layers of dark blotting paper or flannel. On the young roots, they will be seen as a mold-like or gossainerlike covering. Root-hairs soon die: they do not grow into roots. New ones form as the root grows.

Osmosis. - The water with its nourishment goes through the

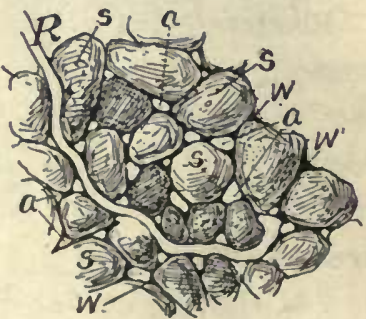

FIG. 46. - ROOT-HAIR, much enlarged, in contact with the soil particles (s). Air-spaces at $a$; water-films on the particles, as at $w$.

thin walls of the root-hairs and rootlets by the process of osmosis. If there are two liquids of different density 
on the inside and outside of an organic (either vegetable or animal) membrane, the liquids tend to mix through the membrane. The law of osmosis is that the most rapid flow is toward the denser solution. The protoplasmic lin. ing of the cell wall is such a membrane. The soil water being a weaker solution than the sap in the roots, the flow is into the root. A strong fertilizer sometimes causes a plant to wither, or "burns it." Explain.

Structure of Roots. - The root that grows from the lower end of the caulicle is the first or primary root. Secondary roots branch from the primary root. Branches of secondary roots are sometimes called tertiary roots. Do the secondary roots grow from the cortex, or from the central cylinder of the primary root? Trim or peel the cortex from a root and its branches and determine whether the branches still hold to the central cylinder of the main root.

Internal Structure of Roots. - A section of a root shows that it consists of a central cylinder (see Fig. 45) surrounded by a layer. This layer is called the cortex. The outer layer of cells in the cortex is called the epidermis, and some of the cells of the epidermis are prolonged and form the delicate root-hairs. The cortex resembles the bark of the stem in its nature. The central cylinder contains many tube-like canals, or "vessels" that convey water and food (Fig. 45). Cut a sweet potato across (also a radish and a turnip) and distinguish the central cylinder, cortex and epidermis. Notice the hard cap on the tip of roots. Roots differ from stems in having no real pith.

Microscopic Structure of Roots. - Near the end of any young root or shoot the cells are found to differ from each other more or less, according to the distance from the point. This differentiation takes place in the region just back of the growing point. To study growing points, use 
the hypocotyl of Indian corn which has grown about one half inch. Make a longitudinal section. Note these points (Fig. 47): (a) the tapering root-cap beyond the growing point; $(b)$ the blunt end of the root proper and the rectangular shape of the cells found there; $(c)$ the group of cells in the middle of the first layers beneath the root-

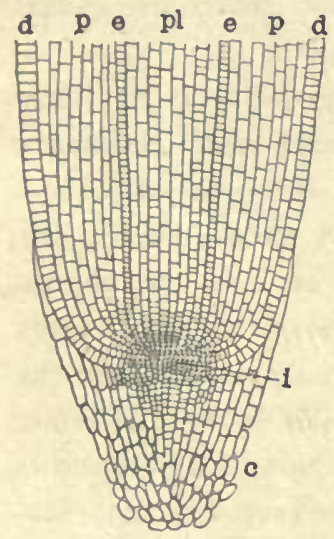

Fig. 47- - GROWING POINT OF ROOT OF INDIAN CORN.

$d, d$, cells which will form the epidermis: $\phi, \beta$, cells that will form bark; $e, e$, endodermis: $A l$, cells which will form the axis cylinder: $i$, initial group of cells, or growing point proper; c, root-cap. cap, - this group is the growing point; (d) study the slight differences in the tissues a short distance back of the growing point. There are four regions: the central cylinder, made up of several rows of cells in the center $(p l)$; the endodermis, (e) composed of a single layer on each side which separates the central cylinder from the bark; the cortex, or inner bark, $(e)$ of several layers outside the endodermis; and the epidermis, or outer layer of bark on the outer edges $(d)$. Make a drawing of the section. If a series of the cross-sections of the hypocotyl should be made and studied, beginning near the growing point and going upward, it would be found that these four tissues become more distinctly marked, for at the tip the tissues have not yet assumed their characteristic form. The central cylinder contains the ducts and vessels which convey the sap.

The Root-cap. - Note the form of the root-cap shown in the microscopic section drawn in Fig. 47. Growing cells, and especially those which are forming tissue by subdividing, are very delicate and are easily injured. The 
cells forming the root-cap are older and tougher and are suited for pushing aside the soil that the root may penetrate it.

Region of most Rapid Growth.-The roots of a seedling bean may be marked at equal distances by waterproof ink or by bits of black thread tied moderately tight. The seedling is then replanted and left undisturbed for two days. When it is dug up, the region of most

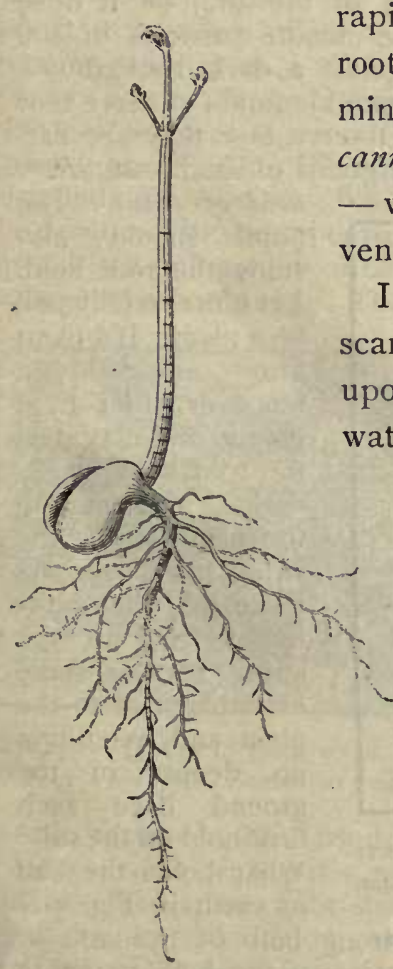

FIG. 49.-THE RESULT.

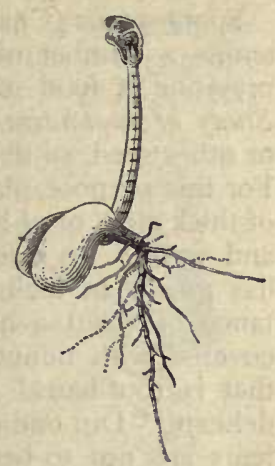

FIG. 48. - THE MARKING OF THE STEM AND ROOT. root can be determined. Give a reason why a root cannot elongate throughout its length, - whether there is anything to prevent a young root from doing so.

In Fig. 48 is shown a germinating scarlet runner bean with a short root upon which are marks made with waterproof ink; and the same root (Fig. 49) is shown after it has grown longer. Which part of it did not lengthen at all ? Which part lengthened slightly? Where is the region of most rapid growth?

Geotropism. - Roots turn toward the earth, even if the seed is planted with the micropyle up. This phenomenon is called positive geotropism. Stems grow away from the earth. This is negative geotropism. 
Suggestions (Chaps. VII and VIII). - 25. Tests for food. Examine a number of roots, including several fleshy roots, for the presence of food material, making the tests used on seeds. 26. Study of root-hairs. Carefully germinate radish, turnip, cabbage, or other seed, so that no delicate parts of the root will be injured. For this purpose, place a few seeds in packing-moss or in the folds of thick cloth or of blotting paper, being careful to keep them moist and warm. In a few days the seed has germinated, and the root has grown an inch or two long. Notice that, except at a distance of about a quarter of an inch behind the tip, the root is covered with minute hairs (Fig. 44). They are actually hairs; that is, root-hairs. Touch them and they collapse, they are so delicate. Dip one of the plants in water, and when removed the hairs are not to be seen. The water mats them together along the root and they are no longer evident. Root-hairs are usually destroyed when a plant is pulled out of the soil, be it done ever so carefully. They cling to the minute particles of soil (Fig. 46). The hairs show best against a dark background. 27. On some of the blotting papers, sprinkle sand; observe how the root-hairs cling to the grains. Observe how they are flattened when they come in contact with grains of sand. 28. Root

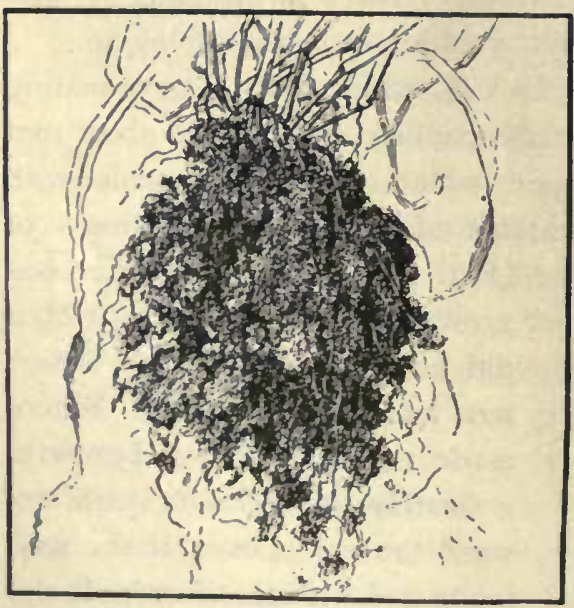

Fig. 50. - The Grasp of a Pl.ant on the PartlCLES OF EARTH. A grass plani pulled in a garden. hold of plant. The pupil should also study the root hold. Let him carefully pull. up a plant. If a plant grow alongside a fence or other rigid object, he may test the root hold by securing a string to the plant, letting the string hang over the fence, and then adding weights to the string. Will a stake of similar size to the plant and extending no deeper in the ground have such firm hold on the soil? What holds the ball of earth in Fig. 50? 29. Roots exert pressure. Place a strong bulb of hyacinth or daffodil on firm-packed earth in a pot; cover the bulb nearly to the top with loose earth; place in a cool cellar; after some days 
or weeks, note that the bulb has been raised out of the earth by the forming roots. All roots exert pressure on the soil as they grow. Explain. 30. Response of roots and stems to the force of gravity, or geotropism. Plant a fast-growing seedling in a pot so that the plumule extends through the drain hole and suspend the pot with mouth up (i.e. in the usual position). Or use a pot in which a plant is already growing, cover with cloth or wire gauze to prevent the soil from falling, and suspend the pot in an inverted position (Fig. $5 \mathrm{I}$ ). Notice the behavior of the stem, and after a few days remove the soil and observe the position of the root. 31 . If a pot is laid on one side, and changed every two days and laid on its opposite side, the effect on the root and stem will be interesting. 32. If a fleshy root is planted wrong end up, what is the result? Try it with pieces of horse-radish root. 33. By planting radishes on a slowly revolving wheel the effect of gravity may be neutralized. 34. Region of

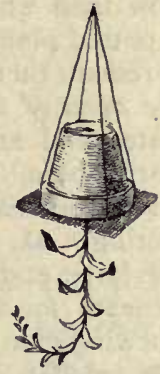

FIG. 5 I. PLANT GROWING IN INVERTED POT. root most sensitive to gravity. Lay on its side a pot containing a growing plant. After it has grown a few days, wash away the earth surrounding the roots. Which turned downward most decidedly, the tip of root or the upper part? 35. Soil texture. Carefully turn up soil in a rich garden or field so that you have unbroken lumps as large as a hen's egg. Then break these lumps apart carefully

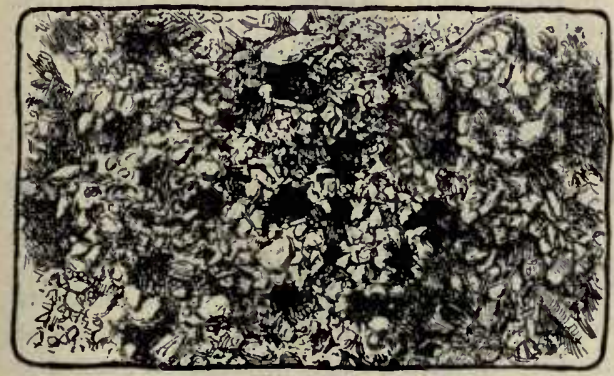

FIG. 52.- HOLES IN SOIL MADE BY ROOTS, now decayed. Somewhat magnified.

with the fingers and determine whether there are any traces or remains of roots (Fig. 52). Are there any pores, holes, or channels made by roots? Are the roots in them still living? 36. Compare another lump from a clay bank or pile where no plants have been growing. Is there any difference in texture? 37. Grind up this clay lump very fine, put it in a saucer, cover with water, and set in the sun. After a time it will have the appearance shown in the lower saucer in Fig. 43. Compare this with mellow garden soil. In which will plants grow best, even if the plant-food were the same in both? Why? 38. To test the effect of moisture on the plant, let a plant in a pot or box dry 
out till it wilts; then add water and note the rapidity with which it recovers. Vary the experiment in quantity of water applied. Does the plant call for water sooner when it stands in a sunny window than when in a cool shady place? Prove it. 39. Immerse a potted plant above the rim of the pot in a pail of water and let it remain there. What is the consequence? Why? 40. To test the effect of temperature on roots. Put one pot in a dish of ice water, and another in a dish of warm water, and keep them in a warm room. In a short time notice how stiff and vigorous is the one whose roots are warm, whereas the other may show signs of wilting. 41. The process of osmosis. Chip away the shell from the large end of an egg so as to expose the uninjured membrane beneath for an area about as large as a dime. With sealing-wax, chewing-gum, or paste stick a quill about three inches long to the smaller end of the egg. After the tube is in place, run a hat pin into it so as to pierce both shell and membrane; or use a short glass tube, first scraping the shell thin with a knife and then boring through it with the tube. Now set the egg upon the mouth of a pickle jar nearly full of water, so that the large end with the exposed membrane is beneath the water. After several hours, observe the tube on top of the egg to see whether the water has forced its way into the egg and increased its volume so that part of its contents are forced up into the tube. If no tube is at hand, see whether the contents are forced through the hole which has been made in the small end of the egg. Explain how the law of osmosis is verified by your result. If the eggshell contained only the membrane, would water rise into it? If there were no water in the bottle, would the egg-white pass down into the bottle? 42. The region of mast rapid growth. The pupil should make marks with waterproof ink (as Higgins' ink or indelible marking ink) on any soft growing roots. Place seeds of bean, radish, or cabbage between layers of blotting paper or thick cloth. Keep them damp and warm. When stem and root have grown an inch and a hilf long each, with waterproof ink mark spaces exactly one quarter inch apart (Figs. 48, 49). Keep the plantlets moist for a day or two, and it will be found that on the stem some or all of the marks are more than one quarter inch apart; on the root the marks have not separated. The root has grown beyond the last mark.

Note To TEACHER. - The microscopic structure of the root can be determined only by the use of the compound microscope; but a good general conception of the structure may be had by a careful attention to the text and pictures and to explanations by the teacher, if such microscopes are not to be had. See note at close of Chapter X. 


\section{CHAPTER IX}

\section{THE STEM - KINDS AND FORMS ; PRUNING}

The Stem System. - The stem of a plant is the part that bears the buds, leaves, flowers, and fruits. Its office is to hold these parts up to the light and air; and through its tissues the various food-materials and the life-giving fluids are distributed to the growing and working parts.

The entire mass or fabric of stems of any plant is called its stem system. It comprises the trunk, branches, and twigs, but not the stalks of leaves and flowers that die and fall away. The stem system may be herbaceous or woody, annual, biennial, or perennial ; and it may assume many sizes and shapes.

Stems are of Many Forms. - The general way in which a plant grows is called its habit. The habit is the appearance or general form. Its habit may be open or loose, dense, straight, crooked, compact, straggling, climbing, erect, weak, strong, and the like. The roots and leaves are the important functional or working parts; the stem merely connects them, and its form is exceedingly variable.

Kinds of Stems. - The stem may be so short as to be scarcely distinguishable. In such cases the crown of the plant - that part just at the surface of the ground - bears the leaves and flowers; but this crown is really a very short stem. The dandelion, Fig. 33, is an example. Such plants are often said to be stemless, however, in order to distinguish them from plants that have long or conspic- 
uous stems. These so-called stemless plants die to the ground every year.

Stems are erect when they grow straight up (Figs. 53, 54). They are trailing when they run along on the ground,

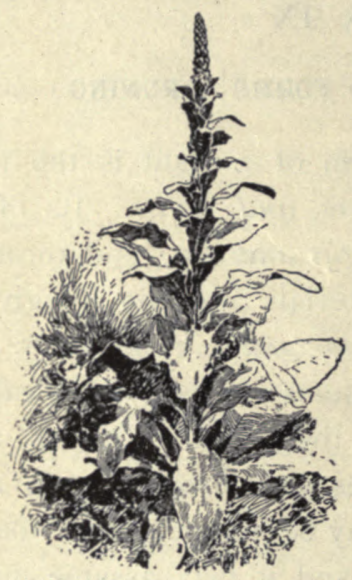

Fig. 53.- STRICT SiMPLE STEM OF MULLEIN.

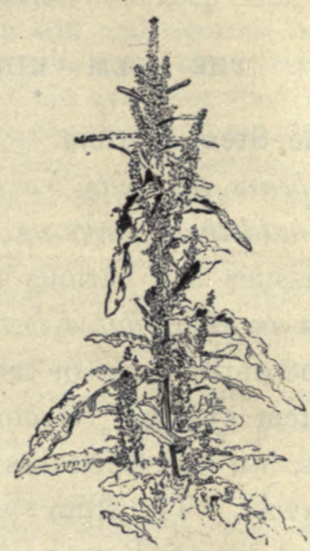

Fig. 54. - STRICT UPRIGHT STEM OF NARROW-LEAVED DOCK.

as melon, wild morning-glory (Fig. 55). They are creeping when they run on the ground and take root at places,

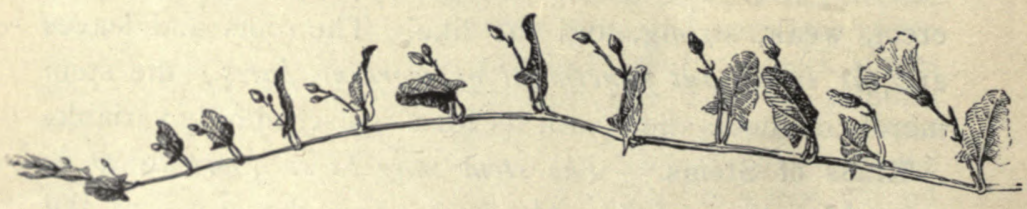

Fig. 55. - Trailing Stem of Wild Morning Glory (Convolvulus arvensis).

as the strawberry. They are decumbent when they lop over to the ground. They are ascending when they lie mostly or in part on the ground but stand more or less upright at their ends; example, a tomato. They are 
climbing when they cling to other objects for support (Figs. 36, 56).

Trees in which the main trunk or the "leader" continues to grow from its tip are said to be excurrent in growth. The branches are borne along the sides of the trunk, as in common pines (Fig. 57) and spruces. Excurrent means nunning out or running up.

Trees in which the main trunk does not continue are said to be deliquescent. The branches arise from one common point or from each other. The stem is lost in the branches. The apple tree, plum (Fig. 58), maple, elm, oak, China tree, are familiar examples. Deliquescent means dissolving or melting away.

Each kind of plant has its own peculiar habit or direction of growth; spruces always grow to a single stem or trunk, pear

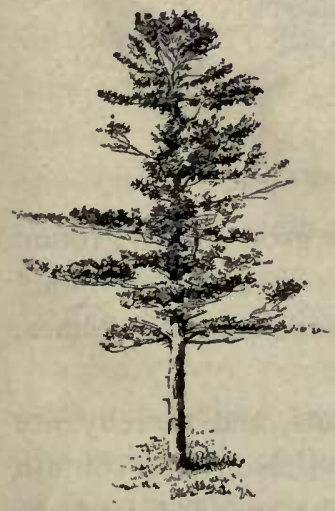

FIG. 57.- EXCURRENT

TRUNK. A pine.

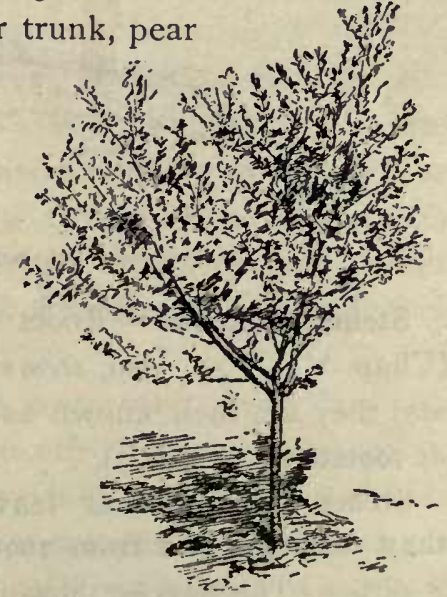

Fig. 58. - Deliquescent TRUNK OF PLUM TREE, 
trees are always deliquescent, morning-glories are always trailing or climbing, strawberries are always creeping. We do not know why each plant has its own habit, but the habit is in some way associated with the plant's gcnealogy or with the way in which it has becn obliged to live.

The stem may be simple or branched. A simple stem usually grows from the terminal bud, and side branches. either do not start, or, if they start, they soon perish. Mulleins (Fig. 53) are usually simple. So are palms.

Branched stems may be of very different habit and shape. Some stem systems are narrow and erect; these are said to be strict (Fig. 54). Others are diffuse, open, branchy, twiggy.

Nodes and Internodes. - The parts of the stem at which buds grow are called nodes or joints and the spaces between the buds are internodes. The stem at nodes is usually enlarged, and the pith is usually interrupted. The distance between the nodes is influenced by the vigor of the plant: how?

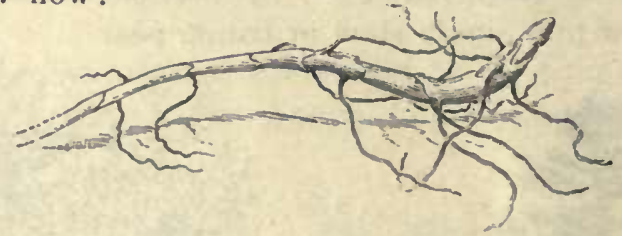

FIG. 59. - RHIZOME OR ROOTSTOCK.

Stems vs. Roots. - Roots sometimes grow above ground (Chap. VII); so, also, stems sometimes grow underground, and they are then known as subterranean stems, rhizomes, or rootstocks (Fig. 59).

Stems normally bear leaves and buds, and thereby are they distinguished from roots; usually, also, they contain a pith. The leaves, however, may be reduced to mere scales, and the buds beneath them may be scarcely visible. 
Thus the "eyes" on a white potato are cavities with a bud or buds at the bottom (Fig. 6o). Sweet potatoes have no evident "eyes" when first dug (but they may develop adventitious buds before the next growing-season). The white potato is a stem : the sweet potato is probably a root.

How Stems elongate. - Roots clongate by growing near the tip. Stems elongate by growing more or less throughout the young or soft part or "between joints" (Figs. 48, 49). But any part

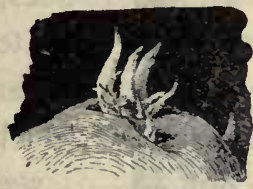

Fig. $60,-$ SPROUTS ARISING FROM THE BUDS, or eyes, of a potato tuber. of the stem soon reaches a limit beyond which it cannot grow, or becomes "fixed"; and the new parts beyond elongate until they, too, become rigid. When a part of the stem once becomes fixed or hard, it never increases in length: that is, the trunk or woody parts never grow longer or higher; branches do not become farther apart or higher from the ground.

Stems are modified in form by the particular or incidental conditions under which they grow. The struggle for light is the chief factor in determining the shape and direction of any limb (Chap. II). This is well illustrated in any tree or bush that grows against a building or on the margin of a forest (Fig. 4). In a very dense thicket the innermost trees shoot up over the others or they perish. Examine any stem and endeavor to determine why it took its particular form.

The stem is cylindrical, the outer part being bark and the inner part being wood or woody tissue. In the dicotyledonous plants, the bark is usually easily separated from the remainder of the cylinder at some time of the year; in monocotyledonous plants the bark is not free. Growth in thickness takes place inside the covering and not on the very 
outside of the plant cylinder. It is evident, then, that the covering of bark must expand in order to allow of the expan-

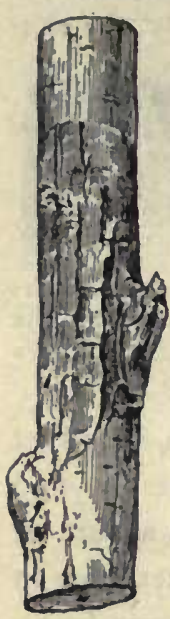

FIG. 61.--

Cracking

OF THE

BARK ON AN

ELM

BRANCH, sion of the woody cylinder within it. The tissues, therefore, must be under constant pressure or tension. It has been determined that the pressure within a growing trunk is often as much as fifty pounds to the square inch. The lower part of the limb in Fig. 6I shows that the outer layers of bark (which are long since dead, and serve only as protective tissue) have reached the limit of their expanding capacity and have begun to split. The pupil will now be interested in the bark on the body of an old elm tree (Fig. 62); and he should be able to suggest one reason why stems remain cylindrical, and why the old bark becomes marked with furrows, scales, and plates.

Most woody plants increase in diameter by the addition of an annual layer or "ring" on the outside of the woody cylinder, underneath the bark. The monocotyledonous plants comprise very few trees and shrubs in temperate climates (the palms, yuccas, and other tree-like plants are of this class), and they do not increase greatly in diameter and they rarely branch to any extent. Consult the woodpile for information as to the annual rings.

Bark-bound Trees. - If, for any reason, the bark should become so dense and strong that the trunk cannot expand, the tree is said to be "bark-bound." Such condition is not rare in orchard trees that have been neglected. 
When good tillage is given to such trees, they may not be able to overcome the rigidity of the old bark, and, therefore, do not respond to the treatment. Sometimes the thinner-barked parts may outgrow in diameter the trunk or the old branches below them. The remedy is to release the tension. This may be done either by softening the bark (by washes of soap or lye), or by separating it. The latter is done by slitting the bark-bound part (in spring), thrusting the point of a knife through the bark to the wood and then drawing the blade down the entire length of the barkbound part. The slit is scarcely discernible at first, but it opens with the growth of the tree, filling up with new tissue beneath. Let the pupil consider the ridges which he now and then finds on trees, and determine whether they have any significance - whether the tree has ever been released or injured by natural agencies.

The Tissue covers the Wounds and "heals" them.

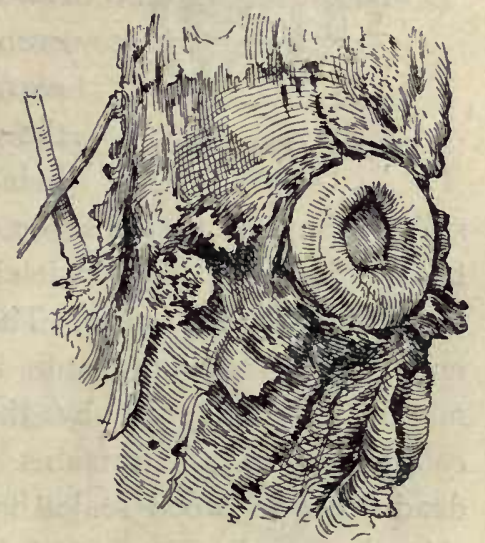

Fig. 63.- Proper CU'Tring OF A BRANCH. The wound will soon be "healed."

- This is seen in Fig. 63, in which a ring of tissue rolls out over the wound. This ring of healing tissue forms most rapidly and uniformly when the wound is smooth and regular. Observe the healing on broken and splintered limbs; also the difference in rapidity of healing between wounds on strong and weak limbs. There is difference in the rapidity of the healing process in different kinds of trees. Compare the apple tree and the peach. This tissue may in 
turn become bark-bound, and the healing may stop. On large wounds it progresses more rapidly the first few years

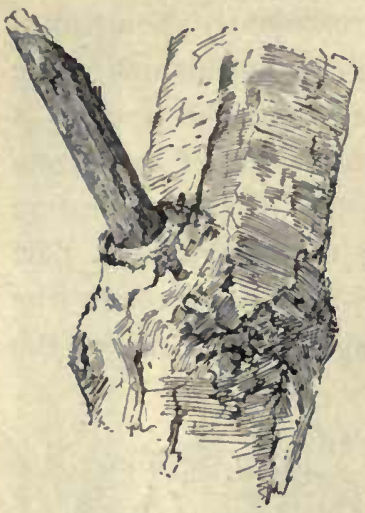

FIG. 64. - ERRONEOUS PRUNING. than it does later. This roll or ring of tissue is called a callus.

The callus grows from the living tissue of the stem just about the wound. It cannot cover long dead stubs or very rough broken branches (Fig. 64). Therefore, in pruning the branches should be cut close to the trunk and made even and smooth; all long stubs must be avoided. The seat of the wound should be close to the living part of the trunk, for the

stub of the limb that is severed has no further power in itself of making healing tissue. The end of the remaining stub is merely covered over by the callus, and usually remains a dead piece of wood sealed inside the trunk (Fig. 65). If wounds do not heal over speedily, germs and fungi obtain foothold in the dying wood and rot sets in. Hollow trees are those in which the decayfungi have progressed into the inner wood of the trunk; they have been infected (Fig. 66).

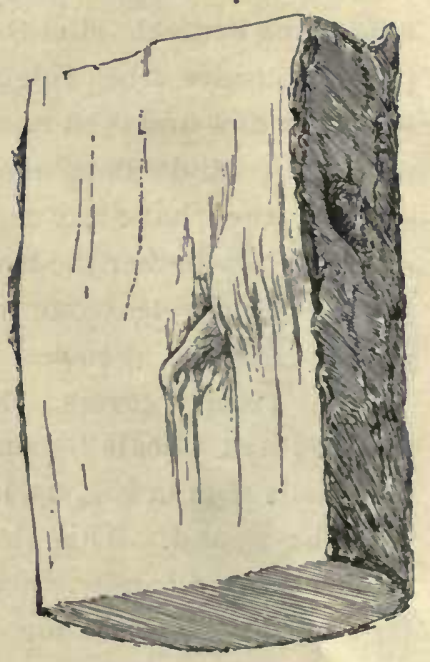

FIG. 65. - KNOT IN A HEMLOCK LOG.

Large wounds should be protected with a covering of paint, melted wax, or other adhesive and lasting material, 


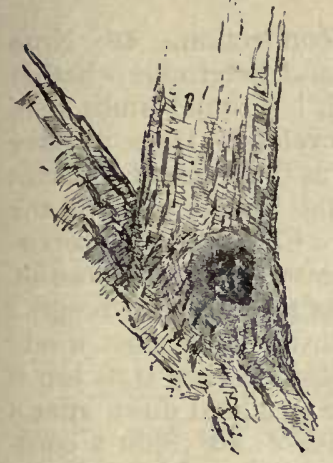

Fig. 66.-A KNOT HOLE, and the beginning of a hollow trunk.

to keep out the germs and fungi. A covering of sheet iron or tin may keep out the rain, but it will not exclude the germs of decay; in fact, it may provide tlie very moist conditions that such germs need for their growth. Deep holes in trees should be treated by having all the decayed parts removed down to the clean wood, the surfaces painted or otherwise sterilized, and the hole filled with wax or cement.

Stems and roots are living, and they should not be wounded or mutilated unnecessarily. Horses should never be hitched to trees. Supervision should be exercised over persons who run telephone, telegraph, and electric light wires, to see that they do not mutilate trees. Electric light wires and trolley wires, when carelessly strung or improperly insulated, may kill trees (Fig. 67).

SugGestions. - Forms of stems. 43. Are the trunks of trees ever perfectly cylindrical? If not, what may cause the irregularities? Do trunks often grow more on one side than the other? 44. Slit a rapidly growing limb, in spring, with a knife blade, and watch the result during the season. 45. Consult the woodpile, and observe the variations in thickness of the annual rings, and especially of the same ring at different places in the circumference. Cross-sections of

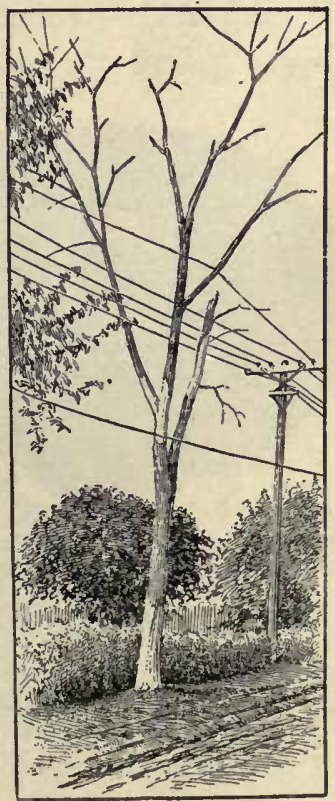

FIG. 67.-ELM TREE KILLED BY A DIRECT CURRENT FROM AN ELECTRIC RAILROAD SYSTEM. 
horizontal branches are interesting in this connection. 46. Note the enlargement at the base of a branch, and determine whether this enlargement or bulge is larger on long, horizontal limbs than on upright ones. Why does this bulge develop? Does it serve as a brace to the limb, and is it developed as the result of constant strain? 47. Strength of stems. The pupil should observe the fact that a stem has wonderful strength. Compare the proportionate height, diameter, and weight of a grass stem with those of the slenderest tower or steeple. Which has the greater strength? Which the greater height? Which will withstand the most wind? Note that the grass stem will regain its position even if its top is bent to the ground. Note how plants are weighted down after a heavy rain and how they recover themselves. 48. Split a cornstalk and observe how the joints are tied together and braced with fibers. Are there similar fibers in stems of pigweed, cotton, sunflower, hollyhock?

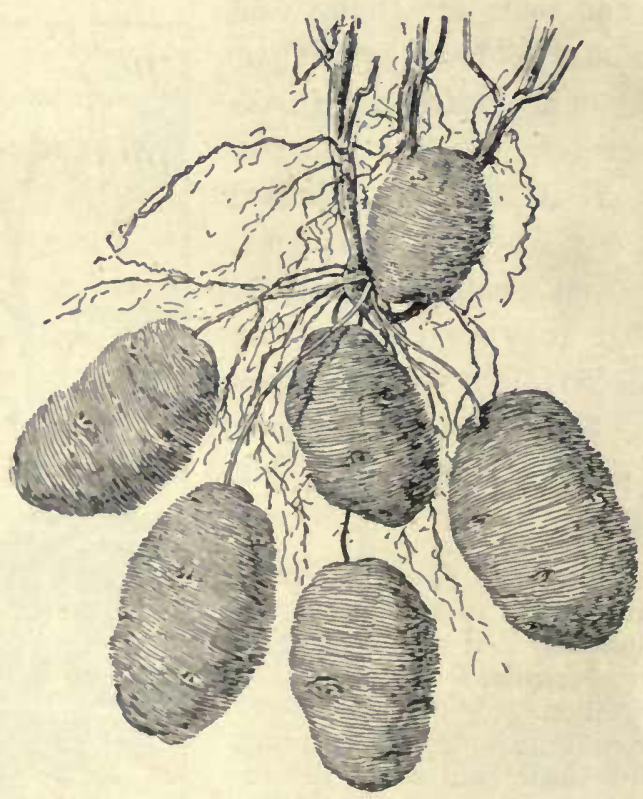

FIG. 68. - POTATo. What are roots, and what stems? Has the plant more than one kind of stem? more than two kinds ? Explain. 


\section{CHAPTER X \\ THE STEM - ITS GENERAL STRUCTURE}

THERE are two main types of stem structure in flowering plants, the differences being based on the arrangement of bundles or strands of tissue. These types are endogenous and exogenous (page 20). It will require patient laboratory work to understand what these types and structures are.

Endogenous, or Monocotyledonous Stems. - Examples of endogenous stems are all the grasses, cane-brake, sugarcane, smilax or green-brier, palms, banana, canna, bamboo, lilies, yucca, asparagus, all the cereal grains. For our study, a cornstalk may be used as a type.

A piece of cornstalk, either green or dead, should be in the hand of each pupil while studying this lesson. Fig. 69 will also

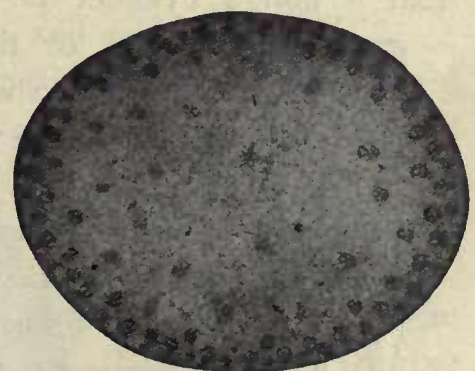

Fig. 69. - Cross-Section OF. CORNSTALK, showing the scattered fibrovascular bundles. Slightly enlarged. be of use. Is there a swelling at the nodes? Which part of the internode comes nearest to being perfectly round? There is a grooved channel running along one side of the internode: how is it placed with reference to the leaf? with reference to the groove in the internode below it? What do you find in each groove at its lower end? (In a dried stalk only traces of this are usually seen.) Does any bud on a cornstalk besides the one at 
the top ever develop? Where do suckers come from? Where does the ear grow?

Cut a cross-section of the stalk between the nodes (Fig. 69). Does it have a distinct bark? The interior consists of soft "pith" and tough woody parts. The wood is found in strands or fibers. Which is more abundant? Do the

- fibers have any definite arrangement? Which strands are largest? Smallest? The firm smooth rind (which cannot properly be called a bark) consists of small wood strands packed closely together. Grass stems are hollow cylinders; and the cornstalk, because of the lightness of its contents, is also practically a cylinder. Stems of this kind are admirably adapted for providing a strong support to leaves and fruit. This is in accordance with the well-known law that a hollow cylinder is much stronger than a solid

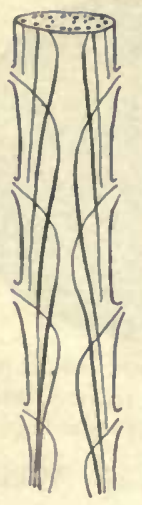

Fig. 70. - DiAGRAM TOSIIOW THE COURSE OF Finro-vascuLAR BUNDLES IN MosocotyLEDONS. cylinder of the same weight of material. Cut a thin slice of the inner soft part and hold it up to the light. Can you make out a number of tiny compartments or cells ? These cells consist of a tissue called parenchyma, the tissue from which when young all the other tissues arise and differentiate (Parenchyma $=$ parent + chyma, or tissue). The numerous walls of these cells may serve to brace the outer wall of the cylinder; but their chief function in the young stalk is to give origin to other cells. When alive they are filled with cell sap and protoplasm.

Trace the woody strands through the nodes. Do they ascend vertically? Do they curve toward the rind at certain places? Compare their course with the strands shown in Fig. 70. The zuoody strands consist chiefly of tough fibrous cells that give rigidity 
and strength to the plant, and of long tubular intermpted canals that serve to convey sap upward from the root and to convey food downward from the leaves to the stem and roots.

Monocotyledons, as shown by fossils, existed before dicotyledons appeared, and it is thought that the latter were developed from ancestors of the former. It will be interesting to trace the relationship in stem structure. It will first be necessary to learn something of the structure of the wood strand.

Wood Strand in Monocotyledons and Dicotyledons. - Each wood strand (or fibro-vascular bundle) consists of two parts - the bast and the wood proper. The wood is on the side of the strand toward the center of the stem and con-

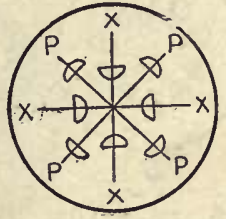

FIG. 7I, - DiAgRAM OF WOOD STRANDS OR FIBRO-VASCULAR BUNDLES IN A ROOT, showing the wood $(x)$ and bast

(p) separated. tains large tubular canals that take the watery sap upward from the roots. The bast is on the side toward the bark

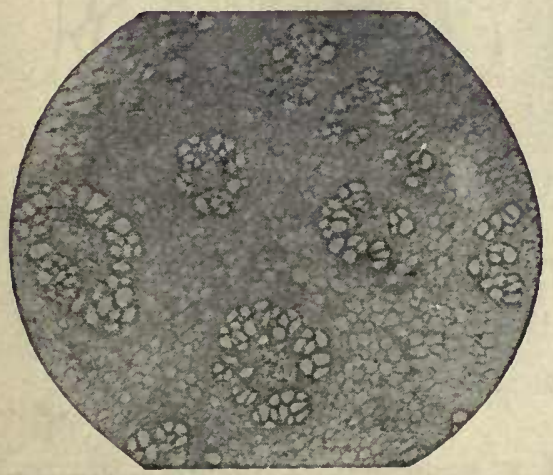

Fig. 72. - PART OF CROSS-SECTION OF ROOTSTOCK OF ASPaRAGUS, showing a few fibrovascular bundles. An endogenous stem. and contains fine tubes through which diffuses the dense sap containing digested food from the leaves. In the root (Fig. 7I) the bast and the wood are separate, so that there are two kinds of strands.

In monocotyledons, as already said, the strands (or bundles) are usually scattered in the stem with no definite arrangement (Figs. 72, 73). In dicotyledons the strands, or bundles, are arranged in a 


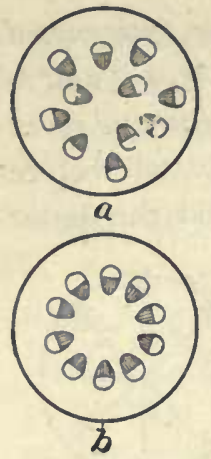

FIG. 73. - THE SCATTERED BUNDLES OR SIRANDS, in monocotyledons at $a_{3}$ and the bun. dles in a circle in dicotyledons at $b$.
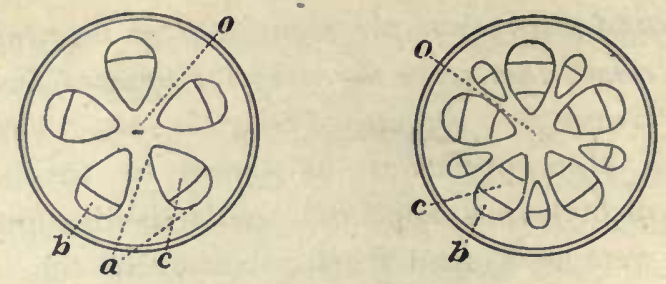

Fig. 74. - Dicotyledonous Stem of ONE YeAR AT LEFT WITH FIVE BUNDLFS, and a two-year stem at right.

0 , the pith; $c$, the wood part; $b$, the bast part; $a$, one year's growth. ring. As the dicotyledonous seed germinates, five bundles are usually formed in its hypocotyl (Fig. 74); soon five more are interposed between them, and the multiplication continues, in tough plants, until the bundles touch (Fig. 74, right). The inner parts thus form a ring of wood and the outer parts form the inner bark or bast. A new ring of wood or bast is formed on stems of dicotyledons each year and the age of a cut stem is easily determined:

When cross-sections of monocotyledonous and dicotyledonous bundles are examined under the microscope, it is readily seen

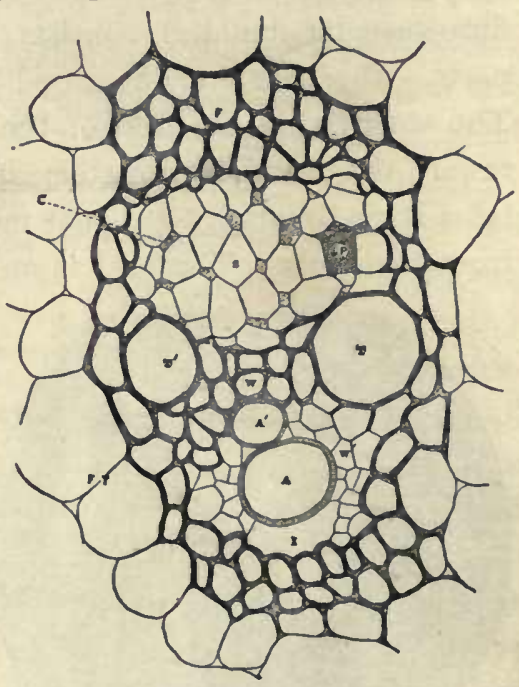

Fig. 75. - Fibro-vascular Bundle of INDIAN CORN, much magnified.

$A$, annular vessel : $A^{\prime}$, a.jnular or spiral vessel : $T T^{*}$, thick-walled vessels: $W$, tracheids or woody tissue: $F$, sheath of fibrous tissue surrounding the bundle: $F T$, fundamental tissue or pith; $S$, sieve tissue: $P$, sieve plate: $C$, companion cell ; $I$, intercellular space, formed by tearing down of adjacent cells; $W^{\prime}$, wood parenchyma. 
why dicotyledonous bundles form rings of wood and monocotyledonous cannot (Figs. 75 and 76). The dicotyledonous bundle (Fig. 76) has, running across it, a layer of brickshaped cells called cambium, which cells are a specialized form of the parenchyma cells and retain the power of
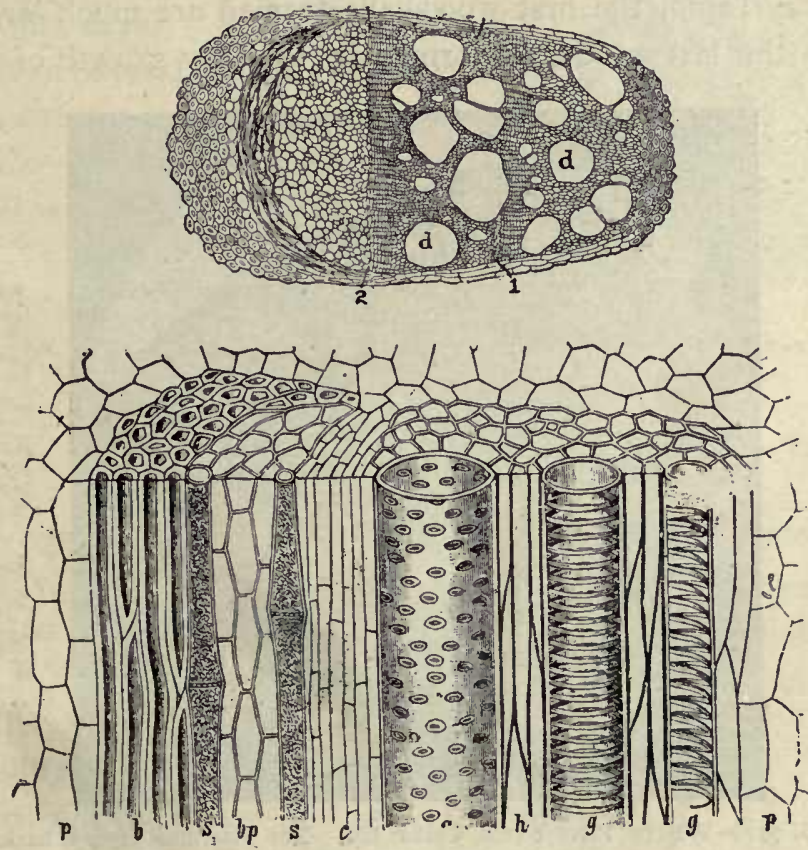

Fig. 76. - THE Dicotyledonous BUNDLE OR WOOD STRAND. Upper figure is of moonseed :

$c$, cambium ; $d$, ducts ; 1 , end of first year's growth ; 2 , end of second year's growth ; bast part at left and wood part at right. Lower figure (from Wettstein) is sunflower: $h$, woodcells; $g$, vessels; $c$, cambium; $p$, fundamental tissue or parenchyma; $b$, bast; $b p$, bast parenchyma; $s$, sieve-tubes.

growing and multiplying. The bundles containing cambium are called open bundles. There is no cambium in monocotyledonous bundles (Fig. 75) and the bundles are called closed bundles. Monocotyledonous stems soon cease to grow in diameter. The stem of a palm tree is almost 
as large at the top as at the base. As dicotyledonous plants grow, the stems become thicker each year, for the delicate active cambium layer forms new cells from early spring until midsummer or autumn, adding to the wood within and to the bark without. As the growth in spring is very rapid, the first wood-cells formed are much larger than the last wood-cells formed by the slow growth of the

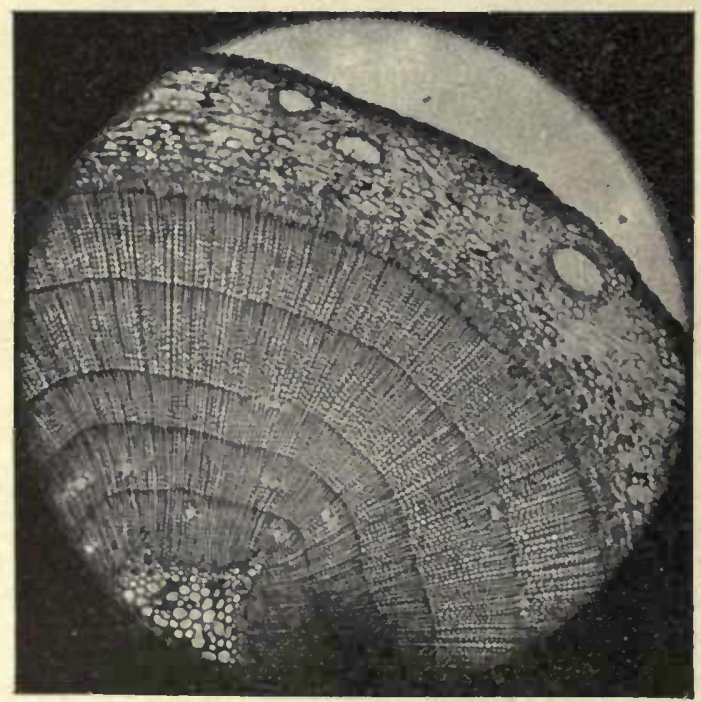

FIG. 77.-White PINE STEM, 5 years old. The outermost layer is bark.

late season, and the spring wood is less dense and lighter colored than the summer wood; hence the time between two years' growth is readily made out (Figs. 77 and 78 ). Because of the rapid growth of the cambium in spring and its consequent soft walls and fluid contents, the bark of trees "peels" readily at that season.

Medullary Rays. - The first year's growth in dicotyledons forms a woody ring which almost incloses the pith, and this is left as a small cylinder which does not grow 
larger, even if the tree should live a century. It is not quite inclosed, however, for the narrow layers of soft cells separating the bundles remain between them (Fig. 78), forming radiating lines called medullary rays or pith rays.

The Several Plant Cells and their Functions. - In the wood there are some parenchyma cells that are still with thin walls, but have lost

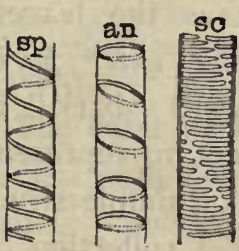

FIG. 79.- MARKINGS

IN CELL WALLS OF WOOD FIBERS. $s p$, spiral ; $a n$, annular: sc, scalariform. the power of division. They are now storage cells. There are also

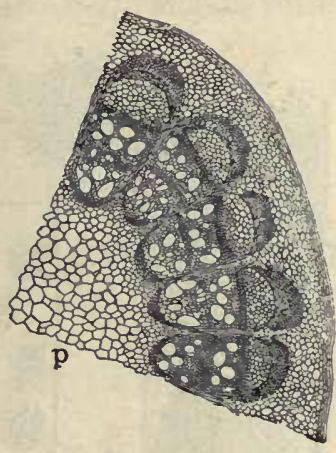

FIG. 78. - ARRANGEMENT OF TISSUES IN TWO-YEAR OLD STEM OF MOONSEED. wood fibers which $p$, pith; $f$, parenchyma. The fibroare thick-walled and rigid $(h$, Fig. vascular bundles, or wood strands, are very prominent, with thin medullary rays between.

$76)$, and serve to support the sap-canals or wood vessels (or tracheids) that are formed by the absorption of the end walls of upright rows of cells; the canals pass from the roots to the twigs and even to ribs of the leaves and serve to transport the root water. They are recognized (Fig. 79) by the peculiar thickening of the wall on the inner surface of the tubes, occurring in the form of spirals. Sometimes the whole wall is thickened except in spots called pits ( $g$, Fig. 76). These thin spots (Fig. 80) allow the sap to pass to other cells or to neighboring vessels.

The cambium, as we have seen, consists of cells whose function is growth. These

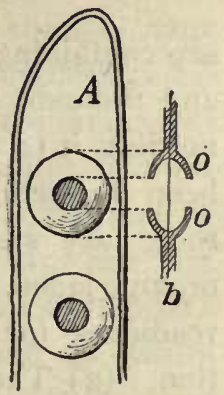

FIG. 80. - PITS IN The Cell Wall.

Longitudinal section of wall at $b$, showing pit borders at 0,0 . 
cells are thin-walled and filled with protoplasm. During the growing season they are continually adding to the

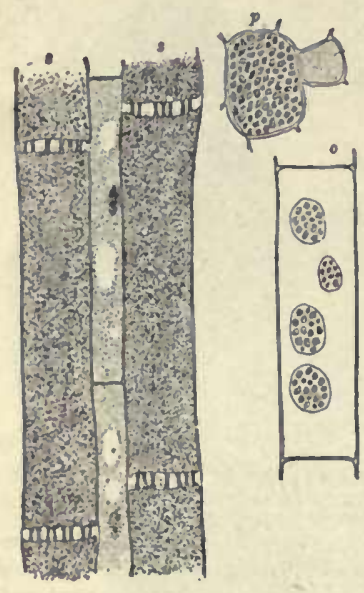

FIG. 81. - SIEVE-TUBES, s, s;

phows a top view of a sieve-plate, with a companion cell, $c$, at the side: O shows sieve-plates in the side of the cell. In $s, s$ the protoplasm is shrunken from the walls by reageuts. wood within and the bark without ; hence the layer moves outward as it deposits the new woody layer within.

The bark consists of inner or fibrous bark or new bast (these fibers in flax become linen), the green or middle bark which functions somewhat as the leaves, and the corky or outer bark. The common word "bark" is seen therefore not to represent a homogeneous or simple structure, but rather a collection of several kinds of tissue, all separating from the wood beneath by means of cambium. The new bast contains (I) the sieve-tubes (Fig. 8I) which transport the sap containing organic substances, as sugar and proteids, from the leaves to the parts needing it (s, Fig. 76). These tubes have been formed like the wood vessels, but they have sieve-plates to allow the dense organic-laden sap to pass with sufficient readiness for purposes of rapid distribution. (2) There are also thick-walled bast fibers (Fig. 82) in the bast that serve for support. (3) There is also some parenchyma (parent tissue) in the new bast; it is now in part a storage tissue. Some-

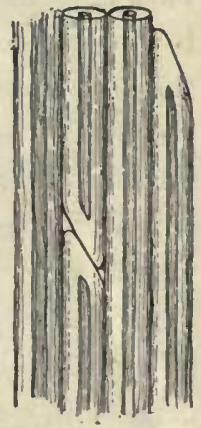

FIG. 82.-THICKWALLED BAST Cells. 
times the walls of parenchyma cells in the cortex thicken at the corners and form brace cells (Fig. 83) (collenchyma) for support; sometimes the whole wall is thickened, forming grit cells or stone cells (Fig.

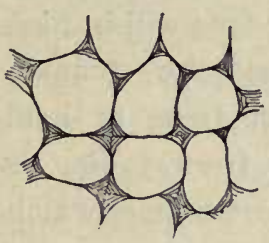

FIG. 83. - COLLEN CHYMA IN WILD JEWELWEED OR TOUCH-ME-NOT (IMPATIENS).
84 ; examples in tough parts of pear, or in stone of fruits). Some parts serve for secretions (milk, rosin, etc.) and are called latex tubes.

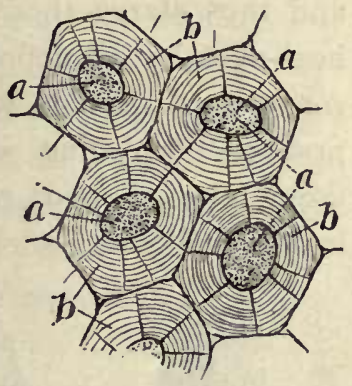

FIG. 84. - GRIT CELLS.

The outer bark of old shoots consists of corky cells that protect from mechanical injury, and that contain a fatty substance (suberin) impermeable to water and of service to keep in moisture. There is sometimes a cork cambium (or phellogen) in the bark that serves to extend the bark and keep it from splitting, thus increasing its power to protect.

Transport of the "Sap."-We shall soon learn that the common word "sap" does not represent a single or simple substance. We may roughly distinguish two kinds of more or less fluid contents: (1) the root water, sometimes called mineral sap, that is taken in by the root, containing its freight of such inorganic substances as potassium, calcium, iron, and the rest ; this root water rises, we have found, in the rood vessels, - that is, in the young or "sapwood" (p. 96); (2) the elaborated or organized materials passing back and forth, especially from the leaves, to build up tissues in all parts of the plant, some of it going down to the roots and root-hairs; this organic material is transported, as we have learned, in the sieve-tubes of the inner bast, - that is, in the "inner bark." Removing the bark from a trunk in 
a girdle will not stop the upward rise of the root water so long as the wood remains alive; but it will stop the passage of the elaborated or food-stored materials to parts below and thus starve those parts; and if the girdle does not heal over by the deposit of new bark, the tree will in time starie to death. It will now be seen that the common practice of placing wires or hoops about trees to hold them in position or to prevent branches from falling is irrational, because such wires interpose barriers over which

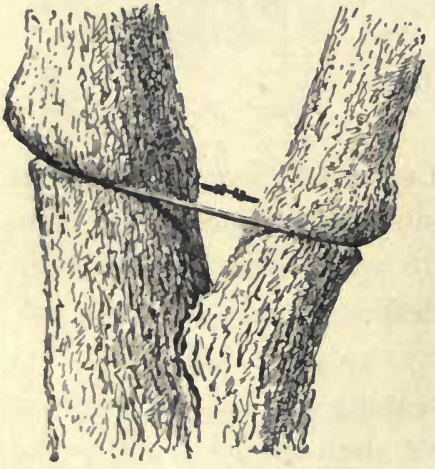

Fig. 85. - THE WRONG WAY TO BRACE, A TRER, (See Fig. I18). the fluids cannot pass; in time, as the trunk increases in diameter, the wire girdles the tree. It is much better to bolt the parts together by rods extending through the branches (Fig. 85). These bolts should fit very tight in their holes. Why?

Wood. - The main stem or trunk, and sometimes the larger branches, are the sources of lumber and timber. Different kinds of wood have value for their special qualities. The business of raising wood, for all purposes, is known as forestry. The forest is to be considered as a crop, and the crop must be harvested, as much as corn or rice is harvested. Man is often able to grow a more productive forest than nature does.

Resistance to decay gives value to wood used for shingles (cypress, heart of yellow pine) and for fence posts (mulberry, cedar, post oak, bois d'arc, mesquite).

Hardness and strength are qualities of great value in building. Live oak is used in ships. Red oak, rock maple, 
and yellow pine are used for floors. The best flooring is sawn with the straight edges of the annual rings upward; tangential sawn flooring may splinter. Chestnut is common in some parts of the country, being used for ceiling and inexpensive finishing and furniture. Locust and bois d'arc (osage orange) are used for hubs of wheels; bois d'arc makes a remarkably durable pavement for streets. Ebony is a tropical wood used for flutes, black piano keys, and fancy articles. Ash is straight and elastic; it is used for handles for light implements. Hickory is very strong as well as elastic, and is superior to ash for handles, spokes, and other uses where strength is wanted. Hickory is never sawn into lumber, but is split or turned. The "second growth," which sprouts from stumps, is most useful, as it splits readily. Fast.growing hickory in rich land is most valuable. The supply of useful hickory is being rapidly exhausted.

Softness is often important. White pine and sweet gum because of their softness and lightness are useful in boxmaking. "Georgia" or southern pine is harder and stronger than white pine; it is-much used for floors, ceilings, and some kinds of cabinet work. White pine is used for window-sash, doors, and molding, and cheaper grades for flooring. Hemlock is the prevailing lumber in the east for the framework and clapboarding of buildings. Redwood and Douglas spruce are common building materials on the Pacific coast. Cypress is soft and resists decay and is superior to white pine for sash, doors, and posts on the outside of houses. Cedar is readily carved and has a unique use in the making of chests for clothes, as its odor repels moths and other insects. Willow is useful for baskets and light furniture. Basswood or linden is used for light ceiling and sometimes for cheap floors.

Whitervood 
(incorrectly called poplar) is employed for wagon bodies and often for house finishing. It often resembles curly maple.

Beauty of grain and polish gives wood value for furniture, pianos, and the like. Mahogany and whitc oak are most beautiful, although red oak is also used. Oak logs which are first quartered and then sawn radially expose the beautiful silver grain (medullary rays). Fig. 86 shows one

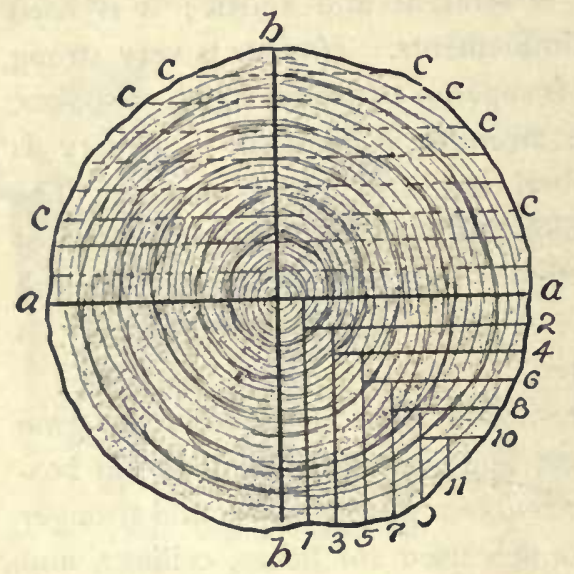

FIG, 86. - THE MAKING OF ORIINARY BOARDS, ANU ONE WAY OF MAKING "QUARTEREI" BOA K US. mode of quartering. The log is quartered on the lines $a, a, b, b$; then succeeding boards are cut from each quarter at $I$, 2,3 , etc. The nearer the heart the better the "grain": why? Ordinary boards are sawn tangentially, as c,c. Curly pine, curly walnut, and bird's-eye maple are woods that owe their beauty of grain to wavy lines or buried knots. Merely a stump of curly walnut is worth several hundred dollars. Such wood is sliced very thin for veneering and glued over other woods in making pianos and other pieces. If the cause of wavy grain could be found out and such wood grown at will, the discovery would be very useful. Maple is much used for furniture. Birch may be colored so as very closely to represent mahogany, and it is useful for desks.

Special Products of Trees. - Cork from the bark of the cork oak in Spain, latex from the rubber and sap from the 
sugar maple trees, turpentine from pine, tannin from oak bark, Peruvian bark from cinchona, are all useful products.

Suggestions. - Parts of a root and stem through which liquids rise. 49. Pull up a small plant with abundant leaves, cut off the root so as to leave two inches or more on the plant (or cut a leafy shoot of squash or other strong-growing coarse plant), and stand it in a bottle with a little water in the bottom which has been colored with red ink (eosin). After three hours examine the root; make cross-sections at several places. Has the water colored the axis cylinder? The cortex? What is your conclusion? Stand some cut flowers or a leafy plant with cut stem in the same solution and examine as before: conclusion? 50. Girdle a twig of a rapidly growing bush (as willow) in early spring when growth begins (a) by very carefully removing only the bark, and $(b)$ by cutting away. also the sapwood. Under which condition do the leaves wilt? Why? 51. Stand twigs of willow in water; after roots have formed under the water, girdle the twig (in the two ways) above the roots. What happens to the roots, and why? 52. Observe the swellings on trees that have been girdled or very badly injured by wires or otherwise: where are these swellings, and why? 53. Kinds of wood. Let each pupil determine the kind of wood in the desk, the floor, the door and window casings, the doors themselves, the sash, the shingles, the fence, and in the small implements and furniture in the room; also what is the cheapest and the most expensive lumber in the community. 54. How many kinds of wood does the pupil know, and what are their chief uses?

Note to Teacher. - The work in this chapter is intended to be mainly descriptive, for the purpose of giving the pupil a rational conception of the main vital processes associated with the stem, in such a way that he may translate it into his daily thought. It is not intended to give advice for the use of the compound microscope. If the pupil is led to make a careful study of the text, drawings, and photographs on the preceding and the following pages, he will obtain some of the benefit of studying microscope sections without being forced to spend time in mastering microscope technique. If the school is equipped with compound microscopes, a teacher is probably chosen who has the necessary skill to manipulate them and the knowledge of anatomy and physiology that goes naturally with such work; and it would be useless to give instruction in such work in a text of this kind. The writer is of the opinion that the introduction of the compound microscope into first courses in botany has been productive of harm. Good and vital teaching demands first that the pupil have a normal, 
direct, and natural relation to his subject, as he commonly meets it, that the obvious and significant features of the plant world be explained to him and be made a means of training him. The beginning pupil cannot be expected to know the fundamental physiological processes, nor is it necessary that these processes should be known in order to have a point of view and trained intelligence on the things that one customarily sees. Many a pupil has had a so-called laboratory course in botany without having arrived at any real conception of what plants mean, or without having had his mind opened to any real sympathetic touch with his environment. Even if one's knowledge be not deep or extensive, it may still be accurate as far as it goes, and his outlook on the subject may be rational.

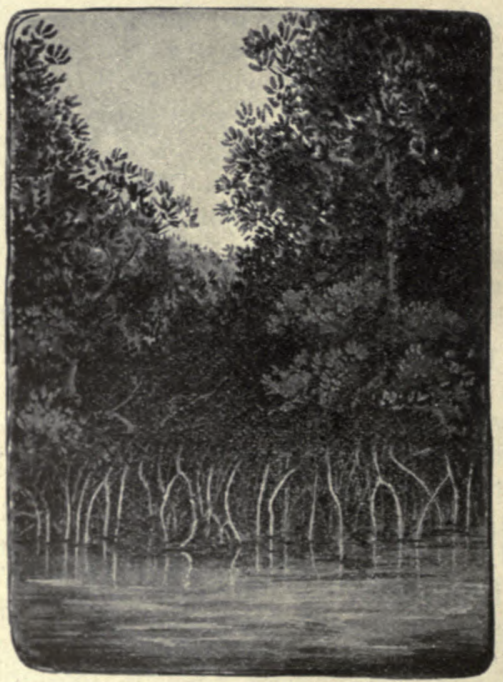

Fig. 87.- The MANY-STemmed Thickets of MANgrove of SouthernMOST SEACOASTS, many of the trunks being formed of aërial roots. 


\section{CHAPTER XI}

\section{LEAVES - FORM AND POSITION}

LEAVES may be studied from four points of view, - with reference (I) to their kinds and shapes; (2) their position, or arrangement on the plant ; (3) their anatomy, or structure;

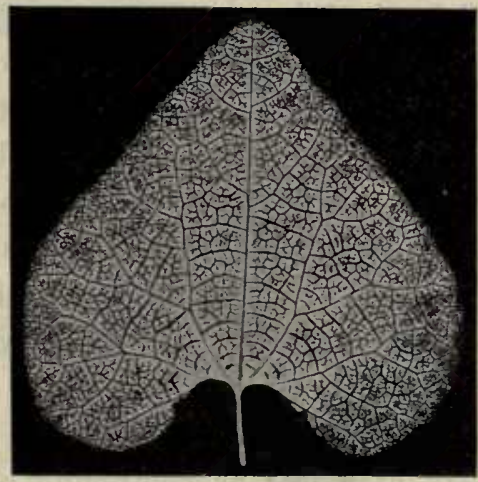

Fig. 88. - A Simple NetTed-veined Leaf.

(4) their function, or the work they perform. This chapter is concerned with the first $\&$ two categories.

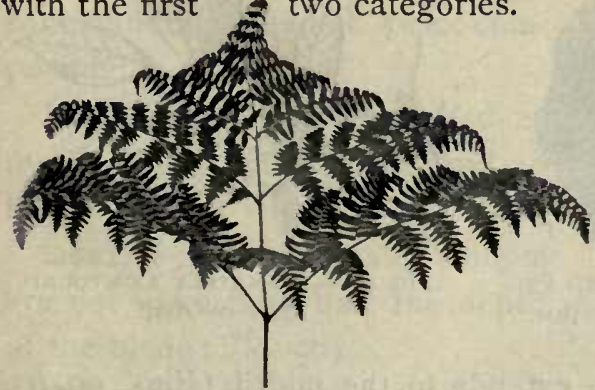

Fig. 90.-COMPOUND OR BRANCHED LEAF OF BRAKE (a common fern).

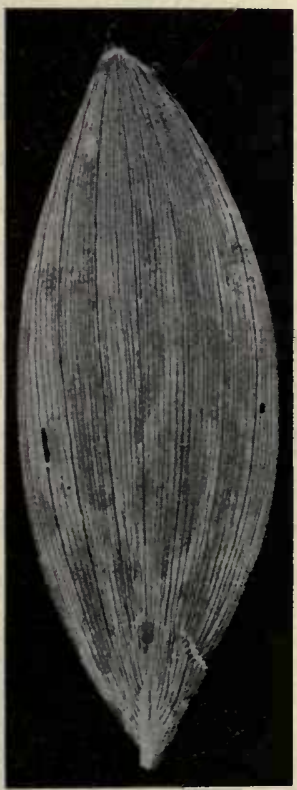

FIG. 89.-A SIMPLE PARALLEL-VEINED LEAF.

Kinds. - Leaves are simple or unbranched (Figs. 88, $89)$, and compound or branched (Fig. 90). 
The method of compounding or branching follows the mode of veining. The veining, or venation, is of two gen-

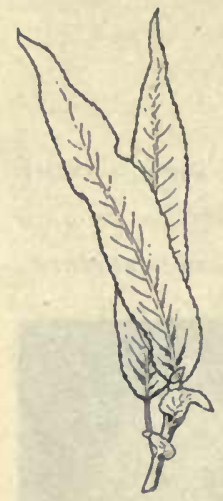

Fig. 91. - CoMPLETE LEAVES OF

WILLOW. eral kinds: in some plants the main veins diverge, and there is a conspicuous network of smaller veins; such leaves are netted-veined. They are characteristic of the dicotyledons. In other plants the main veins are parallel, or nearly so, and there is no conspicuous network; these are parallel-veined leaves (Figs. 89, I02). These leaves are the rule in monocotyledonous plants. The venation of nettedveined leaves is pinnate or feather-like when the veins arise from the side of a continuous midrib (Fig. 9I); palmate or digitate (hand-like) when the veins arise from the apex of the petiole (Figs. 88, 92). If leaves were divided between the main veins, the former would be pinnately and the latter digitately compound.

It is customary to speak of a leaf as compound only when the parts or branches are completely separate blades,

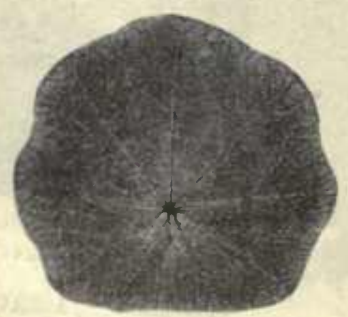

Fig. 92. - Digitate-Veined PELTATE LEAF OF NASTURTIUM.

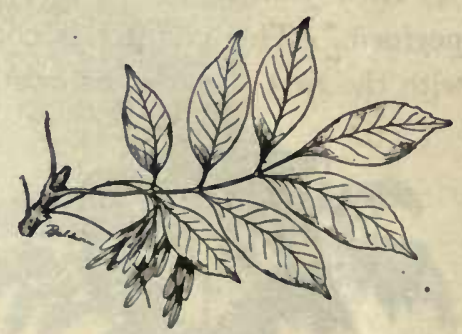

Fig. 93.- PINNATELY COMPOUND LEAF OF ASH.

as when the division extends to the midrib (Figs. 90, 93, 94, 95). The parts or branches are known as leaflets. 
Sometimes the leaflets themselves are compound, and the whole leaf is then said to be bi-compound or twice-com-

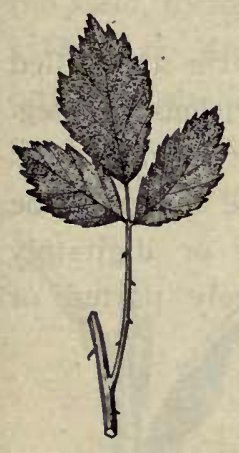

FIG. 94. - DIGITATELY COMPOUND LEAF OF RASPBERRY.

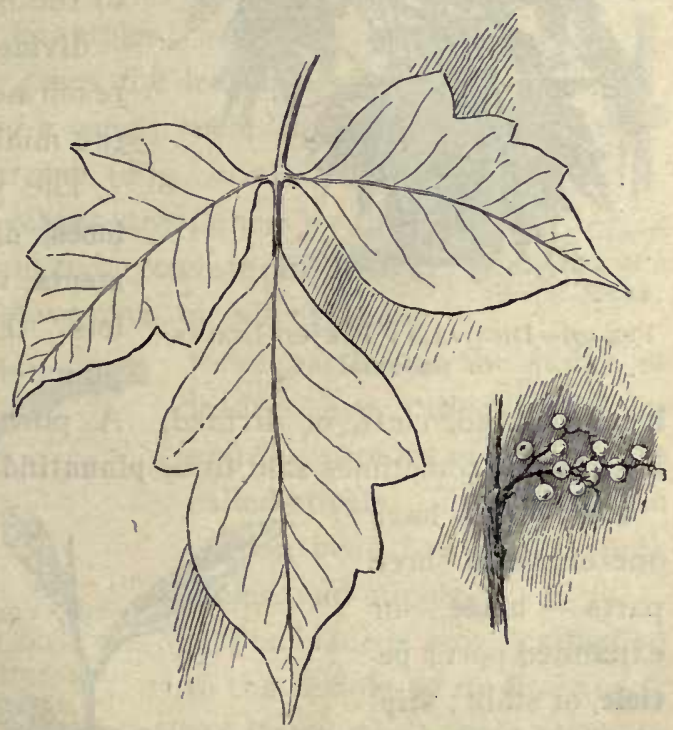

Fig. 95. - PoIson IVy. LeAf and Fruit.

pound (Fig. 90). Some leaves are three-compound, fourcompound, or five-compound. Decompound is a general term to express any degree of compounding beyond twice-compound.

Leaves that are not divided as far as to the midrib are said to be :

lobed, if the openings or sinuses are not more than half the depth of the blade (Fig. 96);

cleft, if the sinuses are deeper than the middle;

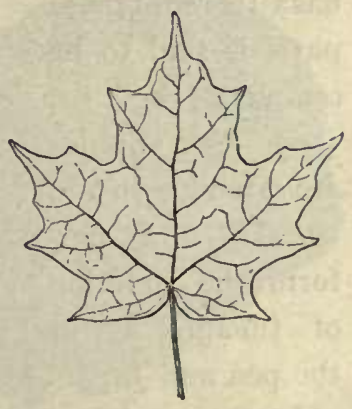

FIG. 96. - LOBED LEAF OF SUGAR MaPLE. 


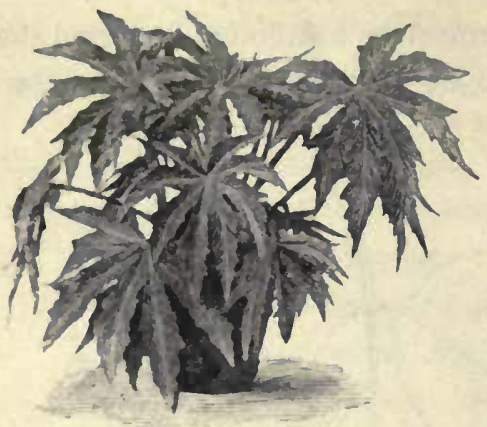

Fig. 97. - Digitately Parted Leaves OF BEGONIA.

parted, if the sinuses reach two thirds or more to the midrib (Fig. 97); divided, if sinuses reach nearly or quite to the midrib.

The parts are called lobes, divisions, or segments, rather than leaflets. The leaf may be pinnately or digitately lobed, parted, cleft, or divided. A pinnately parted or cleft leaf is sometimes said to be pinnatifid.

Leaves may have one or all of three parts - blade, or expanded part; petiole, or stalk ; stipules, or appendages at the base of the petiole. A leaf that has all three of these parts is said to be complete (Figs. 9I, 106). The stipules are often green and leaflike and perform the function of foliage, as in

FIG. 98. - OBLONG-
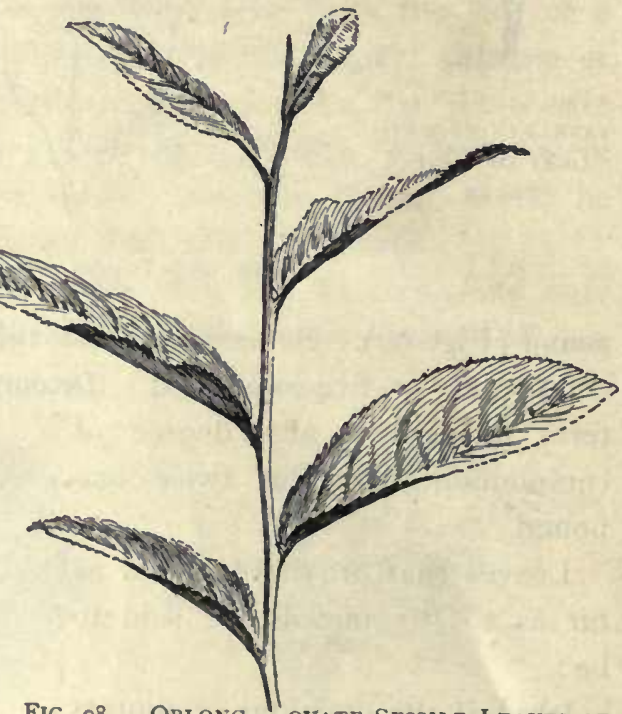
ovate Sessile Leaves of TEA.

the pea and Japanese quince (the latter common in yards).

Leaves and leaflets that have no stalks are said to be sessile (Figs. 98, I03), i.e. sitting. Find several examples. 
The same is said of flowers and fruits. The blade of a sessile leaf may partly or wholly surround the stem, when it is said to be clasping. Examples: aster (Fig. 99), corn. In some cases the leaf runs down the stem, forming a wing; such leaves are said to be decurrent (Fig. IOO). When opposite sessile leaves are joined by their bases, they are said to be connate (Fig. IOI).

Leaflets may have one or all of these

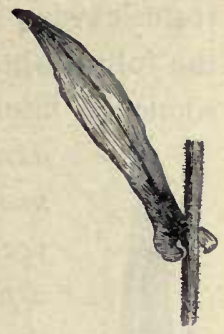

FIG. 99. - ClaspING LEAF OF A WILD ASTER.

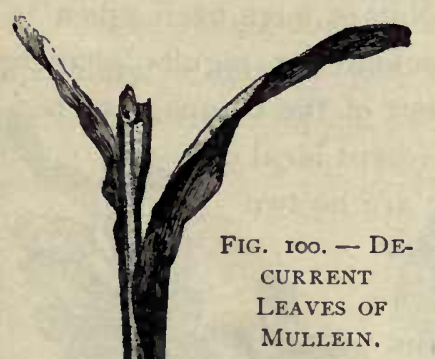

three parts, but the stalks of leaflets are called petiolules and the stipules of leaflets are called stipels. The leaf of the garden bean has leaflets, petiolules, and stipels.

The blade is usually attached to the petiole by its lower edge. In pinnate-veined leaves, the petiole seems to continue through the leaf as a midrib (Fig.91). In some plants, however, the petiole joins the blade inside or beyond the margin (Fig. 92). Such leaves are said to be peltate or shield-shaped. This mode of attachment is particularly common in floating leaves (e.g. the water lilies). Peltate leaves are usually digitate-veined.

How to Tell a Leaf. - It is often difficult to distinguishcompound leaves from leafy branches, and leaflets

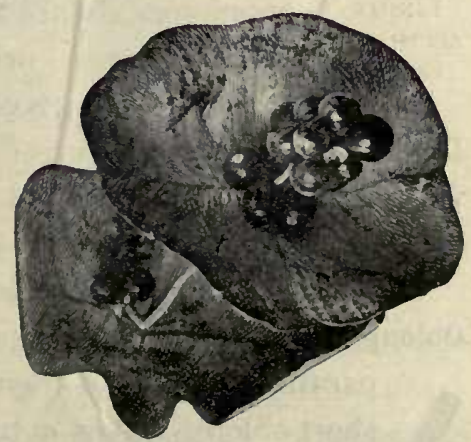

Fig. ior. - Two Pairs of Connate LEAVES OF HONEYSUCKI.E. 
from leaves. As a rule leaves can be distinguished by the following tests: (I) Leaves are temporary structures, sooner or later falling. (2) Usually buds are borne in their

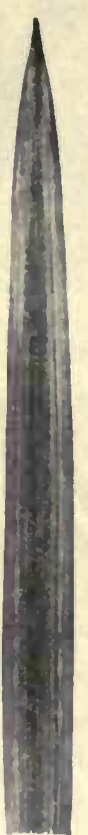
axils. (3) Leaves are usually borne at joints or notcs. (4) They arise on wood of the current year's growth. (5) They have a more or less definite arrangement. When leaves fall, the twig that bore them remains; when leaflets fall, the main petiole or stalk that bore them also falls.

Shapes. - Leaves and leaflets are infinitely variable in shape. Names have been given to some of the more definite or regular shapes. These names are a part of the language of botany. The names represent ideal or typical shapes; there are no two leaves alike and very few that perfectly conform to the definitions. The shapes are likened to those of familiar objects or of geometrical FIG. roz. - figures. Some of the LINEAR-
ACUMANATE

LEAF OF

GRASS. follows (name original examples in each class):

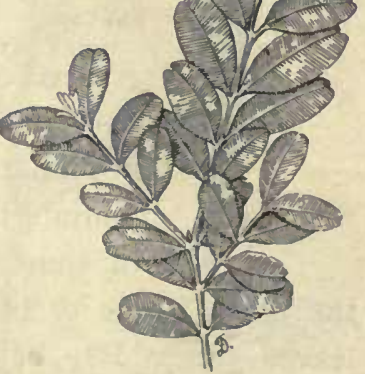

FIG. IO3. - SHORT-OBLONG LEAVES OF BOX.

Linear, several times longer than broad, with the sides I nearly or quite parallel. Spruces and most grasses are examples (Fig. 102). In linear leaves, the main veins are usually paralle] to the midrib.

Oblong, twice or thrice as long as broad, with the sides parallel for most of their length. Fig. IO3 shows the short-oblong leaves of the box, a plant that is used for permanent edgings in gardens, 
Elliptic differs from the oblong in having the sides gradually tapering to either end from the middle. The

European beech (Fig. 104) has elliptic leaves. (This tree is often planted in this country.)

Lanceolate, four to six times longer than broad, widest below the middle, and tapering to either end. Some of the narrow-leaved willows are examples. Most of the willows and the peach have oblong-lanceolate leaves.

Spatulate, a narrow leaf that is broadest

toward the apex. The top is usually

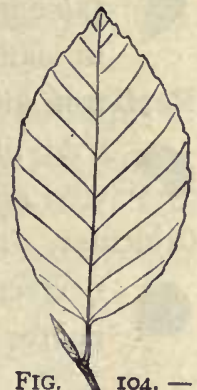

ELLIPTIC LEAF OF PURPLE BEECH. rounded.

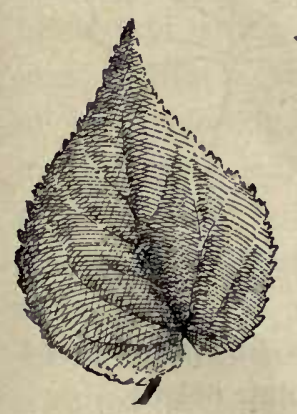

FIG. I05. - OVA TE SER RATE LEAF OF HIBISCUS.

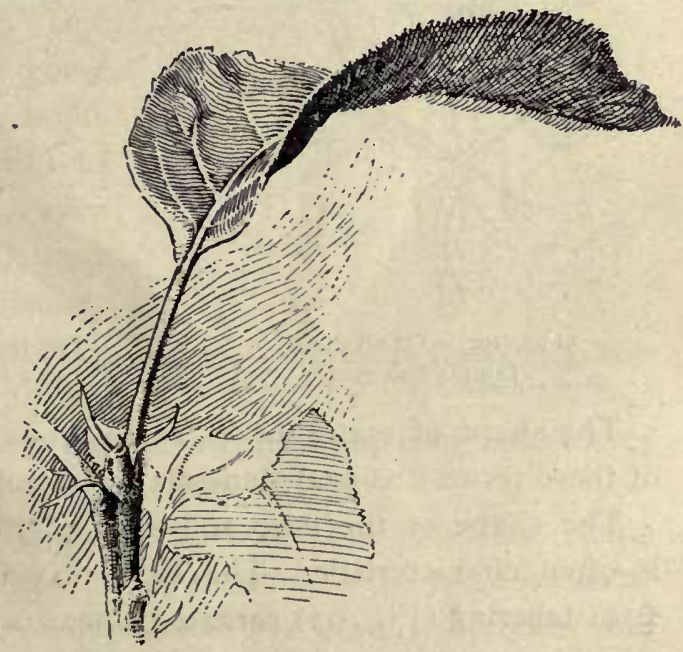

FIG. IC6. - LEAF OF APPLE, showing blade, petiole, and small narrow stipules.

Ovate, shaped somewhat like the longitudinal section of an egg: about twice as long as broad, tapering from near the base to the apex. This is one of the commonest leaf forms (Figs. I05, 106). 
Obovate, ovate inverted, - the wide part towards the apex. Leaves of mullein and leaflets of horse-chestnut and false indigo are obovate. This form is commonest in leaflets of digitate leaves: why?

Reniform, kidney-shaped. This form is sometimes seen in wild plants, particularly in root-leaves. Leaves of wild ginger are nearly reniform.

Orbicular, circular in general outline. Very few leaves are perfectly circular, but there are many that are nearer circular than any other shape (Fig. IO7).

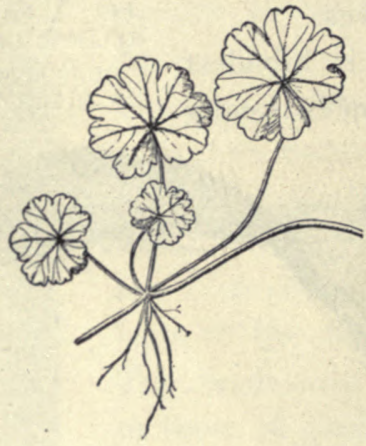

Fig. I07. - ORBICULAR LOBED LEAVES.

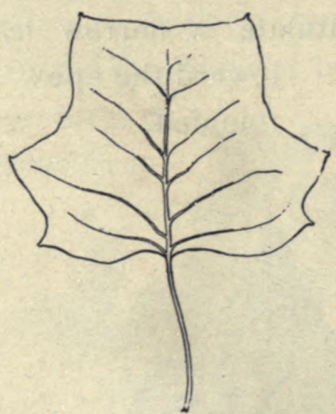

Fig. IO8. - TRUNCATE LEAF OF TULIP TREE.

The shape of many leaves is described in combinations of these terms: as ovate-lanceolate, lanceolate-oblong.

The shape of the base and apex of the leaf or leaflet is often characteristic. The base may be rounded (Fig. I04), tapering (Fig. 93), cordate or heart-shaped (Fig. IO5), truncate or squared as if cut off. The apex may be blunt or obtuse, acute or sharp, acuminate or long-pointed, truncate (Fig. 108). Name examples.

The shape of the margin is also characteristic of each kind of leaf. The margin is entire when it is not indented or cut in any way (Figs. 99, 103). When not 
entire, it may be undulate or wavy (Fig. 92), serrate or saw-toothed (Fig. I05), dentate or more coarsely notched (Fig. 95), crenate or round-toothed, lobed, and the like. Give examples.

Leaves often differ greatly in form on the same plant. Observe the different shapes of leaves on the young growths of mulberries (Fig. 2) and wild grapes; also on vigorous squash and pumpkin vines. In some cases there may be simple and compound leaves on the same plant. This is marked in the so-called Boston ivy or ampelopsis (Fig. I09), a vine that is used to cover brick and stone buildings. Different degrees of compounding, even in the same leaf, may often be found in honey locust and Kentucky coffee tree. Remarka-

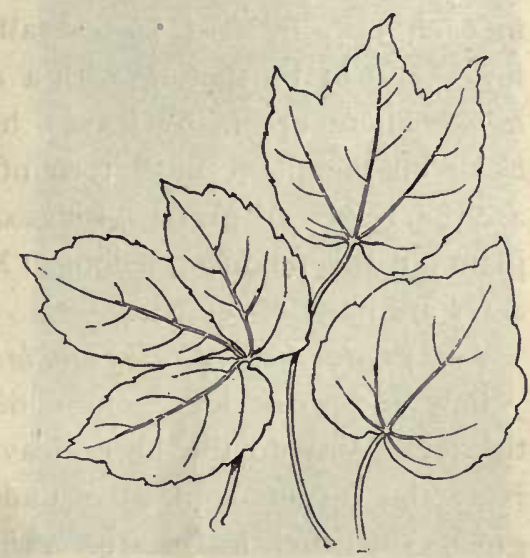

FIG. IOg. - DIFFERENT FORMS OF LEAVES FROM ONE PLANT OF AMPELOPSIS.

ble differences in forms are seen by comparing seed-leaves with mature leaves of any plant (Fig. 30).

The Leaf and its Environment. - The form and shape of the leaf often have direct relation to the place in which the leaf grozes. Floating leaves are usually expanded and flat, and the petiole varies in length with the depth of the water. Submerged leaves are usually linear or threadlike, or are cut into very narrow divisions: thereby more surface is exposed, and possibly the leaves are less injured by moving water. Compare the sizes of the leaves on the ends of branches with those at the base of the 
branches or in the interior of the tree top. In dense foliage masses, the petioles of the lowermost or undermost leaves tend to elongate - to push the leaf to the light.

On the approach of winter the leaf usually ceases to work, and dies. It may drop, when it is said to be deciduous; or it may remain on the plant, when it is said to be persistent. If persistent leaves remain green during the winter, the plant is said to be evergreen. Give examples in each class. Most leaves fall by breaking off at the lower end of the petiole with a distinct joint or articulation. There are many leaves, however, that wither and hang on the plant until torn off by the wind; of such are the leaves of grasses, sedges, lilies, orchids, and other plants of the monocotyledons. Most leaves of this character are parallel-veined.

Leaves also die and fall from lack of light. Observe the yellow and weak leaves in a dense tree top or in any thicket. Why do the lower leaves die on house plants? Note the carpet of needles under the pines. All evergreens shed their leaves after a time. Counting back from the tip of a pine or spruce shoot, determine how many years the leaves persist. In some spruces a few leaves may be found on branches ten or more years old.

Arrangement of Leaves. - Most leaves have a regular position or arrangement on the stem. This position or direction is determined largely by exposure to sunlight. In temperate climates they usually hang in such a way that they receive the greatest amount of light. One leaf shades the other to the least possible degree. If the plant were placed in a new position with reference to light, the leaves would make an effort to turn their blades.

When leaves are opposite the pairs usually alternate. That is, if one pair stands north and south, the next pair 
stands east and west. See the box-elder shoot, on the left in Fig. I IO. One pair does not shade the pair beneath. The leaves are in four vertical ranks.

There are several kinds of alternate arrangement. In the elm shoot, in Fig. I IO, the third bud is vertically above the first. This is true no matter which bud is taken as the starting point. Draw a thread around the stem until the two buds are joined. Set a pin at each bud. Observe that two buds are passed (not counting the last) and that the thread makes one circuit of the stem. Representing the number of buds by a denominator, and the number of circuits by a numerator, we have the fraction $\frac{1}{2}$, which expresses

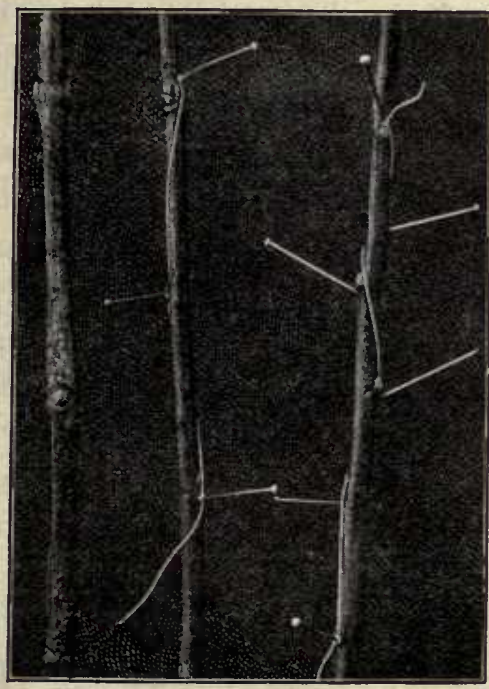

Fig. IIO. - PHYLLOTAXY OF BOX ELDER, ELM, APPLE.

the part of the circle that lies between any two buds. That is, the buds are one half of 360 degrees apart, or I 80 degrees. Looking endwise at the stem, the leaves are seen to be 2-ranked. Note that in the apple shoot (Fig. IIO, right) the thread makes two circuits and five buds are passed: two-fifths represents the divergence between the buds. The leaves are 5-ranked.

Every plant has its own arrangement of leaves. For opposite leaves, see maple, box elder, ash, lilac, honeysuckle, mint, fuchsia. For 2-ranked arrangement, see all grasses, Indian corn, basswood, elm. For 3-ranked 
arrangement, see all sedges. For 5-ranked (which is one of the commonest), see apple, cherry, pear, peach, plum; poplar, willow. For 8-ranked, see holly, osage orange, some willows. More complicated arrangements occur in bulbs, house leeks, and other condensed parts. The buds or "eyes" on a potato tuber, which is an underground stem

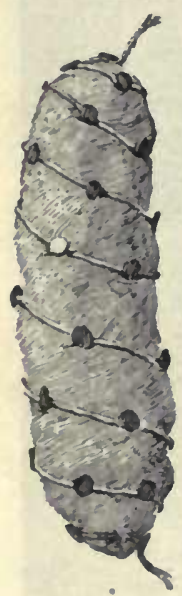

FIG. III. -

Phyllotaxy OF THE POTATO TUBER. Work it out on a fresh long tuber. (why ?), show a spiral arrangement (Fig. I I I). The arrangement of leaves on the stem is known as phyllotaxy (literally, "leaf arrangement"). Make out the phyllotaxy on six different plants nearest the schoolhouse door.

In some plants, several leaves occur at one level, being arranged in a circle around the stem. Such leaves are said to be verticillate, or whorled. Leaves arranged in this way are usually narrow: why?

Although a definite arrangement of leaves is the rule in most plants, it is subject to modification. On shoots that receive the light only from one side or that grow in difficult positions, the arrangement may not be definite. Examine shoots that grow on the under side of dense tree tops or in other partially lighted positions.

Suggestions. - 55. The pupil should match leaves to determine whether any two are alike. Why? Compare leaves from the same plant in size, shape, color, form of margin, length of petiole, venation, texture (as to thickness or thinness), stage of maturity, smoothness or hairiness. 56. Let the pupil take an average leaf from each of the first ten different kinds of plants that he meets and compare them as to the above points (in Exercise 55 ), and also name the shapes. Determine how the various leaves resemble and differ. 57. Describe the stipules of rose, apple, fig, willow, violet, péa, or others. 58. In what part of the world are parallel-veined leaves the more common? 59. Do 
you know of parallel-veined leaves that have lobed or dentate margins? 60. What becomes of dead leaves? 61. Why is there no grass or other undergrowth under pine and spruce trees? 62. Name several leaves that are useful for decorations. Why are they useful? 63. What trees in your vicinity are most esteemed as shade trees? What is the character of their foliage? 64. Why are the internodes so long in water-sprouts and suckers ? 65. How do foliage characters in corn or sorghum differ when the plants are grown in rows or broadcast? Why? 66. Why may removal of half the plants increase the yield of cotton or sugarleets or lettuce? 67. How do leaves curl when they wither? Do different leaves behave differently in this respect? 68. What kinds of leaves do you know to be eaten by insects? By cattle? By horses? What kinds are used for human food? 69. How would you describe the shape of leaf of peach? apple? elm? hackberry? maple? sweet-gum? corn? wheat? cotton? hickory? cowpea? strawberry? chrysanthemum? rose? carnation? 70. Are any of the foregoing leaves compound? How do you describe the shape of a compound leaf? 71. How many sizes of leaves do you find on the bush or tree nearest the schoolroom door? 72. How many colors or shades? 73. How many lengths of petioles? 74. Bring in all the shapes of leaves that you can find.

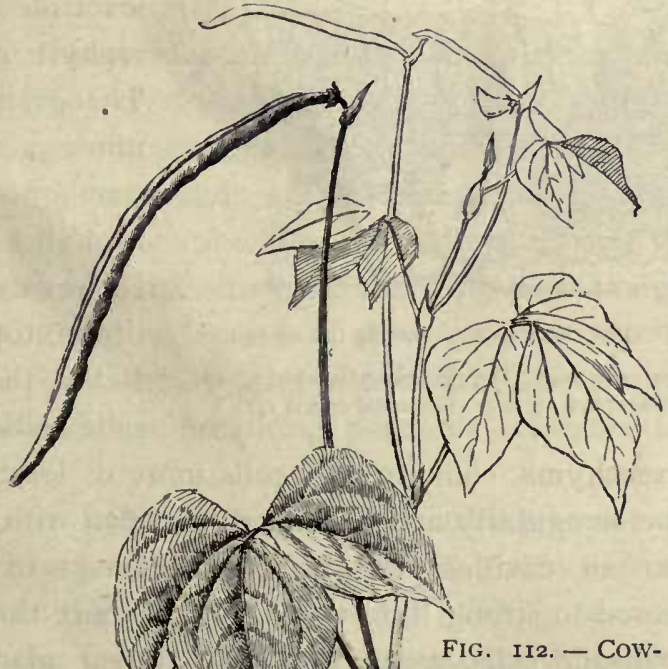

PEA. Describe the leaves. For what is the plant used? 


\section{CHAPTER XII}

\section{LEAVES - STRUCTURE OR ANATOMY}

BESIDEs the framework, or system of veins found in blades of all leaves, there is a soft cellular tissue called mesophyll, or leaf parenchyma, and an epidermis or skin that covers the entire outside part.

Mesophyll. - The mesophyll is not all alike or homogeneous. The upper layer is composed of elongated cells placed perpendicular to the surface of the leaf. These are called palisade cells. These cells are usually filled

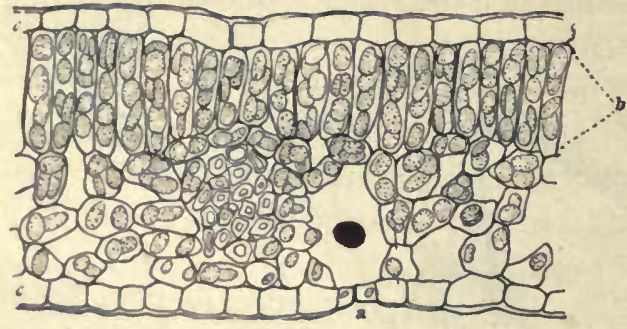

FIG. 113. - SECTION OF A LEAF, showing the air spaces. Breathing-pore or stoma at $a$. The palisade cells which chiefly contain the chlorophyll are at b. Epidermal cells at $c$. with green bodies called chlorophyll grains. The grain contains a great number of chlorophyll drops imbedded in the protoplasm. Below the palisade cells is the spongy parenchyma, composed of cells more or less sphercal in shape, irregularly arranged, and provided with many intercellular air cavities (Fig. I13). In leaves of some plants exposed to strong light there may be more than one layer of palisade cells, as in the India-rubber plant and oleander. Ivy when grown in bright light will develop two such layers of cells, but in shaded places it may be 
found with only one. Such plants as iris and compass plant, which have both surfaces of the leaf equally exposed to sunlight, usually have a palisade layer beneath each epidermis.

Epidermis. - The outer or epidermal cells of leaves do not bear chlorophyll, but are usually so transparent that the green mesophyll can be seen through them. They often become very thick-walled, and are in most plants devoid of all protoplasm except a thin layer lining the walls, the cavities being filled with cell sap. This sap is sometimes colored, as in the under epidermis of begonia leaves. It is not common to find more than one layer of epidermal cells forming each surface of a leaf. The epidermis serves to retain moisture in the leaf and as a general protective covering. In desert plants the epidermis, as a rule, is very thick and has a dense cuticle, thereby preventing loss of water.

There are various outgrowths of the epidermis. Hairs are the chief of these. They may be (I) simple, as on primula, geranium, nægelia; (2) once branched, as on wallflower; (3) compound, as on verbascum or mullein; (4) disk-like, as on shepherdia; (5) stellate, or star-shaped, as in certain crucifers. In some cases the hairs are glandular, as in Chinese primrose of the greenhouses (Primula Sinensis) and certain hairs of pumpkin flowers. The hairs often protect the breathing pores, or stomates, from dust and water.

Stomates (sometimes called breathing-pores) are small openings or pores in the epidermis of leaves and soft stems that allow the passage of air and other gases and vapors (stomate or stoma, singular; stomates or stomata, plural). They are placed near the large intercellular spaces of the mesophyll, usually in positions least affected by direct 
sunlight. Fig. II 4 shows the structure. There are two guard-cells at the mouth of each stomate, which may in most cases open or close the passage as the conditions of the atmosphere may require. The guard-cells contain

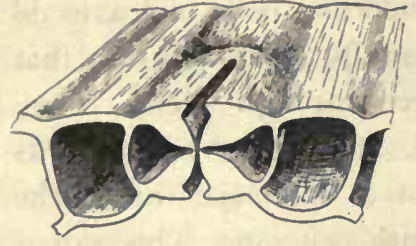

Fig. 114. - DIAGRAM OF STOMATE OF IRIS (Osterhout).

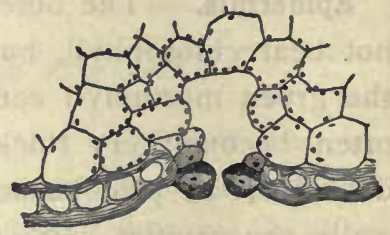

FIG. II5, - STOMATE OF IVY, showing compound guard-cells.

chlorophyll. In Fig. I I 5 is shown a case in which there are compound guard-cells, that of ivy. On the margins of certain leaves, as of fuchsia, impatiens, cabbage, are openings known as water-pores.

Stomates are very numerous, as will be seen from the numbers showing the pores to each square inch of leaf surface :

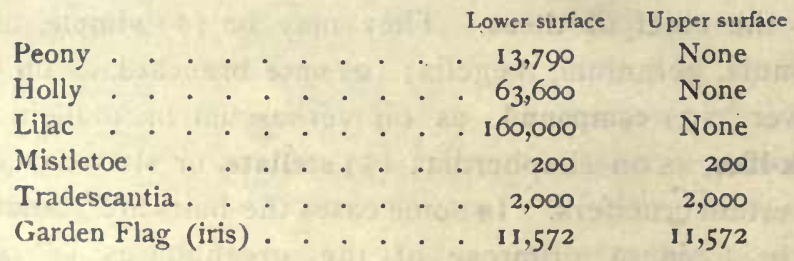

The arrangement of stomates on the leaf differs with each kind of plant. Fig. I 6 shows stomates and also the

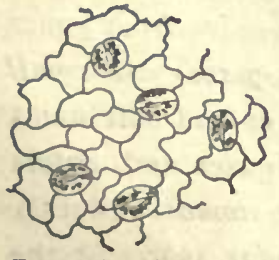

FIG. II6. - STOMATES OF GERANIUM LEAF. outlines of contiguous epidermal cells. The function or work of the stomates is to regulate the passage of gases into and out of the plant. The directly active organs or parts are guard-cells, on either side the opening. One method of opening is as follows: The 
thicker walls of the guard-cells (Fig. I14) absorb water from adjacent cells, these thick walls buckle or bend and part from each other at their middles on either side the opening, causing the stomate to open, when the air gases may be taken in and the leaf gases may pass out. When moisture is reduced in the leaf tissue, the guard cells part with some of their contents, the thick walls straighten, and the faces of the two opposite ones come together, thus closing the stomate and preventing any water vapor from passing out. When a leaf is actively at work making new organic compounds, the stomates are usually open; when unfavorable conditions arise, they are usually closed. They also commonly close at night, when growth (or the utilizing of the new materials) is most likely to be active. It is sometimes safer to fumigate greenhouses and window gardens at night, for the noxious vapors are less likely to enter the leaf. Dust may clog or cover the stomates. Rains benefit plants by washing the leaves as well as by providing moisture to the roots.

Lenticels. - On the young woody twigs of many plants (marked in osiers, cherry, birch) there are small corky spots or eleva-

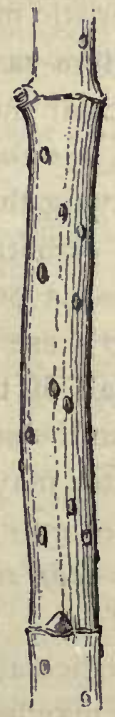

FIG. II7. - LEN-

TICELS ON YOUNG SHOOT OF RED OSIER (CORNUS). tions known as lenticels (Fig. II7). They mark the location of some loose cork cells that function as stomates, for green shoots, as well as leaves, take in and discharge gases; that is, soft green twigs function as leaves. Under some of these twig stomates, corky material may form and the opening is torn and enlarged: the lenticels are successors to the stomates. The stomates lie in the epi- 
dermis, but as the twig ages the epidermis perishes and the bark becomes the external layer. Gases continue to pass in and out through the lenticels, until the branch becomes heavily covered with thick, corky bark. With the growth of the twig, the lenticel scars enlarge lengthwise or crosswise or assume other shapes, often becoming characteristic markings.

Fibro-vascular Bundles. - We have studied the fibrovascular bundles of stems (Chap. X). These stem bundles continue into the leaves, ramifying into the veins, carrying the soil water inwards and bringing, by diffusion, the elaborated food out through the sieve-cells. Cut across a petiole and notice the hard spots or areas in it; strip these parts lengthwise of the petiole: what are they?

Fall of the Leaf. - In most common deciduous plants, when the season's work for the leaf is ended, the nutritious matter may be withdrawn, and a layer of corky cells is completed over the surface of the stem where the leaf is attached. The leaf soon falls. It often falls even before it is killed by frost. Deciduous leaves begin to show the surface line of articulation in the early growing season. This articulation may be observed at any time during the summer. The area of the twig once covered by the petioles is called the leaf-scar after the leaf has fallen. In Chap. XV are shown a number of leaf-scars. In the plane tree (sycamore or buttonwood), the leaf-scar is in the form of a ring surrounding the bud, for the bud is covered by the hollowed end of the petiole; the leaf of sumac is similar. Examine with a hand lens leaf-scars of several woody plants. Note the number of bundle-scars in each leaf-scar. Sections may be cut through a leaf-scar and examined with the microscope. Note the character of cells that cover the leafscar surface. 
Suggestions. - To study epidermal hairs: 75. For this study, use the leaves of any hairy or woolly plant. A good hand lens will reveal the identity of many of the coarser hairs. A dissecting microscope will show them still better. For the study of the cell structure, a compound microscope is necessary. Cross-sections may be made so as to bring hairs on the edge of the sections; or in some cases the hairs may be peeled or scraped from the epidermis and placed in water on a slide. Make sketches of the different kinds of hairs. 76. It is good practice for the pupil to describe leaves in respect to their covering: Are they smooth on both surfaces? Or hairy? Woolly? Thickly or thinly hairy? Hairs long or short? Standing straight out or lying close to the surface of the leaf ? Simple or branched? Attached to the veins or the plane surface? Color? Most abundant on young leaves or old? 77. Place a hairy or woolly leaf under water. Does the hairy surface appear silvery? Why? Other questions: 78. Why is it good practice to wash the leaves of house plants? 79. Describe the leaf-scars on six kinds of plants : size, shape, color, position with reference to the bud, bundle-scars. 80. Do you find leaf-scars on monocotyledonous plants - corn, cereal grains, lilies, canna, banana, palm, bamboo, green brier? 81. Note the table on page $\mathbf{8 8}$. Can you suggest a reason why there are equal numbers of stomates on both surfaces of leaves of tradescantia and flag, and none on upper surface of other leaves? Suppose you pick a leaf of lilac (or some larger leaf), seal the petiole with wax and then rub the under surface with vaseline; on another leaf apply the vaseline to the upper surface; which leaf withers first, and why? Make a similar experiment with iris or blue flag. 82. Why do leaves and shoots of house plants turn towards the light? What happens when the plants are turned around? 83. Note position of leaves of beans, clover, oxalis, alfalfa, locust, at night. 


\section{CHAPTER XIII}

\section{LEAVES - FUNCTION OR WORK}

WE have discussed (in Chap. VIII) the work or function of roots and also (in Chap. X) the function of stems. We are now ready to complete the view of the main vital activities of plants by considering the function of the green parts (leaves and young shoots).

Sources of Food. - The ordinary green plant has but two sources from which to secure food, - the air and the soil. When a plant is thoroughly dried in an oven, the water passes off ; this water came from the soil. The remaining part is called the dry substance or dry matter. If the dry matter is burned in an ordinary fire, only the ash remains; this ash came from the soil. The part that passed off as gas in the burning contained the elements that came from the air; it also contained some of those that came from the soil - all those (as nitrogen, hydrogen, chlorine) that are transformed into gases by the heat of a common fire. The part that comes from the soil (the ash) is small in amount, being considerably less than ro per cent and sometimes less than I per cent. Water is the most abundant single constituent or substance of plants. In a corn plant of the roasting-ear stage, about 80 per cent of the substance is water. A fresh turnip is over 90 per cent water. Fresh wood of the apple tree contains about 45 per cent of water.

Carbon. - Carbon enters abundantly into the composition of all plants. Note what happens when a plant is burned 
without free access of air, or smothered, as in a charcoal pit. A mass of charcoal remains, almost as large as the body of the plant. Charcoal is almost pure carbon, the ash present being so smali in proportion to the large amount of carbon that we look on the ash as an impurity. Nearly half of the dry substance of a tree is carbon. Carbon goes off as a gas when the plant is burned in air. It does not go off alone, but in combination with oxygen in the form of carbon dioxid gas, $\mathrm{CO}_{2}$.

The green plant secures its carbon from the air. In other words, much of the solid matter of the plant comes from one of the gases of the air. By volume, carbon dioxid forms only a very small fraction of $I$ per cent of the air. It would be very disastrous to animal life, however, if this percentage were much increased, for it excludes the lifegiving oxygen. Carbon dioxid is often called "foul gas." It may accumulate in old wells, and an experienced person will not descend into such wells until they have been tested with a torch. If the air in the well will not support combustion, - that is, if the torch is extinguished, - it usually means that carbon dioxid has drained into the place. The air of a closed schoolroom often contains far too much of this gas, along with little solid particles of waste matters. Carbon dioxid is often known as carbonic acid gas.

Appropriation of the Carbon. - The carbon dioxid of the air readily diffuses itself into the leaves ant other green parts of the plant. The leaf is delicate in texture, and when very young the air can diffuse directly into the tissues. The stomates, however, are the special inlets adapted for the admission of gases into the leaves and other green parts. Through these stomates, or diffusion-pores, the outside air enters into the air-spaces of the plant, and is finally absorbed by the little cells containing the living matter. 
Chlorophyll ("leaf green") is the agent that secures the energy by means of which carbon dioxid is utilized. This material is contained in the leaf cells in the form of grains (p. 86); the grains themselves are protoplasm, only the coloring matter being chlorophyll. The chlorophyll bodies or grains are often most abundant near the upper surface of the leaf, where they can secure the greatest amount of light. Without this green coloring matter, there would be no reason for the large flat surfaces which the leaves possess, and no reason for the fact that the leaves are borne most abundantly at the ends of branches, where the light is most available. Plants with colored leaves, as coleus, have chlorophyll, but it is masked by other coloring matter. This other coloring matter is usually soluble in hot water: boil a coleus leaf and notice that it becomes green and the water becomes colored.

Plants grown in darkness are yellow and slender, and do not reach maturity. Compare the potato sprouts that have grown from a tuber lying in the dark cellar with those that have grown normally in the bright light. The shoots have become slender and are devoid of chlorophyll; and when the food that is stored in the tuber is exhausted, these shoots will have lived useless lives. A plant that has been grown in darkness from the seed will soon die, although for a time the little seedling will grow very tall and slender: why? Light favors the production of chlorophyll, and the chlorophyll is the agent in the making of the organic carbon compounds. Sometimes chlorophyll is found in buds and seeds, but in most cases these places are not perfectly dark. Notice how potato tubers develop chlorophyll, or become green, when exposed to light.

Photosynthesis. - Carbon dioxid diffuses into the leaf; during sunlight it is used, and oxygen is given off. How the 
carbon dioxid which is thus absorbed may be used in making an organic food is a complex question, and need not be studied here; but it may be stated that carbon dioxid and water are the constituents. Complex compounds are built up out of simpler ones.

Chlorophyll absorbs certain light rays, and the energy thus directly or indirectly obtained is used by the living matter in uniting the carbon dioxid absorbed from the air with some of the water brought up from the roots. The ultimate result usually is starch. The process is obscure, but sugar is generally one step; and our first definite knowledge of the product begins when starch is deposited in the leaves. The process of using the carbon dioxid of the air has been known as carbon assimilation, but the term now most used is photosynthesis (from two Greek words, meaning light and to put together).

Starch and Sugar. - All starch is composed of carbon, hydrogen, and oxygen $\left(\mathrm{C}_{6} \mathrm{H}_{10} \mathrm{O}_{5}\right)_{n}$. The sugars and the substance of cell walls are very similar to it in composition. All these substances are called carbohydrates. In making fruit sugar from the carbon and oxygen of carbon dioxid and from the hydrogen and oxygen of the water, there is a surplus of oxygen ( 6 parts $\mathrm{CO}_{2}+6$ parts $\mathrm{H}_{2} \mathrm{O}$ $=\mathrm{C}_{6} \mathrm{H}_{12} \mathrm{O}_{6}+6 \mathrm{O}_{2}$ ). It is this oxygen that is given off into the air during sunlight.

Digestion. - Starch is in the form of insoluble granules. When such food material is carried from one part of the plant to another for purposes of growth or storage, it is made soluble before it can be transported. When this starchy material is transferred from place to place, it is usually changed into sugar by the action of a diastase. This is a process of digestion. It is much like the change of starchy foodstuffs to sugary foods by the saliva. 
Distribution of the Digested Food. - After being changed to the soluble form, this material is ready to be used in grozuth, either in the leaf, in the stem, or in the roots. With other more complex products it is then distributed

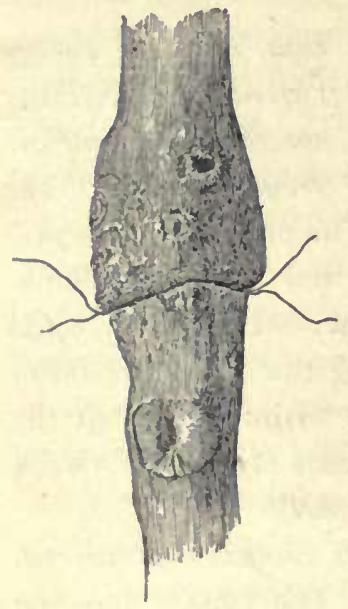

Fig, Ix8. - TRUNK GIRDI.ED BY A WIRE. See Fig. 85 . throughout all of the growing parts of the plant; and when passing down to the root, it seems to pass more readily through the inner bark, in plants which have a definite bark. This gradual downward diffusion through the inner bark of materials suitable for growth is the process referred to when the "descent of sap" is mentioned. Starch and other products are often stored in one growing season to be used in the next season. If a tree is constricted or strangled by a wire around its trunk (Fig. II 8), the digested food cannot readily pass down and it is stored above the girdle, causing an enlargement.

Assimilation. - The food from the air and that from the soil unite in the living tissues. The "sap" that passes upwards from the roots in the growing season is made up largely of the soil water and the salts which have been absorbed in the diluted solutions (p. 67). This upwardmoving water is conducted largely through certain tubular canals of the young wood. These cells are never continuous tubes from root to leaf; but the water passes readily from one cell or canal to another in its upward course.

The upward-moving water gradually passes to the growing parts, and everywhere in the living tissues, it is of 
course in the most intimate contact with the soluble carbohydrates and products of photosynthesis. In the building up or reconstructive and other processes it is therefore available. We may properly conceive of certain of the simpler organic molecules as passing through a series of changes, gradually increasing in complexity. There will be formed substances containing nitrogen in addition to carbon, hydrogen, and oxygen. Others will contain also sulfur and phosphorus, and the various processes may be thought of as culminating in protoplasm. Protoplasm is the living matter in plants. It is in the cells, and is usually semifluid. Starch is not living matter. The complex process of building up the protoplasm is called assimilation.

Respiration. - Plants need oxygen for respiration, as animals do. We have seen that plants need the carbon dioxid of the air. To most plants the nitrogen of the air is inert, and serves only to dilute the other elements; but the oxygen is necessary for all life. We know that all animals need this oxygen in order to breathe or respire. In fact, they have become accustomed to it in just the proportions found in the air; and this is now best for them. When animals breathe the air once, they make it foul, because they use some of the oxygen and give off carbon dioxid. Likewise, all living parts of the plant must have a constant supply of oxygen. Roots also need it, for they respire. Air goes in and out of the soil by diffusion, and as the soil is heated and cooled, causing the air to expand and contract.

The oxygen passes into the air-spaces and is absorbed by the moist cell membranes. In the living cells it makes possible the formation of simpler compounds by which energy is released. This energy enables the plant to 
work and grow, and the final products of this action are carbon dioxid and water. As a result of the use of this oxygen by night and by day, plants give off carbon dioxid. Plants respire; but since they are stationary, and more or less inactive, they do not need as much oxygen as animals, and they do not give off so much carbon dioxid. A few plants in a sleeping room need not disturb one more than a family of mice. It should be noted, however, that germinating seeds respire vigorously, hence they consume much oxygen; and opening buds and flowers are likewise active.

Transpiration. - Much more water is absorbed by the roots than is used in growth, and this surplus water passes from the leaves into the atmosphere by an evaporation process known as transpiration. Transpiration takes place more abundantly from the under surfaces of leaves, and through the pores or stomates. A sunflower plant of the height of a man, during an active period of growth, gives off a quart of water per day. A large oak tree may transpire 150 gallons per day during the summer. For every ounce of dry matter produced, it is estimated that 15 to 25 pounds of water usually passes through the plant.

When the roots fail to supply to the plant sufficient water to equalize that transpired by the leaves, the plant wilts. Transpiration from the leaves and delicate shoots is increased by all of the conditions which increase evaporation, such as higher temperature, dry air, or wind. The stomata open and close, tending to regulate transpiration as the varying conditions of the atmosphere affect the moisture content of the plant. However, in periods of drought or of very hot weather, and especially during a hot wind, the closing of these stomates cannot sufficiently prevent evaporation. The roots may be very active and yet fail to absorb sufficient moisture to equalize that given 
off by the leaves. The plant shows the effect (how?). On a hot dry day, note how the leaves of corn "roll" towards afternoon. Note how fresh and vigorous the same leaves appear early the following morning. Any injury to the roots, such as a bruise, or exposure to heat, drought, or cold may cause the plant to wilt.

Water is forced up by root pressure or sap pressure. (Exercise 99.) Some of the dew on the grass in the morning may be the water forced up by the roots; some of it is the condensed vapor of the air.

The wilting of a plant is due to the loss of water from the cells. The cell walls are soft, and collapse. A toy balloon will not stand alone until it is inflated with air or liquid. In the woody parts of the plant the cell walls may be stiff enough to support themselves, even though the cell is empty. Measure the contraction due to wilting and drying by tracing a fresh leaf on page of notebook, and then tracing the same leaf after it has been dried between papers. The softer the leaf, the greater will be the contraction.

Storage. - We have said that starch may be stored in twigs to be used the following year. The very early flowers on fruit trees, especially those that come before the leaves, and those that come from bulbs, as crocuses and tulips, are supported by the starch or other food that was organized the year before. Some plants have very special storage reservoirs, as the potato, in this case being a thickened stem although growing underground. (Why a thickened stem? p. 84.) It is well to make the starch test on winter twigs and on all kinds of thickened parts, as tubers and bulbs.

Carnivorous Plants. - Certain plants capture insects and other very small animals and utilize them to some extent as food: Such are the sundew, that has on the leaves 
sticky hairs that close over the insect; the Venus's flytrap of the Southern states, in which the halves of the leaves

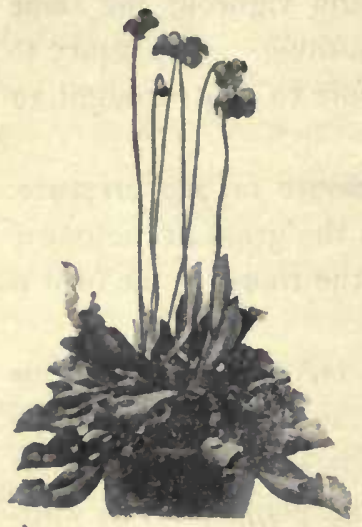

FIG. IIg. - TII E, COMMON Pitcier Plant (Sarracenia purpurea) of the North, showing the tubular leaves and the odd, long-stalked flowers. close over the prey like the jaws of a steel trap; and the various kinds of pitcher plants that collect insects and other organic matter in deep, water-filled, flasklike leaf pouches (Fig. I 19).

The sundew and Venus's flytrap are sensitive to contact. Other plants are sensitive to the touch without being insectivorous. The common cultivated sensitive plant is an example. This is readily grown from seeds (sold by seedsmen) in a warm place. Related wild plants in the south are sensitive. The utility of this sensitiveness is not understood.

Parts that Simulate Leaves. - We have learned that leaves are endlessly modified to suit the conditions in which the plant is placed. The most marked modifications are in adaptation to light. On the other hand, other organs often perform the functions of leaves. Green shoots function as leaves. These shoots may look like leaves, in which case they are called cladophylla. The foliage of common asparagus is made up of fine branches: the real morphological leaves are the minute dry functionless scales at the bases of these branchlets. (What reason is there for calling them leaves?) The broad "leaves" of the florist's smilax are cladophylla: where are the leaves on this plant? In most of the cacti, the entire plant body performs the functions of leaves until the parts become cork-bound. 
Leaves are sometimes modified to perform other functions than the vital processes: they may be tendrils, as the terminal leaflets of pea and sweet pea; or spines, as in barberry. Not all spines and thorns, however, represent modified leaves: some of them (as of hawthorns, osage orange, honey locust) are branches.

Suggestions. - To test for chlorophyll. 84. Purchase about á gill of wood alcohol. Secure a leaf of geranium, clover, or other plant that has been exposed to sunlight for a few hours, and, after dipping it for a minute in boiling water, put it in a white cup with sufficient alcohol to cover. Place the cup in a shallow pan of hot water on the stove where it is not hot enough for the alcohol to take fire. After a time the chlorophyll is dissolved by the alcohol, which has become an intense green. Save this leaf for the starch experiment (Exercise 85). Without chlorophyll, the plant cannot appropriate the carbon dioxid of the air. Starch and photosynthesis. 85. Starch is present in the green leaves which have been exposed to sunlight; but in the dark no starch can be formed from carbon dioxid. Apply iodine to the leaf from which the chlorophyll was dissolved in the previous experinent. Note that the leaf is colored purplish brown throughout. The leaf contains starch. 86. Secure a leaf from a plant which has been in the darkness for about two days. Dissolve the chlorophyll as before, and attempt to stain this leaf with iodine. No purplish brown color is produced. This shows that the starch manufactured in the leaf may be entirely removed during darkness. 87. Secure a plant which has been kept in darkness for twenty-four hours or more. Split a small cork

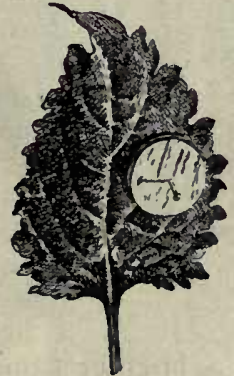

FIG. 120. - ExCLUDING LIGH'T AND $\mathrm{CO}_{2}$ FROM PART OF A LEAF.

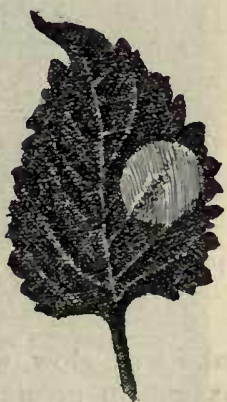

FIG. I2I. - THE

RESULT. and pin the two halves on opposite sides of one of the leaves, as shown in Fig. I20. Place the plant in the sunlight again. After a morning of bright sunshine dissolve the chlorophyll in this leaf with alcohol ; then stain the leaf with the iodine. Notice that the leaf is stained deeply except where the cork was; there sunlight and carbon dioxid were excluded, Fig. I 2 I. There is no starch in the 
covered area. 88. Plants or parts of plants that have developed no chlorophyll can form no starch. Secure a variegated leaf of coleus, ribbon grass, geranium, or of any plant showing both white and green areas. On a day of bright sunshine, test one of these leaves by the alcohol and iodine method for the presence of starch. Observe that the parts devoid of green color have formed no starch. However, after starch has once been formed in the leaves, it may be changed into soluble substances and removed, to be again converted into starch in certain other parts of the living tissues. To test the giving off of oxygen by day.

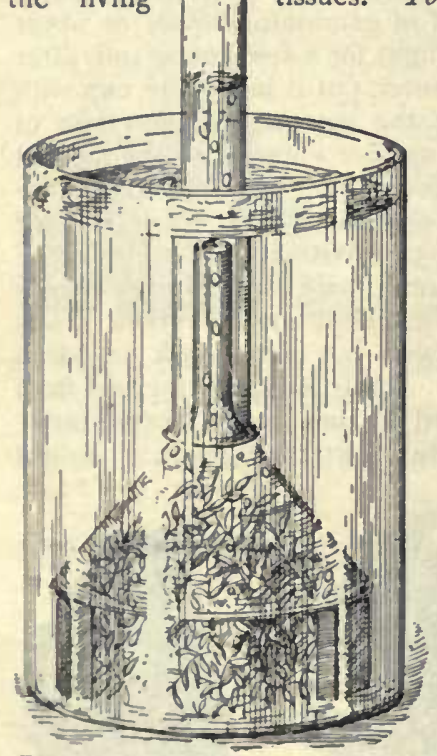

FIG. 122. - TO SHOW THE ESCAPE OF OXYGEN.

89. Make the experiment illustrated in Fig. 122 . Under a funnel in a deep glass jar containing fresh spring or stream water place fresh pieces of the common waterweed elodea (or anacharis). Have the funnel considerably smaller than the vessel, and support the funnel well up from the bottom so that the plant can more readily get all of the carbon dioxid available in the water. Why would boiled water be undesirable in this experiment? For a home-made glass funnel, crack the bottom off a narrow-necked bottle by pressing a red-hot poker or iron rod against it and leading the crack around the bottle. Invert a testtube over the stem of the funnel. In sunlight bubbles of oxygen will arise and collect in the test-tube. If a sufficient quantity of oxygen has collected, a lighted taper inserted in the tube will glow with a brighter flame, showing the presence of oxygen in greater quantity than in the air. Shade the vessel. Are bubbles given off? For many reasons it is impracticable to continue this experiment longer than a few hours. 90. A simpler experiment may be made if one of the waterweeds Cabomba (water-lily family) is available. Tie a lot of branches together so that the basal ends shall make a small bundle. Place these in a large vessel of spring water, and insert a test-tube of water as before over the bundle. The bubbles will arise from the cut surfaces. Observe the bubbles on pond scum and waterweeds on a bright day. To illustrate the results of respiration 
$\left(\mathrm{CO}_{2}\right)$. 91. In a jar of germinating seeds (Fig. I 23) place carefully a small dish of limewater and cover tightly. Put a similar dish in

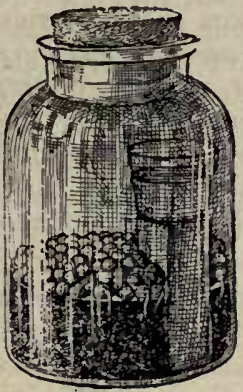

FIG. I23. - To II,LUS-

TRATE A PRODUC'T

OF RESPIRATION. another jar of about the same air space. After a few hours compare the cloudiness or precipitate in the two vessels of limewater. 92. Or, place a growing plant in a deep covered jar away from the light, and after a few hours insert a lighted candle or splinter. 93. Or, perform a similar experiment with fresh roots of beets or turnips (Fig. I24) from which the leaves are mostly removed. In this case, the jar need not be kept dark; why? To test transpiration. 94. Cut a succulent

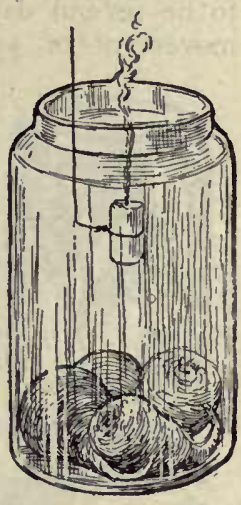

FIG. 124. - RESPIRATION OF THICK ROOTS. shoot of any plant, thrust the end of it through a hole in a cork, and stand it in a small bottle of water. Invert over this a fruit jar, and observe that a mist soon accumulates on the inside of the glass. In time drops of water form. 95. The experiment may be varied as shown in Fig. 25: 96. Or, invert the fruit jar over an entire plant, as shown in Fig. I 26 , taking care to cover the soil with oiled paper or rubber cloth to prevent evaporation from the soil. 97. The test may also be made by placing the pot, properly protected, on bal-

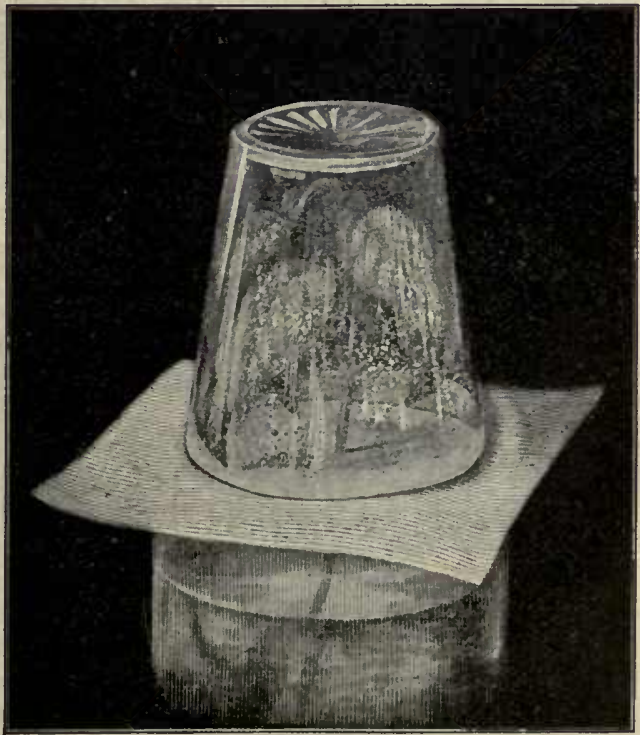

Fig. I25. - TO IlluStrate TRANSPIRATION. 
ances, and the loss of weight will be noticed (Fig. 127). 98. Cut a winter twig, seal the severed end with wax, and allow the twig to lie several days; it shrivels. There must be some upward movement of water even in winter, else plants would shrivel and die. 99. To illustrate sap pressure.

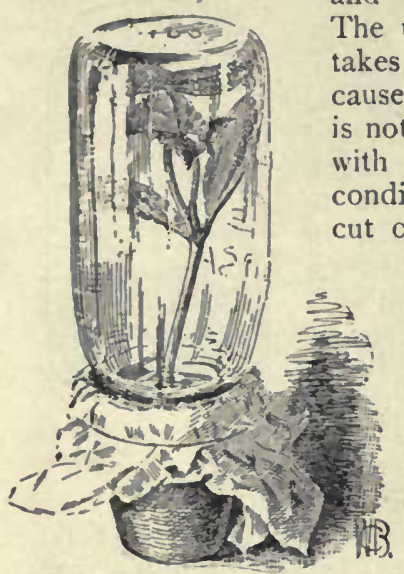

FIG. 126. - TO ILLUSTRATE

TRANSPIRATION.

low (Fig. I28). Some plants yield a below (Fig. 128). Some plants yield a large amount of water under a pressure sufficient to raise a column several feet; others force
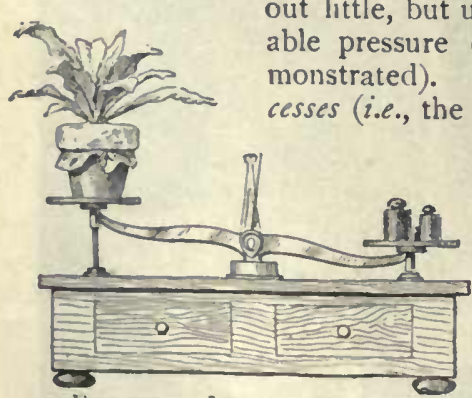

FIG. 127. - LOSS OF WVATER. out little, but under considerable pressure (less easily demonstrated). The vital processes (i.e., the life processes). 100. The pupil having studied roots, stems, and leaves, should now be able to describe the main vital functions of plants : what is the root function? stem function? leaf function? 101. What is meant by the "sap"? 102. Where and how does the plant secure its water? oxygen? carbon? hydrogen? nitrogen? sulfur? potassium?

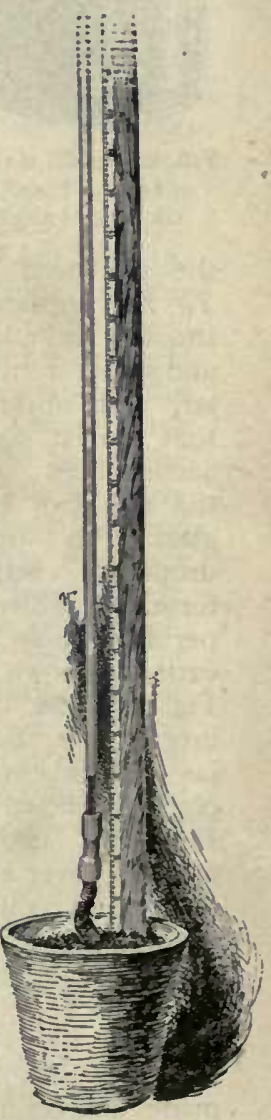

FIG. I28. - To show SAP PRESSURE. 
calcium? iron? phosphorus? 103. Where is all the starch in the world made? What does a starch-factory establishment do? Where are the real starch factories? 104. In what part of the twenty-four hours do plants grow most rapidly in length? When is food formed and stored most rapidly? 105. Why does corn or cotton turn yellow in a long rainy spell? 106. If stubble, corn stalks, or cotton stalks are burned in the field, is as much plant-food returned to the soil as when they are plowed under? 107. What process of plants is roughly analogous to perspiration of animals? 108. What part of the organic world uses raw mineral for food? 109. Why is earth banked over celery to blanch it? 110. Is the amount of water transpired equal to the amount absorbed? 111. Give some reasons why plants very close to a house may not thrive or may even die. 112. Why are fruit-trees pruned or thinned out as in Fig. I29?' Proper balance between top and root. 113. We have learned that the leaf parts and the root parts work together. They may be said to balance each other in activities, the root supplying the top and the top supplying the root (how?). If half the roots were cut from a tree, we should expect to reduce the top also, particularly if the tree is being transplanted. How would you prune a tree or

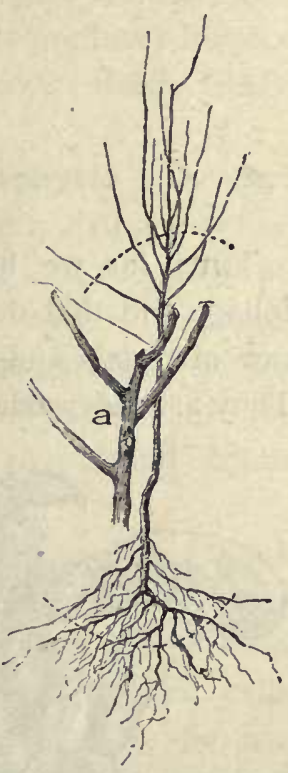

FIG. 130. - AN APPLE TREE, with suggestions as to pruning when it is set in the orchard. At $a$ is shown a pruned top.

bush that is being transplanted? Fig. I 30 may be suggestive.
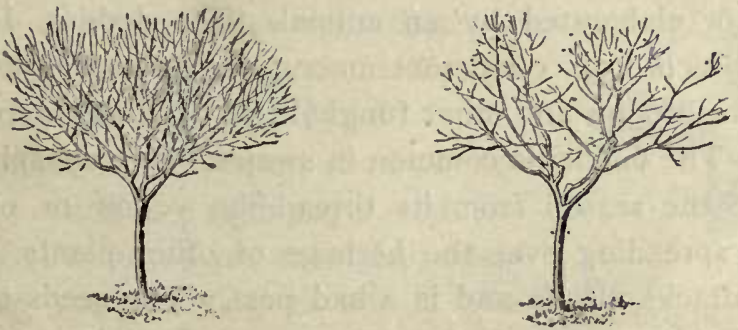

FIG. 129. - BEFORE, AND AFTER PRUNING. 


\section{CHAPTER XIV}

\section{DEPENDENT PLANTS}

THus far we have spoken of plants with roots and foliage and that depend on themselves. They collect the raw materials and make them over into assimilable food. They are independent. Plants without green foliage can-

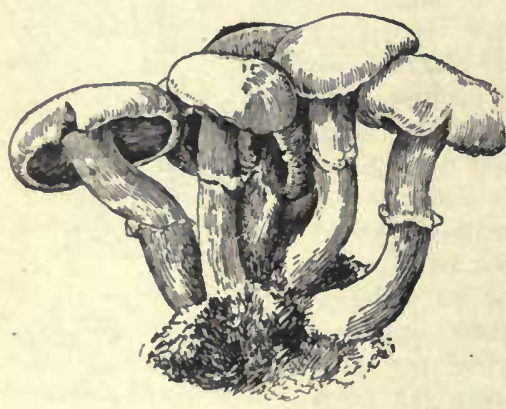

Fig. 131.-A MUSHROOM, example of a saprophytic plant. This is the edible cultivated mushroom. not make food; they must have it made for them or they die. They are dependent. A sprout from a potato tuber in a dark cellar cannot collect and elaborate carbon dioxid. It lives on the food stored in the tuber.

All plants with naturally white or blanched parts are dependent. Their leaves do not develop. They live on organic matter - that which has been made by a plant or elaborated by an animal. The dodder, Indian pipe, beech drop, coral root among flower-bearing plants, also mushrooms and other fungi (Figs. I I, I 32) are examples. The dodder is common in swales, being conspicuous late in the season from its thread-like yellow or orange stems spreading over the herbage of other plants. One kind attacks alfalfa and is a bad pest. The seeds germinate in the spring, but as soon as the twining stem at- 


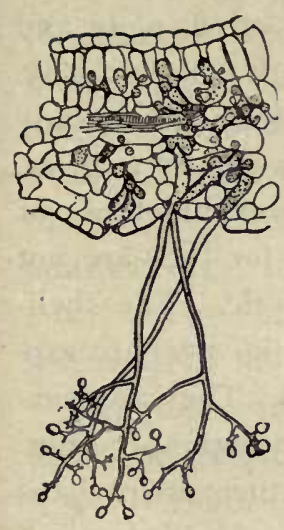

Fig.132. - A PARASITIC FUnGUS, magnified. The mycelium, or vegetative part, is shown by the dottedshaded parts ramify. ing in the leaf tissue. The rounded haustoria projecting into the cells are also shown. The long fruiting parts of the fungus hang from the under surface of the leaf.

taches itself to another plant, the dodder dies away at the base and becomes wholly dependent. It produces flowers in clusters and seeds itself freely (Fig. 133).

Parasites and Saprophytes. - A plant that is dependent on a living plant or animal is a parasite, and the plant or animal on which it lives is the host. The dodder is a true parasite; so are the rusts, mildews, and other fungi that attack leaves and shoots and injure them.

The threads of a parasitic fungus usually creep through the intercellular spaces in the leaf or stem and send suckers (or haustoria) into the cells (Fig. I32). The threads (or the hyphæ) clog the air-spaces of the leaf and often plug the stomates, and they also appropriate and disorganize the cell fluids; thus they injure or kill their host. The mass of hyphæ of a fungus is called mycelium. Some of the hyphæ finally grow out of the leaf and produce spores or reproductive cells that answer the purpose of seeds in distributing the plant (b, Fig. 132).

A plant that lives on dead or decaying matter is a saprophyte. Mushrooms (Fig. I3I) are examples; they live on the decaying matter in the soil. Mold on bread and cheese is an
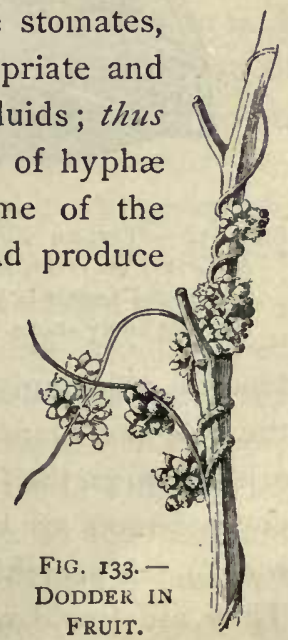
example. Lay a piece of moist bread on a plate and invert a tumbler over it. In a few days it will be moldy. The spores were in the air, or perhaps they had already fallen on the bread but had not had opportunity to grow. Most green plants are unable to make any direct use of the humus or vegetable mold in the soil, for they are not

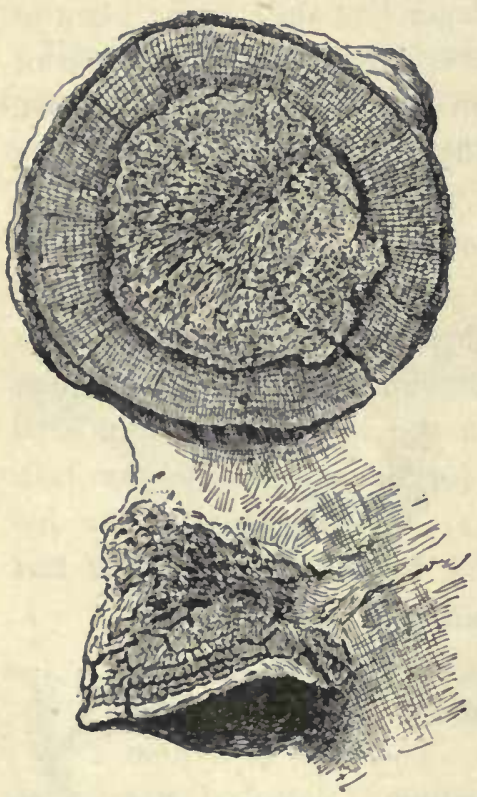

Fig. 134. - TINDER FUNGUS (Polyporus igniarius) on beech log. The external part of the fungus is shown below; the heart-rot injury above. saprophytic. The shelffungi (Fig. I34) are saprophytes. They are common on logs and trees. Some of them are perhaps partially parasitic, extending the mycelium into the wood of the living tree and causing it to become black-hearted (Fig. 134).

Some parasites spring from the ground, as other plants do, but they are parasitic on the roots of their hosts. Some parasites may be partially parasitic and partially saprophytic. Many (perhaps most) of, these ground saprophytes are aided in securing their food by soil fungi, which spread their delicate threads over the root-like branches of the plant and act as intermediaries between the food and the saprophyte. These funguscovered roots are known as mycorrhizas (meaning "fungus root"). Mycorrhizas are not peculiar to saprophytes. They are found on many wholly independent plants, as, 
for example, the heaths, oaks, apples, and pines. It is probable that the fungous threads perform some of the offices of root-hairs to the host. On the other hand, the fungus obtains some nourishment from the host. The association seems to be mutual.

Saprophytes break down or decompose organic substances. Chief of these saprophytes are many microscopic organ-

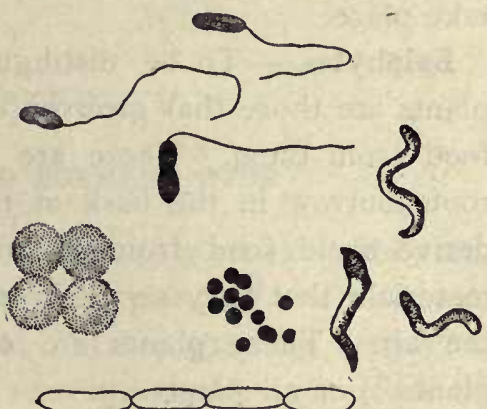
isms known as bacteria (Fig. I35). These innumerable organisms are immersed in water or in dead animals and

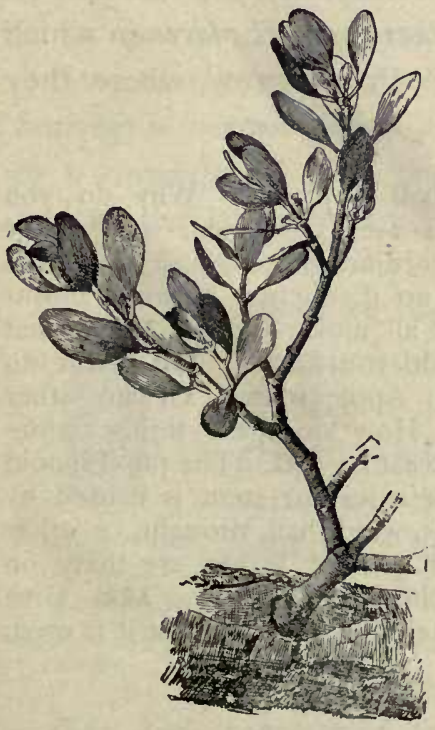

FIG. I36. - AMERICAN MISTLETOE. GROWING ON A WALNUT BRANCH. plants, and in all manner of moist organic products. By breaking down organic combinations, they produce decay. Largely through their agency, and that of many true but microscopic fungi, all things pass into soil and gas. Thus are the bodies of plants and animals removed and the continuing round of life is maintained.

Some parasites are greenleaved. Such is the mistletoe (Fig. 136). They anchor themselves on the host and absorb its juices, but they also appropriate and use 
the carbon dioxid of the air. In some small groups of bacteria a process of organic synthesis has been shown to take place.

Epiphytes. - To be distinguished from the dependent plants are those that grow on other plants without taking food from them. These are green-leaved plants whose roots burrow in the bark of the host plant and perhaps derive some food from it, but which subsist chiefly on materials that they secure from air dust, rain water, and the air. These plants are epiphytes (meaning "upon plants") or air plants.

Epiphytes abound in the tropics. Certain orchids are among the best known examples (Fig. 37). The Spanish moss or tillandsia of the South is another. Mosses and lichens that grow on trees and fences may also be called epiphytes. In the struggle for existence, the plants probably have been driven to these special places in which to find opportunity to grow. Plants grow where they must, not where they will.

Suggestions. - 114. Is a puffball a plant? Why do you think so? 115. Are mushrooms ever cultivated, and where and how? 116. In what locations are mushrooms and toadstools usually found? (There is really no distinction between mushrooms and toadstools. They are all mushrooms.) 117. What kinds of mildew, blight, and rust do you know? 118. How do farmers overcome potato blight? Apple scab? Or any other fungous "plant disease"? 119. How do these things injure plants? 120. What is a plant disease? 121. The pupil should know that every spot or injury on a leaf or stem is caused by something, - as an insect, a fungus, wind, hail, drought, or other agency. How many uninjured or perfect leaves are there on the plant growing nearest the schoolhouse steps? 122. Give formula for Bordeaux mixture and tell how and for what it is used. 


\section{CHAPTER XV}

\section{WINTER AND DORMANT BUDS}

A bud is a growing point, terminating an axis either long or short, or being the starting point of an axis. All branches spring from buds. In the growing season the bud is active; later in the season it ceases to increase the axis in length, and as winter approaches the growing point becomes more or less thickened and covered by protecting scales, in preparation for the long resting season. This resting, dormant, or winter body is what is commonly spoken of as a "bud." A winter bud may be defined as an inactive covered growing point, waiting for spring.

Structurally, a dormant bud is a shortened axis or branch, bearing miniature leaves or flowers or both, and protected by a covering. Cut in two, lengthwise, a bud of the horse-chestnut or other plant that has large buds. With a pin separate

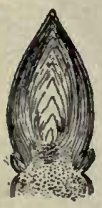

FIG. I37.-BUD OF APRICOT, showing the miniature leaves. the tiny leaves. Count them. Examine the big bud of the rhubarb as it lies under the ground in late winter or early spring ; or the crown buds of asparagus, hepatica, or other early spring plants. Dissect large buds of the apple and pear (Figs. 137, 138).

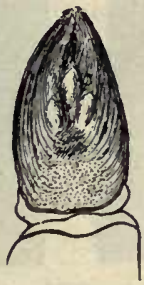

FIG. 138. - BUD OF PEAR, showing both leaves and flowers. The latter are the little knobs in the center.

The bud is protected by firm and dry scales. These scales are modified leaves. The scales fit close. Often 
the bud is protected by varnish (see horse-chestnut and the balsam poplars). Most winter buds are more or less woolly. Examine them under a lens. As we might expect, bud coverings are most prominent in cold and dry climates. Sprinkle water on velvet or flannel, and note the result and give a reason.

All winter buds give rise to branches, not to leaves alone; that is, the leaves are borne on the lengthening axis. Sometimes the axis, or branch, remains very short, - so short that it may not be noticed. Sometimes it grows several feet long.

Whether the branch grows large or not depends on the chance it has, - position on the plant, soil, rainfall, and

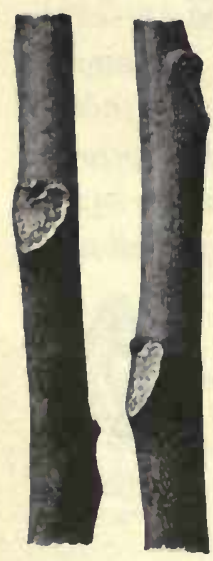

FIG. 139. - IJEAFSCARS, - Ailanthus. many other factors. The new shoot is the unfolding and enlarging of the tiny axis and leaves that we saw in the bud. If the conditions are congenial, the shoot may form more leaves than were tucked away in the bud. The length of the shoot usually depends more on the lengths of the internodes than on the number of leaves.

Where Buds are. - Buds are borne in the axils of the leaves, - in the acute angle that the leaf makes with the stem. When the leaf is growing in the summer, a bud is forming above it. When the leaf falls, the bud remains, and a scar marks the place of the leaf. Fig. 139 shows the large leaf-scars of ailanthus. Observe those on the horse-chestnut, maple, apple, pear, basswood, or any other tree or bush.

Sometimes two or more buds are borne in one axil; the extra ones are accessory or supernumerary buds. Observe them in the Tartarian honeysuckle (common in yards), 
walnut, butternut, red maple, honey locust, and sometimes in the apricot and peach.

If the bud is at the end of a shoot, however short the shoot, it is called a terminal bud. It continues the growth of the axis in a direct line. Very often three or more buds are clustered at the tip (Fig. 140); and in this case there may be more buds than leaf scars. Only one of them, however, is strictly terminal.

A bud in the axil of a leaf is an axillary or lateral bud. Note that there is normally at least one bud in the axil of every leaf on a tree or shrub in late summer and fall. The axillary buds, if they grow, are the starting points of new shoots the following season. If a leaf is pulled off early in summer, what will become of the young bud in its axil? Try this.

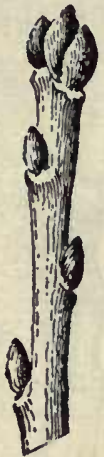

FIG. I40. - TER-

MINAL, BUD BETWEEN TWO OTHER BUDS.

- Currant.

Bulbs and cabbage heads may be likened to buds; that is, they are condensed stems, with scales or modified leaves

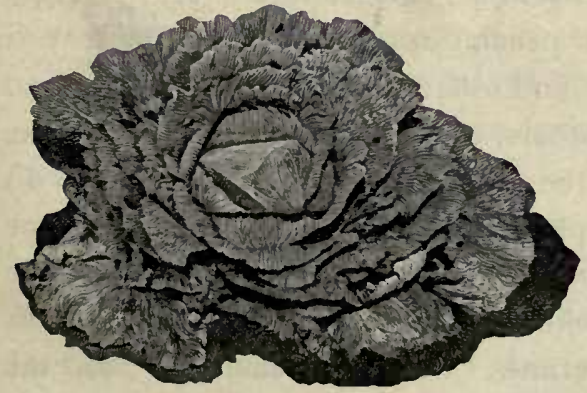

FIG. I4I. - A Gigantic BUD, - Cabbage. densely overlapping and forming a rounded body (Fig. 14I). They differ from true buds, however, in the fact that they are condensations of whole main stems rather than embryo stems borne in the axils of leaves. But bulblets (as of tiger lily) may be scarcely distinguishable from buds on the one hand and from bulbs 
on the other. Cut a cabbage head in two, lengthwise, and see what it is like.

The buds that appear on roots are unusual or abnormal, - they occur only occasionally and in no definite order. Buds appearing in unusual places on any part of the plant are called adventitious buds. Such usually are the buds that arise when a large limb is cut off, and

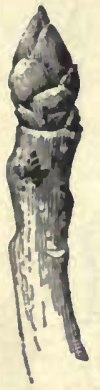

FiG. 142.FRUIT-BUD OF PEAR.

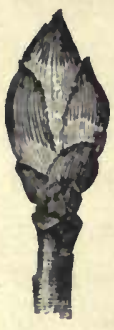

FIG. 143.-THE OPENING OF THE PEAR FRUIT-BUD. from which suckers fall very soon, leaving a little ring of scars. With terminal buds, this ring marks the end

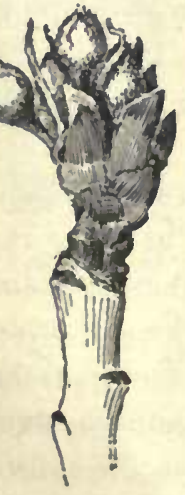

FIG. I45. - OPENING OF THE PEAR-BUd. or water sprouts arise.

How Buds Open. -When the bud swells, the scales are pushed apart, the little axis elongates and pushes out. In most plants the outside scales

of the year's growth: how? Notice peach, apple, plum, willow, and other plants. In

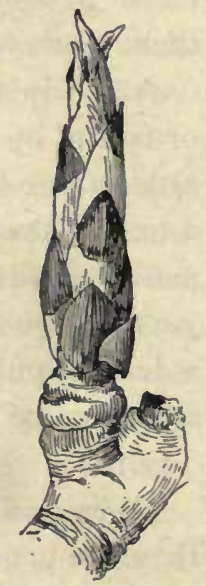

FIG. I44.-OPENING PEAR LEAF-BUD. some others, all the scales grow for a time, as in the pear (Figs. 142, 143, 144). In other plants the inner bud scales become green and almost leaf-like. See the maple and hickory.

Sometimes Flowers come out of the Buds. - Leaves may or may not accompany the flowers. We saw the embryo flowers in Fig. 138. The bud is shown again in Fig. 142. In Fig. 143 it is opening. In Fig. 145 
it is more advanced, and the woolly unformed flowers are appearing. In Fig. I 46 the growth is more advanced.

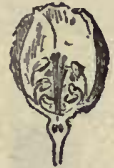

FIG. 146.-A SINGLE FLOWER IN THE PEAR CLUSTER, as seen at 7 A.M. on the day of its opening. At Io o'clock it will be fully expanded.

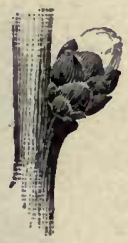

FIG. 147. - THE OPENING OF THE FLOWERBUD OF APRICOT,

Buds that contain or produce only leaves are

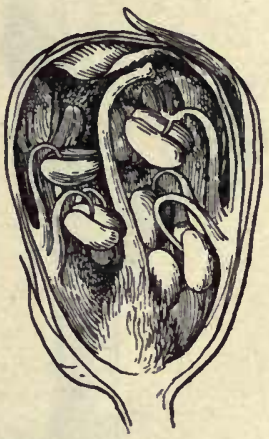

FIG. I48. - APRICOT FLOWER-BUD, enlarged.

leaf-buds. Those which contain only flowers are flowerbuds or fruit-buds. The latter occur on peach, almond, apricot, and many very early spring-flowering plants. The single flower is emerging from the apricot bud in Fig. 147. A longitudinal section of this bud, enlarged, is shown in Fig. 148. Those that contain both leaves and flowers are mixed buds, as in pear, apple, and most late springflowering plants.

Fruit buds are usually thicker or stouter than leaf-buds. They are borne in different positions on different plants. In some plants (apple, pear) they are on the ends of short branches or spurs; in others (peach, red maple) they are along the sides of the last year's growths. In Fig. I49 are shown
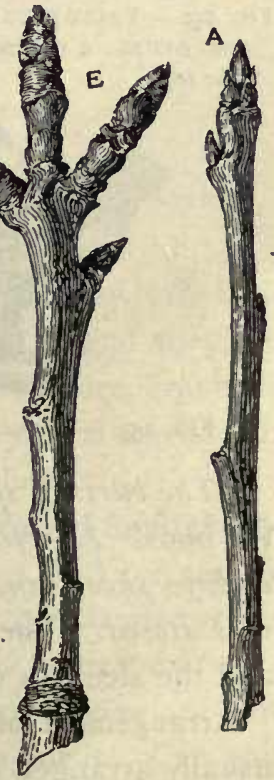
three fruit-buds and one leaf-bud on $E$, and leaf-buds on A. See also Figs. 150, 151, 152, 153, and explain.

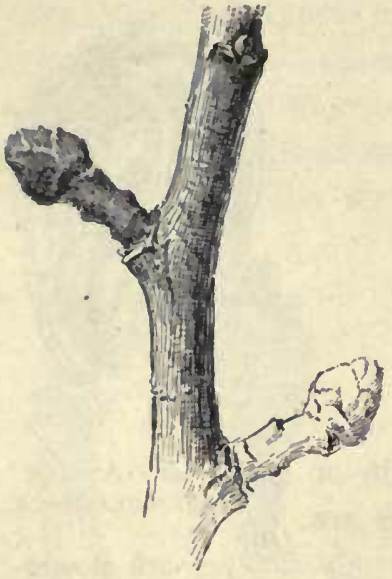

FIG, 150. - FRUIT-BUDS OF APPLE. ON SPURS: a dormant bud at the top.

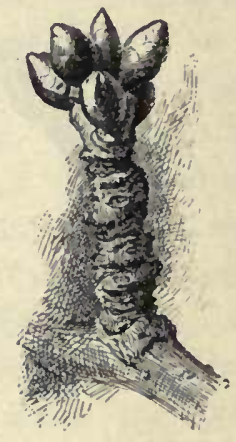

F1G. 151.- ClusTER OF FRUITBUDS OF SWEET ChERRY, with one pointed leaf-bud in center.

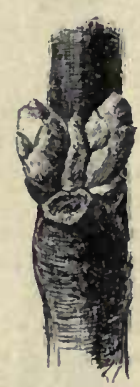

FIG. 152. - TwO

FRUIT-BUDS OF PEACH with a leafbud between.

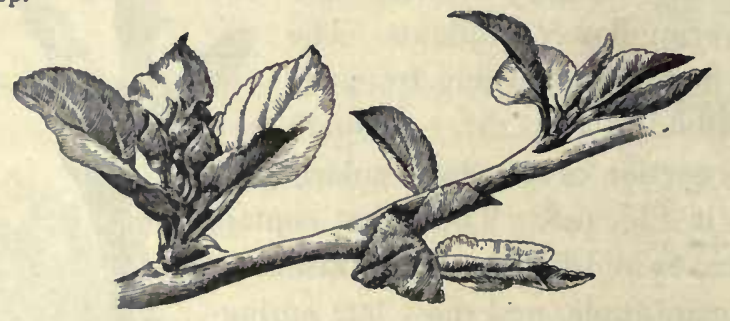

Fig. 153.- OPENiNG OF LeAF-BUdS ANd Flower-BUDS OF APPLE.

"The burst of spring" means in large part the opening of the buds. Everything was made ready the fall before. The embryo shoots and flowers were tucked azvay, and the food was stored. The warm rain falls, and the shutters open and the sleepers wake: the frogs peep.and the birds come.

Arrangement of Buds.- - We have found that leaves are usually arranged in a definite order; buds are borne in the axils of leaves: therefore buds must exhibit phyllotaxy. 
Moreover, branches grow from buds: branches, therefore, should show a definite arrangement; usually, however, they do not show this arrangement because not all the buds grow and not all the branches live. (See Chaps. II and III.) It is apparent, however, that the mode of arrangement of buds determines to some extent the form of the tree: compare bud arrangement in pine or fir with that in maple or apple.

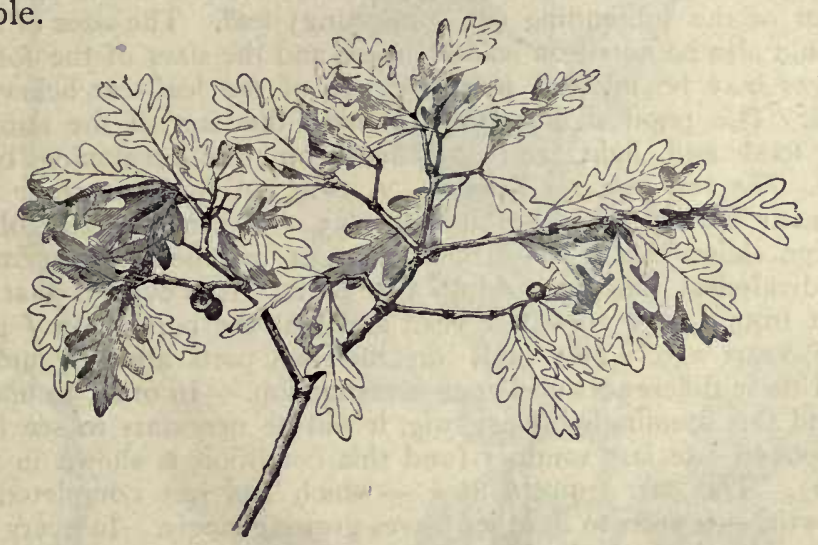

FIG. I54. - OAK SPRAY. How are the leaves borne with reference to the annual growths?

The uppermost buds on any twig, if they are well matured, are usually the larger and stronger and they are the most likely to grow the next spring; therefore, branches tend to be arranged in tiers (particularly well marked in spruces and firs). See Fig. 154 and explain it.

Winter Buds show what has been the Effect of Sunlight.Buds are borne in the axils of the leaves, and the size or vigor of the leaf determines to a large extent the size of the bud. Notice that, in most instances, the largest buds are nearest the tip (Fig. 157). If the largest ones are not near the tip, there is some special reason for it. Can you state it ? Examine the shoots on trees and bushes. 
Suggestions. - Some of the best of all observation lessons are those made on dormant twigs. There are many things to be learned, the eyes are trained, and the speciniens are everywhere accessible. 123. At whatever time of year the pupil takes up the study of branches, he should look for three things: the ages of the various parts, the relative positions of the buds and leaves, the different sizes of similar or comparable buds. If it is late in spring or early in summer, he should watch the development of the buds in the axils, and he should determine whether the strength or size of the bud is in any way related to the size and vigor of the subtending (or supporting) leaf. The sizes of buds should also be noted on leafless twigs, and the sizes of the former leaves may be inferred from the size of the leaf-scar below the bud. The pupil should keep in mind the fact of the struggle for food and light, and its effects on the developing buds. 124. The bud and the branch. A twig cut from an apple tree in early spring is shown in Fig. 155. The most hasty observation shows that it has various parts, or members. It seems to be divided at the point $f$ into two parts. It is evident that the part from $f$ to $h$ grew last year, and that the part below $f$ grew two years ago. The buds on the two parts are very unlike, and these differences challenge investigation. - In order to understand this seemingly lifeless twig, it will be necessary to see it as it looked late last summer (and this condition is shown in Fig. 156). The part from $f$ to $h$, - which has just completed its growth, - is seen to have its leaves growing singly. In every axil (or angle which the leaf makes when it joins the shoot) is a bud. The leaf starts first, and as the season advances the bud forms in its axil. When the leaves have fallen, at the approach of winter, the buds remain, as seen in Fig. 155. Every bud on the last year's growth of a winter twig, therefore, marks the position occupied by a leaf when the shoot was growing. - The part below $f$, in Fig. 1 56, shows a wholly different arrangement. The leaves are two or more together (aaaa), and there are buds without leaves $(b b b b)$. A year ago this part looked like the present shoot from $f$ to $h$, - that is, the leaves were single, with a bud in the axil of each. It is now seen that some of these bud-like parts are longer than others, and that the longest ones are those which have leaves. It must be because of the leaves that they have increased in length. The body $c$ has lost its leaves through some accident, and its growth has ceased. In other words, the parts at aaaa are like the shoot $f h$, except that they are shorter, and they are of the same age. One grew from the end or terminal bud of the main branch, and the others from the side or lateral buds. Parts or bodies that bear leaves are, therefore, branches. - The buds at $b 6 b 6$ have no leaves, and they remain the same 
size that they were a year ago. They are dormant. The only way for a mature bud to grow is by making leaves for itself, for a leaf

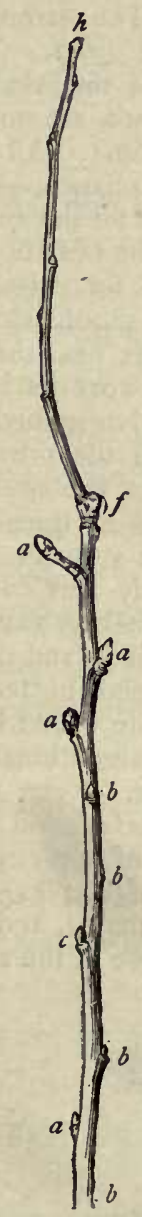

FIG. 155.-AN

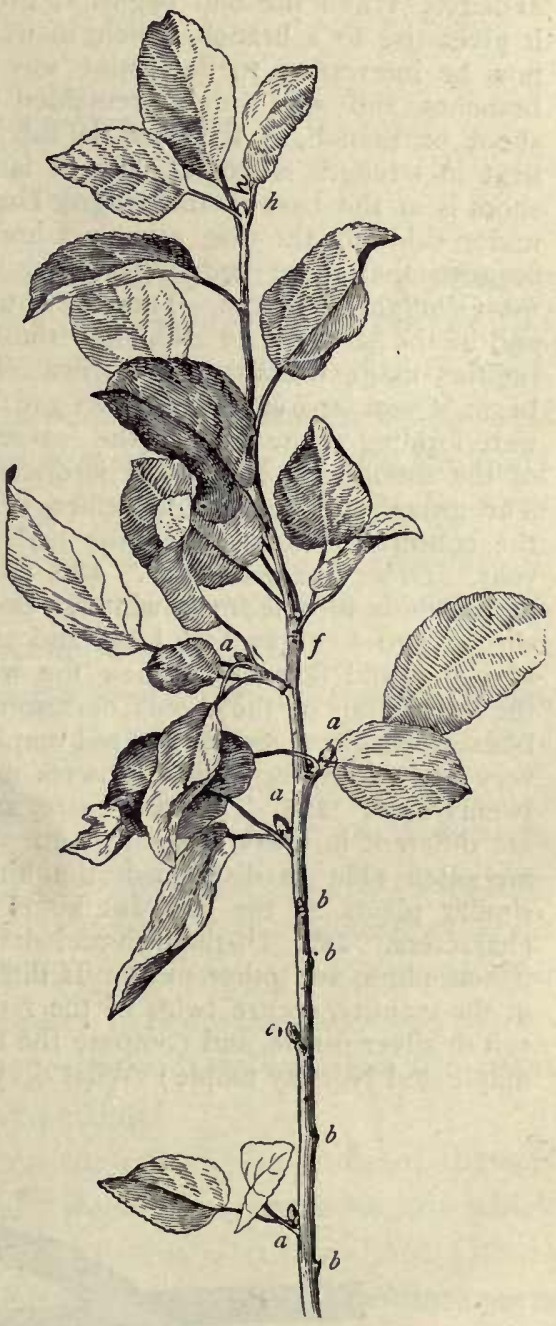

Fig. I56. - Same twig before leaves fell.

will never stand below it again. The twig, therefore, has buds of two ages, - those at $b b b b$ are two seasons old, and those on the 
tips, of all the branches (aaaa, $h$ ), and in the axil of every leaf, are one season old. It is only the terminal buds that are not axillary. When the bud begins to grow and to put forth leaves, it gives rise to a branch, which, in its turn, bears buds. - It will now be interesting to determine why certain buds gave rise to branches and why others remained dormant. The strongest shoot or branch of the year is the terminal one $(f h)$. The next in strength is the uppermost lateral one, and the weakest shoot is at the base of the twig. The dormant buds are on the under side (for the twig grew in a horizontal position). All this suggests that those buds grew which had the best chance, - the most sunlight and room. There were too many buds for the space, and in the struggle for existence those that had the best opportunities made the largest growths. This struggle for existence began a year ago, however, when the buds on the shoot below $f$ were forming in the axils of the leaves, for the buds near the tip of the shoot grew larger and stronger than those near its base. The growth of one year, therefore, is very largely determined by the conditions under which the buds were formed the previous year. Other bud characters. 125. It is easy to see the swelling of the buds in a room in winter. Secure branches of trees and shrubs, two to three feet long, and stand them in vases or jars, as you would flowers. Renew the water frequently and cut off the lower ends of the shoots occasionally. In a week or two the buds will begin to swell. Of red maple, peach, apricot, and other very early-flowering things, flowers may be obtained in ten to twenty days. 126. The shape, size, and color of the winter buds are different in every kind of plant. By the buds alone botanists are often able to distinguish the kinds of plants. Even such similar plants as the different kinds of willows have good bud characters. 127. Distinguish and draw fruit-buds of apple, pear, peach, plum, and other trees. If different kinds of maples grow in the vicinity, secure twigs of the red or swamp maple, and the soft or silver maple, and compare the buds with those of the sugar maple and Norway maple: What do you learn?

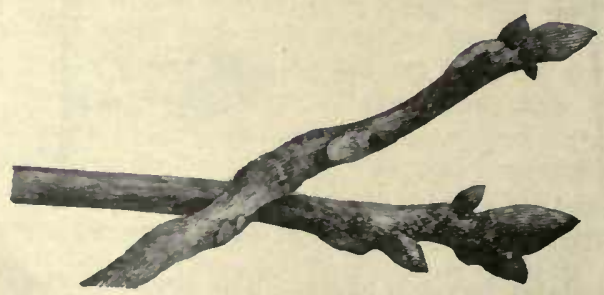

FIG. I57. - BUDS OF THE HICKORY. 


\section{CHAPTER XVI}

\section{BUD PROPAGATION}

WE have learned (in Chap. VI) that plants propagate by means of seeds. They also propagate by means of bud parts, - as rootstocks (rhizomes), roots, runners, layers, bulbs. The pupil should determine how any plant in which he is interested naturally propagates itself (or spreads its kind). Determine this for raspberry, blackberry, strawberry, Junegrass or other grass, nut-grass, water lily, May apple or mandrake, burdock, Irish potato, sweet potato, buckwheat, cotton, pea, corn, sugar-cane, wheat, rice.

Plants may be artificially propagated by similar means, as by layers, cuttings, and grafts. The last two we may discuss here.

Cuttings in General. - A bit of a plant stuck into the groiund stands a chance of growing; and this bit is a cutting. Plants have preferences, however, as to the kind of a bit which shall be used, but there is no way of telling what this preference is except by trying. In some instances this preference has not been discovered, and we say that the plant cannot be propagated by cuttings.

Most plants prefer that the cutting be made of the soft or growing parts (called "wood" by gardeners), of which the "slips" of geranium and coleus are examples. Others grow equally well from cuttings of the hard or mature parts or wood, as currant and grape; and in some instances this mature wood may be of roots, as in the blackberry. In some cases cuttings are made of tubers, as in the Irish 
potato (Fig. 60). Pupils should make cuttings now and then. If they can do nothing more, they can make cuttings of potato, as the farmer does; and they can plant them in a box in the window.

The Softwood Cutting. - The softwood cutting is made from tissue that is still growing, or at least from that which is not dormant. It comprises one or two joints, with

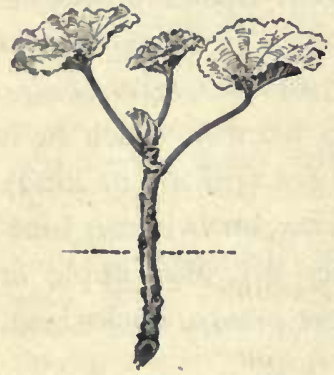

Fig. I58.- Geranium Cutting.

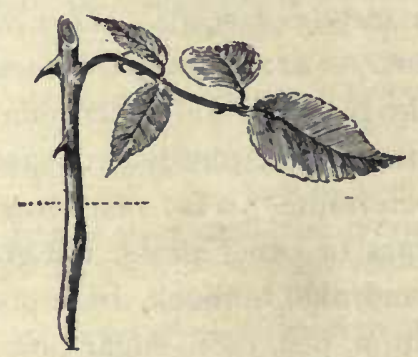

Fig. 159. -- Rose CUtTing.

a leaf attached (Figs. 158, 159). It must not be allowed to wilt. Therefore, it must be protected from direct sunlight and dry air until it is well established; and if it has many leaves, sume of them should be removed, or at least cut in two, in order to reduce the evaporating surface. The soil should be uniformly moist. The pictures show the depth to which the cuttings are planted.

For most plants, the proper age or maturity of wood for the making of cuttings may be determined by giving the twig a quick bend: if it snaps and hangs by the bark, it is in proper condition; if it bends withont breaking, it is too young and soft or too old; if it splinters, it is too old and woody. The tips of strong upright shonts usually make the best cuttings. Preferably, each cutting should have a joint or node near its base; and if the internodes are very short it may comprise two or three joints. 
The stem of the cutting is inserted one third or more its length in clean sand or gravel, and the carth is pressed firmly about it. A newspaper may be laid over the bed to exclude the light - if the sun strikes it - and to prevent too rapid evaporation. The soil should be moist clear through, not on top only.

- Loose sandy or gravelly soil is used. Sand used by masons is good material in which to start most cuttings; or fine gravel - sifted of most of its earthy matter - may be used. Soils are avoided which contain much decaying organic matter, for these soils are breeding places of fungi, which attack the soft cutting and cause it to "damp

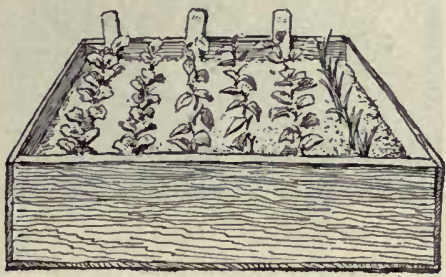

FIG. I60. - CUTTING-BOX. off," or to die at or near the surface of the ground. If the cuttings are to be grown in a window, put three or four inches of the earth in a shallow box or a pan. A soap box cut in two lengthwise, so that it makes a box four or five inches deep - as a gardener's flat - is excellent (Fig. 160). Cuttings of common plants, as geranium, coleus,

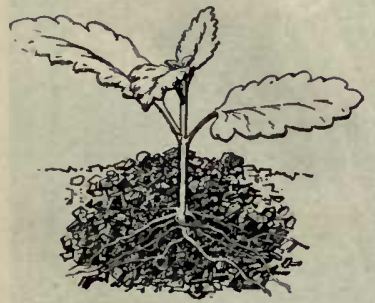

FIG. 161. - VERBENA CUTTING READY FOR TRANSPLANTING. fuchsia, carnation, are kept at a living-room temperature. As long as the cuttings look bright and green, they are in good condition. It may be a month before roots form. When roots have formed, the plants begin to make new leaves at the tip. Then they may be transplanted into other boxes or into pots. The verbena in Fig. $16 \mathrm{I}$ is just ready for transplanting. 


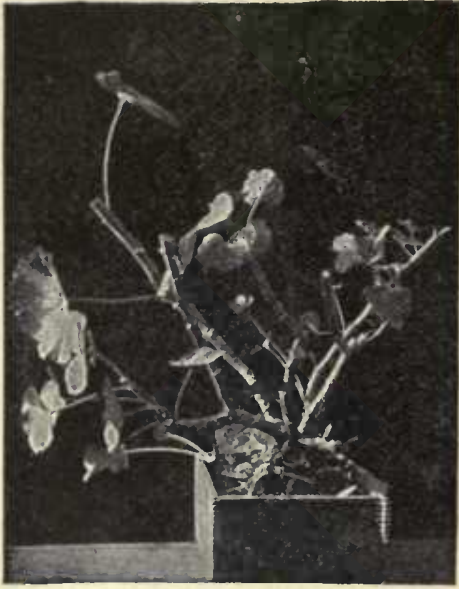

Fig. I62. - Old Geranium Plant CUT RACK TO MAKE IT THROW OUT SHOOTS FROM WHICH CUTTINGS CAN BE MADE.
It is not always easy to find growing shoots from which to make the cuttings. The best practice, in that case, is to cut back an old plant, then keep it warm and well watcred, and thereby force it to throw out nere shoots. The old geranium plant from the window garden, or the one taken up from the lawn bed, may be treated this way (see Fig. I62). The best plants of geranium and coleus and most window plants are those which are not more than one year old. The geranium and fuchsia cuttings which are made in January, February, or March will give compact blooming plants for the next winter; and thereafter new ones should take their pluces (Fig. 163).

The Hardwood Cutting. - Best results with cuttings of mature wood are

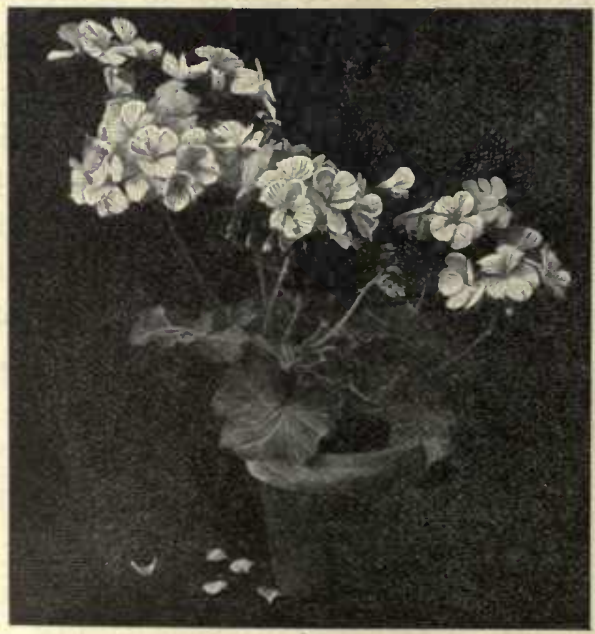

Fig. 163. - EARLy Winter Geranium, from a spring cutting. 
secured when the cuttings are made in the fall and then buried nntil spring in sand in the cellar. These cuttings are usually six to ten inches long. They are not idle while they rest. The lower end calluses or heals, and the roots form more readily when the cutting is planted in the spring. But if the proper season has passed, take cuttings at any time in winter, plant them in a deep box in the window, and watch. They will need no shading or special care. Grape, currant, gooseberry, willow, and poplar readily take root from the hardwood. Fig. I64 shows a currant cutting. It has only one bud above the ground.

The Graft. - When the cutting is inserted in a plant rather than in the soil, it is a graft; and the graft may grow. In this case the cutting grows fast to the other plant, and the two become one. When the cutting is inserted in a plant, it is no longer called a cutting, but a cion; and the plant in which it is inserted is called the stock. Fruit trees are grafted in order that a certain variety or kind may be perpetuated, as a Baldwin or Ben Davis variety of apple, Seckel or Bartlett pear, Navel or St. Michael orange.

Plants have preferences as to the stocks on which they will grow; but we can find out what their choice is only by making the experiment. The pear grows well on the quince, but the quince does not thrive on the pear. The pear grows on some of the hawthorns, but it is an unwilling subject on the apple. Tomato plants will grow on potato plants and potato plants on tomato plants. 
When the potato is the root, both tomatoes and potatoes may be produced, although the crop will be very small; when the tomato is the root, neither potatoes nor tomatoes will be produced. Chestnut will grow on some kinds of oak. In general, one species or kind is grafted on the same species, -as apple on apple, pear on pear, orange on orange.

The forming, growing tissue of the stem (on the plants we have been discussing) is the cambium (Chap. X), lying on the outside of the woody cylinder beneath the bark. In order that union may take place, the cambium of the cion and of the stock must come together. Therefore the cion is set in the side of the stock. There are many ways of shaping the cion and of preparing the stock to receive it. These ways are dictated largely by the relative sizes of cion and stock, although many of them are matters of personal preference. The underlying principles are two: securing close contact between the cambiums of cion and stock; covering the wounded surfaces to prevent evaporation and to protect the parts from disease.

On large stocks the commonest form of grafting is the cleft-graft. The stock is cut off and split; and in one or both sides a wedge-shaped cion is firmly inserted. Fig. 165 shows the cion; Fig. 166, the cions set in the stock; Fig. 167 , the stock waxed. It will be seen that the lower bud - that lying in the wedge - is covered by the wax; but being nearest the food supply and least exposed to weather, it is the most likely to grow : it will push through the wax.

Cleft-grafting is practiced in spring, as grouth begins. The cions are cut previously, when perfectly dormant, and from the tree which it is desired to propagate. The cions are kept in sand or moss in the cellar. Limbs of various. 
sizes may be cleft-grafted, - from one half inch up to four inches in diameter; but a diameter of one to one and one half inches is the most convenient size. All the leading or main branches of a tree top may be grafted. If the remaining parts of the top are gradually cut away and the cions grow well, the entire top will be changed over to the new variety.

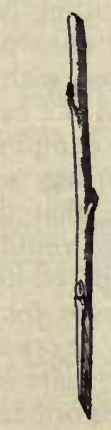

Fig. I65. -

CiON OF

APPLE.

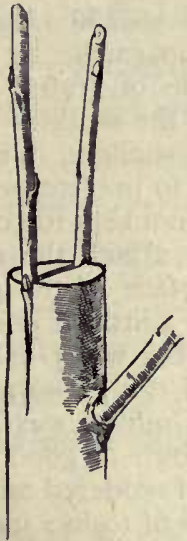

FIG, 166, - Тн F, Cion Insertel).

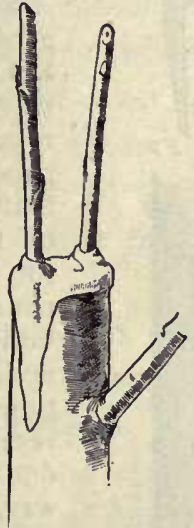

FIG. I67. - THE

PAR'TS WAXED.

Another form of grafting is known as budding. In this case a single bud is used, and it is slipped underneath the bark of the stock and securely tied (not waxed) with soft material, as bass bark, corn shuck, yarn, or raffia (the last a commercial palm fiber). Budding is performed when the bark of the stock will slip or peel (so that the bud can be inserted), and when the bud is mature enough to grow. Usually budding is performed in late summer or early fall, when the winter buds are well formed; or it may be practiced in spring with buds cut in winter. In ordinary summer budding (which is the usual mode) the "bud" or cion forms a union with the stock, and then lies dormant till the following spring, as if it were still on its own twig. 
Budding is mostly restricted to young trees in the nursery. In the spring following the budding, the stock is cut off just above the bud, so that only the shoot from the bud grows to make the future tree. This prevailing form of budding (shield-budding) is shown in Fig.
168.

SugGestions. - 128. Name the plants that the gardener propagates by means of cuttings. 129. By means of grafts. 130. The cutting-box may be set in the window. If the box does not receive direct sunlight, it may be covered with a pane of glass to prevent evaporation. Take care

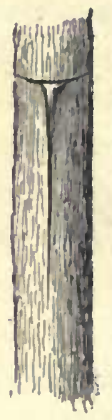
that the air is not kept too close, else the dampingoff fungi may attack the cuttings, and they will rot at the surface of the ground. See that the pane is raised a little at one end to afford ventilation; and if the water collects in drops on the under side of the glass, remove the pane for a time. 131. Grafting wax is made of beeswax, resin, and tallow. A good recipe is one part (as one pound) of rendered tallow, two parts of beeswax, four parts of rosin; melt together in a kettle ; pour the liquid into a pail or tub of water to solidify it; work with the hands until it has the

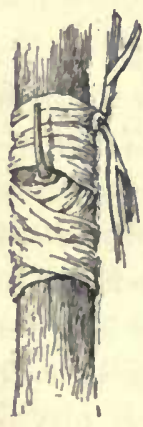

FIG. $168 .-$ BUD. DING. The "bud"; the opening to receive it; the bud tied. color and "grain" of taffy candy, the hands being greased when necessary. The wax will keep any length of time. For the little grafting that any pupil would do, it is better to buy the wax of a seedsman. 132. Grafting is hardly to be recommended as a general school diversion, as the making of cuttings is; and the account of it in this chapter is inserted chiefly to satisfy the general curiosity on the subject. 133. In Chap. V we had a definition of a plant generation: what is "one generation" of a grafted fruit tree, as Le Conte pear, Baldwin, or Ben Davis apple? 134. The Elberta peach originated about 1880 : what is meant by "originated"? 135. How is the grape propagated so as to come true to name (explain what is meant by "coming true")? currant? strawberry? raspberry? blackberry? peach? pear? orange? fig? plum? cherry? apple? chestnut? pecan? 


\section{CHAPTER XVII}

\section{HOW PLANTS CLIMB}

WE have found that plants struggle or contend for a place in which to live. Some of them become adapted to grow in the forest shade, others to grow on other plants, as epiphytes, others to climb to the light. Observe how woods grapes, and other forest climbers, spread their foliage on the very top of the forest tree, while their long flexile trunks may be bare.

There are several ways by which plants climb, but most climbers may be classified into four groups : (I) scramblers, (2) root climbers, (3) tendril climbers, (4) twiners.

Scramblers. - Some plants rise to light and air by resting their long and weak stems on the tops of bushes and quick-growing herbs. Their stems may be elevated in part by the growing twigs of the plants on which they recline. Such plants are scramblers. Usually they are provided with prickles or bristles. In most weedy swamp thickets, scrambling plants may be found. Briers, some roses, bedstraw or galium, bittersweet (Solanum Dulcamara, not the Celastrus), the tear-thumb polygonums, and other plants are familiar examples of scramblers.

Root Climbers. - Some plants climb by means of true roots. These roots seek the dark places and therefore enter the chinks in walls and bark. The trumpet creeper is a familiar example (Fig. 36). The true or English ivy, which is often grown to cover buildings, is another instance. Still another is the poison ivy. Roots are 
distinguished from stem tendrils by their irregular or indefinite position as well as by their mode of growth.

Tendril climbers. - A slender coiling part that serves to hold a climbing plant to a support is known as a tendril.

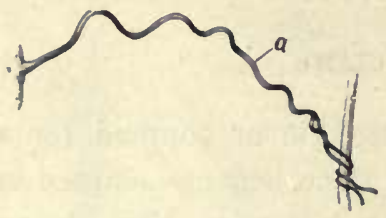

FIG. I69. - TENDRIL, to show where the coil is changed.

The free end swings or curves until it strikes some object, when it attaches itself and then coils and draws the plant close to the support. The spring of the coil also allows the plant to move in the wind, thereby enabling the plant to maintain its hold. Slowly pull a well-matured tendril from its support, and note how strongly it holds on. Watch the tendrils in a wind-storm. Usually the tendril attaches to the support by coiling about it, but the Virginia creeper and Boston ivy (Fig. I 70) attach to walls by means of disks on the ends of the tendrils.

Since both ends of the tendril are fixed, when it finds a support, the coiling would tend to twist it in two. It will be found, however, that the tendril coils in different di-

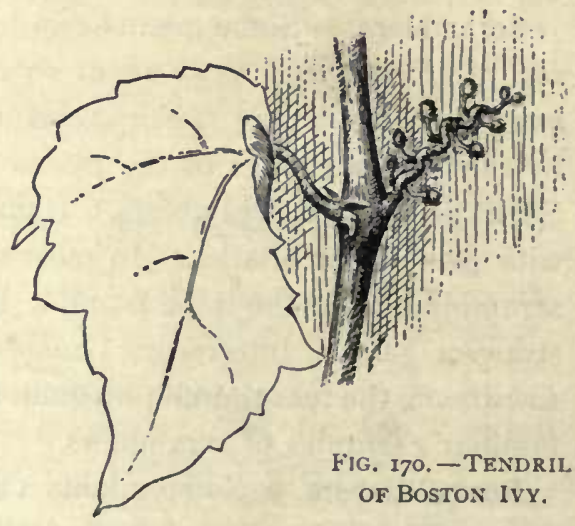
rections in different parts of its length. In Fig. I69, showing an old and stretched-out tendril, the change of direction in the coil occurred at $a$. In long tendrils of cucumbers and melons there may be several changes of direction.

Tendrils may represent either branches or leaves. In the 
Virginia creeper and grape they are branches; they stand opposite the leaves in the position of fruit clusters, and sometimes one branch of a fruit cluster is a tendril. These tendrils are therefore homologous with fruit-clusters, and fruit-clusters are branches.

In some plants tendrils are leaflets (Chap. XI). Examples are the sweet pea and common garden pea. In Fig. I 7 I, observe the leaf with its two great stipules, petiole, six normal leaflets, and two or three pairs of leaflet tendrils and a terminal leaflet tendril. The cobea, a common garden climber, has a similar arrangement. In some cases tendrils are stipules, as probably in the green briers (smilax).

The petiole or midrib may act as a tcndril, as in various kinds of clematis. In Fig. I 72 , the common wild clematis or "old man vine," this mode is seen.

Twiners. - The entire

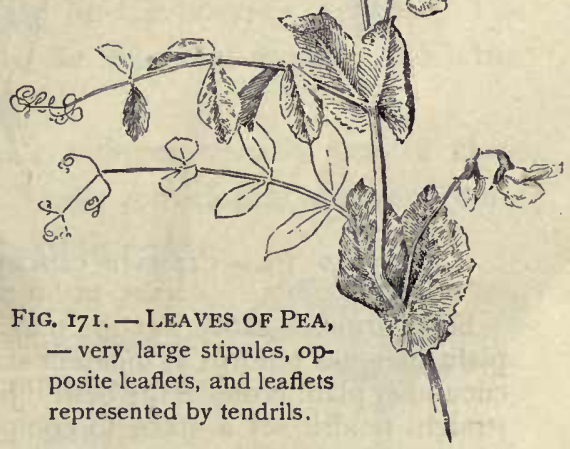
plant or shoot may wind about a support. Such a plant is a twiner. Examples are bean, hop, morning-glory, moonflower, false bittersweet or waxwork (Celastrus), some honeysuckles, wistaria, Dutchman's pipe, dodder. The free tip of the twining branch sweeps about in curves, much as the tendril does, until it finds support or becomes old and rigid.

Each kind of plant usually coils in only one direction. Most plants coil against the sun, or from the observer's left across his front to his right as he faces the plant. 
Examples are bean, morning-glory. The hop twines from the observer's right to his left, or with the sun.

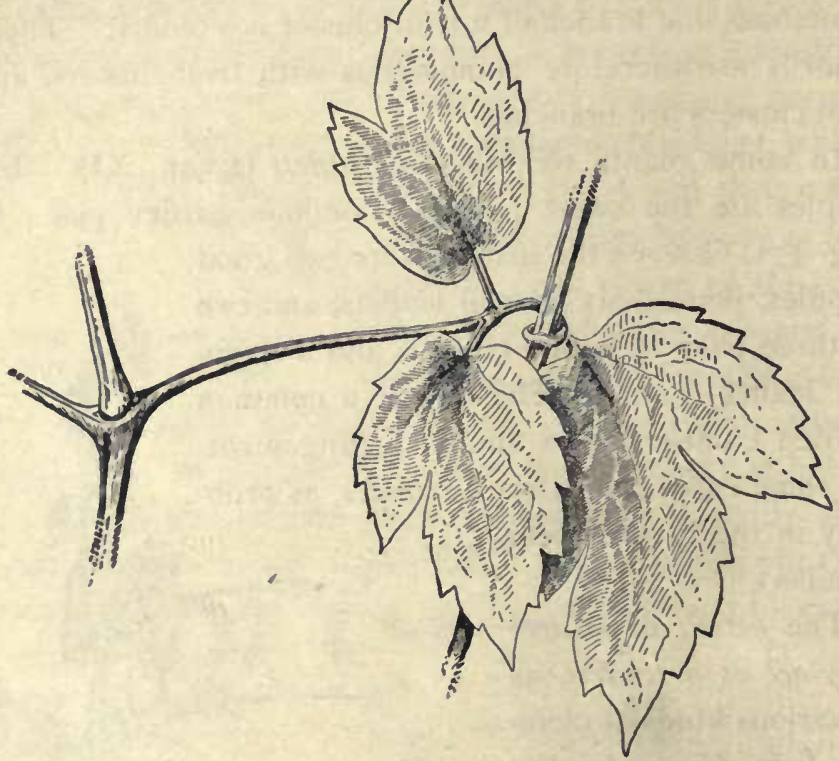

Fig. 172. - ClematiS CLIMBING BY LEAF-TENDRIL.

Suggestrons. - 136. Set the pupil to watch the behavior of any plant that has tendrils at different stages of maturity. A vigorous cucumber plant is one of the best. Just beyond the point of a young straight tendril set a stake to compare the position of it. Note whether the tendril changes position from hour to hour or day to day. 137. Is the tip of the tendril perfectly straight? Why? Set a small stake at the end of a strong straight tendril, so the tendril will just reach it. Watch, and make drawing. 138. If a tendril does not find a support, what does it do? 139. To test the movement of a free tendril, draw an ink line lengthwise of it, and note whether the line remains always on the concave side or the convex side. 140. Name the tendril-bearing plants that you know. 141. Make similar observations and experiments on the tips of twining stems. 142. What twining plants do you know, and which way do they twine? 143. How does any plant that you know get up in the world? 144. Does the stem of a climbing plant contain more or less substance (weight) than an erect self-supporting stem of the same height? Explain. 


\section{CHAPTER XVIII}

\section{THE FLOWER - ITS PARTS AND FORMS}

The function of the flower is to produce seed. It is probable that all its varied forms and colors contribute to this supreme end. These forms and colors please the human fancy and add to the joy of living, but the flower exists for the good of the plant, not for the good of man. The parts of the flower are of two general kinds - those that are directly concerned in the production of seeds, and those that act as covering and protecting organs. The former parts are known as the essential organs; the latter as the floral envelopes.

Envelopes. - The floral envelopes usually bear a close resemblance to leaves. These envelopes are very commonly of two series or kinds - the outer and the inner. The outer series, known as the calyx, is usually smaller and green. It usually comprises the outer cover of the flower bud. The calyx is the lowest whorl in Fig. I73.

The inner series, known as the corolla, is usually colored and more

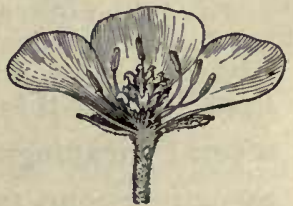

FIG. I73. - FLOWER OF A ButTercup in SecTION.

special or irregular in shape than the calyx. It is the showy part of the flower, as a rule. The corolla is the second or large whorl in Fig. 173 .

The calyx may be composed of several leaves. Each leaf is a sepal. If it is of one piece, it may be lobed or divided, in which case the divisions are called calyx-lobes. 
In like manner, the corolla may be composed of petals, or it may be of one piece and variously lobed. A calyx of one piece, no matter how deeply lobed, is gamosepalous. A corolla of one piece is gamopetalous. When these series are of separate pieces, as in Fig. 173 , the flower is said to be polysepalous and polypetalous. Sometimes both

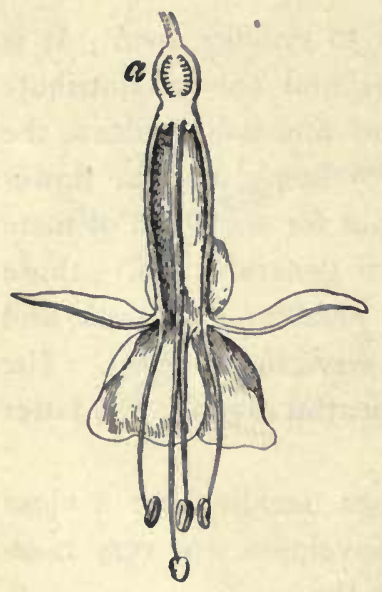

FIS. 174. - FLOWER OF FUCHSIA IN SECTION. series are of separate parts, and sometimes only one of them is so formed.

The floral envelopes are homologons with leaves. Sepals and petals, at least when more than three or five, are in more than one whorl, and one whorl stands below another so that the parts overlap. They are borne on the expanded or thickened end of the flower stalk; this end is the torus. In Fig. I 73 all the parts are seen as attached to the torus. This part is sometimes called the recoptacle, but this word is a common-language term of several meanings, whereas torus has no other meaning. Sometimes one part is attached to another part, as in the fuchsia (Fig. 174), in which the petals are borne on the calyx-tube.

Subtending Parts. - Sometimes there are leaf-like parts just below the calyx, looking like a second calyx. Such parts accompany the carnation flower. These parts are bracts (bracts are small specialized leaves); and they form an involucre. We must be careful that we do not mistake them for true flower parts. Sometimes the bracts are large and petal-like, as in the great white blooms of the 
flowering dogwood: here the real flowers are several, small and greenish, forming a small cluster in the center.

Essential Organs. - The essential organs are of two series. The outer series is composed of the stamens. The inner series is composed of the pistils.

Stamens bear the pollen, which is made up of grains or spores, each spore usually being a single plant cell. The stamen is of two parts, as is readily seen in Figs. 173 , I 74, - the enlarged terminal part or anther, and the stalk or filament. The filament is often so short as to seem to be absent, and the anther is then said to be sessile. The anther bears the pollen spores. It is made up of two or four parts (known as sporangia or spore-cases), which burst and discharge the pollen. When the pollen is shed, the stamen dies.

The pistil has three parts : the lowest, or seedbearing part, which is the ovary; the stigma at the upper extremity, which is a flattened or expanded surface, and usually roughened or sticky; the stalklike part or style, connecting the uvary and stigma.

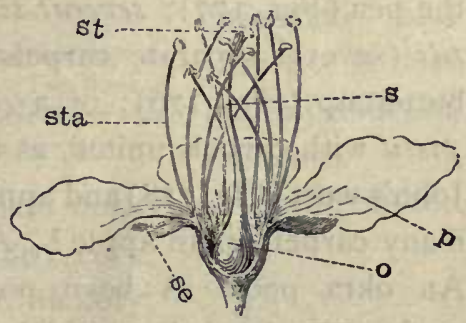

FIG. 175. - THE STRUCTURE OF A Plum Blossom.

se, sepals; $\not$, petals; sta, stamens; 0 , ovary: $s$, style; st, stigma. The pistil consists of the ovary, style, and stigma. It contains the seed part. The stamens are tipped with anthers, in which the pollen is borne. The ovary, 0 , ripens into the fruit.

Sometimes the style is apparently wanting, and the stigma is said to be sessile on the ovary. These parts are shown in the fuchsia (Fig. 174). The ovary or seed vessel is at $a$. A long style, bearing a large stigma, projects from the flower. See also Figs. 175 and 176 .

Stamens and pistils probably are homologous with leaves. A pistil is sometimes conceived to represent anciently a 
leaf as if rolled into a tube; and an anther, a leaf of which the edges may have been turned in on the midrib.

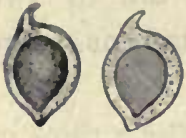

FiG. 176. - SIMPLE

PISTILS OF BUTTERCUP, one in longitudinal section.

The pistil may be of one part or compartment, or of many parts. The different units or parts of which it is composed are carpels. Each carpel is homologous with a leaf. Each carpel bears one or more seeds. A pistil of one carpel is simple; of two or more carpels, compound. Usually the structure of the pistil may be determined by cutting horizontally across the lower or seedbearing part, as Figs. I77, I78 explain. A flower may contain a simple pistil (one carpel), as the pea (Fig. 177); several simple pistils (several separate carpels), as the buttercup (Fig. 176); or a compound pistil with carpels united, as the Saint John's wort (Fig. I 78) and apple. How many carpels in an apple? A peach ? An okra pod? A bean pod? The seed cavity in each carpel is called a locule (Latin locus, a place). In these locules the seeds are borne.

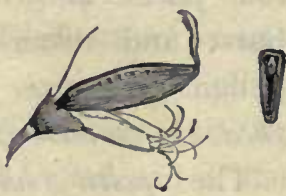

Fig. I77. - PISTIL OF GARDEN PEA, the stamens being pulled down in order to disclose it; also a section showing the single compartment (compare Fig. I88).

Conformation of the Flower. - A

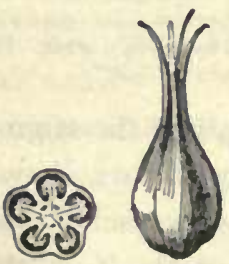

FIG. $178 .-$ CoMPOUND Pistil OF a ST. JOHN'S WORT. It has 5 carpels. flower that has calyx, corolla, stamens, and pistils is said to be complete (Fig. I73); all others are incomplete. In some flowers both the floral envelopes are wanting: such are naked. When one of the floral envelope series is wanting, the remaining series is said to be calyx, and the flower is therefore apetalous (without petals). The knot- 


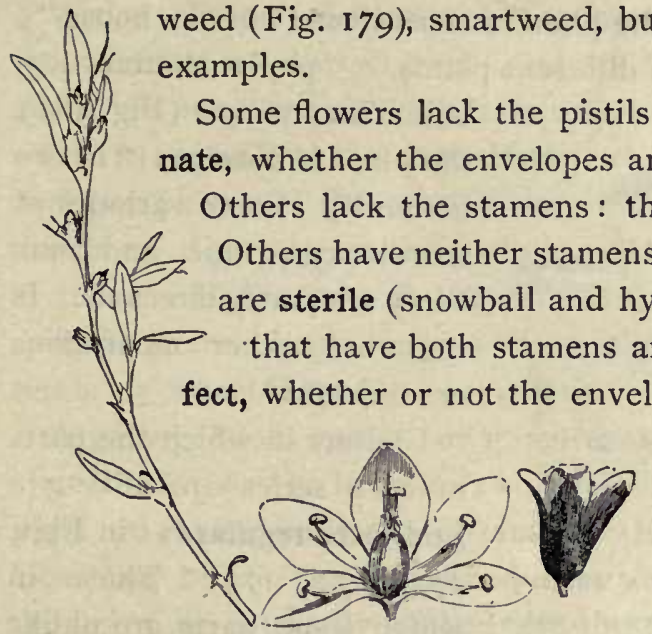

FIG. 179. - KNOTWEED, a very common but inconspicuous plant along hard walks and roads. Two flowers, enlarged, are shown at the right. These flowers are very small and borne in the axils of the leaves.
Those that lack eitherstamens or pistils are imperfect or diclinous. Staminate and pistillate flowers are imperfect or diclinous.

When staminate and pistillate flowers are borne on the same plant, e.g. oak (Fig. I80), corn, beech, chestnut, hazel, walnut, hickory, pine, begonia (Fig. I $8 \mathrm{I}$ ), watermelon,

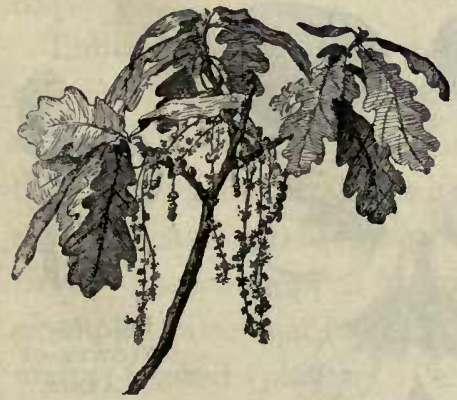

Fig. I80.-STaminate Catkins of OAK. The pistillate flowers are in the leaf axils, and not shown in this picture.

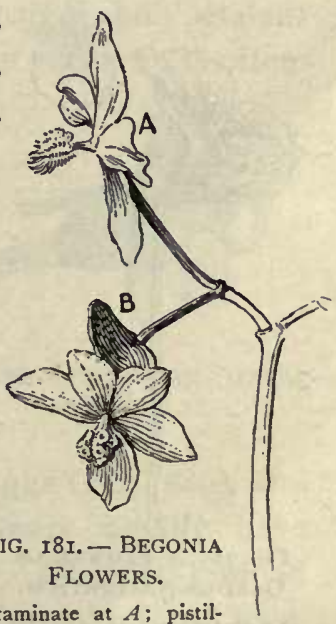

Staminate at $A$; pistillate below, with the winged ovary at $B$. 
gourd, pumpkin, the plant is monœcious ("in one house"). When they are on different plants, e.g. poplar, cottonwood,

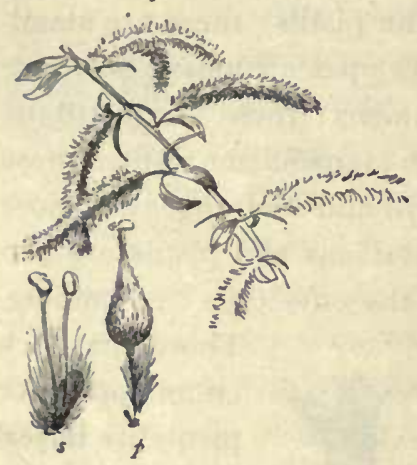

FiG. 182. CATKINS OF A WILLOW.

A staminate flower is shown at $s$, and a pistillate flower at $p$. The staminate and pistillate are on different plants. bois d'arc, willow (Fig. I82), the plant is diøcious (" in two houses"). Some varieties of strawberry, grape, and mulberry are partly diœcious. Is the rose either monœcious or diøcious?

Flowers in which the parts of each series are alike are said to be regular (as in Figs. I73, 174, 175). Those in which some parts are unlike other parts of the same series are irregular. Their regularity may be in calyx, as in nasturtium (Fig. 183); in corolla (Figs. 184, 185); in the

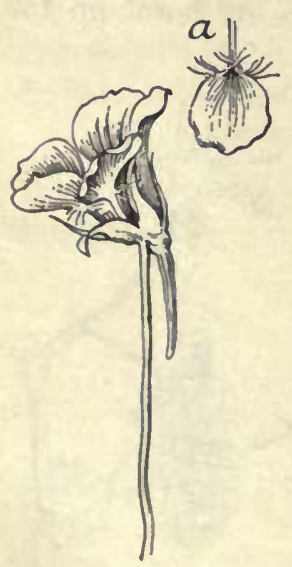

FIG. 183. - FLOWER OF GARDEN NASTURTIUM.

Separate petal at $a$. The caly $x$ is produced into a spur. stamens (compare nasturtium, catnip, Fig. 185, sage); in the pistils. Irregularity is most frequent in the corolla.
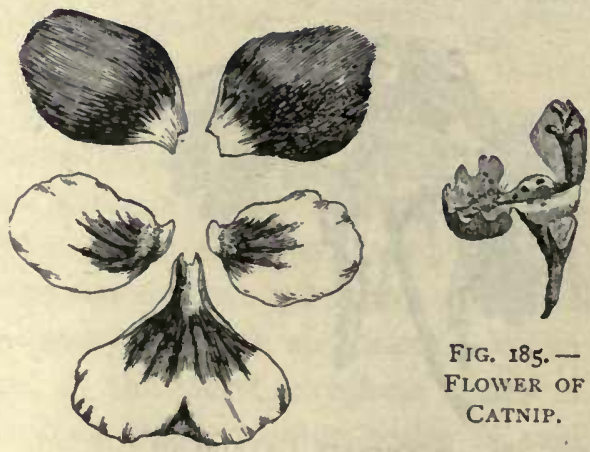

FIG. 185. FLOWER OF Catnip.
FIG. I84. - ThE FIVE PriTALS OF THE PANSY, detached to show the form. 
Various Forms of Corolla. - The corolla often assumes very definite or distinct forms, especially when gamopetalous. It may have a long tube with a wide-flaring limb, when it is said to be funnelform, as in morning-glory and pumpkin. If the tube is very narrow and the limb stands at right angles to it, the corolla is salverform, as in phlox. If the tube is very short and the limb widespreading and nearly circular in outline, the corolla is rotate or wheel-shaped, as in potato.

A gamopetalous corolla or gamosepalous calyx is often cleft in such way as to make two prominent parts. Such parts are said to be lipped or labiate. Each of the lips or lobes may be notched or toothed. In 5-membered flowers, the lower lip is usually 3-lobed and the upper one 2 -lobed. Labiate flowers are characteristic of the mint family (Fig. 185), and the family therefore is called the Labiatæ. (Literally, labiate means merely "lipped," without specifying the number of lips or lobes; but it is commonly used to designate 2-lipped flowers.) Strongly 2-parted polypetalous flowers may be said to be labiate; but the term is oftenest used for gamopetalous corollas.

Labiate gamopetalous flowers that are closed in the throat (or entrance to the tube) are said to be grinning or personate (personate means masked, or personlike). Snap-dragon is a typical

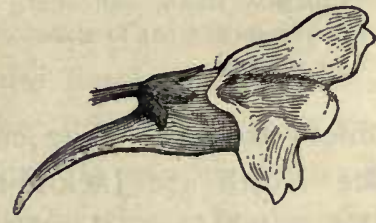

Fig. I86. - PERSONATE Flower OF TOA DFLAX. example; also toadflax or butter-and-eggs (Fig. 186), and many related plants. Personate flowers usually have definite relations to insect pollination. Observe how an insect forces his head into the closed throat of the toadflax. 
The peculiar flowers of the pea tribes are explained in Figs. $187,188$.

Spathe Flowers. - In many plants, very simple (often naked) flowers are borne in dense, more or less fleshy spikes, and the spike is inclosed in or attended by a leaf, sometimes corolla-like, known as a spathe. The spike of flowers is technically known as a spadix. This type of flower is characteristic of the great arum family, which is

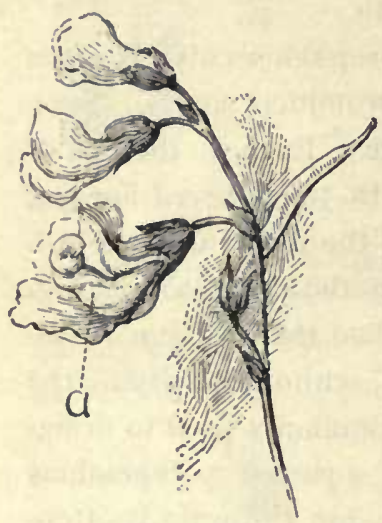

FIG. 187. - FLOWERS OF THE

CoMmon BEAN, with one flower opened $(a)$ to show the structure.

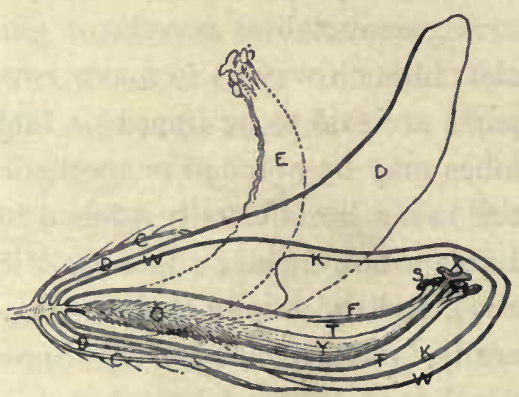

FIG. I88. - Diagram of AI.FALFA Flower IN SECTION :

$C$, calyx, $D$, standard; $W$, wing; $K$, keel; $T$, stamen-tube; $F$, filament of tenth stamen; $X$, stigma: $Y$, style: $O$, ovary: the dotted lines at $E$ show position of stamen-tube, when pushed upward by insects. Enlarged.

chiefly tropical. The commonest wild representatives in the North are Jack-in-the-pulpit, or Indian turnip, and skunk cabbage. In the former the flowers are all diclinous and naked. In the skunk cabbage all the flowers are perfect and have four sepals. The common calla is a good example of this type of inflorescence.

Compositous Flowers. - The head (anthodium) or socalled "flower" of sunflower (Fig. I89), thistle, aster, dandelion, daisy, chrysanthemum, goldenrod, is composed of several or many little flowers, or florets. These 
florets are inclosed in a more or less dense and usually green involucre. In the thistle (Fig. 190) this involucre is prickly. A longitudinal section discloses the florets, all attached at bottom to a common torus, and densely packed in the involucre. The pink tips of these florets constitute the showy part of the head.

Each floret of the thistle (Fig. 190) is a com-

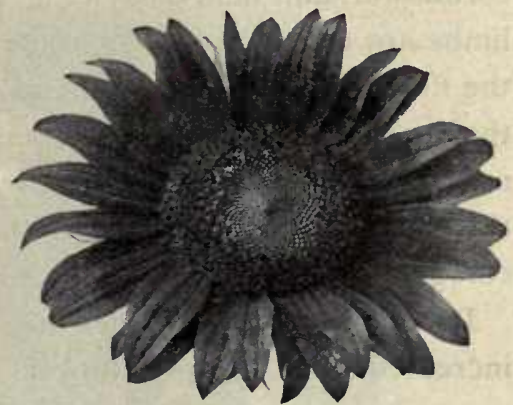

FIG. I89. - HEAD OF SUNFLOWER. plete flower. At $a$ is the ovary. At $b$ is a much-divided plumy calyx, known as the pappus. The corolla is longtubed, rising above the pappus, and is enlarged and 5-lobed
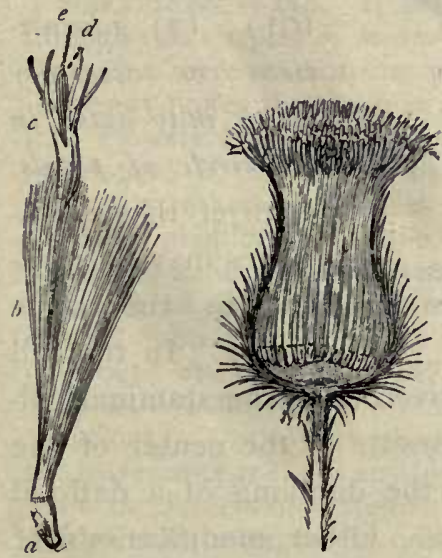

Fig. Igo. - Longitudinal Section OF THISTLE HEAD; also a FLORET of THISTLE. at the top, $c$. The style projects at $e$. The five anthers are united about the style in a ring at $d$. Such anthers are said to be syngenesious. These are the various parts of. the florets of the Compositæ. In some cases the pappus is in the form of barbs, bristles, or scales, and sometimes it is wănting. The pappus, as we shall see later, assists in distributing the seed. Often the florets are not all alike. The corolla of those in the outer circles may be developed into a long, straplike, or tubular part, and the head then has the ap- 
pearance of being one flower with a border of petals. Of such is the sunflower (Fig. 189), aster, bachelor's button or cornflower, and field daisy (Fig. 2 I I). These long corollalimbs are called rays. In some cultivated composites, all the florets may develop rays, as in the dahlia and chrysanthemum. In some species, as dandelion, all the florets naturally have rays. Syngenesious arrangement of anthers is the most characteristic single feature of the composites.

Double Flowers. - Under the stimulus of cultivation and increased food supply, flowers tend to become double.

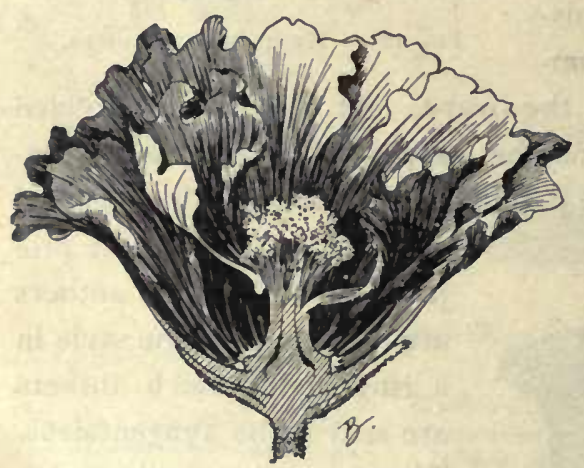

Fig. 191. - PETALS ARISING FROM THE STAMINAL COLUMN OF HOLIYHOCK, and accessory petals in the corolla-whorl.
True doubling arises in two ways, morphologically: (I)stamens or pistils may produce petals (Fig. I91); (2) advcntitious or accessory petals may arise in the circle of petals. Both of these categories may be present in the same flower. In the full

double hollyhock the petals derived from the staminal column are shorter and make a rosette in the center of the flower. In Fig. 192 is shown the doubling of a daffodil by the modification of stamens. Other modifications of flowers are sometimes known as doubling. For example, double dahlias, chrysanthemums, and sunflowers are forms in which the disk flowers have developed rays. The snowball is another case. In the wild snowball the external flowers of the cluster are large and sterile. In the culti- 
vated plant all the flowers have become large and sterile. Hydrangea is a similar case.

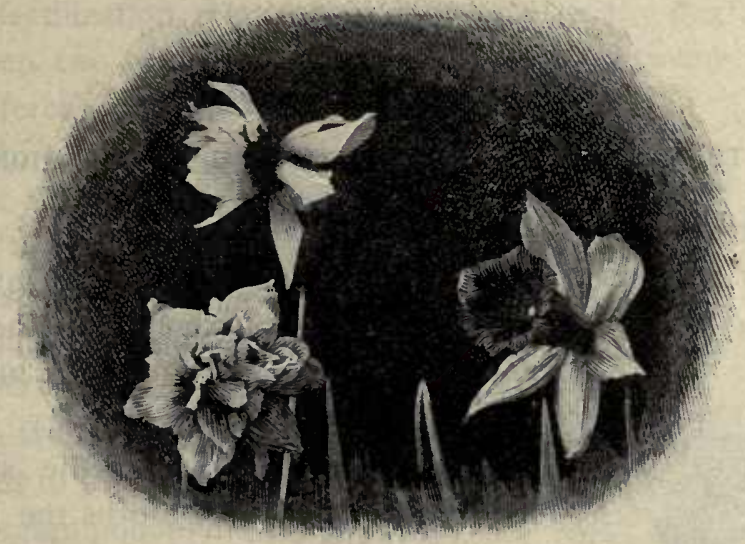

FIG. I92. - NARCISSUS OR DAFFODIL. Single flower at the right.

SugGestions. - 145. If the pupil has been skillfully conducted through this chapter by means of careful study of specimens rather than as a mere memorizing process, he will be in mood to challenge any flower that he sees and to make an effort to understand it. Flowers are endlessly modified in form; but they can be understood if the pupil looks first for the anthers and ovaries. How may anthers and ovaries always be distinguished? 146. It is excellent practice to find the flowers in plants that are commonly known by name, and to determine the main points in their structure. What are the flowers in Indian corn? pumpkin or squash? celery? cabbage? potato? pea? tomato? okra? cotton? rhubarb? chestnut? wheat? oats? 147. Do all forest trees have flowers? Explain. 148. Name all the moncecious plants you know. Dicecious. 149. What plants do you know that bloom before the leaves appear? Do any bloom after the leaves fall? 150. Explain the flowers of marigold, hyacinth, lettuce, clover, asparagus, garden calla, aster, locust, onion, burdock, lily-of-the-valley, crocus, Golden Glow rudbeckia, cowpea. 151. Define a flower.

Note TO THE TEACHER. - It cannot be urged too often that the specimens themselves be studied. If this chapter becomes a mere recitation on names and definitions, the exercise will be worse than useless. Properly taught by means of the flowers theniselves, the names become merely incidental and a part of the pupil's language, and the subject has living interest. 


\section{CHAPTER XIX}

\section{THE FLOWER - FERTILIZATION AND POLLINATION}

Fertilization. - Seeds result from the union of two ele. ments or parts. One of these elements is a cell-nucleus

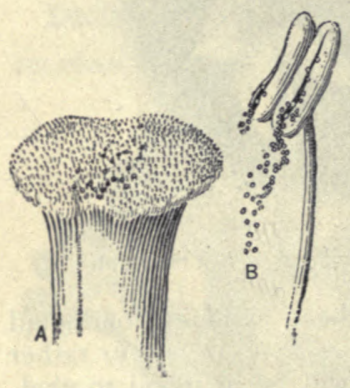

FIG. I93. $-B$, Pollen escaping from anther; $A$, pollen germinating on a stigma. Enlarged. of the pollen-grain. The other element is the cell-nucleus of an eggcell, borne in the ovary. The pollen-grain falls on the stigma (Fig. 193). It absorbs the juices exuded by the stigma, and grows by sending out a tube (Fig. 194). This tube grows downward through the style, absorbing food as it goes, and finally reaches the egg-cell in the interior of an ovule in the ovary (Fig. 195), and fertilization, or union of a nucleus of the pollen and the nucleus of the egg-cell in the ovule, takes place. The ovule and embryo within then develops into a seed. The growth of the pollen-tube is often spoken of as germination of the pollen, but it is not germination in the sense in which the word is used when speaking of seeds.

Better seeds - that is, those that produce stronger and more fruitful plants - often result when the pollen comes from another flower. Fertilization effected between different flowers is cross-fertilization; that resulting from the

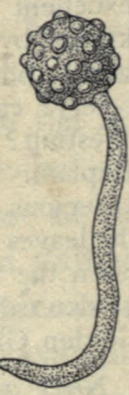

FIG. 194. A POLLENGRAIN AND THE GROW. ING TUBE. 
application of pollen to pistils in the same flower is closefertilization or self-fertilization. It will be seen that the cross-fertilization relationship may be of many degreesbetween two flowers in the same cluster, between those in different clusters on the same branch, between those on different plants. Usually fertilization takes place only between plants of the same species or kind.

In many cases there is, in effect, an apparent selection of pollen when pollen from two or more sources is applied to the stigma. Sometimes the foreign pollen, if from the same kind of plant, grows, and fertilization results, while pollen from the same flower is less promptly effective. If, however, no foreign pol-

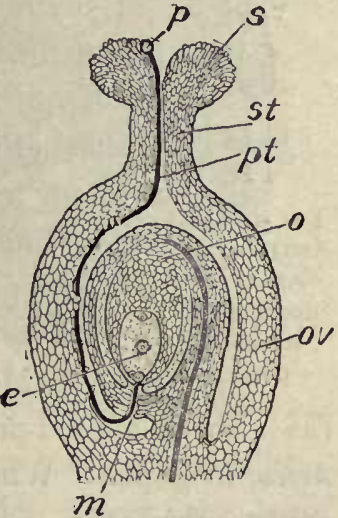

FIG. I95. - DIAGRAM TO REPRESENT FERTILIZATION.

$s$, stigma; $s t$, style; or', ovary; $o$, ovule; $p$, pollen-grain; $p t$, pollen-tube; $\ell$, egg-cell; $m$, micropyle. same purpose.

In order that the pollen may grow, the stigma must be ripe. At this stage the stigma is usually moist and sometimes sticky. A ripe stigma is said to be receptive. The stigma may remain receptive for several hours or even days, depending on the kind of plant, the weather, and how soon pollen is received. Watch a certain flower every day to see the anther locules open and the stigma ripen. When fertilization takes place, the stigma dies. Observe, also, how soon the petals wither after the stigma has received pollen.

Pollination. - The transfer of the pollen from anther to stigma is known as pollination. The pollen may 
fall of its own weight on the adjacent stigma, or it may be carried from flower to flower by wind, insects, or other agents. There may be self-pollination or cross-pollination, and of course it must always precede fertilization.

Usually the pollen is discharged by the bursting of the anthers. The commonest method of discharge is through a slit on either side of the anther (Fig. 193). Sometimes it discharges through a pore at the apex, as in azalea (Fig. FIG. 196.ANTHER OF Azalea, opening by terminal pores. I96), rhododendron, huckleberry, wintergreen. In some plants a part of the anther wall raises or falls as a lid, as in barberry (Fig. 197), blue cohosh, May apple. The opening of an anther (as also of a seed-pod) is known as dehiscence (de, from; hisco, to gape): When an anther or seed pod opens, it is said to dehisce.

Most flowers are so constructed as to increase the chances of cross-pollination. We have seen that the stigma may have the power of choosing foreign pollen. The commonest means of necessitating cross-pollination is the different times of maturing of stamens and pistils in the same flower. In most cases the stamens mature first: the flower is then proterandrous. When the pistils mature first, the flower is proterogynous. (Aner, andr, is a Greek root often used, in combinations, for stamen, and gyne for pistil.) The difference in time of ripening may be an hour or two, or it may be a day. The ripening of the stamens

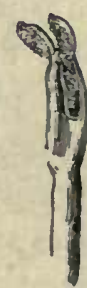

FIG. I97. BARBERRY STAMEN, with anther opening by lids. and pistils at different times is known as dichogamy, and flowers of such character are said to be dichogamous. There is little chance for dichogamous flowers to pollinate themselves. Many flowers are imporfectly dichogamous - 
some of the anthers mature simultaneously with the pistils, so that there is chance for self-pollination in case foreign pollen does not arrive. Even when the stigma receives pollen from its own flower, cross-fertilization may result. The hollyhock is proterandrous. Fig. I98 shows a flower recently

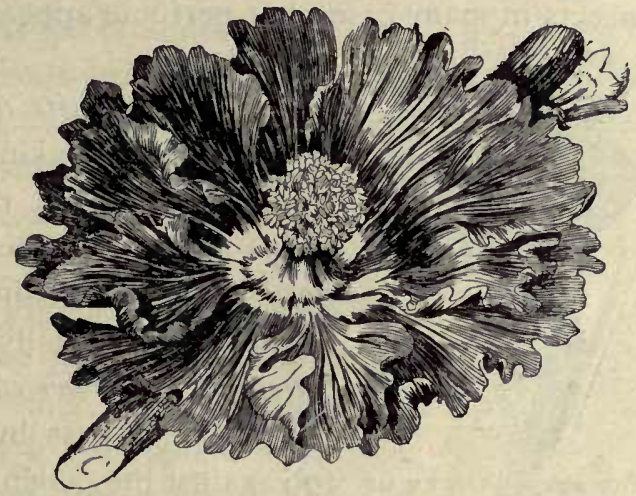

FIG. I98. - FIOWER OF HOLLYHOCK; proterandrous. expanded. The center is occupied by the column of stamens. In Fig. 199, showing an older flower, the long styles are conspicuous.

Some flowers are so constructed as to prohibit self-pollination. Very irregular flowers are usually of this kind.

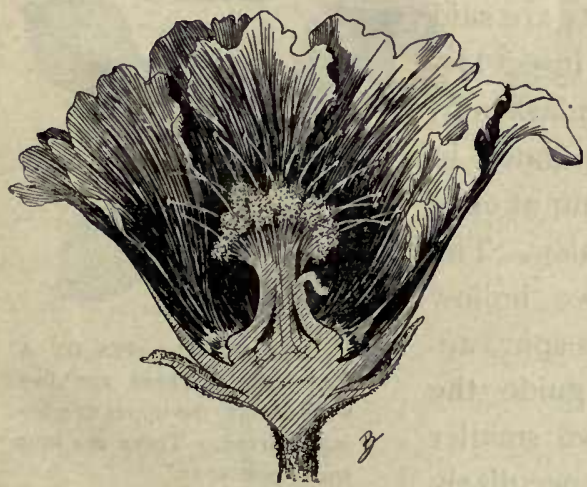

FIG. I99. - OlJER FLOWER OF HOLLYHOCK. With some of them, the petals form a sac to inclose the anthers and the pollen cannot be shed on the stigma but is retained until a bee forces the sac open; the pollen is rubbed on the hairs of the bee and transported. Regular flowers usually depend mostly on dichogamy and the selective power of the pistil to insure crossing. Flowers that are very 
irregular and provided with nectar and strong perfume are usually pollinated by insects. Gaudy colors probably attract insects in many cases, but perfume appears to be a greater

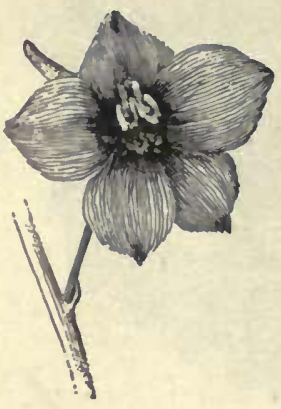

FIG. 200. - FLOWER OF LARKSPUR. attraction.

The insect visits the flower for the ncctar (for the making of honey) and may unknowingly carry the pollen. Spurs and sacs in the flower are nectaries (Fig. 200), but in spurless flowers the nectar is usually secreted in the bottom of the flower cup. This compels the insect to pass by the anther and rub against the pollen before it reaches the nectar. Sometimes the anther is a long lever poised on the middle point and the insect bumps against one end and lifts it, thus bringing the other end of the lever with the pollen sacs down on its back. Flowers that are pollinated by insects are said to be entomophilous (" insect loving"). Fig. 200 shows a larkspur. The envelopes are separated in Fig. 20r. The long spur at once suggests insect pollination. The spur is a sepal. Two hollow petals project into this spur, apparently serving to guide the bee's tongue. The two smaller petals, in front, are peculiarly

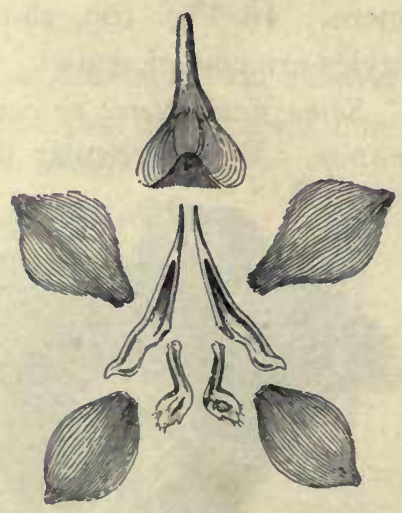

FIG. 201. - ENVELOPES OF A LARKSPUR. There are five wide sepals, the upper one being spurred. There are four small petals. colored and perhaps serve the bee in locating the nectary. The stamens ensheath the pistils (Fig. 202). As the insect stands on the flower and thrusts its head into the center, 
the envelopes are pushed downward and outward and the pistil and stamens come in contact with its abdomen. Since the flower is proterandrous, the pollen that the pistils receive from the bee's abdomen must come from another flower. Note $\dot{a}$ somewhat similar arrangement in the toadflax or butter-andeggs. .

In some cases (Fig. 203) the stamens are longer than the pistil in one flower and shorter in another. If the insect visits such flowers, it gets pollen on its head from the long-stamen flower, and deposits this pollen on the stigma in the long-pistil flower. Such flowers are di-

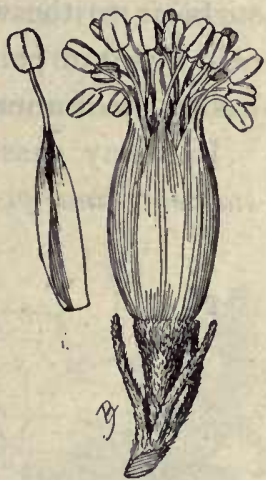

FIG, 202. - STAMENS OF LARKSPUR, surrounding the pistils. morphous (of two forms). If pollen from its own flower and from another flower both fall on the stigma, the probabilities are that the stigma will choose the foreign pollen.
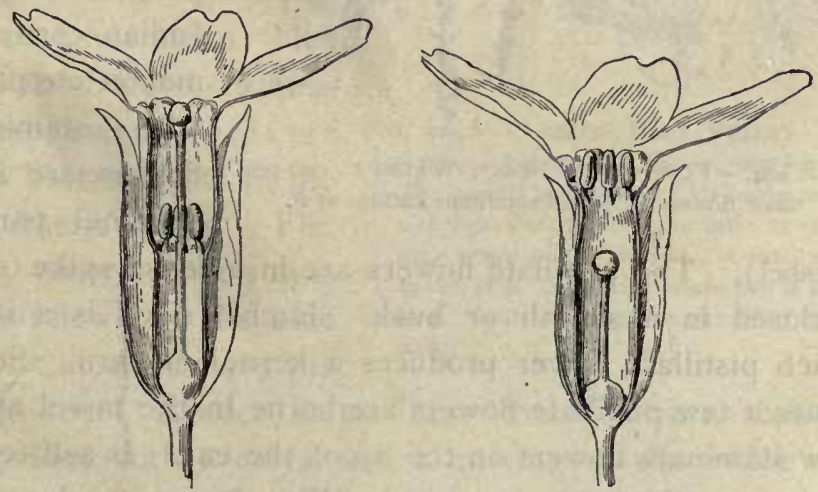

FIG. 203. - DimorPHIC FLOWERS OF PRIMROSE.

Many flowers are pollinated by the wind. They are said to be anemophilous ("wind loving"). Such flowers pro- 
duce great quantities of pollen, for much of it is wasted. They usually have broad stigmas, which expose large surfaces to the wind. They are usually lacking in gaudy colors and in perfume. Grasses and pine trees are typical examples of anemophilous plants.

In many cases cross-pollination is insured because the stamens and pistils are in different flowers (diclinous).

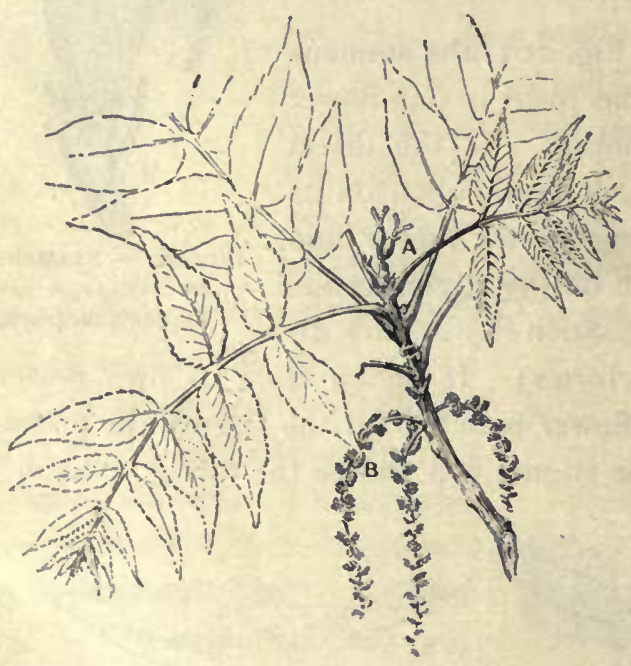

Fig. 204. - Flowers OF BLACK WALNUT: two pistillate flowers at $A$, and staminate catkins at $B$.

Monœcious and diœcious plants may be pollinated by wind or insects, or other agents (Fig. 204). They are usually wind - pollinated, although willows are often, if not mostly, insectpollinated. The Indian corn is a monœcious plant. The staminate flowers are in a terminal panicle (tassel). The pistillate flowers are in a dense spike (ear), inclosed in a sheath or husk. Each "silk". is a style. Each pistillate flower produces a kernel of corn. Sometimes a few pistillate flowers are borne in the tassel and a few staminate flowers on the tip of the ear. Is self-fertilization possible with the corn? Why does a "volunteer" stalk standing alone in a garden have only a few grains on the ear? What is the direction of the prevailing wind in summer? If only two or three rows of corn are 
planted in a garden where prevailing winds occur, in which direction would they better run?

Although most flowers are of such character as to insure or increase the chances of cross-pollination, there are some that absolutely forbid crossing. These flowers are usually borne beneath or on the ground, and they lack showy colors and perfumes. They are known as cleistogamous flowers (meaning " hidden flowers"). The plant has normal showy flowers that may be insect-pollinated, and in addition is provided with these simplified flowers. Only a few plants bear cleistogamous flowers. Hogpeanut, common blue violet, fringed winter-

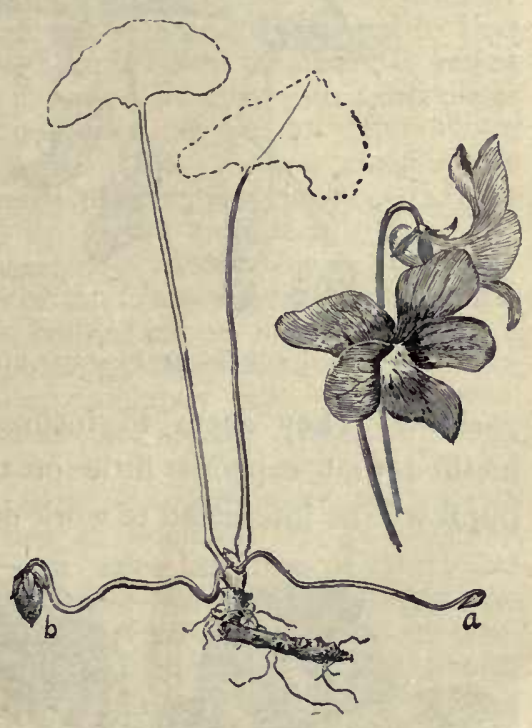
green, and dalibarda are the best subjects in the Northern states. Fig. 205 shows a cleistogamous flower of the blue violet at $a$. Above the Fig. 205. - Common Blue Violet. The familiar flowers are shown, natural size. The corolla is spurred. Late in the season, cleistogamous flowers are often borne on the surface of the ground. A small one is shown at $a$. A neariy mature pod is shown at $b$. Both $a$ and $b$ are one third natural size.

true roots, slender stems bear these flowers, that are provided with a calyx, and a curving corolla which does not open. Inside are the stamens and pistils: Late in the season the cleistogamous flowers may be found just underneath the mold. They never rise above ground. The following summer one may find a seedling plant, in 
some kinds of plants, with the remains of the old cleistogamous flower still adhering to the root. Cleistogamous flowers usually appear after the showy flowers have

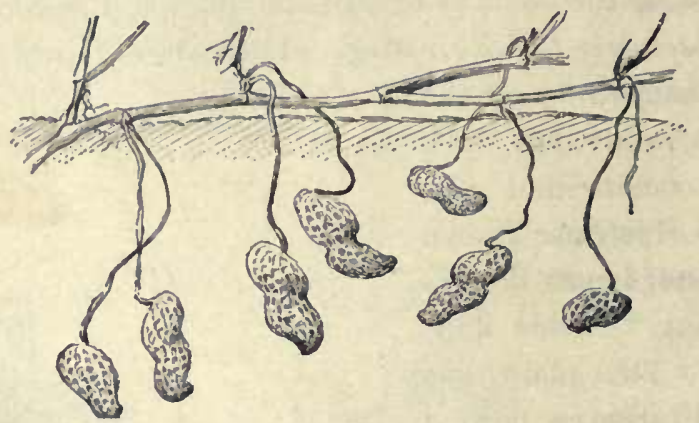

FIG. 206. - PODS OF PEANUTS RIPENING UNDERGROUND.

passed. They seem to insure a crop of seed by a method that expends little of the plant's energy. The pupil will be interested to work out the fruiting of the pea-

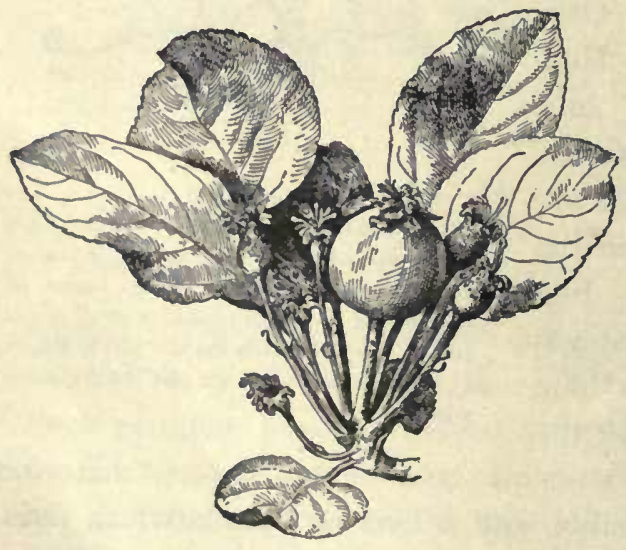

FIG. 207.-STRUGgle FOR EXISTENCE AMONG THE APPLE. FLOWERS. nut (Fig. 206). Unbaked fresh peanuts grow readily and can easily be raised in the North in

a warm sandy garden.

SugGestions. 152. Not all the flowers produce seeds. Note that an apple tree may bloom very full, but that only relatively few apples may result (Fig. 207). More pollen is produced than is needed to fertilize the flowers; this increases the chances that sufficient 
stigmas will receive acceptable pollen to enable the plant to perpetuate its kind. At any time in summer, or even in fall, examine the apple trees carefully to determine whether any dead flowers or flower stalks still remain about the apple; or, examine any full-blooming plant to see whether any of the flowers fail. 153. Keep watch on any plant to see whether insects visit it. What kind? When? What for? 154. Determine whether the calyx serves any purpose in protecting the flower. Very carefully remove the calyx from a bud that is normally exposed to heat and sun and rain, and see whether the flower then fares as well as others. 155. Cover a single flower on its plant with a tiny paper or muslin bag so tightly that no insect can get in. If the flower sets fruit, what do you conclude? 156. Remove carefully the corolla from a flower nearly ready to open, preferably one that has no other flowers very close to it. Watch for insects. 157. Find the nectar in any flower that you study. 158. Remove the stigma. What happens? 159. Which of the following plants have perfect flowers : pea, bean, pumpkin, cotton, clover, buckwheat, potato, Indian corn, peach, chestnut, hickory, watermelon, sunflower, cabbage, rose, begonia, geranium, cucumber, calla, willow, cottonwood, cantaloupe? What have the others? 160. On windpollinated plants, are either anthers or stigmas more numerous? 161. Are very small colored flowers usually borne singly or in clusters? 162. Why do rains at blooming time often lessen the fruit crop? 163. Of what value are bees in orchards? 164. The crossing of plants to improve varieties or to obtain new varieties. - It may be desired to perform the operation of pollination by hand. In order to insure the most definite results, every effort should be made rightly to apply the pollen which it is desired shall be used, and rigidly to exclude all other pollen. (a) The first requisite is to remove the anthers from the flower which it is proposed to cross, and they must be removed before the pollen has been shed. The flower-bud is therefore opened and the anthers taken out. Cut off the floral envelopes with small, sharppointed scissors, then cut out or pull out the anthers, leaving only the pistil untouched; or merely open the corolla at the end and pull out the anthers with a hook or tweezers; and this method is often the best one. It is best to delay the operation as long as possible and yet not allow the bud to open (and thereby expose the flower to foreign pollen) nor the anthers to discharge the pollen. (b) The flower must next be covered with a paper bag to prevent the access of pollen (Figs. 208, 209). If the stigma is not receptive at the time (as it usually is not), the desired pollen is not applied at once. The bag may be removed from time to time to allow of examination of the pistil, and when the stigma is mature, which is told by its glutinous or roughened appearance, 
the time for pollination has come. If the bag is slightly moistened, it can be puckered more tightly about the stem of the plant. The time required for the stigma to mature varies from several hours to a few days. (c) When the stigma is ready, an unopened anther from the desired flower is crushed on the finger nail or a knife blade, and the pollen is rubbed on the stigma by means of a tiny brush, the point of a knife blade, or a sliver of wood. The

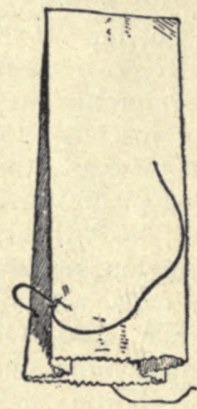

FIG. 208. - A PAPER BAG, with string inserted.

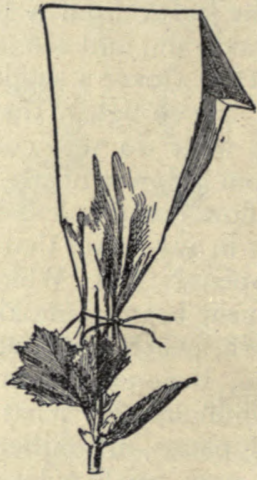

FIG. 209. - THE BAG TIED OVER A FLOWER.

flower is again covered with the bag, which is allowed to remain for several days until all danger of other pollination is past. Care must be taken completely to cover the stigmatic surface with pollen, if possible. The seeds produced by a crossed flower produce hybrids, or plants having parents belonging to different varieties or species. 165. One of the means of securing new forms of plants is by making hybrids. Why?

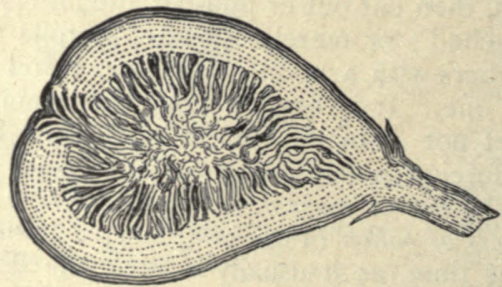

FIG. 2I0. - FIG. The fig is a hollow torus with flowers borne on the inside, and pollinated by insects that enter at the apex. 


\section{CHAPTER XX}

\section{FLOWER-CLUSTERS}

Origin of the Flower-cluster. - We have seen that branches arise from the axils of leaves. Sometimes the leaves may be reduced to bracts and yet branches are borne in their axils. Some of the branches grow into long limbs; others become short spurs; others bear flowers. In fact, a flower is itself a specialized branch.

Flowers are usually borne near the top of the plant. Often they are produced in great numbers. It results, therefore, that flower branches usually stand close together, forming a cluster. The shape and arrangement of the flower-cluster differ with the kind of plant, since each plant has its own mode of branching.

Certain definite or well-marked types of flower-clusters have received names. Some of these names we shall discuss, but the

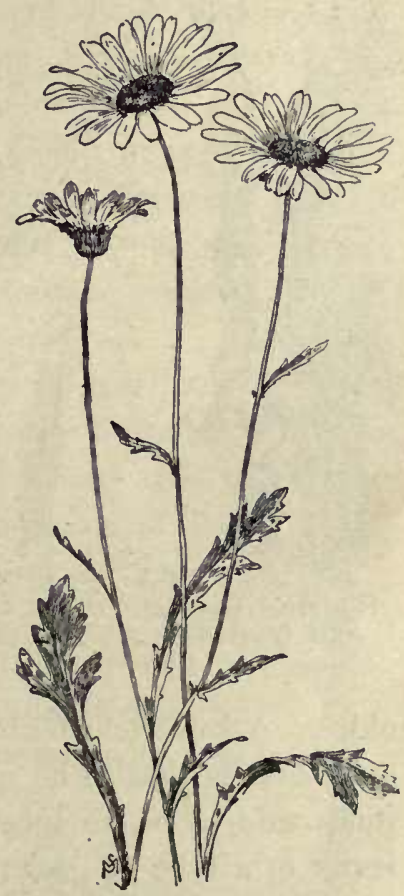

FIG. 2II. - TERMINAL FLOWERS OF THE WHITEWEED (in some places called ox-eye daisy). flower-clusters that perfectly match the definitions are the exception rather than the rule. The determining of the 
kinds of flower-clusters is one of the most perplexing subjects in descriptive botany. We may classify the subject around three ideas: solitary flowers, centrifugal or determinate clusters, centripetal or indeterminate clusters.

Solitary Flowers. - In many cases flowers are borne singly; they are separated from other flowers by leaves. They are then said to be solitary. The solitary flower may

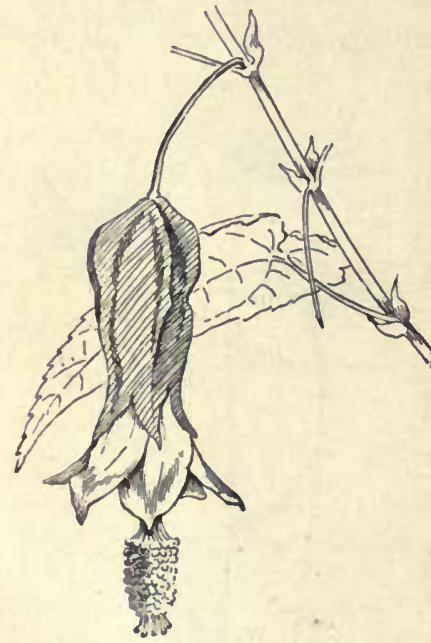

FIG, 212. - IAATERAL FlowER OF aN Abutilon. A greenhouse plant. be either at the end of the main shoot or axis (Fig. 211 ), when it is said to be terminal; or from the side of the shoot (Fig. 2I2), when it is said to be lateral or axillary.

Centripetal Clusters. - If the flower-bearing axils were rather close together, an open or leafy flower-cluster might result. If the plant continues to grow from the tip, the older flowers are left farther and farther behind. If the cluster were so short as to be flat or convex on top, the outermost flowers would be the older. A flower-cluster in which the lower or outer flowers open first is said to be a centripetal cluster. It is sometimes said to be an indeterminate cluster, since it is the result of a type of growth which may go on more or less continuously from the apex.

The simplest form of a definite centripetal cluster is a raceme, which is an open elongated cluster in which the flowers are borne singly on very short branches and open from below (that is, from the older part of the shoot) 
upwards (Fig. 213). The raceme may be terminal to the main branch; or it may be lateral to it, as in Fig. 2 I4.

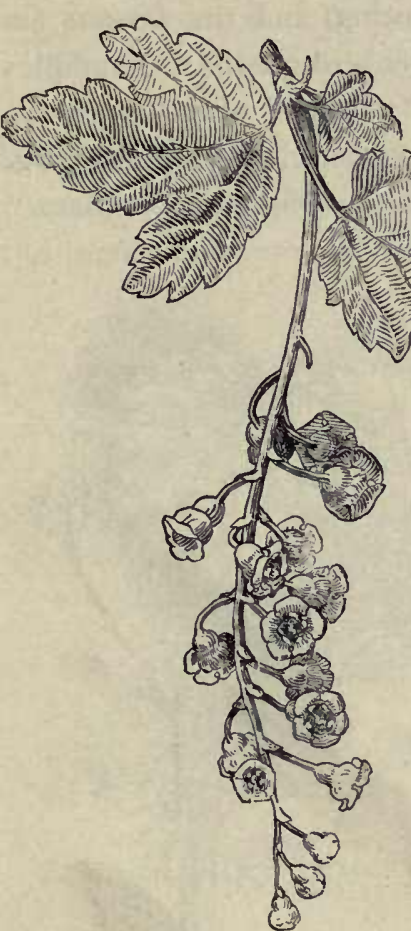

FIG. 2I3.-RACENE OF CURRANT.

Racemes often bear the flowers on one side of the stem, thus forming a single row. When a centripetal flowercluster is long and dense and the flowers are sessile or nearly so, it is called a spike (Fig. 2I5). Common examples of spikes are plantain, mignonette, mullein.

A very short and dense spike is a head. Clover (Fig. 216) is a good example. The sunflower and related Terminal or lateral ? plants bear many small flowers in a very dense and often flat head. Note that in the sunflower (Fig. I89) the outside or exterior flowers

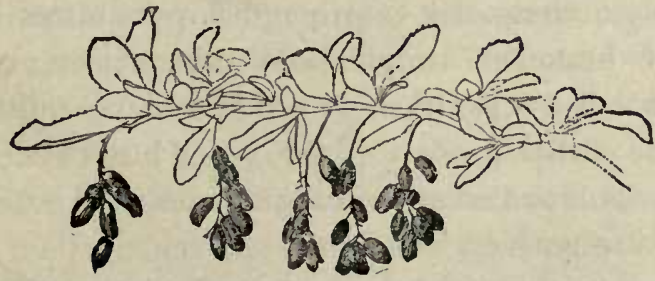

Fig. 214. - Lateral Racemes (in fruit) OF BarberRY.

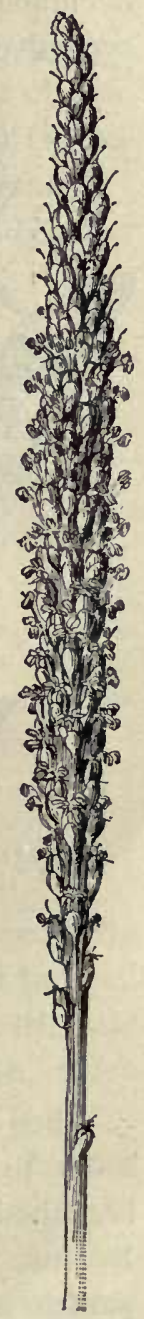

FIG. 215.SPIKE OF Plantain. 
open first. Another special form of spike is the catkin, which usually has scaly bracts, the whole cluster being deciduous after flowering or fruiting, and the flowers (in typical cases) having only stamens or pistils. Examples

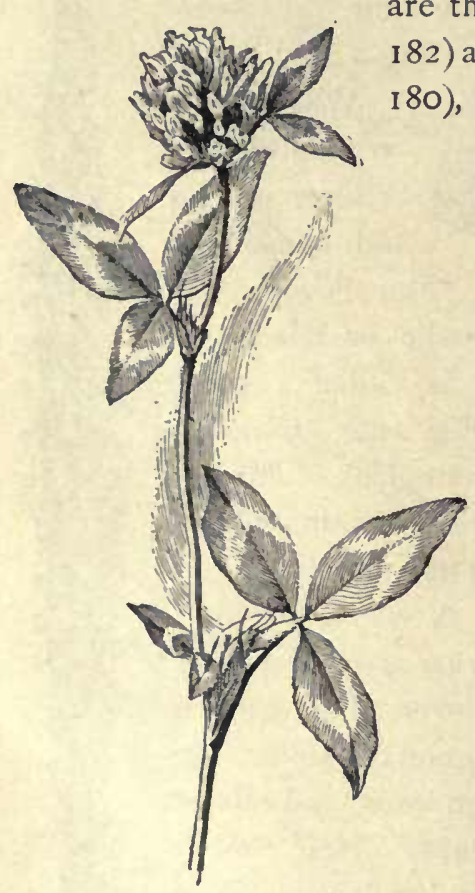

Fig. 2r6. - HE.AD OF CIOVER BLOSSOMS.

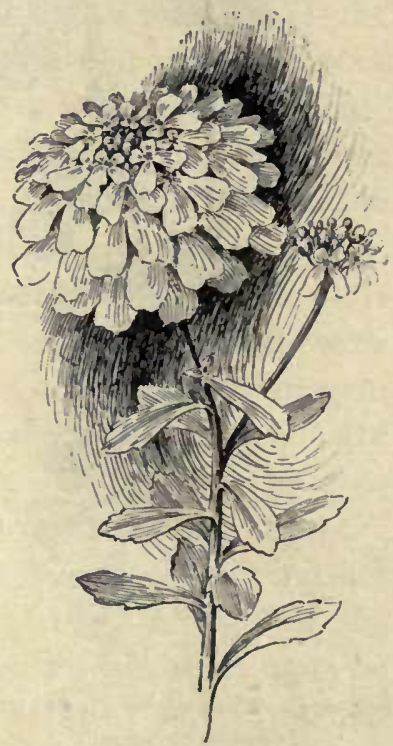

Fig. 217. - CORYMB OF CANDYTUFT.

When a loose, elongated centripetal flower-cluster has some primary branches simple, and others irregularly branched, it is called a panicle. It is a branching raceme. Because of the earlier growth of the lower branches, the panicle is usually broadest at the base or conical in outline. True panicles are not very common.

When an indeterminate flower-cluster is short, so that 
the top is convex or flat, it is a corymb (Fig. 2I7). The outermost flowers open first. Centripetal flower-clusters are sometimes said to be corymbose in mode.

When the branches of an indeterminate cluster arise from a common point, like the frame of an umbrella, the cluster is an umbel (Fig. 218). Typical umbels occur in carrot, parsnip, caraway and other plants of the parsley family: the family is known as the Umbelliferæ, or umbel-bearing

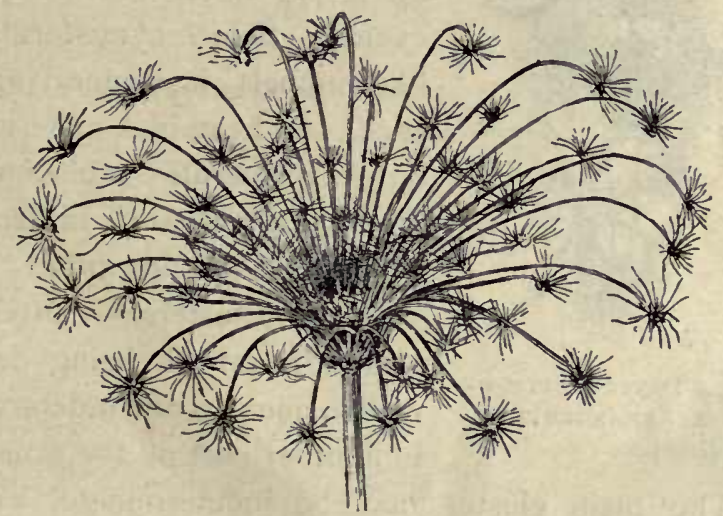

Fig, 218. - Remains of a Last Year's UMbel of Wild Carrot.

family. In the carrot and many other Umbelliferæ, there are small or secondary umbels, called umbellets, at the end of each of the main branches. (In the center of the wild carrot umbel one often finds a single, blackish, often aborted flower, comprising a I-flowered umbellet.)

Centrifugal or Determinate Clusters. - When the terminal or central flower opens first, the cluster is said to be centrifugal. The growth of the shoot or cluster is determinate, since the length is definitely determined or stopped by the terminal flower. Fig. 219 shows a determinate or centrifugal mode of flower bearing. 


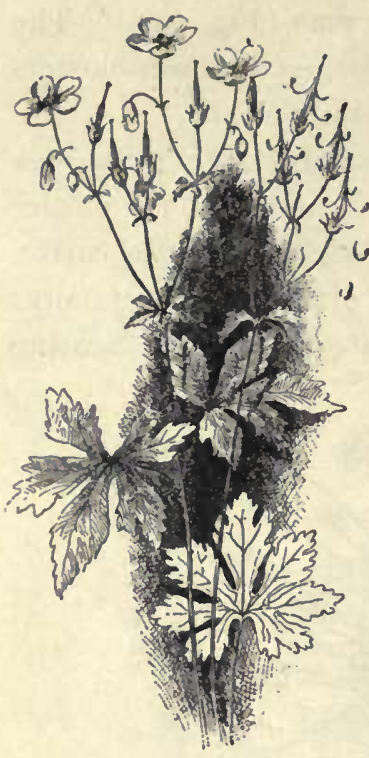

FIG. 219. - DFTERMINATF OR

CYMOSE ARRANGeMENT. Wild geranium.

Dense centrifugal clusters are usually flattish on top because of the cessation of growth in the main or central axis. These compact flower-clusters are known as cymes. Centrifugal clusters are sometimes said to be cymose in mode. Apples, pears (Fig. 220), and elders bear flowers in cymes. Some cyme-forms are like umbels in general appearance. A head-like cymose cluster is a glomerule ; it blooms from the top downwards rather than from the base upwards.

Mixed Clusters. - Often the cluster is mixed, being determinate in one part and indeterminate in another part of the same cluster. The main cluster may be indeterminate, but the branches determinate. The cluster has the appearance of a panicle, and is usually so called, but it is really a thyrse. Lilac is a familiar example of a thyrse. In some cases the main cluster is determinate and the branches are indeterminate, as in hydrangea and elder.

Inflorescence. - The mode or method of flower arrangement is known as the inflorescence. That is, the inflorescence is cymose, co-

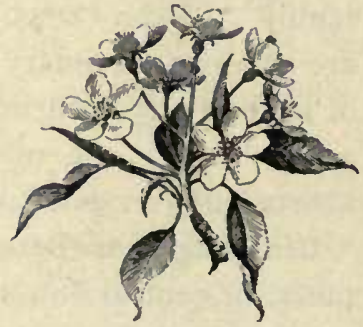

FIG. 220. - CYME OF PEAR. Often imperfect. rymbose, paniculate, spicate, solitary, determinate, indeterminate. By custom, however, the word "inflorescence" 

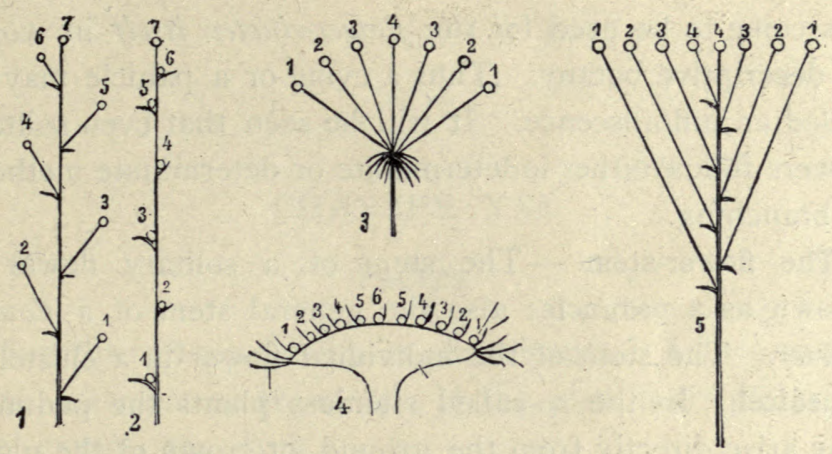

Fig. 221.-FORMS OF CENTRIPETAL FLOWER-CLUSTERS.

I, raceme; 2, spike; 3 , umbel; 4 , head or anthodium; 5 , corymb.

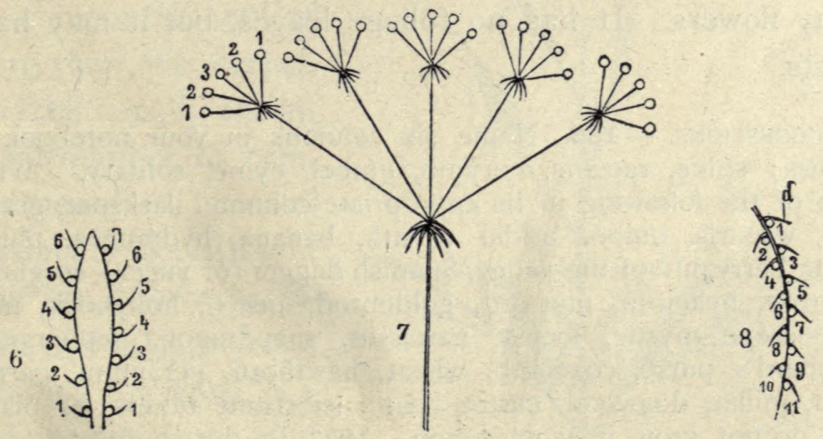

FIG. 222. - CENTRIPETAL INFLORESCENCE, continued.

6 , spadix; 7 , compound umbel: 8 , catkin.
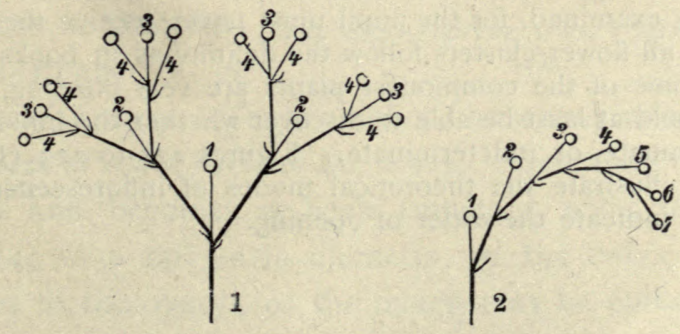

Fig. 223. - Centrifugal Inflorescence.

I, cyme; 2 , scirpioid raceme (or half cyme). 
has come to be used for the flower-cluster itself in works on descriptive botany. Thus a cyme or a panicle may be called an inflorescence. It will be seen that even solitary flowers follow either indeterminate or determinate methods of branching.

The flower-stem. - The stem of a solitary flower is known as a peduncle; also the general stem of a flowercluster. The stem of the individual flower in a cluster is a pedicel. In the so-called stemless plants the peduncle may arise directly from the ground, or crown of the plant, as in dandelion, hyacinth, garden daisy; this kind of peduncle is called a scape. A scape may bear one or many flowers. It has no foliage leaves, but it may have bracts.

Suggestions. - 166. Name six columns in your notebook as follows: spike, raceme, corymb, umbel, cyme, solitary. Write each of the following in its appropriate column: larkspur, grape, rose, wistaria, onion, bridal wreath, banana, hydrangea, phlox, China berry, lily-of-the-valley, Spanish dagger (or yucca), sorghum, tuberose, hyacinth, mustard, goldenrod, peach, hollyhock, mullein, crépe myrtle, locust, narcissus, snapdragon, peppergrass, shepherd's purse, coxcomb, wheat, hawthorn, geranium, carrot, elder, millet, dogwood, castor bean ; substitute others for plants that do not grow in your region. 167. In the study of flowerclusters, it is well to choose first those that are fairly typical of the various classes discussed in the preceding paragraphs. As soon as the main types are well fixed in the mind, random clusters should be examined, for the pupil must never receive the impression that all flower-clusters follow the definitions in books. Clusters of some of the commonest plants are very puzzling, but the pupil should at least be able to discover whether the inflorescence is determinate or indeterminate. Figures 221 to 223 (from the German) illustrate the theoretical modes of inflorescence. The numerals indicate the order of opening. 


\section{CHAPTER XXI}

\section{FRUITS}

THE ripened ovary, with its attachments, is known as the fruit. It contains the seeds. If the pistil is simple, or of one carpel, the fruit also will have one compartment. If the pistil is compound, or of more than one carpel, the fruit usually has an equal number of compartments. The compartments in pistil and fruit are known as 10cules (from Latin locus, meaning "a place").

The simplest kind of fruit is a ripened I-loculed ovary. The first stage in complexity is a ripened 2-or

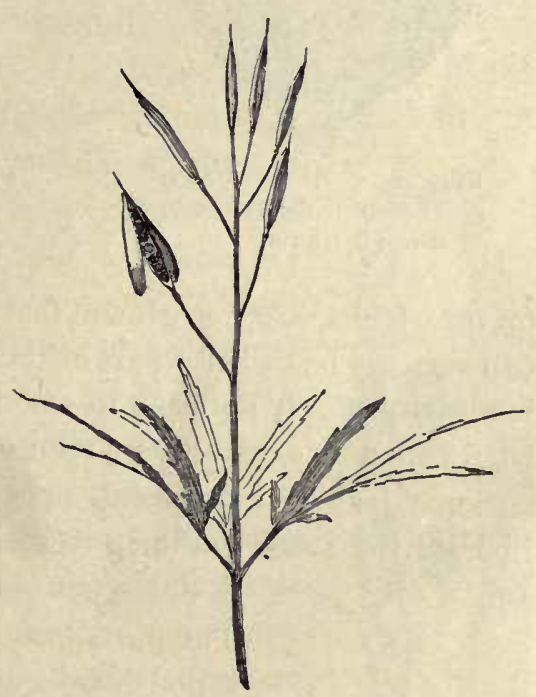
many-loculed ovary. Very complex forms may arise by the attachment of other parts to the ovary. Sometimes the style persists and becomes a beak (mustard pods, dentaria, Fig. 224), or a tail as in clematis; or the calyx may be attached to the ovary; or the ovary may be embedded in the receptacle, and ovary and receptacle together constitute the fruit: or an involucre may become a part of the 
fruit, as possibly in the walnut and hickory (Fig. 225), and cup of the acorn (Fig. 226). The chestnut and the beech bear a prickly involucre, but the nuts,

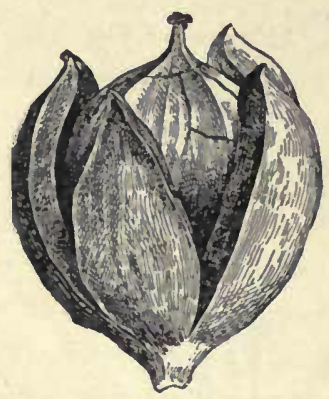

FIG. 225. - HICKORY-NUT. The nut is the fruit, contained in a husk.

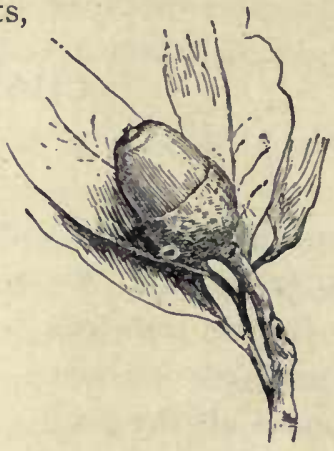

Fig. 226. - LIVE-OAK ACORN. The fruit is the "seed" part; the involucre is the "cup."

or true fruits, are not grown fast to it, and the involucre can scarcely be called a part of the fruit. A ripened ovary is a pericarp. A pericarp to which other parts adhere has been called an accessory or reënforced fruit. (Page 169.)

Some fruits are dehiscent, or split open at maturity and liberate the seeds; others are indehiscent, or do not open.

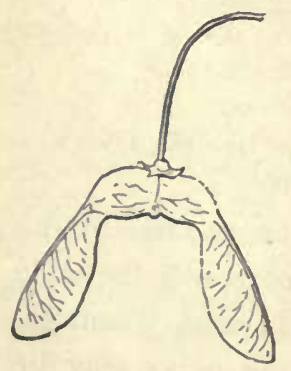

FIG. 227. - KEY OF Sugar Maple. A dehiscent pericarp is called a pod. The parts into which such a pod breaks or splits are known as valves. In indehiscent fruits the seed is liberated by the decay of the envelope, or by the rupturing of the envelope by the germinating seed. Indehiscent winged peri- AMErican Elm. carps are known as samaras or key fruits. Maple (Fig. 227), elm (Fig. 228), and ash (Fig. 93) are examples. 
Pericarps. - The simplest pericarp is a dry, oneseeded, indehiscent body. It is known as an akene. A

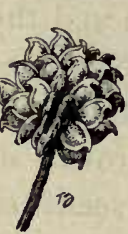

FIG. 229.AKENES OF BUTTERCUP. head of akenes is shown in Fig. 229, and the structure is explained in Fig. 230. Akenes may be seen in buttercup, hepatica, anemone, smartweed, buckwheat.

A I-loculed pericarp which dehisces along the front edge (that is, the inner edge, next
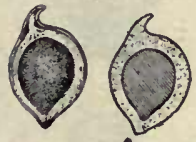

FIG. 230.- AKENES OF BUTTERCUP, one in longitudinal section. the center of the flower) is a follicle. The fruit of the larkspur (Fig. 23I) is a follicle. There are usually five of

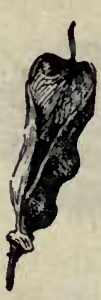

FIG. 231. -

Follicle OF LARKSPUR. these fruits (sometimes three or four) in each larkspur flower, each pistil ripening into a follicle. If these pistils were united, a single compound pistil would be formed. Columbine, peony, ninebark, milkweed, also have follicles.

ples (Fig. 232); in fact, this character gives name to the pea family,-Leguminosæ.

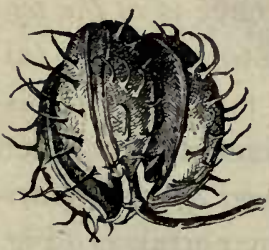

Fig. 233.-CAPSULE OF CASTOR - OIL BEAN AFIER DEHISCENCE.

Often the valves of the legume twist forcibly and expel the seeds, throwing them some distance. The

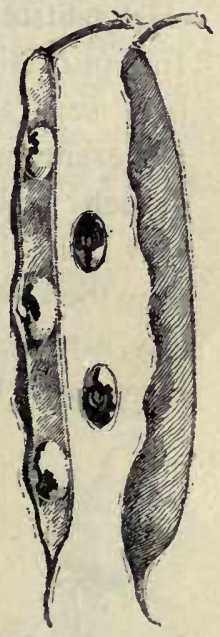

FIG. 232.-A BEAN POD. word "pod" is sometimes restricted to legumes, but it is better to use it generically for all dehiscent pericarps.

A compound pod - dehiscing pericarp of two or more carpels - is a capsule (Figs. 233, 234, 


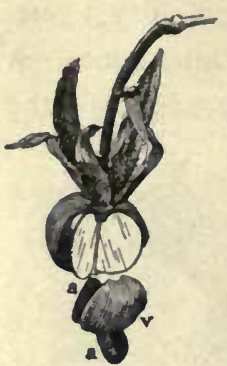

FIG. 234. $-\mathrm{CAP}$ SULE OF MORNING GLORY.

236, 237). Some capsules are of one locule, but they may have been compound when young (in the ovary stage) and the partitions may have vanished. Sometimes one or more of the carpels are uniformly crowded out by the exclusive growth of other carpels (Fig. 235). The seeds or parts which are crowded out are said to be aborted.

There are several ways in which capsules dehisce or open. When they break along the partitions (or septa), the mode is known as septicidal dehiscence (Fig. 236); In septicidal dehiscence the fruit separates into parts representing the original carpels. These carpels may still be entire, and they then dehisce individually, usually along the inner
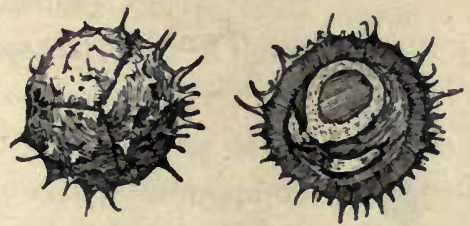

FIG. 235. - THREE-CARPELED FRUIT of Horse-chestnut. Two locules are closing by abortion of the ovules. edge as if they were follicles. When the compartments

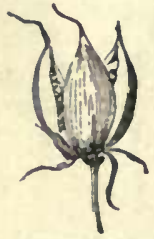

F1G. 236. ST. JohN's WorT. Septicidal.

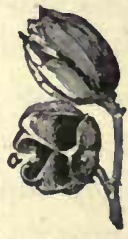

FIG. 237.LOCULICIDAL POD OF DAY-LILY. split in the middle, between the partitions, the mode is loculicidal dehiscence (Fig. 237). In some cases the dehiscence is at the top, when it is said to be apical (although several modes of dehiscence are here included). When the whole top comes off, as in purslane and garden portulaca (Fig. 238 ), the pod is known as a pyxis. In some cases apical dehiscence is by means of a hole or clefts.

The peculiar capsule of the mustard family, or Cruci. 
feræ, is known as a silique when it is distinctly longer than broad (Fig. 224), and a silicle when its breadth nearly

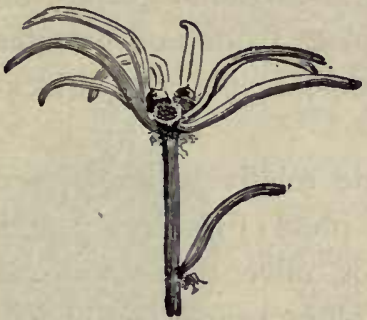

Fig. 238. - PyXIS OF PORTULACA OR ROSE-MOSS.

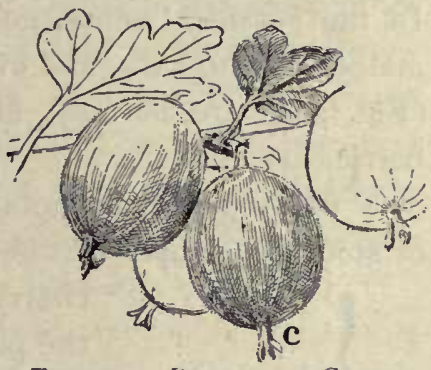

FIG. 239. - BERRIES OF GOOSEBERRY. Remains of calyx at $c$.

equals or exceeds its length. A cruciferous capsule is 2-carpeled, with a thin partition, each locule containing seeds in two rows. The two valves detach from below upwards. Cabbage, turnip, mustard, water-cress, radish,
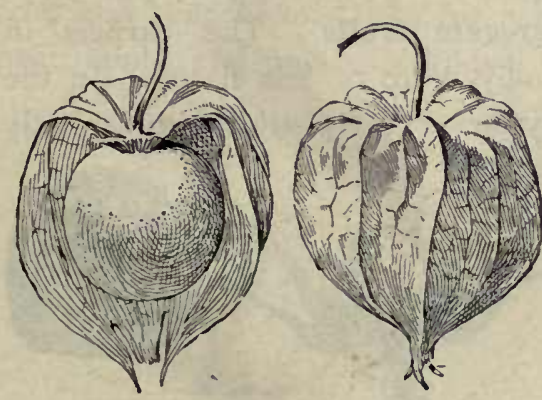

FIG. 240.-BERRY OF THE GROUND CHERRY OR HUSK TOMATO, contained in the inflated calyx.

The pericarp may be fleshy and indehiscent. A pulpy pericarp with several or many seeds is a berry (Figs. 239, 240, 24I). To the horticulturist a berry is a small, soft, edible fruit, without rape, shepherd's purse, sweet alyssum, wallflower, honesty, are examples.

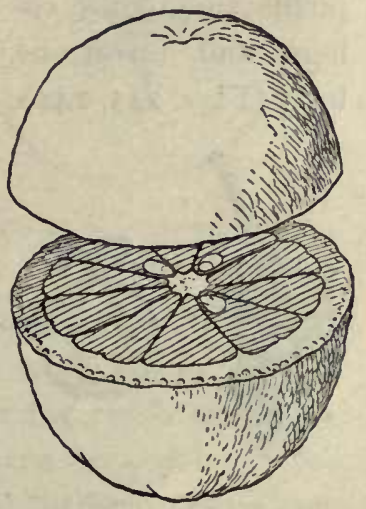

PIG. 24I.- ORANGE; example of a berry. 
particular reference to its structure. The botanical and horticultural conceptions of a berry are, therefore, unlike. In the botanical sense, gooseberries, currants, grapes, tomatoes, potato-balls, and even eggplant fruits and oranges (Fig. 24I) are berries; strawberries, raspberries, blackberries are not.

A fleshy pericarp containing one relatively large seed or stone is a drupe. Examples are plum (Fig. 242); peach,

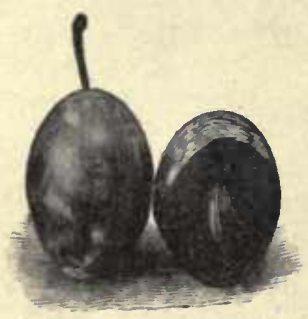

FIG. 242. - PLUM; example of a drupe. cherry, apricot, olive. The walls of the pit in the plum, peach, and cherry are formed from the inner coats of the ovary, and the flesh from the outer coats. Drupes are also known as stone-fruits.

Fruits that are formed by the subsequent union of separate pistils are aggregate fruits. The carpels in aggregate fruits are usually more or less fleshy. In the raspberry and blackberry flower, the pistils are essentially distinct, but as the pistils ripen they cohere and form one body (Figs. 243, 244).
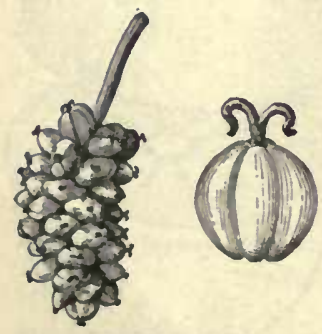

Fig. 244.-AGGREgate FRUIT OF MULBERRY: and a separate fruit.

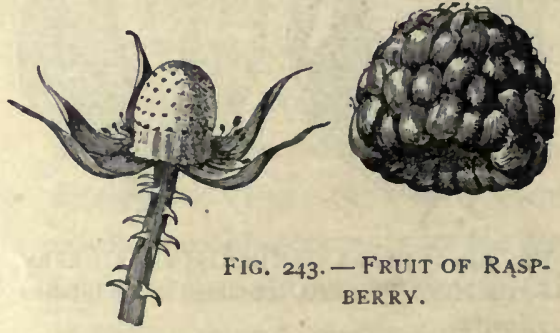

Each of the carpels ur pistils in the raspberry and blackberry is a little drupe, or drupelet. In the raspberry the entire fruit separates from the torus, leaving the torus on the plant. In the blackberry and dew- 
berry the fruit adheres to the torus, and the two are removed together when the fruit is picked.

Accessory Fruits. - When the pericarp and some other part grow together, the fruit is said to be accessory or

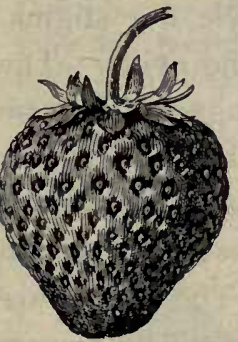

FIG. 245. - STRAWBERRY; fleshy torus in which akenes are embedded. reënforced. An example is the strawberry (Fig. 245). The edible part is a greatly enlarged torus, and the pericarps are akenes embedded in it. These akenes are commonly called seeds.

Various kinds of reënforced fruits have received special names. One of these is the hip, characteristic of roses. In this case, the torus is deep and hollow, like an urn, and the separate akenes are borne inside it. The mouth of the receptacle may close, and the walls sometimes become fleshy; the fruit may then be mistaken for a berry. The fruit of the pear, apple, and quince is known as a

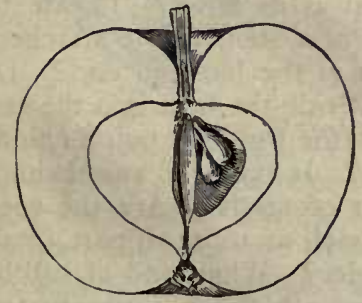

FIG. 246. - SECTION OF AN APPLE.

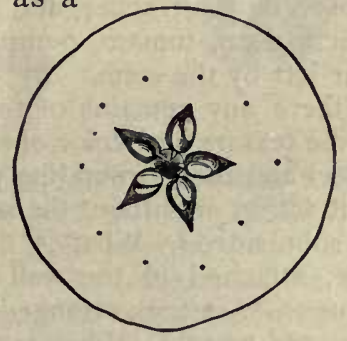

FIG. 247.-CROSS-SECTION OF AN APPLE.

pome. In this case the five united carpels are completely buried in the hollow torus, and the torus makes most of the edible part of the ripe fruit, while the pistils are represented by the core (Fig. 246). Observe the sepals on the top of the torus (apex of the fruit) in Fig. 246. Note the outlines of the embedded pericarp in Fig. 247. 
Gymnospermous Fruits. - In pine, spruces, and their kin, there is no fruit in the sense in which the word is used in the preceding pages, because there is no ovary. The uvules are naked or uncovered, in the axils of the scales of the young cone, and they have neither style nor stigma. The pollen falls directly on the mouth of the ovule. The ovule ripens into a seed, which is usually winged. Because the ovule is not borne in a sac or ovary, these plants are called gymnosperms (Greek for "naked seeds"). All the true cone-bearing plants are of this class; also certain other plants, as red cedar, juniper, yew. The plants are monœcious or sometimes diœcious. The staminate flowers are mere naked stamens borne beneath scales, in small yellow catkins which soon fall. The pistillate flowers are naked ovules beneath scales on cones that persist (Fig. 29). Gymnospermous seeds may have several cotyledons.

SugGeSTIONS. - 168. Study the following fruits, or any five fruits chosen by the teacher, and answer the questions for each: Apple, peach, bean, tomato, pumpkin. What is its form ? Locate the scar left by the stem. By what kind of a stem was it attached ? Is there any remains of the blossom at the blossom end? Describe texture and color of surface. Divide the fruit into the seed vessel and the surrounding part. Has the fruit any pulp or flesh? Is it within or without the seed vessel? Is the seed vessel simple or subdivided? What is the number of seeds? Are the seeds free, attached to the wall of the vessel, or to a support in the center? Are they arranged in any order? What kind of wall has the seed vessel? What is the difference between a peach stone and a peach seed? 169. The nut fruits are always available for study. Note the points suggested above. Determine what the meat or edible part represents, whether cotyledons or not. Figure 248 is suggestive. 170. Mention all the fleshy fruits you know, tell where they come from, and refer them to their proper groups. 171. What kinds of fruits can you buy in the market, and to what groups or classes do they belong? Of which ones are the seeds only, and not the pericarps, eaten? 172. An ear of corn is always available for study. What is it - a fruit or a collection of fruits ? How are the grains arranged on the cob? How many rows do you count on each of several ears? Are all the rows on an ear 
equally close together ? Do you find an ear with an odd number of rows? How do the parts of the husk overlap? Does the husk serve as protection from rain? Can birds pick out the grains? How do insect enemies enter the ear? How and when do weevils lay eggs on corn? 173. Study a grain of corn. Is it a seed? Describe the shape of a grain. Color. Size. Does its surface show any projections or depressions? Is the seed-coat thin or thick? Transparent or opaque? Locate the hilum. Where is the silk scar? What is the silk? Sketch the grain from the two points of view that show it best. Where is the embryo? Does the grain have endosperm? What is dent corn? Flint corn? How many kinds of corn do you know ? For what are they used?
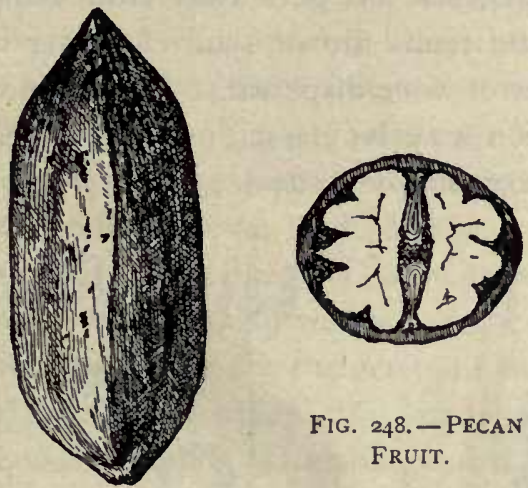

FIG. 248. - PECAN

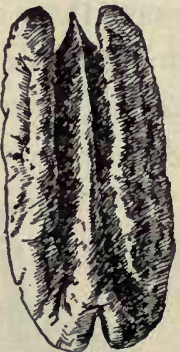

FRUIT.

Note to Teacher. - There are few more interesting subjects to beginning pupils than fruits, - the pods of many kinds, forms, and colors, the berries, and nuts. This interest may well be utilized to make the teaching alive. All common edible fruits of orchard and vegetable garden should be brought into this discussion (some of the kinds are explained in "Lessons with Plants"). Of dry fruits, as pods, burs, nuts, collections may be made for the school museum. Fully mature fruits are best for study, particularly if it is desired to see dehiscence. For comparison, pistils and partially grown fruits should be had at the same time. If the fruits are not ripe enough to dehisce, they may be placed in the sun to dry. In the school it is well to have a collection of fruits for study. The specimens may be kept in glass jars. Always note exterior of fruit and its parts: interior of fruit with arrangement and attachment of contents. 


\section{CHAPTER XXII}

\section{DISPERSAL OF SEEDS}

IT is to the plant's advantage to have its seeds distributed as widely as possible. Ii "as a better chance of surviving in the struggle for existence. It gets away from competition. Many seeds and fruits are of such character as to increase their chances of wide dispersal. The commonest means of dissemination may be classed under four heads : explosive fruits; transportation by wind; transportation by birds; burs.

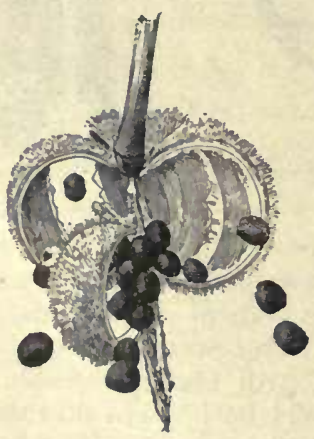

FIG. 249. - EXPLOSION OF THE BALSAM POD.

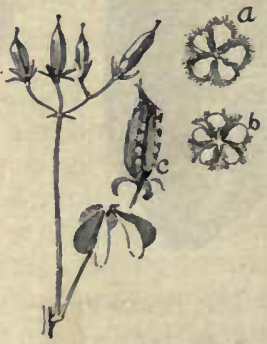

Fig. 250.-Explosive Fruits of Oxalis.

An exploding pod is shown at $c$. The dehiscence is shown at $b$. The structure of the pod is seen at $a$.

Explosive Fruits. - Some pods open with explosive force and discharge the seeds. Even bean and everlasting peas do this. More marked examples are the locust, witch hazel, garden balsam (Fig. 249), wild jewel-weed or impatiens (touch-me-not), violet, crane's-bill or wild geranium, bull nettle, morning glory, and the oxalis (Fig. 250). The 
oxalis is common in several species in the wild and in cultivation. One of them is known as wood sorrel. Figure 250 shows the common yellow oxalis. The pod opens loculicidally. The elastic tissue suddenly contracts when dehiscence takes place, and the seeds are thrown violently. The squirting cucumber is easily grown in a garden (procure seeds of seedsmen), and the fruits discharge the seeds with great force, throwing them many feet.

Wind Travelers. - Wind-transported seeds are of two general kinds: those that are provided with wings, as the flat seeds of catalpa (Fig. 25I) and cone-bearing trees and the samaras of ash, elm, tulip-tree, ailanthus, and maple; and those which have feathery buoys or parachutes to enable them to float in the air. Of the latter kind are the fruits of many composites, in which the pappus is copious and soft. Dandelion and thistle are examples. The silk of the milkweed and probably the hairs on the cotton seed have a similar office, and also the wool of the cat-tail. Recall the cottony seeds of the willow and poplar.

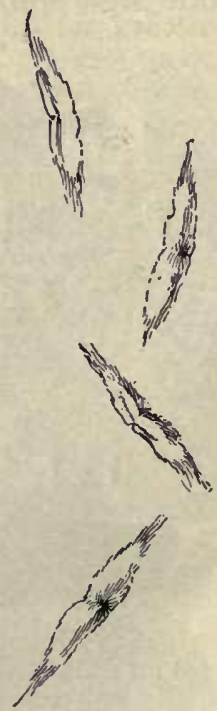

FIG. 25I. - WINGED Seens of Catalpa.

Dispersal by Birds. - Seeds of berries and of other small fleshy fruits are carried far and wide by birds. The pulp is digested, but the seeds are not injured. Note how the cherries, raspberries, blackberries, June-berries, and others spring up in the fence rows, where the birds rest. Some berries and drupes persist far into winter, when they supply food to cedar birds, robins, and the winter birds. Red cedar is distributed by birds. Many of these pulpy 
fruits are agreeable as human food, and some of them have been greatly enlarged or "improved " by the arts of the cultivator. The seeds are usually indigestible.

Burs. - Many seeds and fruits bear spines, hooks, and hairs, which adhere to the coats of animals and to clothing. The burdock has an involucre with hooked scales, containing the fruits inside. The clotbur is also an involucre. Both are compositous plants, allied to thistles, but the

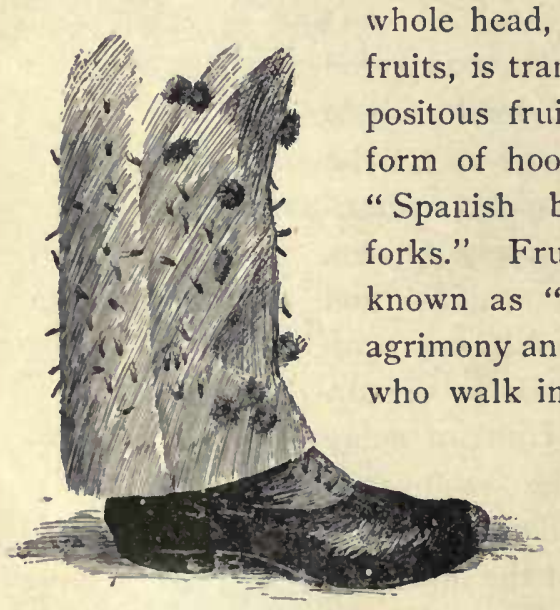

Fig. 252. - STEALING A RIDE.

whole head, rather than the separate fruits, is transported. In some compositous fruits the pappus takes the hooks and spines, as in the "Spanish bayonets" and "pitchFruits of various kinds are known as "stick tights," as of the agrimony and hound's-tongue. Those who walk in the woods in late summer and fall are aware that plants have means of disseminating themselves (Fig. 252). If it is impossible to identify the burs which one

finds on clothing, the seeds may be planted and specimens of the plant may then be grown.

Suggestions. - 174. What advantage is it to the plant to have its seeds widely dispersed? 175. What are the leading ways in which fruits and seeds are dispersed? 176. Name some explosive fruits. 177. Describe wind travelers. 178. What seeds are carried by birds? 179. Describe some bur with which you are familiar. 180. Are adhesive fruits usually dehiscent or indehiscent? 181. Do samaras grow on low or tall plants, as a rule? 182. Are the cotton fibers on the seed or on the fruit? 183. Name the ways in which the common weeds of your region are disseminated. 184. This lesson will suggest other ways in which 
seeds are transported. Nuts are buried by squirrels for food; but if they are not eaten, they may grow. The seeds of many plants are blown on the snow. The old stalks of weeds, standing through the winter, may serve to disseminate the plant. Seeds are carried by water down the streams and along shores. About woolen mills strange plants often spring up from seed brought in the fleeces. Sometimes the entire plant is rolled for miles before the winds. Such plants are "tumbleweeds." Examples are Russian thistle, hair grass or tumblegrass (Panicum capillare), cyclone plant (Cycloloma platyphyllum), and white amaranth (Amarantus albus). About seaports strange plants are often found, having been introduced in the earth that is used in ships for ballast. These plants are usually known as "ballast plants." Most of them do not persist long. 185. Plants are able to spread themselves by means of the great numbers of seeds that they produce. How many seeds may a given elm tree or apple tree or raspberry bush produce?
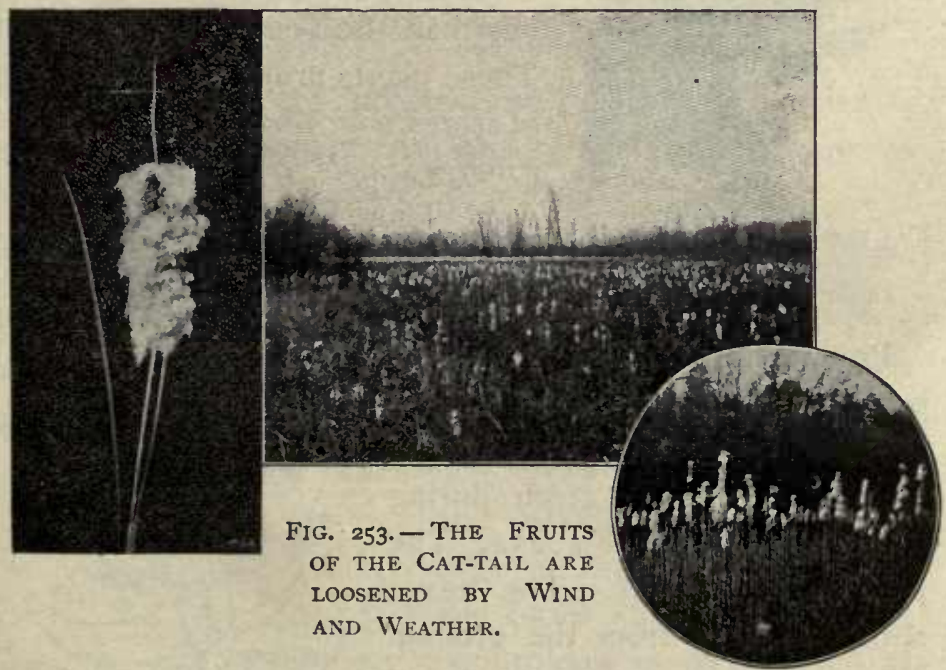


\section{CHAPTER XXIII}

\section{PHENOGAMS AND CRYPTOGAMS}

THE plants thus far studied produce flowers; and the flowers produce seeds by means of which the plant is prop-

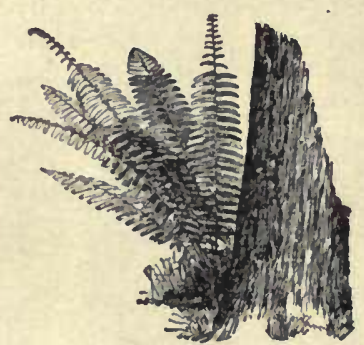

Fig. 254.-ChristMas FERN.

- Dryopteris acrostichoides; known also as Aspidium. agated. There are other plants, however, that produce no seeds, and these plants (including bacteria) are probably more numerous than the seed-bearing plants. These plants propagate by means of spores, which are generative cells, usually simple, containing no embryo. These spores are very small, and sometimes are not visible to the naked eye.

Prominent among the sporepropagated plants are ferns. The common Christmas fern (so called because it remains green during winter) is shown in Fig. 254. The plant has no trunk. The leaves spring directly from the ground. The leaves of ferns are called fronds. They vary in shape, as other leaves do. Some of the fronds in Fig. 254 are seen to be narrower at the top. If these are examined more closely (Fig. 255),

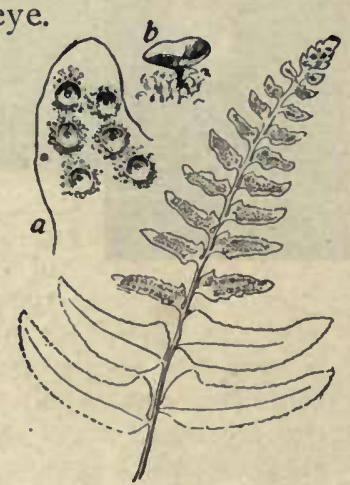

Fig. 255.-FRUITING FroND OF CHRISTMAS FERN.

Sori at $a$. One sorus with its indusium at $b$. 
it will be seen that the leaflets are contracted and are densely covered beneath with brown bodies. These bodies are collections of sporangia or spore-cases.

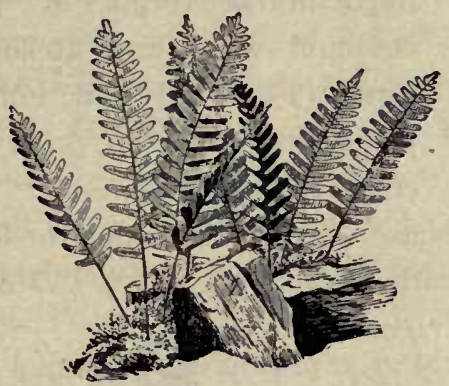

Fig. 256.-COMmON POLYPODE FERN. Polypodium vulgare.

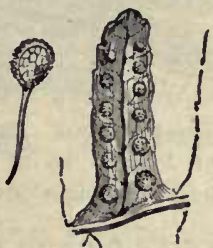

FIG. 257.-SORI AND SPO. RANGIUM OF POLYPODE. A chain of cells lies along the top of the sporangium, which springs back elastically on drying, thus disseminating the spores.

The sporangia are collected into little groups, known as sori (singular, sorus) or fruit-dots. Each sorus is covered with a thin scale or shield, known as an indusium. This indusium separates from the frond at its edges, and the sporangia are exposed. Not all ferns have indusia. The polypode (Figs. 256, 257) does not; the sori are naked. In the brake (Fig. 258)

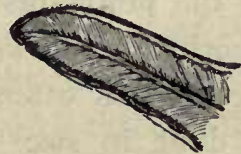

FIG. 258. - THE BRAKE FRUITS UNDERNEATH THE REVOLUTE EDGES OF THE LEAF.

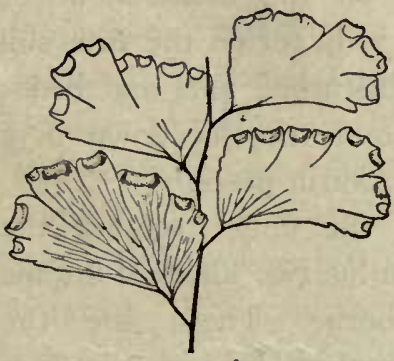

Fig. 259.-Fruiting Pinnules of MAIDENHAIR FERN.

and maidenhair (Fig. 259) the edge of the frond turns over and forms an indusium. The nephrolepis or sword fern of greenhouses is allied to the polypode. The sori are in a single row on either side the midrib (Fig. 260). The indusium is circular or kidneyshaped and open at one edge 


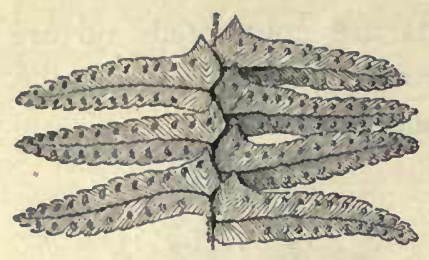

FIG. 260. - PART OF FROND OF

SWORD FERN. To the pupil: Is this illustration right side up? or finally all around. The Boston fern, Washington fern, Pierson fern, and others, are horticultural forms of the common sword fern. In some ferns (Fig. 26I) an entire frond becomes contracted to cover the sporangia.

The sporangium or spore-case of a fern is a more or less globular body and usually with a stalk (Fig. 257). It contains the spores. When ripe it bursts and the spores are set free.

In a moist, warm place the spores germinate. They produce a small, flat, thin, green, more or less heartshaped membrane (Fig. 262). This is the prothallus. Sometimes the prothallus is an inch or more across, but oftener it is less than a dime in size. Although easily seen, it is commonly unknown except to botanists. Prothalli may

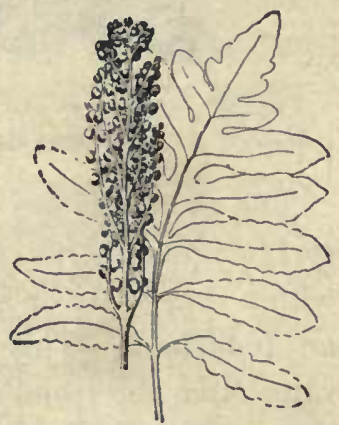

FIG. 26I. - FERTILE AND StERILE FroNdS OF THE SEnsitive FERN. often be found in greenhouses where ferns are grown.

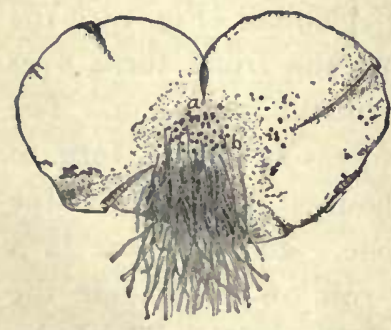

FIG. 262. - ProthalLUS OF A FERN. Enlarged.

Archegonia at $a$; antheridia at $b$. Look on the moist stone or brick walls, or on the firm soil of undisturbed pots and beds; or spores may be sown in a damp, warm place.

On the under side of the prothallus two kinds of organs are borne. These are the archegonium (containing eggcells) and the antheridium (con- 
taining sperm-cells). These organs are minute specialized parts of the prothallus. Their positions on a particular prothallus are shown at $a$ and $b$ in Fig. 262, but in some ferns they are on separate prothalli (plant diœcious). The sperm-cells escape from the antheridium and in the water that collects on the prothallus are carried to the archegonium, where fertilization of the egg takes place. From the fertilized egg-cell a plạnt grows, becoming a "fern." In most cases the prothallus soon dies. The prothallus is the gametophyte (from Greek, signifying the fertilized plant).

The fern plant, arising from the fertilized egg in the archegonium, becomes a perennial plant, each year producing spores from its fronds (called the sporophyte); but these spores - which are merely detached special kinds of cells - produce the prothallic phase of the fern plant, from which new individuals arise. A fern is fertilized but once in its lifetime. The "fern" bears the spore, the spore gives rise to the prothallus, and the egg-cell of the prothallus (when fertilized) gives rise to the fern.

A similar alternation of generations runs all through the vegetable kingdom, although there are some groups of plants in which it is very obscure or apparently wanting. It is very marked in ferns and mosses. In algæ (including the seaweeds) the gametophyte is the "plant," as the non-botanist knows it, and the sporophyte is inconspicuous. There is a general tendency, in the evolution of the vegetable kingdom, for the gametophyte to lose its relative importance and for the sporophyte to become larger and more highly developed. In the seed-bearing plants the sporophyte generation is the only one seen by the nonbotanist. The gametophyte stage is of short duration and the parts are small; it is confined to the time of fertilization. 
The sporophyte of seed plants, or the "plant" as we know it, produces two kinds of spores -- one kind becoming pollen grains and the other kind embryo-sacs. The pollen-spores are borne in sporangia, which are united into what are called anthers. The embryo-sac, which contains the egg-cell, is borne in a sporangium known as an ovule. A gametophytic stage is present in both pollen and embryo sac: fertilization takes place, and a sporophyte arises. Soon this sporophyte becomes dormant, and is then known as an embryo. The embryo is packed away within tight-fitting coats, and the entire body is the seed. When the conditions are right the seed grows, and the sporophyte grows into herb, bush, or tree. The utility of the alternation of generations is not understood.

The spores of ferns are borne on leaves; the spores of seed-bearing plants are also borne amongst a mass of specially developed conspicuous leaves known as flowers, therefore these plants have been known as the flowering plants. Some of the leaves are developed as envelopes (calyx, corolla), and others as spore-bearing parts, or sporophylls (stamens, pistils). But the spores of the lower plants, as of ferns and mosses, may also be borne in specially developed foliage, so that the line of demarcation between flowering plants and flowerless plants is not so definite as was once supposed. The one definite distinction between these two classes of plants is the fact that one class produces seeds and the other does not. The seed-plants are now often called spermaphytes, but there is no single coördinate term to set off those which do not bear seeds. It is quite as well, for popular purposes, to use the terms phenogams for the seed-bearing plants and cryptogams for the others. These terms have been objected to in recent years because their etymology does not express literal facts 
(phenogam signifying "showy flowers," and cryptogam "hidden flowers"), but the terms represent distinct ideas in classification. The cryptogams include three great series of plants - the Thallophytes or algæ, lichens, and fungi; the Bryophytes or mosslike plants; the Pteridophytes or fernlike plants.

Suggestions. - 186. The parts of a fern leaf. The primary complete divisions of a frond are called pinnæ, no matter whether the frond is pinnate or not. In ferns the word "pinna" is used in essentially the same way that leaflet is in the once-compound leaves of other plants. The secondary leaflets are called pinnules, and in thrice, or more, compound fronds, the last complete parts or leaflets are ultimate pinnules. The diagram (Fig. 263) will aid in making the subject clear. If the frond were not divided to the midrib, it would be simple, but this diagram represents a compound frond. The general outline of the frond, as bounded by the dotted line, is ovate. The stipe is very short. The midrib of a compound frond is known as the rachis. In a decompound frond, this main rachis is called the primary rachis. Segments (not divided to the rachis) are seen at the tip, and down to $h$ on one side and to $m$ on the

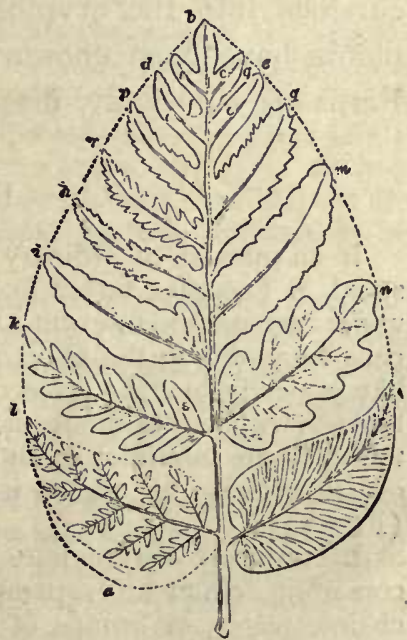

Fig. 263. - DiAgRAM TO EXPLAIN THE TERMINOLOGY OF THE FROND. other. Pinnæ are shown at $i, k, l, 0, n$. The pinna 0 is entire; $n$ is crenate-dentate; $i$ is sinuate or wavy, with an auricle at the base ; $k$ and $l$ are compound. The pinna $k$ has twelve entire pinnules. (Is there ever an even number of pinnules on any pinna?) Pinna $l$ has nine compound pinnules, each bearing several entire ultimate pinnules. The spores. - 187. Lay a mature fruiting frond of any fern on white paper, top side up, and allow it to remain in a dry, warm place. The spores will discharge on the paper. 188. Lay the full-grown (but not dry) cap of a mushroom or toadstool bottom down on a sheet of clean paper, under a ventilated box in a warm, dry place. A day later raise the cap. 


\section{CHAPTER XXIV}

\section{STUDIES IN CRYPTOGAMS}

THE pupil who has acquired skill in the use of the compound microscope may desire to make more extended excursions into the cryptogamous orders. The following plants have been chosen as examples in various groups. Ferns are sufficiently discussed in the preceding chapter.

\section{BACTERIA}

If an infusion of ordinary hay is made in water and allowed to stand, it becomes turbid or cloudy after a few days, and a drop under the microscope will show the presence of minute oblong cells swimming in the water perhaps by means of numerous hairlike appendages, that project through the cell wall from the protoplasm within. At the surface of the dish containing the infusion the cells are non-motile and are united in long chains. Each of these cells or organisms is a bacterium (plural, bacteria). (Fig. 135.)

Bacteria are very minute organisms, - the smallest known, consisting either of separate oblong or spherical cells, or of chains, plates, or groups of such cells, depending on the kind. They possess a membrane-like wall which, unlike the cell walls of higher plants, contains nitrogen. The presence of a nucleus has not been definitely demonstrated. Multiplication is by the fission of the vegetative cells; but under certain conditions of drought, cold, or exhaustion of the nutrient medium, the protoplasm of the ordinary cells may become invested with a thick wall, thus forming an endospore which is very resistant to extremes of environment. No sexual reproduction is known.

Bacteria are very widely distributed as parasites and saprophytes in almost all conceivable places. Decay is largely caused by bacteria, accompanied in animal tissue by the liberation of foul-smelling gases. Certain species grow in the reservoirs and pipes of water supplies, rendering the water brackish and often undrinkable. Some kinds of fermentation (the breaking down or decomposing of organic compounds, usually accompanied by the 
formation of gas) are due to these organisms. Other bacteria oxidize alcohol to acetic acid, and produce lactic acid in milk and butyric acid in butter. Bacteria live in the mouth, stomach, intestines, and on the surface of the skin of animals. Some secrete gelatinous sheaths around themselves; others secrete sulfur or iron, giving the substratum a vivid color.

Were it not for bacteria, man could not live on the earth, for not only are they agents in the process of decay, but they are concerned in certain healthful processes of plants and animals. We have learned in Chap. VIII how bacteria are related to nitrogen-gathering.

Bacteria are of economic importance not alone because of their effect on materials used by man, but also because of the diseaseproducing pozver of certain species. Pus is caused by a spherical form, tetanus or lock-jaw by a rod-shaped form, diphtheria by short oblong chains, tuberculosis or "consumption" by more slender oblong chains, and typhoid fever, cholera, and other diseases by other forms. Many diseases of animals and plants are caused by bacteria. Disease-producing bacteria are said to be pathogenic.

'The ability to grow in other nutrient substances than the natural one has greatly facilitated the study of these minute forms of life. By the use of suitable culture media and proper precautions, pure cultures of a particular disease-producing bacterium may be obtained with which further experiments may be conducted.

Milk provides an excellent collecting place for bacteria coming from the air, from the coat of the cow and from the milker. Disease germs are sometimes carried in milk. If a drop of milk is spread on a culture medium (as agar), and provided with proper temperature, the bacteria will multiply, each one forming a colony visible to the naked eye. In this way, the number of bacteria originally contained in the milk may be counted.

Bacteria are disseminated in water, as the germ of typhoid fever and cholera ; in milk and other fluids; in the air ; and on the bodies of flies, feet of birds, and otherwise.

Bacteria are thought by many to have descended from algæ by the loss of chlorophyll and decrease in size due to the more specialized acquired saprophytic and parasitic habit.

\section{ALGE}

The algæ comprise most of the green floating "scum "which covers the surfaces of ponds and other quiet waters. The masses of plants are often called "frog spittle." Others are attached to stones, pieces of wood, and other objects submerged in streams 
and lakes, and many are found on moist ground and on dripping rocks. Aside from these, all the plants comınonly known as seaweeds belong to this category; these latter are inhabitants of salt water.

The simplest forms of algæ consist of a single spherical cell, which multiplies by repeated division or fission. Many of the forms found in fresh water are filamentous, i.e. the plant body consists of long threads, either simple or branched. .Such a plant body is termed a thallus. This term applies to the vegetative body of all plants that are not differentiated into stem and leaves. Such plants are known as thallophytes (p. I8I). All algæ contain chlorophyll, and are able to assimilate carbon dioxid from the air. This distinguishes them from the fungi.

Nostoc. - On wet rocks and damp soil dark, semitransparent irregular or spherical gelatinous masses about the size of a pea are often found. These consist of a colony of contorted filamentous algæ embedded in the jelly-like mass. The chain of cells in the filament is necklace-like. Each cell is homogeneous, without apparent nucleus, and blue-green in color, except one cell which is larger and clearer than the rest. The plant therefore belongs to the group of blue-green alga. The jelly probably serves to maintain a more even moisture and to provide mechanical protection. Multiplication is wholly by the breaking up of the threads. Occasionally certain cells of the filament thicken to become restingspores, but no other spore formation occurs.

Oscillatoria. - The blue-green coatings found on damp soil and in water frequently show under the microscope the presence of filamentous algæ composed of many short

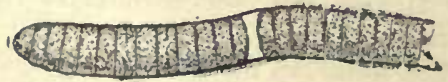

FIG. 264.-Fillament of Oscillatoria, showing one dead cell where the strand will break.

homogeneous cells (Fig. 264). If watched closely, some filaments will be seen to wave back and forth slowly, showing a peculiar power of movement characteristic of this plant. Multiplication is by the breaking up of the threads. There is no true spore formation.

Spirogyra. - One of the most common forms of the green algæ is spirogyra (Fig. 265). This

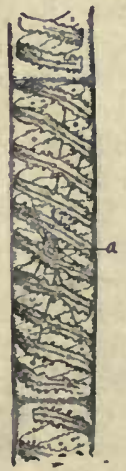

F1G. 265. - STRAND OF SPIROGYRA, showing the chlorophyll bands. There is a nucleus at $a$. How many cells, or paris of cells, are shown in this figure? 
plant often forms the greater part of the floating green mass (or "frog spittle") on ponds. The threadlike character of the thallus can be seen with the naked eye or with a hand lens, but to study it carefully a microscope magnifying two hundred diameters or more must be used. The thread is divided into long cells by cross walls which, according to the species, are either straight or curiously folded (Fig. 266). The chlorophyll is arranged in beautiful spiral bands near the wall of each cell. From the character of these bands the plant takes its name. Each cell is provided with a nucleus and other protoplasm. The nucleus is suspended near the center of the cell ( $a$, Fig. 265 ) by delicate strands of protoplasm radiating toward the wall and terminating at certain points in the chlorophyll band. The remainder of the protoplasm forms a thin layer lining the wall. The interior of the cell is filled with cell-sap. The protoplasm and nucleus cannot be easily seen, but if the plant is stained with a dilute alcoholic solution of eosin they become clear.

Spirogyra is propagated vegetatively by the breaking off of parts of the threads, which continue to grow as new plants. Resting-spores,

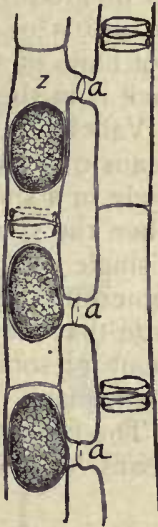

FIG. 266. - CoNJUGATION OF 'S P I R OGYRA. Ripe zygospores on the left; $a$, connecting tubes. which may remain dormant for a time, are formed by a process

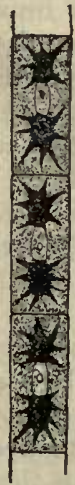

FIG. 267. - STRAND, OR FILAMENT OF ZYGNEMA, freed from its gelatinous covering. known as conjugation. Two threads lying side by side send out short projections, usually from all the cells of a long series (Fig. 266). The projections or processes from opposite cells grow toward each other, meet, and fuse, forming a connecting tube between the cells. The protoplasm, nucleus, and chlorophyll band of one cell now pass through this tube, and unite with the contents of the other cell. The entire mass then becomes surrounded by a thick cellulose wall, thus completing the restingspore, or zygospore (z, Fig. 266).

Zygnema is an alga closely related to spirogyra and found in similar places. Its life history is practically the same, but it differs from spirogyra in having two star-shaped chlorophyll bodies (Fig. 267) in each cell, instead of a chlorophyll-bearing spiral band. 
Vaucheria is another alga common in shallow water and on damp soil. The thallus is much branched, but the threads are not divided by cross walls as in spirogyra. The plants are attached by means of colorless root-like organs which are much like the root hairs of the higher plants: these are rhizoids. The chlorophyll is in the form of grains scattered through the thread.

Vaucheria has a special mode of asexual reproduction by means of swimming spores or swarm-spores. These are formed singly in a short enlarged lateral branch known as the sporangium. When the sporangium bursts, the entire contents escape, forming a single large swarm-spore, which swims about by means of numerous lashes or cilia on its surface. The swarm spores are so large that they can be seen with the naked eye. After swimming about for some time they come to rest and germinate, producing a new plant.

The formation of resting-spores of vaucheria is acomplished by means of special organs, ögonia (0, Fig. 268) and antheridia

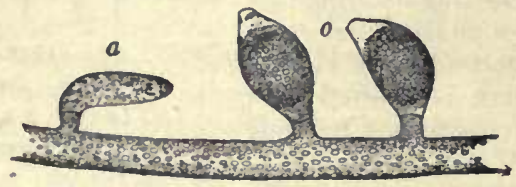

Fig. 268. - THREAD OF VAUCHERIA WITH OÖGONIA AND ANTHERIDIA.

(a, Fig. 268). Both of these are specially developed branches from the thallus. The antheridia are nearly cylindrical, and curved toward the oögonia. The upper part of an antheridium is cut off by a cross wall, and within it numerous ciliated sperm-cells are formed. These escape by the ruptured apex of the antheridium. The oögonia are more enlarged than the antheridia, and have a beak-like projection turned a little to one side of the apex. They are separated from the thallus thread by a cross wall, and contain a single large green cell, the egg-cell. The apex of the ooggonium is dissolved, and through the opening the sperm-cells enter. Fertilization is thus accomplished. After fertilization the egg-cell becomes invested with a thick wall and is thus converted into a resting-spore, the oöspore.

Fucus. - These are rather large specialized algæ belonging to the group known as brown seaweeds and found attached by a disk to the rocks of the seashore just below high tide (Fig. 269). They are firm and strong to resist wave action and are so attached as to avoid being washed ashore. They are very abundant algæ. In shape the plants are long, branched, and multicellular, with either flat or terete branches. They are olive-brown. Propagation is by the breaking off of the branches. No zoöspores are produced, as in many other seaveeds; and reproduction is wholly sexual. 
The antheridia, bearing.sperm-cells, and the ögonia, each bearing eight egg-cells, are sunken in pits or conceptacles. These pits are aggregated in the swollen lighter colored tips of some of the branches (s, s, Fig. 269). The egg-cells and sperm-cells escape from the pits and fertilization takes place in the water. The matured eggs, or spores, reproduce the fucus plant directly.

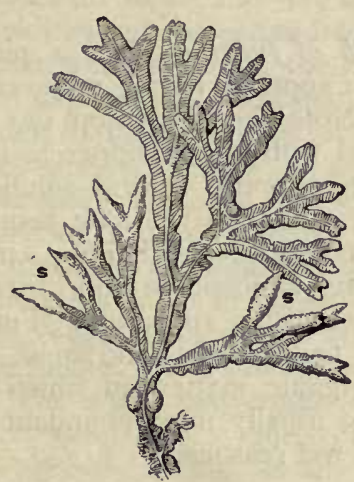

F1c. 269. - FucUs. Fruiting branches at $s, s$. On the stem are two air-bladders.

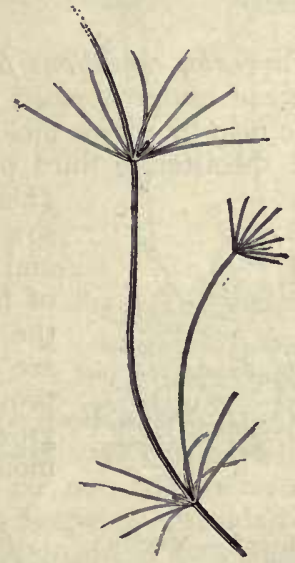

FIG. 270. - NITELLA.

Nitella. - This is a large branched and specialized fresh-water alga found in tufts attached to the bottom in shallow ponds (Fig. 270). Between the whorls of branches are long internodes consisting of a single cylindrical cell, which is one of the largest cells known in vegetable tissue. Under the microscope the walls of this cell are found to be lined with a layer of small stationary chloroplastids, within which layer the protoplasm, under favorable circumstances, will be found in motion, moving up one side and down the other (in rotation). Note the clear streak up the side of the cell and its relation to the moving current.

\section{FUNGI}

Some forms of fungi are familiar to every one. Mushrooms and toadstools, with their varied forms and colors, are common in fields, woods, and pastures. In every household the common molds are familiar intruders, appearing on old bread, vegetables, and even within tightly sealed fruit jars, where they form a feltlike layer dusted over with blue, yellow, or black powder. The strange occurrence of these plants long mystified people, who 
thought they were productions of the dead matter upon which they grew, but now we know that a mold, as any other plant, cannot originate spontaneously; it must start from something which is analogous to a seed. The "seed" in this case is a spore. A spore may be produced by a vegetative process (growing out from the ordinary plant tissues), or it may be the result of a fertilization process.

Favorable conditions for the growth of fungi. - Place a piece of bread under a moist bell jar and another in an uncovered place near by. Sow mold on each. Note the result from day to day. Moisten a third piece of bread with weak copper sulfate

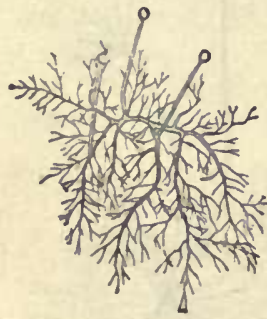

FIG. 27 T. - MUCOR MUCEDO, showing habit. (blue vitriol) or mercuric chlorid solution, sow mold, cover with bell jar, note results, and explain. Expose pieces of different kinds of food in a damp atmosphere and observe the variety of organisms appearing. Fungi are saprophytes or parasites, and must be provided with organic matter on which to grow. They are usually most abundant in moist places and wet seasons.

Mold. - One of these molds (Mucor mucedo), which is very common on all decaying fruits and vegetables, is shown in Fig. $27 \mathrm{r}$, somewhat magnified. When fruiting, this mold appears as a dense mass of long white hairs, often over an inch high, standing erect from the fruit or vegetable on which it is growing.

The life of this mucor begins with a minute rounded spore (a, Fig. 272), which lodges on the decaying material. When the spore germinates, it sends out a delicate thread that grows rapidly in length and forms very many branches that soon permeate every part of the substance on which the plant grows (b, Fig. 272). One of these threads is termed a hypha. All the threads together form the mycelium of the fungus. The mycelium disorganizes the material in which it grows, and thus the mucor plant (Fig. 27I) is nourished. It corresponds, physiologically to the roots and stems of otherplants.
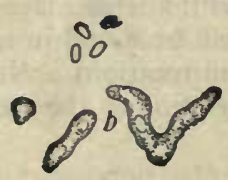

FIG. 272. - SPORES OF MUCOR, some germinating.

When the mycelium is about two days old, it begins to form the long fruiting stalks which we first noticed. To study them, use a compound microscope magnifying about two hundred diameters. One of the stalks, magnified, is shown in $a$, Fig. 274 . It consists of a rounded head, the sporangium, sp, supported on a long, 
delicate stalk, the sporangiophore. The stalk is separated from the sporangium by a wall which is formed at the base of the sporangium. This wall, however, does not extend straight across the thread, but it arches up into the sporangium like an inverted pear. It is known as the columella, $c$. When the sporangium is placed in water, the wall immediately dissolves and allows hundreds of spores, which were formed in the cavity within the sporangium, to escape, $b$. All that is left of the fruit is the stalk, with the pear-shaped columella at its summit, $c$. The spores that have been set free by the breaking of the sporangium wall are now scattered by the wind and other agents. Those that lodge in favorable places begin to grow immediately and reproduce the fungus. The others soon perish.

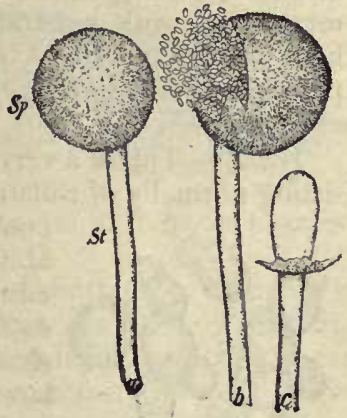

F1G. 274. - MUCOR.

$a$, sporangium; $b$, sporangium bursting; $c$, columella.

The mucor may continue to reproduce itself in this way indefi-

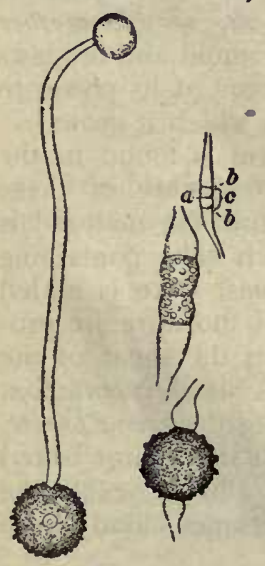

FIG. 273. - MUCOR, showing formation of zygospore on the right; germinating zygospore on th. left. nitely, but these spores are very delicate and usually die if they do not fall on favorable ground, so that the fungus is provided with another means of carrying itself over unfavorable seasons, as winter. 'This is accomplished by means of curious thick-walled resting-spores or zygospores. The zygospores are formed on the mycelium buried within the substance on which the plant grows. They originate in the following way: Two threads that lie near together send out short branches, which grow toward each other and finally meet (Fig. 273). The walls at the ends, $a$, then disappear, allowing the contents to flow together. At the same time, however, two other walls are formed at points farther back, $b, b$, separating the short section, $c$, from the remainder of the thread. This section now increases in size and becomes covered with a thick, dark brown wall ornamented with thickened tubercles. The zygospore is now mature and, after a period of rest, it germinates, either producing a sporangium directly or growing out as mycelium.

The zygospores of the mucors form one of the most interesting and instructive objects among the lower plants. They are, however, very difficult to obtain. One of the mucors (Sporodinia 
grandis) may be frequently found in summer growing on toadstools. This plant usually produces zygospores that are formed on the aërial mycelium. The zygospores are large enough to be recognized with a hand lens. The material may be dried and kept for winter study, or the zygospores may be prepared for permanent microscopic mounts in the ordinary way.

Yeast. - This is a very much reduced and simple fungus, consisting normally of isolated spherical or elliptical cells (Fig. 275)

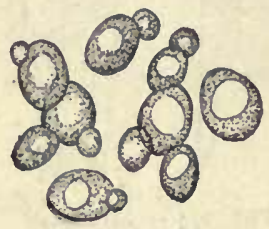

FIG. 275.-YEAST

Pl.ANTS. containing abundant protoplasm and probably a nucleus, although the latter is not easily observed. It propagates rapidly by budding, which consists of the gradual extrusion of a wart-like swelling that is sooner or later cut off at the base by constriction, thus forming a separate organism. Although simple in structure, the yeast is found to be closely related to some of the higher groups of fungi as shown by the method of spore formation. When grown on special substances like potato or carrot, the contents of the cell may form spores inside of the sac-like mother cell, thus resembling the sac-fungi to which blue mold and mildews belong. The yeast plant is remarkable on account of its power to induce alcoholic fermentation in the media in which it grows.

There are many kinds of yeasts. One of them is found in the common yeast cakes. In the process of manufacture of these cakes, the yeast cells grow to a certain stage, and the material is then dried and fashioned into small cakes, each cake containing great numbers of the yeast cells. When the yeast cake is added to dough, and proper conditions of warmth and moisture are provided, the yeast grows rapidly and breaks up the sugar of the dough into carbon dioxid and alcohol. This is fermentation. The gases escape and puff up the dough, causing the bread to rise. In this loosened condition the dough is baked; if it is not baked quickly enough, the bread "falls." Shake up a bit of yeast cake in slightly sweetened water : the water soon becomes cloudy from the growing yeasts.

Parasitic fungi. - Most of the molds are saprophytes. Many other fungi are parasitic on living plants and animals (Fig. 285). Some of them have complicated life histories, undergoing many changes before the original spore is again produced. "The willow miliew and the common rust af reheat will serve to illustrate the habits of parasitic fungi.

The willon mildew (Uncinula salicis). - This is one of the sac fungi. It forms white downy patches on the leaves of willows 
(Fig. 276). These patches consist of numerous interwoven threads that may be recognized under the microscope as the mycelium of the fungus.

The mycelium in this case lives on the surface of the leaf and nourishes itself by sending short branches into the cells of the leaf to absorb food materials from

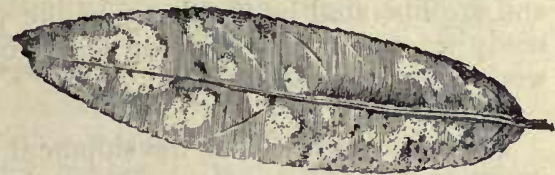

Fig. 276. - Colonies of Willow Mildew. them.

Numerous summer-spores are formed of short, erect branches all over the white surface. One of these branches is shown in Fig.

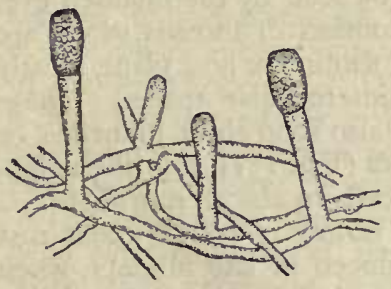

FIG. 277. - SUMMER-SPORES OF WILLOW MiLDEW.

277. When it has grown to a certain length, the upper part begins to segment or divide into spores which fall and are scattered by the wind. Those falling on other willows reproduce the fungus there. This process continues all summer, but in the later part of the season provision is made to maintain the mildew through the winter. If some of the white patches are closely examined in July or August, a number of little black bodies will be seen among the threads. These little bodies are called perithecia, shown in Fig. 278. To the naked eye

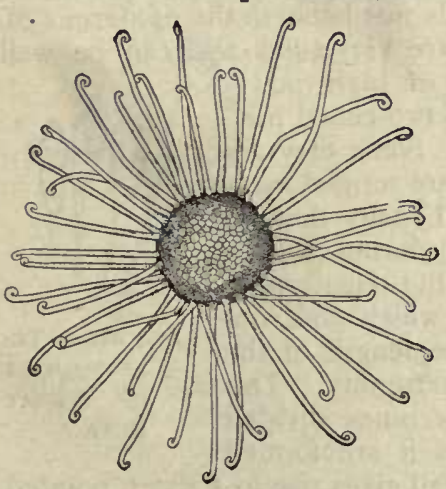

FIG. 278. - PERITHECIUM OF WIL LOW MILDEW. they appear as minute specks, but when seen under a magnification of 200 diameters they present a very interesting appearance. They are hollow spherical bodies decorated around the outside with a fringe of crook-like hairs. The resting-spores of the willow mildew are produced in sacs or asciinclosed within the leath-

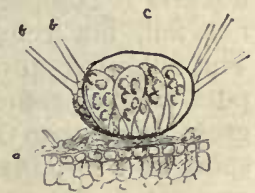

Fig. 279. - SECTION THROUGH PERITHECIUM OF WILLOW MILDEW.

ery perithecia. Figure 279 shows a cross-section of a perithecium with the asci arising from the bottom. The spores remain securely 
packed in the perithecia. They do not ripen in the autumn, but fall to the ground with the leaf, and there remain securely protected among the dead foliage. The following spring they mature and are liberated by the decay of the perithecia. They are then ready to attack the unfolding leaves of the willow and repeat the work of the summer before.

The wheat rust. - The development of some of the rusts, as the common wheat rust (Puccinia graminis), is even more interesting

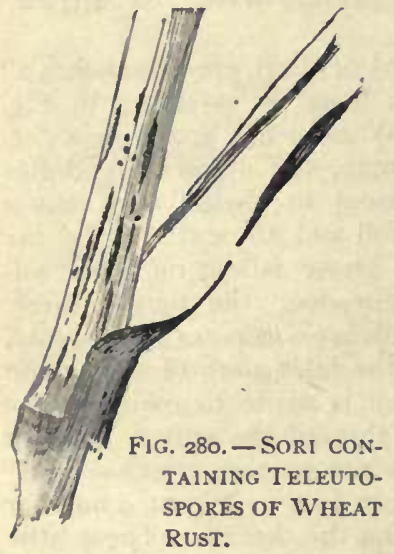
and complicated than that of the mildews. Wheat rust is also a true parasite, affecting wheat and a few other grasses. The mycelium here cannot be seen by the unaided eye, for it consists of threads which are present within the host plant, mostly in the intercellular spaces. These threads also send short branches, or haustoria (Fig. 132), into the neighboring cells to absorb nutriment.

The resting-spores of wheat rust are produced in late summer, when they may be found in black lines breaking through the epidermis of the wheat stalk (black-rust stage). They are formed in masses, called sori (Fig. 280), from the ends of numerous crowded mycelial strands just beneath the epidermis of the host. The individual spores are very small and can be well studied only with a microscope of high power ( $X$ about 400$)$. They are brown two-celled bodies with a thick wall (Fig. 28r). Since they are the resting or winter-spores, they are termed teleutospores ("completed spores"). Usually they do not fall, but remain in the sori during winter. The following spring each cell of the teleutospore puts forth a rather stout thread, which does not grow more than several times the length of the spore and terminates in a blunt extremity. This germ tube, promycelium, now becomes divided into four cells by cross walls, which are formed

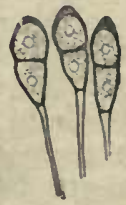

FIG. 281. - TELEUTOSPORE OF WHEAT RUST. from the top downwards. Each cell gives rise to a short, pointed branch which, in the course of a few hours, forms at its summit a single spore called a sporidium. This in turn germinates and produces a mycelium. In Fig. 282 a germinating teleutospore is drawn to show the promycelium, $p$, divided into four cells, 
each producing a short branch with a little sporidium, $s$.

A most remarkable circumstance in the life history of the wheat rust is the fact that the mycelium produced by the sporidium can live only in barberry leaves, and it follows that if no barberry bushes are in the neighborhood the sporidia finally perish. Those which happen to lodge on a barberry bush germinate immediately, producing a mycelium that enters the barberry leaf and grows within its tissues. Very soon the fungus produces a new kind of spores on the barberry leaves. These are called acidiospores. They are formed in long chains in little fringed cups, or acidia, which appear in groups on the lower side of the leaf (Fig. 283). These orange or yellow æcidia are termed cluster-cups. In Fig. 284 is shown a cross-section of one of the cups, outlin-

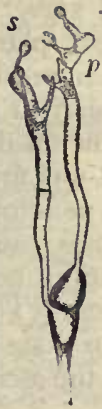

FIG. 282. - GERMINATING TELEUTOSPORE OF WHEAT

RUST. ing the long chains of spores, and the mycelium in the tissues.

The æcidiospores are formed in the spring, and after they have been set free, some of them lodge on wheat or other grasses, where they germinate immediately. The germ-tube enters the

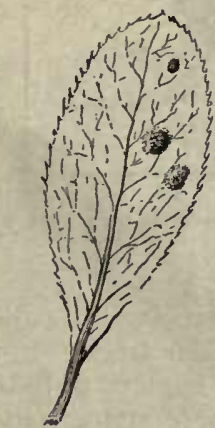

FIG. 283. - LEAF OF BARBERRY WITH ClUSTER-CUPS.

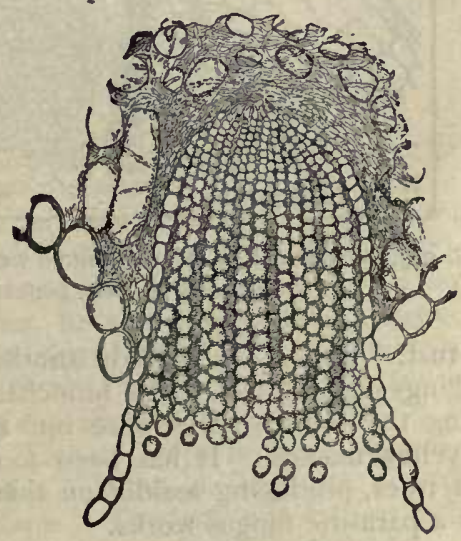

FIG. 284. - SECTION THROUGH A CLUSTER-CUP ON BARBERRY LEAF.

leaf through a stomate, whence it spreads among the cells of the wheat plant. In summer one-celled reddish uredospores ("blight spores," red-rust stage) are produced in a manner similar to the teleutospores. These are capable of germinating immediately, 
and serve to disseminate the fungus during the summer on other wheat plants or grasses. Late in the season, teleutospores are again produced, completing the life cycle of the plant.

Many rusts besides Puccinia graminis produce different spore forms on different plants. The phenomenon is called heterocism, and was first shown to exist in the wheat rust. Curiously enough, the peasants of Europe had observed and asserted that barberry bushes cause wheat to blight long before science explained the relation between the cluster-cups on barberry and the rust on wheat. The true relation was actually demonstrated, as has since been done for many other rusts on their respective hosts, by sowing the æcidiospores on healthy wheat plants and thus producing

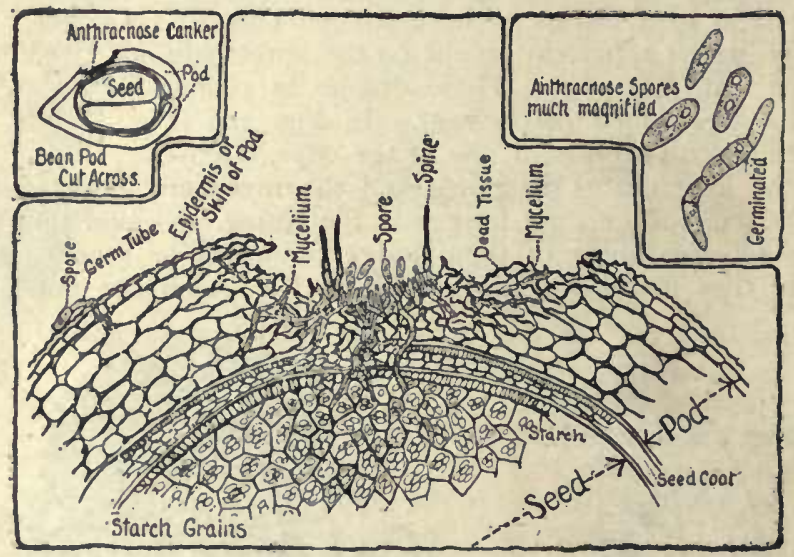

FIG. 285. - How A PARASITIC FUNGUS wORKS. Anthracnose on a bean pod entering the bean beneath. (Whetzel.)

the rust. The cedar apple is another rust, producing the curious swellings often found on the branches of red cedar trees. In the spring the teleutospores ooze out from the "apple" in brownish yellow masses. It has been found that these attack various fruit trees, producing æcidia on their leaves. Fig. 285 explains how a parasitic fungus works.

Puffballs, mushrooms, toadstools, and shelf fungi.- These represent what are called the higher fungi, because of the size and complexity of the plant body as well as from the fact that they seem to stand at the end of one line of evolution. The mycelial threads grow together in extensive strands in rotten wood or in the soil, and send out large complex growths of mycelium in con- 
nection with which the spores are borne. These aërial parts are the only ones we ordinarily see, and which constitute the "mushroom" part (Fig. I3I). Only asexual spores (basidiospores) are produced, and on short stalks (basidia) (Fig. 286). In the puffballs the spores are inclosed and constitute a large part of the "smoke." In the mushrooms and toadstools they are borne on gills, and in the shelf fungi (Fig. I34) on the walls of minute pores of the underside. The mycelium of these shelf fungi frequently lives and grows for a long time concealed in the substratum before the visible fruit bodies are sent out. Practically all timber decay is caused by such growth, and the damage is

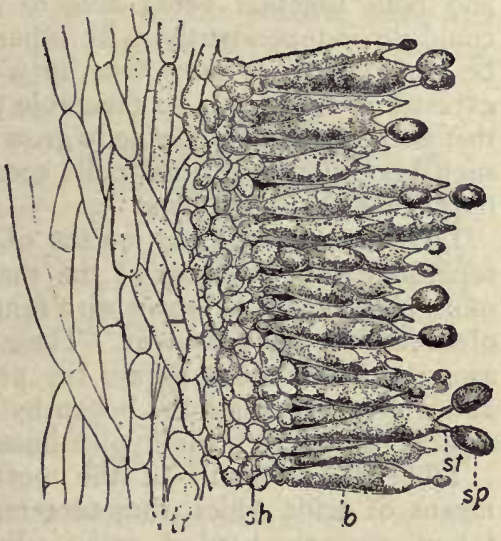

FIG. 286. - PART OF GILL OF THE CULTIVATED MUSHROOM.

$t r$, trama tissue; sh, hymenium; $b$, basidium; $s t$, sterigma; $s p$, spore. (Atkinson.) largely done before the fruiting bodies appear. For other accounts of mushrooms, see Chap. XIV.

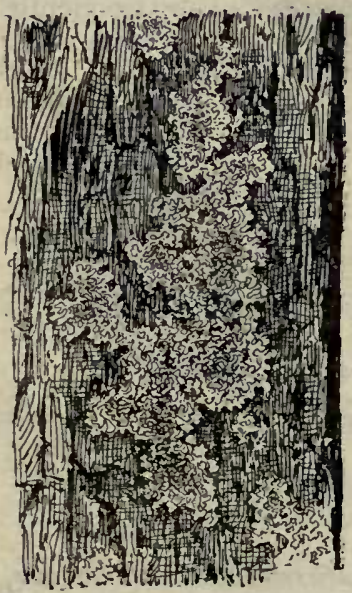

F1G. 287. - LICHEN ON AN OAK TRUNK. (A species of Physcia.)

\section{LICHENS}

Lichens are so common everywhere that the attention of the student is sure to be drawn to them. They grow on rocks, trunks of trees (Fig. 287 ), old fences, and on the earth. They are thin, usually gray ragged objects, apparently lifeless. Their study is too difficult for beginners, but a few words of explanation may be useful.

Lichens were formerly supposed to be a distinct or separate division of plants. They are now known to be organisms, each species of which is a constant association of a fungus and an alga. The thallus is ordinarily made up of fungous mycelium or tissue within which the imprisoned alga is definitely distributed. The result is a growth unlike either component. This association of 
alga and fungus is usually spoken of as symbiosis, or mutually helpful growth, the alga furnishing some things, the fungus others, and both together being able to accomplish work that neither could do independently. By others this union is considered to be a mild form of parasitism, in which the fungus profits at the expense of the alga. As favorable to this view, the facts are cited that each component is able to grow independently, and that under such conditions the algal cells seem to thrive better than when imprisoned by the fungus.

Lichens propagate by means of soredia, which are tiny parts separated from the body of the thallus, and consisting of one or more algal cells overgrown with fungus threads. These are readily observed in many lichens. They also produce spores, usually ascospores, which are always the product of the fungus element, and which reproduce the lichen by germinating in the presence of algal cells, to which the hyphæ immediately cling.

Lichens are found in the most inhospitable places, and, by means of acids which they secrete, they attack and slowly disintegrate even the hardest rocks. By making thin sections of the thallus with a sharp razor and examining under the compound microscope, it is easy to distinguish the two components in many lichens.

\section{LIVERWORTS}

The liverworts are peculiar flat green plants usually found on wet cliffs and in other moist, shady places. They frequently occur in greenhouses where the soil is kept constantly wet.

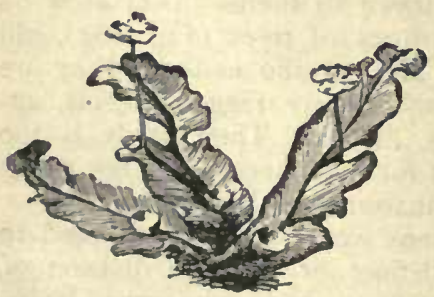

FIG. 288.

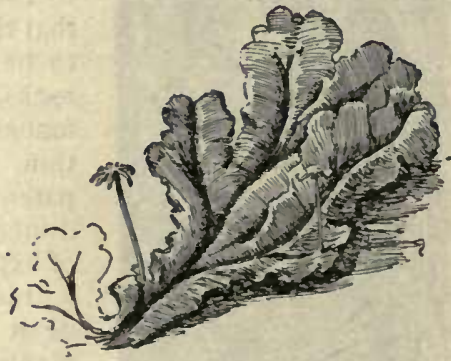

F1G. 289 .

Plants of marchantia.

One of the commonest liverworts is Marchantia polymorpha, two plants of which are shown in Figs. 288, 289. The plant consists of a ribbon-like thallus that creeps along the ground, becoming repeatedly forked as it grows. The end of each branch 
is always conspicuously notched. There is a prominent midrib extending along the center of each branch of the thallus. On the under side of the thallus, especially along the midrib, there are numerous rhizoids which serve the purpose of roots, absorbing nourishment from the earth and holding the plant in its place. The upper surface of the thallus is divided into minute rhombic areas that can be seen with the naked eye. Each of these areas is perforated by a small breathing pore or stomate that leads into a cavity just beneath the epidermis. This space is surrounded by chlorophyllbearing cells, some of which stand in rows from the bottom of the cavity (Fig. 290). The delicate

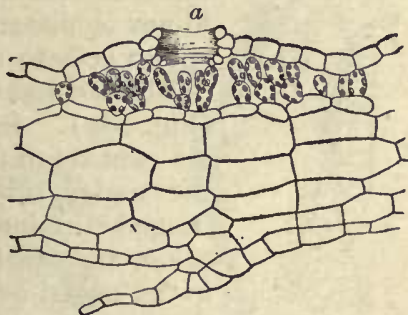

Fig. 290. - SECTION OF THALLUS of MARCHANTIA. Stomate at $a$. assimilating tissue is thus brought in close communication with the outer air through the pore in the thick, protecting epidermis.

At various points on the midrib are little cups containing small green bodies. These bodies are buds or gemma which are outgrowths from the cells at the bottom of the cup. They become loosened and are then dispersed by the rain to other places, where they take root and grow into new plants.

The most striking organs on the thallus of marchantia are the peculiar stalked bodies shown in Figs. 288, 289. These are termed archegoniophores and antheridiophores or receptacles. Their structure and function are very interesting, but their parts are so minute that they can be studied only with the aid of a microscope magnifying from 100 to 400 times. Enlarged drawings will guide the pupil.

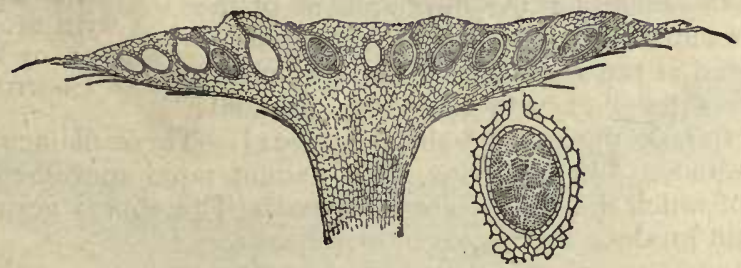

Fig. 29I. - SECTION THROUGH ANTHERIDIOPHORE OF MARCHANTIA, - showing antheridia. One antheridium more magnified.

The antheridiophores are fleshy, lobed disks borne on short stalks (Fig. 29r). The upper surface of the disk shows openings scarcely visible to the naked eye. However, a section of the disk, such as is drawn in Fig. 29I, shows that the pores lead into oblong cavi- 
ties in the receptacle. From the base of each cavity there arises a thick, club-shaped body, the antheritium. Within the anther-

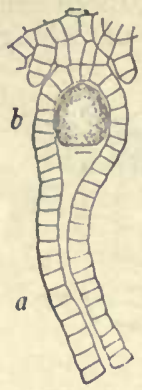

F1G. 292. ARCHEGONIUM OF Marcilantia. idium are formed many sperm.cells which are capable of swimming about in water by means of long lashes or cilia attached to them. When the antheridium is mature, it bursts and allows the ciliated sperm cells to escape.

The archegoniophores are also elevated on stalks (Fig. 289). Instead of a simple disk, the receptacle consists of nine or more finger-like rays. Along the under side of the rays, between delicately fringed curtains, peculiar flask-like bodies, or archegonia, are situated. The archegonia are not visible to the naked eye. They can be studied only with the microscope ( $X$ about 400). One of them much magnified is represented in Fig. 292. Its principal parts are the long neck, $a$, and the rounded venter, $b$, inclosing a large free cell - the egg-cell.

We have seen that the antheridium at maturity discharges its sperm-cells. These swim about in the water provided by the dew and rain. Some of them finally find their way to the archegonia and egg-cells, the latter being fertilized, as pollen fertilizes the ovules of higher plants.

After fertilization the egg-cell develops into the spore capsule or sporogonium. The mature spore capsules may be seen in Fig. 293. They consist of an oval spore-case on a short stalk, the base of which is imbedded in the tissue of the receptacle, from which it derives the necessary nourishment for the development of the sporogonium. At maturity the sporogonium is ruptured at the apex, setting free the spherical spores together with nurnerous filaments

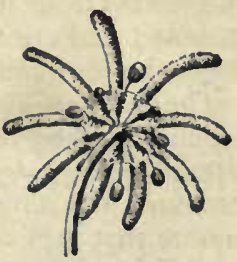

FIG, 293. - ARCHE: GONIOPHORE, WITH SPOROGONIA, OF MARChantia. having spirally thickened walls (Fig. 294). These filaments are called elaters. When drying, they exhibit rapid movements by means of which the spores are scattered. The spores germinate and again produce the thallus of marchantia.

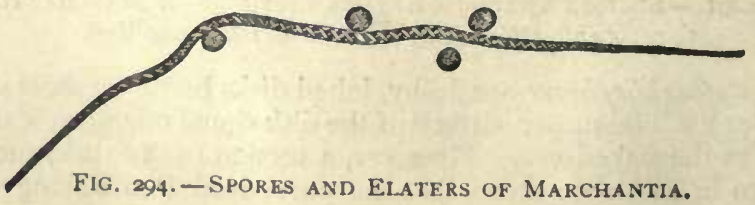




\section{Mosses (Bryophyta)}

If we have followed carefully the development of marchantia, the study of one of the mosses will be comparatively easy. The mosses are more familiar plants than the liverworts. They grow on trees, stones, and on the soil both in wet and dry places. One of the common larger mosses, known as Polytrichum commune, may serve as an example, Fig. 295. This plant grows on rather dry knolls, mostly in the borders of open woods, where it forms large beds. In dry weather these beds have a reddish brown appearance, but when moist they form beautiful green cushions. This color is due, in the first instance, to the color. of the old stems and leaves, and, in the second instance, to the peculiar action of the green living leaves under the influence of changing moisture-conditions. The inner or upper surface of the leaf is covered with thin, longitudinal ridges of delicate cells which contain chlorophyll. These cells are shown
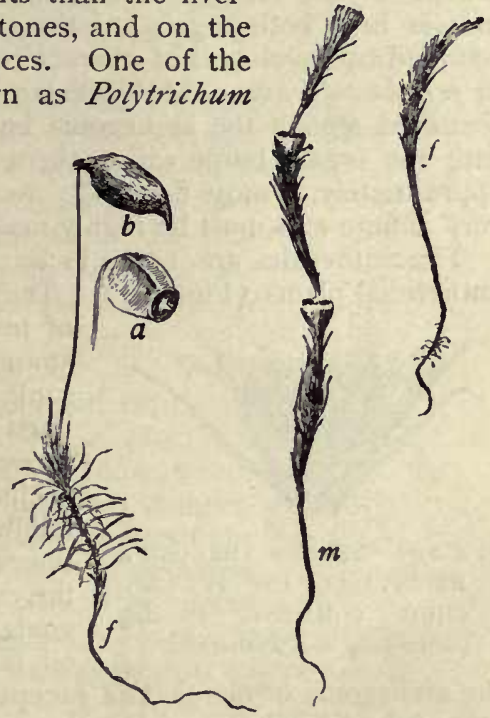

F1G. 295. - PÓLYT'RichuM COMMUNE.

$f, f$, fertile plants, one on the left in fruit; $m$, antheridial plant. in cross-section in Fig. 296, as dots or granules. All the other tissue of the leaf consists of thick-walled, corky cells which do

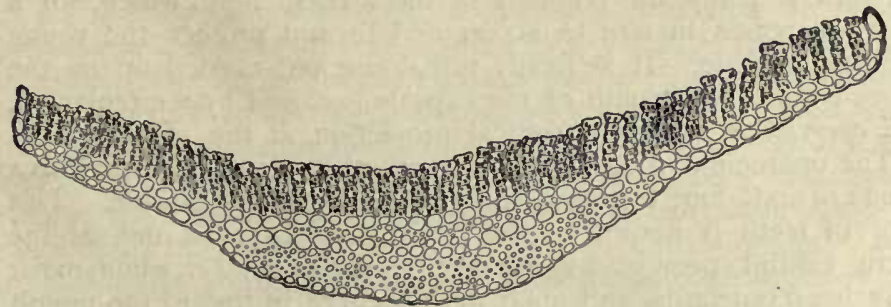

Fig. 296. - Section of Leaf of Polytrichum Commune.

not allow moisture to penetrate. When the air is moist the green leaves spread out, exposing the chlorophyll cells to the air, but in 
dry weather the margins of the leaves roll inward, and the leaves fold closely against the stem, thus protecting the delicate assimilating tissue.

The antheridia and archegonia of polytrichum are borne in groups at the ends of the branches on different plants (many mosses bear both organs on the same branch). 'They are surrounded by involucres of characteristic leaves termed perichatia or perichatal leaves. Multicellular hairs known as paraphyses are scattered among the archegonia and antheridia. The involucres with the organs borne within them are called receptacles, or, less appropriately, "moss flowers." As in marchantia, the organs are very minute and must be highly magnified to be studied.

The antheridia are borne in broad cup-like receptacles on the antheridial plants (Fig. 297). They are much like the antheridia

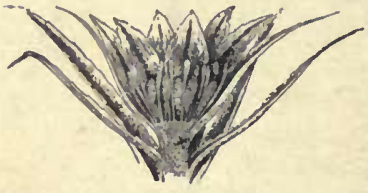

FIG. 297. - SECTION THROUGH A

RECEPTACLE OF POLYTRICHUM COMMUNE, showing paraphyses and antheridia. of marchantia, but they stand free among the paraphyses and are not sunk in cavities. At maturity they burst and allow the sperm cells or spermatozoids to escape. In polytrichum, when the receptacles have fulfilled their function, the stem continues to grow from the center of the cup (m, Fig. 295). The archegonia are borne in other receptacles on different plants. They are like the archegonia of marchantia except that they stand erect on the end of the branch.

The sporogonium which develops from the fertilized egg is shown in $a, b$, Fig. 295. It consists of a long, brown stalk bearing the spore-case at its summit. The base of the stalk is imbedded in the end of the moss stem by which it is nourished. The capsule is entirely inclosed by a hairy cap, the calyptra, $b$. The calyptra is really the remnant of the archegonium, which, for a time, increases in size to accommodate and protect the young growing capsule. It is finally torn loose and carried up on the spore-case. The mouth of the capsule is closed by a circular lid, the operculum, having a conical projection at the center.

The operculum soon drops, or it may be removed, displaying a fringe of sixty-four teeth guarding the mouth of the capsule. This ring of teeth is known as the peristome. In most mosses the teeth exhibit peculiar hygroscopic movements; i.e. when moist they bend outwards, and upon drying curve in toward the mouth of the capsule. This motion, it will be seen, serves to disperse the spores gradually over a long period of time.

Not the entire capsule is filled with spores. There are no elaters, but the center of the capsule is occupied by a columnar 
strand of tissue, the columella, which expands at the mouth into a thin, membranous disk, closing the entire mouth of the capsule except the narrow annular chink guarded by the teeth. In this moss the points of the teeth are attached to the margin of the membrane, allowing the spores to sift out through the spaces between them.

When the spores germinate they form a green, branched thread, the protonema. 'This gives rise directly to moss plants, which appear as little buds on the thread. When the moss plants have sent their little rhizoids into the earth, the protonema dies, for it is no longer necessary for the support of the little plants, and the moss plants grow independently.

Funaria is a moss very common on damp, open soil. It forms green patches of small fine leaves from which arise long brown stalks terminated by curved capsules (Fig. 298). The structure is similar to that of polytrichum, except the absence of plates on the under side of the leaves, the continuous growth of the stem, the curved

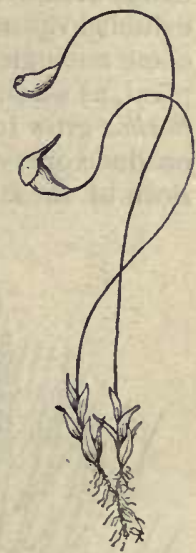

FIG. 298. - FU-

NARIA HY-

GROSCOPICA. capsule, double peristome, monœcious rather than diœcious receptacles, and nearly glabrous unsymmetrical calyptra.

\section{Equisetums, oR Horsetails (Pteridophyta)}

There are about twenty-five species of equisetum, constituting the only genus of the unique family Equisetacea. Among these $E$. arvense (Fig. 299) is common on clayey and sandy soils.

In this species the work of nutrition and that of spore production are performed by separate shoots from an underground rhizome. The fertile branches appear early in spring. The stem, which is 3 to 6 inches high, consists of a number of cylindrical, furrowed internodes, each sheathed at the base by a circle of scale leaves. The shoots are of a pale yellow color. They contain no chlorophyll, and are nourished by the food stored in the rhizome (Fig. 299).

The spores are formed on specially developed fertile leaves or sporophylls which are collected into a spike or cone at the end of the stalk ( $a$, Fig. 299). A single sporophyll is shown at $b$. It consists of a short stalk expanded into a broad, mushroom-like head. Several large sporangia are borne on its under side. The spores formed in the sporangia are very interesting and beautiful 
objects when examined under the microscope ( $x$ about 200 ). They are spherical, green bodies, each surrounded by two spiral bands attached to the spore at their intersection, $s$. 'These bands exhibit hygroscopic movements by means of which the spores become entangled, and are held together. This is of advantage to the plant, as we shall see. All the spores are alike, but some of the prothallia grow to a greater size than the others. The large prothallia produce only archegonia while the smaller ones produce antheridia. Both of these organs are much like those of the ferns, and fertili-
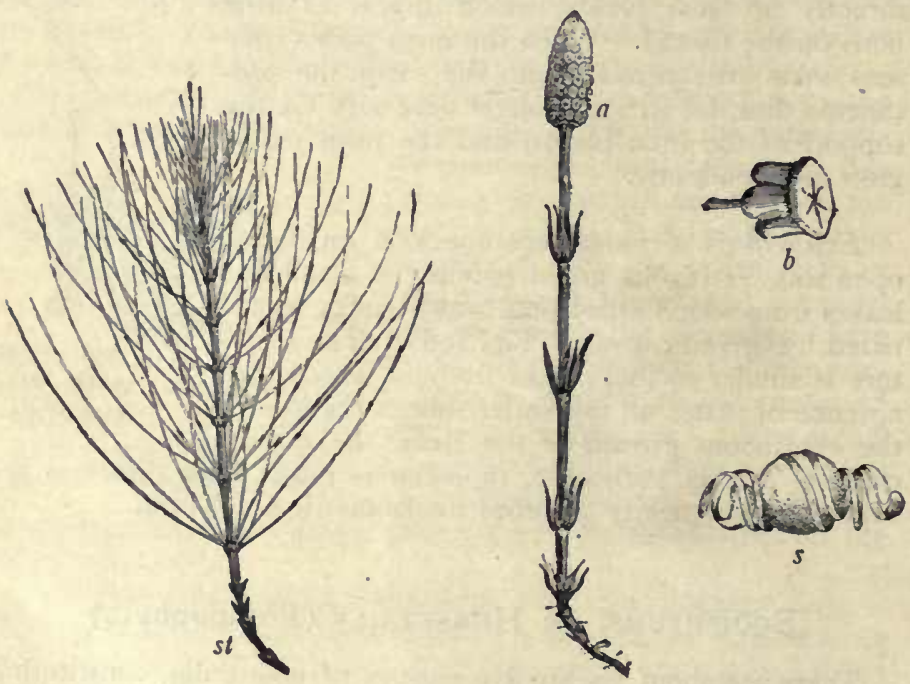

FIG. 299. - EQUISETUM ARVENSE.

st, sterile shoot: $f$, fertile shoot showing the spike at $a ; b$, sporophyll, with sporangia: s, spore.

zation is accomplished in the same way. Since the prothallia are usually diœcious, the special advantage of the spiral bands, holding the spores together so that both kinds of prothallia may be in close proximity, will be easily understood. As in the fern, the fertilized egg-cell develops into an equisetum plant.

The sterile shoots (st, Fig. 299) appear much later in the season. They give rise to repeated whorls of angular or furrowed branches. The leaves are very much reduced scales, situated at the internodes. The stems are provided with chlorophyll and act as assimilating tissue, nourishing the rhizome and the fertile shoots. Nutriment is also stored in special tubers developed on the rhizome. 
Other species of equisetum have only one kind of shoot - a tall, hard, leafless, green shoot with the spike at its summit. Equisetum stems are full of silex, and they are sometimes used for scouring floors and utensils; hence the common name "scouring rush."

\section{Isö̈TES (Pteridophyta)}

Isö̈tes or quillwort is usually found in water or damp soil on the edges of ponds and lakes. The general habit of the plant is seen in Fig. 300, $a$. It consists of a short, perennial stem bearing numerous erect, quill-like leaves with broad sheathing bases. The plants are commonly mistaken for young grasses.

Isoëtes bears two kinds of spores, large roughened ones, the macrospores, and small ones or microspores. Both kinds are formed in sporangia borne in an excavation in the expanded base of the leaf. The macrospores are formed on the outer and the microspores on the inner leaves. A sporangium in the base of a leaf is shown at $b$. It is partially covered by a thin membrane, the velum. The minute triangular appendage at the upper end of the sporangium is called the ligule.

The spores are liberated by the decay of the sporangia. They form rudimentary prothallia of two kinds. The microspores produce prothallia with antheridia, while the macrospores produce prothallia with archegonia. Ferti-

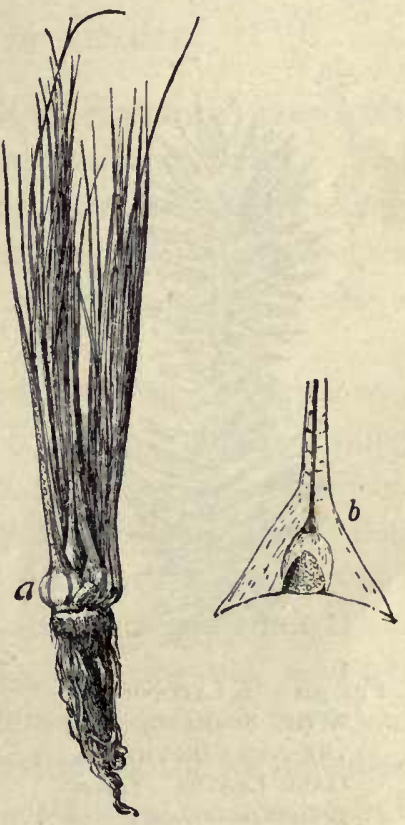

FIG. 300. - ISOẼTES, showing habit of plant at $a ; b$, base of leaf, showing sporangium, velum, and ligule. lization takes place as in the mosses or liverworts, and the fertilized egg-cell, by continued growth, gives rise again to the isoëtes plant.

\section{Club-Mosses (Pteridophyta)}

The club-mosses are low trailing plants of moss-like looks and habit, although more closely allied to ferns than to true mosses. Except one genus in Florida, all our club mosses belong to the 
genus Lycopodium. They grow mostly in woods, having $\mathbf{I}$-nerved evergreen leaves arranged in four or more ranks. Some of them make long strands, as the ground pine, and are much used for Christmas decorations. The spores are all of one kind or form, borne in 7 -celled sporangia that open on the margin into two valves. The sporangia are borne in some species (Fig. 30r)

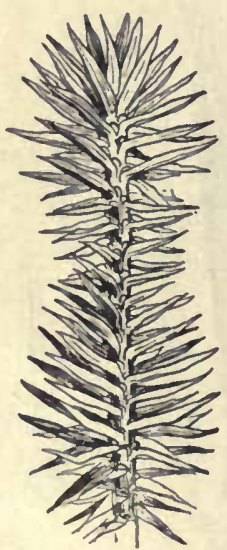

Fig. 301. - A LyCopodium WITH SPORANGIA IN THE AXIIS OF THE FOLIAGE LEAVES. (Lycopodium lucidulum.)

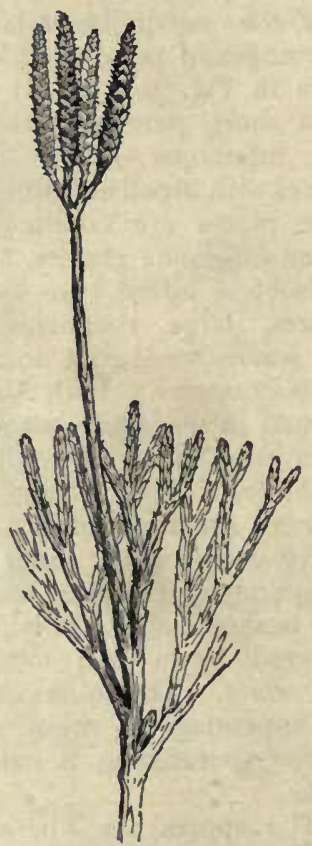

FIG. 302. - A Club-Moss (Lycopodium complanatum).

as small yellow bodies in the axils of the ordinary leaves near the tip of the shoot; in other species (Fig. 302) they are borne in the axils of small scales that form a catkin-like spike. The spores are very numerous, and they contain an oil that makes them inflammable. About roo species of lycopodium are known. The plants grown by florists under the name of lycopodium are of the genus Selaginella, more closely allied to isoëtes, bearing two kinds of spores (microspores and macrospores). 


\section{ANIMAL BIOLOGY}

\section{CHAPTER I}

\section{THE PRINCIPLES OF BIOLOGY}

Biology (Greek, bios, life; logos, discourse) means the science of life. It treats of animals and plants. That branch of biology which treats of animals is called zoology (Gr. zoon, animal; logos, discourse). The biological science of botany (Gr. botane, plant or herb) treats of plants.

Living things are distinguished from the not living by a series of processes, or changes (feeding, growth, development, multiplication, etc.), which together constitute what is called life. These processes are called functions. Both plants and animals have certain parts called organs which have each a definite work, or function; hence animals and plants are said to be organized. For example, men and most animals have a certain organ (the mouth) for taking in nourishment; another (the food tube), for its digestion.

Because of its organization, each animal or plant is said to be an organism. Living things constitute the organic kingdom. Things without life and not formed by life constitute the inorganic, or mineral, kingdom. Mark I for inorganic and $\mathrm{O}$ for organic after the proper words in this list: granite, sugar, lumber, gold, shellac, sand, coal, paper, glass, starch, copper, gelatine, cloth, air, potatoes, alcohol, oil, clay. Which of these things are used for food by animals? Conclusion? 
Energy in the Organic World. - We see animals exerting energy; that is, we see them moving about and doing work. Plants are never seen acting that way; yet they need energy in order to form their tissues, grow, and raise themselves in the air.

Source of Plant Energy. - We notice that green plants thrive only in the light, while animal growth is largely independent of light. In fact, in the salt mines of Poland there are churches and villages below the ground, and children are born, become adults, and live all their lives below ground, without seeing the sun. (That these people are not very strong is doubtless due more to want of fresh air and other causes than want of sunlight.)

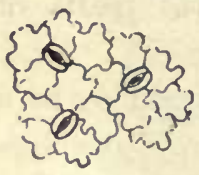

FIG. I.-SURFAces OF A LEAF, magnified.

The need of plants for sunlight shows that they must obtain something - from the sun. This has been found to be energy. This enables them to lift their stems in growth, and form the various structures called tissues which make up their stems and leaves. (See Part I, Chap. XIII.) It is noticed that they take in food and water from the soil through their roots. Experiments also show that green plants take in through pores (Fig. I), on the surface of their leaves, a gas composed of carbon and oxygen, and called carbon dioxid. The energy in the sunlight enables the plant to separate out the carbon of the carbon dioxid and build mineral and water and carbon

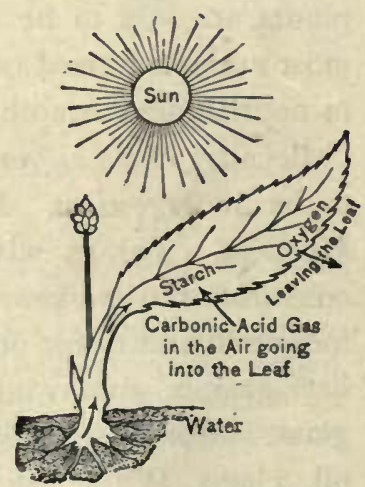

FIG. 2. - A LEAF STORING ENERGY IN SUNLIGHT. 
into organic substances. The oxygen of the carbon dioxid is set free and returns to the air (Fig. 2). Starch, sugar, oil, and woody fiber are examples of substances thus formed. Can you think of any fuel not due to plants?

How Animals obtain Energy. - You have noticed that starch, oil, etc., will burn, or oxidize, that is, unite with the oxygen of the air; thus the sun's energy, stored in these substances, is changed back to heat and motion. The oxidation of oil or sugar may occur in a furnace; it may also occur in the living substance of the active animal.

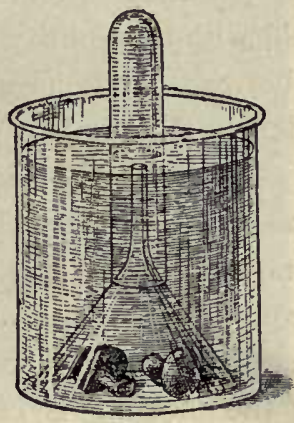

FIG. 3. - Colorless plants, as MUSHROOMS, give off no oxygen.

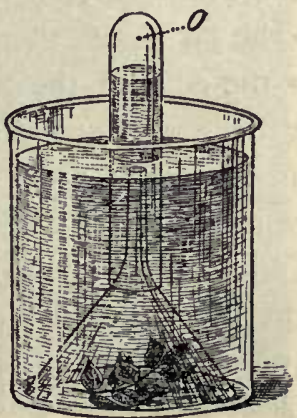

A GREEN LEAF, even after it is cut, gives off oxygen $(O)$ if kept in the sun.

Fortunately for the animals the plants oxidize very little of the substances built up by them, since they do not move about nor need to keep themselves warm. We notice that animals are constantly using plant substances for food, and constantly drawing the air into their bodies. If the sunlight had not enabled the green plant to store up these substances and set free the oxygen (Fig. 3), animals would have no food to eat nor air to breathe; hence we may say that the sunlight is indirectly the source of the life and energy of animals. Mushrooms and other plants without green matter cannot set oxygen free (Fig. 3). 
Experiment to show the Cause of Burning, or Oxidation. - Obtain a large glass bottle (a pickle jar), a short candle, and some matches. Light the candle and put it on a table near the edge, and cover it with the glass jar. The flame slowly smothers and goes out. Why is this? Is the air now in the jar different from that which was in it before the candle was lighted? Some change must have taken place or the candle would continue to burn. To try whether the candle will burn again under the jar without changing the air, slide the jar to the edge of the table and let the candle drop out. Light the candle and slip it up into the jar again, the jar being held with its mouth a little over the edge of the table to receive the candle (Fig. 5). The flame goes out at once. Evidently the air in the jar is not the same as the air outside. Take up the jar and wave it to and fro a few times, so as to remove the old air and admit fresh air. The candle now burns in it with as bright a flame as at first. So we conclude that the candle will not continue to burn unless there is a constant supply of fresh air. The gas formed by the burning is carbon dioxid. It is the gas from which plants extract carbon. (See Plant Biology, Chap. V.) One test for the presence of this gas is that it forms a white, chalky cloud in lime water; another is that it smothers a fire.

Experiment to show that Animals give off Carbon Dioxid. - Place a cardboard over the mouth of a bottle containing pure air. Take a long straw, the hollow stem of a weed, a glass tube, or a sheet of stiff paper rolled into a tube, and pass the tube into the bottle through a hole in the cardboard. Without drawing in a deep breath, send one long breath into the bottle through the tube, emptying the lungs by the breath as nearly as possible (Fig. 4). Next invert the bottle on the table as in the former experiment, 
afterward withdrawing the cardboard. Move the bottle to the edge of the table and pass the lighted candle up into it (Fig. 5). Does the flame go out as quickly as in the former experiment?

If you breathe through a tube into clear lime water, the water turns milky. The effect of the breath on the candle and on the lime water shows that carbon dioxid is continually leaving our bodies in the breath.

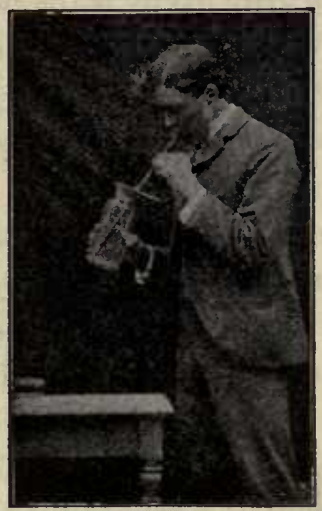

FIG. 4. - Breathing into a bottle.1

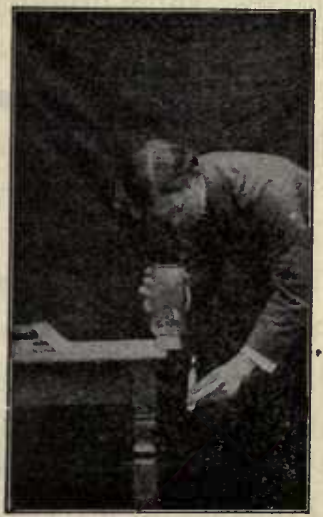

FIG. 5. - Testing the air in the bottle.1

Oxidation and Deoxidation. - The union of oxygen with carbon and other substances, which occurs in fires and in the bodies of animals, is called oxidation. The separation of the oxygen from carbon such as occurs in the leaves of plants is called deoxidation. The first process sets energy free, the other process stores it up. Animals give off carbon dioxid from their lungs or gills, and plants give off oxygen from their leaves. But plants need some energy in growing, so oxidation also occurs in plants, but to a far less extent than in animals. At night, because of the absence of sunlight, no deoxidation is taking place

1 From Coleman's “ Physiology for Beginners," Macmillan Co., N.Y. 
in the plant, but oxidation and growth continue; so at niglut the plant actually breathes out some carbon dioxid. The deepest part of the lungs contains the most carbon dioxid. Why was it necessary to empty the lungs as nearly as possible in the experiment with the candle? Why would first drawing a deep breath interfere with the experiment? Why does closing the draught of a stove, thus shutting off part of the air, lessen the burning? Why does a "firefly" shine brighter at each breath? Why is the pulse and breathing faster in a fever? Very slow in a trance?

The key for understanding any animal is to find how it gets food and oxygen, and how it uses the energy thus obtained to grow, move, avoid its enemies, and get more food. Because it moves, it needs senses to guide it.

The key for understanding a plant is to find how it gets food and sunlight for its growth. It makes little provision against enemies; its food is in reach, so it needs no senses to guide it. The plant is built on the plan of having the nutritive activities near the surface (e.g. absorption by roots; gas exchange in leaves). The animal is built on the plan of having its nutritive activities on the inside (e.g. digestion; breathing).

Cell and Protoplasm. - Both plants and animals are composed of small parts called cells. Cells are usually microscopic in size. They have various shapes, as spherical, flat, cylindrical, fiber-like, star-shaped. The living substance of cells is called protoplasm. It is a stiff, gluey fluid, albuminous in its nature. Every cell has a denser spot or kernel called a nucleus, and in the nucleus is a still smaller speck called a nucleolus. Most cells are denser and tougher on the outside, and are said to have a cell wall, but many cells are naked, or without a wall. Hence the indispensable part of a cell is not the wall but the nucleus, 
and a cell may be defined as a bit of protoplasm containing a nucleus. This definition includes naked cells as well as cells with walls.

One-celled Animals. - There are countless millions of animals and plants the existence of which was not suspected until the invention of the microscope several centuries ago. They are one-celled, and hence microscopic in size. It is believed that the large animals and plants are descended from one-celled animals and plants. In fact, each individual plant or animal begins life as a single cell, called an egg cell, and forms its

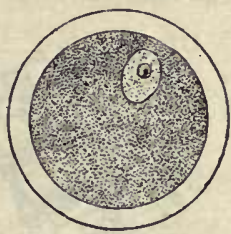

Fig. 6. - Egg cell of mammal with yolk. organs by the subdivision of the egg cell into many cells. An egg cell is shown in Fig. 6, and the first stages in the development of an egg cell are shown in Fig. 7.

The animals to be studied in the first chapter are onecelled animals. To understand them we must learn how
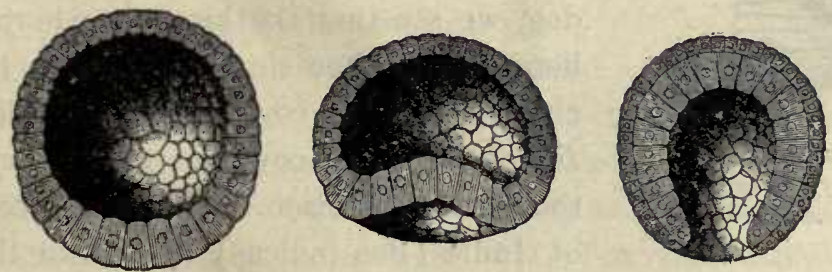

FIG. 7. - Egg cell subdivides into many cells forming a sphere (morula) containing a liquid. A dimple forms and deepens to form the next stage (gastrula).

they eat, breathe, feel, and move. They are called Protozoans (Greek protos, first; zoon, life). All other animals are composed of many cells and are called Metazoans (Greek meta, beyond or after). The cells composing the mucous membrane in man are shown in Fig. 8. The cellular structure of the leaf of a many-celled plant is illustrated in Fig. I. (See also Chap. I, Human Biology.) 
Method of Classifying Animals. - The various animals display differences more or less marked. The question arises, are not some of them more closely related than others? We conclude that they are, since the difference between some animals is very slight, while the difference between others is quite marked.

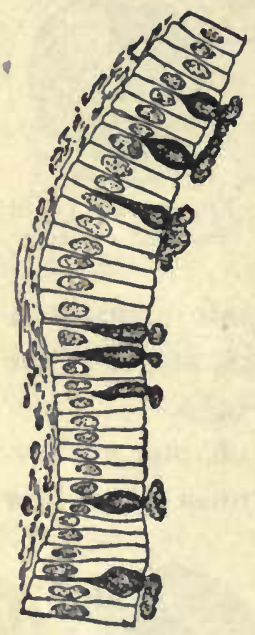

Fig. 8. - Mucous MEMBRANE formed of one layer of cells. A few cells secrete mucus.

To show the different steps in classi. fying an animal, we will take an example, - the cow. Even little children learn to recognize a cow, although individual cows differ somewhat in form, size, color, etc. The varieties of cows, such as short-horn, Jersey, etc., all form one species of animals, having the scientific name taurus. Let us include in a larger group the animals closest akin to a cow. We see a cat, a bison, and a dog; rejecting the cat and the dog, we see that the bison has horns, hoofs, and other similarities. We include it with the cow in a genus called Bos, calling the cow Bos taurus, and the bison, Bos bison. The sacred cow of India (Bos indicus) is so like the cow and buffalo as also to belong in the genus Bos. Why is not the camel, which, like Bos bison, has a hump, placed in the genus Bos?

The Old World buffaloes, - most abundant in Africa and India, - the antelopes, sheep, goats, and several other genera are placed with the genus Bos in a family called the hollow-horned animals.

This family, because of its even number of toes and the habit of chewing the cud, resembles the camel family, 
the deer family, and several other families. These are all placed together in the next higher systematic unit called an order, in this case, the order of ruminants.

The ruminants, because they are covered with hair and nourish the young with milk, are in every essential respect related to the one-toed horses, the beasts of prey, the apes, etc. Hence they are all placed in a more inclusive division of animals, the class called mammals.

All mammals have the skeleton, or support of the body, on the inside, the axis of which is called the vertebral column. This feature also belongs to the classes of reptiles, amphibians, and fishes. It is therefore consistent to unite these classes by a general idea or conception into a great branch of animals called the vertebrates.

Returning from the general to the particular by successive steps, state the branch, class, order, family, genus, and species to which the cow belongs.

The Eight Branches or Sub-kingdoms. - The simplest classification divides the whole animal kingdom into eight branches, named and characterized as follows, beginning with the lowest: I. Protozonss. One-celled. II. Sponges. Many openings. III. Polyps. Circular; cup-like; having only one opening which is both mouth and vent. IV. Echinoderms. Circular; rough-skinned; two openings. V. Mollusks. No skeleton; usually with external shell. VI. VERMEs. Elongate body, no jointed legs. VII. Arthropods. External jointed skeleton; jointed legs. VIII. Vertebrates. Internal jointed skeleton with axis or backbone. 


\section{CHAPTER II}

\section{PROTOZOA (One-celled Animals)}

\section{The Ameba}

Suggestions. - Amebas live in the slime found on submerged stems and leaves in standing water, or in the ooze at the bottom. Water plants may be crowded into a glass dish and allowed to decay, and after about two weeks the ameba may be found in the brown slime scraped from the plants. An ameba culture sometimes lasts only three days. The most abundant supply ever used by the writer was from a bottle of water where some oats were germinating. Use $\frac{1}{5}$ or $\frac{1}{6}$ inch objective, and cover with a thin cover glass. Teachers who object to the use of the compound microscope in a first course should require a most careful study of the figures.

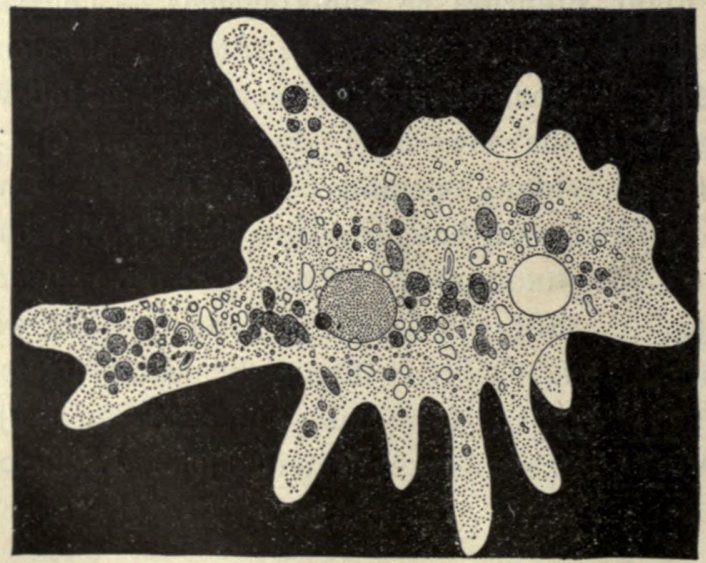

FIG. 9. - AMEBA PROTEUS, much enlarged. 
Form and Structure. - The ameba (also spelled amœba) looks so much like a clear drop of jelly that a beginner cannot be certain that he has found one until it moves. It is a speck of protoplasm (Fig. 9), with a clear outer layer, the ectoplasm; and a granular, internal part, the endoplasm. Is there a distinct line between them ? (Fig. IO.)

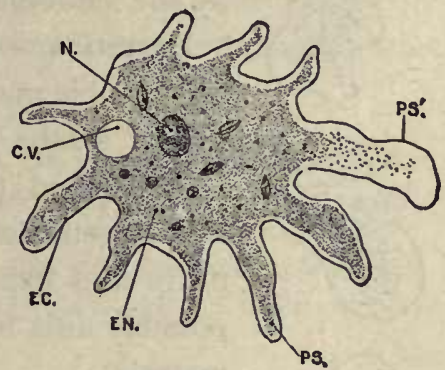

FIG. IO. - AMEBA.

$c v$, contractile vacuole; ec, ectoplasm; ere, endoplasm; $n$, nucleus; $p s$, pseudopod; $p s^{\prime}$, pseudopod forming; ectoplasm protrudes and endoplasm flows into it. and the slender prolongations or pseudopods (Greek, false feet). Does the endoplasm extend into the pseudopods? (Fig. IO.) Are the pseudopods arranged with any regularity?

Sometimes it is possible to see a denser appearing portion, called the nucleus; also a clear space, the contractile vacuole (Fig. 10).

Movements. - Sometimes while the pseudopods are being extended and contracted, the central portion remains
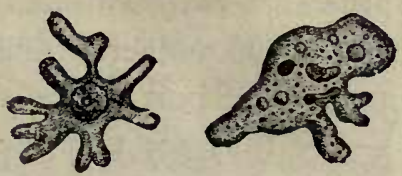

F1G. II. - The same ameba seen at different times. in the same place (this is motion). Usually only one pseudopod is extended, and the body flows into it ; this is locomotion (Fig. II). There is a new foot made for each step.

Feeding. - If the ameba crawls near a food particle, the pseudopod is pressed against it, or a depression occurs (Fig. I2), and the particle is soon embedded in the endoplasm. Often a clear space called a food vacuole is noticed around the food particle. This is the water that is taken in with 
$\therefore$ the particle (Fig. 12). The water and the particle are soon absorbed and assimilated by the endoplasm.

Excretion. - If a particle of sand or other indigestible matter is taken in, it is left behind as the ameba moves on. There is a clear space called the contractile vacuole, which slowly contracts and disappears, then reappears and expands (Figs. 9 and 10). This possibly aids in excreting oxidized or useless material.

Circulation in the ameba consists of the movement of its protoplasmic particles. It lacks special organs of circulation.

Feeling. - Jarring the glass slide seems to be felt, for it causes the activity of the ameba to vary. It does not take in for food every particle that it touches. This may be the beginning of taste, based upon mere chemical affinity. The pseudopods aid in feeling.

Reproduction. - Sometimes an ameba is seen FIG. 12. - THE AMEBA taking food. dividing into two parts. A narrowing takes place in the middle; the nucleus also divides, a part going to each portion (Fig. 13). The mother ameba finally divides into two daughter amebas. Sex is wanting. Source of the Ameba's Energy. - We thus see that the ameba moves without feet, eats without a mouth, digests without a stomach, feels without nerves, and, it should also be stated, breathes without lungs, for oxygen is absorbed from the water by its whole

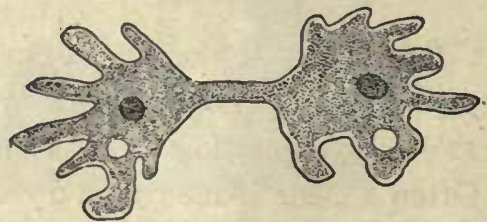

FIG. 13. - AMEBA, dividing. 
surface. Its movements require energy; this, as in all animals, is furnished by the uniting of oxygen with the food. Carbon dioxid and other waste products are formed by the union; these pass off at the surface of the ameba and taint the water with impurities.

Questions. - Why will the ameba die in a very small quantity of water, even though the water contains enough food? Why will it die still quicker if air is excluded from contact with the drop of water?

The ameba never dies of old age. Can it be said to be immortal?

According to the definition of a cell (Chapter $I$ ), is the ameba a unicellular or multicellular animal?

Cysts. - If the water inhabited by a protozoan dries up, it encysts, that is, it forms a tough skin called a cyst. Upon return of better conditions it breaks the cyst and comes out. Encysted protozoans may be blown through the air: this explains their appearance in vessels of water containing suitable food but previously free from protozoans.

\section{The Slipper Animalcule or Paramecium}

SUGGESTIONS. - Stagnant water often contains the paramecium as well as the ameba ; or they may be found in a dish of water containing hay or finely cut clover, after the dish has been allowed to stand in the sun for several days. A white film forming on the surface is a sign of their presence. They may even be seen with the unaided eye as tiny white particles by looking through the side of the dish or jar. Use at first a $\frac{1}{3}$ or $\frac{1}{4}$ in. objective. Restrict their movements by placing cotton fibers beneath the cover glass; then examine with $\frac{1}{5}$ or $\frac{1}{6}$ objective. Otherwise, study figures.

Shape and Structure. - The paramecium's whole body, like the ameba's, is only one cell. It resembles a slipper in shape, but the pointed end is the hind end, the front end being rounded (Fig. 14). The paramecium is propelled by the rapid beating of numerous fine, threadlike append- 
ages on its surface, called cilia (Latin, eyelashes) (Figs.). The cilia, like the pseudopods of the ameba, are merely prolongations of the cell protoplasm,

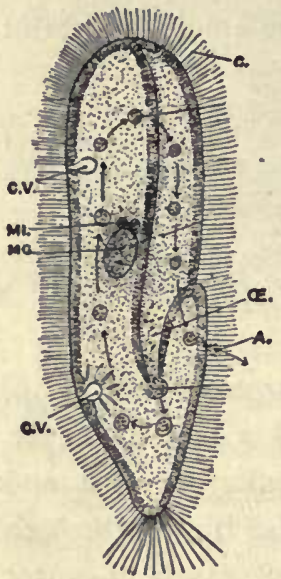

Fig. I4. - PARAMECIUM, showing cilia, $c$.

Two contractile vacuoles, cv; the macronucleus, $m g$; two micronuclei, $m i$; the gullet $(\mathscr{E})$, a food ball forming and ten food balls in their course from gullet to vent, $a$.

but they are permanent. The separation between the outer ectoplasm and the interior granular endoplasm is more marked than in the ameba (Fig. 14).

Nucleus and Vacuoles. - There is a large nucleus called the macronucleus, and beside it a smaller one called the micronucleus. They are hard to see. About one third of the way from each end is a clear, pulsating space (bb. Fig. 15) called the pulsating vacuole. These spaces contract until they disappear, and then reappear, gradually ex-

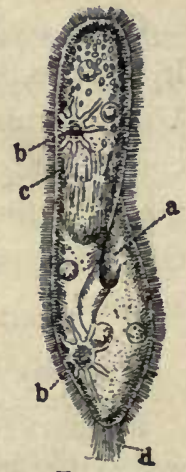

FIG. I5.

panding. Tubes lead from the vacuoles which probably serve to keep the contents of the cell in circulation.

Feeding. - A depression, or groove, is seen on one side, this serves as a mouth (Figs.). A tube which serves as a
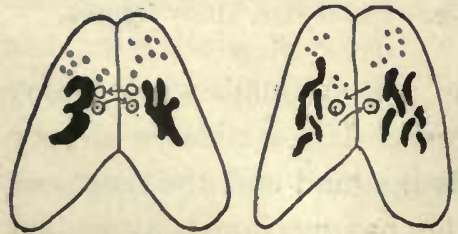

FIG. I6. - Two PARAMEcIA exchanging parts of their nuclei. gullet leads from the mouth-groove to the interior of the cell. The mouth-groove is lined with cilia which sweep food particles inward. The particles accumulate 
in a mass at the inner end of the gullet, become separated from it as a food ball (Fig. 14), and sink into the soft protoplasm of the body. The food balls follow a circular course through the endoplasm, keeping near the ectoplasm.

Reproduction. - This, as in the ameba, is by division, the constriction being in the middle, and part of the nucleus going to each half. Sometimes two individ-

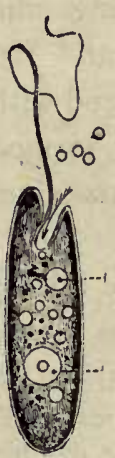

FIG. I8. Euglena. uals come together with their mouth-grooves touching and exchange parts of their nuclei (Fig. 16). They then separate and each divides to form two new individuals.

We thus see that the paramecium, though of only one

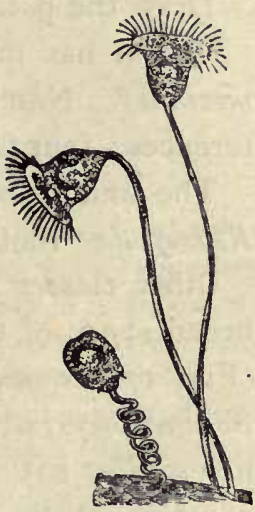

FIG. 17. - VURTICELLA (or bell animalcule), two extended, one withdrawn. cell, is a much more complex and advanced animal than the ameba. The tiny paddles, or cilia, the mouth-groove, etc., have their special duties similar to the specialized organs of the many-celled animals to be studied later.

If time and circumstances allow a prolonged study, several additional facts may be observed by the pupil, e.g. Does the paramecium swim with the same end always foremost, and same side uppermost? Can it move backwards? Avoid obstacles? Change shape in a narrow passage? Does refuse Fig. I9.-SheLL of a Radiolarian.

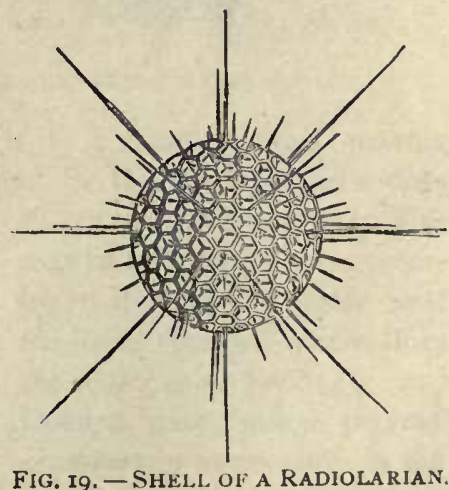


matter leave the body at any particular place? Trace movement of the food particles.

Draw the paramecium.

Which has more permanent parts, the ameba or paramecium? Name two anatomical similarities and three differences; four functional similarities and three differences.

The ameba belongs in the class of protozoans called Rhizopoda "root footed."

Other classes of Protozoans are the Infusorians (in the broad sense of the term), which have many waving cilia (Fig. 17) or one whip-like flagellum (Fig. I8), and the Foraminifers, which possess a calcareous shell pierced with holes (Fig. 19). Much chalky limestone has been formed of their shells. To. which class does the paramecium belong?

Protozoans furnish a large amount of food to the higher animals.

To the Teacher. If plant, animal, and human biology are to be given in one year as planned, and full time allowed for practical work, the portions of the text in small type, as Chapter III, may be omitted or merely read and discussed. Any two of the three parts forming the course may be used for a year's course by using all of the text and spending more time on practical and field work. 


\section{CHAPTER III}

\section{SPONGES}

Suggestions. - In many parts of the United States, fresh-water sponges may, by careful searching, be found growing on rocks and logs in clear water. They are brown, creamy, or greenish in color, and resemble more a cushion-like plant than an animal. They have a characteristic gritty feel. They soon die after removal to an aquarium.

A number of common small bath sponges may be bought and kept for use in studying the skeleton of an ocean sponge. These sponges should not have large holes in the bottom; if so, too much of the sponge has been cut away. A piece of marine sponge preserved in alcohol or formalin may be used for showing the sponge with its flesh in place. Microscopic slides may be used for showing the spicules.

The small fresh-water sponge (Fig. 2I) lacks the more or less vase-

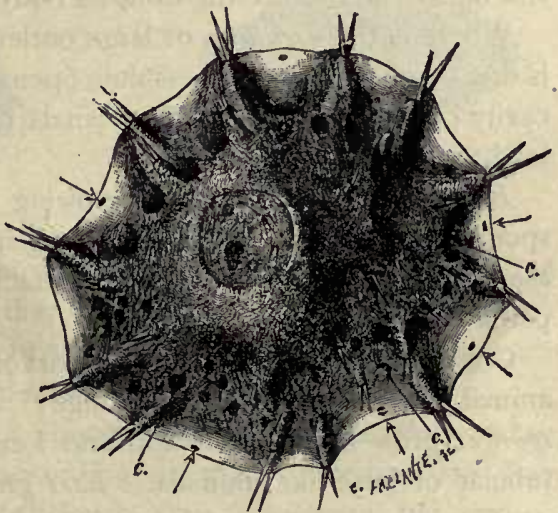

F1G. 21, - FRESH-WATER SPONGE.

like form typical of sponges. It is a rounded mass growing upon a rock or log. As indicated by the arrows, where does

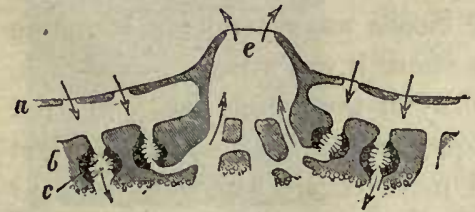

FIG. 22. - SECTION of fresh-water sponge (enlarged).

water enter the sponge? This may be tested by putting coloring matter in the water near the living sponge. Where does the water come out? (Fig. 22.) Does it pass through ciliated chambers in its course? Is the 
surface of the sponge rough or smooth? Do any of the skeletal spicules show on the surface? (Fig. 21.) Does the sponge thin out near its edge?

The egg of this sponge is shown in Fig. 23. It escapes from the parent sponge through the osculum, or large outlet. As in
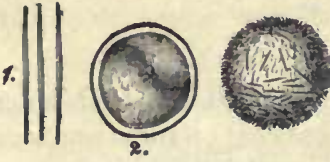

FIG. 23. - EGGS and SPICULES of fresh-water sponge (enlarged).

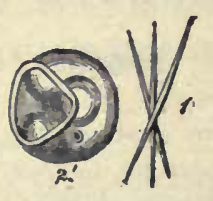
(1) most sponges, the first stage after the egg is ciliated and free-swimming.

\section{Marine Sponges. -} The grantia (Fig. 24) is one of the simplest of marine sponges. What is the shape of grantia? What is its length and diameter? How does the free end differ from the fixed end? Are the spicules projecting from its body few or many?

Where is the osculum, or large outlet? With what is this surrounded? The osculum opens from a central cavity called the cloaca. The canals from the pores lead to the cloaca.

Buds are sometimes seen growing out from the sponge near its base. These are young sponges formed asexually. Later they become detached from the parent sponge.

Commercial "Sponge." — What part of the complete animal remains in the bath sponge? Slow growing sponges grow more at the top and form tall, simple, tubular or vase-like animals. Fast growing sponges

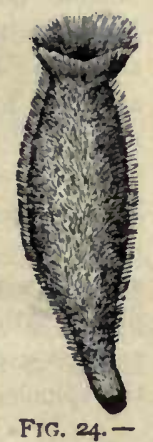

Grantia. grow on all sides at once and form a complicated system of canals, pores, and oscula. Which of these habits of growth do you think

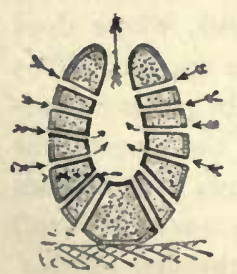

fig. 25. - Plan of a sponge. belonged to the bath sponge? Is there a large hole in the base of your specimen? If so, this is because the cloaca was reached in trimming the lower part where it was attached to a rock. Test the elasticity of the sponge when dry and when wet by squeezing it. Is it softer when wet or dry? Is it more elastic when wet or dry? How many oscula does your specimen have? How many inhalent pores to a square inch? 
Using a probe (a wire with knob at end, or small hat pin), try to trace the canals from the pores to the cavities inside.

Do the fibers of the sponge appear to interlace, or join, according to any system? Do you see any fringe-like growths on the surface which show that new tubes are beginning to form? Was the sponge growing faster at the top, on the sides, or near the bottom?

Burn a bit of the sponge ; from the odor, what would you judge of its composition?

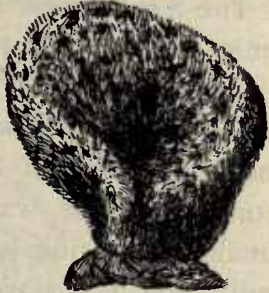

FIG. 26. - Bath Sponge. Is the inner cavity more conspicuous in a simple sponge or in a compound sponge like the bath sponge? Is the bath sponge

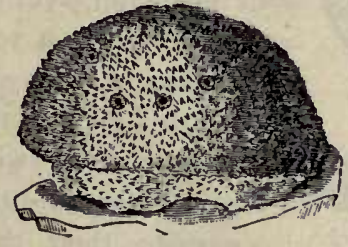

FIG. 27. - Bath Sponge.

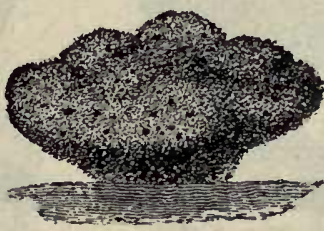

FIG. 28. - Bath Sponge.

branched or lobed? Compare a number of specimens (Figs. 26, 27,28 ) and decide whether the common sponge has a typical

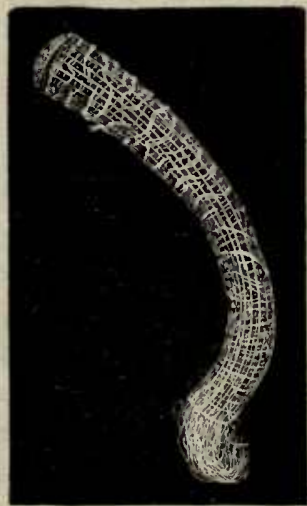

FIG. 29. - Skeleton of a glass sponge. shape. What features do their forms possess in common?

Sponges are divided into three classes, according as their skeletons are flinty (silicious), limy (calcareous), or horny.

Some of the silicious sponges have skeletons that resemble spun glass in their delicacy. Flint is chemically nearly the same as glass. The skeleton shown in Fig. 29 is that of a glass sponge which lives near the Philippine Islands.

'The horny' sponges do not have spicules in their skeletons, as the flinty and limy sponges have, but the skeleton is composed of interweaving fibers of 
spongin, a durable substance of the same chemical nature as silk. (Figs. 30 and $3 \mathrm{r}$ ).

The limy sponges have skeletons made of numerous spicules of lime. The three-rayed spicule is the commonest form.

The commercial sponge, seen as it grows in the ocean, appears: as a roundish mass with a smooth, dark exterior, and having about: the consistency of beef liver. Several large openings (oscula), from which the water flows, are visible on the upper surface. Smaller holes (inhalent pores - many of them so small as to be: indistinguishable) are on the sides. If the sponge is disturbed,

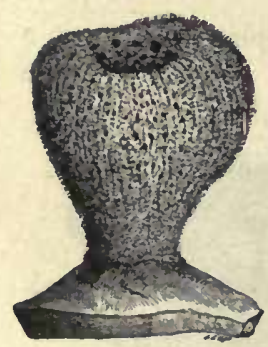

FiG. 3०. - A horny sponge.

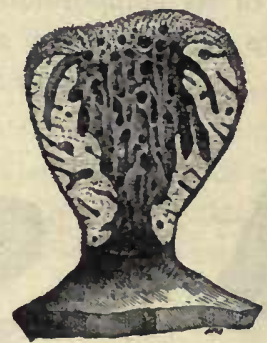

FiG. 3I. - Section of horny sponge. the smaller holes, and: perhaps the larger. ones, will close.

The outer layer of cells serves as a sort. of skin. Since so, much of the sponge: is in contact with: water, most of the cells do their own: breathing, or absorption of oxygen and giving off of carbon dioxid. Nutriment is. passed on from the surface cells to nourish the rest of the body.

Reproduction. - Egg-cells and sperm-cells are produced by certain cells along the canals. The egg-cell, after it is fertilized: by the sperm-cell, begins to divide and form new cells, some of which possess cilia. The embryo sponge passes out at an osculum. By the vibration of the cilia, it swims about for a while. It afterwards settles down with the one end attached to the ocean: floor and remains fixed for the rest of its life. The other end develops oscula. Some of the cilia continue to vibrate and create currents which bring food and oxygen.

The cilia in many species are found only in cavities called ciliated chambers. (Figs. 22, 32.) There are no distinct organs in the sponge and there is very little specialization of cells. The ciliated cells and the reproductive cells are the only specialized cells. The sponges were for a long time considered as colonies of separate one-celled animals classed as protozoans. They are, 
without doubt, many-celled animals. If a living sponge is cut into pieces, each piece will grow and form a complete sponge.

That the sponge is not a colony of one-celled animals, each like an ameba, but is a many-celled animal, will be realized by examining Fig. 32, which shows a bit of sponge highly magnified. A sponge may be conceived as having developed from a one-celled animal as follows: Several one-celled animals happened to live side by side; each possessed a thread-like flagellum (E, Fig. 32) or whip-lash for striking the water. By lashing the water, they caused a stronger current (Fig. 25) than protozoans living singly could cause. Thus they obtained more food and multiplied more rapidly than those living alone. The habit of working together left its impress on the cells and was transmitted by inheritance.

Cell joined to cell formed a ring; ring

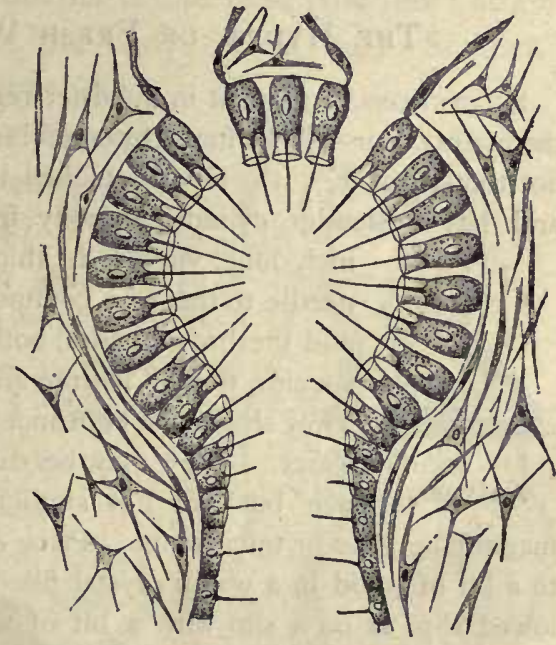

FIG. 32. - Microscopic plan of ciliated chamber. Each cell lining the chamber has a nucleus, a whip-lash, and a collar around base of whip-lash. Question: State two uses of whip-lash. joined to ring formed a tube which was still more effective than a ring in lashing the water into a current and bringing fresh food (particles of dead plants and animals) and oxygen.

Few animals eat sponges; possibly because spicules, or fibers, are found throughout the flesh, or because the taste and odor are unpleasant enough to protect them. Small animals sometimes crawl into sponges to hide. One sponge grows upon shells inhabited by hermit crabs. Moving of the shell from place to place is an advantage to the sponge, while the sponge conceals and thus protects the crab.

Special Report: Sponge "Fisheries." (Localities; how sponges are taken, cleaned, dried, shipped, and sold.) 


\section{CHAPTER IV}

\section{POLYPS (CUPLIKE ANIMALS)}

\section{The Hydra, or Fresh Water Polyp}

Suggestions. - Except in the drier regions of the United States, the hydra can usually be found by careful search in fresh water ponds not too stagnant. It is found attached to stones, sticks, or leaves, and has a slender, cylindrical body from a quarter to half an

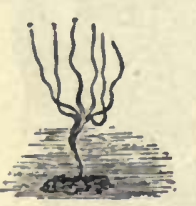

Fig. 33. -

A HYDRA. inch long, varying in thickness from that of a fine needle to that of a conmon pin. The green hydra and the brown hydra, both very small, are common species, though hydras are often white or colorless. They should be kept in a large glass dish filled with water. They may be distinguished by the naked eye but are not studied satisfactorily without a magnifying glass or microscope. Place a living specimen attached to a bit of wood in a watch crystal filled with water, or on a hollowed slip, or on a slip with a bit of weed to support the cover glass, and examine with hand lens or lowest power of microscope. Prepared microscopical sections, both transverse and longitudinal, may be bought of dealers in microscopic supplies. One is shown in Fig. 39.

Is the hy. dra's body round or twosided? (Fig.

\section{5.) What is}

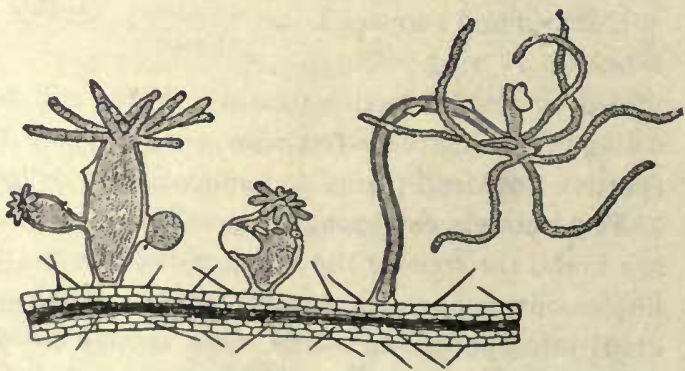

FIG. 34. - Forms assumed by Hydra.

its general shape? Does one individual keep the same shape? (Fig. 34.) How does the length of the thread- 
like tentacles compare with the length of the hydra's body? About how many tentacles are on a hydra's body? Do all have the same number of tentacles? Are the tentacles knotty or smooth? (Fig. 35.) The hydra is usually extended and slender; sometimes it is contracted and rounded. In which of these conditions is the base (the foot) larger around than the rest of the body? (Fig. 34.) Smaller? How many openings into the body are visible? Is there a depression or an eminence at the base of the tentacles? For what is the opening on top of the body probably used? Why are the tentacles placed at the top of the hydra's body? Does the mouth have the most convenient location possible?

The conical projection bearing the mouth is called hypostome (Fig. 34). The mouth opens into the digestive cavity. Is this the same as the general

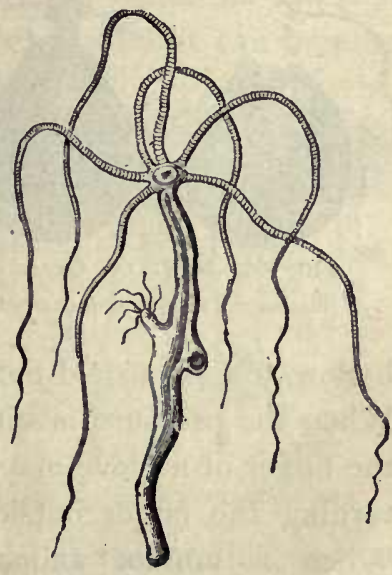

FIG. 35. - HYDRA (much enlarged). body cavity, or does the stomach have a wall distinct from the body cavity? How far down does the body cavity extend? Does it extend up into the tentacles? (Fig. 39.)

If a tentacle is touched, what happens? Is the body ever bent? Which is more sensitive, the columnar body or the tentacles? In searching for hydras would you be more likely to find the tentacles extended or drawn in? Is the hypostome ever extended or drawn in? (Fig. 34.)

Locomotion. - The round surface, or disk, by which the hydra is attached, is called its foot. Can you move on one foot without hopping? The hydra moves by alter- 
nately elongating and rounding the foot. Can you discover other ways by which it moves? Does the hydra always stand upon its foot?

Lasso Cells. - Upon the tentacles (Fig. 35) are numerous cells provided each with a thread-like process (Fig. 36)

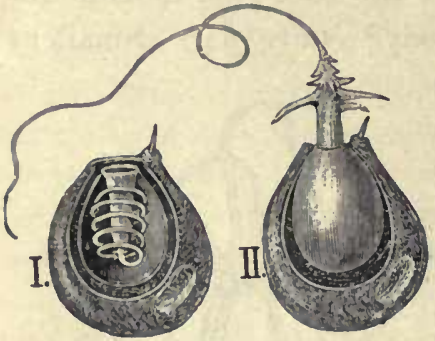

Fig. 36. - NetTling Cell.

II. discharged, and 1, not discharged. which lies coiled within the cell, but which may be thrown out upon a water flea, or other minute animal that comes in reach. The touch of the lasso paralyzes the prey (Fig. 37). These cells are variously called lasso cells, nettling cells, or thread cells. The thread is hollow and is pushed out by the pressure of liquid within. When the pressure is withdrawn the thread goes back as the finger of a glove may be turned back into the glove by turning the finger outside in. When a minute animal, or other particle of food comes in contact with a tentacle, how does the tentacle get the food to the mouth? By bending and bringing the end to the mouth, or by shortening and changing its form, or in both ways? (Fig. 34, C.) Do the neighboring tentacles seem to bend over to assist a tentacle in securing prey? (Fig. 34, C.)

Digestion. - The food particles break up before remaining

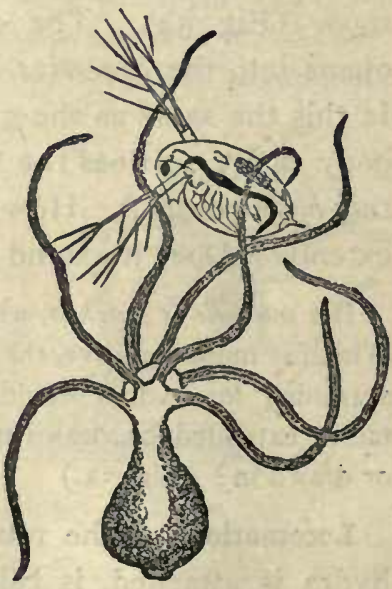

FIG. 37.- HYDRA capturing a water flea. 
long in the stomach, and the nutritive part is absorbed by the lining cells, or endoderm (Fig. 39). The indigestible remnants go out through the mouth. The hydra is not provided with a special vent. Why could the vent not be situated at the end opposite the mouth?

Circulation and Respiration. - Does water have free access to the body cavity? Does the hydra have few or nearly all of its cells exposed to the water in which it lives? From its structure, decide whether it can breathe like a sponge or whether special respiratory cells are necessary to supply it with oxygen and give off carbon dioxid. Blood vessels are unnecessary for transferring oxygen and food from cell to cell.

Reproduction. - Do you see any swellings upon the

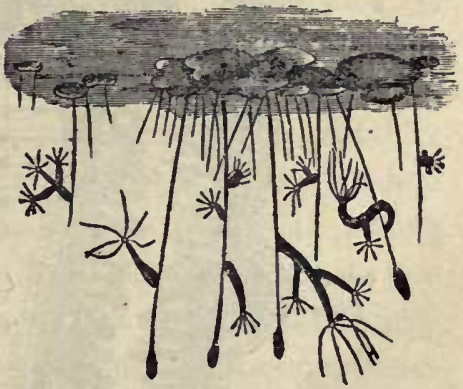

FIG. 38.- HYDRAS on pondweed. side of the hydra? (Fig. 34, A.) If the swelling is near the tentacles, it is a spermary; if near the base it is an ovary. A sperm coalesces with or fertilizes the ovum after the ovum is exposed by the breaking of the ovary wall. Sometimes the sperm from one hydra unites with the oyum of another hydra. This is called cross-fertilization. The same term is applied to the process in plants when the male element, developed in the pollen of the flower, unites with the female element of the ovule of the flower on another plant. The hydra, like most plants and some other animals, is bermaphrodite, that is to say, both sperms and ova are produced by one individual. In the autumn, eggs are produced with hard shells to withstand the cold until spring. Sexual reproduction takes place when food is 
scarce. Asexual generation (by budding) is common with the hydra when food supply is abundant. After the bud

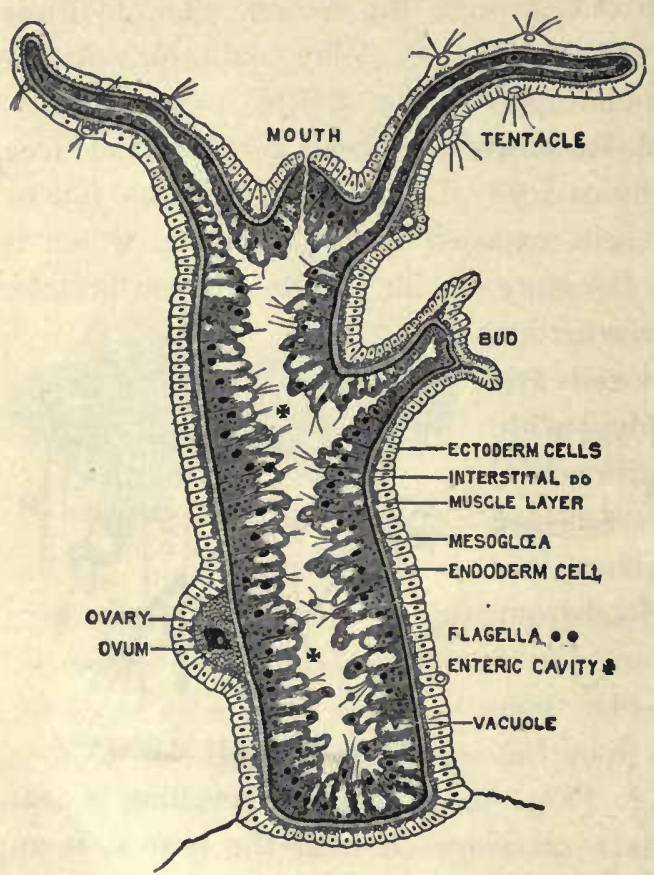

F1G. 39. - Longitudinal section of hydra (microscopic and diagrammatic). grows to a certain size, the outer layer of cells at the base of the bud constricts and the young hydra is detached.

Compare the sponge and the hydra in the following respects: - many celled, or one celled; obtaining food ; breathing; tubes and cavities; openings ; reproduction; locomotion. Which ranks higher

among the metazoa? The metazoa, or many celled animals, include all animals except which branch?

Figure 39 is a microscopic view of a vertical section of a hydra to show the structure of the body wall. There is an outer layer called the ectoderm, and an inner layer called the endoderm. There is also a thin supporting layer (black in the figure) called the mesoglea. The mesoglea is the thinnest layer. Are the cells larger in the endoderm or the ectoderm? Do both layers of cells assist in forming the reproductive bud? The ectoderm cells end on the inside in contractile tails which form a thin line and have the effect of muscle fibers. They serve the hydra for its remarkable changes of shape. When the hydra is cut in pieces, each piece makes a complete hydra, provided it contains both endoderm and ectoderm. 
In what ways does the hydra show "division of labor"? Answer this by explaining the classes of cells specialized to serve a different purpose. Which cells of the hydra are least specialized? In what particulars is the plan of the hydra different from that of a simple sponge? An ingenious naturalist living more than a century ago, asserted that it made no difference to the hydra whether the ectoderm or the endoderm layer were outside or inside, - that it could digest equally well with either layer. He allowed a hydra to swallow a worm attached to a thread, and then by gently pulling in the thread, turned the hydra inside out. More recently a Japanese naturalist showed that the hydra could easily be turned inside out, but he also found that when left to itself it soon reversed matters and returned to its natural condition, that the cells are really specialized and each layer can do its own work and no other.

Habits. - The hydra's whole body is a hollow bag, the cavity extending even into the tentacles. The tentacles may increase in number as the hydra grows but seldom exceed eight. The hydra has more active motion than locomotion. It seldom moves from its place, but its tentacles are constantly bending, straightening, contracting, and expanding. The body is also usually in motion, bending from one side to another. When the tentacles approach the mouth with captured prey, the mouth (invisible. without a hand lens) opens widely, showing five lobes or lips, and the booty is soon tucked within. A hydra can swallow an animal larger in diameter than itself.

The endoderm cells have ameboid motion, that is, they extend pseudopods. They also resemble amebas in the power of intra-cellular digestion; that is, they absorb the harder particles of food and digest them afterwards, rejecting the indigestible portions. Some of these cells have flagella (see Fig. 39) which keep the fluid of the cavity in constant motion.

Sometimes the hydra moves after the manner of a small caterpillar called a "measuring worm," that is, it takes hold first by the foot, then by the tentacles, looping its 


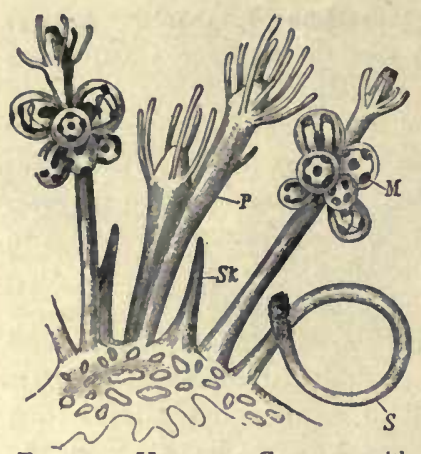

FIG. 40. - HYDROID Colony, with nutritive $(P)$ reproductive $(M)$ and defensive $(S)$ hydranths.

body at each step. Sometimes the body goes end over end in slow somersaults.

The length of the extended hydra may reach one half inch. When touched, both tentacles and body contract until it looks to the unaided eye like a round speck of jelly. This shows sensibility, and a few small star-shaped cells are believed to be nerve cells, but the hydra has not a nervous system. Hydras show their liking for light by moving to the side of the vessel or aquarium whence the light comes.

\section{The Branch Polyps} (sometimes called Colenterata). - The hydra is the only fresh water representative of this great branch of the animal kingdom. This branch is characterized by its members having only one opening to the body. The polyps also include the salt water animals called hydroids, jelly. fishes, and coral polyps.

Hydroids. - Figure 40 shows a hydroid, or group of hydra-like growths, one of which

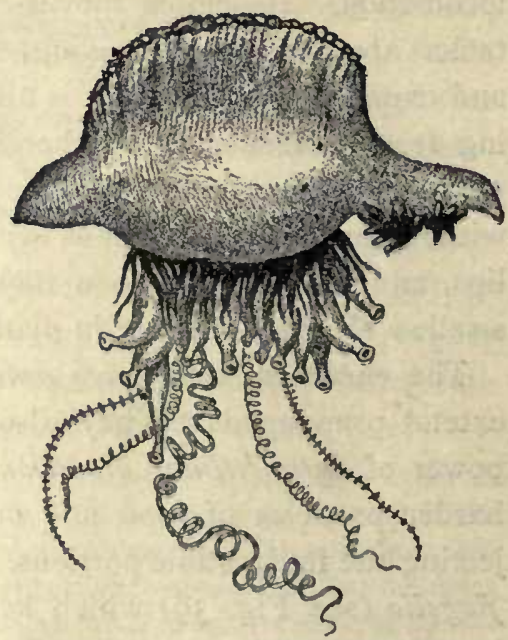

Fig. 4I. - "Portuguese MAN-O'-War" (compare with Fig. 40). A floating hydroid colony with long, stinging (and sensory) streamers. Troublesome to bathers in Gulf of Mexico. Notice balloon-like float. 
eats and digests for the group, another defends by nettling cells, another produces eggs. Each hydra-like part of a hydroid is called a hydranth. Sometimes the buds on the hydra remain attached so long that a bud forms upon the first bud. Thus three generations are represented in one organism. Such growths show us that it is not always easy to tell what constitutes an individual animal. Hydroids may be conceived to have been developed by the failure of budding hydras to separate from the parent, and by

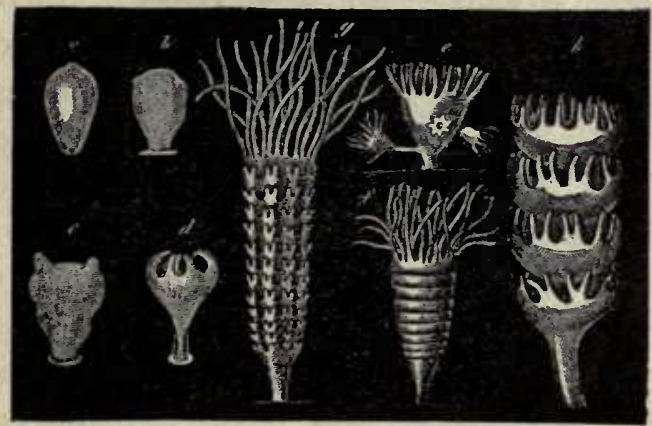

FIG. 42. - The formation of many free swimming jellyfishes from one fixed hydra-like form. The saucer-like parts $(h)$ turn over after they separate and become like Fig. 43 or 44 . Letters show sequence of diagrams.

the gradual formation of the habit of living together and assisting each other. When each hydranth of the hydroid devoted itself to a special function of digestion, defense, or reproduction, this group lived longer and prospered; more eggs were formed, and the habits of the group were transmitted to a more numerous progeny than were the habits of a group where members worked more independently of each other.

As the sponge is a simple example of the devotion of special cells to special purposes, the hydroid is a primitive and simple example of the occurrence of organs, that is of special parts of the body set aside for a special work. 
How many mature hydranths are seen in the hydroid shown in Fig. 40? Why are the defensive hydranths

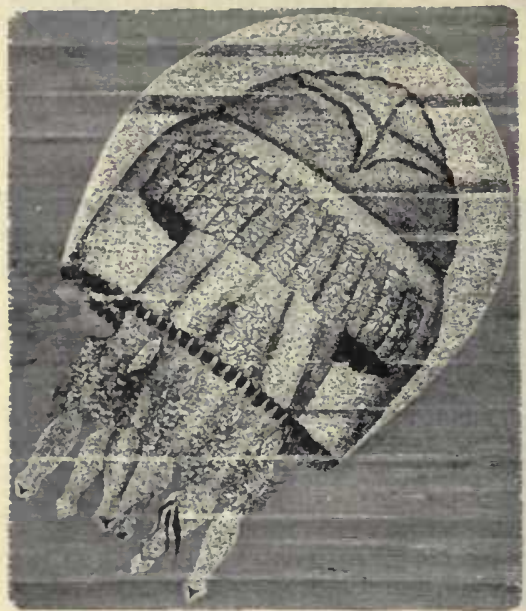

FIG. 43 -A JeLLyFISH. on the outside of the colony? Which hydranths have no tentacles? Why not?

Jellyfish. - Alternation of Generations. Medusa. - With some species of hydroids, a very curious thing happens. - The hydranth that is to produce the eggs falls off and becomes independent of the colony. More surprising still, its appearance changes entirely and instead of being hydra-like, it becomes the large and complex creature called jellyfish (Fig. 43). But the egg of the jellyfish produces a small hydra-like animal which gives rise by budding to a hydroid, and the cycle is complete.

The bud (or reproductive hydranth) of the hydroid

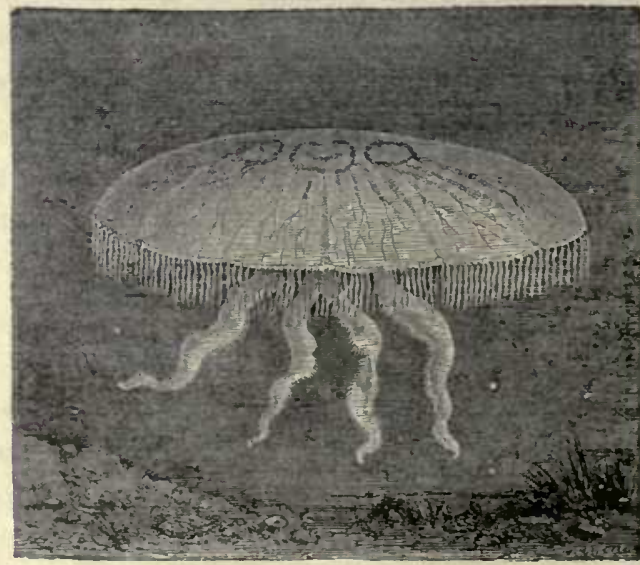

FIG. 44. - A JELLYFISH (medusa). 
does not produce a hydroid, but a jellyfish; the egg of the jellyfish does not produce a jellyfish, but a hydroid. This is called by zoologists, alternation of generations. A complete individual is the life from the germination of one egg to the production of another. So that an "individual" consists of a hydroid colony fixed in one place together with all the jellyfish produced from its buds, and which may now be floating miles away from it in the ocean. Bathers in the surf are sometimes touched and stung by the long, streamer-like tentacles of the jellyfish. These, like the tentacles of the hydra, have nettling cells (Fig. 4I).

The umbrella-shaped free swinming jellyfish is called a medusa (Fig. 44).

Coral Polyps. - Some of the salt water relatives of the hydra produce buds which remain attached to the parent without, however, becoming different from the parent in any way.

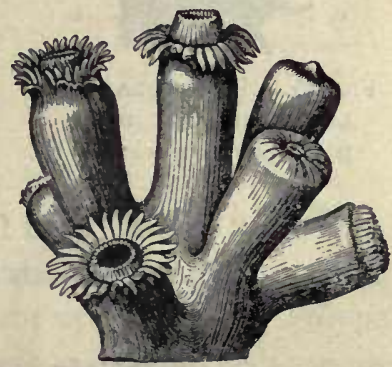

FIG. 45.-CoRAL Polyps (tentacles, a muliple of six). Notice hypostome.

The coral polyps and corallines are examples of colonies of this kind, possessing a common stalk which is formed as the process of multiplication goes on. In the case of coral polyps, the separate animals and the flesh connecting them secrete within themselves a hard, limy, supporting structure known as coral. In some species, the coral, or stony part, is so developed that the polyp seems to be inserted in the coral, into which it withdraws itself for partial protection (Fig. 45).

The corallines secrete a smooth stalk which affords no protection, but they also secrete a coating or sheath which incloses both themselves and the stalk. The 
coating has apertures through which the polyps protrude in order to feed when no danger is near (Fig. 46).

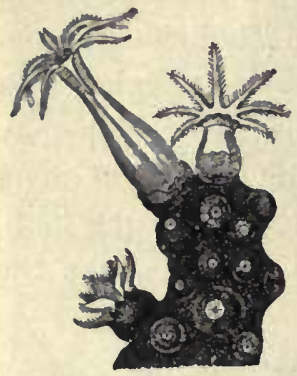

FiG. 46. - RED CORALI.INE with crust and polyps (eight tentacles).

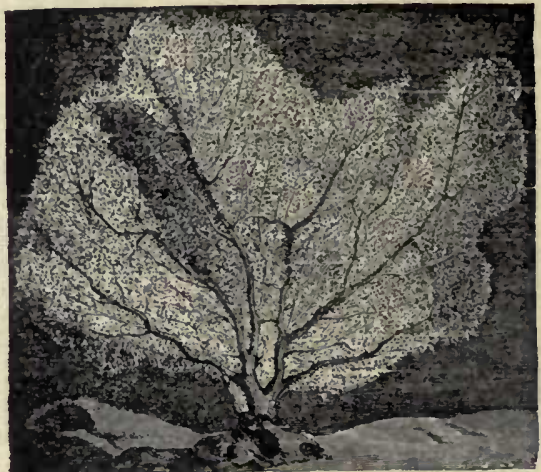

FIG. 47. - SEA FAN (a coralline).

The red "corals" used for jewelry are bits of stalks of corallines. The corallines (Figs. 47,48 ) are not so abundant

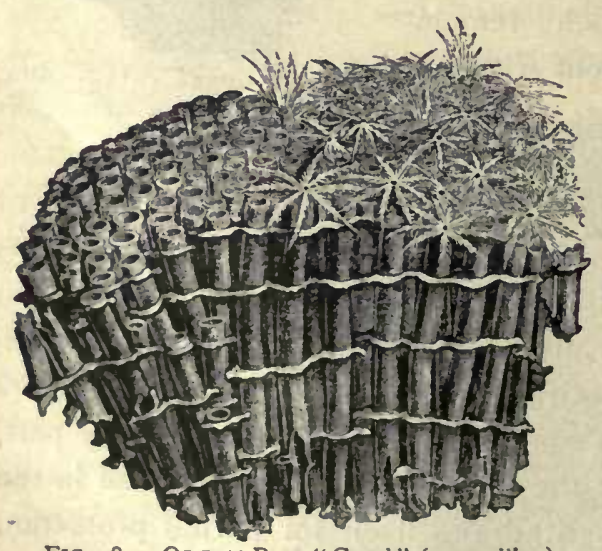

FIG. 48. - ORGaN PIPE "Coral" (a coralline). nor so important as the coral polyps (Figs. 45, 49). Colonies of coral polyps grow in countless numbers in the tropical seas. The coral formed by successive colonies of polyps accumulates and builds up many islands and important additions to continents. The Florida "keys," or islands, and the southern part of the mainland of Florida were so formed. 
The Sea Anemone, like the coral polyp, lives in the sea, but like the fresh water hydra, it deposits no limy support for its body. The anemone is much larger than the

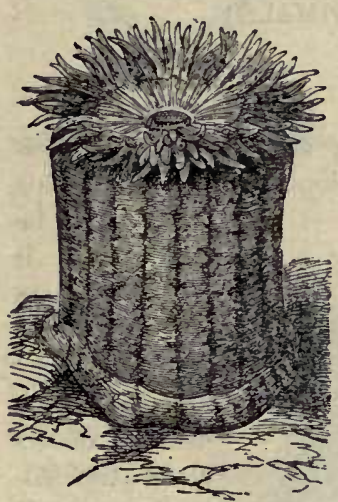

FIG. 50. - SEA ANEMONE. hydra and most coral p o l y p s, many species attaining a height of s e veral inches. It does not form colo-

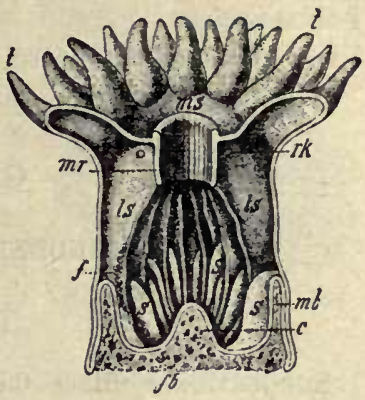

FIG. 49. - UPRIGHT CUT through coral polyp $\times 4$. $m s$, mouth; ìr, gullet; $l s$, ls, fleshy partitions (mesenteries) extending from outer body wall to gullet (to increase absorbing surface); $s, s$, shorter partitions; $m b$, $f b$, stony support (of lime, called coral); $t$, tentacles.

nies. When its arms are drawn in, it looks like a large knob of shiny but opaque jelly. Polyps used to be called zoophytes (plant-animals), because of their flower-like appearance (Figs. 50, 5I).

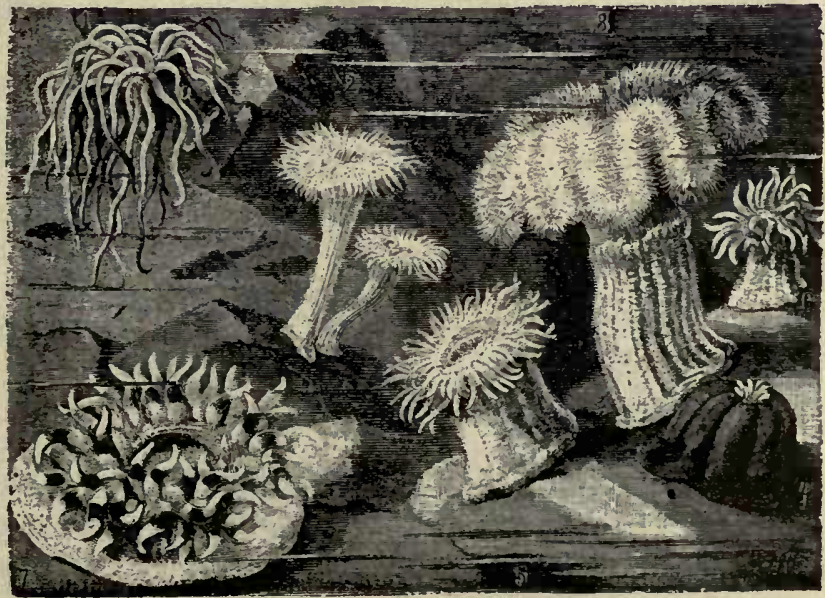




\section{CHAPTER V \\ ECHINODERMS (SPINY ANIMALS) \\ The STARFish}

Suggestions. Since the echinoderms are aberrant though interesting forms not in the regular line of development of animals, this

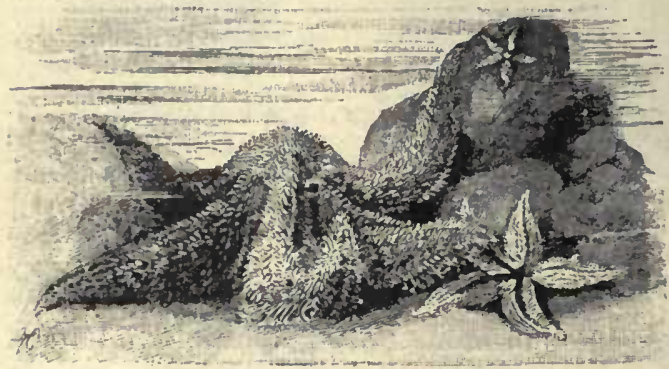

FIG. 52. - Starfish on a rocky shore. chapter may be omitted if it is desired to shorten the course. - The common starfish occurs along the Atlantic coast. It is captured by wading along the shore when the tide is out.

It is killed by immersion in warm, fresh water. Specimens are usually preserved in 4 per cent formalin. Dried starfish and sea urchins are also useful. A living starfish kept in a pail of salt water will be instructive.

\section{External}

Starfish are usually brown or yellow. Why?

Fig. 52.) Has it a head or tail? Right and left sides? What is the shape of the disk, or part which bears the five arms or rays? (Fig. 53.) Does the body as a whole have symmetry on two sides of a line (bilateral symmetry), or around a point (radial symmetry)? Do the separate rays have 
bilateral symmetry? The skeleton consists of limy plates embedded in the tough skin (Fig. 54). Is the skin rough or smooth? Hard or soft? Are the projections (or spines) in the skin long or short? The skin is

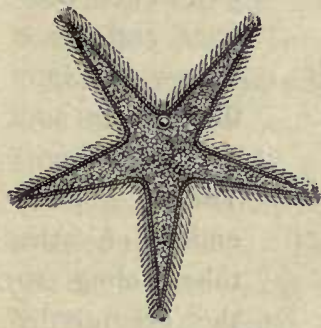

FIG. 55. - Starfish (showing MADREPORITE).

hardened by the limy plates, except around the mouth, which is at the center of

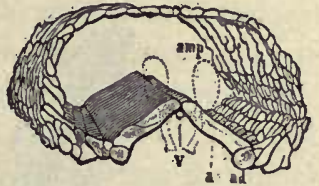

FIG. 54. - LiMy PLATES in portion of a ray. the lower side and surrounded by a membrane. Which is rougher, the mouth side, (oral side) or the opposite (aboral side)? Which side is more nearly flat? The vent is at or near the center of the disk on the aboral surface. It is usually very small and sometimes absent. Why a vent is not of much use will be understood after learning how the starfish takes food.

An organ peculiar to animals of this branch, and called the madreporic plate, or madreporite, is found on the aboral surface between the bases of two rays (Fig. 55). It is wartlike, and usually white or red. This plate is a sieve; the small openings keep out sand but allow water to filter through.

Movements : the Water-tube System. - The water, which is filtered through the perforated madreporite, is needed to supply a system of canals (Fig. 56). The madreporite opens into a canal called the stone canal, the wall of which is hardened by the same kind of material as that found in the skin. The stone canal leads to the ring canal which surrounds the mouth (Fig. $5^{6}$ ). The ring

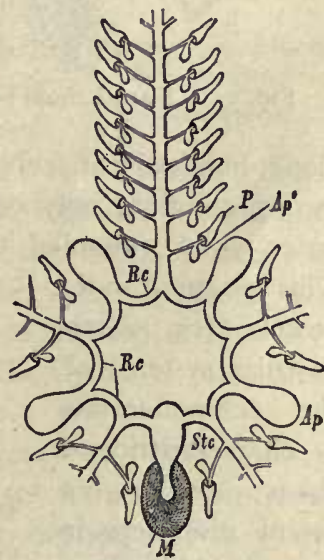

FIG. 56. - WATER tube SYSTEM of starfish. $m$, madreporite; stc, stone canal; $a p$, ampulla. canal sends radial canals into each ray to supply the double row of tube feet found in the groove at the lower side of each ray (Fig. 57). Because of their arrangement in rows, the feet are 
also called ambulacral feet (Latin ambulacra, "forest walks"). There is a water holder (ampulla), or muscular water bulb at the

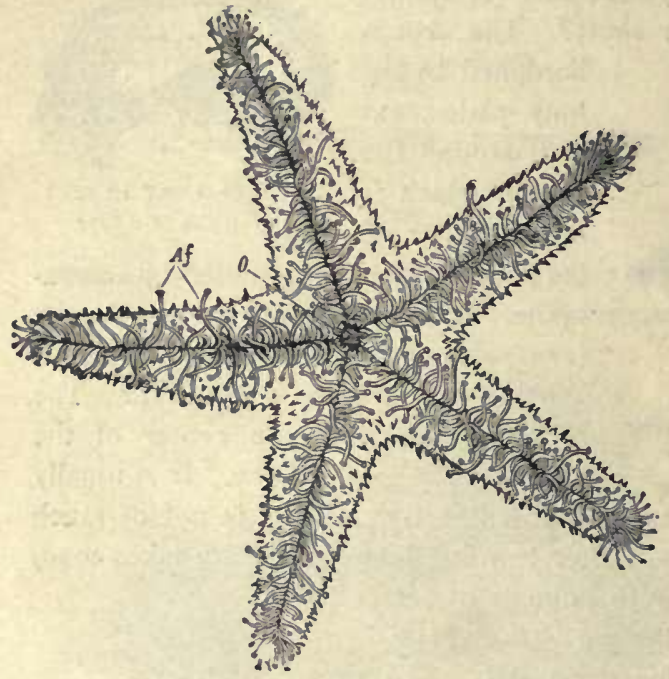

FiG. 57. - Starfish, from below; tube feet extended.

base of each tube foot (Fig. 58). These contract and force the water into the tube feet andl extend them. The cuplike: ends of the: tubes cling to the ground by: suction. The feet contain delicate museles. by which they. contract and' shorten. Thus the animal pulls itself slowly along, hundreds of feet acting together. The tube feet, for their own protection, may contract and retire into the groove, the water which extended them being sent back into the ampulla. This system of water vessels (or watervascular system) of the echinodermata is characteristic of them; i.e. is not found elsewhere in the animal kingdom. The grooves and the plates on each side of them occupy the

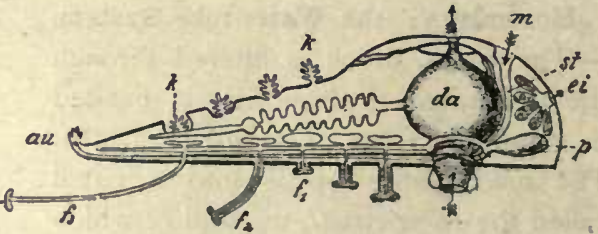

FIG. 58. - SECTION OF ONE RAY and central portion of staifish.

$f_{1}, f_{2}, f_{3}$, tube feet more or less extended; $a w$, eye spot; $k$, gills; $d a$, stomach; $m$, madreporite; st, stone canal: $p$, ampulla: ei, ovary.

ambulacral areas. The rows of spines on each side of the grooves are freely movable. (What advantage?) The spines on the aboral surface are not freely movable. 
Respiration. - The system of water vessels serves the additional purpose of bringing water containing oxygen into contact with various parts of the body, and the starfish was formerly thought to have no special respiratory organs. However there are holes in the aboral wall through which the folds of the delicate lining membrane protrude. These are now supposed to be gills ( $k$, Fig. 58).

The nervous system is so close to the aboral surface that much of it is visible without dissection. Its chief parts are a nerve ring around the mouth, which sends off a branch along each ray. These branches may be seen by separating the rows of tube feet. They end in a pigmented cell at the end of each ray called the eye-spot.

The food of starfish consists of such animals as crabs, snails, and oysters. When the prey is too large to be taken into the mouth, the starfish turns its stomach inside out over the prey (Fig. 59). After the shells separate, the stomach is applied to the soft digestible parts. After the animal is eaten, the stomach is retracted. This odd way of eating is very economical to its digestive powers, for only

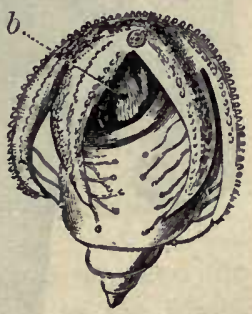

FIG. 59. - Starfish eating a sea snail. $b$, stomach everted. that part of the food which can be digested and absorbed is taken into the body. Only the lower part of the stomach is wide and extensible. The upper portion (next to the aboral surface) is not so wide. This portion receives the secretion from five pairs of digestive glands, a pair of which is situated in each ray. Jaws and teeth are absent. (Why?) The vent is sometimes wanting. Why?

Reproduction. - There is a pair of ovaries at the base of each ray of the female starfish (Fig. $5^{8}$ ). The spermaries of the male have the same position and form as the ovaries, but they are lighter colored, usually white. ${ }^{1}$

Regeneration after Mutilation. - If a starfish loses one or more rays, they are replaced by growth. Only a very ignorant oysterman, angry at the depredations of starfish upon his oyster beds,

${ }^{1}$ The sperm cells and egg cells are poured out into the water by the adults, and the sperm cell, which, like nearly all sperm cells, has a vibratory, taillike flagellum to propel it, reaches and fertilizes the egg cell, 
would chop starfish to pieces, as this only serves to multiply them. This power simulates multiplication by division in the simplest animals.

Steps in Advance of Lower Branches. - The starfish and other echinodermata have a more developed nervous system, sensory organs, and digestion, than forms previously studied; most dis-

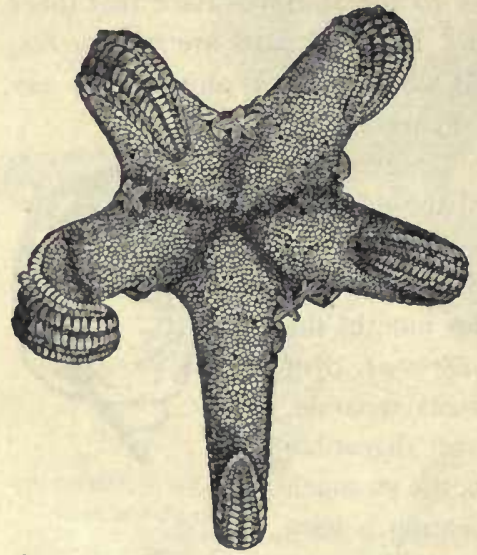

FIG. 60. - Young starfish crawling upon their mother. (Challenger Reports.) tinctive of all, they have a body cavity distinct from the food cavity. The digestive glands, reproductive glands, and the fluid which serves imperfectly for blood, are in the body cavity. There is no heart or blood vessels. The motions of the stomach and the bending of the rays give motion to this fluid in the body cavity. It cannot be called blood, but it contains white blood corpuscles.

The starfish when first hatched is an actively swimming bilateral animal, but it soon becomes starlike (Fig. 60). The limy plates of the starfish belong neither to the outer nor inner layer (endoderm and ectoderm) of the body wall, but to a third or middle layer (mesoderm) ; for echinoderms, like the polyps, belong to the three-layered animals. In this its skeleton differs from the shell of a crawfish, which is formed by the hardening of the skin itself.

Protective Coloration. - Starfish are brown or yellow. This makes them inconspicuous on the brown rocks or yellow sands of the seashore. This is an example of protective coloration.

\section{The Sea Urchin}

External Features. - What is the shape of the body? What kind of symmetry has it? Do you find the oral (or mouth) surface? The aboral surface? Where is the body flattened? What is the shape of the spines? What is their use? How are the tube 
feet arranged? Where do the rows begin and end? Would you think a sea urchin placed upside down in water, could right itself less or more readily than a starfish? What advantage in turning would each have that the other would not have? The name sea urchin has no reference to a mischievous boy, but means sea hedgehog (French oursin, hedgehog), the name being suggested by its spines.

Comparison of Starfish and Sea Urchin. - The water system of the sea urchin, consisting of madreporite, tubes, and water bulbs, or ampullæ, is similar to that of the starfish.

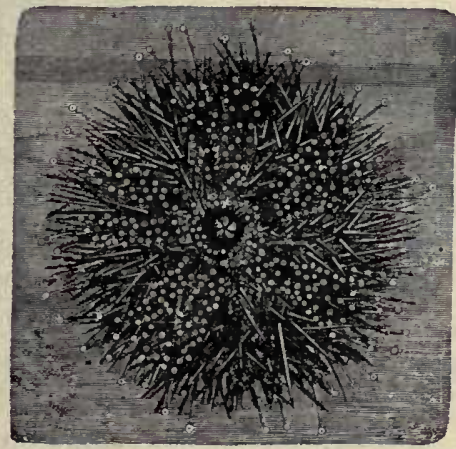

FIG.6r. - A SEA URCHIN crawling up the glass front wall of an aquarium (showing mouth spines and tube feet).

The tube feet and locomotion are alike. There is no need for well-developed respiratory organs in either animal, as the whole body, inside and out, is bathed in water. The method of reproduction is the same.

The starfish eats soft animal food. The food of the sea urchin is mainly vegetable, and it needs teeth (Fig. 62, 63);

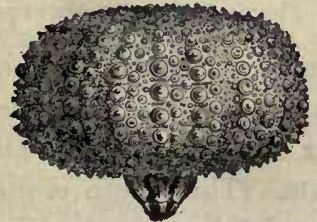

FIG.62. - A SEA URCHIN with spines removed, the limy plates showing the knobs on which the spines grew.

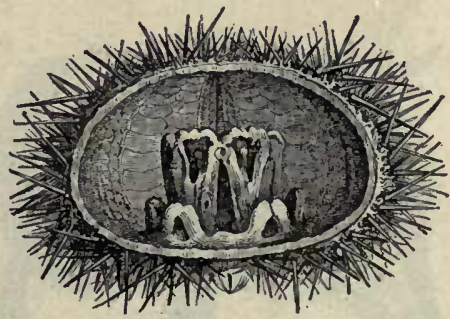

FIG. 63. - SECTION OF SEA URCHIN with soft parts removed, showing the jaws which bear the teeth protruding in Fig. 62.

its food tube is longer than that of a starfish, just as the food tube of a sheep, whose food digests slowly, is much longer than that of a dog. 
The largest species of sea urchins are almost as big as a child's head, but such size is unusual. The spines are mounted

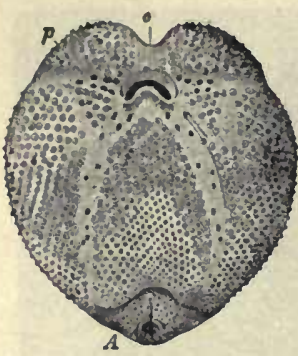

FIG. 64. - THE SEA OTTER, an urchin with mouth $(0)$ and vent $(A)$ on same side of body. on knobs, and the joint resembles a ball-and-socket joint, and allows a wide range of movement. Some sea urchins live on sandy shores, other species live upon the rocks. The sand dollars are lighter colored. (Why?) They are usually flatter and have lighter, thinner walls than the other species. The fiveholed sand cake or sand dollar has its weight still further diminished by the holes, which also allow it to rise more easily through the water.

Both starfish and sea urchin rest on the flattened lower surface of the body, while the tube feet are stretching forward for another step.

\section{Other Echinoderms}

The sea cucumbers, or holothurians, resemble the sea urchin in many respects,

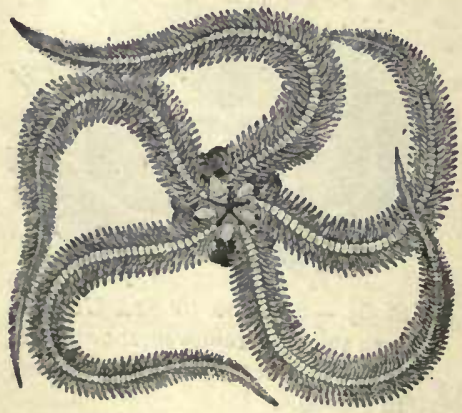

Fig. 66. - A BRITtLE STAR.

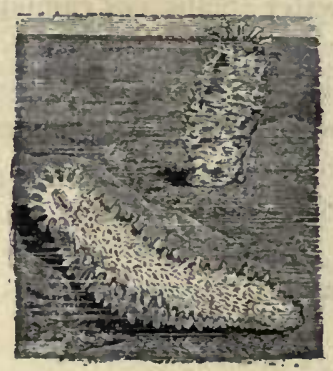

Fig. 65.-SEA CUCUMbers. but their bodies are elongated, and the limy plates are absent or very minute. The mouth is surrounded by tentacles (Fig. $65)$.

The brittle stars resemble the starfish in form, but their rays are very slender, more distinct

from the disk, and the tube feet are on the edges of the rays, not under them (Fig. 66). 
The crinoids are the most ancient of the echinoderms. (Figs. 67, 68.) Their fossils are very abundant in the rocks. They inhabited the geological seas, and it is believed that some of the other echinoderms descended from them. A few now inhabit the deep seas. Some species are fixed by stems when young, and later break away and become freeswimming, others remain fixed throughout life.

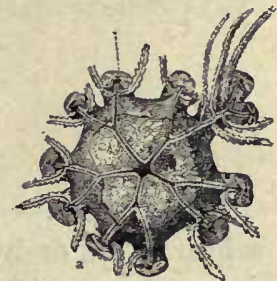

FIG.68.-DISK OF CRINolD from above, showing mouth in center and vent near it, at right (arms removed).

The four classes of the branch echinoderms are Starfish (asteroids), Sea urchins (echincids), Sea cucumbers (holothurians), and Sea lilies (crinoids).

\section{Comparative Review}

FiG.67.-

CRINOID,

Make a table like this as large as the page of the arms closed. notebook will allow, and fill in without guessing.

\begin{tabular}{|c|c|c|c|c|c|}
\hline & АмевА & SPONGE & HYDRA & $\begin{array}{l}\text { Coral } \\
\text { Polyp }\end{array}$ & STARFISH \\
\hline \multicolumn{6}{|c|}{$\begin{array}{l}\text { Is body round, two- } \\
\text { sided, or irregular }\end{array}$} \\
\hline \multicolumn{6}{|c|}{ What organs of sense } \\
\hline \multicolumn{6}{|c|}{ Openings into body } \\
\hline \multicolumn{6}{|c|}{$\begin{array}{l}\text { Hard or supporting } \\
\text { parts of body }\end{array}$} \\
\hline \multicolumn{6}{|c|}{ How food is taken } \\
\hline \multicolumn{6}{|l|}{ How move } \\
\hline How breathe & & & 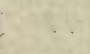 & & \\
\hline
\end{tabular}




\section{CHAPTER VI}

\section{WORMS}

SUGGESTIONS :- Earthworms may be found in the daytime after a heavy rain, or by digging or turning over planks, logs, etc., in damp places. They may be found on the surface at night by searching with a lantern. Live specimens may be kept in the laboratory in a box packed with damp (not wet) loam and dead leaves. They may be fed on bits of fat meat, cabbage, onion, etc., dropped on the surface. When studying live worms, they should be allowed to crawl on damp paper or wood. An earthworm placed in a glass tube with rich, damp soil, may be watched from day to day.

External Features. - Is the body bilateral? Is there a dorsal and ventral surface? Can you show this by a test with live worm? Do you know of an animal with dorsal

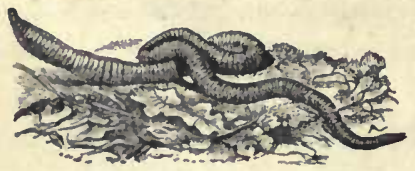

Fig. 69. - AN EARTHWORM. and ventral surface, but not bilateral?

Can you make out a head? A head end? A neck? Touch the head and test whether it can be made to crawl backwards. Which end is more tapering? Is the mouth at the tip of the head end or on the upper or lower surface? How is the vent situated? Its shape? As the worm lies on a horizontal surface, is the body anywhere flattened? Are there any very distinct divisions in the body? Do you see any eyes?

Experiment to find whether the worm is sensitive (I) to touch, (2) to light, (3) to strong odors, (4) to irritating liquids. Does it show a sense of taste? The experiments should show whether 
it avoids or seeks a bright light, as a window ; also whether any parts of the body are especially sensitive to touch, or all equally sensitive. What effect when a bright light is brought suddenly near it at night?

Is red blood visible through the skin? Can you notice any pulsations in a vessel along the back? Do all earthworms have the same number of divisions or rings? Compare the size of the rings or segments. Can it crawl faster on glass or on paper?

A magnifying glass will show on most species tiny bristlelike projections called sete. How are the setæ arranged? (d, Fig. 7o.) How many on one ring of the worm? How do they point? Does the worm feel smoother when it is pulled forward or backward between

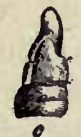

FIG. 70.- MOUTH AND SETA.

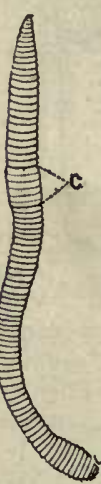

Fig.71.EARTHWORM, mouth end above. the fingers? Why? Are setæe on the lower surface? Upper surface? The sides? What is the use of the setæe? Are they useful below ground? Does the worm move at a uniform rate? What change in form occurs as the front part of the body is pushed forward? As the hinder part is pulled onward? How far does it go at each movement? At certain seasons a broad band, or ring, appears, covering several segments and making them seem enlarged (Fig. 7I). This is the clitellum, or reproductive girdle. Is this girdle nearer the mouth or the tail ?

Draw the exterior of an earthworm. always crawls with the same surface to the ground; this is called the ventral surface, the opposite surface is the dorsal surface. This is the first animal studied to which 


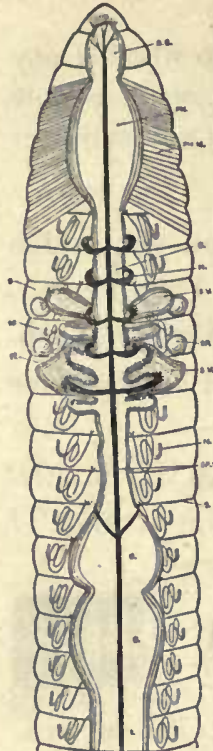

FIG. 72, - FOOD TUBE of earthworm. (Top view.) these terms are applicable. What are the ventral and dorsal surfaces of a fish, a frog, a bird, a horse, a man?

The name "worm" is often carelessly applied to various crawling things in general. It is properly applied, however, only to segmented animals without jointed appendages. Although a caterpillar crawls, it is not a worm for several reasons. It has six jointed legs, and it is not a developed animal, but only an early stage in the life of a moth or butterfly. A "grubworm" also has jointed legs (Fig. 167). It does not remain a grub, but in the adult stage is a beetle. A worm never develops into another animal in the latter part of its life; its setæ are not jointed.

The Food Tube. - The earthworm has no teeth, and the food tube, as might be

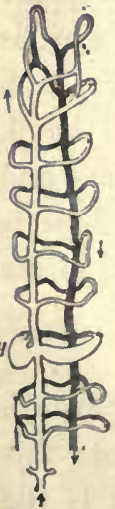
inferred from the form of the body is simple and.straight. Its parts, recognizable because of slight differences in size and structure, are named the pharynx (muscular), gullet, crop, gizzard

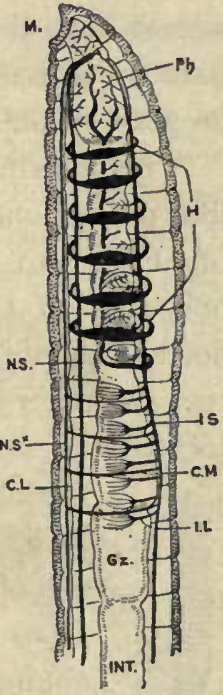

FIG. 73.-FOOD TUBE AND BLOOD VESSELS of earthworm showing the ring-like hearts. (Side view.) (muscular), and stomach-intestine. The last extends through three fourths of the length of the body (Fig. 72). The functions of the parts of the food tube are indicated by their names.

Circulation. - There is a large dorsal blood FiG. 74. vessel above the food tube (Fig. 73). From the 
front portion of this tube arise several large tubular rings or "hearts" which are contractile and serve to keep the blood circulating. They lead to a ventral vessel below the food tube (Fig. 74). The blood is red, but the coloring matter is in the liquid, not in the blood cells.

Nervous System. - Between the ventral blood vessels is a nerve cord composed of two strands (see Fig. 75). There is a slight swelling, or ganglion, on each strand, in each segment (Fig. 75). The strands separate near the front end of the worm, and a branch goes up each side of the gullet and enters the two pear-shaped cerebral ganglia, or "brain" (Fig. 75).

Food. - The earthworm eats earth containing organic matter, the inorganic part passing through the vent in the form of circular casts; these are found in the morning at the top of the earthworm's burrow.

The earthworm has no teeth. It excretes - through the mouth an alkaline fluid which softens and partly digests the food before it

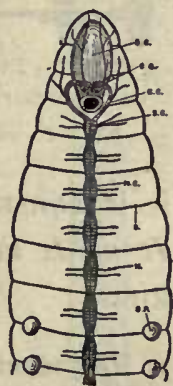

FIG. $75 .-$

GaNGLIA NEAR MOUTH and part of nerve chain of earthworm. is eaten. When this fluid is poured out upon a green leaf, the leaf at once turns brown. The starch in the leaf is also acted upon. The snout aids in pushing the food into the mouth.

Kidneys. - Since oxidation is occurring in its tissues, and impurities are forming, there must be some way of removing impurities from the tissues. The earthworm does not possess one-pair organs like the kidneys of higher animals to serve this purpose, but it has numerous pairs of small tubular organs called nephridia which serve the purpose. Each one is simply a tube with several coils. There is a pair on the floor of each segment. Each neph- 
ridium has an inner open end within the body cavity, and its outer end opens by a pore on the surface between the setæ. The nephridia absorb waste

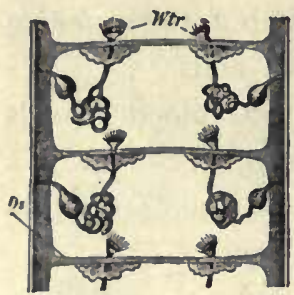

FIG. 76. - TWO PAIRS OF NEPHRIDIA in a worm (diagram). from the liquid in the celom, or body cavity surrounding the food tube, and convey it to the outside.

Respiration. - The skin of the earthworm is moist, and the blood capillaries approach so near to the surface of the body that the oxygen is constantly passing in from the air, and carbon dioxid passing out; hence it is constantly breathing through all parts of its skin. It needs no lungs nor special respiratory organs of any kind.

Reproduction. - When one individual animal produces both sperm cells and egg cells, it is said to be hermaphrodite. This is true of the earthworm. The egg cell is always fertilized, however, not by the sperm cells of the same worm, but by sperm cells formed by another worm. The openings of these ovaries consist of two pairs of small pores found on the ventral surface of the fourteenth segment in most species (see Fig. 77). There are also two pairs of small receptacles for temporarily holding the foreign sperm cells. One pair of the openings from these receptacles is found (with diffculty) in the wrinkle behind the ninth segment (Fig. 77), and the other pair behind the tenth segment. The sperm-

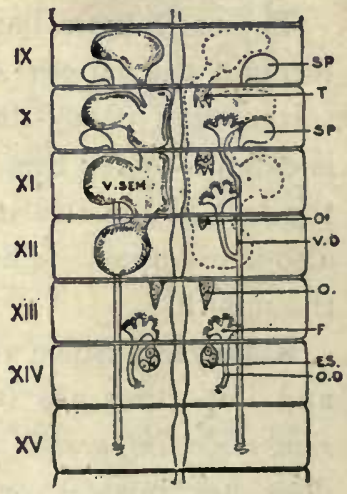

FIG. 77.- Sperm $(s p)$ and egg glands (es) of worm. aries are in front of the ovaries (Fig. 77), but the sperm ducts are longer than the oviducts, and open behind them on the fifteenth segment (Figs. 77, 78). The worms exchange sperm cells, but not 
egg cells. The reproductive girdle, or clitellum, already spoken of, forms the case which is to hold the eggs (see Fig. 7I). When the sperm cells have been exchanged, and the ova are ready for fertilization, the worm draws itself backward from the collar-like case or clitellum so that this slips over the head. As it passes the fourteenth segment, it collects the ova, and as it passes the ninth and tenth segments, it collects the sperm cells previously received from another worm. The elastic, collar-like clitellum closes at the ends after it has slipped over the worm's head, forming a capsule. The ova are fertilized in this capsule, and some of them hatch into worms in a few days. These devour the eggs which do not hatch. The eggs develop into complete but very small worms before escaping from the capsule.

Habits. - The earthworm is omnivorous. It will eat bits of meat as well as leaves and other vegetation. It has also the advantage, when digging its hole, of eating the earth which must be excavated. Every one has noticed the fresh "casts" piled up at the holes in the morning. As the holes are partly filled by rains, the casts are most abundant after rains. The chief showing setæ, enemies of the earthworm are moles and birds. The worms work at night and retire so early in pores, and the morning that the very early bird has the openings. advantage in catching worms. Perhaps the nearest to an intelligent act the earthworm accomplishes is to conceal the mouth of its hole by plugging it with a pebble or bit of leaf. Worms hibernate, going below danger of frost in winter. In dry weather they burrow several feet deep.

The muscular coat of the body wall is much thicker than the skin. It consists of two layers : an outer layer of fibers which mu around the body just beneath the skin, and an 
inner, thicker layer of fibers which run lengthwise. The worm crawls by shortening the longitudinal muscles. As the bristles (setce) point backward, they prevent the front part of the body from slipping back, so the hinder part is drawn forward. Next, the circular muscles contract, and the bristles preventing the hind part from slipping back, the fore portion is pushed forward. Is the worm thicker when the hinder part is being pulled up or when the fore part is being thrust forward? Does the earthworm pull or push itself along, or does it do both? Occasionally it travels backward, e.g. it sometimes goes backward into its hole. Then the bristles are directed forward.

The right and left halves of the body are counterparts of each other, hence the earthworm is bilaterally symmetrical. The lungs and gills of animals must always be kept moist. The worm cannot live long in dry air, for respiration in the skin ceases when it cannot be kept moist, and the worm smothers. Long immersion in water is injurious to it, perhaps because there is far less oxygen in water than in the air.

Darwin wrote a book called "Vegetable Mold and Earthworms." He estimated that there were fifty thousand earthworms to the acre on farm land in England, and that they bring up eighteen tons of soil in an acre each year. As the acids of the food tube act upon the mineral grains that pass through it, the earthworm renders great aid in forming soil. By burrowing it makes the soil more porous and brings up the subsoil.

Although without eyes, the worm is sensitive to light falling upon its anterior segments. When the light of a lantern suddenly strikes it at night, it crawls quickly to its burrow. Its sense of touch is so keen that it can detect a light puff of breath. Which of the foods kept in a box of 
damp earth disappeared first? What is indicated as to a sense of taste?

Why is the bilateral type of structure better adapted for development and higher organization than the radiate type of the starfish? The earthworm's body is a double tube; the hydra's body is a single tube; which plan is more advantageous, and why? Would any other color do just as well for an earthworm? Why, or why not?

The sandzoorm (Nereis) lives in the sand of the seashore, and swims in the sea at night (Fig. 79). It is more advanced in structure than the earthworm, as it has a distinct head (Fig. 80), eyes, two teeth, two lips, and several pairs of antennæ, and two rows of muscular projections which serve as feet. It is much used by fishermen for bait. If more easily obtained, it may be studied instead of the earthworm.

There are four classes in the branch Vermes:

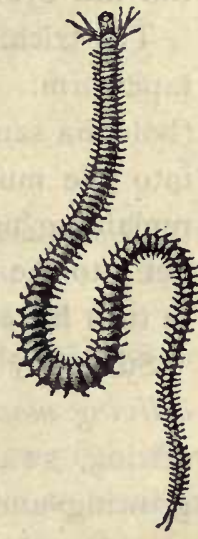

FIG. 79. - SAND WORM $\times \frac{2}{3}$

(Nereis).

I) the worms, including sandworms and leeches; 2) the

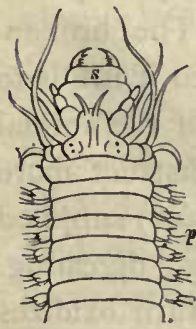

FIG. 80. - HEAD OF SANDWORM (enlarged). roundworms, including trichina, hairworms, and vinegar eels; 3) flatzoorms, including tapeworm and liver fluke; 4) rotifers, which are microscopic aquatic forms.

The tapeworm is a flatworm which has lost most of its organs on account of its parasitic life. Its egg is picked up by an herbivorous animal when grazing. The embryo undergoes only partial development in the body of the herbivorous animal, e.g. an ox. The next stage will not develop until the beef is eaten by a carnivorous animal, to whose food canal it attaches itself and soon develops a long chain of segments called a "tape." Each segment absorbs fluid food through its 
body wall. As the segments at the older end mature, each becomes full of eggs, and the segments become detached and pass out of the canal, to be dropped and perhaps picked up by an herbivorous animal and repeat the life cycle.

The trichina is more dangerous to human life than the tapeworm. It gets into the food canal in uncooked pork (bologna sausage, for example), multiplies there, migrates into the muscles, causing great pain, and encysts there, remaining until the death of the host. It is believed to get into the bodies of hogs again when they eat rats, which in turn have obtained the cysts from carcasses.

Summary of the Biological Process. - An earthworm is a living machine which doe's work (digging and crawling; seizing, swallowing, and digesting food; pumping blood; growing and reproducing). To do the work it must have a continual supply of energy. The energy for its work is set free by the protoplasm (in its microscopic cells) undergoing a destructive chemical change (oxidation). The waste products from the breaking down of the protoplasm must be continually removed (excretion). The brokendown protoplasm must be continually replaced if life is to continue (the income must exceed the outgo if the animal is still growing). The microscopic cells construct more protoplasm out of food and oxygen (assimilation) supplied them by the processes of nutrition (eating, digesting, breathing, circulating). This protoplasm in turn oxidizes and releases more energy to do work, and thus the cycle of life proceeds, 


\section{CHAPTER VII}

\section{CRUSTACEANS}

\section{CRawfish}

Suggestions. - In regions where crawfish are not found, a live crab may be used. Locomotion and behavior may be studied by providing a tub of water, or better, a large glass jar such as a broad candy jar. For suggestions on study of internal structure, see p. $5^{8}$.

Habitat. - Do you often see crawfish, or crayfish, moving about, even in water where they are known to be abundant? What does your answer suggest as to the time when they are probably most active?

Why do you never see one building its chimney, even where crawfish holes are abundant? Is the chimney always of the same color as the surface soil? Are the crawfish holes only of use for protection? In what kind of spots are crawfish holes always dug? Why? What becomes of crawfish when the pond or creek dries up? How deep are the holes? How large are the lumps of mud of which the chimney is built? How does it get them out of the hole? Why is the mud built into a chimney instead of thrown away? (What would happen to a well with its mouth no higher than the ground?) Why are crawfish scarce in rocky regions, as New England?

How does the color of the crawfish compare with its surroundings? Is its color suited to life in clear or muddy water? Define protective coloration. 
Habits. - Does the crawfish walk better in water or out of it? Why? Does it use the legs with the large claws to assist in walking? Do the swimmerets (under the abdomen) move fast or slow? (Observe it from below in a large jar of clear water.) What propels it backward? Forward? Does the crawfish move at a more uniform rate when swimming backward or forward? Why? In which way can it swim more rapidly? Do the big legs with claws offer more resistance to the water while it is swimming backward or forward? How does it hold the tail after the stroke, while it is darting backward through the water? Hold a crawfish with its tail submerged and its head up. Can the tail strike the water with much force? Allow it to grasp a pencil: can it sustain its own weight by its grip?

Feeding. - Offer several kinds of food to a crawfish that has not been alarmed or teased. Does it prefer bread, meat, or vegetables? How does it get the food to its mouth? Does it eat rapidly or slowly? Does it tear the food with the big pincers? Can it gnaw with the small appendages near the mouth?

Breathing. - Does the crawfish breathe with gills or lungs? Place a few drops of ink near the base of the hind legs of a crawfish resting quietly in shallow water. Where is the ink drawn in? Where does it come out? To explain the cause and purpose of this motion, place a crawfish in a large glass jar containing water, and see the vibratory motion of the parts under the front portion of the body. There is a gill paddle, or gill bailer, under the shell on each side of the body that moves at the same rate.

Senses. - Crawfish are best caught with a piece of meat or beef's liver tied to a string. Do they always lose hold as soon as they are lifted above the water? What do you 
conclude as to the alertness of their senses? Does the cov. ering of its body suggest the possession of a delicate or dull sense of touch?

Of what motions are the eyes capable? Touch one of the eyes. The result? Can a crawfish see in all directions? To test this, place a crawfish on a table and try whether you can move to a place where you can see the

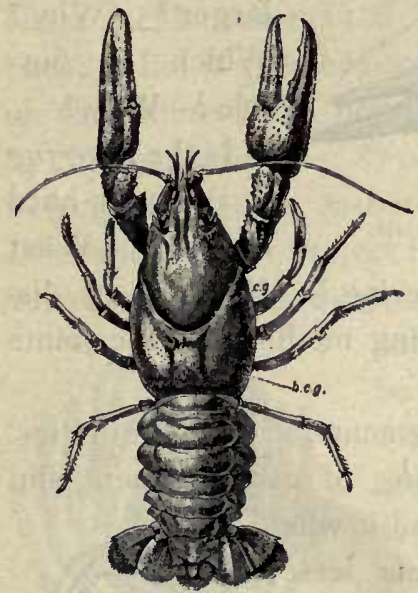

FIG. 8I. - CRAWFISH (dorsal surface).

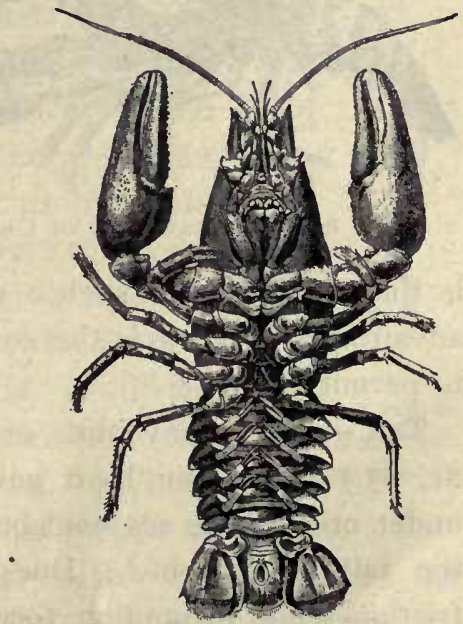

FIG. 82.

crawfish without seeing its eyes. What are the advantages and disadvantages of having the eyes on stalks?

Touch the body and the several appendages of the crawfish. Where does it seem most sensitive to touch? Which can reach farther, the antennæ or the big claws? Why are short feelers needed as well as long ones?

Make a loud and sudden noise without jarring the crawfish. Is it affected by sound?

External Anatomy (Figs. 81, 82, 83, 84).--Is the body of the crawfish rounded out (convex) everywhere, or is any part of its surface either flat or rounded in (concave)? 
What color has the crawfish? Is this color of any use to the crawfish?

Make out the two distinct regions or divisions of the body (Fig. 8I). The anterior (front) region is called the headchest or cephalothorax, and the posterior (rear) region is

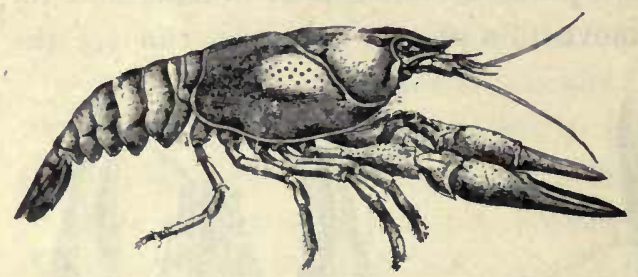

Fig, 83. - LATERAL VIEW OF CRAWFISH. called the tail. Which region is larger? Why? Which is flexible? Why?

Is the covering of the body hard or soft? What is the advantage of such a covering? What are its disadvantages? How is the covering modified at the joints to permit motion?

Tail. - How many joints, or segments, of the tail? (Figs. 81, 83.) Does the hard covering of each segment slip under or over the segment behind it when the tail is straight? Does this lessen friction while swimming forward?

Is there a pair of swimmerets to each segment of the tail? (Figs. 82, 86.) Notice that each swimmeret has a main stalk (protopod), an outer branch (exopod), and an inner branch (endopod) (Fig. 84). Are the stalk and the branches each in

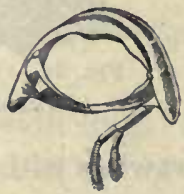

FIG. 84. FOURTH ABDOMINAL, SEgMENT OF CRAIVFISH with swimmeret. one piece or jointed? The middle part of the tail fin is called the telson. By finding the position of the vent, decide whether the food tube goes into the telson (Fig. 82). Should it be called an abdominal segment. Are the side pieces of the tail fin attached to the telson or to the sixth segment? Do these side pieces correspond 
to swimmerets? Do they likewise have the $\mathrm{Y}$-shaped structure? (Fig. 86.)

If the swimmerets on the first abdominal segment are large, the specimen is a male. If they are small, it is a female. Which sex is shown in Fig. 82 ? Fig. 86 ?

Carapace. - The covering of the head chest (cephalothorax) is called the carapace. Has it free edges? The gills are on the sides of the body and are covered by the carapace (Fig. 87). The projection in front is called the rostrum, meaning beak. Does the rostrum project beyond the eyes? There is a transverse groove across the cara-

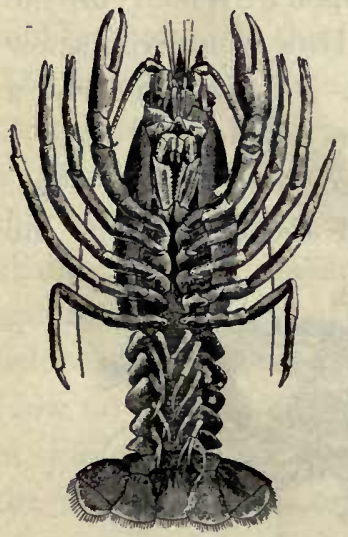

FIG. 86. - CRAWFISH (ventral surface). pace which may be said to divide the head from the abdomen. Where

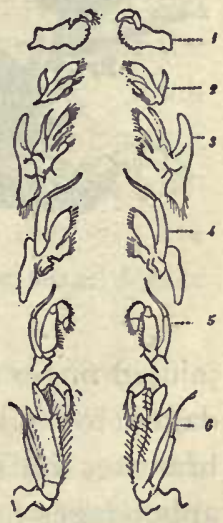

FIG. 85.-I, mandible; 2,3 , maxillz; $4,5,6$, maxillipeds. does this groove end at the sides?

Legs. - How many legs has the crawfish? How many are provided with large claws? Small claws? Is the outer claw hinged in each of the large grasping pincers? The inner claw?

Appendages for Taking Food. If possible to watch a living crawfish eating, notice whether it places the food directly into the mouth with the large claws. Bend the large claws under and see if they will reach the mouth. Attached just in front of the legs the crawfish has three pairs of finger-like appendages, called foot jaws (maxillipeds), with which it passes the food from the large pincers 
to its mouth (Figs. 85, 86). They are in form and use more like fingers than feet. In front of the foot jaws are two

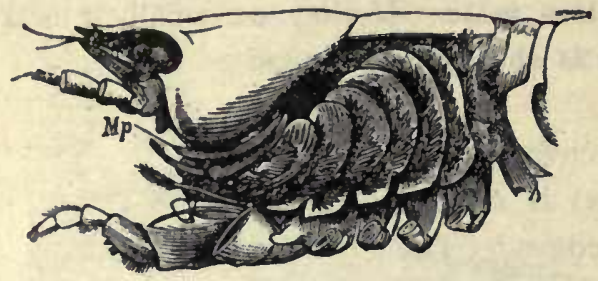

FIG. 87. - Gill cover removed and gills exposed. $M p$, gill bailer.

pairs of thin jaws (maxillæ) and in front of the thin jaws are a pair of stout jaws (mandibles) (Fig. 85). Do the jaws move sidewise or up and down? Which of the jaws has a jointed finger (palp) attached to it ? Do all of the appendages for taking food have both exopod and endopod branches on a basal stalk or protopod? Which of the appendages have a scalloped edge? How would you know from looking at the crawfish that it is not merely a scavenger? Why are there no pincers on the hind feet?

Sense Organs. - Find the antenne, or long feelers (Figs. $82,90)$. Are the antennæ attached above or below the eyes? (Fig. 87.)

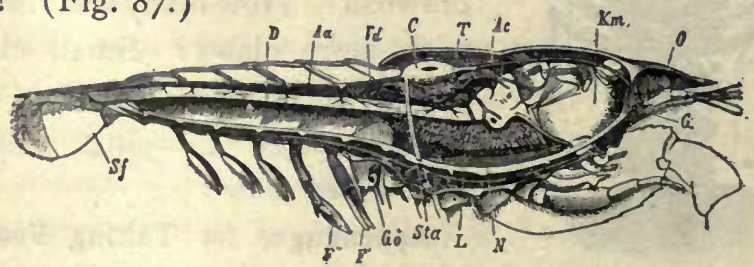

Fig. 88. - Lengthiwise Section of Male Crawfish.

c, heart: $A c$, artery to head: $A a$, artery to abdomen; $K m$, stomach; $D$, intestine;

$L$, liver; $T$, spermary: Go, opening of sperm duct; $G$, brain; $N$, nerve chain.

Find the pair of antennules, or small feelers. Are their divisions like or unlike each other? Compare the length of the antennules and the antennæ. Compare the flexibility of the antennæ with that of the other appendages. 
Observe the position of the eyes (Figs. 81, 88). How long are the eyestalks? Is the stalk flexible or stiff? Touch the eye. Where is the joint which enables the stalk to move? Is the outer covering of the eye hard or soft? A mounted preparation of the transparent covering (cornea) of the eye, seen with lower power of microscope, reveals that the cornea is made up of many divisions, called facets. Each facet is the front of a very small eye, hundreds of which make up the whole eye, which is therefore called a compound eye. The elongated openings to the ear sacs are located each on the upper side of the base of a small feeler just below the eye.

Respiratory System. - The respiratory organs are gills located on each side of the thorax in a space between the carapace and body (Fig. 87). The gills are white, curved, and feathery. Is the front gill the largest or the smallest? The gills overlap each other; which is the outermost gill? On the second maxilla is a thin, doubly curved plate called a gill bailer (Fig. 85). The second maxilla is so placed that the gill bailer comes at the front end of the gill chamber. The bailer paddles continually, bringing the water forward out of the gill. The gills are attached below at the base of the legs. Are the gills thick or thin ? How far upward do they go ? Does the backward motion in swimming aid or hinder the passage of the water through the gills? Does a crawfish, when at rest on the bottom of a stream, have its head up or down stream? Why?

Openings. - The slitlike vent is on the under side of the telson (Figs. 82, 88). The mouth is on the under side of the thorax behind the mandibles. At the base of the long antennx are the openings from the green glands, two glands in the head which serve as kidneys (Fig. 89). The openings of the reproductive argans are on the third 


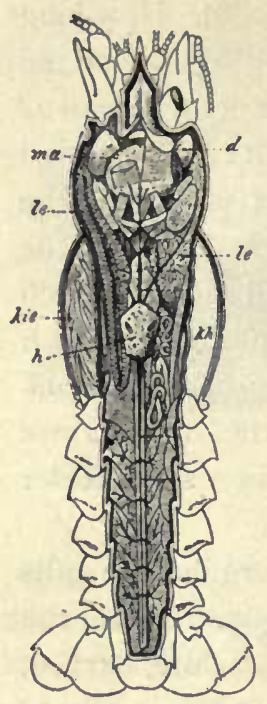

Fig. 89. - Level lengthwise section showing

\section{$k$, heart. \\ $d$, green gland. \\ le, liver. \\ kie, gills. \\ $k h$, gill cavity. \\ ma, stomach.}

(After Huxley.)

pair of legs in the female, and the fifth pair of legs in the male (Fig. 88). The eggs are carried on the swimmerets.

Internal Structure. - SugGestions. If studied by dissection, it will be necessary to have several crawfish for each pupil, one for gaining general knowledge, and others for studying the systems in detail. Specimens should have lain in alcohol for several days.

The Food Tube. - Is the stomach in the head portion of the cephalothorax or in the thoracic portion? (Figs. 88, 89). Is the stomach large or small? What is its general shape? Does the gullet lead upward or backward? Is it long or short? (Fig. 88.) The mid tube, which is the next portion of the food tube, is smaller than the stomach. On each side of it are.openings from the bile ducts which bring the secretion from the digestive gland, sometimes called the liver. Does this gland extend the whole length of the thorax? Is it near the floor or the top of the cavity? The third and last portion of the food tube is the intestine. It extends from the thorax

to the vent. Is it large or small? Straight or curved? The powerful flexor muscles of the tail lie in the abdomen below the intestines. Compare the size of these muscles with the extensor muscle above the intestine (Fig. 90). Why this difference? Does the food tube extend into the telson? Locate the vent (Fig. 90).

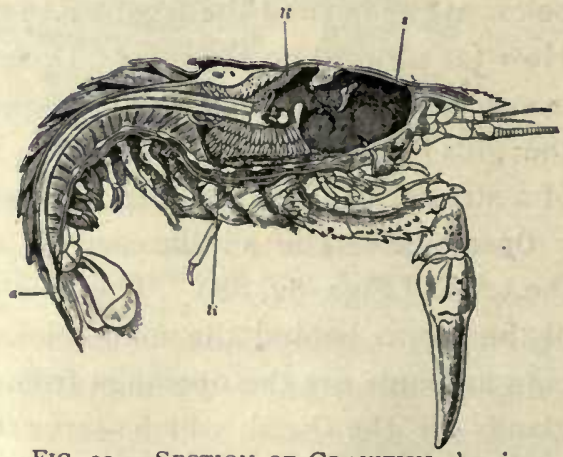

FIG, 90. - SECTION of CRAWFish showing slomach $s$, liver $l i$, and vent $a$. 
The Circulation. - The blood is a liquid containing white corpuscles. It lacks red corpuscles and is colorless. The heart is in the upper part of the thorax. It is surrounded by a large, thin bag, and thus it is in a chamber (called the pericardial sinus). The blood from the pulmonary veins enters this sinus before it enters the heart. The origin of this pericardial sinus by the fusing of veins is shown in Fig. I 30 . Does one artery, or do several arteries, leave the heart? There is a larger dorsal artery lying on the intestine and passing back to the telson; there are three arteries passing forward close to the dorsal surface (Figs. 89, 9I). One large artery (the sternal) passes directly downward (Figs. $88,9 \mathrm{I})$, and sends a branch forward and another backward near the ventral surface. The openings into the heart from the sinus have valvular lips which prevent a backward flow of blood into the sinus. Hence, when

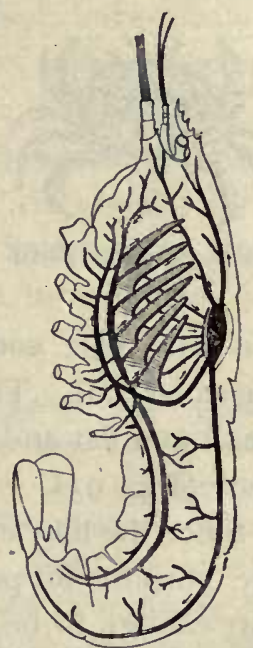

Fig. 91. - Showing heart and main blood vessels. the heart contracts, the blood is sent out into the sev-

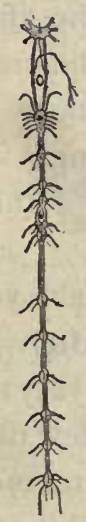

F1G. 92. eral arteries. The arteries take a supply of fresh blood to the eyes, stomach, muscles, liver, and the various organs. After it has given oxygen to the several organs and taken up carbon dioxid, it returns by veins to pass through the gills on each side, where it gives out the useless gas and takes up oxygen from the water. It is then led upward by veins into the pericardial sinus again.

The central nervous system consists of a double chain of ganglia (Fig. 92). This main nerve chain lies along the ventral surface below the food tube (Fig. 9o), except one pair of ganglia which lie above the esophagus or gullet (Fig. 88), and are called the supra-esophageal ganglia, or brain.

Crustacea. - The crawfish and its kindred are placed in the class called Crustacea. 
Decapods. - All crustacea which have ten feet belong in the order called decap'oda (ten-footed). This order

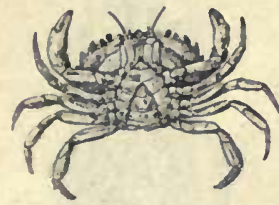

FIG. 93.-CRAB FROM BELOW. includes the crabs, lobsters, shrimp, etc. The crabs and lobsters are of considerable importance because of use as food. Small boys sometimes catch crawfish, and in some instances are known to cook and eat them for amusement,

the only part cooked being the muscular tail. The crab's tail is small and flat and held under the body (Fig. 93).

Since the limy covering to serve the purpose of protection is not

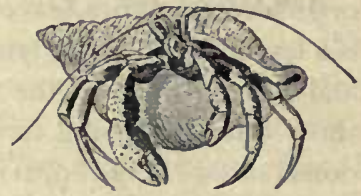

FiG. 94.- - HERMIT CRAB, using shell of sea snail for a house. soft enough to be alive and growing, it is evident that the crustacea are hampered in their growth by their crusty
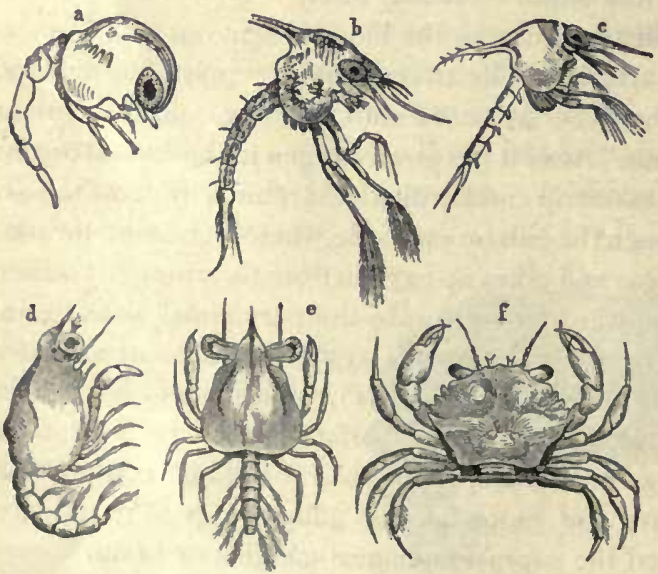

Fig. 95. - DeVelopment of a Crab.

$a$, nauplius just after hatching; $b, c, d$, zoëa; $e$, megalops; $f$, adult.

Question: Which stage is most like \& crayfish? Compare with metamorphoses of insects. covering. During the first year the craw. fish sheds its covering, or molts three times, and once each year thereafter. It grows very fast for a few days just after molting, while the covering is soft and extensible. Since it is at 
the mercy of birds, fish, and other enemies while in this soft and defenseless condition, it stays hidden until the covering hardens. Hence it cannot eat much, but probably by the absorption of water the tissues grow; that is, enlarge. In the intervening periods, when growth is impossible, it develops; that is, the tissues and organs change in structure and become stronger. "Soft-shelled crab" is a popular dish, but there is no species by that name, this being only a crab just after molting which has been found by fishermen in spite of its hiding.

General Questions. - How do crawfish choose their food? How long can they live out of water? Why do their gills remain moist out of water longer than a fish? How do they breathe out of water? Are they courageous or cowardly animals? When they lose appendages in fighting or molting, these are readily reproduced, but an organ molts several times in regaining its size. Have you seen crawfish with one claw smaller than the other? Explain.

Compare the crawfish and crab (Figs. 81, 93, and 95) in the following particulars: shape, body, eyes, legs, abdomen, habitat, movement.

\section{KEY TO THE FOUR CLASSES IN BRANCH ARTHROPODS}

I. INSECTS . . . 3 body divisions, 6 legs

2. ARACHNIDS . . 2 body divisions, 8 legs

3. MYRIAPODS . . many body divisions, many legs

4. Crustaceans - gill breathers, skeleton (external) limy

By the aid of the key and of figures 96-105, classify the following Arthropods : tick, thousand-leg centipede, king crab, pill bug, spider, scorpion, beetle. 


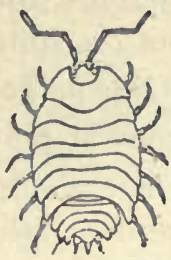

FiG. 96. - PILL BUG.

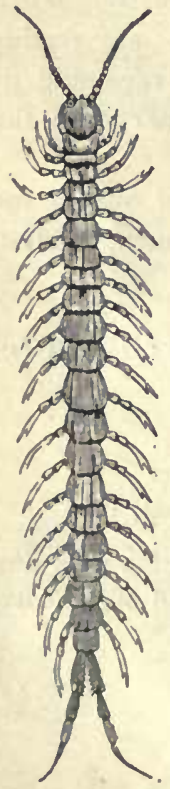

FIG. I00. Centipede.
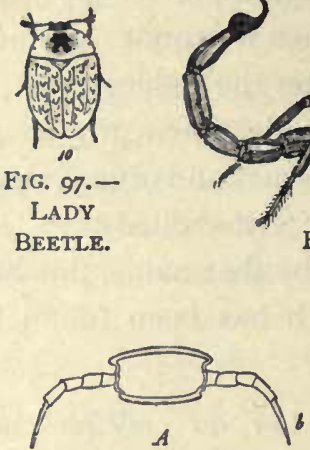

FIG. IOI. - ONE SEGMENT OF CENTIPEDE with one pair of legs.

$\boldsymbol{B}$

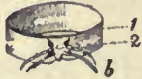

FIG. 102, ONE SEGMENT OF THOUSAND LEGS with two pairs of legs.

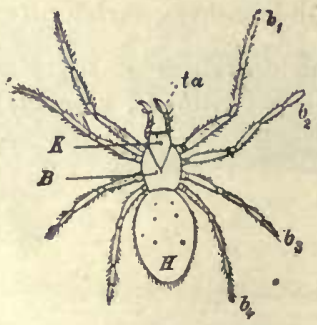

FIG. IO4. - A SPIDER.

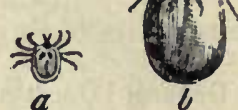

FIG. 99. - TICK before and after feeding.

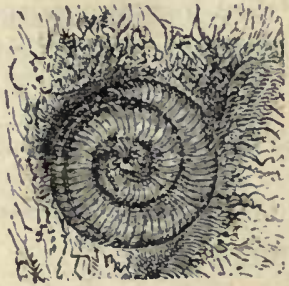

FIG. 103.-THOUSAND LEGS.

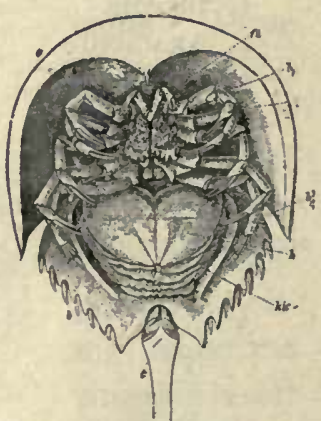

FIG. I05. - KING CRAB.

Illustrated Study. Classification of ARThropods. Key on p. 61 . 


\section{CHAPTER VIII}

\section{INSECTS}

\section{The GRASSHOPPER}

Suggestions. - Collect grasshoppers, both young and fullgrown, and keep alive in broad bottles or tumblers and feed on fresh grass or lettuce. When handling a live grasshopper, never hold it by its legs, as the joints are weak. To keep them for some time and observe their molts, place sod in the bottom of a box and cover the box with mosquito netting or wire gauze.

What is the general shape of its body? (Fig. I06.) Where is the body thickest? Is it bilaterally symmetrical, that is, are the two sides of the body alike? Is the skeleton, or hard part of the body, internal or external? Is the skeleton as stiff and thick as that of a crawfish? What is the length of your specimen? Its color?

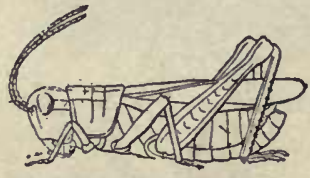

FIG. I06. - A GRASSHOPPER. Why does it have this coloration? In what ways does the grasshopper resemble the crawfish? Differ from it ?

The Three Regions of the Body. - The body of the grasshopper is divided into three regions, - the head, thorax, and abdomen. Which of these three divisions has no distinct subdivisions? The body of the grasshopper, like that of the earthworm, is made of ringlike segments. Are the segments most distinct in the head, thorax, or abdomen? Which region is longest? Shortest? Strongest? Why? Which region bears the chief sense organs? The appendages for taking food? The locomotory appendages? Which division of the body is most active in breathing ? 
The Abdomen. - About how many segments or rings in the abdomen? Do all grasshoppers have the same number of rings? (Answer for different species and different individuals of the same species.) The first segment and the last two are incomplete rings. Does the flexibility of the abdomen reside in the rings, or the joints between the rings? Is there merely a thin, soft line between the rings, or is there a fold of the covering? Does one ring slip into the ring before it or behind it when the abdomen is bent?

As the grasshopper breathes, does each ring enlarge and diminish in size? Each ring is divided into two parts

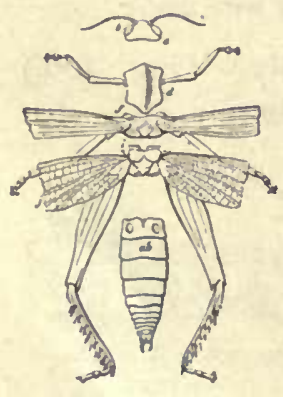

FIG, 107.-A GRASSHOPPER DISSECTED. by folds. Does the upper half-ring overlap the lower half-ring, or the reverse? With magnifying glass, find a small slit, called a spiracle, or breathing hole, on each side of each ring just above the side groove (Fig. 106). A tube leads from each spiracle. While the air is being taken in, do the two portions of the rings move farther apart? When they are brought together again, what must be the effect? In pumping the air, the abdomen may be said to work like a bellows. Bellows usually have folds to allow motion. Is the comparison correct?

How many times in a minute does the grasshopper take in air? If it is made to hop vigorously around the room and the breathing is again timed; is there any change?

Find the ears on the front wall of the first abdominal ring (Fig. 107). They may be seen by slightly pressing the abdomen so as to widen the chink between it and the thorax. The ears are merely glistening, transparent membranes, oval in form. A nerve leads from the inner 
surface of each membrane. State any advantage or disadvantage in having the ears located where they are.

Ovipositor. - If the specimen is a female, it has an eggplacer or ovipositor, consisting of four blunt projections at the end of the abdomen (Fig. 107). If it is a male, there are two appendages above the end of the abdomen, and smaller than the parts of the ovipositor. Females are larger and more abundant than males. In laying the eggs, the four blunt points are brought tightly together and then forced into the ground and opened (Fig. 108). By repeating this, a pit is made almost as deep as the abdomen is long. The eggs are laid in the bottom of the pit.

Draw a side view of the grasshopper.

Thorax. - This, the middle portion of the body, consists of three

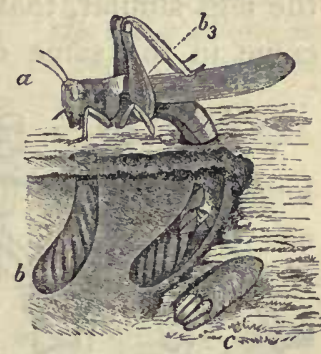

FIG. IO8. - GRASSHOPPER LAYING EGGS. (Riley.) segments or rings (Fig. I07). Is the division between the rings most apparent above or below? Which two of the three rings are more closely united?

The front ring of the thorax is called prothorax. Is it larger above or below? Does it look more like a collar or a cape? (Fig. Iо6.) A spiracle is found on the second ring (mesothorax, or middle thorax) just above the second pair of legs. There is another in the soft skin between the prothorax and mesothorax just under the large cape or collar. The last ring of the thorax is called the metathorax (rear thorax).

How many legs are attached to each ring of the thorax? Can a grasshopper walk? Run? Climb? Jump? Fly? Do any of the legs set forward? (See Fig. 106.) 
Outward? Backward? Can you give reasons for the position of each pair? (Suggestion: What is the use of each pair?) If an organ is modified so that it is suited to serve some particular purpose or function, it is said to be specialized. Are any of the legs specialized so that they serve for a different purpose than the other legs?

The leg of a grasshopper (as of all insects) is said to have five parts, all the small parts after the first four parts being counted as one part and called the foot. Are all the legs similar, that is, do the short and long joints in all come in the same order? Numbered in order from the

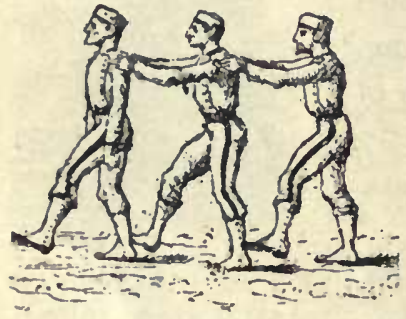

FIG. 109. - HOW A GRASSHOPPER WALKS.

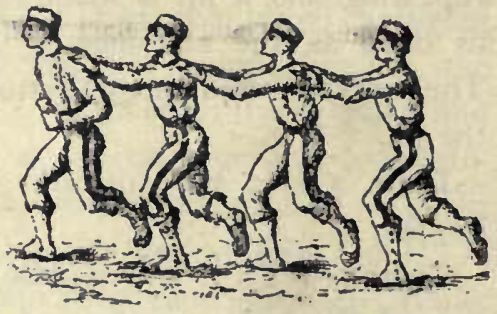

FIG. IIO.- How A SPIDER WALKS.

body, which joint of the leg is the largest, - the first, second, third, or fourth? Which joint is the shortest? The slenderest? Which joint has a number of sharp points or spines on it? Find by experiment whether these spines are of use in walking (Fig. 106). Jumping? Climbing? In what order are the-legs used in walking? How many legs support the body at each step?

All animals that have ears have ways of communicating by sounds. Why would it be impossible for the grasshopper to have a voice, even if it had vocal cords in its throat? The male grasshoppers of many species make a chirping, or stridulation, by rubbing the wing against the leg. Look on the inner side (why not outer side?) of the 
largest joint of the hind leg for a row of small spines visible with the aid of a hand lens (Fig. III). The sound is produced by the outer wings rubbing against the spines. Have you noticed whether the sound is produced while the insect is still or in motion? Why? The male grasshoppers of some species, instead of having spines, rub the under side of the front wing on the upper side of the hind wing.

Wings. - To what is the first pair of wings attached? The second pair? Why are the wings not attached to the prothorax? Why are the wings attached

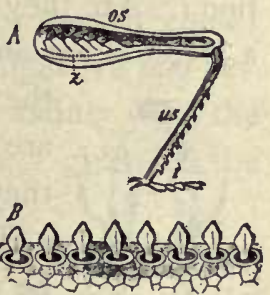

FIG. III. $-A$, Row of SPINES, $z$, used in chirping.

$B$, the same more enlarged. so near the dorsal line of the body? Why are the second and third rings of the thorax more solidly joined than the first and second rings?

Compare the first and second pairs of wings in shape, size, color, thickness, and use (Fig. 1 12). How are the

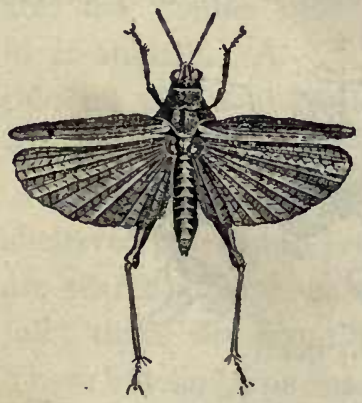

FIG. II2. - GRASSHOPPER IN FLIGHT. second wings folded so as to go under the first wings? About how many folds in each?

Draw a hind wing opened out.

Head. - What is the shape of the head viewed from the front, the side, and above? Make sketches. What can you say of a neck? Is the head movable in all directions?

What is the position of the large eyes? Like the eyes of the crawfish, they are compound, with many facets. But the grasshopper has also three simple eyes, situated one in the middle of the forehead and one just above each antenna. They are too small to be seen without a hand lens. How does 
the grasshopper's range of vision compare with that of the crawfish?

Are the antennæ flexible? What is their shape? Position? Are they segmented? Touch an antenna, a wing, a leg, and the abdomen in succession. Which seems to be

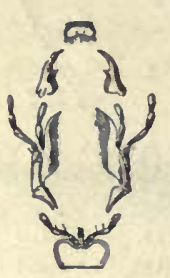
the most sensitive to touch? The antenna are for feeling; in some species of insects they also are organs of hearing and smelling.

The mouth parts of a grasshopper should be compared with the mouth parts of a beetle shown in Fig. II3, since they correspond

FIG. Ir3. closely. If the grasshopper is fed with a blade of fresh grass, the function of each organ may be plainly seen. It is almost impossible to understand these functions by studying a dead specimen, but a fresh specimen is much better than a dry one.

The upper lip, or labrum, is seen in front. Is it tapering or expanded? In what direction is it movable? The dark pointed biting jaws (mandibles) are next. Are they curved

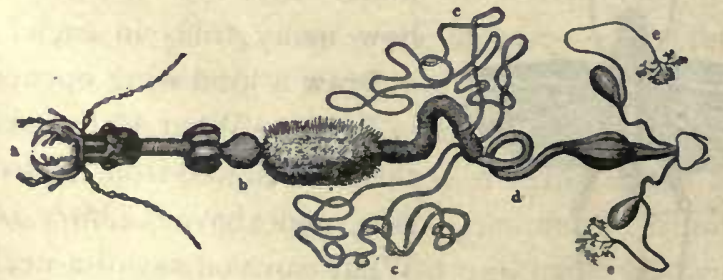

Fig. II4. $-a$, Foon TUbe of BeEtle.

$b$, gizzard : $d$, intestine; $c$, biliary vessels. See Fig. 127 .

or straight? Sharp or blunt pointed ? Notched or smooth? Do they work up and down, or sideways? The holding jaws (maxilla), each with two jaw fingers (maxillary palpi), are behind the chewing jaws. Why? The lower lip (labium) has a pair of lip fingers (labial palpi) upon it. The brown 
tongue, usually bathed in saliva, is seen in the lower part of the mouth. Since the grasshopper has no lips, or any way of producing suction, it must lap the dew in drinking. Does it merely break off bits of a grass blade, or does it chew ?

The heart, circulation, nervous system, digestive and respiratory organs of the grasshopper agree mainly with the general description of the organs of insects given in the next section.

Microscopic Objects. - These may be bought ready mounted, or may be examined fresh. A portion of the covering of the large eye may be cut off and the dark layer on the inside of the covering scraped off to make it transparent. What is the shape of the facets? Can you make any estimate of their number? A portion of the transparent hind wing may be used, and the "veins" in it studied. A
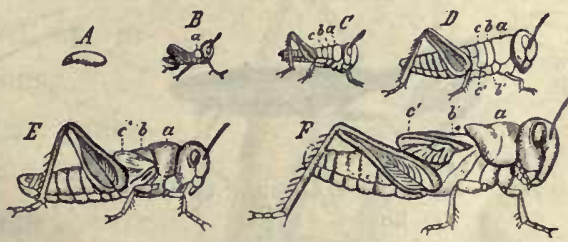

FIG. II5. - EGG AND MOLTS OF A GRASSHOPPER.

thin bit of an abdominal segment containing a spiracle will show the structure of these important organs.

Growth of the Grasshopper. - Some species hibernate in sheltered places and lay eggs in the spring, but adult species are scarce at that season. Most species lay the eggs in the fall ; these withstand the cold and hatch out in the spring. Those hatched from one set of eggs sometimes stay together for a few days. They eat voraciously, and as they grow, the soft skin becomes hardened by the deposit of horny substance called chitin. This retards further growth until the insect molts, the skin first splitting above the prothorax. After hatching, there are five successive periods of growth. At which molt do the very short wings first appear? (Fig. I I5.) 
After the last molt the animal is complete, and changes no more in size for the rest of its life. There has been an

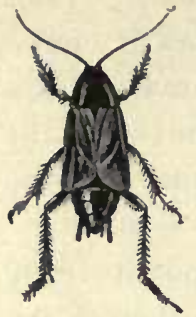

FIG. I16.COCKROACH. attempt among writers to restrict the term grasshopper to the long-winged, slender species, and to call the shorter winged, stouter species locusts according to old English usage.

Economic Importance of Grasshoppers. Great injury is often done to vegetation by grasshoppers; however, the millions of tiny but ravenous eaters hatched in early spring are usually soon thinned out by the birds. The migratory locusts constitute a plague when they appear, and

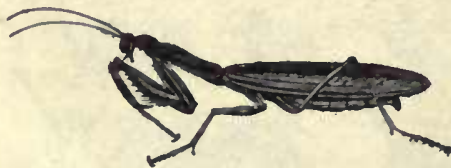

FIG. II7. - PRAYING MANTIS, or devil's horse.

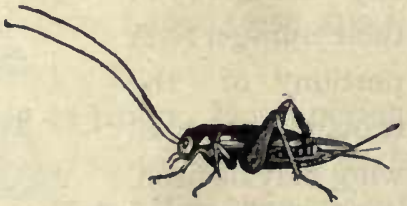

FIG. II8. - CRICKET.

they have done so since ancient times. The Rocky Mountain locusts flying eastward have darkened the sky, and where they settled to the earth ate almost every green thing. In I 874-5 they produced almost a famine in Kansas, Nebraska,

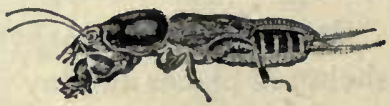

FIG, IIg. - MOLE CRICKET. and other Western states. The young hatched away from the mountains were not healthy,

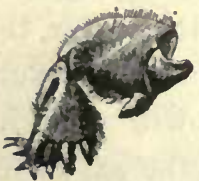

FIG. 120, - FRONT

LEG OF MOLE CRICKET. $\times 3$. and died prematurely, and their devastations came to an end. Of course the migrations may occur again. Packard calculates that the farmers of the West lost $\$ 200,000,000$ because of grasshopper ravages in $1874-5$. 
The cockroaches (Fig. I 6 ), kindred of the grasshoppers, are household pests that have migrated almost everywhere that ships go. The praying mantis (Fig. II7), or devil's horse, also belongs to this order. It is beneficial, since it destroys noxious insects. Which of its legs are specialized? The walking stick (Fig. I2I) and cricket (Fig. I I 8), like most members of the order, are vegetarian.

Are grasshoppers more common in fields and meadows, or in wooded places? How many different colors have you seen on grasshoppers? Which colors are most common?

Grasshoppers are very scarce in Europe as they love dry, warm countries. Why do locusts migrate? Give an instance in ancient times.

How long do most grasshoppers live? Does a grasshopper spread its wings before it flies? Does it jump and fly together? Can it select the place for alighting?

Note to TEACHER. - Field work in Zoology should be systematic. Every trip has a definite region and definite line of

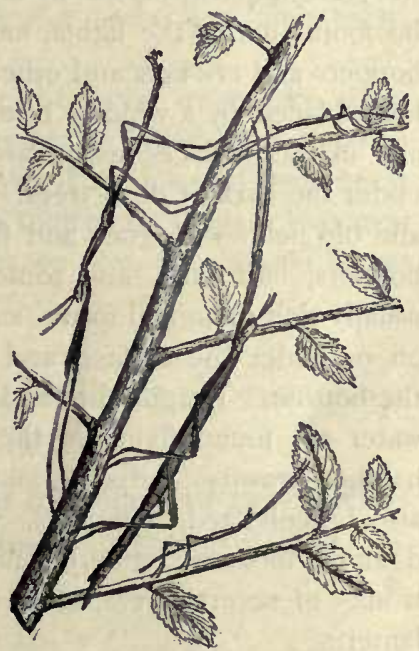

FIG. I2I. - FouR WALKING STICK INSECTS. study in view, but every animal seen should be noted. The habitat, adaptation by structure and habits to the environment, relations to other animals, classification of animals seen, should be some of the ideas guiding the study. The excursions may be divided somewhat as follows, according as opportunities offer: Upland woods, lowland woods, upland pastures, fields, swamps, a freshwater lake, a pond, lower sea beach, higher sea beach, sand hills along shore, roadside, garden, haunts of birds, insect visits to flowers, ground insects, insects in logs.

An alphabetical letter file may be used for filing individual field observations. These should be placed before the class orally or in writing. If accepted as reliable (repeated and revised if necessary), the observations should be filed 
away and credit given the student on a regular scale. Thus will grading and marks be placed to encourage intelligent study of nature rather than book or laboratory cram. One per cent to be added to the final grade may be credited for every species of pupa, every rare insect (with an observed fact as to its habits) brought in, every bird migration observed, every instance of protective coloration, mimicry (p. I46), outwitting of enemy, instance of injurious insects, and how to combat them, etc. Sharp eyes and clear reasoning will then count as much on school grades as a memory for words or mechanical following of laboratory directions. On scale of 100 , class work $=50$, examination $=25$, field $w$ ork $=25$.

Collecting Insects. - In cities and towns insects, varying with the season, are attracted by electric lights. Beetles and bugs will be found under the lights, moths on posts near the lights, grasshoppers and crickets and other insects in the grass near by. A lamp placed by a window brings many specimens. In the woods and in rocky places insects are found under logs and stones, and under the bark of dead trees. In open places, prairies, meadows, and old fields with grass and flowers, it will be easy to find grasshoppers, butterflies, and some beetles. Ponds and streams are usually rich in animal forms, such as bugs and beetles, which swim on or under the surface, and larvæ of dragon flies crawling on the bottom. Dragon flies and other insects that lay eggs on the water are found flying in the air above. (In the spring, newly hatched crawfish, tadpoles, and the eggs of frogs and toads should also be collected, if found.) Moths may be caught at night by daubing molasses or sirup made from brown sugar upon the trunks of several trees, and visiting the trees at intervals with a lantern.

An insect net for catching butterflies and for dredging ponds may be made by beñding a stout wire into a circle one foot in diameter, leaving enough straight wire to fasten with staples on an old broomstick. To the frame is fastened a flour sack, or cone made of a piece of mosquito netting.

Butterflies and moths should be promptly killed, or they will beat their wings to pieces. The quickest method is by dropping several drops of gasoline upon the ventral (under) side of the thorax and abdomen. (Caution: Gasoline should never be used near an open fire, or lamp, as explosions and deaths result from 
the flame being led through the gasoline-saturated air to the vessel containing it.)

A cigar box and a bottle with a notched cork may be used for holding specimens. Cigar boxes may be used for holding collections of dried insects. Cork or ribbed packing paper may be fixed in the bottom for supporting the insect pins. Moth balls or tobacco may be placed in each box to keep out the insect pests which infest collections.

It is pleasant and profitable to take to the fields a small book like this one, or even Comstock's "Manual of Insects," or Kellogg's "American Insects," and study the insects and their habits where they are found.

Captured insects which, in either the larval or perfect stage, are injurious to vegetation, should always be killed after studying their actions and external features, even if the internal structure is not to be studied. Beneficial insects, such as ladybugs, ichneumon flies, bees, mantis (devil's horse), dragon flies, etc., should be set free uninjured.

\section{Anatomy and General Characteristics of the Class INSECTA}

The body of an insect is divided by means of two marked narrowings into three parts: the head, chest, and abdomen.

The head is a freely movable capsule bearing four pairs of appendages. Hence it is regarded as having been formed by the union of four rings, since the ancestor of the insects is believed to have consisted of similar rings, each ring bearing a pair of unspecialized legs.

The typical mouth parts of an insect (Fig. I23) named in order

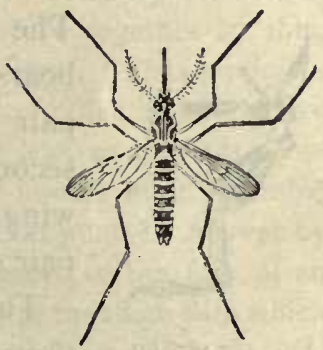

FIG. 122. - YELLOW FEVER Mosquito, showing head, thorax, abdomen.

from above, are (I) an upper lip (labrum, ol), (2) a pair 
of biting jaws (mandibles, ok), (3) a pair of grasping jaws (maxilla, $A, B$ ), and (4) a lower lip (labium, $m, a, b$ ).

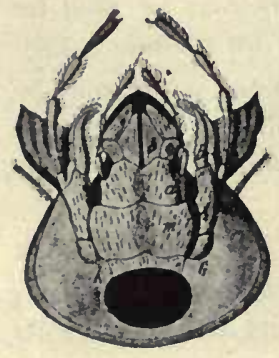

FIG. 123. - MOUTH

PARTS OF BEETLE. The grasping jaws bear two pairs of jointed jaw fingers (maxillary palpi, $D, C)$, and the lower lip bears a pair of similar lip fingers (labial palpi, $d$ ). The biting jaws move sideways; they usually have several pointed notches which serve as teeth. Why should the grasping jaws be beneath the chewing jaws? Why is it better for the lower lip to have fingers than the upper lip?

Why are the fingers (or palpi) jointed? (Watch a grasshopper or beetle eating.) Why does an insect need grasping jaws?

The chest, or thorax, consists of three rings (Fig. 124) called the front thorax (prothorax), middle thorax (mesothorax) and hind thorax (metathorax), or first, second, and third rings.

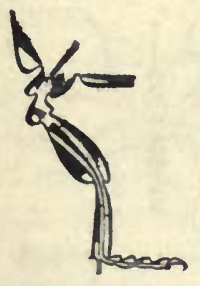

FIG. 125. - LEG OF INSFCT. The first ring bears the first

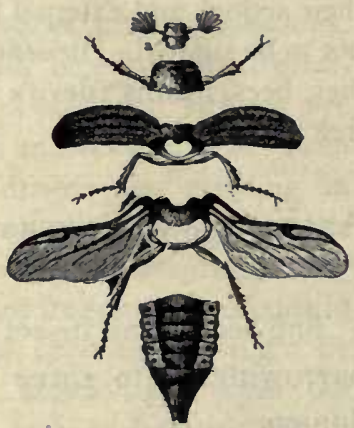

Fig. 124. - EXTERNAL PARTS OF A BEETLE. pair of legs, the second ring bears the second pair of legs and the upper or front wings, and the third ring bears the third pair of legs and the under or hind wings.

Thesix feet of insects are characteristic of them, since no other adult animals have that number, the spider having eight, the crawfish and crabs having ten, the centipedes still more, while the birds and beasts have less than six. Hence the insects 
are sometimes called the Six-Footed class (Hexapoda). The insects are the only animals that have the body in three divisions. Man, beasts, and birds have snly two divisions (head and trunk); worms are not divided.

Define the class insecta by the two facts characteristic of them (i.e. possessed by them alone), viz. : Insects are animals with — and Why would it be ambiguous to include "hard outer skeleton" in this definition? To include "bilateral symmetry"? "Segmented body"? The definition of a class must include all the individuals of the class, and exclude all the animals that do not belong to the class.

The leg of an insect (Fig. 125) has five joints (two short joints, two long, and the foot). Named in order from above, they are (1) the hip (coxa), (2) thigh ring (trochanter), (3) thigh (femur), (4) the shin (tibia), (5) the foot, which has five parts. Which of the five joints of a wasp's leg (Fig. 122) is thickest? Slenderest? Shortest? One joint (which?) of the foot (Fig. 1 22) is about as long as the other four joints of the foot combined. Is the relative length of the joints of the leg the same in

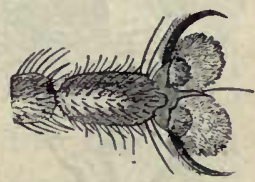

F1G. 126. - Foot OF FLY, with climbing pads. grasshoppers, beetles, etc., as in the wasp (Figs.)? Figure 125 is a diagram of an insect's leg cut lengthwise. The leg consists of thick-walled tubes $(o, n)$ with their ends held together by thin, easy-wrinkling membranes which serve as joints. Thus motion is provided for at the expense of strength. When handling live insects they should never be held by the legs, as the legs come off very easily. Does the joint motion of insects most resemble the motion of hinge joints or ball-and-socket joints? Answer by tests of living insects. There are no muscles in the foot of an insect. The claw is moved by a muscle $(m)$ in the thigh with which it is connected by the long tendon $(z, s, t, v)$. In which part are the breathing muscles? As the wings are developed from folds of the dorsal skin, the wing has two layers, an upper and a lower layer. These inclose the so-called "nerves" or ribs of the wing, each of which consists of a blood tube inclosed in an air tube. 
The abdomen in various species consists of from five io eleven overlapping rings with their foldlike joints between them. Does each ring overlap the ring in front or the one behind it ?

The food tube (Fig. 127) begins at the mouth, which usually bears salivary glands (4, Fig. 127, which represents internal organs of the grasshopper). The food tube expands first into a croplike enlargement; next to this is an organ (6, Fig. 127), which resembles the gizzard

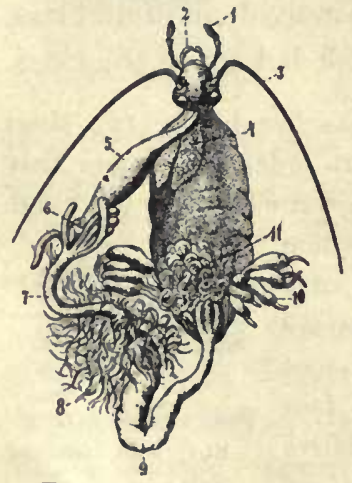

FIG. 127. - VISCERA OF Grasshopper. Key in text. Compare with Fig. $\mathrm{Ir}_{4}$.

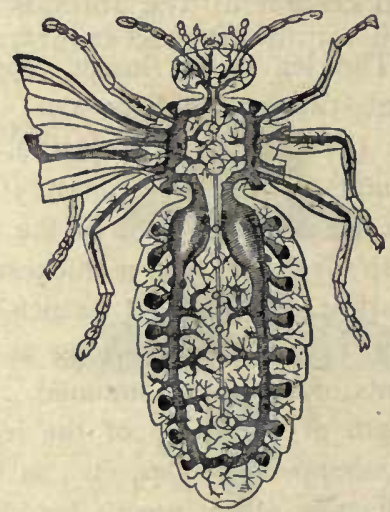

FIG. 128.-AIR TUBES OF INSECT.

in birds, as its inner wall is furnished with chitinous teeth (b, Fig. I 14). These reduce the food fragments that were imperfectly broken up by the biting jaws before swallowing. Glands comparable to the liver of higher animals open into the food tube where the stomach joins the small intestine. At the junction of the small and large intestine (9) are a number of fine tubes (8) which correspond to kidneys and empty their secretion into the large intestine.

The breathing organs of the insects are peculiar to them (see Fig. 128). They consist of tubes which are 
kept open by having in their walls continuous spirals of horny material called chitin. Most noticeable are the two large membranous tubes filled with air and situated on each side of the body. Do these tubes extend through the thorax? (Fig. 128.) The air reaches these two main tubes by a number of pairs of short windpipes, or tracheas, which begin at openings (spiracles). In which division are the spiracles most numerous? (Fig. 128.)
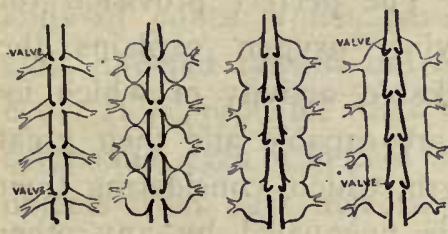

Fig. I30.-DIAGRAMS OF Evolution OF PERICARDIAL, SAC around insect's heart from a number of veins (Lankester).

Which division is without spiracles? Could an insect

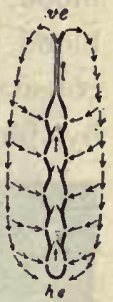

FIG. I29. INSECT'S HEART (plan). be drowned, i.e. smothered, by holding its body under water? Could it be drowned by immersing all of it but its head? The motion of the air through the breathing tubes is caused by a bellowslike motion of the abdomen. This is readily observed in grasshoppers, beetles, and wasps. As each ring slips into the ring in front of it, the abdomen is shortened, and the impure air, laden with carbon dioxid, is forced out. As the rings slip out, the abdomen is extended and the fresh air comes in, bringing oxygen.

\section{The Circulation. -}

Near the dorsal surface of the abdomen (Fig.

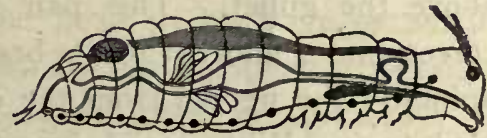

I 3 I) extends the long, slender heart (Fig. I29). The heart has divisions separated by valvelike partitions. The blood comes into each of the heart compartments through a pair of openings. The heart contracts from the rear toward 
the front, driving the blood forward. The blood contains bodies corresponding to the white corpuscles of human blood, but lacks the red corpuscles and the red color. The blood is sent even to the wings. The veins in the wings consist of horny tubes inclosing air tubes surrounded by blood spaces, and the purification of the blood is

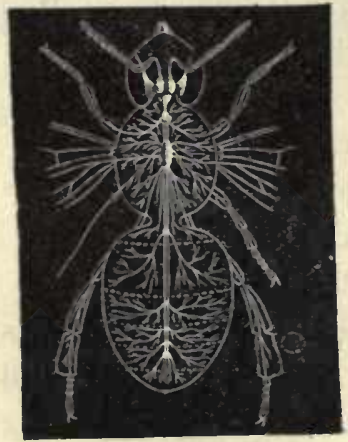

FIG. I32. - Nervous SYSTEM OF BEE. taking place throughout the course of the circulation. Hence the imperfect circulation is no disadvantage. The perfect provision for supplying oxygen explains the remarkable activity of which insects are capable and their great strength, which, considering their size, is unequaled by any other animals.

The Nervous System. - The heart in backboned animals, e.g. man, is ventral and the chief nerve trunk is dorsal. As already stated, the heart of an insect is dorsal; its chief nerve chain, consisting of a double row of ganglia, is near the ventral surface (Fig. I3I). All the ganglia are below the food tube except the first pair in the head, which are above the gullet. This pair may be said to correspond somewhat to the brain of backboned animals; the nerves from the eyes and feelers lead to it. With social insects, as bees and ants, it is large and complex (Fig. 132). In a typical insect they are the largest ganglia.

The Senses. - The sense of smell of most insects is believed to be located in the feelers.

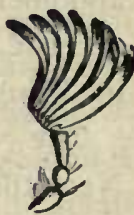

FIG. 133.FEELER of a beetle. The organ of hearing is variously located in different insects. Where is it in the grasshopper? The organs of 
sight are highly developed, and consist of two compound eyes on the side of the head and three simple eyes on the top or front of the head between the compound eyes. The simple eye has nerve cells, pigments, and a lens resembling the lens in the eyes of vertebrates (Fig. 134). The compound eye (Fig. 135) has thousands of facets, usually hexagonal, on its surface, the facets being the outer ends of cones which have their inner ends directed toward the center of the eye. It is probable that the large, or

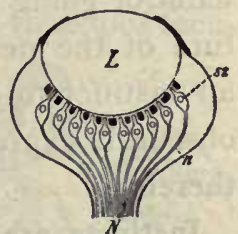

FIc, 134.-Diagram of simple eye of insect.

$L$, lens: $N$, optic nerve. compound, eyes of insects only serve to distinguish bright objects from dark objects. The simple eyes afford dis-

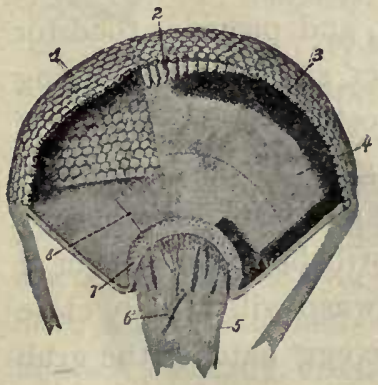

FIG. 135. - COMPOUND EYE OF INSECT.

$\mathbf{r}$, hexagonal facets of crystalline cones. 6 , blood vessel in optic nerve. tinct images of objects within a few inches of the eye. In general, the sight of insects, contrary to what its complex sight organs would lead us to expect, is not at all keen. Yet an insect can fly through a forest without striking a twig or branch. Is it better for the eyes that are immovable in the head to be large or small? Which has comparatively larger eyes, an insect or a beast?

Inherited Habit, or Instinct. - Insects and other animals inherit from their parents their particular form of body and of organs which perform the different functions. For example, they inherit a nervous system with a structure similar to that of their parents, and hence with a tendency to repeat similar impulses and acts. Repeated acts constitute a habit, and an inherited habit is called an in. 
stinct. Moths, for example, are used to finding nectar in the night-blooming flowers, most of which are white. The habit of going to white flowers is transmitted in the structure of the nervous system; so we say that moths have an instinct to go to white objects; it is sometimes more obscurely expressed by saying they are attracted or drawn thereby.

Instincts are not Infallible. - They are trustworthy in only one narrow set of conditions. Now that man makes many fires and lights at night, the instinct just mentioned often causes the death of the moth. The instinct to provide for offspring is necessary to the perpetuation of all but the simplest animals. The dirt dauber, or mud wasp, because of inherited habit, or instinct, makes the cell of the right size, lays the egg, and provides food for offspring that the mother will never see. It seals stung and semiparalyzed spiders in the cell with the egg. If you try the experiment of removing the food before the cell is closed, the insect will bring more spiders; if they are removed again, a third supply will be brought; but if taken out the third time, the mud wasp will usually close the cell without food, and when the egg hatches the grub will starve.

The Development of Insects. - The growth and molting of the grasshopper from egg to adult has been studied. All insects do not develop exactly by this plan. Some hatch from the egg in a condition markedly different from the adult. The butterfly's egg produces a wormlike caterpillar which has no resemblance to the butterfly. After it grows it forms an inclosing case in which it spends a quiet period of development and comes out a butterfly. This change from caterpillar to butterfly is called the metamorphosis. The life of an insect is divided into four 
stages: (1) egg, (2) larva, (3) pupa, and (4) imaga, or perfect insect (Figs. I 36, I 37, I38).

The egg stage is one of development, no nourishment being absorbed. The larval stage is one of voracious feeding and rapid growth. In the pupa stage no food is taken and there is no growth in size, but rapid development takes place. In the perfect stage food is eaten, but no growth in size takes place. In this stage the eggs are produced. When

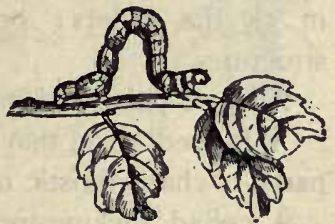

FIG. I36. - Measuring worm, the larva of a moth.

there is very little resemblance between

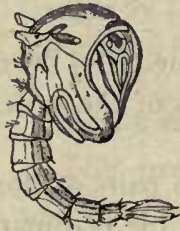
the larva and imago, and no pupal stage, the metamorphosis, or change, is said to be complete. When, as with the grasshopper, no very marked change takes place between the larva and imago, there being no pupal stage, the metamorphosis is said to be in-

FIG. 137.-Pupa of a mosquito.

complete. By studying the illustrations and specimens, and by thinking of your past observations of insects, determine which of the insects in the following list have a complete metamorphosis: beetle, house fly, grasshopper, butterfly, cricket, wasp.
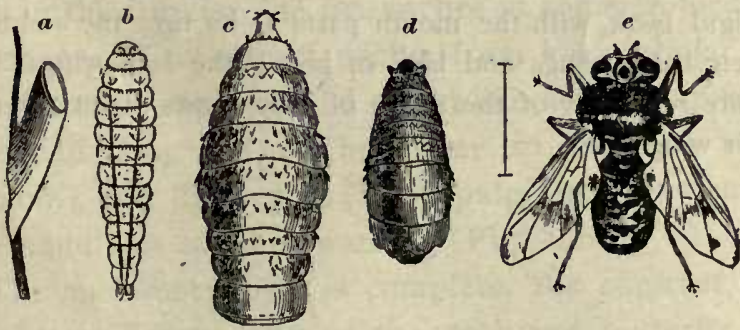

Fig. 138. - The Four Stages of A Botfly, all enlarged.

$a$, egg on hair of horse (bitten off and swallowed); $b$, larva; $c$, larva with hooks for holding to lining of stomach; $d$, pupal stage, passed in the earth; $e$, adult horse fly. 


\section{RECOGNITION-CHARACTERS FOR THE PRINCIPAL ORDERS OF ADULT WINGED INSECTS}

(All are wingless when young, and wingless adult forms occur in all the orders: order APTERA lacks wing-bearing thoracic structures.)

A single pair of wings is characteristic of the order DIPTERA.

A jointed beak, that is sheath-like, inclosing the other mouth parts, is characteristic of the order Hemiptera.

A coiled sucking proboscis and a wing covering of dust-like microscopic scales are characteristic of the order LEPIDOPTERA.

Horny sheath-like fore wings, covering the hind wings and meeting in a straight line down the niddle of the back, will distinguish the order ColeEOPTERA.

Hind wings folded like a fan beneath the thickened and overlapping fore wings, will distinguish most members of the order ORTHOPTERA.

The possession of a sting (in females) and of two pairs of thin membranous wings - the small hind wing hooked to the rear margin of the fore wing - will distinguish the common HyMenoptera.

Besides these, there remain a number of groups most of which have in the past been included under the order Neuroptera, among which the Mayflies will be readily recognized by the lack of mouth parts and by the possession of two or three long tails; the dragon flies by the two pairs of large wings, enormous eyes, and minute bristle-like antennæ; the scorpion flies, by the possession of a rigid beak, with the mouth parts at its tip ; the caddis flies, by their hairy wings and lack of jaws; the lace wings, by the exquisite regularity of the series of cross veins about the margin of their wings, etc. 


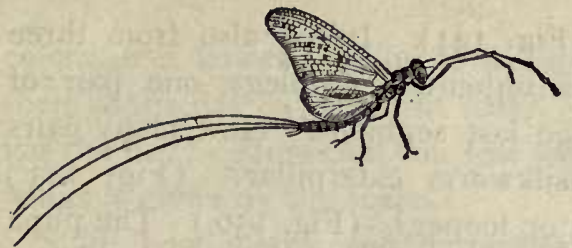

F1G, 139. - MAY FLY. What order (see table)?

Exercise in the Use of the Table or Key.Write the name of the order after each of the following names of insects :-

Wasp (Fig..I22)

Weevil (Fig. I63)

Squash bug ( Fig. 184)

Ant lion (Fig. 170)

Dragon fly (Fig. 177)

Ichneumon fly (Fig. I59)
House fly (Fig. I72)

Flea (Fig. 173)

Silver scale or earwig

(Fig. 140)

Codling moth (Fig. I4I)

Botfly (Fig. I 38 )

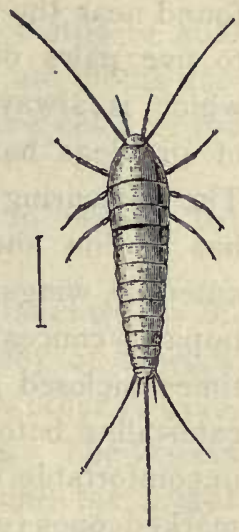

FIG. I40. - SILVER SCALE. (Order?)

\section{Moths and Butterflies. - Order__ ? Why__ (p. 82)?}

The presence of scales on the wings is a never-failing test of a moth or butterfly. The wings do not fold at all. They are so large and the legs so weak and delicate that the butterfly keeps its balance with difficulty when walking in the wind.

The maxillæ are developed to form the long sucking proboscis. How do they fit together to form a tube? (See Fig. 147.) The proboscis varies from a fraction of an inch in the "miller" to five inches in some tropical moths, which use it to extract nectar from long tubular flowers. When not in use, it is held coiled like a watch spring under the head (Fig. 148). The upper lip (labrum), under lip (labium), and lip fingers (labial palpi) are very small, and the mandibles small or wanting (Fig. 146).

The metamorphosis is complete, the contrast between the caterpillar or larva of the moth and butterfly and the adult form being very great. The caterpillar has the three pairs of jointed legs typical of insects; these are 
found near the head (Fig. I4I). It has also from three to five pairș of fleshy unjointed proplegs, one pair of which is always on the last segment. How many pairs of proplegs has the silkworm caterpillar? (Fig. 143.) The measuring worm, or looper? (Fig. 136.) The pupa has a thin shell. Can you see external signs of the antennæ, wings, and legs in this stage? (Fig. 143.) The pupa is concealed by protective coloration, and is sometimes inclosed in a silken cocoon which was spun by the caterpillar before the last molt. Hairy caterpillars are uncomfortable for birds to eat. The naked and brightly marked ones (examples of warning coloration) often contain an acrid and distasteful fluid. The injuries from lepidoptera are done in the caterpillar stage. The codling moth (Fig. I4I) destroys apples to the estimated value of $\$ 6,000,000$ annually. The clothes moth (Fig. 17 1 ) is a household pest. The tent caterpillar denudes trees of their leaves. The only useful caterpillar is the silkworm (Fig. 143). In Italy and Japan many of the country dwellings have silk rooms where thousands of these caterpillars are fed and tended by women and children. Why is the cabbage butterfly so called? Why can it not eat cabbage? Why does sealing clothes in a paper bag prevent the ravages of the clothes moth?

Flight of Lepidoptera. - Which appears to use more exertion to keep afloat, a bird or a butterfly? Explain why. Of all flying insects which would more probably be found highest up mountains? How does the butterfly suddenly change direction of flight? Does it usually fly in a straight or zigzag course? Advantage of this? Bright colors are protective, as lepidoptera are in greatest danger when at rest on flowers. Are the brightest colors on upper or under side of wings of butterfly? Why? (Think of the 
colors in a flower.) Why is it better for moths to hold their wings flat out when at rest? Where are moths during the day? How can you test whether the color of the wings is given by the scales?

State how moths and butterflies differ in respect to: body, wings, feelers, habits.

Insects and Flowers. - Perhaps we are indebted to insects for the bright colors and sweet honey of flowers. Flowers need insects to carry their pollen to other flowers, as cross-fertilization produces the best seeds. The insects need the nectar of the flowers for food, and the bright colors and sweet odors are the advertisements of the flowers to attract insects. Flowers of brightest hues are the ones that receive the visits of insects. Moths, butterflies, and bees carry most pollen (see Plant Biology, Chap. VI).

Comparative Study. - Make a table like this, occupying entire page of notebook, leaving no margins, and fill in accurately:-

\begin{tabular}{|c|c|c|c|c|c|c|}
\hline 3 & $\begin{array}{l}\text { GRASS- } \\
\text { HOPPER }\end{array}$ & $\begin{array}{l}\text { BUTTER- } \\
\text { FLY }\end{array}$ & $\begin{array}{c}\text { FLY } \\
\text { pp. } 92,93\end{array}$ & $\begin{array}{r}\text { DRAGON } \\
\text { FLY, p. } 93 \\
\end{array}$ & $\begin{array}{r}\text { BEETLE } \\
\text { pp. } 90,9 \mathrm{I} \\
\end{array}$ & $\begin{array}{c}\text { BEE } \\
\text { pp. } 88,89\end{array}$ \\
\hline \multicolumn{7}{|l|}{$\begin{array}{l}\text { Number and kind } \\
\text { of wings }\end{array}$} \\
\hline \multicolumn{7}{|l|}{ Description of legs } \\
\hline \multicolumn{7}{|l|}{$\begin{array}{l}\text { Antennæ (length, } \\
\text { shape, joints) }\end{array}$} \\
\hline \multicolumn{7}{|l|}{$\begin{array}{l}\text { Biting or sucking } \\
\text { mouth parts }\end{array}$} \\
\hline $\begin{array}{l}\text { Complete or incom- } \\
\text { plete metamor- } \\
\text { phosis }\end{array}$ & & & & & & \\
\hline
\end{tabular}




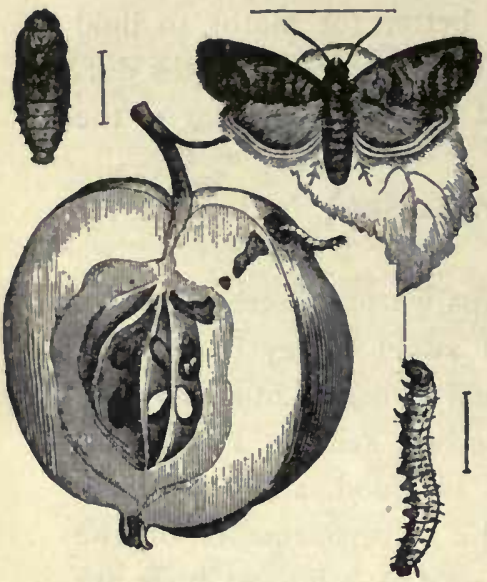

Fig. 14I. - CoDLiNG Moth, from egg to adult. (See Farmers' Bulletin, p. 95.)

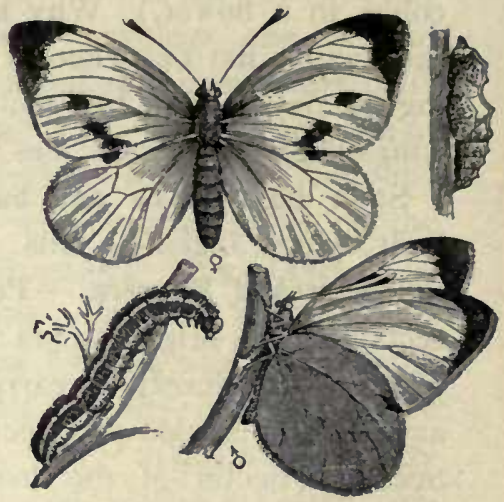

Fig. 142, - Cabbage Butterfly, male and female, larva and pupa.

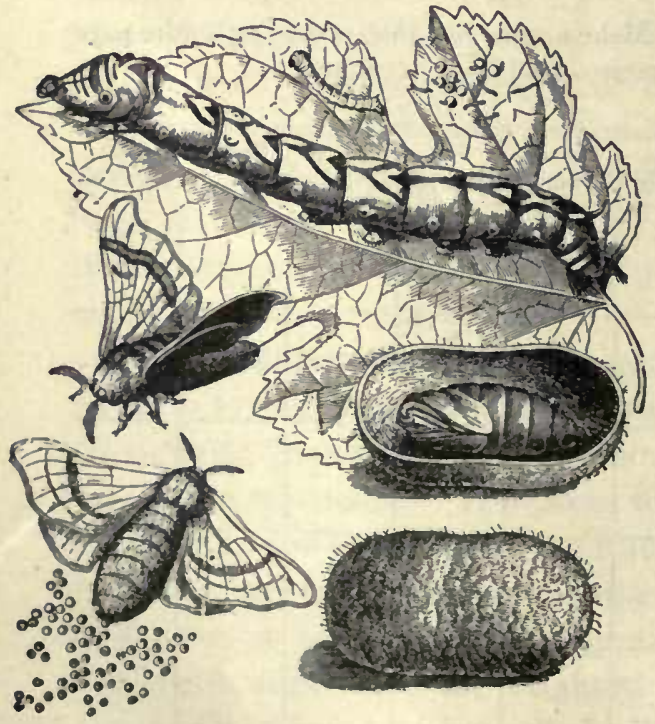

FIG. I43. - LIFE HISTORY OF SILKWORM.
(1)
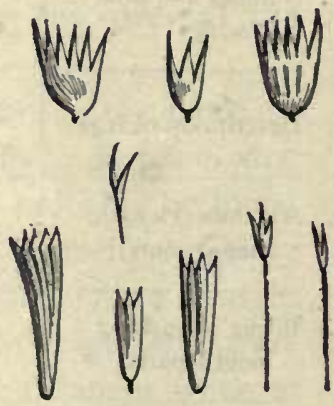

FIG. 144. - SCALES FROM BUTTERFLIES' WINGS, as seen under microscope. 
TO THE TEACHER: These illustrated studies require slower and more careful study than the text. One, or at most troo, studies will suffice for a lesson. The questions can be answered by studying the figures. Weak observers will often fail and they should not be told, but should try again until they succeed.

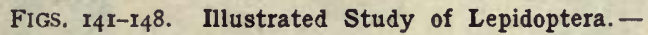
Study the stages in the development of codling moth, silkworm moth, and cabbage butterfly.

Where does each lay its eggs? What does the larva of each feed upon? Describe the pupa of each. Describe the adult forms. Find the spiracles and prolegs on the silkworm. Compare antenne of moth and butterfly. Which has larger body compared to size of wings ?

Describe the scales from a butterfly's wings as seen under microscope (144). How are the scales arranged on moth's wing (I45)? By what part is scale attached to wing? Do the scales overlap?

Study butterfly's head and proboscis (Figs. 146-148). What shape is compound eye? Are the antennæ jointed? Is the proboscis jointed? Why not call it a tongue? (See text.)

Which mouth parts have almost disappeared? What is the shape of cut ends of halves of proboscis? How are the halves joined to form a tube?

If you saw a buttelfy on a flower, for what purpose would you think it was there? What, if you saw it on a leaf? How many spots on fore wing of female cabbage butterfly? (Fig. 124, above.)

Does the silkworm chrysalis fill its cocoon ? Eggs may be obtained from U. S. Dept. of Agriculture.

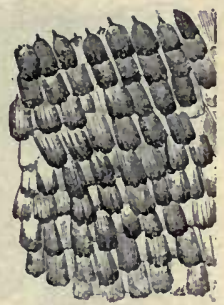

FIG. I45.-SCALES ON MOTH'S WING.

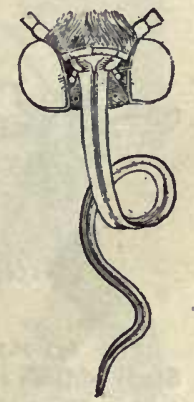

FIG. 146. - HEAD OF BUtTERFly.
FIG. $148 .-\mathrm{HEAD}$ OF BUTTERFLY (side view).

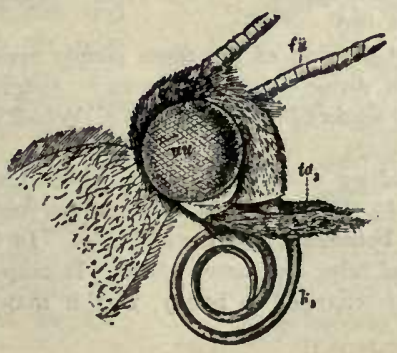

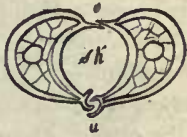

FIG. I47. - SECTION of PRoBoscis of butterfly showing lapping jount and dovetail joint. 


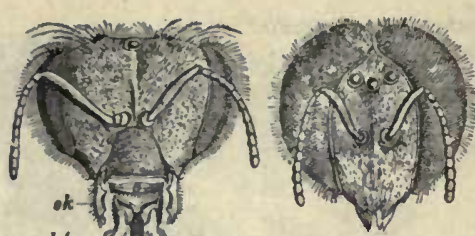

F1G. 150.

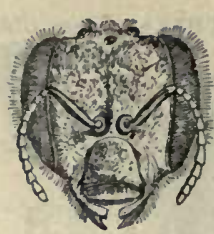

F1G. 151.

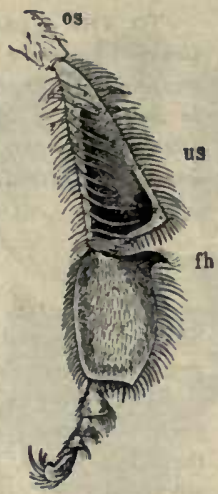

FIG. 152.

FIG. 153.

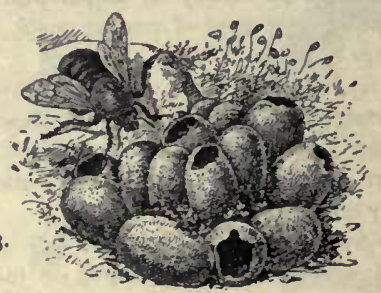

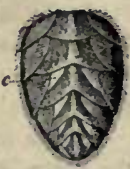

FIG. 157.

Fig. 154 .

F1G. 155 .

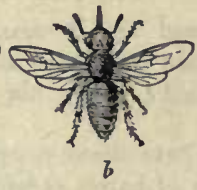

F1G. 156.

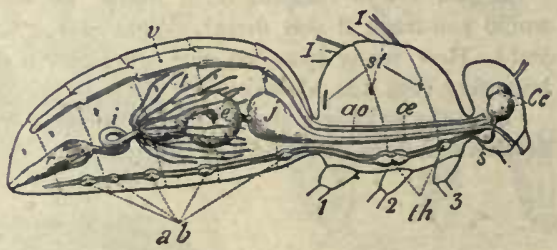

FIG. 158.--Anatomy of bee.

FIGS. 149-161. Illustrated Study of Bees and their Kindred. - Head of worker (Fig. 149) : o, upper lip; ok, chewing jaws; $u k$, grasping jaws; $k t$, jaw finger: $2 t$, lip finger; $z$, tongue.

How do heads of drone (150) and queen (15I) differ as to mouth, size of the two compound eyes, size and position of the three simple eyes? Is the head of a worker more like head of drone or head of queen? Judging by the head, which is the queen, drone, and worker in Figs. $154^{-1} 5^{6}$ ? Which of the three is largest ? Smallest? Broadest?

Figure 152 shows hind leg of worker. What surrounds the hollow, $u s$, which serves as pollen basket? The point, $f h$, is a tool for removing wax which is secreted (c, Fig. 157) between rings on abdomen. In Fig. 158, find relative positions of heart, $v$, food tube, and nerve chain. Is crop, $J$, in thorax or abdomen? In this nectar is changed to honey, that it may not spoil. Compare nerve chain in Fig. 132. 
Compare the cells of bumble bee (Fig. 153) with those of hive bee. They differ not only in shape but in material, being made of web instead of wax, and they usually contain larvæ instead of honey. Only a few of the queens among bumble bees and wasps survive the winter. How do ants and honey bees provide for the workers

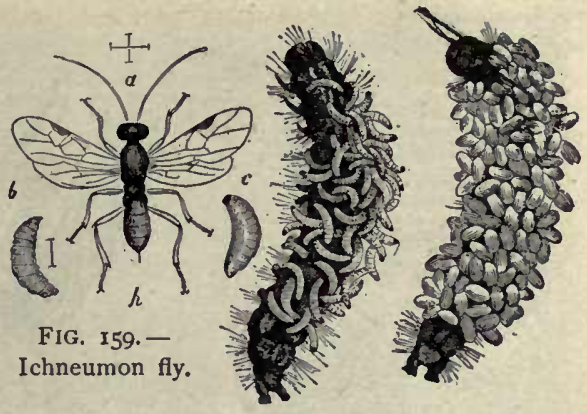
also to survive the winter? Name all the social insects that you can think of. Do they all belong to the same order?

The ichneumon fly shown enlarged in Fig. 159 lays its eggs under a caterpillar's skin. What becomes of the eggs? The true size of the insect is shown by the cross lines at $a$. The eggs are almost microscopic in size. The pupæ shown (true size) on caterpillar are sometimes mistaken for eggs. The same mistake is made about the pupa cases of ants. Ichneumon flies also use tree-borers as "hosts" for their eggs and larva. Is this insect a friend of man?

The digging wasp (Figs, 160 and $16 \mathrm{r}$ ) supplies its larva with caterpillars and closes the hole, sometimes using a stone

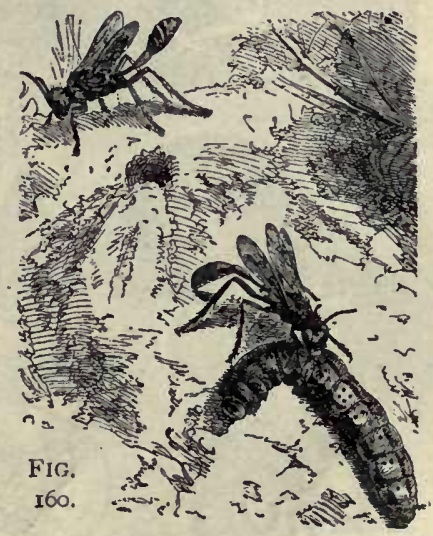
as pounding tool. Among the few other uses of tools among lower animals are the elephant's use of a branch for a fly brush, and the ape's use of a walking stick. This wasp digs with fore feet like a dog and kicks the dirt out of the way with its hind feet.

Are the wings of bees and wasps more closely or less closely veined than the wings of dragon flies? (Fig. 177.) For an interesting account of the order "Joined-wings" (bees and their kindred) see Comstock's "Ways of the Sixfooted," Ginn \& Co.

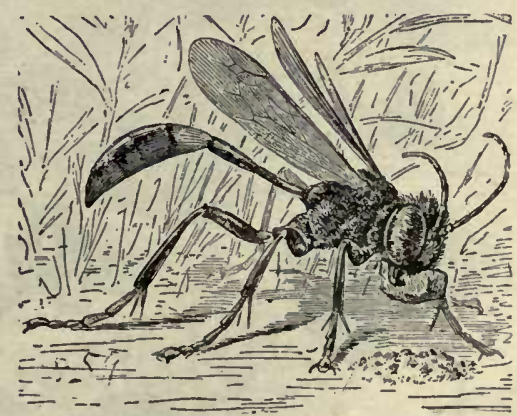

FIG. I6r. - Wasp using pebble.

From Peckham's "Solitary Wasps," Houghton, Miftlin \& Co. 


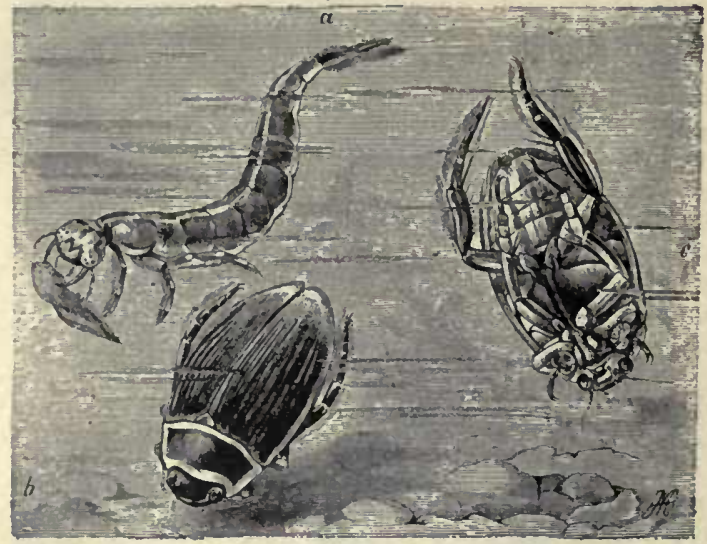

\author{
Illustrated \\ Study of \\ Beetles.
}

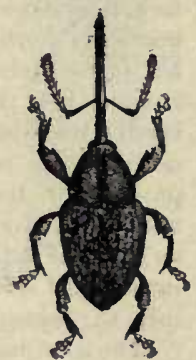

FIG. 162. - Diving beetle (Dysticus), with larva, a. FIG. 163. - Weevil.

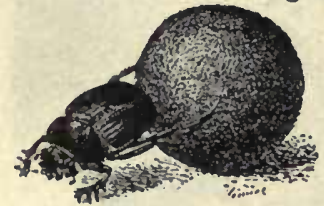

Fig. I64.

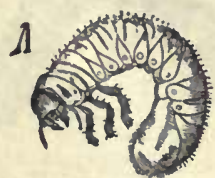

FIG. 167. - MAY BEETLE.

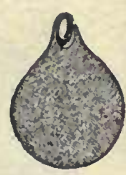

FIG. 165.
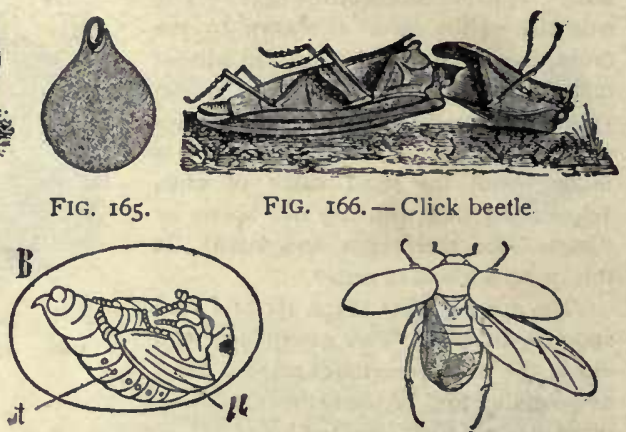

FIG. 166. - Click beetle

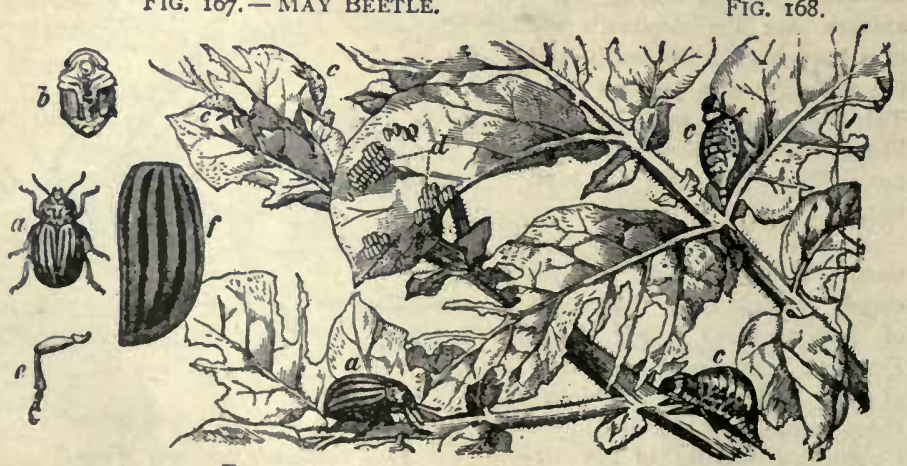

FIG. I69. - Colorado beetle (potato bug). 
Illustrated Study of Beetles (Figs, $162-169$ ). - Write the life history of the Colorado beetle, or potato bug (Fig. I69), stating where the eggs are laid and describing the form and activities of each stage (the pupal stage, $b$, is passed in the ground).

Do the same for the May beetle (Figs. I67-I68). (It is a larva - the white grub - for three years; hogs root them up.) Beetles, like moths, may be trapped with a lantern set above a tub of water.

Where does a Scarab (or sacred beetle of the Egyptians), also called tumble bug (Fig. I64), lay its eggs (Fig. I65)? Why ?

How does the click̋ beetle, or jack snapper (Fig. I66), throw itself into the air? For what purpose?

The large proboscis of the weevil (Fig. I63) is used for piercing a hole in which an egg is laid in grain of corn, boll of cotton, acorn, chestnut, plum, etc.

How are the legs and body of the diving beetle suited for swimming (Fig. I62)? Describe its larva.

What is the shape of the lady bug (Fig. 97)? It feeds upon plant lice (Fig. I85). Is any beetle of benefit to man?

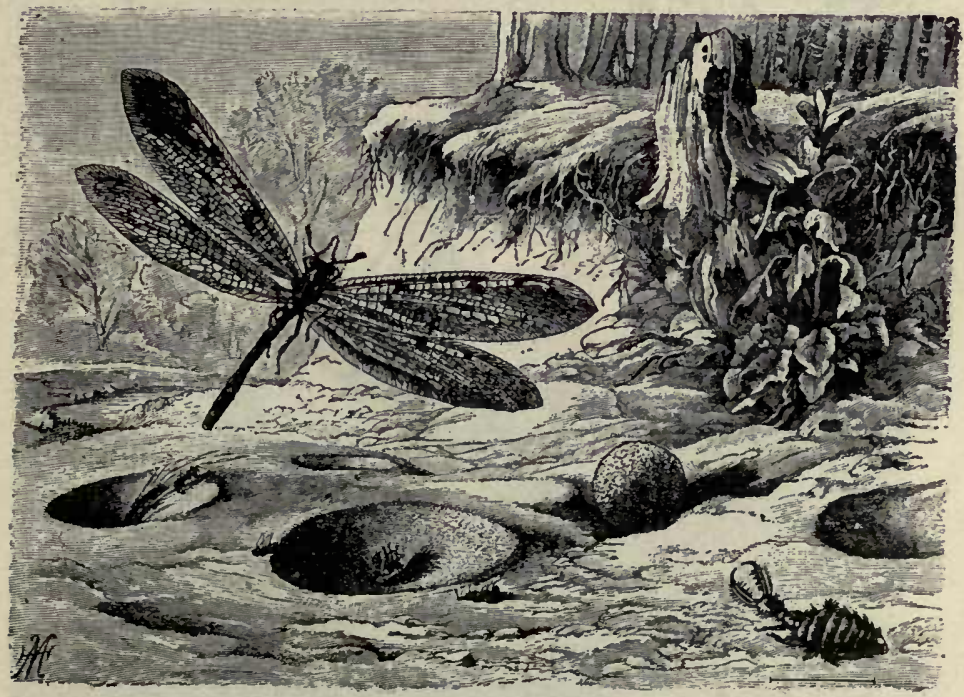

FIG. I70. - Life history of ant lion.

Illustrated Study of Ant Lion, or Doodle Bug (Fig. I70). - Find the pitfall (what shape?) ; the larva (describe it) ; the pupa case (ball covered with web and sand); the imago. Compare imago with dragon fly (Fig. 177).

How does ant lion prevent ant from climbing out of pitfall (see Fig. 170)? What is on edge of nearest pitfall? Explain.

Ant lions may be kept in a box half filled with sand and fed on ants. How is the pitfall dug? What part of ant is eaten? How is unused food removed?

How long is it in the larval state? Pupal state? Keep net over box to prevent adult from flying away when it emerges. 


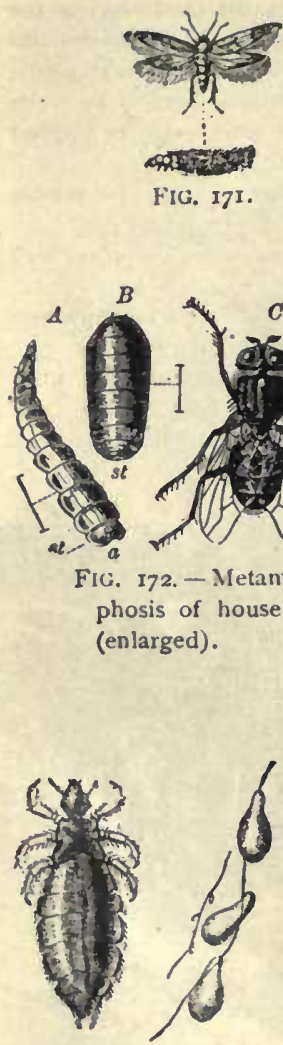

FI(i, 174, - Louse and its eggs attached to a hair. Natural size and magnified.

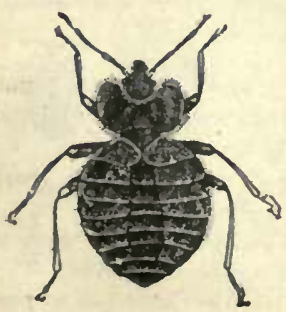

Fic. $175 .-$ Bed bug. $\times 5$.

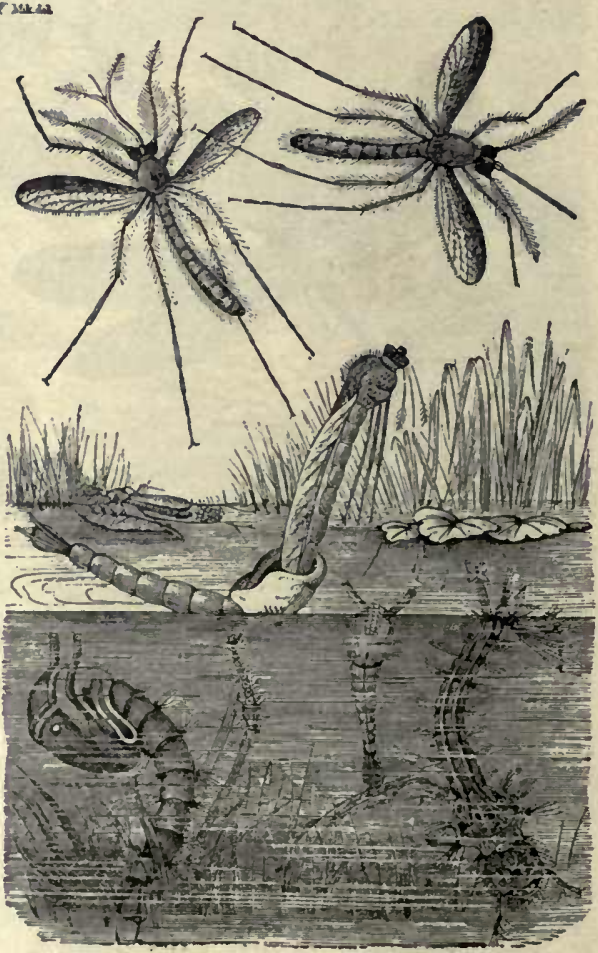

FIG. I76. - I ife history of mosquito. 
Illustrated Study of Insect Pests (Figs, r7 $1-176)$. - Why does the clothes moth (I7I) lay its eggs upon woolen clothing? How does the larva conceal itself ? The larva can cut through paper and cotton, yet sealing clothes in bags of paper or cotton protects them. Explain.

The house fly eats liquid sweets. It lays its eggs in horse dung. Describe its larval and pupal forms. Banishing horses from city would have what beneficial effect?

Describe the louse and its eggs, which are shown attached to a hair, natural size and enlarged.

Describe the bed bug. Benzine poured in cracks kills bed bugs. Do bed bugs bite or suck ? Why are they wingless ?

Describe the larva, $f_{1}$ pupa, $g$, and the adult flea, all shown enlarged. Its mandibles, $b, b$, are used for piercing. To kill fleas lather dog or cat completely and let lather remain on five minutes before washing. Eggs are laid and first stages passed in the ground.

How does the mosquito lay its eggs in the water without drowning (I76) ? Why are the eggs always laid in still water? Which part of the larva (wiggletail) is held to the surface in breathing? What part of the pupa (called tumbler, or bull head) is held to the surface in breathing? Give differences in larva and pupa. Where does pupa change to perfect insect? Describe mouth parts of male mosquito (at left) and female (at right). Only female mosquitoes suck blood. Males suck juice of plants. Malarial mosquito alights with hind end of body raised at an angle. For figure see Human Biology, Chap. X. Why does killing fish and frogs increase mosquitoes? I oz. of kerosene for $\mathrm{I}_{5} \mathrm{ft}$. of surface of water, renewed monthly, prevents mosquitoes.

What is the use to the squash bug (Fig. 184) of having so bad an odor?

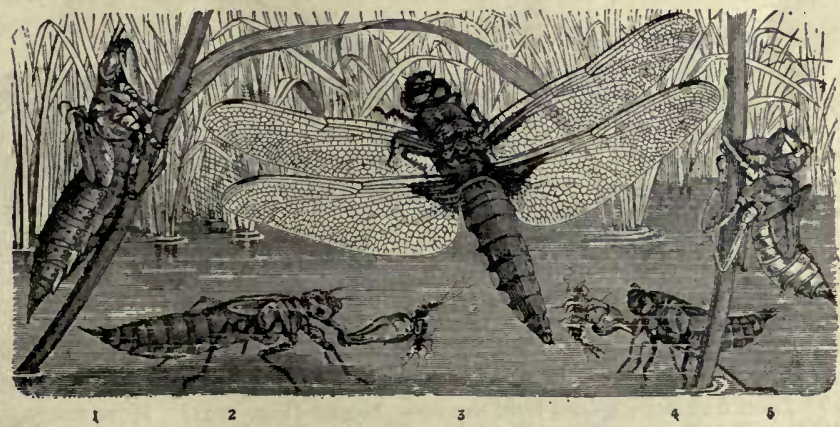

FIG. 177. Illustrated Study of Dragon Fly. -3 shows dragon fly laying its eggs in water while poised on wing. Describe the larval form (water tiger). The extensible tongs are the maxillæ enlarged. The pupa (I) is active and lives in water. Where does transformation to adult take place (5)? Why are eyes of adult large? its legs small? Compare front and hind wings.

Do the eyes touch each other? Why is a long abdomen useful in flight? Why would long feelers be useless? What is the time of greatest danger in the development of the dragon fly? What other appropriate name has this insect? Why should we never kill a dragon fly? 

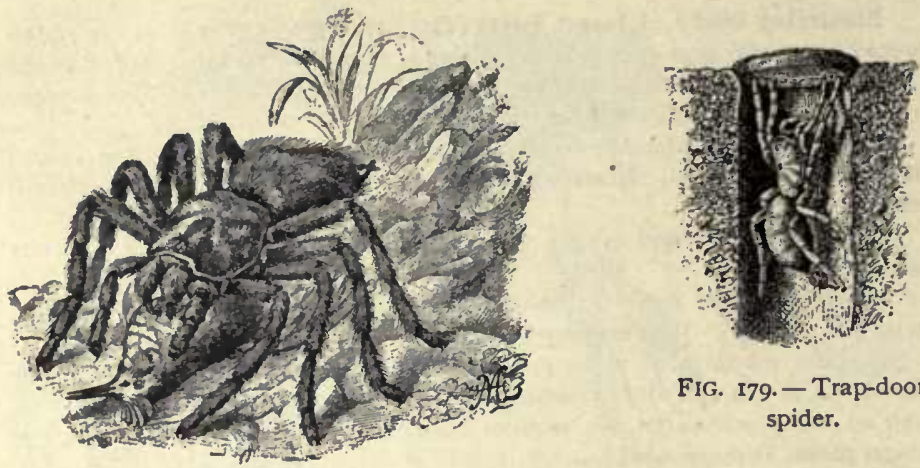

FIG. I79. - Trap-door spider.

FIG. 178. - The tarantula.

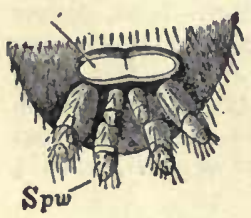

FIG. I80.

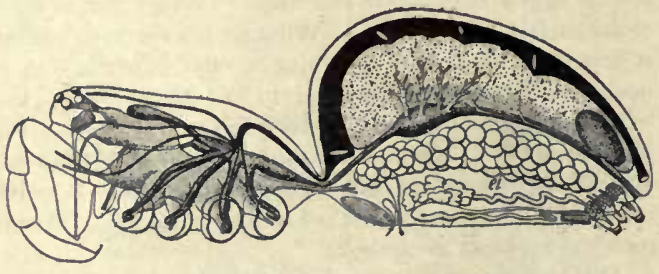

FIG. I8I. - Anatomy of spider.

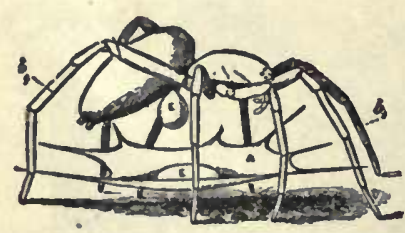

FIG. I82. - Laying egg.

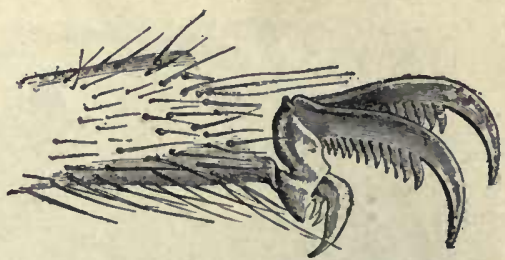

FIG. I83. - Foot of spider.

Illustrated Study of Spiders (Figs. 178-183). - The tarantula, like most spiders, has eight simple eyes (none compound). Find them (Fig. I78). How do spiders and insects differ in body? Number of legs ? Which have more joints to legs? Does trap-door spider hold the door closed (Fig. I79)? How many pairs of spinnerets for spinning web has a spider (Spw, I80)? Foot of spider has how many claws? How many combs on claws for holding web? Spiders spin a cocoon for holding eggs. From what part of abdomen are eggs laid $\left(E, 1_{82}\right.$; $2, I 8 I)$ ? Find spider's air sacs, $l u$, Fig. I8I; spinning organs, $s p$; fang, $k f$; poison gland, $g$; palpi, kt; eyes, au; nerve ganglia, og, ug; sucking tube, sr; stomach, $d$; intestine, $m a$; liver, $l e ;$ heart, $h$, (black); vent, $a$. Give two reasons why a spider is not an insect. How does it place its feet at each step (Fig. Iro)? (Does the size of its nerve ganglia indicate great or little intelligence? Why do you think first part of body corresponds to both head and thorax of insects ? 
The following Farmer's Bulletins are available for free distribution to those interested, by the U. S. Department of Agriculture, Washington, D.C. :-

Farmer's Bulletin No. 47, Insects affecting the Cotton Plant; No. 59, Bee Keeping; No. 70, The Principal Insect Enemies of the Grape; No. 8o, The Peach Twig Borer; No. 99, Three Insect Enemies of Shade Trees; No. I 20, The Principal Insects affecting the Tobacco Plant; No. 127, Important Insecticides; No. 132, The Principal Insect Enemies of Growing Wheat; No. 145, Carbon Bisulphid as an Insecticide; No. 146, Insecticides and Fungicides; No. 152,

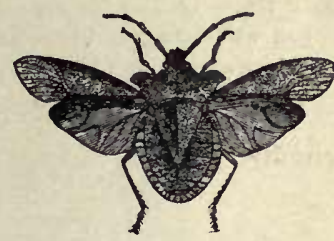

FIG. 184. - Squash bug, or stink bug. revised, Mange in Cattle; No. 153 , Orchard Enemies in the Pacific Northwest ; No. 155, How Insects affect Health in Rural Districts; No. 159 , Scab in Sheep; No. 165 , Silkworm Culture; No. 171, The Control of the Codling Moth; No. 172, Scale Insects and Mites on Citrus Trees; No. 196, Usefulness of the Toad; No. 209, Controlling the Boll Weevil in Cotton Seed and at Ginneries; No. 21 I, The Use of Paris Green in controlling the
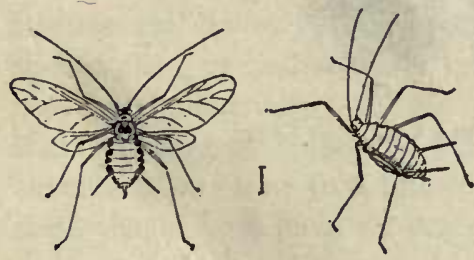

F1G. I85. - Female plant louse, with and without wings (enlarged). Cotton Boll Weevil ; No. 2 I2, The Cotton Bollworm; No. 216, The Control of the Boll Weevil; No. 223, Miscellaneous Cotton Insects in Texas; No. 247, The Control of the Codling Moth and Apple Scab. The following bulletins of the Bureau of Entomology may be obtained from the same source at the prices affixed: Bulletin No. 25 (old series), Destructive Locusts, $1_{5}$ c.; No. I (new series), The Honey Bee, r5c.; No. 3, The San José Scale, roc.; No. 4, The Principal Household Insects of the U. S., I oc.; No. I , The Gypsy Moth in America, 5c.; No. I4, The Periodical Cicada, 15c.; No. 15, The Chinch Bug, Ioc.; No. 16, The Hessian Fly, Ioc.; Nos. 19, 23, and 33, Insects Injurious to Vegetables, Ioc. 
each; No. 25, Notes on Mosquitoes of the U. S., roc.; No. 42 Some Insects attacking the Stems of Growing Wheat, Rye, Barley,
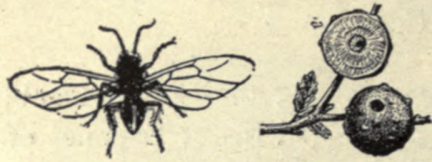

FIG. I86.- Gall fly (enlarged) and oak gall with larva, and one from which a developed insect has escaped. and Oats, 5c.; No. 5o, The Cotton Bollworm, 25c.; No. $5 \mathrm{I}$, The Mexican Boll Weevil, $25 \mathrm{c}$.

Bureau of Plant ? idustry Bulletin No. 88, Weevil-resisting Adaptations of the Cotton Plant, roc. This gives an instructive account of the struggle of a plant for existence against an insect enemy.

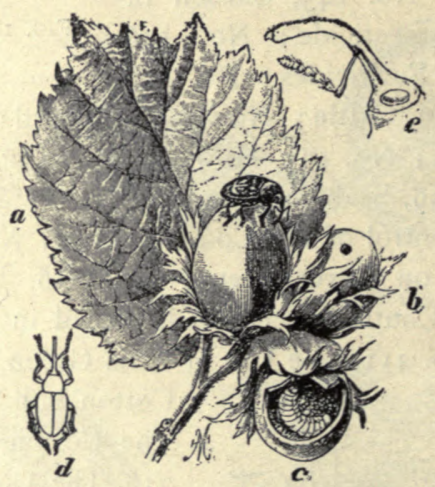

FIG. 187.-Weevil on a Corylus or filbert. 


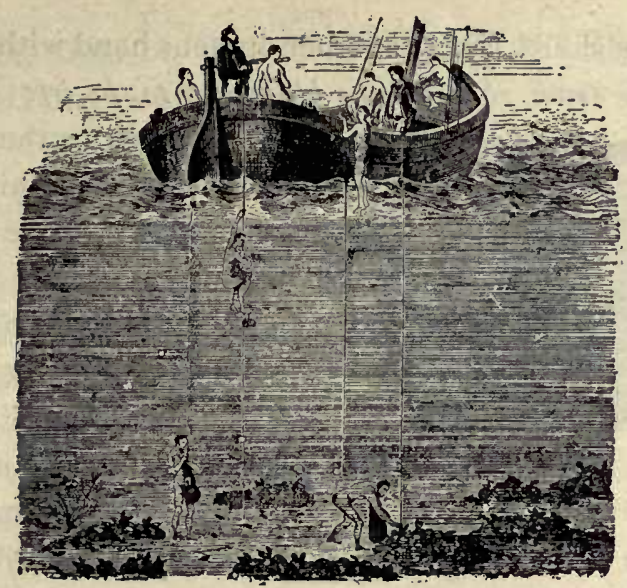

Pearl divers.

\section{CHAPTER IX}

\section{MOLLUSKS}

\section{The Fresh-Water Mussel}

SugGESTIONS. - The mussel is usually easy to procure from streams and lakes by raking or dredging. In cities the hardshelled clam, or quahog, is for sale at the markets, and the following descriptions apply to the anodon, unio, or quahog, with slight changes in regard to the siphons. Mussels can be kept alive for a long time in a tub with sand in the bottom. Pairs of shells should be at hand for study.

External Features. - The shell is an elongated oval, broader and blunter at one end (Fig. I 88). Why does the animal close its shell? Does it open the shell? Why? Does it thrust the foot forward and pull up to it, or thrust the foot back and push? (Mussels and clams have no bones.) Does it go with the blunt or the more tapering end of the shell forward? (Fig. I88.) Can a mussel swim? Why, or why not? 
Lay the shells, fitted together, in your hand with the hinge side arvay from you and the blunt end to the left (Fig. I88).

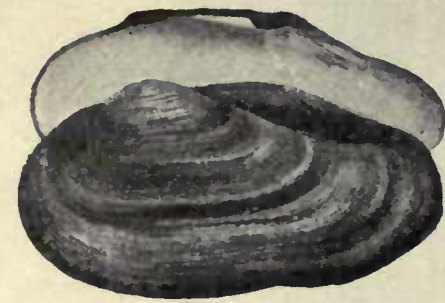

FIG. I88. - ANoDoN, or fresh-water mussel.

Is the right or the left shell uppermost? Which is the top, or dorsal, side? Which is the front, or anterior, end? Is the straight edge at the top or the bottom? Our word "valve" is derived from a word meaning shell, because the Romans used

shells for valves in pumps. Is the mussel a univalve or a bivalve? Which kind is the oyster? The snail ?

Does the mussel have bilateral symmetry? Can you find a horny covering, or epidermis, over the limy shell of a fresh specimen? Why is it necessary? Does water dissolve lime? Horn? Find a bare spot. Does any of - the shell appear to be missing there?

The bare projection on each shell is called the umbo. Is the umbo near the ventral or the dorsal line? The posterior or anterior end? Is the surface of the umbones worn? Do the umbones rub against the sand as the mussel plows its way along? How are the shells held together? Where is the ligament attached? (Fig. 189.) Is it opposite the umbones or more to the front or rear? (Fig. 189.) Is the liga-

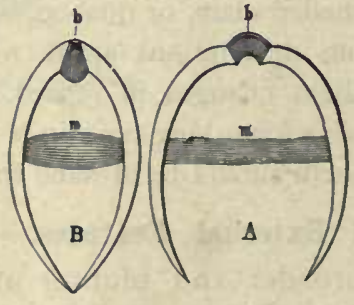

Fig. 189.-DiaGraM OF SHELl open and closed, showing muscle, $m$, and ligament, $b$. ment of the same material as the shell? Is the ligament in a compressed condition when the shell is open or when it is closed? (Fig. 189.) When is the muscle relaxed? 
Notice the lines on the outside of the shell (Figs. 188 and 190). What point do they surround? They are lines of growth. Was each line once the margin of the shell? If the shell should increase in size, what would the present margin become? (Fig. 19I.) Does growth take place on the margin only? Did the shell grow thicker as it grew larger? Where is it thinnest?

Draw the outside of the shell from

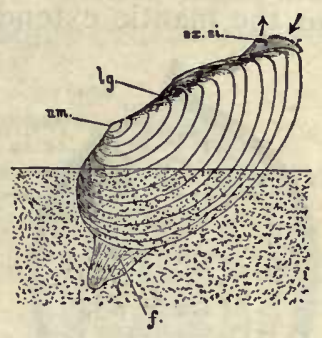

FIG. Igo. - MUSSEL crawling in sand. the side. Draw a dorsal view. By the drawings write the names of the margins of the shell (p. 98) and of other parts learned, using lines to indicate the location of the parts.

Study the surface of the shell inside and out. The inside is called mother-of-pearl. Is it of lime? Is the deeper layer of the shell of lime? (When weak hydrochloric acid or strong vinegar is dropped on limy substances, a gas, carbon dioxid, bubbles up.) Compare the thickness of the epidermal layer, the middle chalky layer, and the inner, pearly layer.

Anatomy of the Mussel. - What parts protrude at any time beyond the edge of the shell? (Fig. 190.) The shell

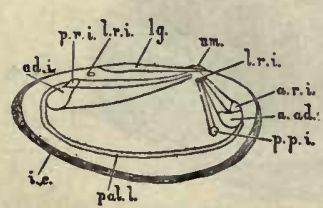

FIG. Igr. - D I A G R A M. Change of points of attachment of muscles as mussel enlarges. (Morgan.) is secreted by two folds of the outer layer of the soft body of the mussel. These large, flaplike folds hang down on each side, and are called the mantle. The two great flaps of the mantle hang down lower than the rest of the body and line the shell which it secretes (Fig. 192). The epidermis of the mantle secretes the shell just as the epidermis of the crawfish secretes its crust. Can you find 
the pallial line, or the line to which the mantle extended on each shell when the animal was alive? A free portion of the mantle extended like a fringe below the pallial line.

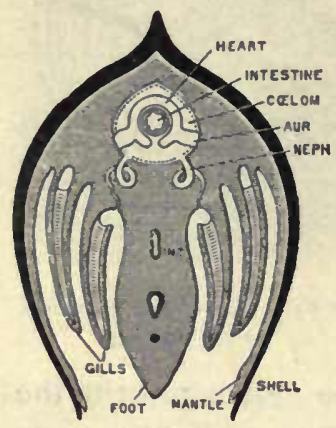

Fig. I92.-Cross SfCtion

of Mussel. (Diagram, after Parker.)

The shells were held together by two large adductor muscles. The anterior adductor (Fig. 193) is near the front end, above the foot. The posterior adductor is toward the rear end, but not so near the end as the anterior. Can you find both muscle scars in the shells? Are they nearer the ventral or dorsal surface? The points of attachment traveled downward and farther apart as the animal grew (see Fig. 19I). Higher than the larger scars are small scars, or impressions, where the protractor and retractor muscles that extend and draw in the foot were attached.

The muscular foot extends downward in the middle, halfway between the shells (Fig. 193). On each side of the foot and behind it hang down the two pairs of gills, the outer pair and the inner pair (Fig. 192). They may be compared to four V-shaped troughs with

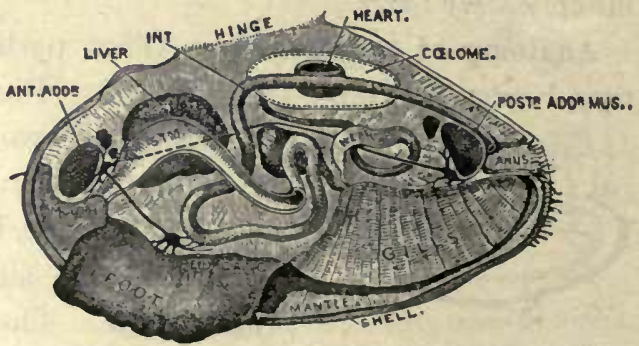
Fig. 193.-ANATOMy of MUSSEL. (Beddard.) their sides full of holes. The water enters the troughs through the holes and overflows above. Is there a marked difference in the size of the two pairs of gills? A kind of 
chamber for the gills is made by the joining of the mantle flaps below, along the ventral line. The mantle edges are separated at two places, leaving openings called exhalent and inhalent siphons.

Fresh water with its oxygen, propelled by cilia at the opening and on the gills, enters through the lower or inhalent siphon, passes between the gills, and goes to an upper passage, leaving the gill chamber by a slit whicin separates the gills from the foot. For this passage, see arrow (Fig. 194). The movement of the water is opposite to the way the arrow points. After going upward and backward, the water emerges by the exhalent siphon. The gills originally consisted of a great number of filaments. These are now united, but not completely so, and the gills still have a perforated or lattice structure. Thus they present a large surface for absorbing oxygen from the water.
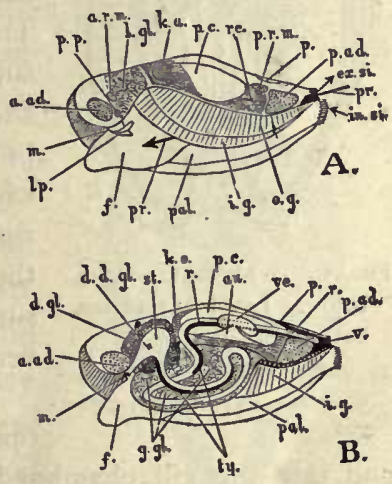

FIG. 194. - MUSSEL. $A$, left shell and mantle flap removed. $B$, section through body.

Question: Guided by other figures, identify the parts to which lines are drawn.

The mouth is in front of the foot, between it and the anterior adductor muscle (Fig. 194). On each side of the mouth are the labial palps, which are lateral lips (Fig. 195). They have cilia which convey the food to the mouth after the inhalent siphon has sent food beyond the gill chamber and near to the mouth. Thus both food and oxygen enter at the inhalent siphon. The foot is in the position of a lower lip, and if regarded as a greatly extended lower lip, the animal may be said to have what is to us the absurd habit of using its lower lip as a foot. The foot is some- 
times said to be hatchet-shaped (Fig. 195). Do you see any resemblance? Does the foot penetrate deep or shal-

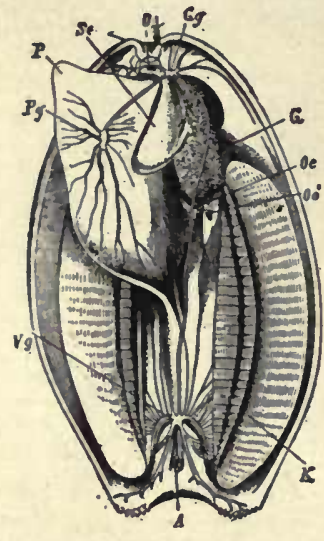

FIG. 195. - MUSSEL. From

below. Level cut across both shells.

Se, palp: $P$, foot; $O$, mouth: $G$, liver; $G g, V g, P g$, ganglia. low into the sand? (Fig. 190.) Why, or why not?

The food tube of the mussel is comparatively simple. Behind the mouth it enlarges into a swelling called the stomach (Fig. 193). The bile ducts of the neighboring liver empty into the stomach. The intestine makes several turns in the substance of the upper part of the foot, and then passing upward, it runs approximately straight to the vent (or anus), which is in the wall of the exhalent siphon. The intestine not only runs through the pericardial cavity (celome) surrounding the heart, but through the ventricle of the heart itself (Fig. 196).

The kidneys consist of tubes which open into the pericardial chamber above

and into the gill chamber below (Neph., Fig. 193). The tubes are surrounded by numerous blood vessels (Fig. 198) and carry off the waste matter from the blood.

The nervous system consists of three pairs of ganglia and nerves (Fig. 197). The ganglia are distinguishable because of

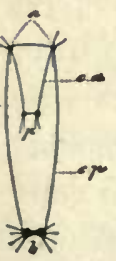

FIG. 197. their orange color. The pedal ganglia on the front of the foot are easily seen also; the visceral ganglia on the posterior adductor muscle may be seen without removing the mussel

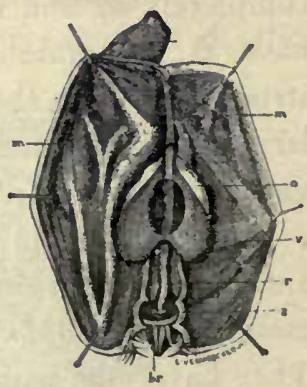

FIG. Ig6. - HEART OF MUSSEL, with intestine passing through it. from the shell (Fig. 193). The reproductive organs open into the rear portion of the gill cavity (Fig. 193). The sperms, having been set free in the water, are drawn into the ova by the same current that brings the food. The eggs 
are hatched in the gills. After a while the young mussels go out through the siphon.

Summary. - In the gills (Fig. 198) the blood gains what? Loses what? From the digestive tube the blood absorbs nourishment. In the kidneys the blood is partly purified by the loss of nitrogenous waste.

The cilia of the fringes on the inhalent, or lower, siphon, vibrate continually and drive water and food particles into the mouth cavity. Food particles that are brought near the labial palps are conveyed by them to the mouth. As the water passes along the perforated gills, its oxygen is absorbed ; the mantle also absorbs oxygen from the water as it passes. The water, as stated before, goes next through a passage between the foot and palp into the cavity above the gills and on out through the exhalent siphon. By stirring the water, or placing a drop of ink near the

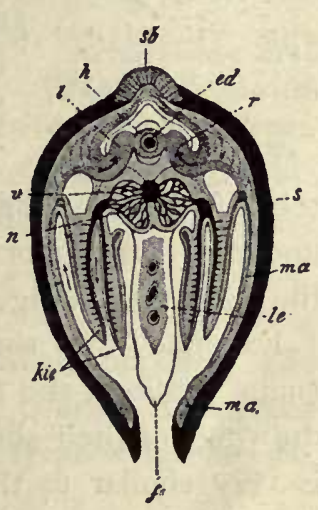
siphons of a mussel kept in a tub, the direction of its flow may be seen. The pulsations of the heart are plainly visible in a living mollusk.

FIG. I98. - DIAGRAM OF MUSSEL CUT ACROSS, showing mantle, $m a$; gills, kie; foot, $f$; heart, $h$; intestine, $e d$.

Habits of the Musse1. - Is it abundant in clear or muddy water; swift, still, or slightly moving water? Describe its track or furrow. What is its rate of travel? Can you distinguish the spots where the foot was attached to the ground? How long is one "step " compared to the length of the shell? The animal usually has the valves opened that it may breathe and eat. The hinge ligament acts like the case spring of a watch, and holds the valves open unless the adductor muscles draw them together (Fig. I89). 
When the mussel first hatches from the egg, it has a triangular shell. It soon attaches itself to some fish and thus

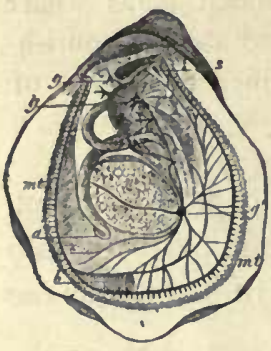

FIG. 199.- OrSTER.

$C$, mouth; $a$, vent; $g, g^{\prime}$, ganglia; $n t$, mantle; $b$, gill.

travels about; after two months it drops to the bottom again.

Other Mollusca. - The oyster's shells are not an exact pair, the shell which lies upon the bottom being hollowed out to contain the body, and the upper shell being flat. Can you tell by examining an oyster shell which was the lower valve? Does it show signs of having been attached to the bottom? The young oyster, like the young mussel, is free-swimming. Like the arthropoda, most mollusks undergo a metamorphosis to reach the adult stage (Fig. 199).

Examine the shells of clams, snails, scallops, and cockles. Make drawings of their shells. The slug is very similar to the snail except

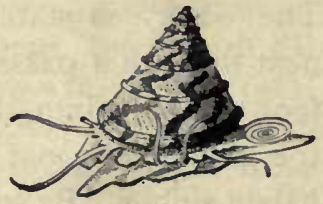

FIG. 200.-TROCHUS. that it has no shell. If the shell of the snail shown in Fig. 202 were removed, there would be left a very good

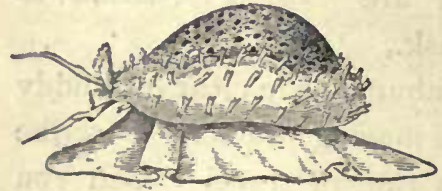

FIG. 201.- CYPRAeA. (Univalve, with a long opening to shell.) representation of a slug.

Economic Importance of Mollusca. - Several species of clams are eaten. One of them is the hard-shell clam (quahog) found on the At. lantic coast from Cape Cod to Texas. Its shell is white. It often burrows slightly beneath the surface. The soft-shell clam is better liked as food. It lives along the shores of all northern seas. It burrows a foot beneath the surface and extends its siphons 
through the burrow to the surface when the tide is in, and draws into its shell the water containing animalcules and oxygen.

Oysters to the value of many millions of dollars are gathered and sold every year. The most valuable oyster fisheries of the United States are in Chesapeake Bay. The young oysters, or "spat," after they attach themselves to the bottom in shallow water, are transplanted. New oyster beds are formed in this way. The beds are sometimes strewn with pieces of rock, broken pottery, etc., to encourage the oysters to attach themselves. The dark spot in the fleshy body of the oyster is the digestive gland, or liver. The cut ends of the tough adductor muscles are noticeable in raw oysters. The starfish is very destructive in oyster beds.

Pearls are deposited by bivalves around some irritating particle that gets between the shell and the mantle. The pearl oyster furnishes most of the pearls; sometimes pearls of great value are obtained from fresh-water mussels in the United States. Name articles that are made partly or wholly of motherof-pearl.

\section{Study of a Live} Snail or Slug. - Is its body dry or moist? Do land

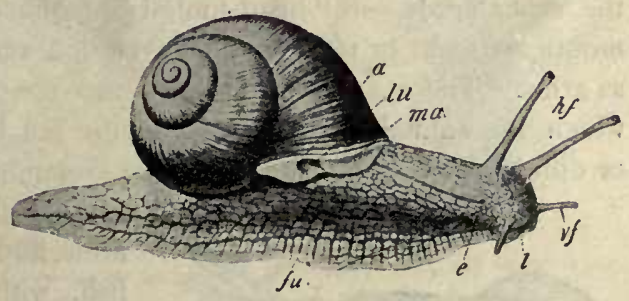

FIG. 202. - A SNAIL.

l, mouth: $v f, h f$, feclers: $e$, opening of egg duct; $f u$, foot; $m a$, mantle: $l u$, opening to lung; $a$, vent.

snails and slugs have lungs or gills? Why? How many pairs of tentacles has it? What is their relative length and position? The eyes are dark spots at bases of tentacles of snail and at the tips of the rear tentacles of slug. Touch the tentacles. What happens? Do the tentacles simply stretch, or do they turn inside 
out as they are extended? Is the respiratory opening on the right or left side of the body? On the mantle fold or on the body?

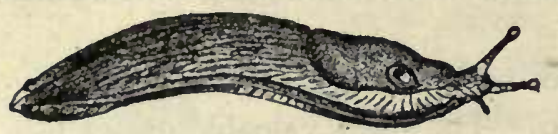

FIG. 203.-A SLUG.

(Figs. 202-3-4.) How often does the aperture open and close?

Place the snail in a moist tumbler. Does the whole under surface seem to be used in creeping? Does the creeping surface change shape as the snail creeps? Do any folds or wrinkles seem to move either toward the front or rear of its body? Is enough mucus left to mark the path traveled? The fold moves to the front, adheres, and smooths out as the slug or snail is pulled forward.

Cephalopods. - The highest and best developed mollusks are

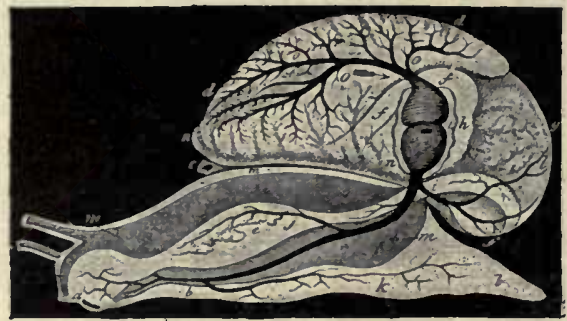

FIG. 204. - Circulation AND RESPIRATION IN SNAIL.

$a$, mouth; $b, b$, foot; $c$. vent: $d, d$, lung; $h$, heart. Blood vessels are black. (Perrier.) the cephalopods, or "head-footed" mollusks. Surrounding the mouth are eight or ten appendages which serve both as feet and as arms. These appendages have two rows of sucking disks by which the animal attaches itself to the sea bottom, or seizes fish or other prey with a firm grip. The commonest examples are the

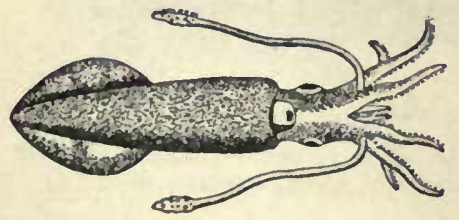

FIG. 205. - A SQUID. squid, with a long body and ten arms, and the octopus, or devilfish, with a short body and eight arms. Cephalopods have strong biting mouth parts and complex eyes somewhat resembling the eyes of backboned, or vertebrate, animals. The large and staring eyes add to the uncanny, terrifying appearance.

The sepia or "ink" discharged through the siphon of the squid makes a dark cloud in the water and favors its escape from 
enemies almost as much as its swiftness (Fig. 205). The squid sometimes approaches a fish with motion so slow as to be imperceptible, and then suddenly seizes it, and quickly kills it by. biting it on the back behind the head.

The octopus is more sluggish than the squid. Large species called

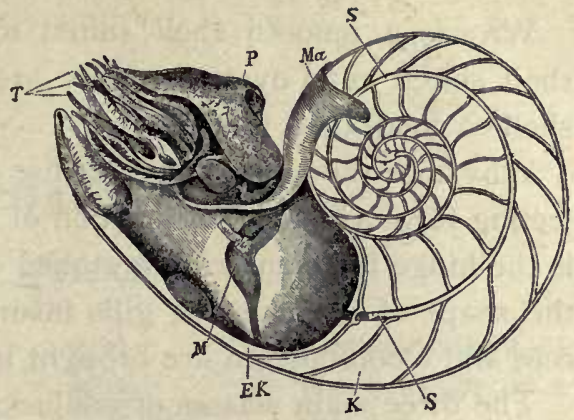

Fig. 206. - Pearly Nautilus. (Sliell sawed through to show chambers used when it was smaller, and siphuncle, $S$, connecting them. Tentacles, $T$.)

devilfish sometimes have a spread of arms of tiventy-five feet. The pearly nautilus (Fig. 206) and the female of the paper argonaut (Fig. 207) are examples of cephalopods that have shells. The cuttlefish is closely related to the squid.

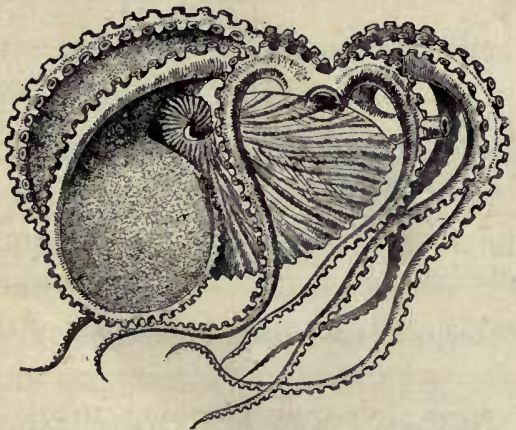

FIG. 207. - PAPER ARgONAUT (female). $\times 1 / 3$ (i.e. the animal is three times as long and broad as figure).

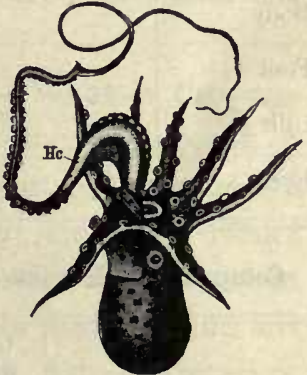

FIG. 208. - PAPER ARGO. NAUT (male). $\times 1 \frac{1}{2}$.

General Questions. - The living parts of the mussel are very soft, the name mollusca having been derived from the Latin word mollis, soft. Why is it that the softest animals, the mollusks, have the hardest coverings?

To which class of mollusks is the name acephala (headless) appropriate ? Lamellibranchiata (platelike gills)? 
Why is a smooth shell suited to a clam and a rough shell suited to an oyster? Why are the turns of a snail's shell so small near the center?

Why does the mussel have no use for head, eyes, or projecting feelers? In what position of the valves of a mussel is the hinge ligament in a stretched condition? How does the shape of the mussel's gills insure that the water current and blood current are brought in close contact?

The three main classes of mollusks are: the pelecypoda (hatchet-footed); gastropoda (stomach-footed); and cephalopoda (head-footed). Give an example of each class.

\section{Comparison of Mollusks}

\begin{tabular}{l|l|l|l|l}
\hline \hline & Mussel & SNaIl & & SQUID \\
\hline Shell & & & & \\
\hline Head & & & & \\
\hline Body & & & & \\
\hline Foot & & & \\
\hline Eyes & & & \\
\hline \hline
\end{tabular}

Comparative Review. - (To occupy an entire page in notebook.)

\begin{tabular}{|c|c|c|c|c|c|}
\hline & $\begin{array}{l}\text { GRASS- } \\
\text { HOPPER }\end{array}$ & SPIDER & Crayfish & Centipede & Mússel \\
\hline \multicolumn{6}{|l|}{ Bilateral or radiate } \\
\hline \multicolumn{6}{|l|}{$\begin{array}{l}\text { Appendages for lo- } \\
\text { comotion }\end{array}$} \\
\hline \multicolumn{6}{|l|}{$\begin{array}{l}\text { Names of divisions } \\
\text { of body }\end{array}$} \\
\hline \multicolumn{6}{|l|}{$\begin{array}{l}\text { Organs and method } \\
\text { of breathing }\end{array}$} \\
\hline Locomotion & & & & & \\
\hline
\end{tabular}




\section{CHAPTER $\mathrm{X}$}

\section{FISHES}

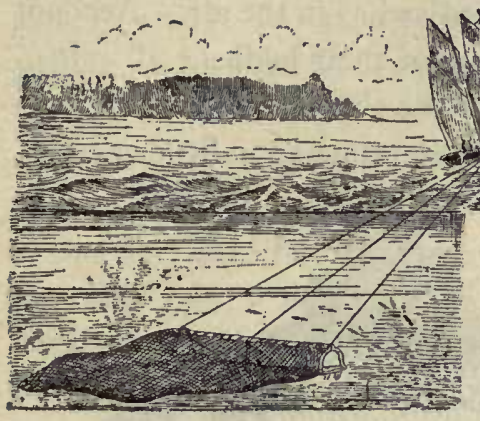

SUGGestions. The behavior of a live fish in clear water, preferably in a glass vessel or an aquarium, should be studied. A skeleton may be prepared by placing a fish in the reach of ants. Skeletons of animals placed on ant beds are cleaned very thoroughly. The study of the perch, that follows, will apply to almost any common fish.

Movements and External Features. - What is the general shape of the body of a fish? How does the dorsal, or upper, region differ in form from the ventral? Is there a narrow part or neck where the head joins the trunk? Where is the body thickest? What is the ratio between the length and height? (Fig. 209.) Are the right and left sides alike? Is the symmetry of the fish bilateral or radial?

The body of the fish may be divided into three regions, - the head, trunk, and tail. The trunk begins with the foremost scales; the tail is said to begin at the vent, or anus. Which regions bear appendages? Is the head movable independently of the trunk, or do they move together? State the advantage or disadvantage in this. Is the body depressed (flattened vertically) or compressed 
(flattened laterally)? Do both forms occur among fishes? (See figures on pages 123,124 .)

How is the shape of the body advantageous for movement? Can a fish turn more readily from side to side, or up and down? Why? Is the head wedge-shaped or conical? Are the jaws flattened laterally or vertically? The fish swims in the water, the bird swims in the air. Account for the differences in the shape of their bodies.

Is the covering of the body like the covering of any animal yet studied? The scales are attached in little pockets,

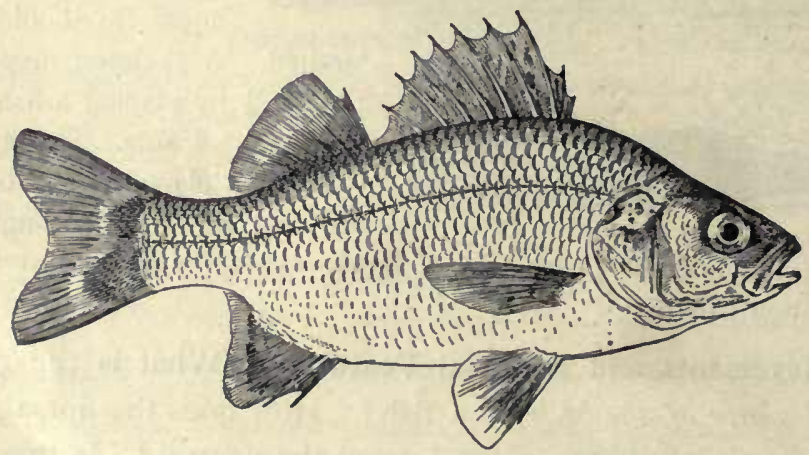

FIG. 209. - White PerCh (Morone Americana).

.or folds, in the skin. Observe the shape and size of scales on different parts of the body. What parts of the fish are without scales? Examine a single scale; what is its shape? Do you see concentric lines of growth on a scale? Sketch a few of the scales to show their arrangement. What is the use of scales? Why are no scales needed on the head? How much of each scale is hidden? Is there a film over the scale? Are the colors in the scale or on it?

The Fins. - Are the movements of the fish active or sluggish? Can it remain stationary without using its fins? 
Can it move backward? How are the fins set in motion? What is the color of the flesh, or muscles, of a fish? Count the fins. How many are in pairs? (Fig. 209.) How many are vertical? How many are on the side? How many are on the middle line? Are the paired or unpaired fins more effective in balancing the fish? In turning it from side to side? In raising and lowering the fish ? In propelling it forward? How are some of the fins useful to the fish besides for balancing and swimming?

The hard spines supporting the fins are called the fin rays. The fin on the dorsal line of the fish is called the dorsal fin. Are its rays larger or smaller than the rays of the other fins? The perch is sometimes said to have two dorsal fins, since it is divided into two parts. The fin forming the tail is called the tail fin, or caudal fin. Are its upper and lower corners alike in all fishes? (Fig. 228.) On the ventral side, just behind the vent, is the ventral fin, also called the anal fin. The three fins mentioned are unpaired fins. Of the four-paired fins, the pair higher on the sides (and usually nearer the front) are the pectoral fins. The pair nearer the ventral line are the pelvic fins. They are close together, and in many fish are joined across the ventral line. The ventral fins are compared to the legs, and the pectoral fins to the arms, of higher vertebrates. (Fig. 244.) Compare fins of fish, pages 123, 124 .

Make a drawing of the fish seen from the side, omitting the scales unless your drawing is very large.

Are the eyes on the top or sides of the head, or both? Can a fish shut its eyes? Why, or why not? Is the eyeball bare, or covered by a membrane? Is the covering of the eyeball continuous with the skin of the head? Is there a fold or wrinkle in this membrane or the surrounding skin? Has the eye a pupil? An iris? Is the eye of 
the fish immovable, slightly movable, or freely movable? Can it look with both eyes at the same object? Is the range of vision more upward or downward? To the front

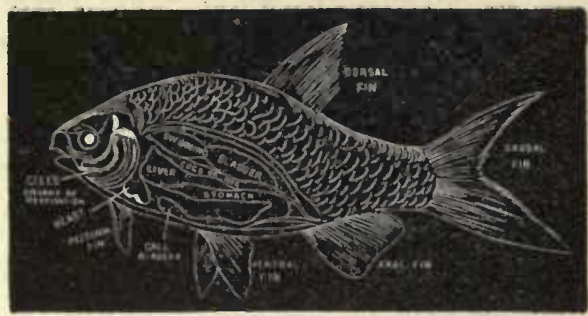

Fig. 2IO. - BLACKBOARD OUTLINE OF FISH. or side? In what direction is vision impossible? Can a fish close its eyes in sleep? Does the eyeball appear spherical or flattened in front? The ball is really spherical, the lens is very convex, and fish are nearsighted. Far sight would be useless in a dense medium like water.

In what direction are the nostrils from the eyes? (Fig. 211.) There are two pairs of nostrils, but only one pair of nasal cavities, with two nostrils opening into each. There are no nasal passages to the mouth, as the test with a probe shows that the cavities do not open into the mouth. What two functions has the nose in man? What function has it in the fish?

There are no external ears. The ear sacs are embedded in the

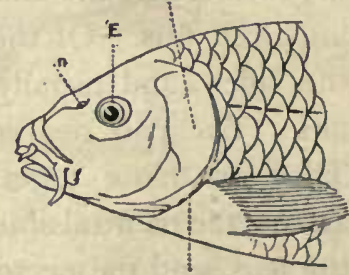

FIG. 2II. - HEAD OF CARP. bones of the skull. Is hearing acute or dull? When fishing, is it more necessary not to talk or to step lightly, so as not to jar the boat or bank?

What is the use of the large openings found at the back of the head on each side? (Fig. 21 I.) Under the skin at the sides of the head are thin membrane bones formed from the skin; they aid the skin in protection. Just under these membrane bones are the gill covers, of true bone. Which 
consists of more parts, the membranous layer, or the true bony layer in the gill cover? (Figs. $2 \mathrm{II}$ and $2 \mathrm{I} 2$.)

Is the mouth large or small? Are the teeth blunt or pointed? Near the outer edge, or far in the mouth? (Fig. 212.) Does the fish have lips? Are the teeth in one continuous row in either jaw? In the upper jaw there are also teeth on the premaxillary bones. These bones are in front of the maxillary bones, which are without teeth. Teeth are also found in the roof of the mouth, and the tongue bears horny appendages similar to teeth. Are the teeth of the fish better suited for chewing or for

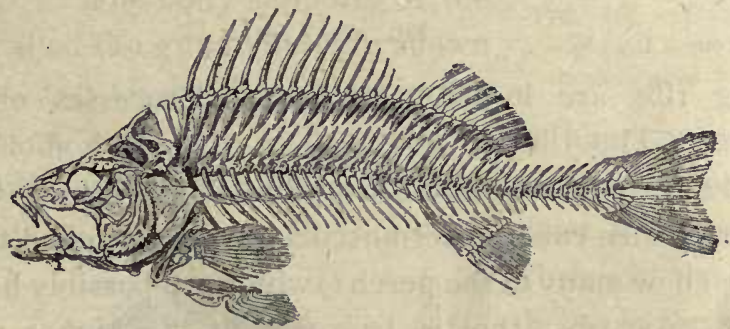

Fig. 212. - SkEleton OF PERCH.

grasping ? Why are teeth on the tongue useful? Watch a fish eating: does it chew its food? Can a fish taste? Test by placing bits of brown paper and food in a vessel or jar containing a live fish. Is the throat, or gullet, of the fish large or small?

The skeleton of a fish is simpler than the skeleton of other backboned animals. Study Fig. 212 or a prepared skeleton. At first glance, the skeleton appears to have two vertebral columns. Why? What bones does the fish have that correspond to bones in the human skeleton? Are the projections (processes) from the vertebræ long or short? The ribs are attached to the vertebræ of the trunk, the last rib being above the vent. The tail begins at the 
vent. Are there more tail vertebræ or trunk vertebræ? Are there any neck (cervical) vertebræ (i.e. in front of those that bear ribs)? The first few ribs (how many?) are attached to the central body of the vertebræ. The re-

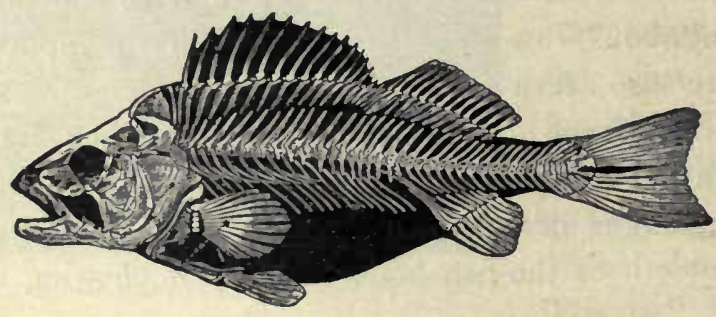

FIG. 213 .

maining ribs are loosely attached to processes on the vertebræ. The ribs of bony fishes are not homologous with the ribs of the higher vertebrates. In most fishes there are bones called intermuscular bones attached to the first ribs (how many in the perch?) which are possibly homologous to true ribs; that is, true ribs in the higher vertebrates may have been developed from such beginnings.

Which, if any, of the fin skeletons (Fig. 214) are not attached to the general skeleton? Which fin is composed chiefly of tapering, pointed rays? Which fins consist of
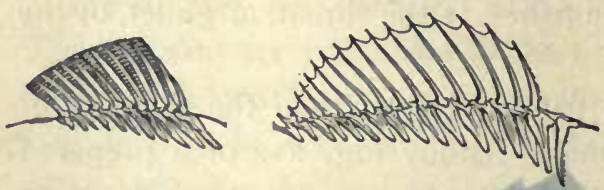

FIG. 214. - SOFT-RAYED AND SPINY-RAYED FINS, rays which subdivide and widen toward the end? Which kind are stiff, and which are flexible? Which of the fin rays are segmented, no in two portions? The outer segment is called the radial, the inner the basal segment. Which segments are longer? There is one basal segment that lacks a radial segment; find it (Fig. 212). 
What is the advantage of the backbone plan of struce ture over the armor-plate plan? You have seen the spoollike body of the vertebra in canned salmon. Is it concave, flat, or convex at the ends?

The gills are at the sides of the head (Fig. 215) under the opercula, or gill covers. What is the color of the gills? Do the blood vessels appear to be very near the surface of the gills, or away from the surface? What advantage in this? Are the gills smooth or wrinkled? (Fig. 215.) What advantage? The bony supports of the gills, called the gill arches, are shown in Fig. $216\left(k_{1}\right.$ to $\left.k_{4}\right)$. How many

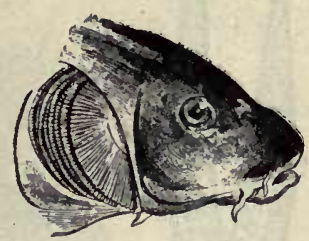

FIG. 215.-CARP, with right gill cover removed to show gills. arches on each side? The gill arches have projections: on their front sides, called gill rakers, to prevent food

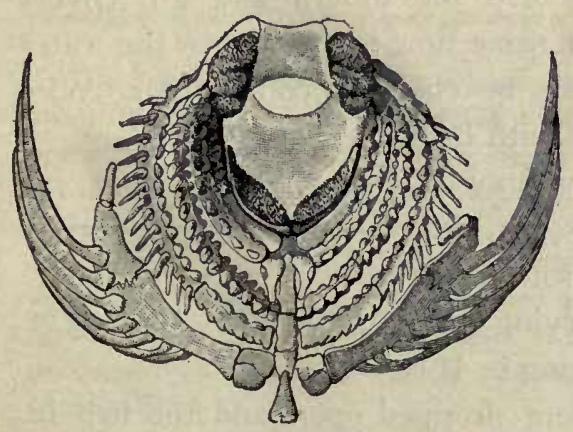

Fig. 216. - SKELETON AROUND THROAT OF Fish.

from being washed through the clefts between the arches. The fringes on the rear of the gill arches are called the gill filaments $(\alpha$, Fig. 216). These filaments support the thin and muchwrinkled borders of the gills, for the gills are constructed on the plan of exposing the greatest possible surface to the water. Compare the plan of the gills and the human lungs. The gill opening on each side is guarded by seven rays ( $k h$, Fig. 2I6) along the hinder border of the 
gill cover. These rays grow from the tongue bone. $(Z u$, Fig. 216. This is a rear view.)

Watch a live fish and determine how the water is forced between the gills. Is the mouth opened and closed in the

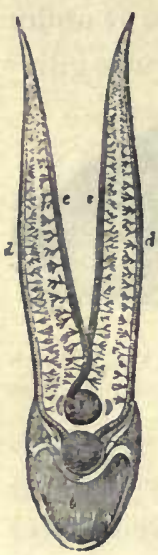

FIG. 217. Circulation IN GILLS. act of breathing? Are the openings behind the gill covers opened and closed? How

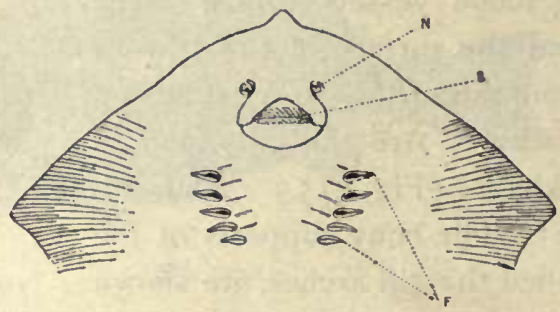

FiG. 218. - NOSTRILS, MOUTH, AND GILL OPENINGS OF STING-RAY.

many times per minute does fresh water reach the gills? Do the mouth and gill covers open at the same time? Why must the water in contact with the gills be changed constantly? Why does a fish usually rest with its head up stream? How may a fish be kept alive for a time after it is removed from the water? Why does drying of the gills prevent breathing? If

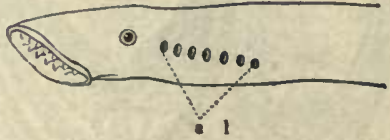

FIG. 219. - GILL OPENINGS OF EEL. the mouth of a fish were propped open, and the fish returned to the water, would it suffocate? Why, or why not?

Food Tube. - The gullet is short and wide. The stomach is elongated (Fig. 220). There is a slight constriction, or narrowing, where it joins the intestine. Is the intestine straight, or does it lie in few or in many loops? (Fig. 220.) The liver has a gall bladder and empties into the intestine through a bile duct. Is the 
liver large or small? Simple or lobed? The spleen (mi, Fig. 220) lies in a loop of the intestine. The last part of the intestine is straight and is called the rectum. Is it of the same size as the other portions of the intestine? The fish does not possess a pancreas, the most important digestive gland of higher vertebrates.

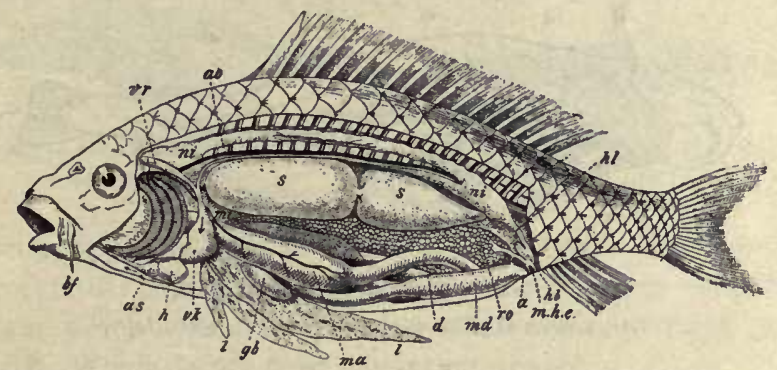

Fig. 220. - ANATOMY OF CARP. (See also colored figure 4.)

$b f$, barbels on head (for feeling); $h$, ventricle of heart; $a s$, aortic bulb for regulating flow to gills; $v k$, venous sinus; $a o$, dorsal aorta; $m a$, stomach; $l$, liver; $g b$, gall cyst; $m i$, spleen: $d$, small intestine; $m d$, large intestine; $a$, vent; $s, s$, swim bladder; $n i$, $n i$, kidney: $h l$, ureter; $h b$, bladder; ro, eggs (roe); $m$ he, opening of ducts from kidney and ovary.

Questions: Are the kidneys dorsal or ventral ? The swim bladder? Why ? Why is the swim bladder double? Does blood enter gills above or below ?

The ovary lies between the intestine and the air bladder. In Fig. 220 it is shown enlarged and filled with egg masses called roe. It opens by a pore behind the vent. The silver lining of the body cavity is called the peritoneum. (See Chap. VII, Human Biology.)

Is the air bladder simple or partly divided in the perch? In the carp? (Fig. 220.) Is it above or below the center of the body? Why? The air bladder makes the body of the fish about as light as water that it may rise and sink with little effort. When a fish dies, the gases of decomposition distend the bladder and the abdomen, and the fish turns over. Why?

Where are the kidneys? (Fig. 220.) Their ends unite close under the spinal column. The ureters, or tubes, leading from them, unite. and after passing a small urinary bladder, lead to a tiny urinary pore just behind the opening from the ovary. (Colored figure 4.)

The Circulation. - The fish, unlike other vertebrates, has its breathing organs and its heart in its head. The gills have already been described. The heart of an air-breathing vertebrate is near 
its lungs. Why? The heart of a fish is near its gills for the same reason. The heart has one auricle and one ventricle. (Colored figure I.)

Blood returning to the heart comes through several veins into a sinus, or antechamber, whence it passes down through a valve

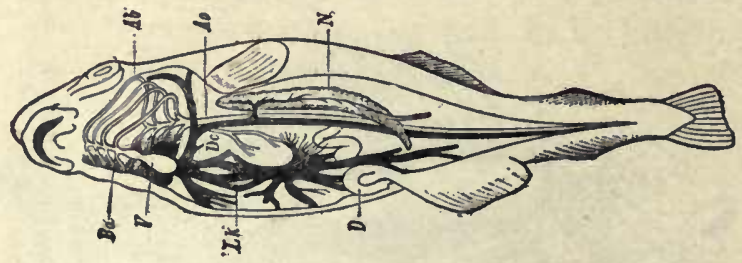

Fig. 221. - Plia OF CiRculation.

$A b$, arteries to gills; $B a$, aortic bulb; $V$, ventricle.

into the auricle; from the auricle it goes forward into the ventricle. The ventricle sends it into an artery, not directly, but through a

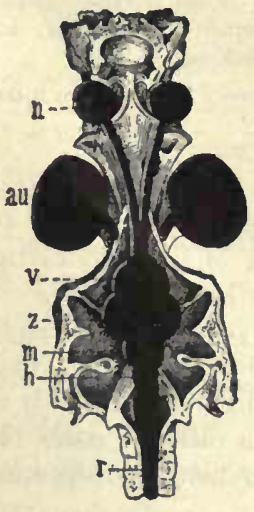

FIG. 222. - BRAIN OF

PERCH, from above.

$n$, end of nerve of smell; au, eye; $v, z, m$, fore, mid, and hind brain: $h$, spinal bulb; $r$, spinal cord. bulb (as, Fig. 220), which serves to maintain a steady flow, without pulse beats, into the large artery (aorta) leading to the gills. The arteries leading from the gills join to form a dorsal aorta (Ao, Fig. $22 \mathrm{I}$ ), which passes backward, inclosed by the lower processes of the spinal column. After going through the capillaries of the various organs, the blood returns to the heart through veins.

The color of the blood is given by red corpuscles. These are nucleated, oval, and larger than the blood corpuscles of other vertebrates. The blood of the fish is slightly above the temperature of the water it inhabits.

Notice the general shape of the brain (Fig. 222). Are its subdivisions distinct or indistinct? Are the lobes in pairs? The iniddle portion of the brain is the widest, and consists of the two optic lobes. From these lobes the optic nerves pass beneath the brain to the eyes ( $S n$, Fig. 223). In 
front of the optic lobes lie the two cerebral lobes, or the cerebrum. The small olfactory lobes are seen (Fig. 224) in front of the cerebrum. The olfactory nerves may be traced to the nostrils. Back of the optic lobes (mid brain) is the cerebellum (hind brain), and

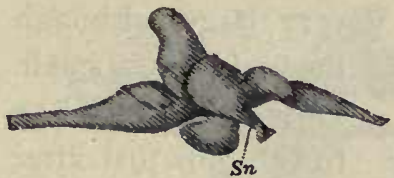

Fig. 223. - BRAIN OF PERch, side view. back of it is the medulla oblongata, or beginning of the spinal cord.

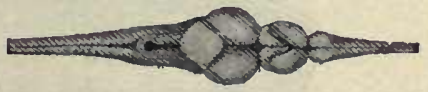

FIG. 224. - BRAIN OF PERCH, from above.

Taking the eyeball for comparison, is the whole brain as large as one eyeball? (Fig. 222.) Judging from the size of the parts of the brain, which is more important with the fish, thinking or perception? Which is the most important sense?

The scales along a certain line on each side of the fish, called the lateral line, are perforated over a series of lateral line sense organs, supposed to be the chief organs of touch (see Fig. 209).

Questions. - Which of the fins of the fish have a use which corresponds to the keel of a boat? The rudder? A

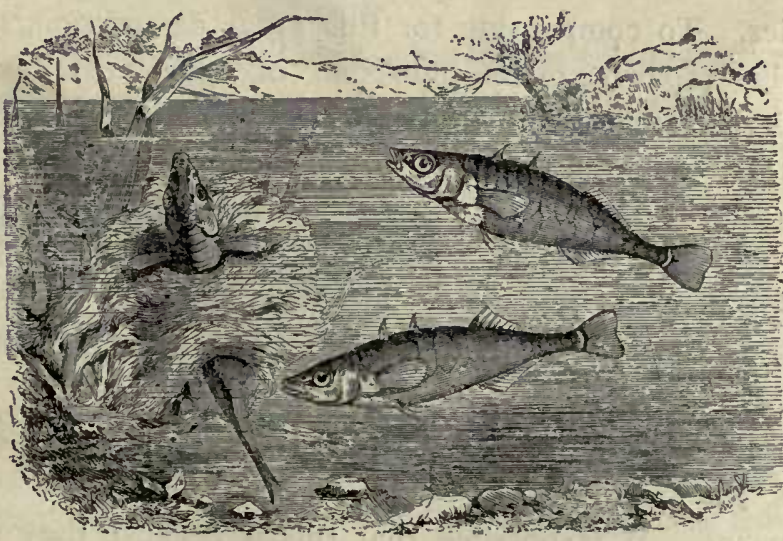

Fig. 225. - THE STICKLEback. Instead of depositing the eggs on the bottom, it makes a nest of water plants - the only fish that does so - and bravely defends it. 


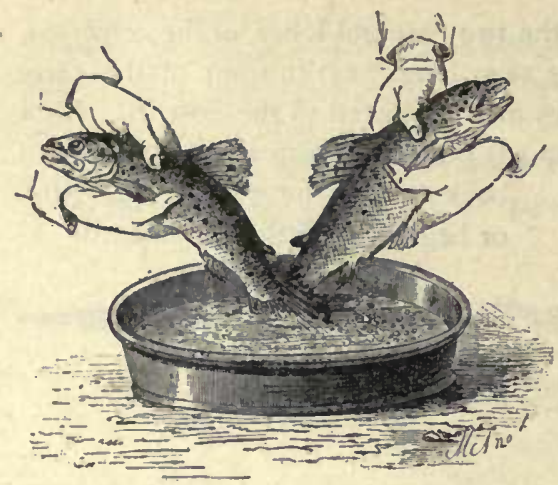

Fig. 226. - Artificial Fecundation. The egg-cells and sperm-cells are pressed out into a pan of water. paddle for sculling? An oar? State several reasons why the head of the fish must be very large, although the brain is very small. Does all the blood go to the gills just after leaving the heart?

Make a list of the different species of fish found in the waters of your neigh-

borhood; in the markets of your town.

Reproduction. - The female fish deposits the unfertilized eggs, or ova, in a secluded spot on the bottom. Afterward the male fish deposits the sperms in the same place (see Fig. 225). The eggs, thus unprotected, and newly hatched fish as well, are used for food by fish of the same and other species. To compensate for this great destruction, most fish lay (spawn) many thousands of eggs, very few of which reach maturity. Higher vertebrates (c.g. birds) have, by their superior intelligence, risen above this wasteful method of reproduction. Some kinds of marine fish, notably cod, herring, and salmon, go many miles up fresh rivers

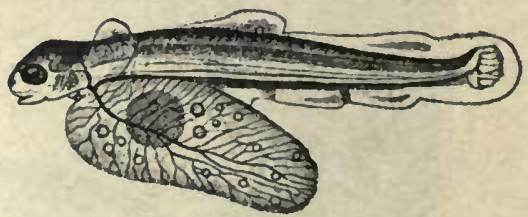

Fig. 227.- NEwLy HATChED TROUT, with yolk-sac adhering, eyes large, and fins mere folds of the skin. (Enlarged.)

to spawn. It is possible that this is because they were originally fresh-water species; yet they die if placed in fresh water except during the spawning season. They go 
because of instinct, which is simply an inherited habit. Rivers may be safer than the ocean for.their young. They are worn and exhausted by the journey, and never survive to lay eggs the second time.

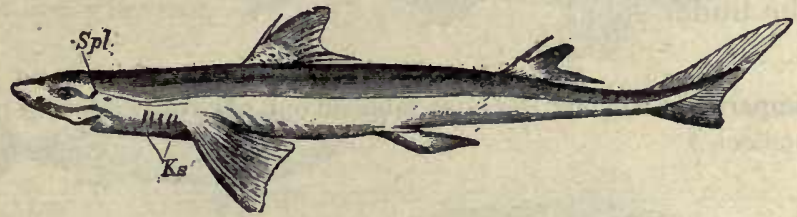

FIG. 228.-A SHARK (Acanthias vulgaris).

The air bladder is developed from the food tube in the embryo fish, and is homologous with lungs in the higher vertebrates. Are their functions the same?

Fish that feed on flesh have a short intestine. Those that eat plants have a long intestine. Which kind of food is more quickly digested?

There are mucous glands in the skin of a fish which supply a secretion to facilitate movement through the water; hence a freshly caught fish, before the secretion has dried, feels very slippery.

The air bladder, although homologous to lungs, is not a breathing organ in common fishes. It is filled by the formation of gases from the blood, and can be made smaller by the contraction of muscles along the sides of the body; this causes the fish to sink. In the gar and other ganoids, the air bladder contains blood vessels, is connected with the gullet, and is used in breathing. Organs serving the same purpose in different animals are said to be analogous. To what in man are the gills of the fish analogous? Organs having a like position and origin are said to be homologous. The air bladders of a fish are homologous with the lungs of man; but since they have not the same use they are not analogous. 
How does the tail of a shark or a gar differ from the tail of common fishes? (Fig. 228.) Do you know of fish destitute of scales? Do you know of fish with whiplike feelers on the head? (Figs.) Why are most fishes white on the under side?

Comparative Review. - (Copy table on one page or two facing pages of notebook.)

\begin{tabular}{l|l|l|l|l|l}
\hline & $\begin{array}{c}\text { Is there } \\
\text { A Head? } \\
\text { A Necx? }\end{array}$ & $\begin{array}{c}\text { Method of } \\
\text { Feeding }\end{array}$ & $\begin{array}{c}\text { Digestive } \\
\text { Organs and } \\
\text { Digestion }\end{array}$ & $\begin{array}{c}\text { Reproduc- } \\
\text { Tion }\end{array}$ & Senses \\
\hline Ameba & & & & & \\
\hline Sponge & & & & & \\
\hline Hydra & & & & & \\
\hline Starfish & & & & & \\
\hline Earthworm & & & & & \\
\hline Wasp & & & & \\
\hline
\end{tabular}

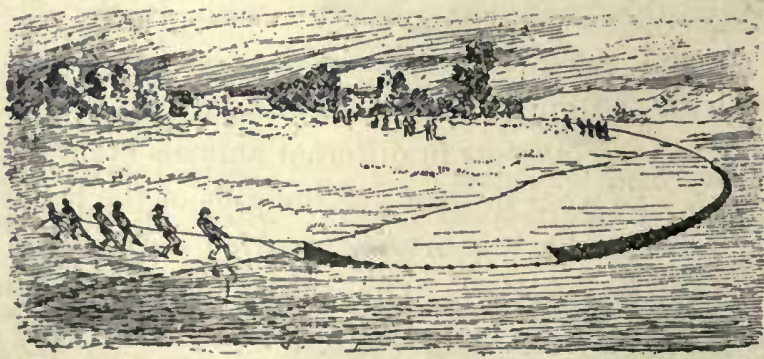

FIG. 229. - DKAWING THE SEINE. 

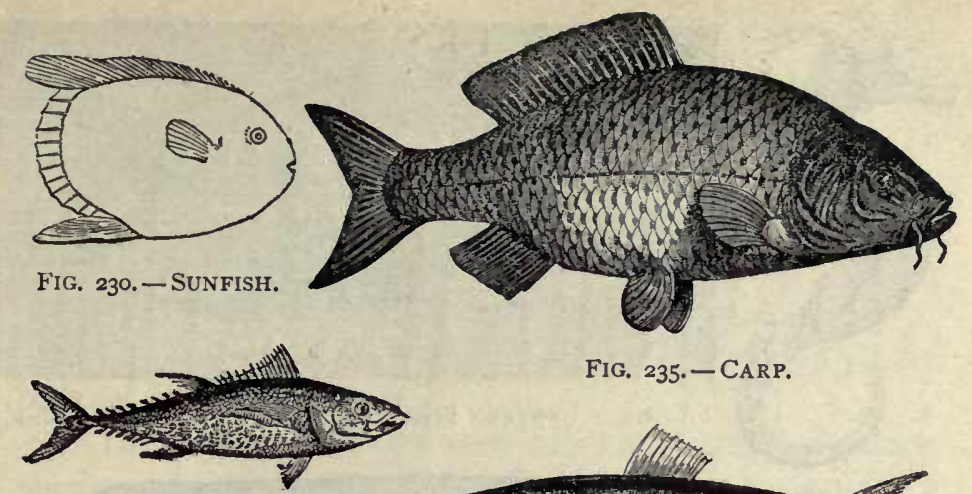

FIG. 235.-CARP.

FIG. 231. - TUNNY.
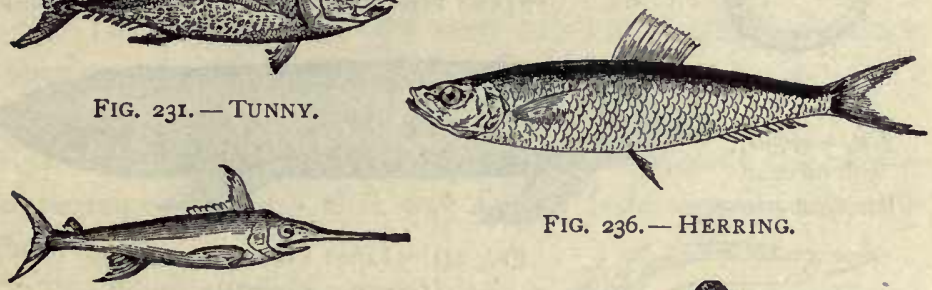

FIG. 236.- HERRING.

FIG. 232.-SWORDFISH.
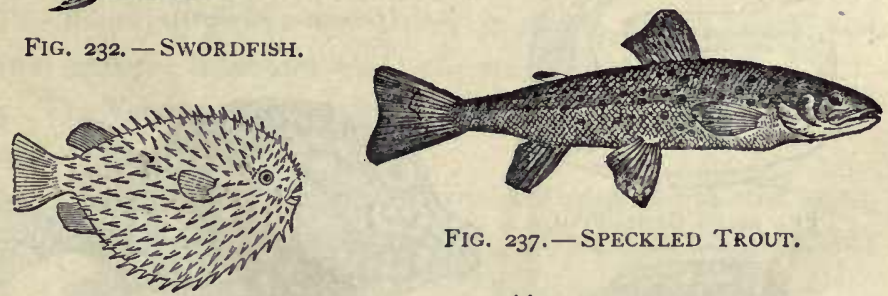

FIG. 237.-SPECKLED TROUT.

FIG. 233.-SWELLFISH.

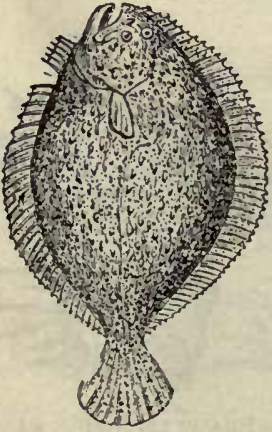

FIG. 234. - TURBOT.

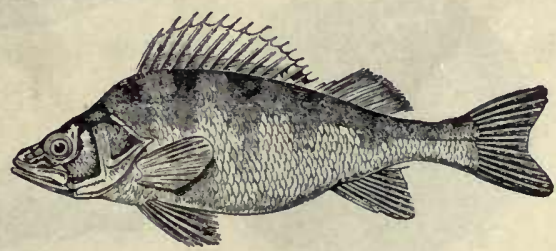

FIG. 238.- PERCH.

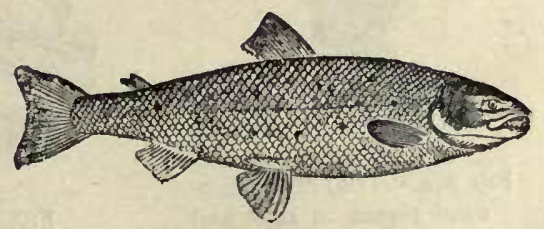

FIG, 239. - SALMON.

Seven Food Fish. Three Curious Fish.

SPECIAL REPORTS. (Encyclopedia, texts, dictionary.) 

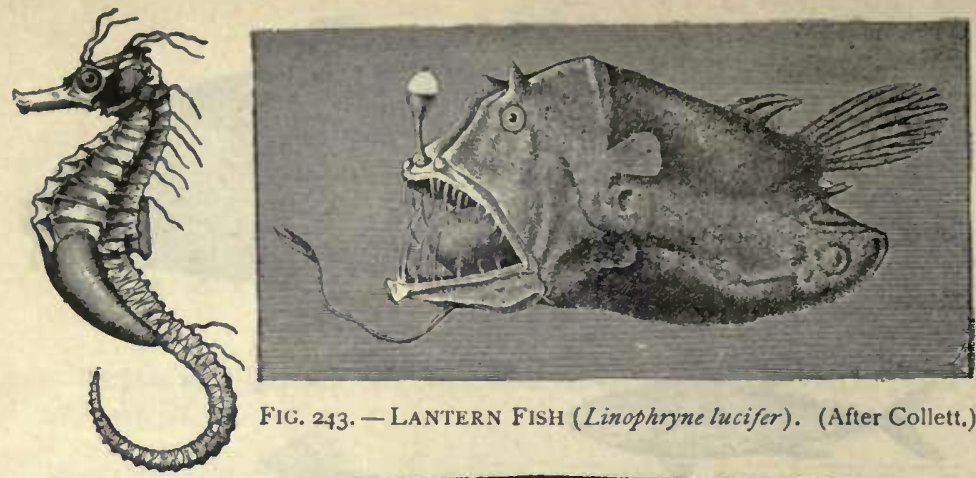

FIG. 243. - LANTERN FISH (Linophryne lucifer). (After Collett.)

FIG. 240.-

SEA HORSE

(Hippocampus), with incubating pouch, Brt.
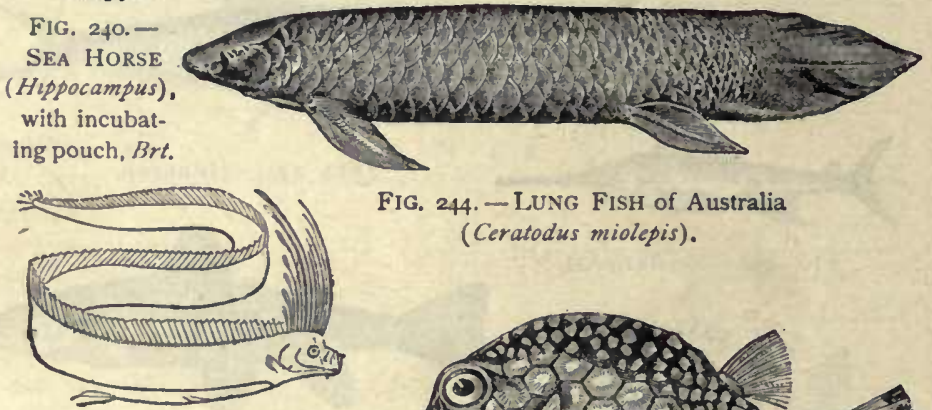

FIG. 24I. - BANU FISH.

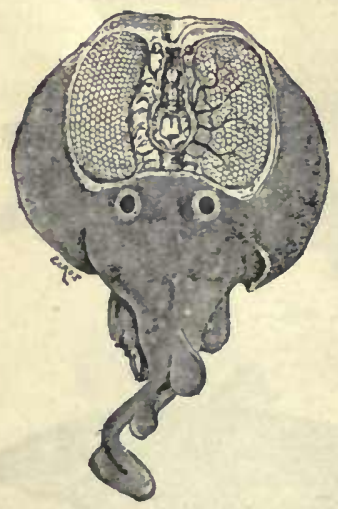

FIG. 242, - TORPEDO. Electrical organs at right and left of brain.

FIG. 244. - LUNG FisH of Australia (Ceratodus miolepis).

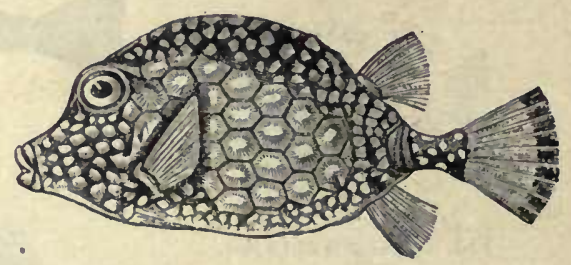

FIG. 245. - TRUNK FISH.

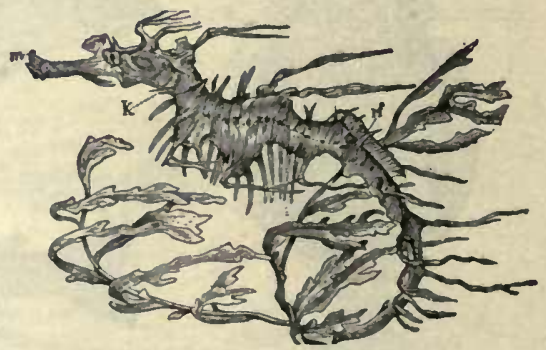

FIG. 246. - SEAWEED FISH. $\times \frac{1}{6}$ (Phyllopteryx eques).

Remarkable Fish. SPECIAL REPORTS. (Encyclopedia, texts, dictionary.) 


\section{RECOGNITION GROUP CHARACTERS}

The commoner members of the several branches may be recog. nized by the following characters :-

r. The Protozoans are the only one-celled animals.

2. The Sponges are the only animals having pores all over the body for the inflow of water.

3. The Polyps are the only many-celled animals having a single opening into the body, serving for both mouth and vent. They are radiate in structure, and usually possess tentacles.

4. The Echinoderms are marine animals of more or less radiate appearance, having a food tube in the body separate from the body wall.

The following groups are plainly bilateral: that is, dorsal and ventral surfaces, front and hind ends are different.

5. The Vermes have usually a segmented body but lack jointed legs.

6. The Arthropods have an external skeleton and jointed legs.

7. The Mollusks have soft bodies, no legs, no skeleton, but usually a limy shell.

8. The Vertebrates have an internal skeleton of bones, and usually two pairs of legs. 


\section{CHAPTER XI}

\section{BATRACHIA}

THE theory of evolution teaches that animal life began in a very simple form in the sea, and that afterward the higher sea animals lost their gills and developed lungs and legs and came out to live upon the land; truly a marvelous procedure, and incredible to many, although the process is repeated every spring in countless instances in pond and brook.

In popular language, every cold-blooded vertebrate breathing with lungs is called a reptile. The name reptile is properly applied only to lizards, snakes, turtles, and alligators. The common mistake of speaking of frogs and salamanders as reptiles arises from considering them only in their adult condition. Reptiles hatch from the egg as tiny reptiles resembling the adult forms; frogs and salamanders, as every one knows, leave the egg in the form of tadpoles (Fig. 248). The fact that frogs and salamanders begin active life as fishes, breathing by gills, serves to distinguish them from other cold-blooded animals, and causes naturalists to place them in a separate class, called batrachia (twice breather) or amphibia (double life).

\section{TADPOLES}

SugGeSTIONS. - Tadpoles may be studied by placing a number of frog's eggs in a jar of water, care being taken not to place a large number of eggs in a small amount of water. When they hatch, water plants (e.g. green algæ) should be added for food. The f thavior of frogs may be best studied in a tub of water. A toad in cuptivity should be given a cool, moist place, and fed well. A piece of meat placed near a toad may attract flies, and the toad may be observed while catching them, but the motion is so swift as to be almost imperceptible. Live flies may be put into a glass jar with a toad. Toads do not move about until twilight, except 
in cloudy, wet weather. They return to ponds and brooks in spring at the time for laying eggs. This time for both frogs and toads is shown by trilling. All frogs, except tree frogs, remain in or near the water all the year.

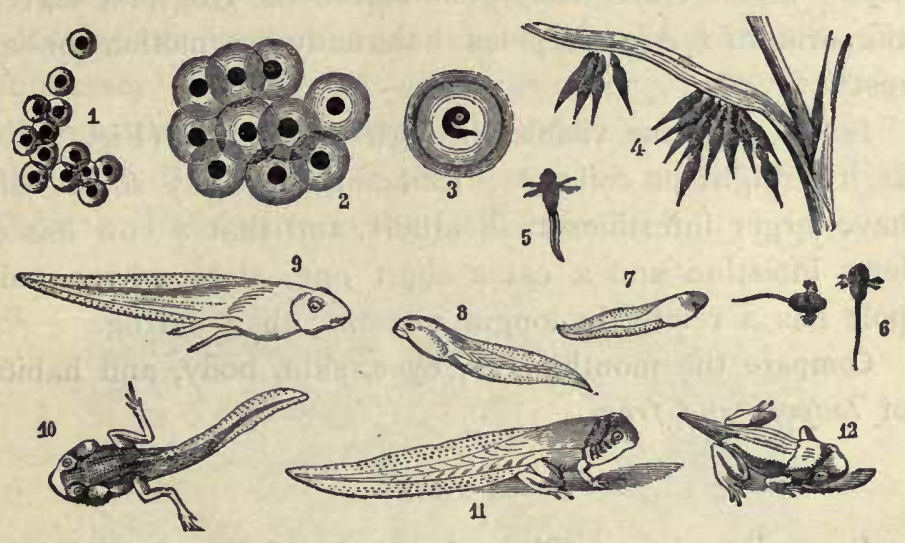

Fig. 248. - METAMORPHOSES OF THE FROG, numbered in order.

Do eggs hatch and tadpoles grow more rapidly in a jar of water kept in a warm place or in a cold place? In pond water or drinking water? Can the tadpoles be seen to move in the eggs before hatching? When do the external gills show? (Fig. 248.)

What parts may be described in a tadpole? What is the shape of the tail? Compare the tadpole with the fish as to (I) general shape, (2) covering, (3) fins, (4) tail, (5) gills.

Do the external gills disap-

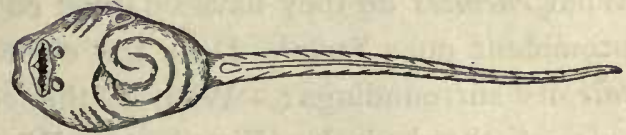
FIG. 249. - TADPOLE, from below, showing intestine and internal gills. (Enlarged.)

pear before or after any rudiments of limbs appear? (6, 7, Fig. 248.) Can you locate the gills after they become internal? (Fig. 249.) 
In what state of growth are the legs when the tadpole first goes to the surface to breathe? Which legs appear first? What advantage is this? What becomes of the tail? Is the tail entirely gone before the frog first leaves the. water? Are tadpoles habitually in motion or at rest?

Is the intestine visible through the skin? (Fig. 249.) Is it straight or coiled? Remembering why some fish have larger intestines than others, and that a cow has a long intestine and a cat a short one, state why a tadpole has a relatively longer intestine than a frog.

Compare the mouth, jaws, eyes,-skin, body, and habits of tadpole and frog.

\section{FroGS}

Prove that frogs and toads are beneficial to man. Did you ever know of a frog or toad destroying anything useful, or harming any one, or causing warts? How many pupils in class ever had warts? Had they handled frogs before the warts came? Frogs are interesting, gentle, timid animals. Why are they repulsive to some people?

Environment. - Where are frogs found in greatest numbers? What occurs when danger threatens them? What encmies do they have? What color, or tint, is most prominent on a frog? Does the color "mimic" or imitate its surroundings? What is the color of the under side of the body? (Fig. 250.) Why is there greater safety in that color? What enemies would see water frogs from below? Do tree frogs mimic the bark? The leaves?

Can a frog stay under water for an indefinite time? Why, or why not? What part of a frog is above the 
surface when it floats or swims in a tub of water? Why? Do frogs croak in the water or on the bank? Why do they croak after a rain? Do toads croak?

Are the eggs laid in still or flowing water? In a clear place or among sticks and stems ? Singly, or in strings or in masses? (Fig. 248.) Describe an egg. Why do frogs dig into the mud in autumn in cold climates? Why do they not dig in mud at the bottom of a pond? Why is digging unnecessary in the Gulf states?

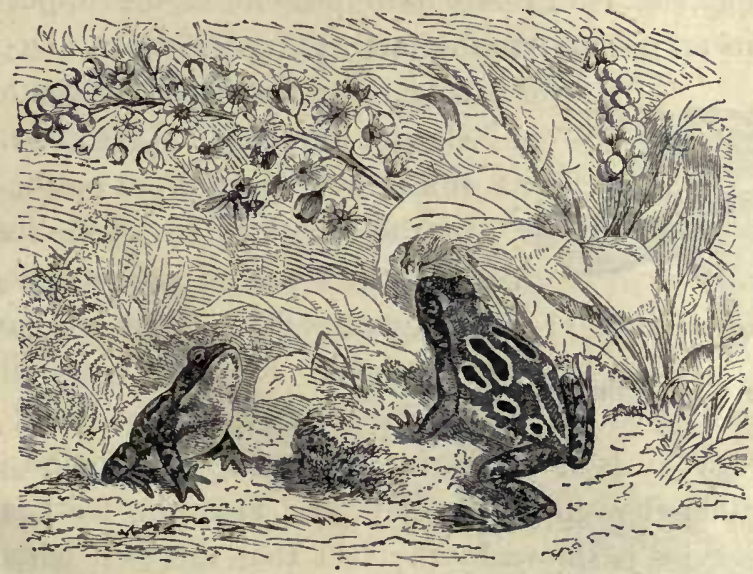

FIG. 250. - PAINTED Frog (Chorophilus ornatus), of Mexico.

Describe the position of the frog when still (Fig. 250). What advantage in this position? Does the frog use its fore legs in swimming or jumping? Its hind legs? How is the frog fitted for jumping? Compare it in this respect with a jumping insect; a jumping mammal. How is it fitted for swimming? Is the general build of its body better fitted for swimming or jumping? How far can a frog jump?

External Features. - The frog may be said to have two regions in its body, the head and trunk. A neck hardly 
exists, as there is only one vertebra in front of the shoulders (Fig. 252), while mammals have seven neck (cervical) vertebræ. There are no tail (caudal) vertebræ, even in the tadpole state of frogs and toads.

The hcad appears triangular in shape when viewed from what direction? The head of a frog is more pointed than the head of a toad. Is the skull a closed case of broad bones or an open structure of narrow bones? (Fig. 252.)

Describe the mouth. Observe the extent of the mouth opening (Fig. 25I). Are teeth present in the upper jaw? The lower jaw? Are the teeth sharp or dull? Does the

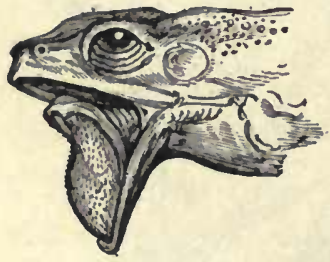

FIG. 25I. - HEAD OF FROG.

frog chew its food? Is the tongue slender or thick? (Fig. 251.) Is it attached to the front or the back of the mouth? In what direction does the free end extend when the tongue lies flat? Is the end pointed or lobed? How far out will the tongue stretch? For what is it used? Why is it better for the teeth to be in the upper jaw rather than in the lower jaw? That the teeth are of little service is shown by the fact that the toad with similar habits of eating has no teeth. Will a toad catch and swallow a bullet or pebble rolled before it? The toad is accustomed to living food, hence prefers a moving insect to a still one.

The Senses. - Compare the eyes with the eyes of a fish in respect to position and parts. Are the eyes protruding or deep-set? Touch the eye of a live frog. Can it be retracted? What is the shape of the pupil? The color of the iris? Is the eye bright or dull? What probably gave rise to the superstition that a toad had a jewel in its head? Is there a third eyelid? Are the 
upper and lower eyelids of the same thickness? With which lid does it wink? Close its eye?

Observe the large oval ear drum or tympanum. What is its direction from the eye? (Fig. 25I.) The mouth? Is there a projecting ear? Does the frog hear well? What reason for your answer? As in the human ear, a tube (the Eustachian tube) leads from the mouth to the inner side of the tympanum.

How many nostrils? (Fig. 25I.) Are they near together or separated? Large or small? A bristle passed into the nostril comes into the mouth not far back in the roof. Why must it differ from a fish in this?

How do the fore and hind legs differ? How many toes on the fore foot or hand? On the hind foot? On which foot is one of the toes rudimentary? Why is the fore limb of no assistance in propelling the body in jumping? Do the toes turn in or out? (Fig. 250.) How does the frog give direction to the jump? What would be the disadvantage of always jumping straight forward when fleeing? Which legs are more useful in alighting?

Divisions of the Limbs. - Distinguish the upper arm, forearm, and hand in the

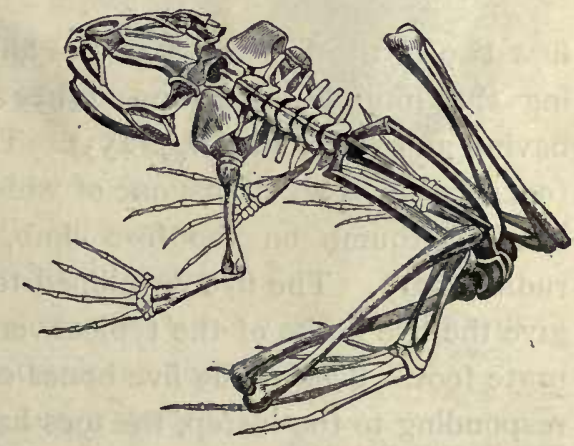

Fig. 252. - SKeleton OF FroG. fore limb (Figs. 252 and 253). Compare with skeleton of man (Fig. 399). Do the arms of a man and a frog both have one bone in the upper arm and two in the forearm? Both have several closely joined bones in the wrist and 
five separate bones in the palm. Do any of the frog's fingers have three joints? Compare also the leg of man

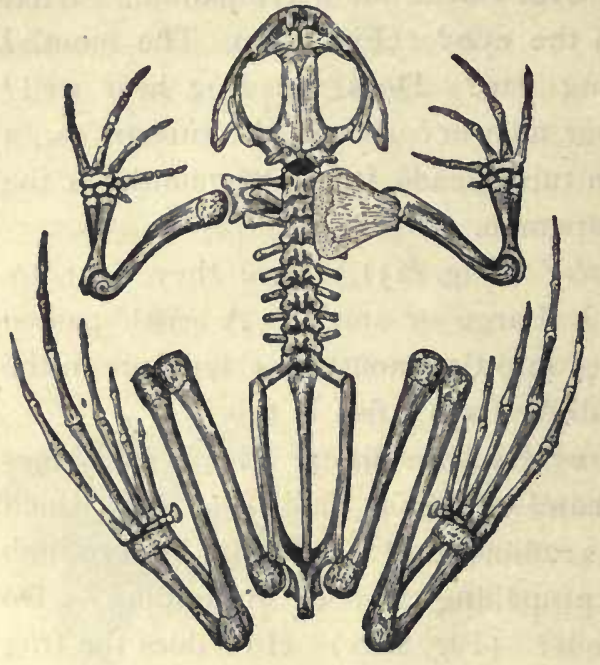

FIG. 253.-SKELETON OF FROG. and the hind leg of the frog (Figs. 253 and 399). Does the thigh have one bone in each? The shank of man has two bones, shin and splint bone. Do you see a groove near the end in the shank bone of a frog (Fig. 252), indicating that it was formed by the union of a shin and splint bone? The first two of the five bones of the ankle are elongated, giving the hind leg the appearance of having an extra joint (Fig. 253). The foot consists of six digits, one of which, like the thumb on the fore limb, is rudimentary. The five developed toes give the five digits of the typical vertebrate foot. Besides the five bones corresponding to the instep, the toes have two, three, or four bones each. How is the hind foot specialized for swim. ming? Which joint of the leg con-

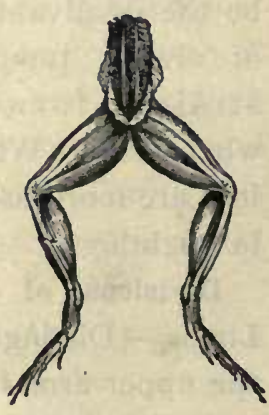

FIG. 254. - LEG MUSCLES OF FROG. tains most muscle? (Fig. 254.) Find other bones of the frog analogous in position and similar in form to bones in the human skeleton. 
Is the skin of a frog tight or loose? Does it have any appendages corresponding to scales, feathers, or hair of other vertebrates? Is the skin rough or smooth? The toad is furnished with glands in the skin which are sometimes swollen; they form a bitter secretion, and may be, to some extent, a protection. Yet birds and snakes do not hesitate to swallow toads whole. Show how both upper and under surfaces of frog illustrate protective coloration.

All batrachians have large and numerous blood vessels in the skin by which gases are exchanged with the air, the skin being almost equal to a third lung. That the skin may function in this way, it must not become dry. Using this fact, account for certain habits of toads as well as frogs.

If a frog is kept in the dark or on a dark surface, its skin will become darker than if kept in the light or on a white dish. Try this experiment, comparing two frogs. This power of changing color is believed to be due to the diminution in size of certain pigment cells by contraction, and enlargement from relaxation. This power is possessed to a certain degree not only by batrachians but also by many fishes and reptiles. The chameleon, or green lizard of the Gulf states, surpasses all other animals in this respect (Fig. 280). What advantage from this power?

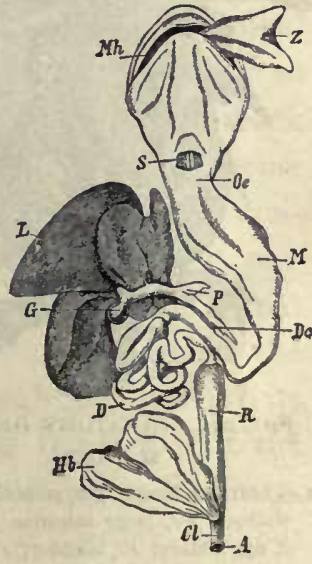

Fig. 255.-Digestive

Canal of Frog.

$M h$, mouth; $Z$; tongue pulled outward; $S$, opening to larynx; Oe, gullet; $M$, stomach: $D$, intestine; $P$, pancreas; $L$, liver; $G$, gall bladder; $R$, rectum; $H b$, bladder; $C l$, cloaca; $A$, vent.

Digestive System. - The large mouth cavity is connected by a short throat with the gullet, or esophagus (Fig. 255). 
A slit called the glottis opens from the throat into the lungs (Fig. 255). Is the gullet long or short? Broad or narrow? Is the stomach short or elongated? Is the division distinct between the stomach and gullet, and stomach and intestine? Is the liver large or small? Is it simple or lobed? The pancreas lies between the stomach and the first bend of the intestines (Fig. 255). What is its shape? A bile duct connects the liver with

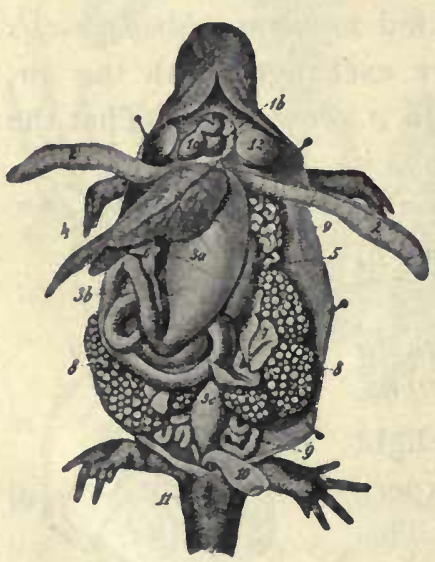

Fig. 256. - ANATOMY OF SALAMANDER.

$1 a$, heart; 2 , lungs: $3 a$, stomach; $3 b$, in. testine: $3 c$, large intestine; 4 , liver: 8, egg masses; 10 , bladder; $\boldsymbol{M}$, vent. the small intestine $(D c$, Fig. 255). It passes through the pancreas, from which it receives several pancreatic ducts. After many turns, the small intestine joins the large intestine. The last part of the large intestine is called the rectum (Latin, straight). The last part of the rectum is called the cloaca (Latin, a drain), and into it the ducts from the kidneys and reproductive glands also open. The kidneys are large, elongated, and flat. They lie under the dorsal wall. The urinary bladder is also large. Does the salamander have a similar digestive system? (Fig. 256.) Why are the liver and lungs (Fig. 256) longer in a salamander than in a frog?

Respiration. - How many lungs? Are they simple or lobed? (Fig. 256.) A lung cut open is seen to be baglike, with numerous ridges on its inner surface. This increases the surface with which the air may come in contact. In the walls of the lungs are numerous 
capillaries. Does the frog breathe with mouth open or closed? Does the frog have any ribs for expanding the chest? What part of the head expands and contracts? Is this motion repeated at a slow or rapid rate? Regularly or irregularly? There are valves in the nostrils for opening and closing them. Is there any indication of opening and closing as the throat expands and contracts ? The mouth and throat (pharynx) are filled with air each time the throat swells, and the exchange of gases (which gases?) takes place continually through their walls and the walls of the lungs. At intervals the air is forced through the glottis into the lungs. After a short time it is expelled from the lungs by the muscular abdominal walls, which press upon the abdominal organs, and so upon the lungs. Immediately the air is forced back into the lungs, so that they are kept filled. In some species the lungs regularly expand at every second contraction of the throat. This is shown by a slight outward motion at the sides. Does the motion of the throat cease when the frog is under water? Why would the frog be unable to breathe (except through the skin) if its mouth were propped open? Why does the fact that the breathing is so slow as to almost cease when hibernating, aid the frog in going through the winter without starving? (Chap. I.) Why must frogs and toads keep their skins moist? Which looks more like a clod? Why?

The Heart and Circulation. - What is the shape of the heart? (Fig. 257.) Observe the two auricles in front and the conical ventricle behind them. The great arterial trunk from the ventricle passes forward beyond the auricles; it divides into two branches which turn to the right and left (Fig. 257). Each branch immediately subdivides into three arteries (Fig. 257), one going to the head, one to the lungs and skin, and a third, the largest, 
passes backward in the trunk, where it is united again to its fellow. (Colored Fig. 2.)

Both of the pulmonary veins, returning to the heart with pure blood from the lungs, empty into the left auricle. Veins with the impure blood from the body empty into the right auricle. Both

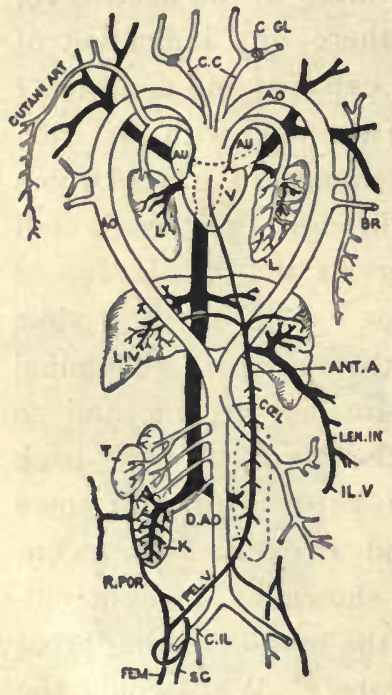

FIG. 257. - PLAN OF FroG'S Circulation.

Venous system is black; the arterial, white. $A U$, auricles; $V$, ventricle: $L$, lung: $L I V$, liver. Aorta has one branch to right, another to left, which reunite below. Right branch only persists in birds, left branch in beasts and man. the auricles empty into the ventricles, but the pure and impure blood are prevented from thoroughly mixing by ridges on the inside of the ventricle. Only in an animal with a four-chambered heart does pure blood from the lungs pass unmixed and pure to all parts of the body,

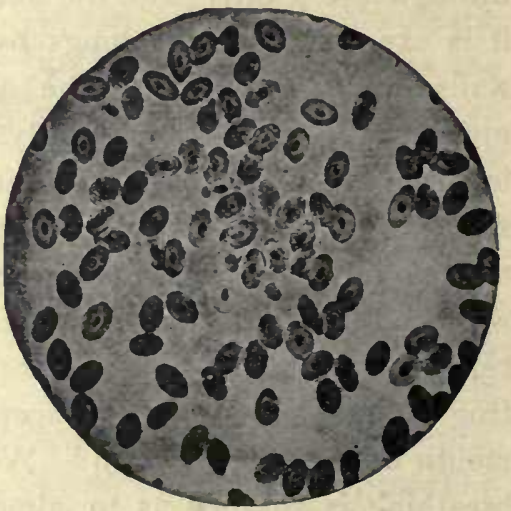

FIG. 258. - FROG'S BLOOD (magnified 2500 areas). Red cells oval, nucleated, and larger than human blood cells. Nuclei of two white cells visible near center. (Pea. body.)

and only such animals are warm-blooded. The purer (i.e. the more oxygenated) the blood, the greater the oxidation and warmth.

The red corpuscles in a frog's blood are oval and larger than those of man. Are all of them nucleated? (Fig. 258.) The flow of blood in the web of a frog's foot is a striking and interesting sight. It may be easily shown by wrapping a small frog in a wet cloth and laying it with one foot extended upon a glass slip on the stage of a miscroscope. 
The brain of the frog (Fig. 259) is much like that of a fish (Fig. 224). The olfactory, cerebral, and optic lobes, cerebellum and medulla are in the same relative position, although their rela-

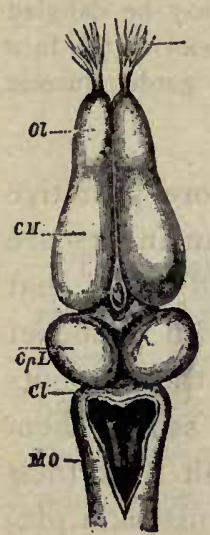

F1G. 259.tive sizes are not the same. Compared with the other parts, are the olfactory lobes more or less developed than in a fish? The cerebral hemispheres? The optic lobes? The cerebellum? There is a cavity in the brain. It is readily exposed on the under surface of the medulla by cutting the membrane, which is there its only covering (Fig. 259).

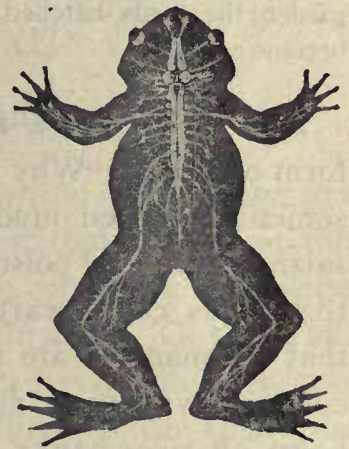

FiG. 260. - NeRVOUS SYSTEM OF FROG.

BRAIN OF FROG.

Frogs and toads are beneficial (why?) and do not the slightest injury to any interest of man. If toads are encouraged to take up their abode in a garden, they will aid in ridding it of insects. A house may be made in a shady corner with four bricks, or better still, a hole a foot deep may be dug to furnish them protection from the heat of the day. A toad's muzzle is not so tapering as a frog's (why ?), its feet are not so fully webbed (why?), and its skin is not so smooth (why?). In case of doubt open the mouth and rub the finger along the upper jaw; a frog has sharp teeth,

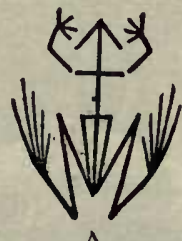

A

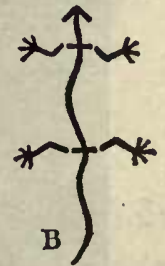

FIG. 26I. - Position of legs in tailless $(A)$ and tailed $(B)$ amphibian. a toad none at all. The tadpoles of frogs, toads, and salamanders are much alike. In toad's spawn the eggs lie in strings inclosed in jelly; frogs spawn is in masses (Fig. 248). 
Any batrachian may easily be passed around the class after placing it in a tumbler with gauze or net tied over top. It should be kept in a box with two inches of moist earth on the bottom. If no live insects are obtainable for feeding a toad, bits of moist meat may be dangled from the end of a string. If tadpoles are placed in a pool or tub in a garden, the toads hatched will soon make destructive garden insects become a rarity.

Does a frog or a salamander have the more primitive form of body? Why do you think so? Salamanders are sometimes called mud puppies. The absurd belief that salamanders are poisonous is to be classed with the belief that toads cause warts. The belief among the ancients that salamanders ate fire arose perhaps from sceing them coming away from fires that had been built over their holes on river banks by travelers. Their moist skin protected them' until the fire became very hot.

Describe the "mud puppy" shown in Fig. 262. In the West the pouched gopher, or rat (Fig. 37I), is sometimes absurdly called a salamander.

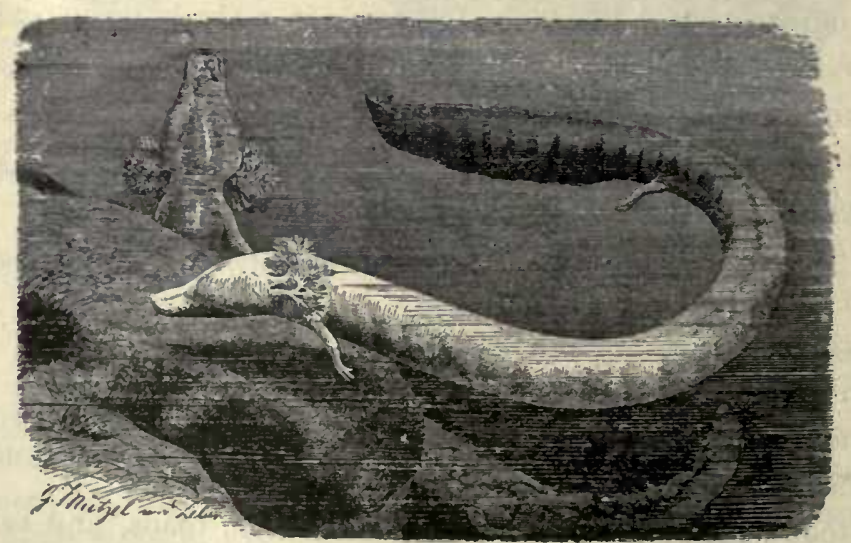

Fig. 262, - BLiND SAlamander (Protens anguinus). $\times \frac{1}{2}$. Found in caves and underground streams in Balkans. Gills external, tail finlike, legs small. 


\section{CHAPTER XII}

\section{REPTILIA (REPTILES)}

THIS class is divided into four orders which have such marked differences of external form that there is no diffi. culty in distinguishing them. These orders are represented by Lizards, Snakes, Turtles, and Alligators. Of these, only the forms of lizards and alligators have similar proportions, but there is a marked difference in their size, lizards being, in general, the smallest, and alligators the largest of the reptiles.

Comparison of Lizards and Salamanders. - To make clear the difference between reptiles and batrachians, it will be well to compare the orders in the two classes which resemble each other in size and shape; namely, lizards and

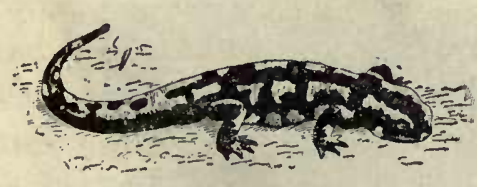

Fig. 263. - A Salamander.

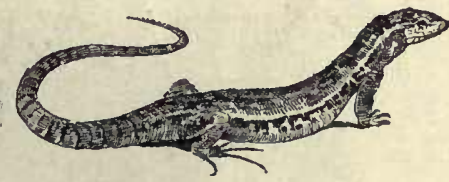

FIG. 264. - A LIZARD.

salamanders (Figs. 263 and 264). State in a tabular form their differences in skin, toe, manner of breathing, development from egg, shape of tail, habitat, habits. Each has an elongated body, two pairs of limbs, and a long tail, yet they are easily distinguished. Are the differences suggested above valid for the other batrachians (frogs) and other reptiles (e.g. turtles)? Trace the same differences 
between the toad or frog (Fig. 250) and the "horned toad," which is a lizard (Fig. 265).

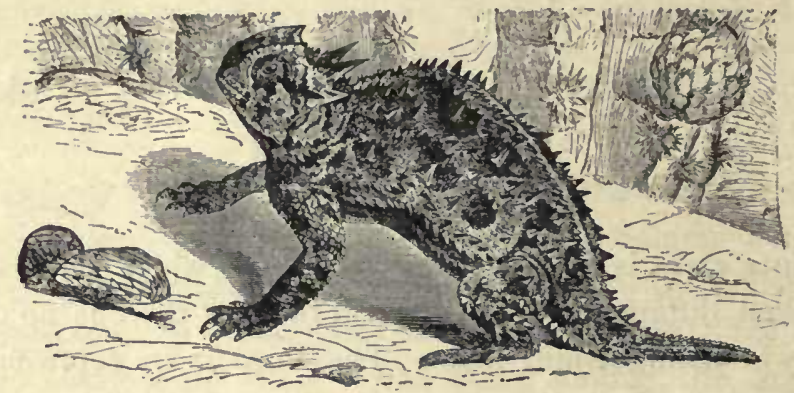

FIG. 265. - "HORNED TOAD" LIZARD, of the Southwest (Phrynosuma cornita). $\times 3$.

\section{Stuny of a TURTle or Tortoise}

Suggestrons. - Because of the ease with which a tortoise or turtle may be caught and their movements and habits studied, it is suggested that one of these be studied as an example of reptiles. Besides a live specimen, a skeleton of one species and the shells of several species should be available.

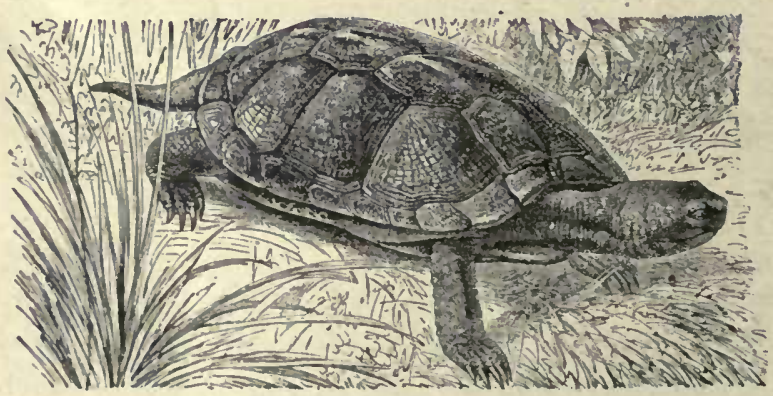

Fig, 266. - European POND TURTle (Emys lutaria). (After Brehms.)

The body (of a turtle or tortoise) is divided distinctly into regions (Fig. 266). Is there a head? Neck? Trunk? Tail? The trunk is inclosed by the so-called shell, which 
consists of an upper portion, the carapace, and a lowet portion, the plastron. How are the other regions covered? What is the shape of the head? Is the mouth at the front, or on the under side? Where are the nostrils? Are the motions of breathing visible? Is there a beak or. snout? Do the jaws contain teeth?

Do the eyes project? Which is thinner and more movable, the upper or lower lid? Identify the third eyelid (nictitating membrane). It is translucent and comes from, and is drawn into, the inner corner of the eye. It cleanses the eyeball. Frogs and birds have a similar membrane. The circular ear drum is in a depression back of the angle of the mouth. What other animal studied has an external ear drum?

The tortoise has a longer, more flexible neck than any other reptile. Why does it have the greatest need for such a neck? Is the skin over the neck tight or loose? Why?

Do the legs have the three joints or parts found on the limbs of most vertebrates? How is the skin of the legs covered? Do the toes have clawes? Compare the front and hind feet. Does the tortoise slide its body or lift it when walking on hard ground? Lay the animal on its back on a chair or table at one side of the room in view of the class. Watch its attempts to right itself. Are the motions suited to accomplish the object? Does the tortoise succeed?

What are the prevailing colors of turtles? How does their coloration correspond to their surroundings?

What parts of the tortoise extend at times beyond the shell? Are any of these parts visible when the shell is closed? What movements of the shell take place as it is closed? Is the carapace rigid throughout? Is the plastron? 
The Skeleton (Fig. 267). - The carapace is covered with thin epidermal plates which belong to the skin. The bony nature of the carapace is seen when the plates are removed, or if its inner surface is viewed (Fig. 267). It is seen to consist largely of wide ribs (how many ?) much flattened and grown together at their edges. The ribs are seen to be rigidly attached to the vertebræ. The rear projections of the vertebræ are flattened into a series of bony plates which take the place of the sharp ridge found along the backs of most

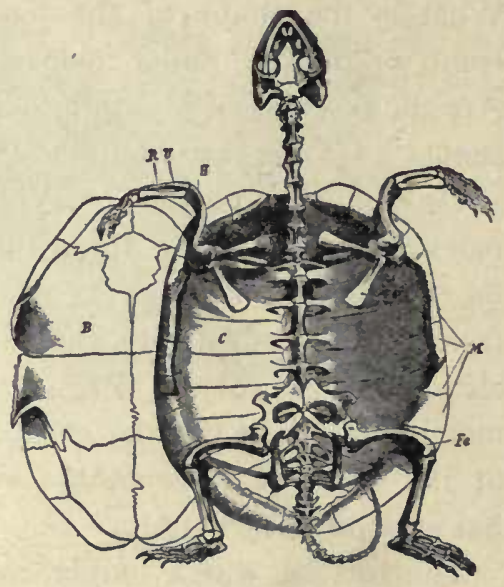

FIG. 267. - SKEIETON OF EUROPEAN TORTOISE.

$C$, rib plates; $M$, marginal plates; $B$, plastron; $H$, humerus bone: $R$, radius; $U$, ulna; $\mathrm{Fe}$, femur.

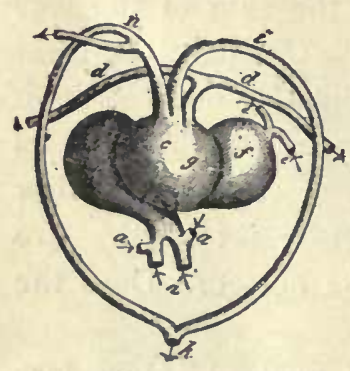

FIG. 268. - THREE-CHAM BERED HEART OF A REPTILE (tortoise).

$a$, veins; $b, f$, right and left auricles; $c g$, ventricle; $d$, arteries to lungs; $e$, veins from lungs; $i, n$, two branches of aorta. Compare with Fig. 269 and colored Fig. 2.

vertebrates. Show that the shell of a turtle is not homologous with the shells of mollusks. Does the turtle have shoulder blades and collar bones? Hip bones? Thigh bones? Shin bone (fibia) and splint bone (fibula)? (Fig. 267.)

Do the plates formed by the ribs extend to the edge of the carapace? See Fig. 267. About how many bony plates form the carapace? The plastron? Do the horny plates outside correspond to the bony plates of the shell? 
How many axial plates? How many ostal (rib) plates? How many border plates? Which p'ates are largest? Smallest? Do the horny plates overlap like shingles, or meet enge to edge? Is there any mark whert they meet on the bony shell? Basing it upon foregoing facts, give a connected and complete description of the structure of the carapace. Compare the skeleton of the twitle with that of the snake, and sultaic ine differences in stricture with differences in habits.

Iraw the tortoise seen from the

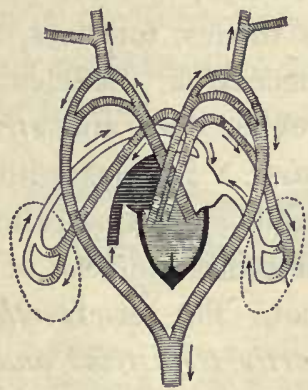

FIG. 269. - PLAN OF REP. TILIAN CIRCULATION. See arrows. side or above, with its shell closed, showing the arrange-

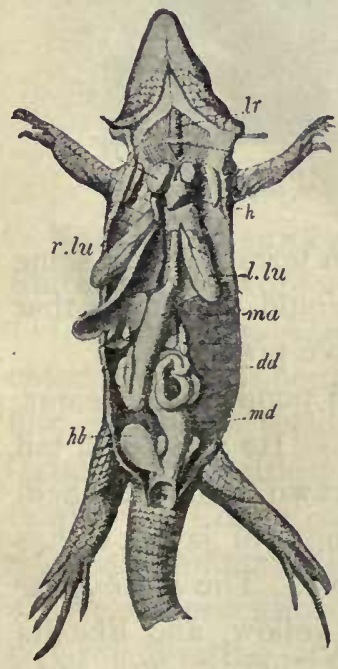

Fig. 270. - REPTILIAN VISCERA (lizard).

$l r$, windpipe; $h$, heart; $l u$, lungs; $l r$, liver: $m a$, stomach; $d d$, $m d$, intestines; $h b$, bladder. ment of the plates.

Place soft or tender vegetable food, lettuce, mushroom, roots, berries, and water, also meat, in reach of the turtle. What does it prefer? How does it eat? It has no lips; how does it drink?

Study the movements of its eyeballs and eyelids, and the respiratory and other movements already mentioned. State a reason for thinking that no species of land animals exists that lacks the simple power of righting itself when turned on its back.

Tortoise, Turtle, Terrapin. - The turtles belong to the order of reptiles called chelonians. No one 
can have any difficulty in knowing a member of this order. The subdivision of the order into families is not so easy, however, and the popular attempts to classify chelonians as turtles, tortoises, and terrapins have not been entirely successful. Species with a vaulted shell and imperfectly webbed toes and strictly terrestrial habits are called tortoises. Species with flattened shells and strictly aquatic habits should be called terrapins (e.g. mud terrapin). They have three instead of two joints in the middle toe of each foot. The term turtle may be applied to species which are partly terrestrial and partly aquatic (e.g. snapping turtle (Fig. 27I)). Usage, however, is by no means uniform.

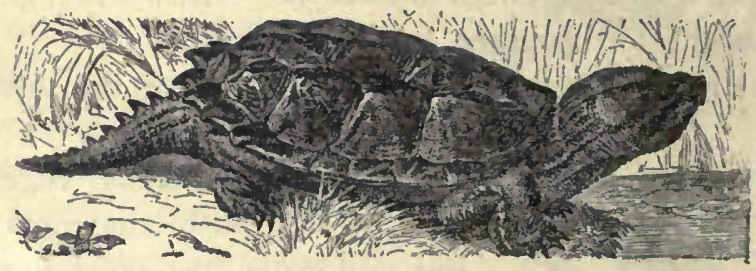

Fig. 271. - SNAPPING TURTLE (Chelydra serpentina).

Most reptiles eat animal food; green terrapins and some land tortoises eat vegetable food. Would you judge that carnivorous chelonians catch very active prey?

The fierce snapping turtle, found in ponds and streams, sometimes has a body three feet long. Its head and tail are very large and cannot be withdrawn into the shell. It is carnivorous and has great strength of jaw. It has been known to snap a large stick in two. The box tortoise is yellowish brown with blotches of yellow, and like its close kinsman, the pond turtle of Europe (Fig. 266), withdraws itself and closes its shell completely. Both lids of the plastron are movable, a peculiarity belonging to these two species. The giant tortoise of the Galapagos Islands, ac- 
cording to Lyddeker, can trot cheerfully along with three full-grown men on its back. "Tortoise shell" used for combs and other articles is obtained from the overlapping scales of the harvbill turtle, common in the West Indies. The diamond-back terrapin, found along the Atlantic Coast from Massachusetts to Texas, is prized for making soup.

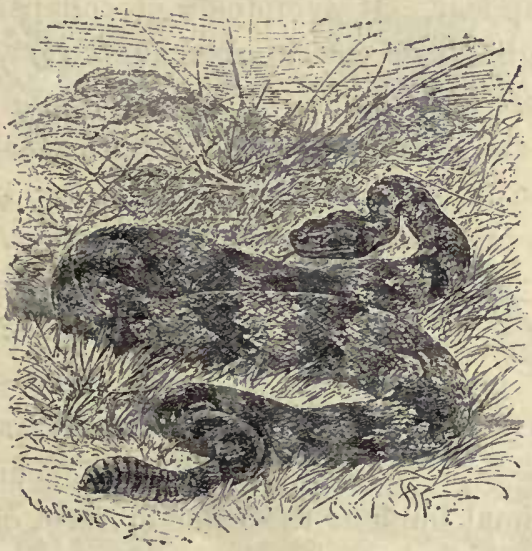

Fig. 272. - A RATTLESNAKE.

\section{Venomous snakes of United} States named in order of virulence : 1. Coral snakes, Elaps, about seventeen red bands bordered with yellow and black (colored figure 6) (fatal). 2. Rattlesnakes (seldom fatal). 3. Copperhead (may kill a small animal size of dog). 4. Water moccasin (never fatal). 5. Ground rattler. - Effects: Pulse fast, breathing slow, blood tubes dilated, blood becomes stored in abdominal blood tubes, stupefaction

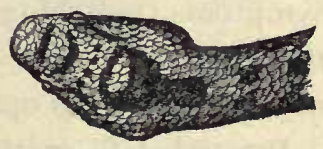

FIG. 273 a. - HEAD OF VIPER, showing typical triangular shape of head of venomous snake.

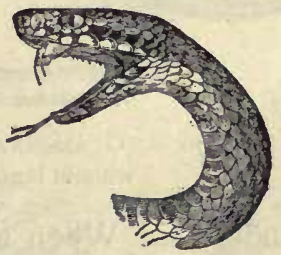

FIG. $2736 .-$ SIDE VIEW, showing poison fangs; also tongue (forked, harmless).

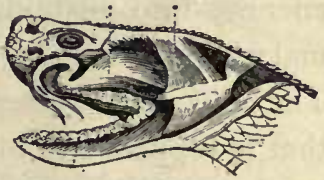

FIG. 274. - VIPER'S HEAD, showing poison sac at base of fangs.

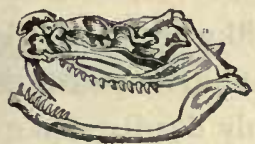

FIG. 275.-SkUI.L, showing teeth, fangs, and quadrate bone to which lower jaw is joined. See Fig. 284 . 
and death from blood being withdrawn from brain. Al. ways two punctures, the closer together the smaller the snake. Remedies: Ligature between wound and heart, lance wound and suck; inject into wound three drops of I per cent solution of chromic acid or potassium permanganate. Give strychnine, hypodermically, until strychnine symptoms (twitchings) appear. If symptoms of collapse recur, repeat dose. Digitalin or caffein acts like strychnine; alcohol has opposite effect.

Protective Coloration and Mimicry. - When an animal imitates the color or form of its inanimate surroundings it

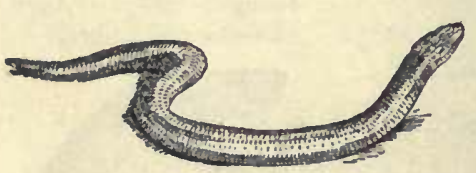

Fig. 276. - "Glass SNAKE," a lizard without legs.

is said to be protectively colored or formed. Give an instance of protective coloration or form among lizards ; butterflies ; grasshoppers; amphibians; echinoderms. When an animal imitates the color or form of another animal it is said to mimic the animal. Mimicry usually enables an animal to deceive enemies into mistaking it for an animal which for some reason they avoid. The milkweed butterfly has a taste that is repulsive to birds. The viceroy butterfly is palatable to birds, but it is left untouched because of its close resemblance to the repulsive milkweed butterfly. The harlequin snake (Elaps) of the Gulf states is the only deadly snake of North America

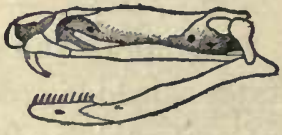

FIG. 277.-SKULL OF ELAPS. See colored Fig. 5 .

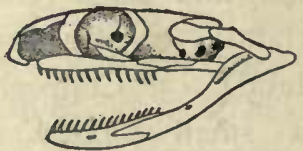

FIG. 278. = SKULL OF LAMPROPELTIS. (Figs. 277, 278). It is very strikingly colored with rings of scarlet, yellow, and black. This is an example of warning coloration. The coral snake (Lampropeltis) has bands of 

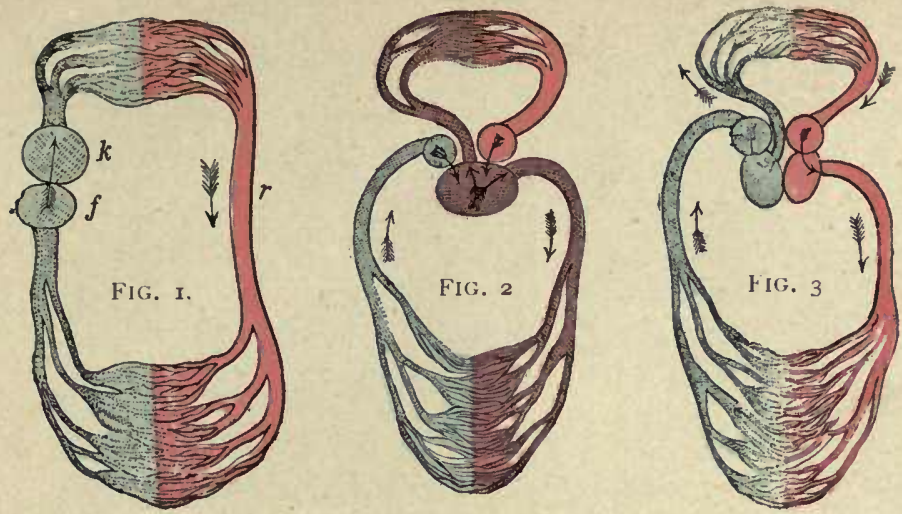

Colorfid Figukes $r$, 2, 3- - Circulation in Fish, Reptile, Mammal.

In which is blood from heart all impure? Mixed? Both pure and inpure?

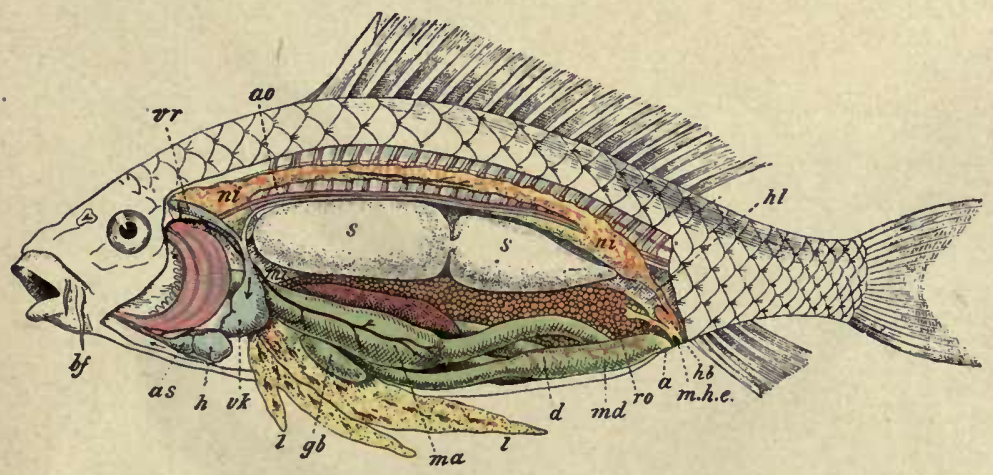

FIG. 4.-ANATOMY OF CARP. For description see Fig. 220, page 117 .

FIG; 5 - HARIEQUIN SNAKE (Elaps)

THE HARMLESS

CORAL SNAKE

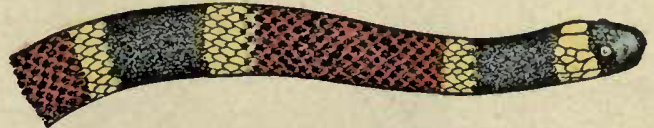

MIMICS THE

DEADLY HARLEQUIN SNAKE.

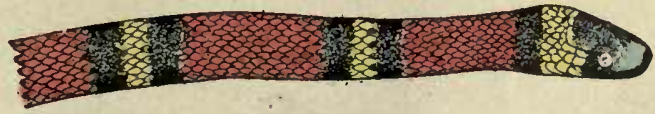

FIG. 6. - CORAL SNAKE (Lampropeltis). 

scarlet, yellow, and black (colored Fig. 6) of the same tints, and it is hardly distinguishable from the harlequin. The

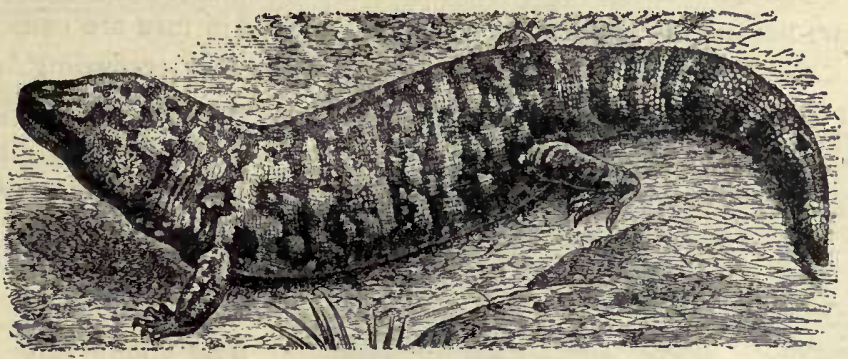

FIG. 279. - GILA MONSTER (Heloderma suspectum), of Arizona. If poisonous, it is the only instance among lizards. It is heavy-built, orange and black mottled, and about 16 inches long. Compare it with the green lizard (Fig. 280).

coral snake is said to mimic the harlequin snake. It also imitates the quiet inoffensive habits of the harlequin snake, which fortunately does not strike except under the greatest provocation. The rattles of the less poisonous and seldom fatal rattlesnake (Fig. 272) may be classed as an example of warning sound which most animals are quick to heed and thus avoid encounters which might be destructive to either the snake or its enemy.

Survival of the Fittest. - The two facts of most far-reaching importance in the history of animals and plants are: (I) Heredity; animals inherit the characteristics of their parents. (2) Variation; animals are not exactly like their parents. The first fact gives stability, the second makes

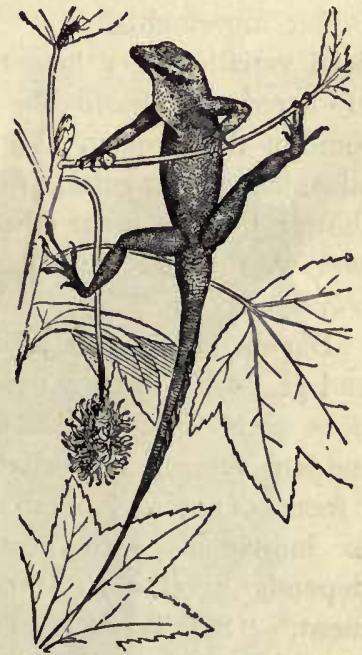

Fig. 280.-Chameleon (Anolis), or green lizard of southern U.S. Far excels European chameleon (Fig. 28I) and all known animals in power of changing color (green, gray, yellow, bronze, and black). 
progress or evolution possible. The climate of the world is slowly changing, and animals must change to adapt themselves to it. A more sudden change of environment (surroundings) of animals occurs because of migration or isolation; these in turn are caused

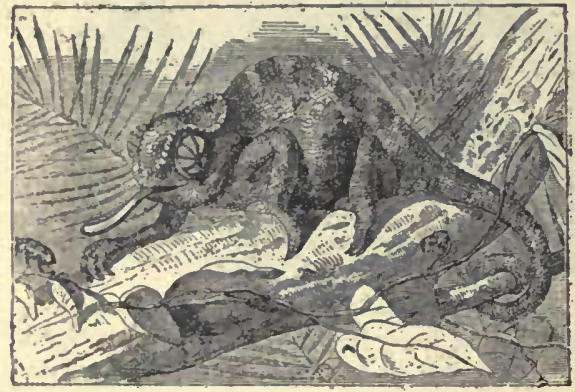

Fig. 281. - Chameleon of Southern Europe.

by the crowding of other animals or by the formation or disappearance of geographical barriers, such as deserts, water, mountain chains.

The young vary in many ways from their parents. Some have a more protective color or form, sharper claws, swifter movements, etc. The individuals possessing such beneficial variations live longer and leave more offspring, and because of heredity transmit the desirable qualities to some of their young. Variations which are disadvantageous for getting food, defense, etc., cause shorter life and fewer offspring. Thus the fittest survive, the unfit perish; an automatic natural selection occurs.

Darwin taught that variations are infinitesimal and gradual. Recent experiments and observations seem to show that many variations are by sudden jumps, somewhat resembling so-called " freaks of nature." As to whether these "sports," or individuals with new peculiarities, survive, depends upon their fitness for their environment. "Survival of the fittest" results from this natural selection, but the selection occurs between animals of marked, not infinitesimal, differences, as Darwin taught. Darwin's theory is

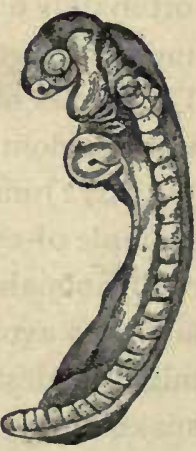

FIG. 282. - ENBRYO OF A TURTLE, showing four gill slits. (Challenger Report.) probably true for species in the usual state of nature; the new theory (of De Vries) is probably true for animals and plants under domestication and during rapid geographical changes. 
Table for Review (for notebooks or blackboards).

\begin{tabular}{|c|c|c|c|c|c|}
\hline & FISH & TADPOLE & FROG & Turtee & LizARD \\
\hline \multicolumn{6}{|c|}{$\begin{array}{l}\text { Limbs, kind and } \\
\text { number }\end{array}$} \\
\hline \multicolumn{6}{|c|}{$\begin{array}{l}\text { Are claws present ? } \\
\text { How many? }\end{array}$} \\
\hline \multicolumn{6}{|c|}{ Covering of body } \\
\hline \multicolumn{6}{|c|}{$\begin{array}{l}\text { Teeth, kind of, if } \\
\text { present }\end{array}$} \\
\hline \multicolumn{6}{|c|}{$\begin{array}{l}\text { Which bones found } \\
\text { in man are lacking? }\end{array}$} \\
\hline \multicolumn{6}{|c|}{ Chambers of heart } \\
\hline \multicolumn{6}{|l|}{ Respiration } \\
\hline Movements & & & & & \\
\hline
\end{tabular}

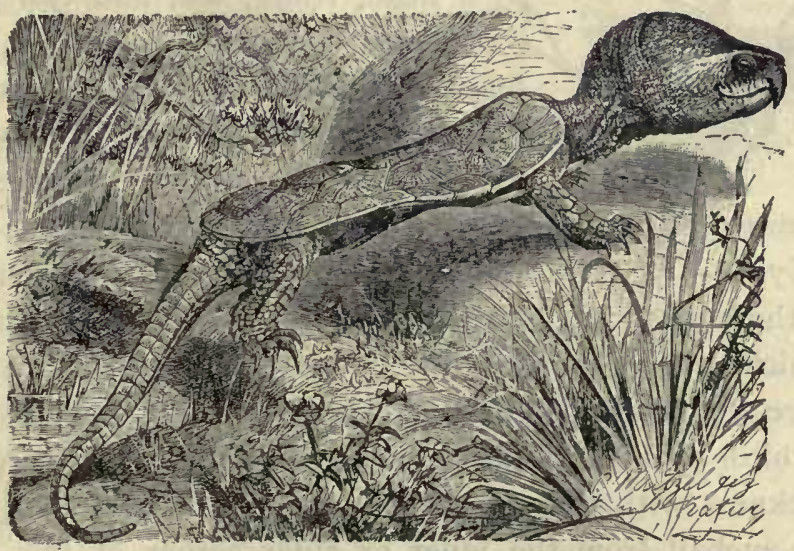

FIG. 283.-BIG-HEADED TURTLE (Platysternum megalocephalum). $\times \frac{1}{3}$. China. This and Fig. 282 suggest descent of turtles from a lizardlike form. Figure 282 shows earlier ancestors to have been gill breathers. 


\section{CHAPTER XIII}

\section{BIRDS}

Suggestions. - The domestic pigeon, the fowl, and the English sparrow are most commonly within the reach of students. The last bird has become a pest and is almost the only bird whose destruction is desirable. The female is somewhat uniformly mottled with gray and brown in fine markings. The male has a black throat with the other markings of black, brown, and white, in stronger contrast than the marking of the female. As the different species of birds are essentially alike in structural features, the directions and questions may be used with any bird at hand. When studying feathers, one or more should be provided for each pupil in the class. The feet and bills of birds should be kept for study.

I Does the body of the bird, like the toad and turtle, have

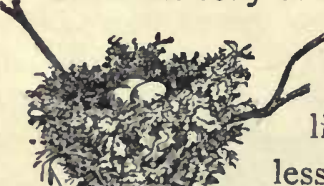

a head, trunk, tail, and two pairs of limbs? Do the fore and hind limbs differ from each other more or less than the limbs of other backboned animals? Does any other vertebrate use them for

Eye. - Does the eyeball have parts corresponding to the eyeball of a fish or frog; viz., cornea, iris, pupil? Which is more movable, the upper or lower eyelid? Are there any lashes? 'The bird (like what other animal?) has a third eyelid, or nictitating membrane. Compare its thickness with that of the other lids. Is it drawn over the eyeball from the inner or outer corner of the eye? Can you see in the human eye any wrinkle or growth which might be regarded as remains, or vestige, of such a membrane? 
How many nostrils? In which mandible are they located? Are they nearer the tip or the base of the mandible? (Fig. 284.) What is their shape? Do the nasal passages go directly down through the mandible or do they go backward? Is the inner nasal opening into the mouth or into the throat?

The beak or bill consists of the upper and lower mandibles. The outside of the beak seems to be of what kinc? of material? Examine the decapitated head of a fowl or of a dissected bird, and find if there is a covering on the bill which can be cut or scraped off. Is the mass of the bill of bony or horny material? With what part of the human head are the mandibles homologous? (Fig. 284.)

Ears. - Do birds have

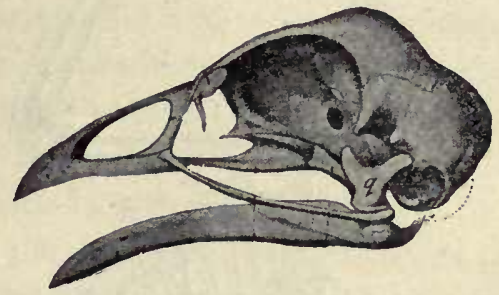

Fig. 284. - SkUll of Domestic Fowl. q, quadrate ("four-sided") bone by which lower jaw is attached to skull (wanting in beasts, present in reptiles; see Fig. 277).

external ears? Is there an external opening leading to the ear? In searching for it, blow or push forward the feathers. If found, notice its location, size, shape, and what surrounds the opening. There is an owl spoken of as the long-eared owl. Are its ears long?

The leg has three divisions: the uppermost is the thigh (called the "second joint" in a fowl); the middle division is the shank (or "drumstick"); and the lowest, which is the slender bone covered with scales, is formed by the union of the ankle and instep. (The bones of the three divisions are, named the femur, tibiotarsus, and tarsometatarsus.) The foot consists entirely of toes, the bones of which are called phalanges. Is there a bone in each claw? (See Fig. 285.) Supply the numerals in this sentence: 
The pigeon has — toes, the hind toe having — joints; of the three front toes, the inner has - joints (count the claw as one joint), the

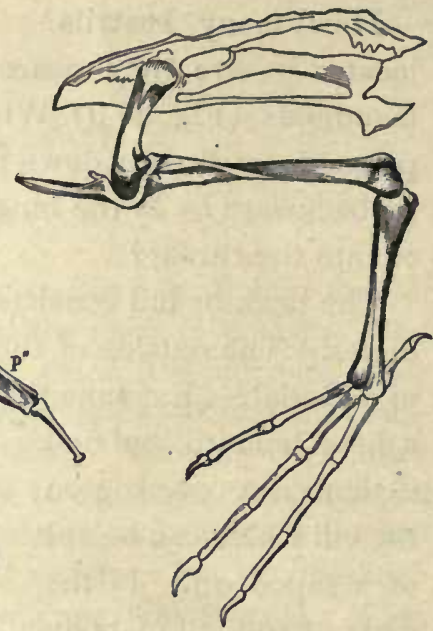

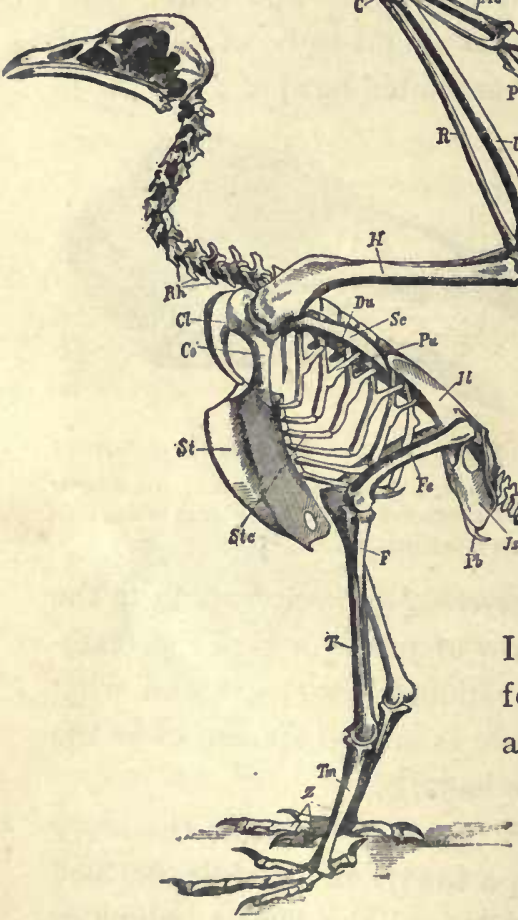

FIG. 286.- SKELETON OF BIRD.

$R h$, vertebra: $C l$, clavicle; $C o$, coracoid; Sc, scapula; St, sternum; $H$, humerus: $R$, radius; $U$, ulna; $P$, thumb; $F e$, femur; $T$, tibia. See Fig. 394. Questions: Which is the stiffest portion of the vertebral column? How are the ribs braced against each other? Which is longer, thigh bone or shin ? Compare shoulder blade with man's (Fig. 399). Which is the extra shoulder bone? Compare tail vertebra with those of extinct bird, Fig. $29 a$.
FIG. 285.-LEG BONES OF BIRD.

middle has joints, and the outer toe has joints (Fig. 285). Is the thigh of a bird bare or feathered? The shin? The ankle? Where is the ankle joint of a bird? Do you see the remains of another bone (the splint bone, or fibula) on the shin bone of the shank? (Fig. 285 or 286.) Why would several joints in the ankle be a disadvan tage to a bird? 
The thigh hardly projects beyond the skin of the trunk, as may be noticed in a plucked fowl. The thigh extends forward from the hip joint (Figs. 286, 299) in order to bring the point of support forward under the center of weight. Why are long front toes more necessary than long hind toes? As the bird must often bring its head to the ground, the hip joints are near the dorsal surface and the body swings between the two points of support somewhat like a silver ice pitcher on its two pivots. Hence stooping, which makes a man so unsteady, does not cause a bird to lose steadiness.

The wing has three divisions which correspond to the upper arm, forearm, and hand of man (Fig. 286). When the wing is folded, the three divisions lie close alongside each other. Fold your arm in the same manner. The similarity of the bones of the first and second divisions to the bones of our upper arm and forcarm is very obvious (Fig. 286). Explain. The hand of a bird is furnished with only three digits (Fig. 287). The three palm bones (metacarpals) are firmly united (Fig. 287). This gives firmness to the stroke in flying.

That the bird is descended from animals which had the

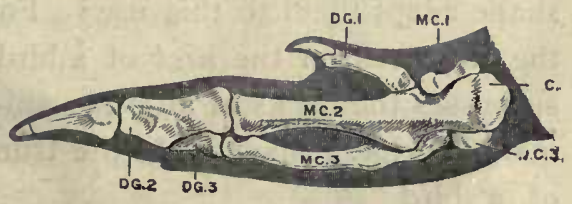

FIs. 287.- HAND AND WRIST OF FOWL (after Parker). DG. I-3, digits; $M C .1-3$, metacarpals; CC. 3 , wrist.

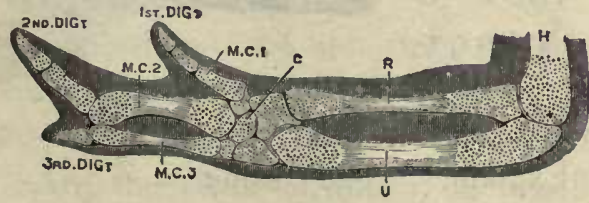
FIG, 288. - HAND, WRIST (c), FOREARM, AND Elbow of Young CHick (after Parker). fingers and palm bones less firmly united is shown by comparing the hands of a chick and of an adult fowl (Figs. 287, 288). The wrist also solidifies with age, the 
five carpals of the chick being reduced to two in the fowl (Figs. 287, 288). The thumb or first digit has a separate

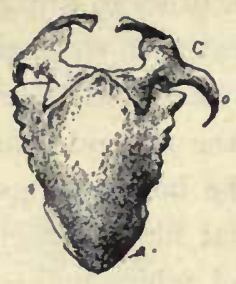

FIG. 289. - BREASTBONE AND SHOULDER BONES OF CASSOWARY. covering of skin from the other digits, as may be seen in a plucked bird. The degenerate hand of the fowl is of course useless as a hand (what serves in its place?) but is well fitted for firm support of the feathers in flying. The two bones of the forearm are also firmly joined. There are eighteen movable joints in our arm and hand; the bird has only the three joints which enable it to fold its wing. The wrist joint is the joint in the forward angle of the wing. Since the fore limbs are taken up with locomotion, the grasping function has been assumed by the jazws. How does their shape adapt them to this use? For the same reason the neck of a bird surpasses the necks of all other animals in what respect? Is the trunk of a bird flexible or inflexible? There is thus a correlation between structure of neck and trunk. Explain. The same correlation is found in which of the reptiles? (Why does rigidity of trunk require flexibility of neck?) Why does

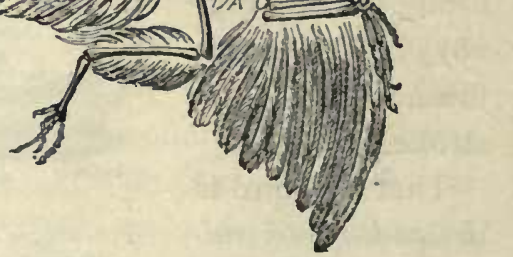

FIG. 290.-A Fossil. BIRD (archaopteryx) found in the rocks of a former geological epoch.

Question: Find two resemblances to reptiles in this extinct bird absent from skeletons of extant birds. 
the length of neck in birds correlate with the length of legs? Examples? (See Figs. 314, 315, 332.) Exceptions? (Fig. 324.) Why does a swan or a goose have a long neck, though its legs are short?

To make a firm support for the wings the vertebræ of the back are immovably joined, also there are three bones in each shoulder, the collar bone, the shoulder blade, and the coracoid bone (Fig. 286). The collar bones are united (why?) and form the "wishbone" or "pulling bone." To furnish surface for the attachment of the large flying muscles there is a prominent ridge or keel on the breastbone (Fig. 286). It is lacking in most birds which do not fly (Fig. 289).

The feathers are perhaps the most characteristic feature of birds. The large feathers of the wings and tail are called quill feathers. A quill feather (Fig. 291 ) is seen to consist of two parts, the shaft, or supporting axis, and the broad vane or web.

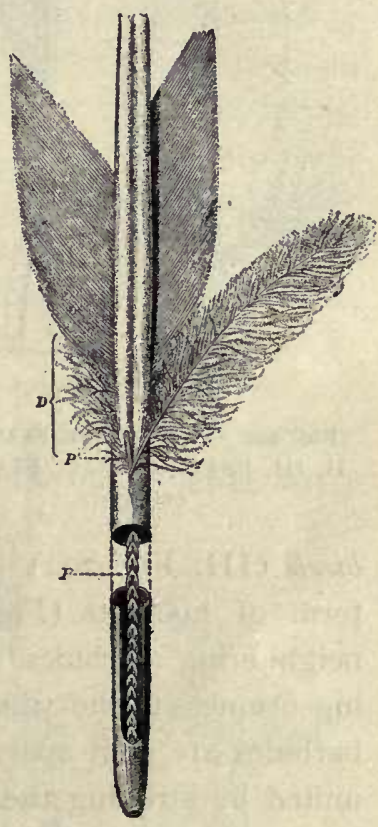

FIG. 29I.-QUILL FEATHER.

$D$, downy portion. What part of the shaft is round? Hollow? Solid? Is the shaft straight? Are the sides of the vane usually equal in width? Can you tell by looking at a quill whether it belongs to the wing or tail, and which wing or which side of the tail it comes from? Do the quills overlap with the wide side of the vane above or beneath the next feather? Can you cause two parts of the vane to unite again 
by pressing together the two sides of a split in the vane? Does the web separate at the same place when pulled until
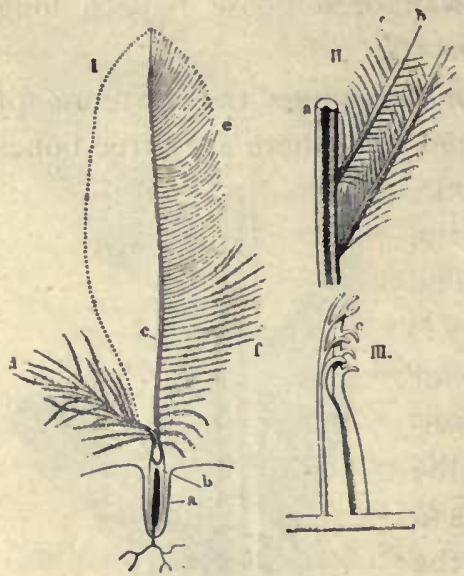

Fig. 292. - I, CONTOUR FEATHER. II, III, PARTS OF QUILL FEATHER, enlarged. it splits again?

The hollow part of the shaft of a quill feather is called the quill. The part of the shaft bearing the vane is called the rachis (rā-kis). The vane consists of slender barbs which are branches of the shaft (II, Fig. 292). As the name indicates (see dictionary), a barb resembles a hair. The barbs in turn bear secondary branches called bar. bules, and these again have shorter branches called bar-

bicels (III, Fig. 292). These are sometimes bent in the form of hooklets (Fig. 292, III), and the hooklets of neighboring barbules interlock, giving firmness to the vane. When two barbules are split apart, and then reunited by stroking the vane between the thumb and finger, the union may be so strong that a pull upon the vane will cause it to split in a new place next time.

There are four kinds of feathers, (I) the quill feathers, just studied; (2) the contour feathers (I, Fig. 292),

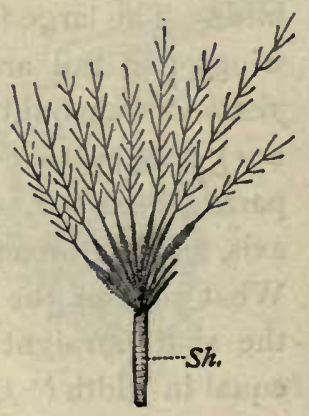

Fig. 293.-A Dows FFATHER, enlarged. which form the general surface of the body and give it its outlines; (3) the downy feathers (Fig. 293), abundant on 
nestlings and found among the contour feathers of the adult but not showing on the surface ; 4 ) the pin feathers, which are hair-like, and which are removed from a plucked bird by singeing. The contour feathers are similar in structure to the quill feathers. They protect the body from blows, overlap so as to shed the rain, and, with the aid of the downy feathers retain the heat, thus accounting for the high temperature of the bird. The downy feathers are soft and fluffy, as they possess few or no barbicels; sometimes they lack the rachis (Fig. 293). The pin feathers are delicate horny shafts, greatly resembling hairs, but they may have a tuft of barbs at the ends.

A feather grows from a small projection (or papilla) found at the bottom of a depression of the skin. The quill is formed by being molded around the papilla. Do you see any opening at the tip of the quill for blood vessels to enter and nourish the feather? What is in the quill? (Fig. 29r.) The rachis? A young contour or quill feather is inclosed in a delicate sheath which is cast off when the feather has been formed. Have you seen the sheath incasing a young feather in a molting bird?

There are considerable areas or tracts on a bird's skin without contour feathers. Such bare tracts are
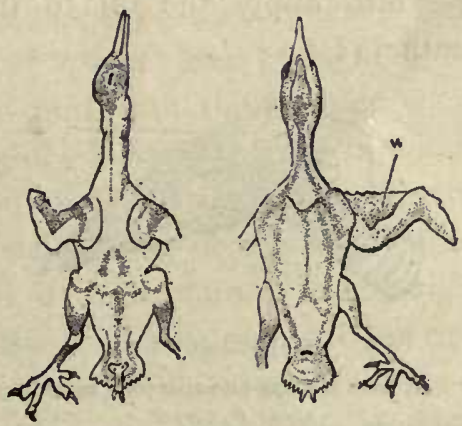

FIG. 294.- DORSAL AND VENTRAl, VIEW OF PLUCKED BIRD, showing regions where feathers grow. found along the ridge of the breast and on the sides of the neck. However, the contour feathers lie so as to overlap and cover the whole body perfectly (Fig. 294).

The shedding of the feathers is called molting. Feathers, 
like the leaves of trees, are delicate structures and lose perfect condition with age. Hence the annual renewal

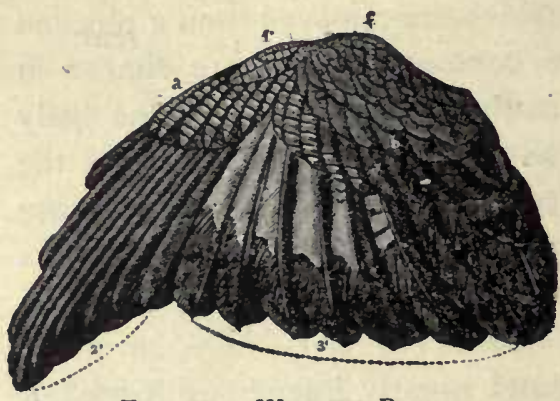

FIG. 295. - WING OF BIRD.

$\boldsymbol{T}$, false quills (on thumb); 2 , primaries; 3 , secondaries: tertiaries (dark) are one above another at right: $a, b$, coverts. of the feathers is an advantage. Most birds shed twice a year, and with many the summer plumage is brighter colored than the winter plumage. When a feather is shed on one side, the corresponding feather on the other side is always shed with it. (What need for this?) A large oii giand is easily found on the dorsal side of the tail. How does the bird apply the oil to the feathers ?

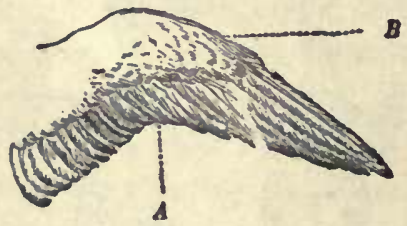

FIG. 296.

$A$, point dividing primaries from second. aries: $B$, coverts.

In describing and classifying birds, it is necessary to know the names of the various external regions of the body and plumage. These may be learned by studying Figs. 295, 296, 297, 298.

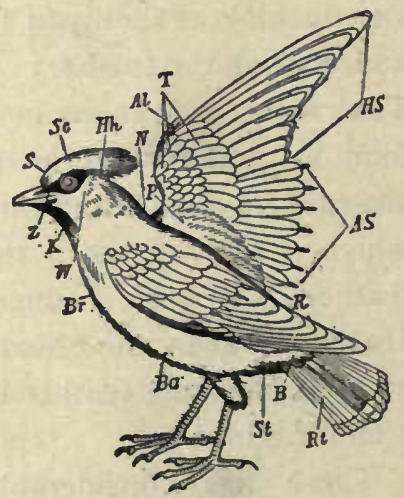

FIG. 297.-CEDAR WAXWING, with regions of body marked.

$S$, forehead; $S c$, crown (with crest): $H h$, nape; $K$, throat; $B r$, breast; $B a$, lower parts; $R$, back; $R t$, tail; $B$, tail coverts; $P$, shoulder feathers (scapulars); $T$, wing coverts; $H S$, primaries: $A S$, secondaries: $A l$, thumb feathers.

The quills on the hand 
are called primaries, those on the forearm are the secondaries, those on the upper arm are the tertiaries. Those on the tail are called the tail quills. The feathers at the base of the quills are called the coverts. The thumb bears one or more quills called the spurious quills. Is the wing concave on the lower or upper side? What advantage is this when the bird is at rest? When it is flying?

Control of Flight. - Did you ever see a bird sitting on a swinging limb? What was its chief means of balancing itself ? When flying, what does a bird do to direct its course upward? Downward? Is the body level when it turns to either side? Birds with long,

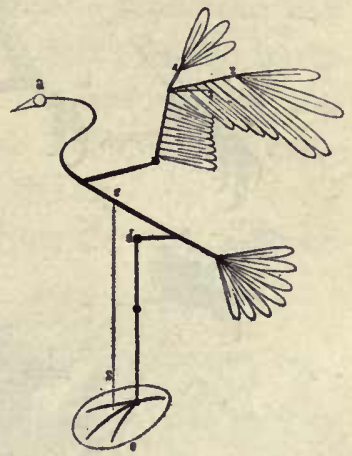

Fig. 298. - PLAN OF BiRD. $s$, center of gravity. pointed wings excel in what respect? Examples? Birds with great wing surface excel in what kind of flight? Examples. Name a common bird with short wings which has a labored, whirring flight. Is its tail large or small?

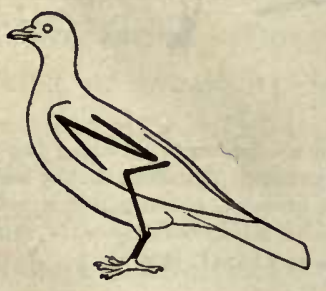

FIG. 299. - POSITION OF LIMBS OF PIGEON.

Does it avoid obstacles and direct its flight well? Why or why not? When a boat is to be turned to the right, must the rudder be pulled to the right or the left? (The rudder drags in the water and thus pulls the boat around.) When the bird wishes to go upward, must its tail be turned up or down? How when it wishes to go down? When a buzzard soars for an hour without flapping its wings, does it move at a uniform rate? For what does it use the momentum gained when going with the wind? 
Flying. - When studying the quill feathers of the wing, you saw that the wider side of the vane is beneath the feather next behind it. During the downward stroke of the wing this side of the vane is pressed by the air against

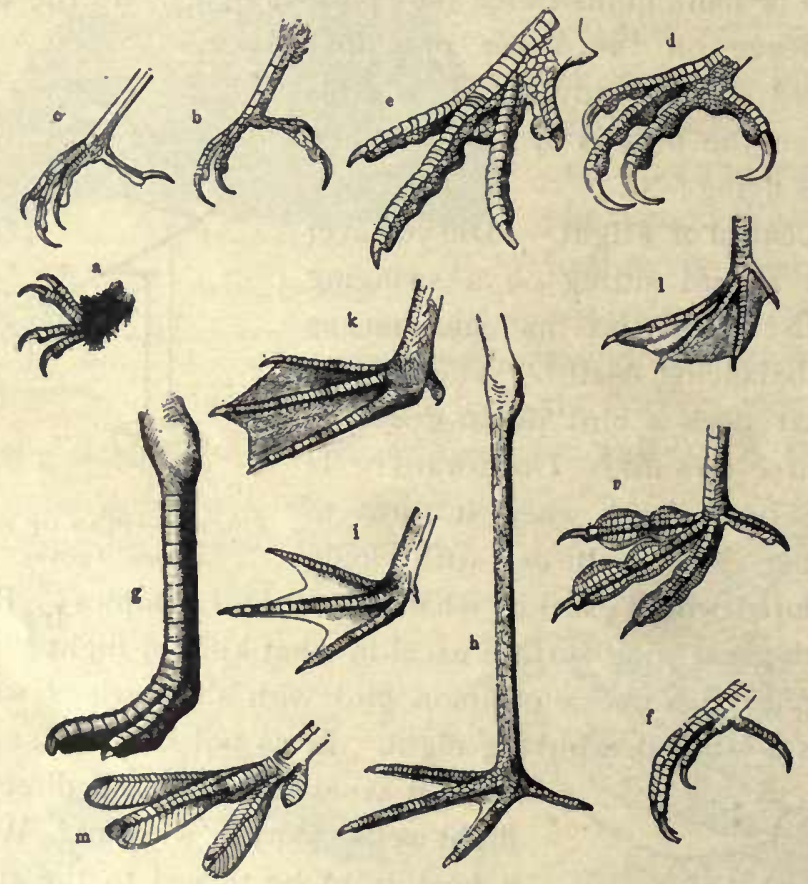

FIG. 300 .

$a$, clambering foot of chimney sweep; $b$, climbing foot of woodpecker; $c$, perching foot of thrusb; $d$, seizing foot of hawk: $e$, scratching foot of pheasant; $f$, stalking fuot of kingfisher: $\mathcal{E}$, running foot of ostrich: $h$, wading foot of heron; $i$, paddling foot of gull: $k$, swimming foot of duck; $l$, steering foot of cormorant; $m$, diving foot of grebe; $n$, skimming foot of coot. Question: Does any bird use its foot as a hand? (Fig. 320.)

the feather above it and the air cannot pass through the wing. As the wing is raised the vanes separate and the air passes through. The convex upper surface of the wing also prevents the wing from catching air as it is raised. Spread a wing and blow strongly against 
its lower surface; its upper surface. What effects are noticed?

Study the scales on the leg of a bird (Fig. 300). Why is the leg scaly rather than feathered from the ankle downward? Which scales are largest? (Fig. 300.) How do the scales on the front and back differ? What can you say of the scales at the bottom of the foot; at the joints of the toes? Explain. How does the covering of the nails and bill compare in color, texture, hardness and firmness of attachment with the scales of the leg?

Draw an outline of the bird seen from the side. Make drawings of the head and feet more detailed and on a larger scale.

Why does a goose have more feathers suitable for making pillows than a fowl? In what country did the domestic fowl originate? (Encyclopedia.) Why does a cock crow for day? (Consider animal life in jungle.)

Activities of a Bird. - Observe a bird eating. Does it seem to chew or break its food before swallowing? Does it have to lift its head in order to swallow food? To swallow drink? Why is there a difference? After feeding the bird, can you feel the food in the crop, or enlargement of the gullet at the base of the neck? (Fig. 304.)

Feel and look for any move-

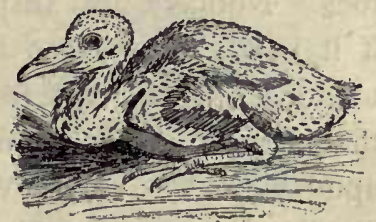

Fig. 3or. - AN ALTRICAL Bird, i.e. poorly developed at hatching. Young pigeon, naked. beak too weak for eating.

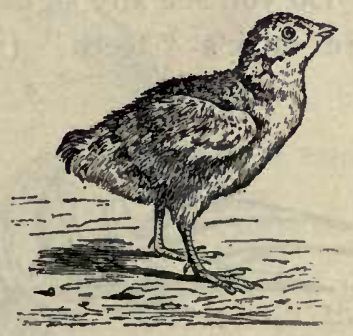

FIG. 302.-A PRECOCIAL BIRD (well developed at hatching). Feathered, able to run and to pick up food. Precocity is a sign of instinctive life and low intelligence. A baby is not precocious.

Question: Is pigeon or fowl ex. posed to more dangers in infancy? 
ments in breathing. Can you find how often it breathes per minute? Place hand under the bird's wing. What do you think of its temperature; or better, what temperature is shown by a thermometer held under its wing ? Do you see any connection between the breathing rate and the temperature? Test (as with the crayfish) whether a bird can see behind its head? Notice the movements of the nictitating membrane. Does it appear to be transparent?

Watch a bird fly around a closed room and review the questions on Control of Flight.

Bend a bird's leg and see if it has any effect upon its toes. Notice a bird (especially a large fowl) walk to see if it bends its toes as the foot is lifted. Pull the rear tendon in a foot cut from a fowl for the kitchen. Does the bird have to use muscular exertion to grasp a stick upon which it sits? Why, or why not? When is this bending of the toes by bending the legs of special advantage to a hawk? To a duck? A wading bird? Why is a fowl safe from a hawk if it stands close to a tree?

Do you see any signs of teeth in the bird's jaws? Why are duck's " teeth" (so called by children) not teeth?

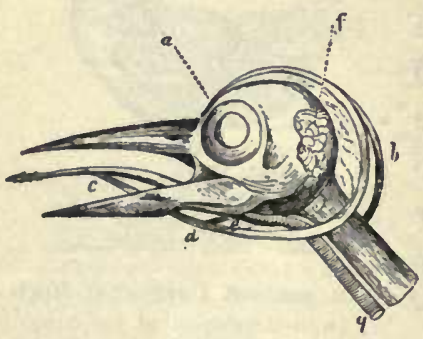

FIG. 303. - HEAD OF WOODPECKER. $c$, tongue; $a, b, d$, hyoid bone; $e, q$, windpipe: $f$, salivary gland.
Can the tongue of a bird be pulled forward? (Fig. 303.) What is its shape? If there is opportunity, dissect and study the slender, bony (hyoid) apparatus to which the base of the tongue is attached (Fig. 303), the opening of the windpipe, or trachea, the slit-like opening of windpipe which is so narrow as to prevent food falling into the windpipe. 
The Internal Organs, or Viscera (Figs. 304 and 305). - The viscera (vis'se-ra), as in most vertebrates, include the food tube and its glands; the lungs, the heart, and larger blood vessels; the kidneys and bladder and the reproductive organs. The lower part, or gullet, is enlarged into a crop. It is largest in grain-eating birds. It

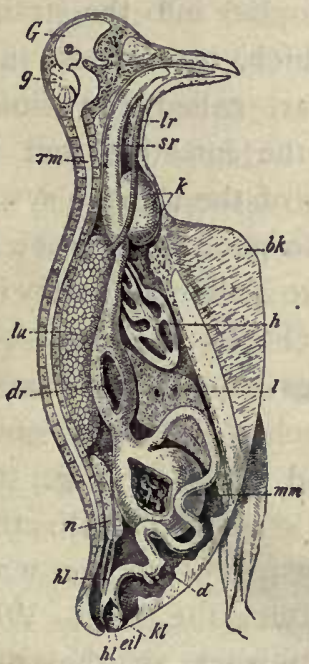

Fig. 304. - ANATOMY OF DOve $\times 1 / 2$. $b k$, keel of breastbone; $G, g$, brain; $l r$, windpipe; $l u$, lıng; $h$, heart; $s r$, gullet; $k$, crop; $d r$, glandular stomach: $m m$, gizzard; $d$, intestine; $n$, kidney: $h l$, ureter; $e i l$, openings of ureter and egg duct into cloaca, $k l$.

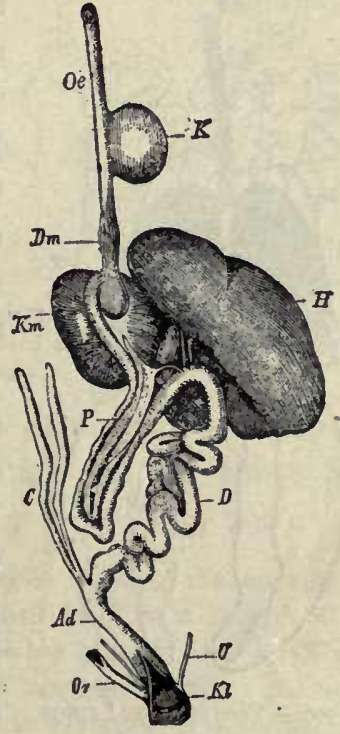

FIG. 305. - FoOD TUBE OF BIRD.

$P$, pancreas: $C$, cæca.

Question: Identify each part by means of Fig. 304.

is found in the V-shaped depression at the angle of the wishbone, just before the food tube enters the thorax. The food is stored and softened in the crop. From the crop the food passes at intervals into the glandular stomach. Close to this is the muscular stomach, or gizzard. Are the places of entrance and exit on opposite sides of the gizzard, or near together? (Fig. 304.) Is the lining of the gizzard 
rough or smooth? Why? Is the gizzard tough or weak? Why are small stones in the gizzard? Why do not hawks and other birds of prey need a muscular gizzard? The liver and pancreas empty their secretions into the intestines by several ducts a little way beyond the gizzard. Beyond the mouths of two cæca (Fig. 305) the many-coiled

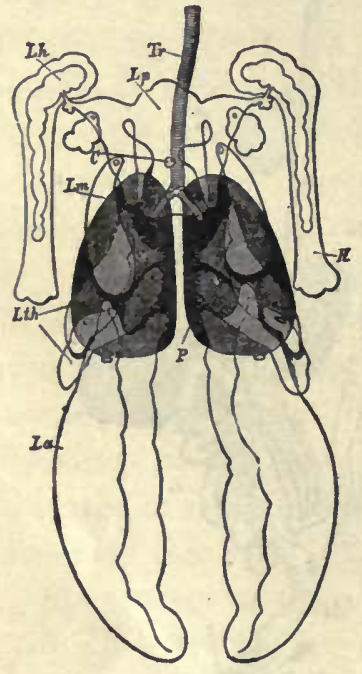

Fig. 306.-Position of LuNGS AND AIR SACS (Pigeon).

$T r$, windpipe; $P$, lungs; $L m$, sac under clavicle with prolongation $(L h)$ into humerus: $L a$, sacs in abdomen. intestine empties into the straight rectum, which terminates in a widened part called the cloaca. Not only the intestine, but the two ureters of the urinary system and the two genital ducts of the reproductive system all empty into the cloaca (Figs. 304, 305).

The lungs have their rear surfaces attached to the spinal column and ribs (lu, Fig. 304). They are connected with thinwalled, transparent air sacs which aid in purifying the blood. When inflated with warm air, they probably make the body of the bird more buoyant. For the names, location, and shape of several pairs of air sacs, see Fig. 306. The connection of the air sacs with hollows in the humerus bones is also shown in the figure. Many of the bones are hollow; this adds to the buoyancy of the bird. The pulmonary artery, as in man, takes dark blood to the lungs to exchange its carbon dioxide for oxygen. Of two animals of the same weight, which expends more energy, the one that flies, or the one that runs the same distance? Does a bird require more oxygen 
or less, in proportion to its weight, than an animal that lives on the ground? Are the vocal cords of a bird higher or lower in the windpipe than those of a man? (Fig. 307.)

The heart of a bird, like a man's heart, has four chambers; hence it keeps the purified blood separate from the impure blood. Since pure blood reaches the organs of a bird, oxidation is more perfect than in the body of any animals yet studied. Birds have higher

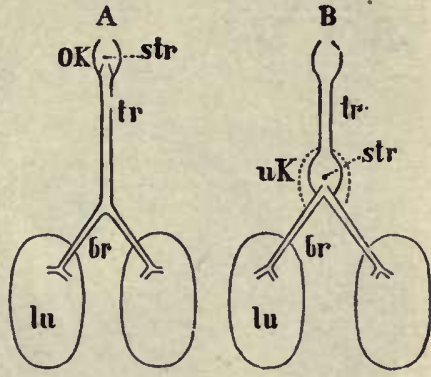

Fig. 307. - POSITION OF VOCAL CORIS (str) OF MAMMAL AND BIRD.

- Question: Does a fowl ever croak after its head and part of its neck are cut off? Explain. temperature than any other class of animals whatsoever. Tell how the jaws, tail, and wings of the fossil bird Archæopteryx differed from living birds (Fig. 290).

Suggestions. - In the field work, besides seeking the answers to definite questions, pupils may be required to hand in a record of the places and times of seeing a certain number of birds ( 20 to 40 ), with the actions and features which made each distinguishable. Also, and more important, each pupil should hand in a record of a careful and thorough outdoor study of one common species (see below) as regards habits, nesting, relation to environment, etc.

Field Study of a Common Species. - (For zuritten report.) Name of species. Haunts. Method of locomotion when not flying. Flying (rate, sailing, accompanying sound if any, soaring).

What is the food? How obtained? Association with birds of its own species. Relation to birds of other species.

Where does it build its nest? Why is such a situation selected? Of what is the nest built? How is the material carried, and how built into the nest? Does the lird's body fill the nest?

Describe the eggs. Does the male bird ever sit or otherwise assist female before hatching? Does it assist after hatching? 


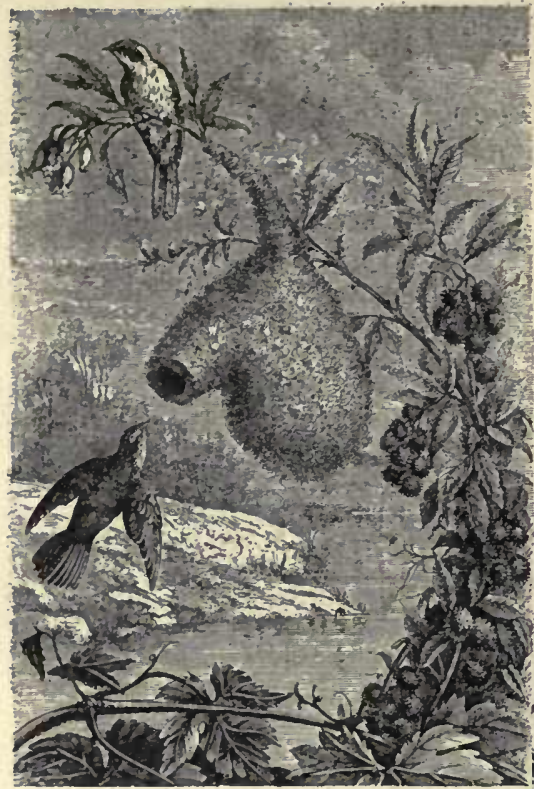

How long is taken to lay a sitting of eggs? How long before the birds are hatched? When hatched are they helpless? Blind? Feathered? (Figs. 30r, 302.) Do the nestlings require much food? How many times is food brought in an hour? How distributed? Even if the old birds sometimes eat fruit do they take fruit to the young? What do they feed to the young? How long be-

Fig. 308. - EURUPEAN TUMTIT'S NEST.

What are the advantages of its shape?

fore they leave the nest? Do the parents try to teach them to fly? Do the parents care for them after the nest is left? What songs or calls has the bird?

General Field Study. (For written report.) Name the best and poorest flyers you know; birds that fly most of the time; birds that seldom fly. Observe birds that pair; live in flocks. Does their sociability vary with the season? Do you ever see birds quarreling?

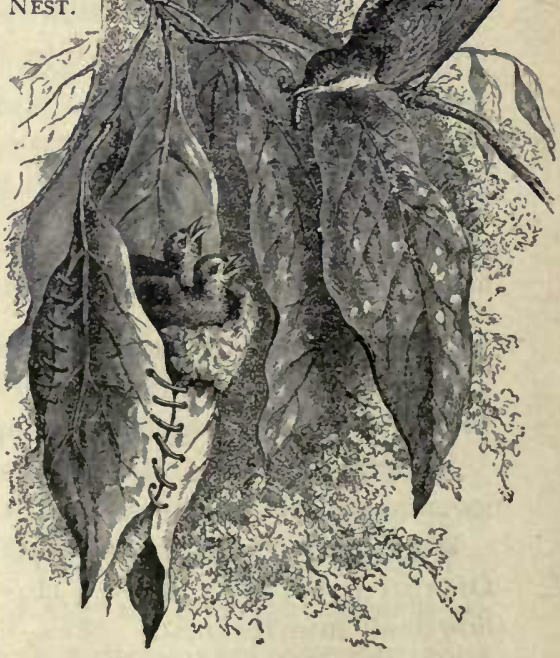

FIG. 309. - TAILOR BIRU'S NesT (India). Instinct for nest building highly perfected. 
Fighting? What birds do you observe whipping or driving birds larger than themselves? Which parent do young birds most resemble? Name the purposes for which birds sing. Which senses are very acute? Why? Dull? Why? Can you test your statements by experiment? A partridge usually sits with 18 to 24 eggs in nest. About how long after laying first egg before sitting begins? Do several partridge hens lay in the same nest?

Haunts. - Name some birds that are found most often in the following localities: about our homes, in gardens and orchards, fields and meadows, in bushes, in the woods, in secluded woods, around streams of water, in thickets, in pine woods.

Size. - Name birds as large as a robin or larger, nearly as large, half as large, much smaller.

Colors. - Which sex is more brilliant? What advantage are bright colors to one sex? What advantage are dull colors to the other

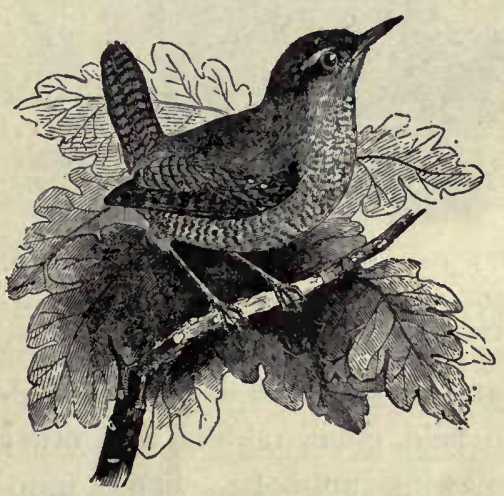

FIG. 3I0. - HOUSE WREN. sex? Which have yellow breasts, red patch on heads, red or chestnut breasts, blue backs, black all over?

Habits. - Name the birds that walk, jump, swim, live in flocks, sing while flying, fly in undulations, in circles, have labored flight.

Such books as Wright's "Birdcraft" (Macmillan, N. Y.), Clark's "Birds of Lakeside and Prairie" (Mumford, Chicago), and Pearson's "Stories of Bird Life" (B. F. Johinson, Richmond), will be of great help. The last book is delightfully written, and is one of the few treating of bird life in the South.

Economic Importance of Birds. - Farmers find their most valuable allies in the class aves, as birds are the deadliest enemies of insects and gnawing animals. To the innumerable robbers which devastate our fields and gardens, nature opposes the army of birds. They are less numerous 


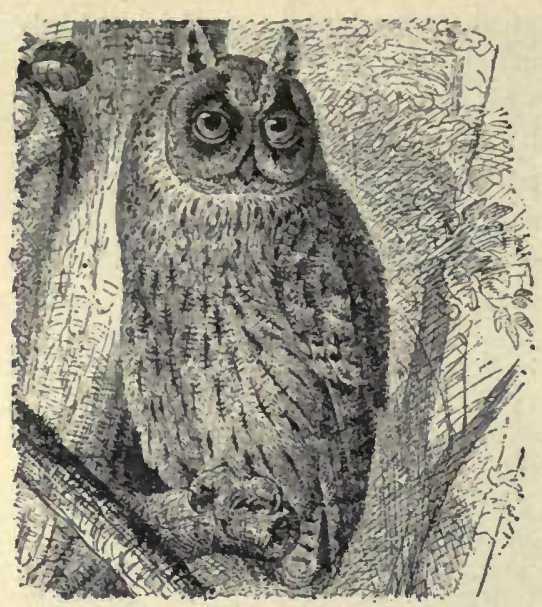

FIG. 3II.- SCREeCh OWl (Megascops asio).

Question: Compare posture of body, position of eyes, and size of eyes, with other birds. than insects and other robbers, it is true, but they are skillful and zealous in pursuit, keen of eye, quick, active, and remarkably voracious. The purely insectivorous birds are the most useful, but the omnivorous and graminivorous birds do not disdain insects. The perchers and the roootpeckers should be protected most carefully. The night birds of prey (and those of the day to a less degree) are very destructive to field mice, rabbits, and other gnawing animals. Some ignorant farmers complain continually about the harm done by birds. To destroy them is as unwise as it would be to destroy the skin which protects the human body because it has a spot upon it! It cannot be repeated too plainly that to hunt useful birds is a wrong and mischievous act, and it is stupid and barbarous to destroy their nests.

Injurious birds are few. Of course birds which are the enemies of other birds are enemies

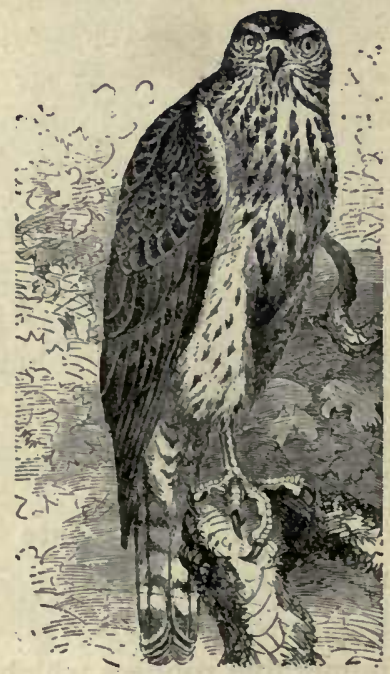

FIG. 312, - GosHAwK, or chicken hawk. 


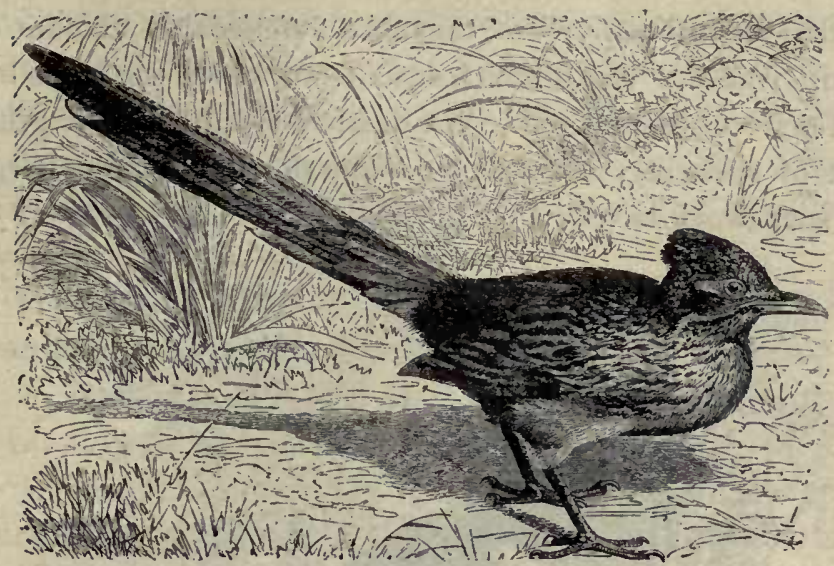

FIG. 313. - RUAD RUNNER, or chaparral bird (Tex, to Cal.). What order? (Key, p. I77.)

of mankind, but examples are scarce (some owls and hawks). Many birds of prey are classed thus by mistake. Sparrow hawks, for instance, do not eat birds except in rare instances; they feed chiefly upon insects. A sparrow hawk often keeps watch over a field where grasshoppers are plentiful and destroys great numbers of them. When a bird is killed because it is supposed to be injurious, the crop should always be examined, and its contents will often surprise those who are sure it is a harmful bird. The writer once found two frogs, three grasshoppers, and five beetles that had been swallowed by a "chicken hawk" killed by an irate farmer, but no sign of birds having been used for food. Fowls should not be raised in open places, but among trees and bushes, where hawks cannot swoop. Birds which live exclusively upon fish are, of course, opposed to human interests. Pigeons are destructive to grain; eagles feed chiefly upon other birds.

If the birds eat the grapes, do not kill the birds, but plant more grapes. People with two or three fruit trees or a small 
garden are the only ones that lose a noticeable amount of food. We cut down the forests from which the birds obtain part of their food. We destroy insect pests at great cost of spraying, etc. The commission the birds charge for such work is very small indeed. (See pages I77-183.)

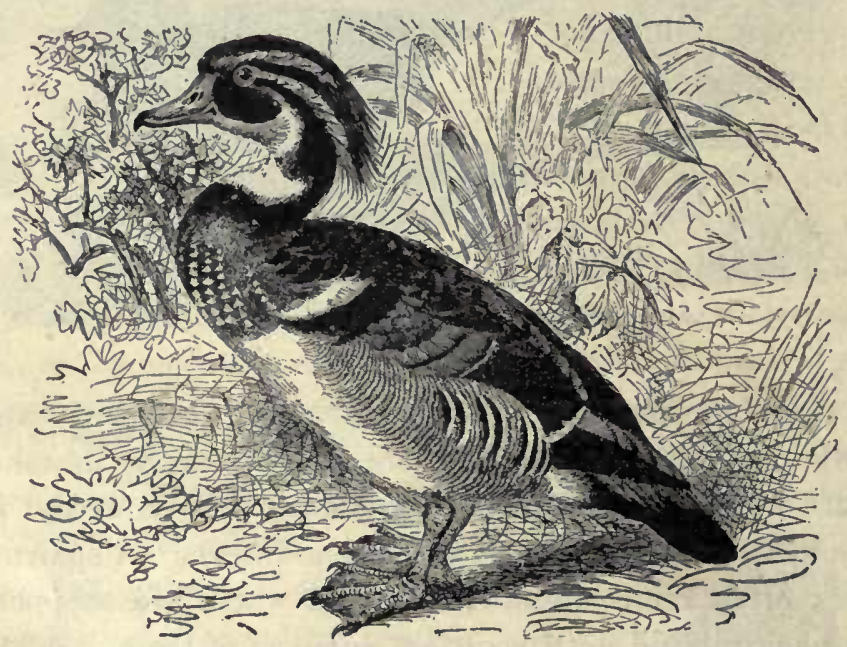

Fig. 314.- Wood Duck, male (Aix sponsa). Nests in hollow trees throughout North America. Also called summer duck in South. Why?

The English sparrow is one bird of which no good word may be said. Among birds, it holds the place held by rats among beasts. It is crafty, quarrelsome, thieving, and a nuisance. It was imported in 1852 to eat moths. The results show how ignorant we are of animal life, and how slow we should be to tamper with the arrangements of nature. In Southern cities it produces five or six broods each year with four to six young in each brood. (Notice what it feeds its young.) It fights, competes with and drives away our native useful birds. It also eats grain and preys upon gardens. They have multiplied more in Aus. 
tralia and the United States than in Europe, because they left behind them their native enemies and their new enemies (crows, jays, shrikes, etc.) have not yet developed, to a sufficient extent, the habit of preying upon them. Nature will, perhaps, after a long time, restore the equilibrium destroyed by presumptuous man.

Protection of Birds. - I. Leave as many trees and bushes standing as possible. Plant trees, encourage bushes.

2. Do not keep a cat. A mouse trap is more useful than a cat. A tax should be imposed upon owners of cats.

3. Make a bird house and place on a pole; remove bark from pole that cats may not climb it, or put a broad band of tin around the pole.

4. Scatter food in winter. In dry regions and in hot weather keep a shallow tin vessel containing water on the roof of an outhouse, or out-of-the-way place for shy birds.

5. Do not wear feathers obtained by the killing of birds. What feathers are not so obtained?

6. Report all violators of laws for protection of birds.

7. Destroy English sparrows.

Migration. - Many birds, in fact most birds, migrate to warmer climates to spend the winter. Naturalists were once content to speak of the migration of birds as a wonderful instinct,
to explain it. As 18 birds have the warmest covering of all animals, the winter migration is not for the purFig. 3i5. - Great Blue Heron. pose of escaping the cold ; it In flight, balancing with legs. is probably to escape starva. tion, because in cold countries food is largely hidden by snow in winter. On the other hand, if the birds remained 
in the warm countries in summer, the food found in northern countries in summer would be unused, while they would have to compete with the numerous tropical birds for food, and they and their eggs would be in danger from snakes, wild cats, and other beasts of prey so numerous in warm climates. These are the best reasons so far given for migration.

The manner and methods of migration have been studied more carefully in Europe than in America. Migration is

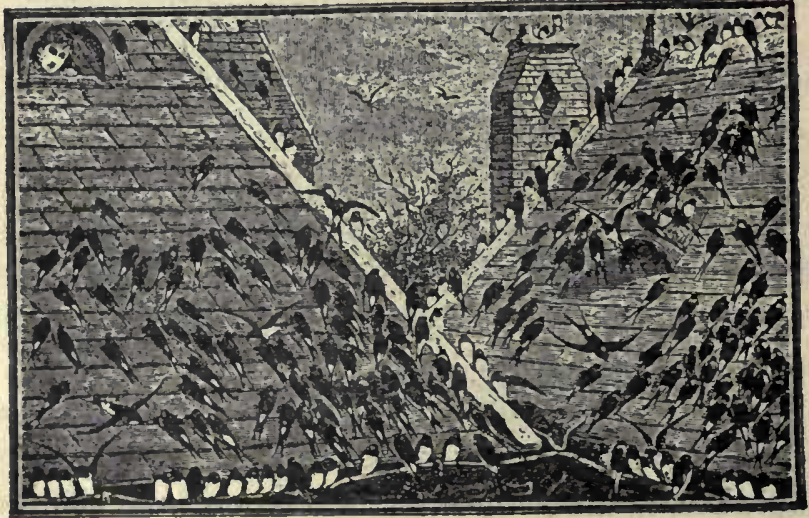

FIG. 316. - EUROPEAN SWALLOWS (Hirundo urbica), assembling for autumn flight to South.

not a blind, infallible instinct, but the route is learned and taught by the old birds to the young ones; they go in flocks to keep from losing the way (Fig. 316); the oldest and strongest birds guide the flocks (Fig. 3I7). The birds which lose their way are young ones of the last brood, or mothers that turn aside to look for their strayed young. The adult males seldom lose their way unless scattered by a storm. Birds are sometimes caught in storms or join flocks of another species and arrive in countries unsuited for them, and perish. For example, a sea or 
marsh bird would die of hunger on arriving in a very dry country.

The landmarks of the route are mountains, rivers, valleys, and coast lines. This knowledge is handed down from one generation to another. It includes the location of certain places on the route where food is plentiful and the birds can rest in security. Siebohm and others have studied

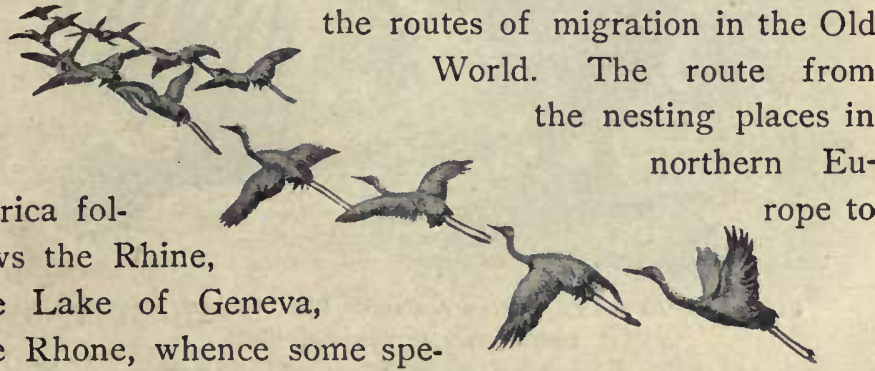
the Rhone, whence some species follow the Italian and others the Span- FIG. 3I7. - CranES ish coast line to Africa. Birds choose the Migrat'Ng, with lowest mountain passes. The Old World leader at point of martin travels every year from the North Cape to the Cape of Good Hope and back again! Another route has been traced from Egypt along the coast of Asia Minor, the Black Sea and Ural Mts. to Siberia.

Field Study of Migration. - Three columns may be filled on the blackboard in an unused corner, taking several months in spring or fall for the work. First column, birds that stay all the year. Second column, birds that come from the south and are seen in the summer only. Third column, birds that come from the north and are seen in winter only. Exact dates of arrival and departure and flight overhead should be recorded in notebooks. Many such records will enable American zoologists to trace the migration routes of our birds. Reports may be sent to the chief of the Biological Survey, Washington, D.C. 
Molting. - How do birds arrange their feathers after they have been ruffled? Do they ever bathe in water?

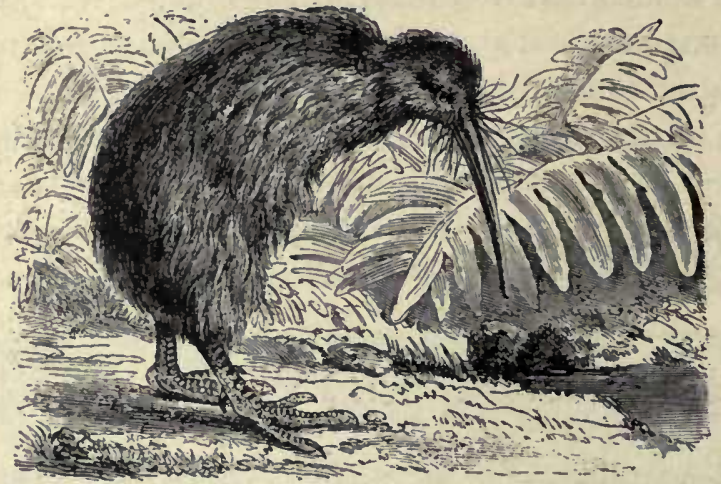

FIG. 318. - AptEkYX, of New Zealand. Size of a hen, wings and tail rudimentary, feathers hair-]ike.

In dust? Dust helps to remove old oil. At what season are birds brightest feathered? Why? Have you ever seen

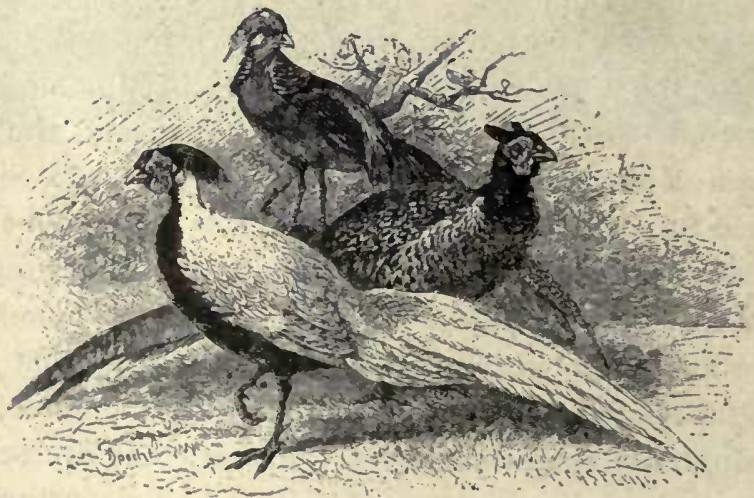

Fig. 319. - Golden, Silver, and Noble Pheasants, males, Order? (Key, p. 177.) Ornaments of males, brightest in season of courtship, are due to sexual selection (Figs. 32I-7-9, 333).

evidence of the molting of birds? Describe the molting process (page I 20 ). 


\section{Adaptations for}

Flying. - Flight is the most difficult and energyconsuming method of moving found among animals, and careful adjustment is necessary. For balancing, the heaviest muscles are placed at the lower and central

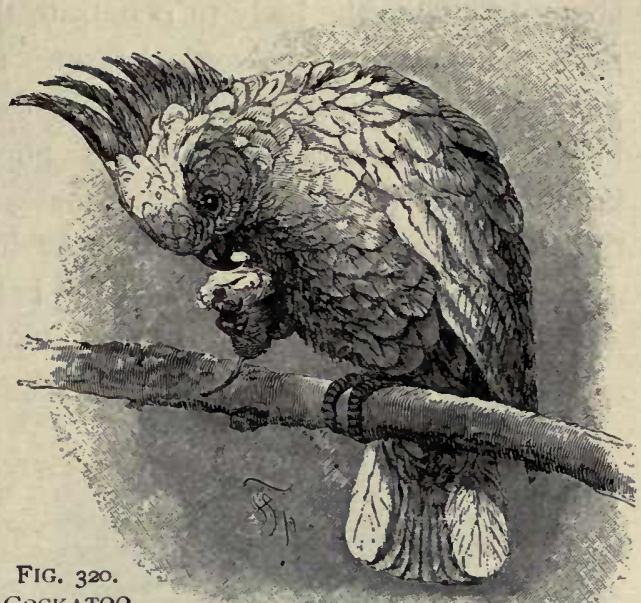
Cockatoo. portion of the body. These. are the flying muscles, and in some birds (humming birds) they make half of the entire weight. Teeth are the densest of animal structures; teeth and the strong chewing muscles required would make the head heavy and balancing

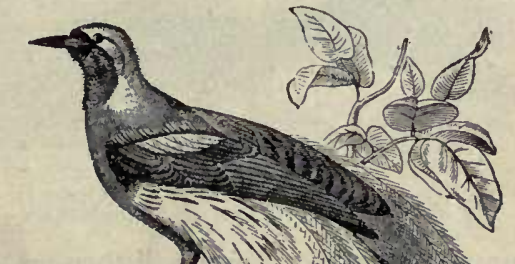

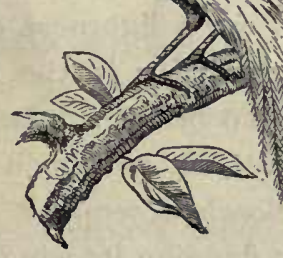

FIG. 32I, - BIRD OF PARAdise (Asia). difficult; hence the chewing apparatus is transferred to the heavy gizzard near the center of gravity of the body. The bird's neck is long and excels all other necks in flexibility, but it is very slender (although apparently heavy), being inclosed in a loose, feathered skin. A cone is the best

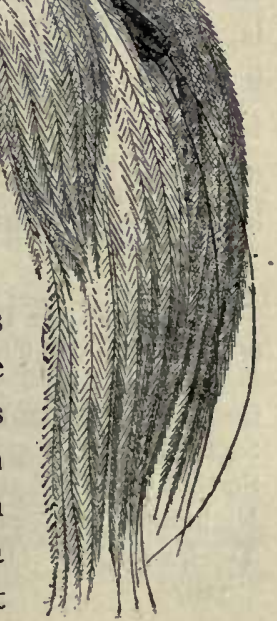


shape to enable the body to penetrate the air, and a small neck would destroy the conical form. The internal organs are compactly arranged and rest in the cavity of the breast bone. The bellows-like air sacs filled with warm air lighten the bird's weight. The bones are hollow and very thin. The large tail quills are used by the bird only in guiding its flight up and down, or balancing on a limb.

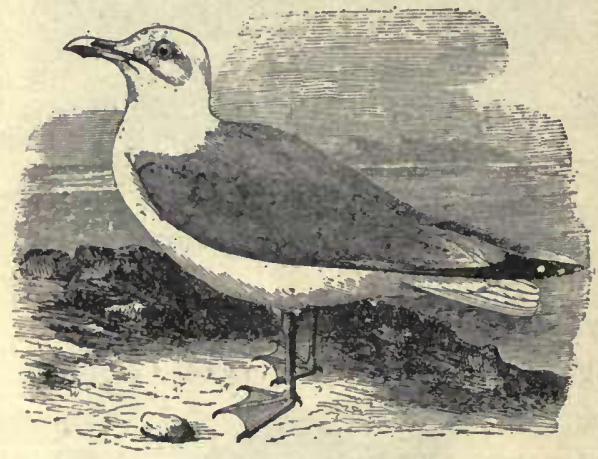

FIG. 322. - HERRING GuLL. (Order ?) The feet also aid a flying bird in balancing. The wing is so constructed as to present to the air a remarkably large surface compared with the small bony support in the wing skeleton. Are tubes ever resorted to by human architects when lightness combined with strength is desired? Which quills in the wing serve to lengthen it? (Fig. 296.) To broaden it? Is flight more difficult for a bird or a butterfly? Which of them do the flying machines more closely resemble? Can any bird fly for a long time without flapping its wings?

Exercise in the Use of the Key.-Copy this list and write the name of the order to which each of the birds belongs. (Key, page 177.)

Cockatoo (Fig. 320) Wren (Fig. 310)

Sacred Ibis (Fig. 328) Apteryx (Fig. 318)

Screech Owl (Fig. 311) Lyre bird (Fig. 327)

Nightingale (Fig. 325) Road Runner (Fig.313)

Top-knot Quail (Fig. Ostrich (Fig. 332)

329)
Pheasant (Fig. 319)

Wood Duck (Fig. 314)

Jacana (Fig. 324)

Sea Gull (Fig. 322)

Heron (Fig. 3I 5 )

Hawk (Fig. 312) 
KEY, OR TABLE, FOR CLASSIFYING BIRDS (Class Aves) INTO ORDERS

$A_{1}$ Wings not suited for flight, 2 or 3 toes

$A_{2}$ Wings suited for flight (except the penguin)

$\mathrm{B}_{1}$ Toes united by a web for swimming, legs short

$\mathrm{C}_{1}$ Feet placed far back; wings short, tip not reaching to base of tail (Fig. 300)

$\mathrm{C}_{2}$ Bill flattened, horny plates under margin of upper bill (Fig. 323)

$\mathrm{C}_{3}$ Wings long and pointed, bill slender

$\mathrm{C}_{4}$ All four toes webbed, bare sac under throat

$\mathrm{B}_{2}$ Toes not united by web for swimming

$\mathrm{C}_{1}$ Three front toes, neck and legs long, tibia (shin, or "drumstick") partly bare

$\mathrm{C}_{2}$ Three front toes, neck and legs not long $\mathrm{D}_{1}$ Claws short and blunt (e, Fig. 300)

$\mathrm{E}_{1}$ Feet and beak stout, young feathered, base of hind toe elevated

$\mathrm{E}_{2}$ Feet and beak weak, young naked

$\mathrm{D}_{2}$ Claws long, curved and sharp, bill hooked and sharp

$\mathrm{D}_{3}$ Claws long, slightly curved, bill nearly straight

$\mathrm{C}_{3}$ Two front and two hind toes (Fig. 300)

$\mathrm{D}_{1}$ Bill straight, feet used for climbing

$\mathrm{D}^{1}$ Bill hooked, both bill and feet used for climbing
RUNNERS

ORDERS

Divers

BILL-STRAINERS

SEA-FLIERS

GORGERS

WADERS

SCR ATCHERS

MESSENGERS

ROBBERS

PERCHERS

FOOT-CLIMBERS

BILL-CLIMBERS

The Food of Birds. - Extracts from Bulletin No. 54 (United States Dept. of Agriculture), by F. E. L. Beal.

The practical value of birds in controlling insect pests should be more generally recognized. It may be an easy matter to exterminate the birds in an orchard or grain field, but it is an extremely difficult one to control the insect pests. It is certain, too, that the value of our native sparrows as weed destroyers is not appreciated. Weed seed forms an important item of the winter food of many of these birds, and it is impossible to estimate the immense numbers of noxious weeds which are thus annually 
destroyed. If crows or blackbirds are seen in numbers about cornfields, or it woodpeckers are noticed at work in an orchard,

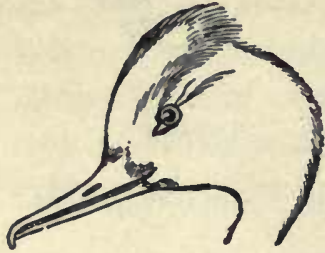

FIG. 323. - HEAD OF DUCK. it is perhaps not surprising that they are accused of doing harm. Careful investigation, however, often shows that they are actually destroying noxious insects; and also that even those which do harm at one season may compensate for it by eating insect pests at another. Insects are eaten at all times by the majority of land birds. During the breeding season most kinds subsist largely on this food, and rear their young exclusively upon it.

Partridges. - Speaking of 13 birds which he shot, Dr. Judd says : These I $_{3}$ had taken weed seed to the extent of 63 per cent of

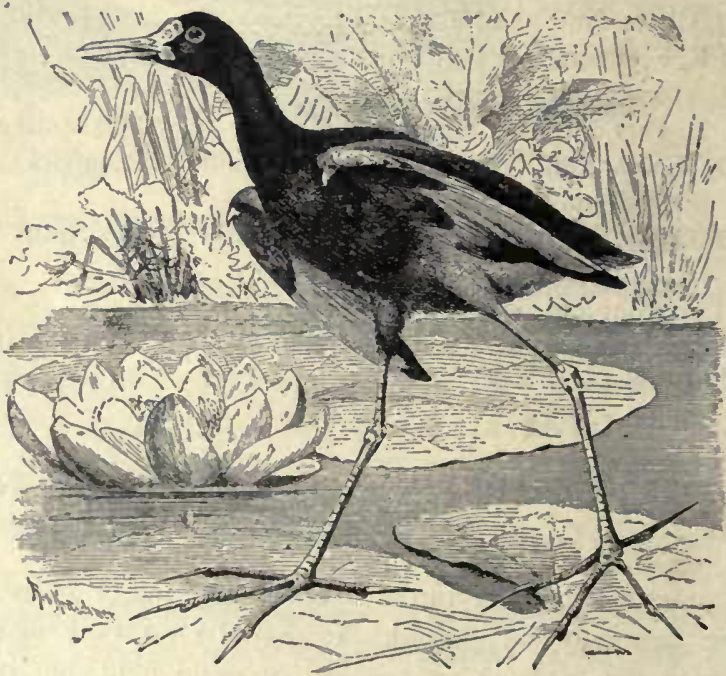

FIG. 324. - JACANA. (Mexico, Southwest Texas, and Florida.)

Questtons: What appears to be the use of such long toes? What peculiarity of wing? head? their food. Thirty-eight per cent was ragweed, 2 per cent tick trefoil, partridge pea, and locust seeds, and 23 per cent seeds of miscellaneous weeds. About I 4 per cent of the quail's food for 
the year consists of animal matter (insects and their allies). Prominent among these are the Colorado potato beetle, the striped squash beetle, the cottonboll-weevil, grasshoppers. As a weed destroyer the quail has few, if any, superiors. Moreover, its habits are such that it is almost constantly on the ground, where it is brought in close contact with both weed seeds and ground-living insects. It is a good ranger, and, if undisturbed, will patrol every day all the fields in its vicinity as it searches for food.

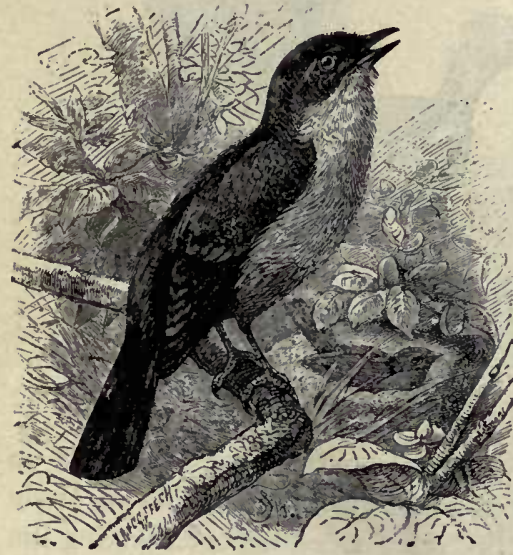

FIG. 325. - NightiNGALE, $\times \frac{2}{3}$.

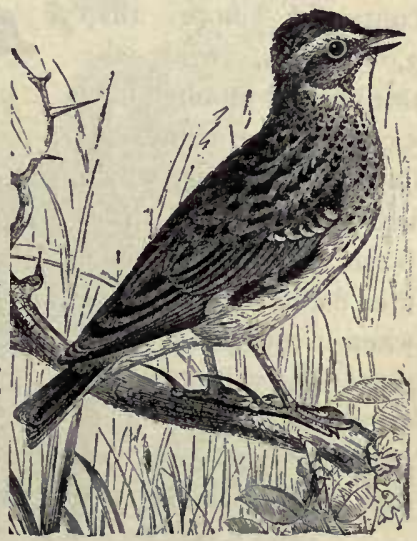

FIG. 326. - SKYLARK, $\times \frac{3}{3}$.

Two celebrated European songsters.

Doves. - The food of the dove consists of seeds of weeds, together with some grain. The examination of the contents of 237 stomachs shows that over 99 per cent of the food consists wholly of vegetable matter.

Cuckoos. - An examination of the stomachs of 46 black-billed cuckoos, taken during the summer months, showed the remains of 906 caterpillars, 44 beetles, 96 grasshoppers, Ioo sawflies, 30 stink bugs, and I5 spiders. Of the yellow-billed cuckoos, or " rain-crow," rog stomachs collected from May to October, inclusive, were examined. The contents consisted of 1,865 caterpillars, 93 beetles, 242 grasshoppers, 37 sawflies, 69 bugs, 6 flies, and 86 spiders. 
Woodpeckers. - Careful observers have noticed that, excepting a single species, these birds rarely leave any conspicuous mark on a healthy tree, except when it is affected by wood-boring larvæ, which are accurately located, dislodged, and devoured by the woodpecker. Of the filckers' or yellowhammers' stomachs examined, three were completely filled with ants. Two of the birds each contained more than 3,000 ants, while the third bird contained fully 5,000. These ants belong to species which live in the ground. It is these insects for which the flicker is reaching when it runs about in the grass. The yellow-bellied woodpecker or sapsucker

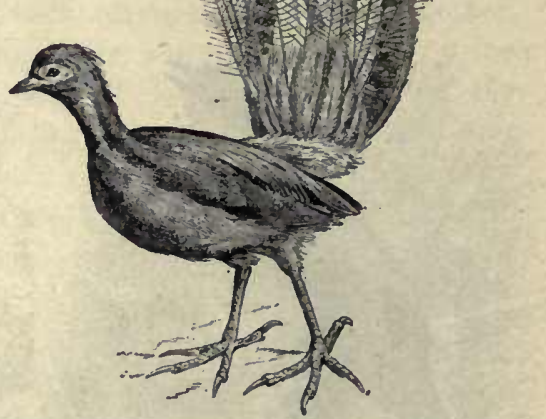

FIG. 327. - LYRE BIRn, male.

(Sphyrapicus varius) was shown to be guilty of pecking holes in the bark of various forest trees, and sometimes in that of apple

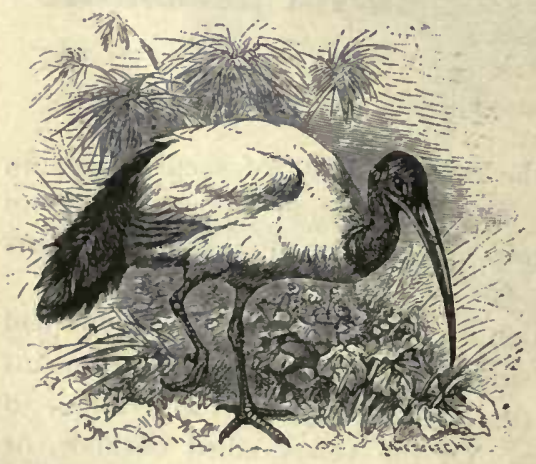

Fig. 328. - SACRED IBIS. (Order ?) trees, and of drinking the sap when the pits became filled. It has been proved, however, that besides taking the sap the bird captures large numbers of insects which are attracted by the sweet fluid, and that these form a very considerable portion of its diet. The woodpeckers seem the only agents which can successfully cope with certain insect enemies of the forests, and, to some extent, with those of fruit trees also. For this reason, if for no other, they should be protected in every possible way. 
The night hawk, or "bull bat," may be seen most often soaring high in air in the afternoon or early evening. It nests upon rocks or bare knolls and flat city roofs. Its food consists of insects taken on the wing; and so greedy is the bird that when food is plentiful, it fills its stomach almost to bursting. Ants (except workers) have wings and fly as they are preparing to propagate. In destroying ants night hawks rank next to, or even with, the woodpeckers, the acknowledged ant-eaters among birds.

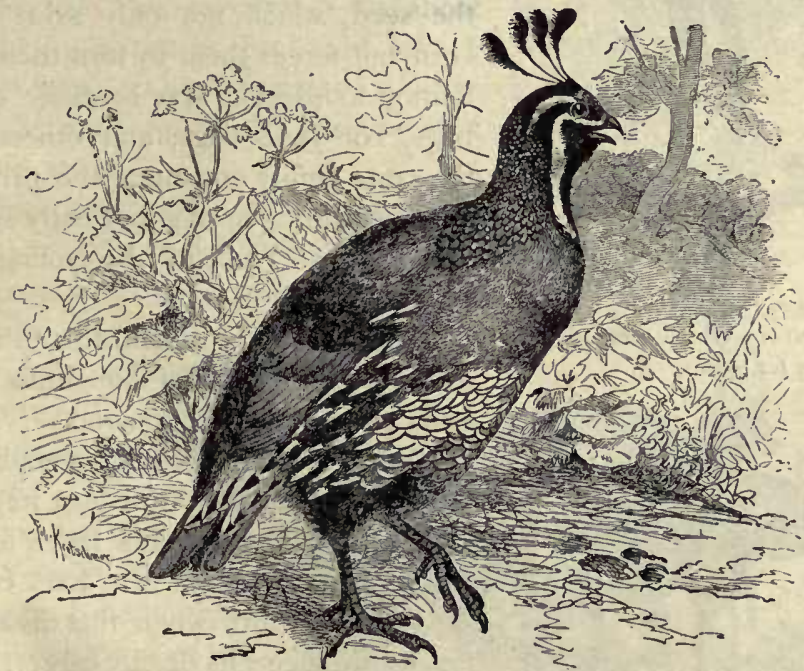

FIG. 329. - TOP-KNOT QUAIL, or California Partridge.

(West Texas to California.)

The kingbird, or martin, is largely insectivorous. In an examination of 62 stomachs of this bird, great care was taken to identify every insect or fragment that had any resemblance to a honeybee; as a result, 30 honeybees were identified, of which 29 were males or drones and I was a worker.

Blue Jay. - In an investigation of the food of the blue jay 300 stomachs were examined, which showed that animal matter comprised 24 per cent and vegetable matter 76 per cent of the bird's diet. The jay's favorite food is mast (i.e. acorns, chestnuts, chinquapins, etc.), which was found in 200 of the 300 stomachs, and amounted to more than 42 per cent of the whole food. 
Crow. - That he does pull up sprouting corn, destroy chickens, and rob the nests of small birds has been repeatedly proved. Nor are these all of his sins. He is known to eat frogs, toads, sala-

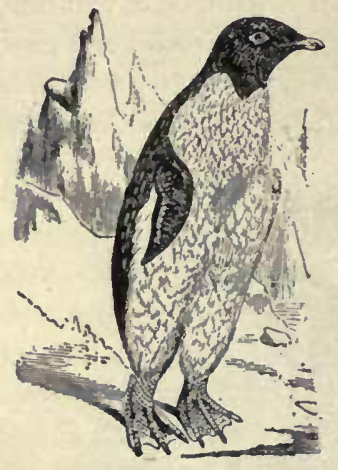

Fig. 330. - PENGUin of PATAGoNIA. Wings used as flippers for swimming.

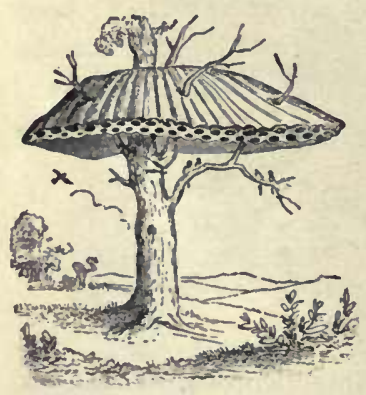

FIG. 331. - Umbrella holding the nests of social weaver bird of Africa; polygamous. manders, and some small snakes, all harmless creatures that do some good by eating insects. Experience has shown that they may be prevented from pulling up young corn by tarring the seed, which not only saves the corn but forces them to turn their attention to insects. May beetles, "dorbugs," or June bugs, and others of the same family constitute the principal food during spring and early summer, and are fed to the young in immense quantities.

Ricebird. - The annual loss to rice growers on account of bobolinks has been estimated at $\$ 2,000,000$.

Meadow Lark. - Next to grasshoppers, beetles make up the most important item of the meadow lark's food, amounting to nearly $2 \mathrm{I}$ per cent. May is the month when the dreaded cut-worm begins its deadly career, and then the lark does some of its best work. Most of these caterpillars are ground feeders, and are overlooked by birds which habitually frequent trees, but the meadow lark finds and devours them by thousands.

Sparrows. - Examination of many stomachs shows that in winter the tree sparrow feeds entirely upon seeds of weeds. Probably each bird consumes about one fourth of an ounce a day. Farther south the tree sparrow is replaced in winter by the white-throated sparrow, the white-crowned sparrow, the fox sparrow, the song sparrow, the field sparrow, and several others; so that all over the land a vast number of these seed eaters are at 
work during the colder months reducing next year's crop of worse than useless plants.

Robin. - An examination of 500 stomachs shows that over 42 per cent of its food is animal matter, principally insects, while the remainder is made up largely of small fruits or berries. Vegetable food forms nearly $5^{8}$ per cent of the stomach contents, over 47 per cent being wild fruits, and only a little more than 4 per cent being possibly cultivated varieties. Cultivated fruit amounting to about 25 per cent was found in the stomachs in June and July, but only a trifle in August. IVild fruit, on the contrary, is eaten in every month, and constitutes during half the year a staple food.

Questions. - Which of these birds are common in your neighborhood? Which of them according to the foregoing report are plainly injurious? Clearly beneficial? Doubtful? Which are great destroyers of weed seeds? Wood-borers? Ants? Grain? Why is the destruction of an ant by a night hawk of greater benefit than the destruction of an ant by a woodpecker? Name the only woodpecker that injures trees. If a bird eats two ounces of grain and one ounce of insects, has it probably done more good or more evil?

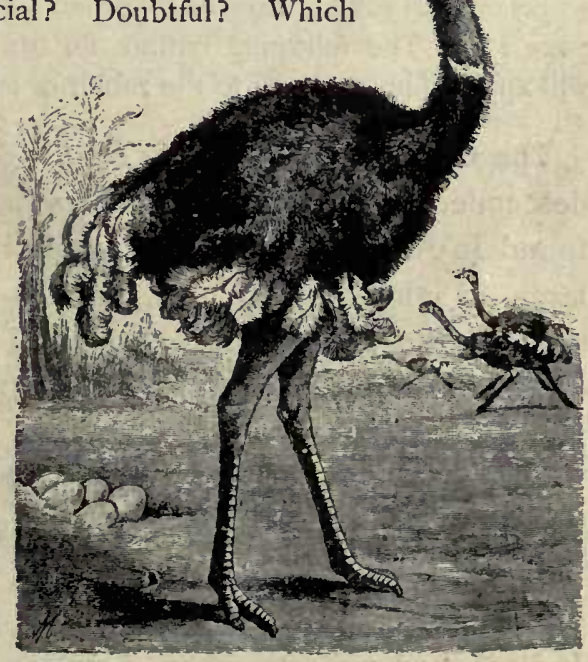

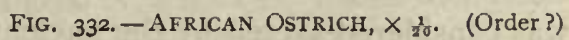




\section{CHAPTER XIV}

\section{MAMMALS (BEASTS AND MAN)}

Suggestions. - A tame rabbit, a house cat, or a pet squirrel may be taken to the school and observed by the class. Domestic animals may be observed at home and on the street. A study of the teeth will give a key to the life of the animal, and the teacher should collect a few mammalian skulls as opportunities offer. The pupils should be required to identify them by means of the chart of skulls (p. 194). If some enthusiastic students fond of anatomy should dissect small mammals, the specimens should be killed with chloroform, and the directions for dissection usual in laboratory works on this subject may be followed. There is a brief guide on page 223. The following outline for the study of a live mammal will apply almost as well to the rabbit or squirrel as to the cat.

The Cat. - The house cat (Felis domestica) is probably descended from the Nubian cat (Felis maniculata, Fig. 333) found in Africa. The wild species is about half again as large as the domestic cat, grayish brown with darker stripes; the tail has dark rings. The lynx, or wild cat of America (Lynx rufus), is quite different. Compare the figures $(333,335)$ and state three obvious differences. To which American species is the house cat closer akin, the lynx (Fig. 335) or the ocelot (Fig. 334)? The domestic cat is found among all nations of the world. What is concluded, as to its nearest relatives, from the fact that the Indians had no cats when America was discovered? It was considered sacred by the ancient Egyptians, and after death its body was embalmed.

The body of the cat is very flexible. It may be divided into five regions, the head, neck, trunk, tail, and limbs. Its 


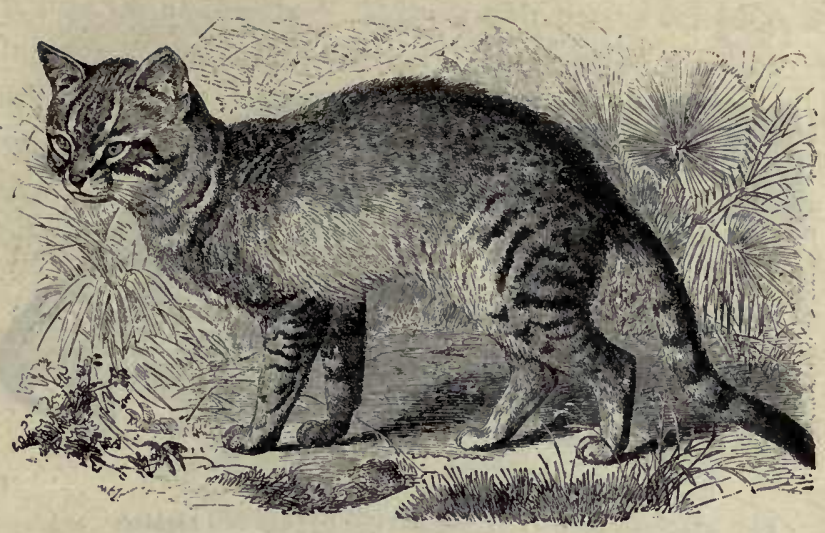

FIG. 333. - WILD CAT UF AFRICA (Felis maniculata), $\times 1 / 8$.

eyes have the same parts as the eyes of other mammals. Which part of its eye is most peculiar? (Fig. 333.) What part is lacking that is present in birds? How are the eyes especially adapted for seeing at night? Does the pupil in the light extend up or down or across the iris? Does it ever become round?

What is the shape and position of the ears? Are they large or small compared with those of most mammals? They are fitted best for catching sound from what direction? What is thus indicated in regard to the cat's habits? (Compare with ears of rabbit.) Touch the whiskers of the cat. What result? Was it voluntary or involuntary motion? Are the nostrils relatively large or small compared with those of a cow? Of man?

Is the neck long or short? Animals that have long fore legs usually have what kind of a neck? Those with short legs? Why? How many toes on a fore foot? Hind foot? Why is this arrangement better than the reverse? Some mammals are sole walkers (plantigrade), some are toe walkers (digitigrade). To which kind does the cat 


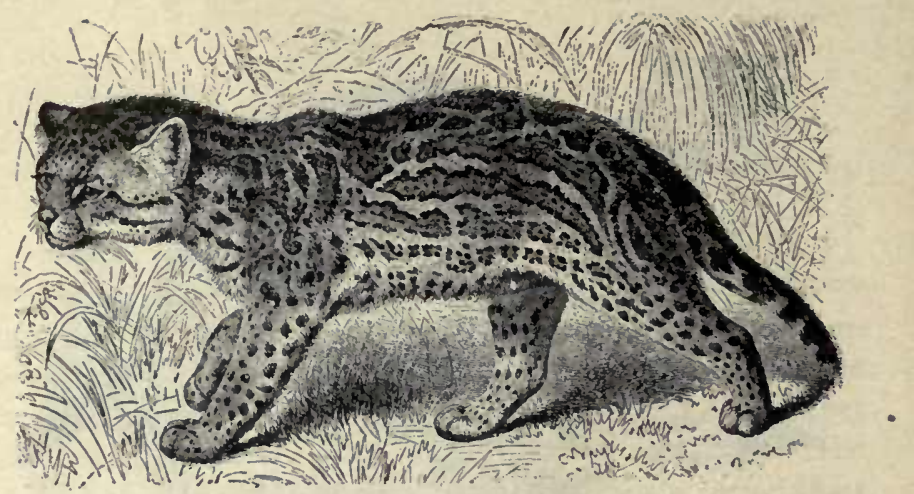

FIs. 334.-OCElor (Felis pardalis), of Texas and Mexico. $\times \frac{3}{\text {. }}$

belong? Does it walk on the ends of the toes? Does it walk with all the joints of the toes on the ground? Where is the hecl of the cat? (Fig. 334.) The wrist? To make sure of the location of the wrist, begin above : find the shoulder blade, the upper arm (one or two bones?), the lower arm (one or two bones?), the wrist, the palm, and the fingers (Fig. 337). Is the heel bone prominent or small?

In what direction does the knee of the cat point? The heel? The elbow? The wrist? Compare the front and hind leg in length; straightness; heaviness; number and position of toes; sharpness of the claws. What makes the dog's claws duller than a cat's? What differences in habit go with this? Judging from the toe that has become useless on the fore foot of the cat, which toe is lacking in the hind foot? Is it the cat's thumb or little finger that does not touch the ground? (Fig. 337.) Locate on your own hand the parts corresponding to the pads on the forefoot of a cat. Of what use are soft pads on a cat's foot?

Some animals have short, soft fur and long, coarse over hair. Does the cat have both? Is the cat's fur soft or coarse? Does the fur have a color near the skin different 
from that at the tip? Why is hair better suited as a covering for the cat than feathers would be? Scales? Where are long, stiff bristles found on the cat? Their length suggests that they would be of what use to a cat in going through narrow places? Why is it necessary for a cat to be noiseless in its movements?

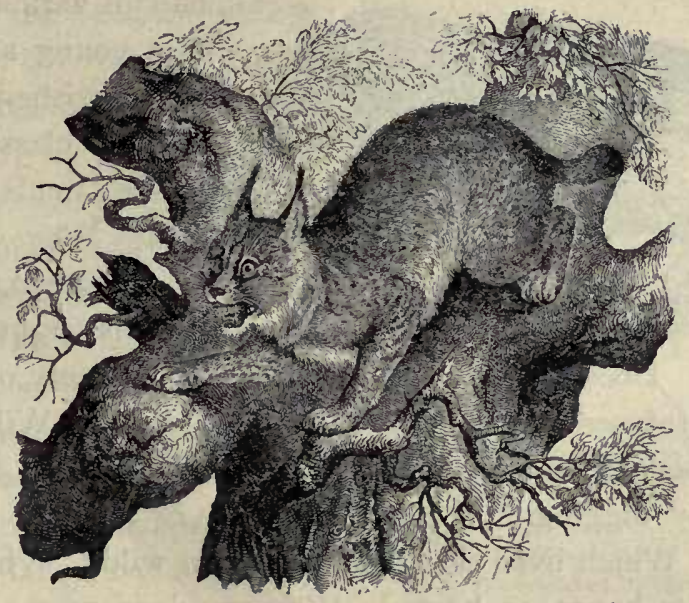

FIG. 335.-LyNX (Lynx rufus). The "Bob-tailed cat" (Nortl America).

Observe the movements of the cat. - Why cannot a cat come down a tall tree head foremost? Did you ever see a cat catch a bird? How does a cat approach its prey? Name a jumping insect that has long hind legs; an amphibian; several mammals (Figs. 362, 374). Does a cat ever trot? Gallop? Does a cat chase its prey? When does the cat move with its heel on the ground? The claws of a cat are withdrawn by means of a tendon (see Fig. 338). Does a cat seize its prey with its mouth or its feet?

How does a cat make the purring sound? (Do the lips move? The sides?) How does a cat drink? Do a cat 
and dog drink exactly the same way? Is the cat's tongue rough or smooth? How is the tongue used in getting the flesh off close to the bone? Can a cat clean a bone entirely of meat?

In what state of development is a newly born kitten? With what does the cat nourish its young? Name ten

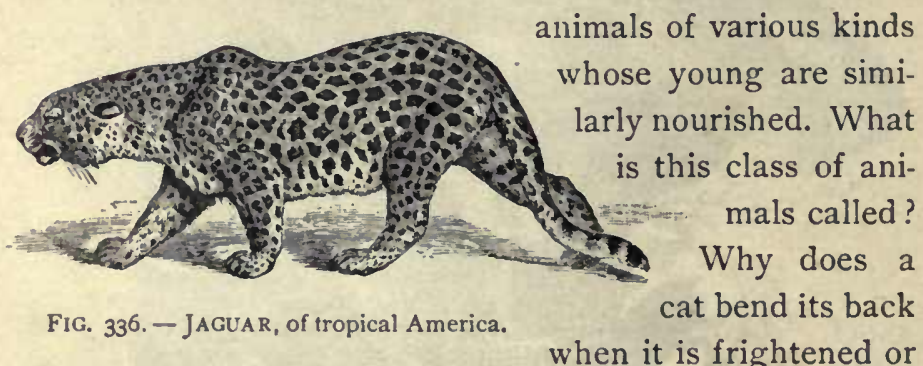

angry? Does a cat or a dog eat a greater variety of food ? Which refuses to eat an animal found dead? Will either bury food for future use? Which is sometimes troublesome by digging holes in the garden? Explain this instinct. Which lived a solitary life when wild? Which had a definite haunt, or home? Why are dogs more sociable than cats? A dog is more devoted to his master. Why? A cat is more devoted to its home, and will return if carried away. Why? Why does a dog turn around before lying down? (Consider its original environment.)

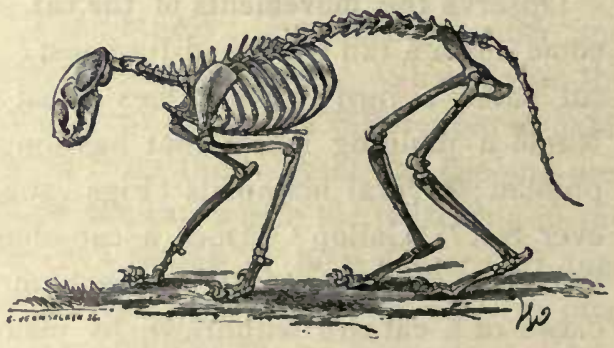

FIG. 337. - SKELETON OF CAT.

The Skeleton (Fig. 337). - Compare the spinal column of a cat in form and flexibility with the spinal column of a fish, a snake, and a bird. 
The skull is joined to the spinal column by two knobs (or condyls), which fit into sockets in the first vertebra. Compare the jaws with those of a bird and a reptile. There is a prominent ridge in the temple to which the powerful chewing muscles are attached. There is also a ridge at the back of the head where the muscles which support the head are attached (Fig. 348).

Count the ribs. Are there more or fewer than in man? The breastbone is in a number of parts, joined, like the vertebræ, by cartilages. Compare it with a bird's sternum; why the difference? The shoulder girdle, by which the front legs are attached to the trunk, is hardly to be called a girdle, as the collar bones (clavicles) are rudimentary. (They often escape notice during dissection, being hidden by muscles.) The shoulder blades, the other bones of this girdle, are large, but relatively not so broad toward the dorsal edge as human shoulder blades. The clav.

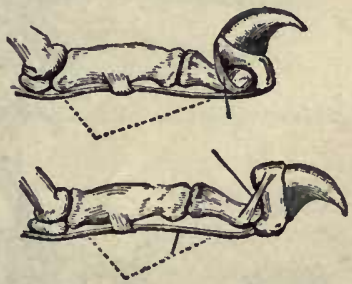

FIG. 338. - CLAW OF CAT (I) retracted by ligament, and (2) drawn down by muscle attached to lower tendon. icles are tiny because they are useless. Why does the cat not need as movable a shoulder as a man? The pelvic, or hip girdle, to which the hind legs are attached, is a rigid girdle, completed above by the spinal column, to which it is immovably joined. Thus the powerful hind legs are joined to the most rigid portion of the trunk.

Mammals. - The cat belongs to the class Mammalia or mammals. The characteristics of the class are that the young are not hatched from eggs, but are born alive, and nourished with milk (hence have lips), and the skin is covered with hair. The milk glands are situated ventrally. The position of the class in the animal kingdom was 
shown when the cow was classified (p. 9). Their care for the young, their intelligence, and their ability to survive when in competition with other animals, causes the mammals to be considered the highest class in the animal kingdom.

According to these tests, what class of vertebrates should rank next to mammals? Compare the heart, lungs, blood, and parental devotion of these two highest classes of animals.

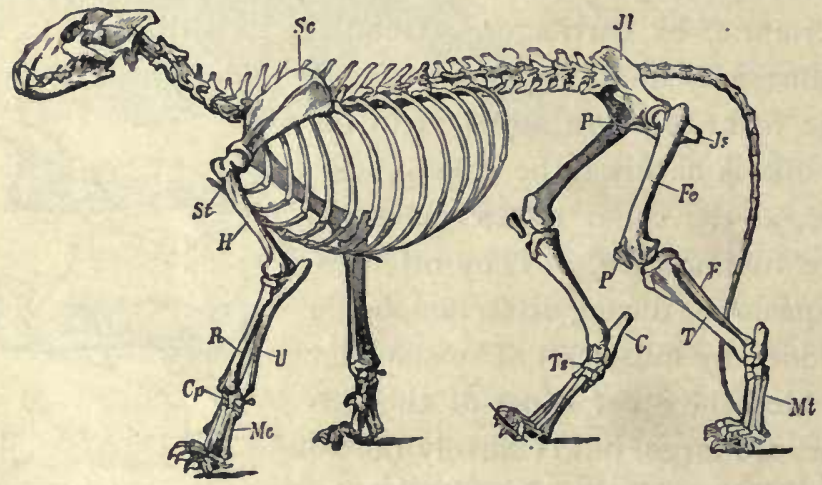

Fig. 339. - SKELETON OF LION (cat family).

The first mammals, which were somewhat like small opossums, appeared millions of years ago, when the world was inhabited by giant reptiles. These reptiles occupied the water, the land, and the air, and their great strength and ferocity would have prevented the mammals from. multiplying (for at first they were small and weak), but the mammals carried their young in a pouch until able to care for themselves, while the reptiles laid eggs and left them uncared for. The first mammals used reptilian eggs for food, though they could not contend with the great reptiles. Because birds and mammals are better parents than reptiles, they have conquered the earth, and the rep- 
tiles have been forced into subordination, and have become smaller and timid.

Classification of Mammals. - Which two have the closest resemblances in the following lists: Horse ${ }_{*}$ cow, deer. Why? Cat, cow, bear. Why? Monkey, man, sheep. Why? Rat, monkey, squirrel. Why? Giraffe, leopard, camel. Why? Walrus, cat, cow. Why? Check the five mammals in the following lists that form a group resembling each other most closely: Lion, bear, pig, dog, squirrel, cat, camel, tiger, man.

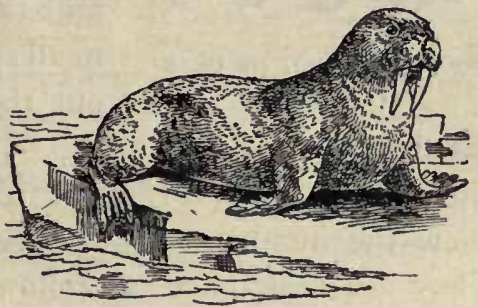
State your reasons. Gi- FIG. 340.-WAt.Rus (Trichechus rosmarus). raffe, leopard, deer, cow, rat, camel, hyena, horse, monkey. State reasons.

Teeth and toes are the basis for subdividing the class mammalia into orders. Although the breathing, circulation, and internal organs and processes are similar in all mammals, the external organs vary greatly because of the varying en-

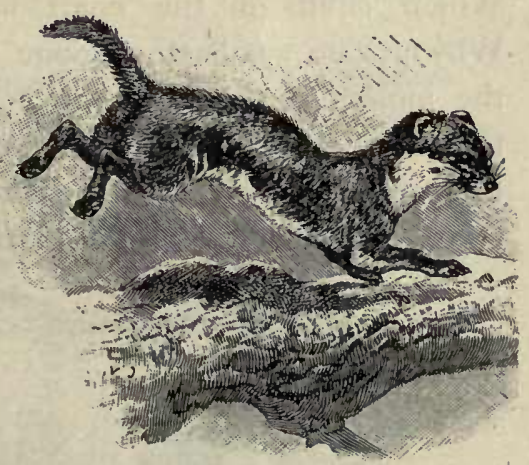
FIG. 34r. - WEASEI, in summer; in Canada in winter it is all white but tip of tail. vironments of different species. The internal structure enables us to place animals together which are essentially alike; e.g. the whale and man are both mammals, since they resemble in breathing, circulation, and multiplication of young. The external organs guide us in separating the class into orders. The teeth vary according to the food 
eaten. The feet vary according to use in obtaining food or escaping from enemies. This will explain the differ-

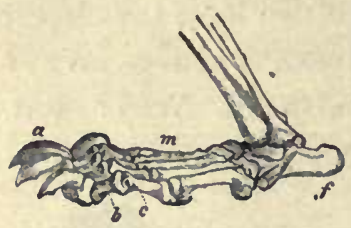

FIG. 342,- FoOT OF BEAR

(Plantigrade).

ence in the length of legs of lion and horse, and of the forms of the teeth in cat and cow. Make a careful study of the teeth and limbs as shown in the figures and in all specimens accessible. Write out the dental formulas as indicated at the top of page 194. The numerals above the line show the number of upper teeth; those below the line show the number of lower teeth in one half of the jaw. They are designated as follows: $I$, incisors ; $C$, canine; $M$, molars. Multiplying by two gives the total number. Which skulls in the chart have the largest canines? Why? The smallest, or none at all? Why? Compare the molars of the cow, the hog, and the dog. Explain their differences. In which skulls are some of the molars lacking? Rudimentary? Why are the teeth that do not touch usually much smaller than those that do?

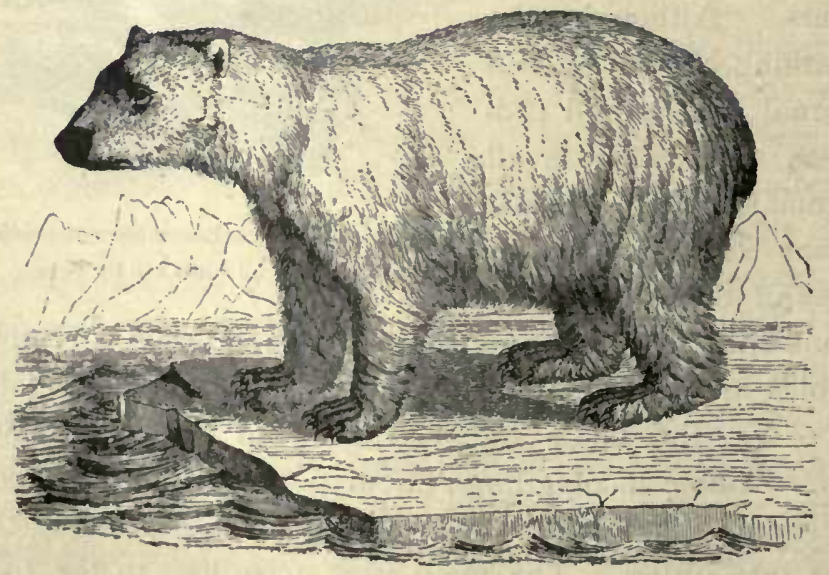

FIG. 343. - POLAR BEAR (Ursus maritimus). 


\section{KEY, OR TABLE, FOR CLASSIFYING MAMMALS} (class Mammalia) INTO ORDERS

$A_{1}$ Imperfect Mammals, young hatched or preOrders

maturely born

$\mathrm{B}_{1}$ Jaws a birdlike beak, egg-laying

Mon'otremes

$\mathrm{B}_{2}$ Jaws not beaklike, young carried in pouch

$A_{2}$ Perfect Mammals, young not hatched, nor Marsu'pials prematurely born

\begin{tabular}{|c|c|}
\hline \multirow{2}{*}{\multicolumn{2}{|c|}{ th }} \\
\hline & \\
\hline $\begin{array}{c}\mathrm{B}_{1} \\
\text { Digits }\end{array}$ & $\begin{array}{l}\mathrm{C}_{2} \text { Teeth with sharp points for piercing } \\
\text { shells of insects }\end{array}$ \\
\hline $\begin{array}{l}\text { with } \\
\text { claws }\end{array}$ & $\begin{array}{l}\mathrm{C}_{3} \text { Canines very long, molars suited for } \\
\text { tearing }\end{array}$ \\
\hline & $\mathrm{C}_{4}$ Canines lacking, incisors very large \\
\hline
\end{tabular}

Eden'tates

Insect'ivors

Car'nivors

Rodents

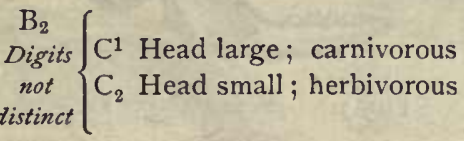

Cetaceans

Sire'neans

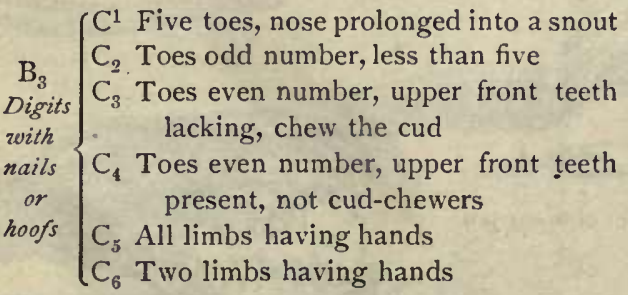

Proboscid'eans

$\left.\begin{array}{c}\text { E'quines } \\ \text { Ru'minants } \\ \text { Suine }\end{array}\right] \begin{gathered}\text { Quad'rumans } \\ \text { Bi'mans }\end{gathered}$

Exercise in Classification. - Copy the following list, and by reference to figures write the name of its order after each mammal :$\begin{array}{lll}\text { Ape (Figs. 405, 406) } & \text { Cow (Figs. 344, 386) } & \text { Antelope (Fig. 39I) } \\ \text { Rabbit (Fig. 345) } & \text { Walrus (Fig. 340) } & \text { Mole }\end{array}$ Dog (Figs. 356, 408) Monkey Hog (Figs. 357, 393) Bat (Figs. 347, 370) Horse

Cat (Figs. 337, 348) Armadillo

(Figs. 349, 365)
(Figs. 352, 401)

Beaver

(Figs. 367, 368)

(Figs. 372, 373) Duckbill (Fig. 359) Ant-eater. Tapir (Fig. 384) Dolphin $(379,397)$

Use chart of skulls and Figs. $381,382,395-400$ in working out this exercise. 
Man's dental formula is $\quad\left(M \frac{5}{5}, C \frac{1}{1}, I \frac{2}{2}\right)^{2}=3^{2}$.

In like manner fill out formulas below:-
Cow .......... $(M-C-I-)^{2}=32$
Whale........ $(M-C-I-)^{2}=0$
Rabbit ........ $(M-C-I-)^{2}=28$
Am. Monkey...(M-C-I- $)^{2}=36$
Walrus........ $(M-C-I-)^{2}=34$
Sloth......... $(M-C-I-)^{2}=18$
Bat.......... $(M-C-I-)^{2}=34$
Ant-eater ...... $(M-C-\Gamma-)^{2}=0$
Cat........... $(M-C-I-)^{2}=30$
$\operatorname{Dog} \ldots \ldots \ldots(M-C-I-)^{2}=42$
Armadillo .... $(M-C-I-)^{2}=28$
Hog $. . . . . .(M-C-I-)^{2}=44$
Horse........ (M-C-I- $)^{2}=40$
Sheep ........ $(M-C-I-)^{2}=32$

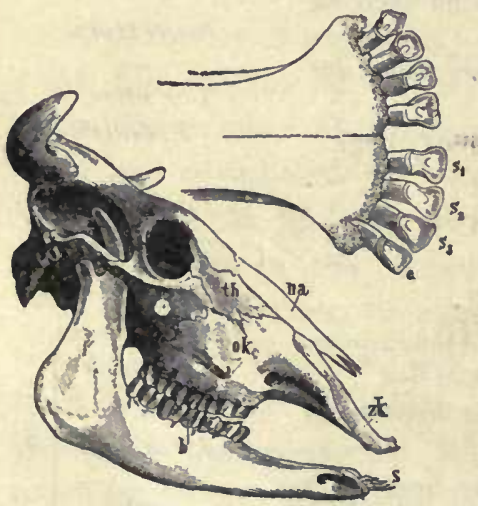

FIG. 344. - Skull and front of lower jaw of Cow.

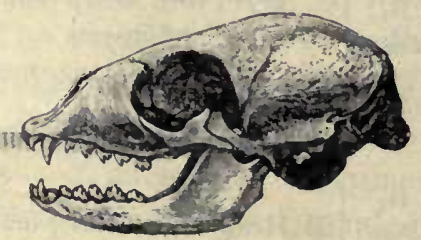

FIG. 346. - WalRUS (see Fig. 34I).
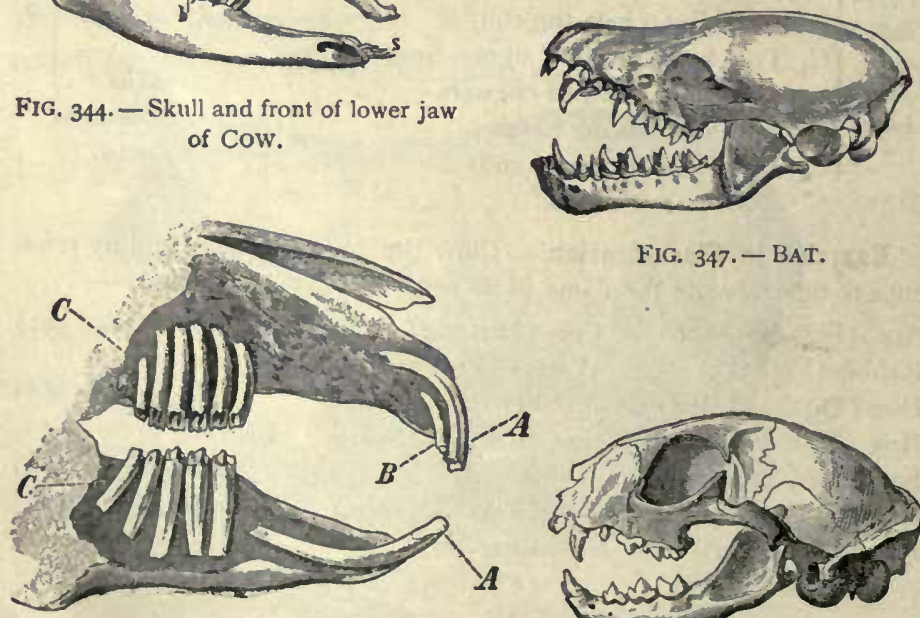

FIG. 347.-BAT.

FIG. 345.- RABBIT.

$A, B$, incisors; $C$, molars.

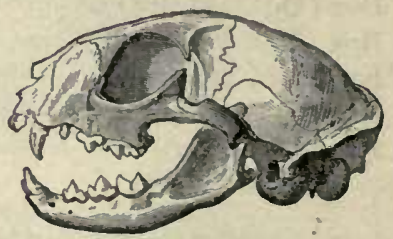

FIG, $348,-$ CAT. 


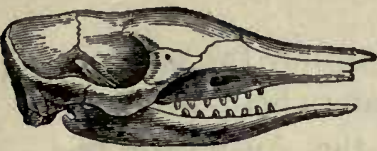

FIG. 349. - ARMADILLO.

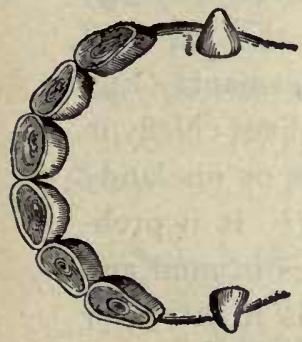

FIG. 350.- HoRSE (front of jaw).

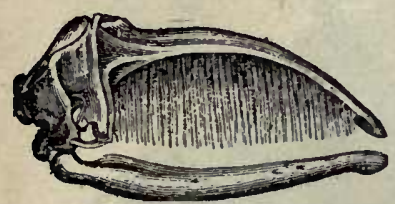

FIG. 351.- GREENLAND WHALE.

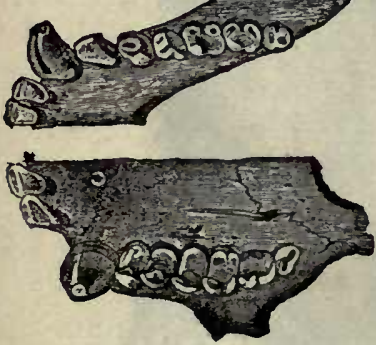

IG. 352.-AMERICAN MONKEY.

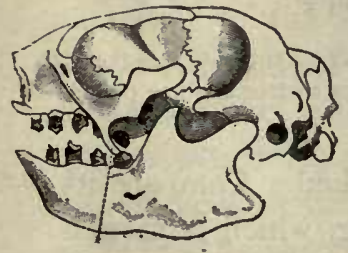

FIG. 353. - SLOTH (Fig. 363).

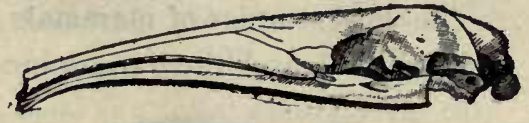

FIG. 354.-ANT-EATER (Fig. 364).
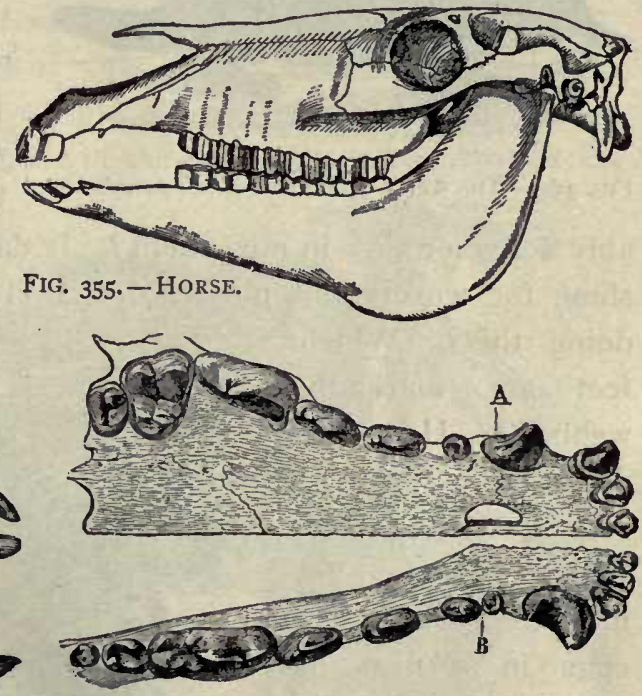

FIG. 356.-DoG. Upper $(A)$ and lower $(B)$ jaw.

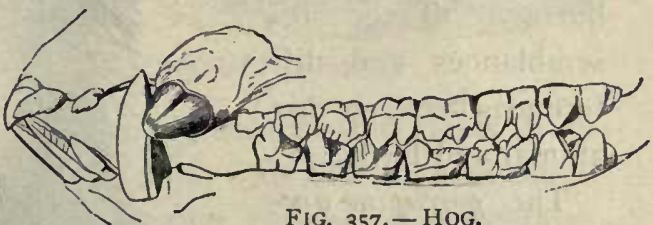

FIG. 357.- HOG.
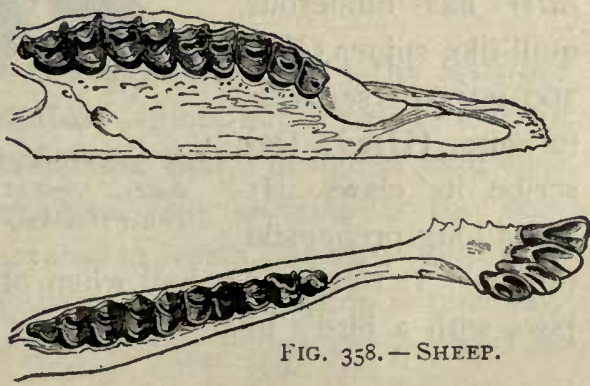
The lowest order of mammals contains only two species, the duckbill and the porcupine ant-eater, both living in

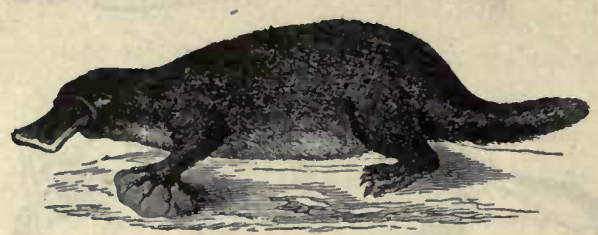

FIG. 359. - DUCKBILI (Ornithorhynchus paradoxus).

the Australian region. Do you judge that the duckbill of Tasmania (Fig. 359) lives chiefly in water or on land? Why? Is it probably active or slow in movement? It daboles in mud and slime for worms and mussels, etc. How is it fitted for doing this? Which feet are markedly webbed? How far does the web extend? The web can be folded back when not in use. It lays two eggs in a nest of grass at the end of a burrow. Trace resemblances and differences between this animal and birds.

The porcupine antcater has numerous quill-like spines (Fig. 360) interspersed with its hairs. (Use ?) Describe its claws. It has a long prehensile

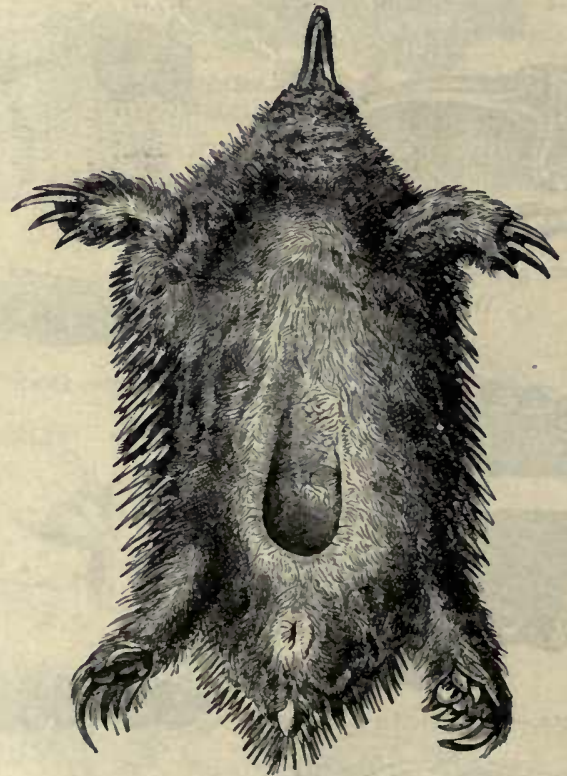

FIG. 360.-SPINY ANT-EATER (Echidna aculeata). View of under surface to show pouch. (After Haacke.) tongue. It rolls into a ball when attacked. Compare its jaws with a bird's bill. It lays one egg, which is carried 
in a fold of the skin until hatched. Since it is pouched it could be classed with the pouched mammals (next order), but it is egg-laying. Suppose the two animals in this order did not nourish their young with milk after hatching, would they most resemble mammals, birds, or reptiles?

Write the name of this order. (See Table, p. I93.) Why do you place them in this order (__ $)$ ? See p. 193.) The name of the order comes from two Greek

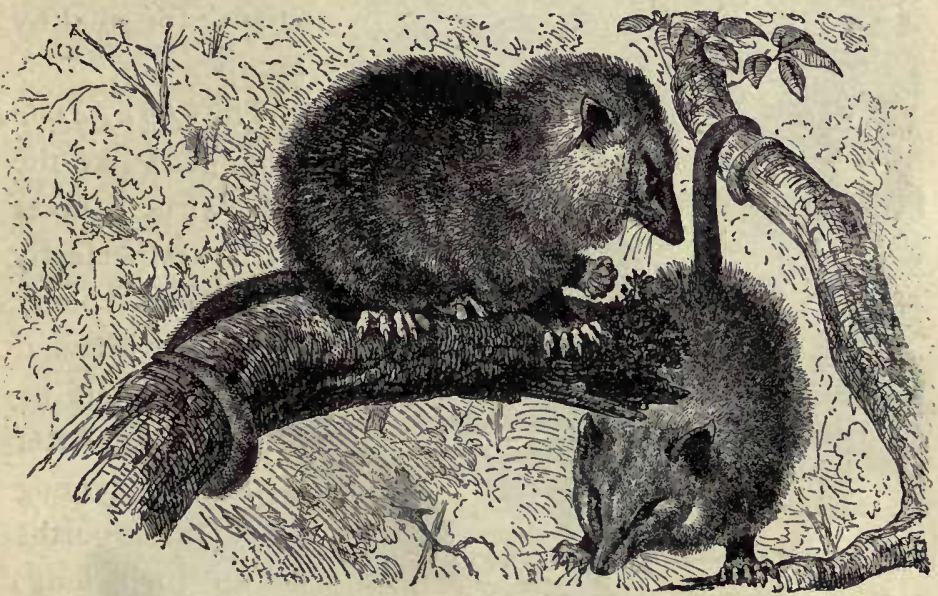

FIG. 36I. - Opossum (Didelphys Virginianus).

words meaning "one opening," because the ducts from the bladder and egg glands unite with the large intestine and form a cloaca. What other classes of vertebrates are similar in this?

Pouched Mammals. - These animals, like the last, are numerous in the Australian region, but are also found in South America, thus indicating that a bridge of land once connected the two regions. The opossum is the only species which has penetrated to North America (Fig. 36I). Are its jaws slender or short? What kinship is thus suggested? As shown by its grinning, its lips are not well de- 
veloped. Does this mean a low or a well-developed mammal? Where does it have a thumb? (Fig. 36I.) Does the thumb have a nail ? Is the tail hairy or bare? Why? Do you think it prefers the ground or the trees? State two reasons for your answer. It hides in a cave or bank or hollow tree all day, and seeks food at night. Can it run fast on the ground? It feigns death when captured,

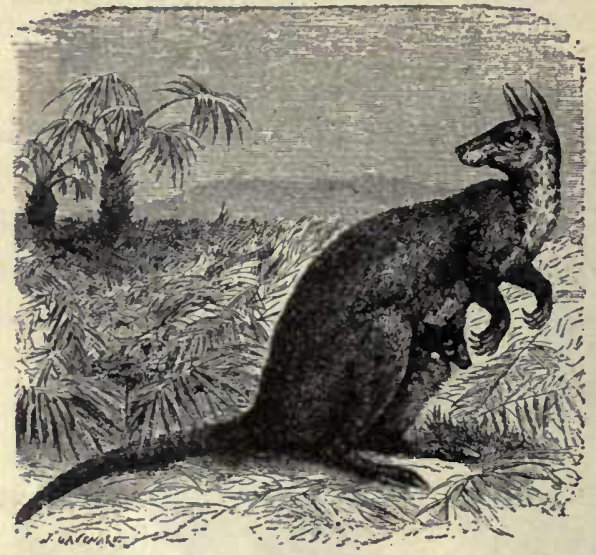

Fig. 362.- Giant KaNGaroo. and watches for a chance for stealthy escape.

The kangaroo (Fig. 362), like the opossum, gives birth to imperfectly developed young. (Kinship with what classes is thus indicated?) After birth, the young (about three fourths of an inch long) are carried in a ventral pouch and suckled for seven or eight months. They begin to reach down and nibble grass before leaving the pouch. Compare fore legs with hind legs, front half of body with last half. Describe tail. What is it used for when kangaroo is at rest? In jumping, would it be useful for propelling and also for balancing the body? Describe hind and fore feet. Order … Why? See key, page 193.

Imperfectly Toothed Mammals. - These animals live chiefly in South America (sloth, armadillo, giant ant-eater) and Africa (pangolin). The sloth (Fig. 363) eats leaves. Its movements are remarkably slow, and a vegetable growth 
resembling moss often gives its hair a green color. (What advantage?) How many toes has it? How are its nails suited to its manner of living? Does it save exertion by hanging from the branches of trees instead of walking upon them?

Judging from the figures $(363,364$, 365 ), are the members of this order better suited for at-

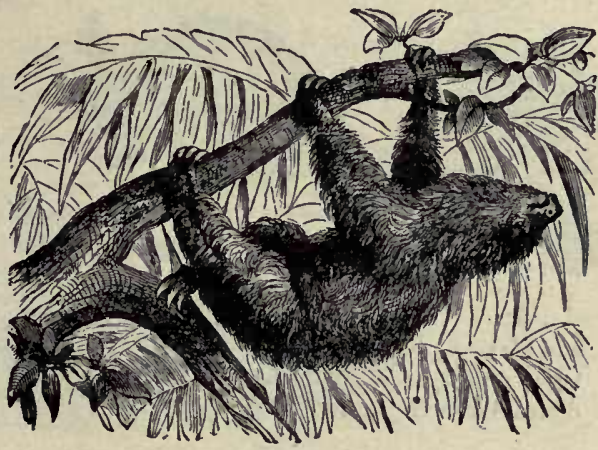

FIG 363 . - SLOTH of South America. tack, active resistance, passive resistance, or concealment

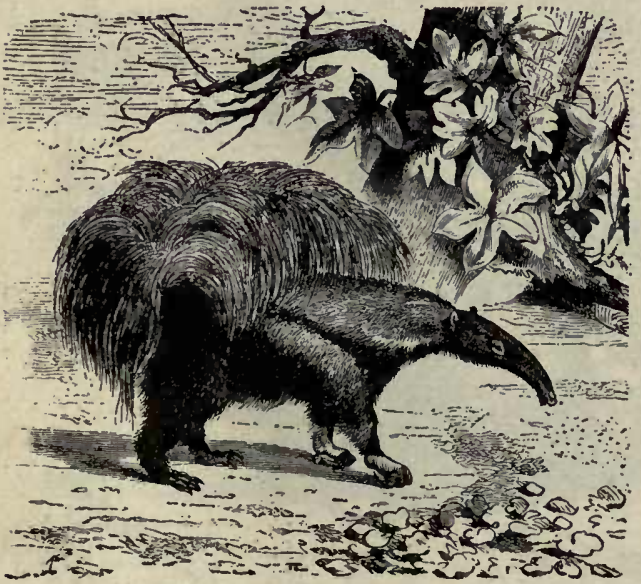

Fig. 364. - GiAnT ANT-EATER of South America. (See Fig. 354.) Find evidences that the edentates are a degenerate order. Describe another ant-eater (Fig. 360).

when contending with other animals? The ant-eater's claws (Fig. 364) on the fore feet seem to be a hindrance in walking; for what are they useful? Why are its jaws so slender? What is probably the use of the enormous bushy tail? The nine-banded armadillo (Fig. 365) lives in Mexico and Texas. It is omnivorous. To escape its enemies, it burrows into 
the ground with surprising rapidity. If unable to escape when pursued, its hard, stout tail and head are turned

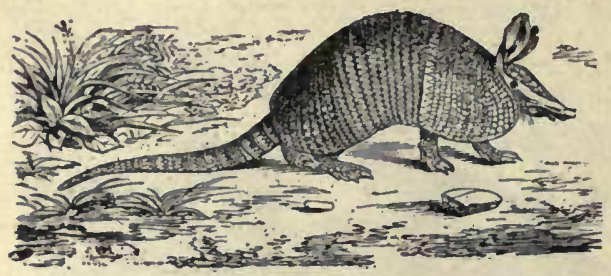

Fig. 365. - NINE-BANDED ARMADILlo of Texas and Mexico. (Dasypus novemcinctus.) it is increasing in numbers; it is very useful, as it digs up and destroys insects. (See Fig. 347.) under to protect the lower side of the body where there are noscales. The three-banded species (Fig. 366) lives in Argentina. Compare the ears and tail of the two speccies; give rea-

sons for differences. Why are the eyes so small? The claws so large? Order Why?

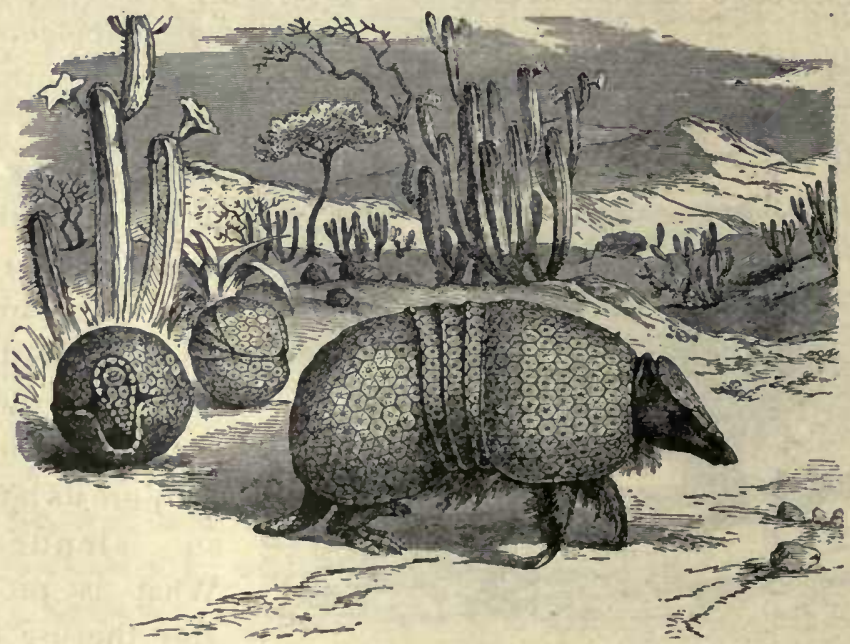

FIG. 366. - THREE-BANDED ARMADILLO (Tolypeutes tricinctus).

Insect Eaters. - The soft interior and crusty covering of insects makes it unnecessary for animals that prey upon them to have flat-topped teeth for grinding them to 
powder, or long cusps for tearing them to pieces. The teeth of insect eaters, even the molars (Fig. 368), have many sharp tubercles, or points, for holding insects and piercing the crusty outer skeleton and reducing it to bits. As most insects dig in the ground or fly in the air, we are not surprised to learn that some insect-eating mam-

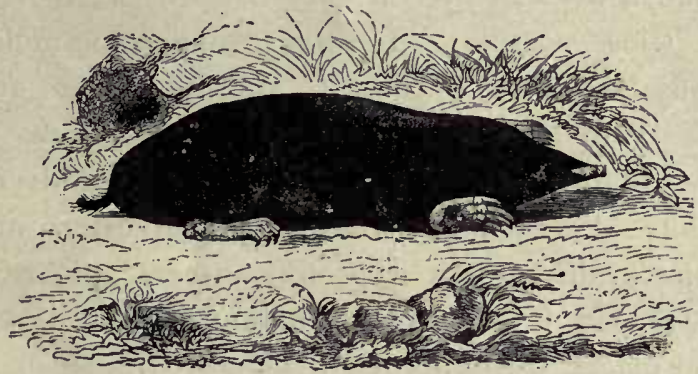

FIG. 367. - THE MOLE.

mals (the bats) fly and others (the moles) burrow. Are the members of this order friends or competitors of man?

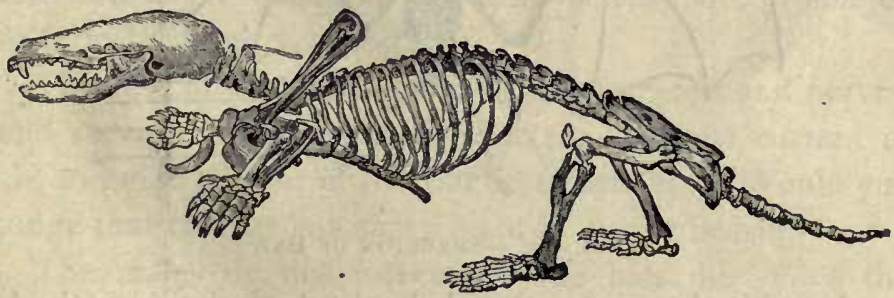

FIG. 368. - SKELETON OF Mole. (Shoulder blade is turned upward.)

Why does the mole have very small eyes? Small ears? Compare the shape of the body of a mole and a rat. What difference? Why? Compare the front and the hind legs of a mole. Why are the hind legs so small and weak? Bearing in mind that the body must be arranged for digging and using narrow tunnels, study the skeleton 
(Fig. 368) in respect to the following: Bones of arm (length and shape), fingers, claws, shoulder bones, breastbone (why with ridge like a bird?), vertebræ (why are the first two so large?), skull (shape). There are no eye sockets, but there is a snout gristle ; for the long, sensitive snout must serve in place of the small and almost useless eyes hidden deep in the fur. Is the fur sleek or rough? Why? Close or thin? It serves to keep the mole clean. The muscles of neck, breast, and shoulders are very strong. Why? The mole eats earthworms as well as insects. It injures plants by breaking and drying out their roots. Experiments show that the Western mole will eat moist grain, though it prefers insects. If a mole is caught, repeat the experiment, making a careful record of the food placed within its reach.

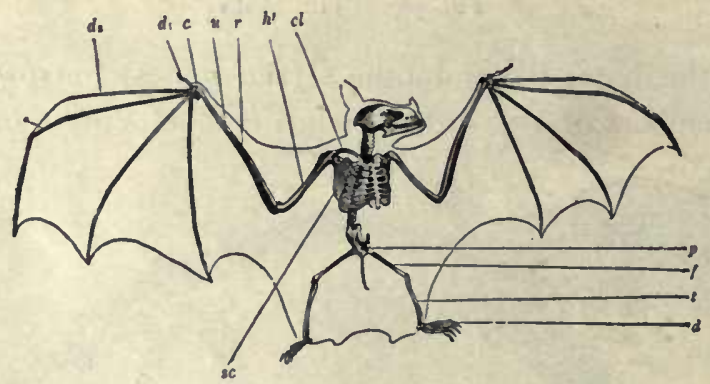

Fig. 369. - SkELETON OF BAT.

As with the mole, the skeletal adaptations of the bat are most remarkable in the hand. How many fingers? (Fig. 369.) How many nails on the hand? Use of nail when at rest? When creeping? (Fig. 369.) Instead of feathers, the flying organs are made of a pair of extended folds of the skin supported by elongated bones, which form a framework like the ribs of an umbrella or a fan. How many digits are prolonged? Does 


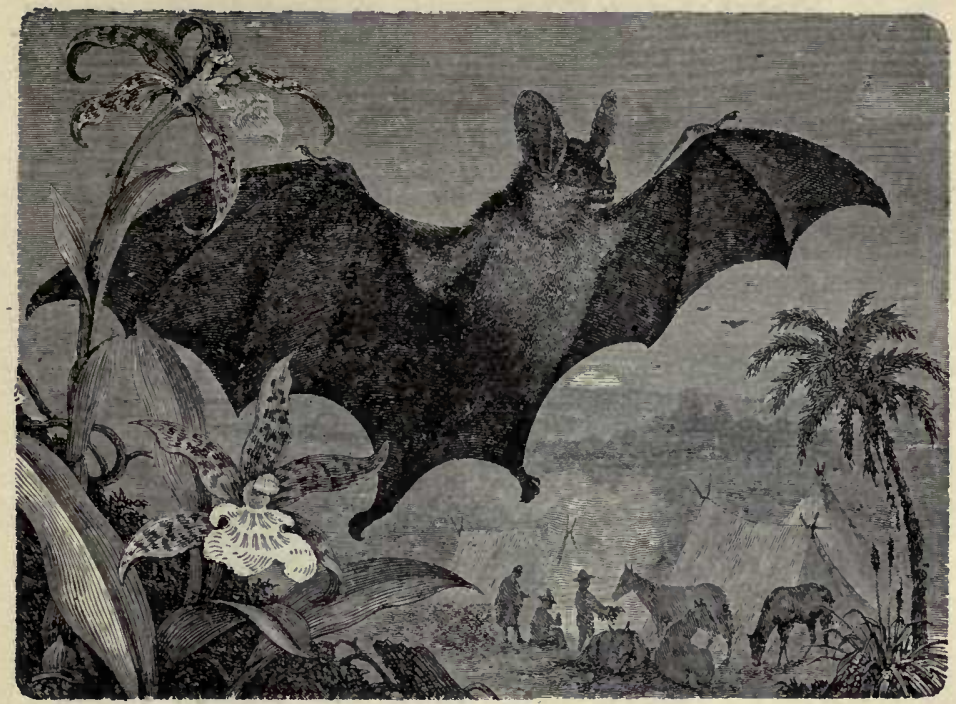

FIG. 370. - VAMPIRE (Phyllostoma spectrum) of South America. $\times \frac{1}{8}$.

the fold of the skin extend to the hind legs? The tail ? Are the finger bones or the palm bones more prolonged to form the wing skeleton?

The skin of the wing is rich in blood vessels and nerves, and serves, by its sensitiveness to the slightest current of air, to guide the bat in the thickest darkness. Would you judge that the bat has sharp sight? Acute hearing?

The moles do not hibernate; the bats do. Give the reason for the difference. If bats are aroused out of a trance-like condition in winter, they may die of starvation. Why? The mother bat carries the young about with her, since, unlike birds, she has no nest. How are the young nourished? Order Why?

(Key, p. 193.)

The Gnawing Mammals. - These animals form the most numerous order of mammals. They lack canine teeth. Inference? The incisors are four in number in all species 
except the rabbits, which have six (see Fig. 345). They are readily recognized by their large incisors. These teeth grow throughout life, and if they are not constantly worn

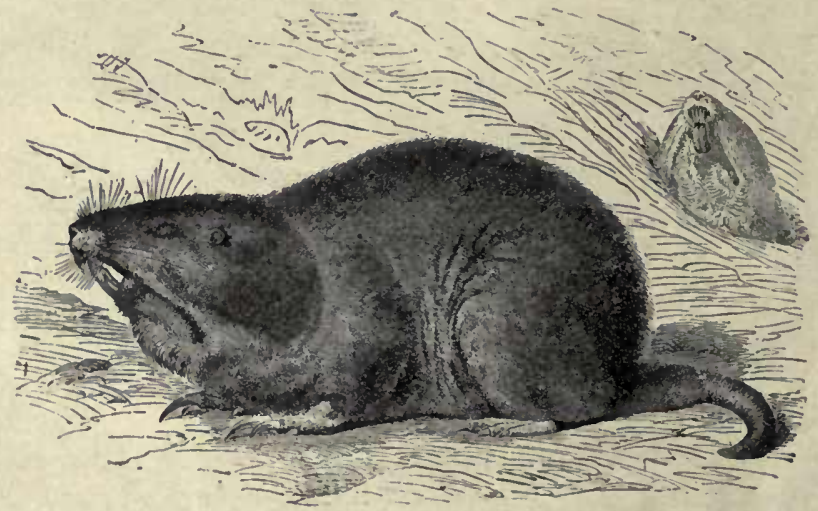

FIG. 371. - POUCHED GOPHER (Geomys bursarius) $\times \frac{1}{4}$, a large, burrowing field rat, with cheek pouches for carrying grain.

away by gnawing upon hard food, they become inconveniently long, and may prevent closing of the mouth and cause starvation. The hard enamel is all on the front surface, the dentine in the rear being softer; hence the incisors sharpen themselves by use to a chisel-like edge.

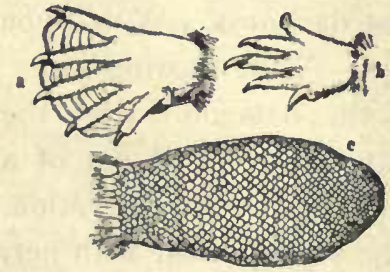

FIG. 372. - Hind foot $a$, fore foot $b$, tail $c$, of BEAVER.

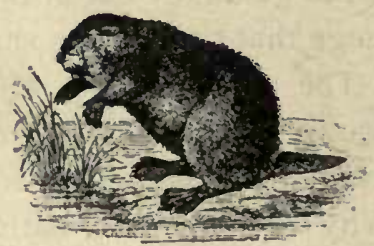

FIG. 373.-BEAVER.

The molars are set close together and have their upper surfaces level with each other. The ridges on them run crosswise so as to form a continuous filelike surface for 
reducing the food still finer after it has been gnawed off (Fig. 345). The lower jaw fits into grooves in place of sockets. This allows the jaw to work back and forth instead of sidewise. The rabbits and some squirrels have a hare lip; i.e. the upper lip is split. What advantage is this in eating? In England the species that burrow are called rabbits; those that do not are called hares.

Name six enemies of rabbits. Why does a rabbit usually sit motionless unless approached very close? Do you usually see one before it dashes off? A rabbit has from three to five litters of from three to six young each year. Squirrels have fewer and smaller litters. Why must the rabbit multiply more rapidly than the squirrel in order to survive? English rabbits have increased in Australia until they are a plague. Sheep raising is interfered with by the loss of grass.

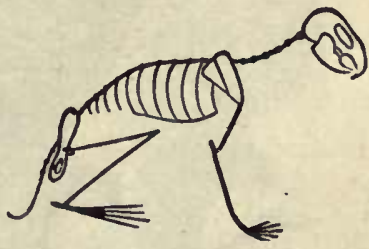

FIG. 374. - POSITION OF LIMBS IN RABBIT.

The Australians now ship them to England in cold storage for food. Rabbits and most rodents lead a watchful, timid, and alert life. An exception is the porcupine, which, because of the defense of its barbed quills, is dull and sluggish.

The common rodents are:-

squirrels beavers

rabbits

rats

mice pouched gopher

prairie dog prairie squirrel

chipmunk

Which of the above rodents are commercially important ? Which are injurious to an important degree? Which have long tails? Why? Short tails? Why? Long ears? Why? 
Short ears? Why? Which are aquatic ? Which dig or bur row? Which are largely nocturnal in habits? Which are arboreal? Which are protected by coloration? Which escape by running? By seeking holes?

Economic Importance. - Rabbits and squirrels destroy the eggs and young of birds. Are rabbits useful? Do they destroy useful food? The use of beaver and muskrat skins as furs will probably soon lead to their extinction. Millions of rabbits' skins are used annually, the hair being made into

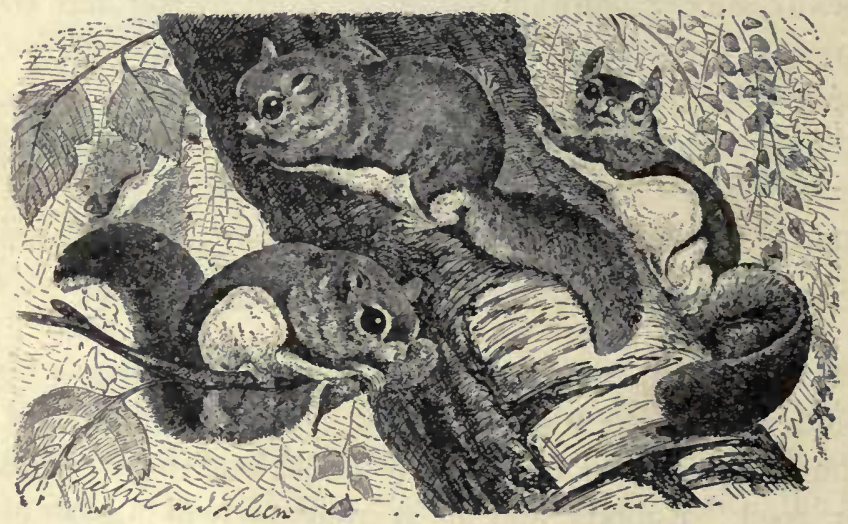

FIG. 375. - FLYING SQUIRREL (Pteromys volucella), $\times 1 / 4$.

felt hats. There are also millions of squirrel skins used in the fur trade. The hairs of the tail are made into fine paint brushes. The skins of common rats are used for the thumbs of kid gloves. Order —. Why?

Elephants. - Elephants, strange to say, have several noteworthy resemblances to rodents. Like them, elephants have no canine teeth ; their molar teeth are few, and marked by transverse ridges and the incisors present are prominently developed (Figs. 376, 377). Instead of four incisors, however, they have only two, the enormous tusks, for there are no incisors in the lower jaw. Elephants and rodents 
both subsist upon plant food. Both have peaceful dispositions, but one order has found safety and ability to survive by attaining enormous size and strength; the other (e.g. rats, squirrels) has found safety in small size. Explain.

Suppose you were - to observe an elephant for the first time, without knowing any of its habits. How would you know that it does not eat meat? That it does eat plant food? That it can defend it-

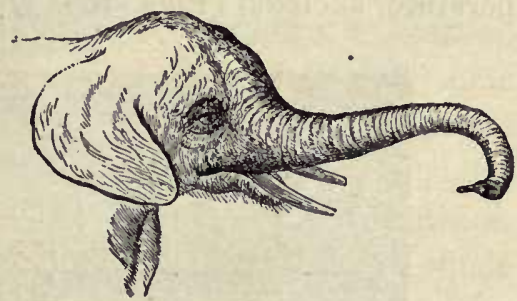

Fig. 376. - HEAD OF AFRICAN ElePHANT. self? Why would you make the mistake of thinking that it is very clumsy and stupid? Why is its skin naked? Thick? Why must its legs' be so straight? Why must it have either a very long neck or a substitute for one? (Fig. 376.) Are the eyes large or small? The ears? The brain cavity? What anatomical feature correlates with the long proboscis? Is the proboscis a new organ not found in other animals, or is it a specialization of one or more old ones? Reasons? What senses are especially active in the proboscis? How is it used in drinking? In

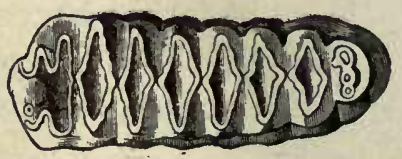

FIG. 377.- MOLAR TOOTH OF AFricaN ELEPHANT. grasping? What evidence that it is a development of the nose? The upper lip?

The tusks are of use in uprooting trees for their foliage and in digging soft roots for food. Can the elephant graze? Why, or why not? There is a finger-like projection on the end of the snout which is useful in delicate manipulations. The feet have pads to prevent jarring; the nails are short and hardly touch the ground. Order

Why'?

Key, page 193. 
Whales, Porpoises, Dolphins. - As the absurd mistake is sometimes made of confusing whales with fish, the pupil may compare them in the following respects: eggs, nourishment of young, fins, skin, eyes, size, breathing, temperature, skeleton (Figs. 209, 379, and 397).

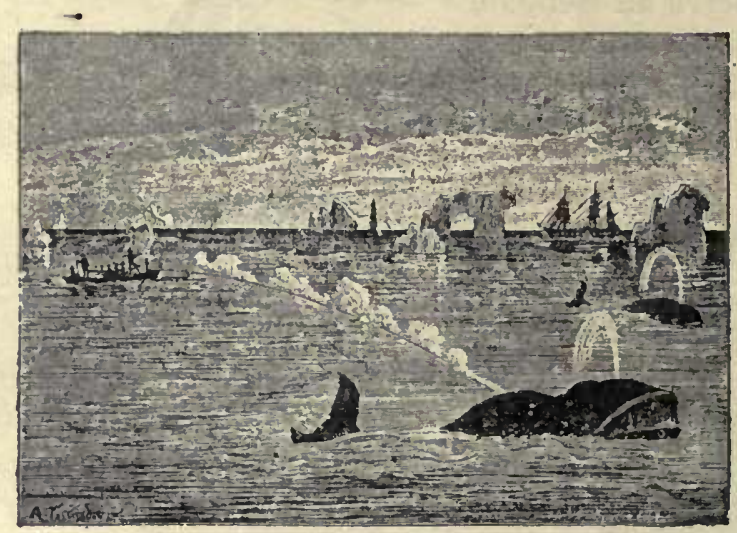

FIG. 378. - HARPOONING GREENLAND WhALE (see Fig. 35r).

Porpoises and dolphins, which are smaller species of whales, live near the shore and eat fish. Explain the expression "blow like a porpoise." They do not exceed five or eight feet in length, while the deep-sea whales are from thirty to seventy-five feet in length, being by far the largest animals in the world. The size of the elephant is limited by the weight that the bone and muscles support and move. The whale's size is not so limited.

The whale bears one young (rarely twins) at a time. The mother carefully attends the young for a long time. The blubber, or thick layer of fat beneath the skin, serves to retain heat and keep the body up to the usual temperature of mammals in spite of the cold water. It also serves, along with the immense lungs, to give lightness to the body. 
Why does a whale need large lungs?

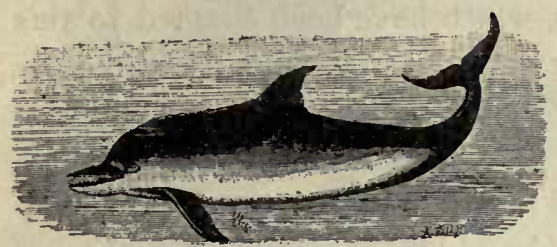

FIG. 379. - DOLPHIN. is horizontal instead of vertical, that it may steer upward rapidly from the depths when needing to breathe. The teeth of some whales do not cut the gum, but are reabsorbed and are replaced by horny plates of "whalebone," which act as strainers. Give evidence, from the flippers, lungs, and other organs, that the whale is descended from a land mammal (Fig. 397). Compare the whale with a typical land mammal, as the dog, and enumerate the specializations of the whale for living in water. What change took place in the general form of the body? It is believed that on account of scarcity of food the land ancestors of the whale, hundreds of thousands of years ago, took to living upon fish, etc., and, gradually becoming swimmers and divers, lost the power of locomotion on land. Order.

Why?

Elephants are rapidly beconing extinct because of the value of their ivory tusks. Whales also furnish valuable products, but they will probably exist much longer. Why?

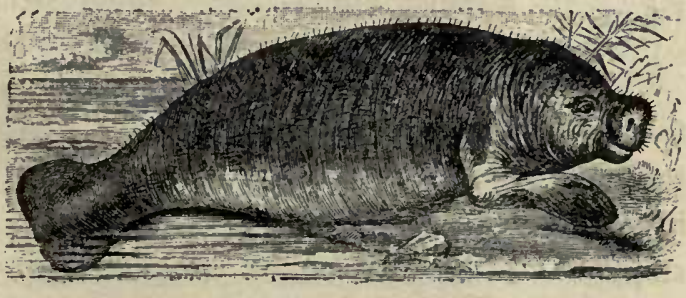

FIG. 380. - MANATEE, or sea cow; it lives near the shore and eats seaweed. (Florida to Brazil.)

The manatees and dugongs (sea cows) are a closely related order living upon water plants, and hence living close to shore and in the mouths of rivers. Order Why? 
Hoofed Mammals. - All the animals in this order walk on the tips of their toes, which have been adapted to this use by the claws having developed into hoofs. The order is subdivided into the odd-toed (such as the horse with one toe and the rhinoceros with three) and the even-toed (as the ox with two toes and the pig with four). All the eventoed forms except the pig and hippopotamus chew the cud and are given the name of ruminants.

Horse and Man Compared (Figs. 38r, 399). - To which finger and toe on man's hand and foot does the toe of a

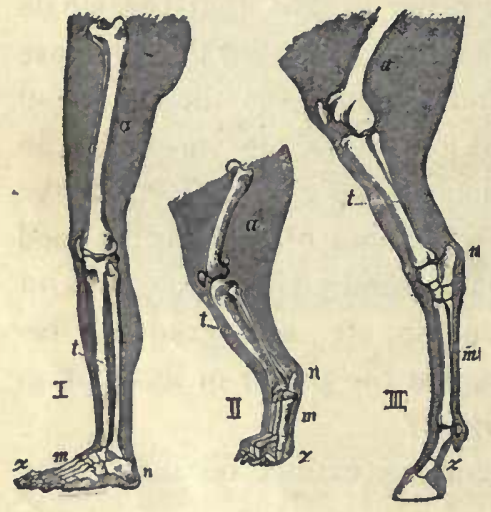

FIG. 38r. - Left leg of man, left hind leg of dog and horse; homologous parts lettered alike. horse's foot correspond? Has the horse kneecaps? Is its heel bone large or small? Is the fetlock on toe, instep, or ankle? Does the part of a horse's hind leg that is most elongated correspond to the thigh, calf, or foot in man? On the fore leg, is the elongated part the upper arm, forearm, or hand? Does the most elongated part of the fore foot correspond to the finger, palm, or wrist? On the hind foot is it toe, instep, or ankle? Is the fetlock at the toe, instep, or heel? (Fig. 385.) Is the hock at the toe, instep, heel, or knee? Order Why?

Specializations of the Mammals. - The early mammals, of which the present marsupials are believed to be typical, had five toes provided with claws. They were not very rapid in motion nor dangerous in fight, and probably ate both animal and vegetable food. 


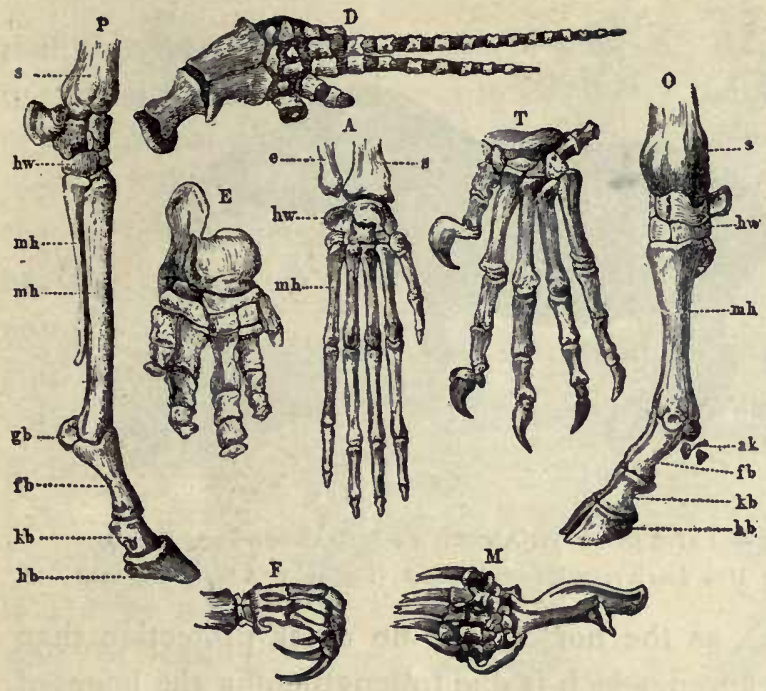

FIG. 382, - SKELETONS OF FEET OF MAMMALS.

$P$, horse; $D$, dolphin; $E$, elephant; $A$, monkey; $T$, tiger; $O$, aurochs: $F$, sloth; $M$, mole.

Question: Explain how each is adapted to its specialized function.

According to the usual rule, they tended to increase faster than the food supply, and there were continual contests for food. Those whose claws and teeth were sharper drove the others from the food, or preyed upon them. Thus the specialization into the bold flesh eating beasts of prey and the timid vegetable feeders began. Which of the flesh eaters has already been studied at length? The insectivora escaped their enemies and found food by learning to burrow
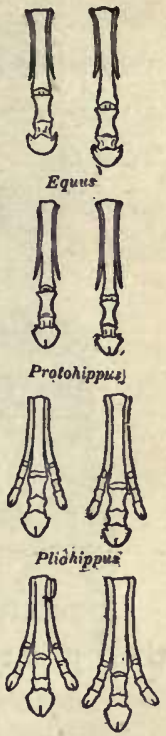

aliohippus

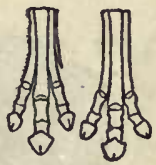

Mesohippes?

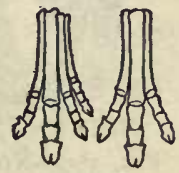

Oroluppus.

FIG. $3^{8} 3$. Feet of the ancestors of the horse. or fly. The rodents accomplished the same result either by acquiring great agility in climbing, or by living in holes, or by running. The proboscidians acquired enormous size and strength. The hoofed animals found safety in flight. 


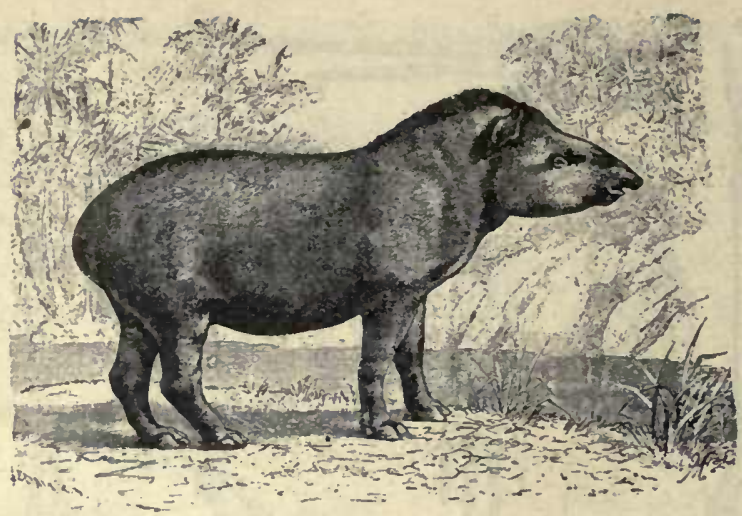

FIG. 384 - TAPIR OF SOUTH AMERICA (Tapirus americanus). $\times$ ts. Questions: How does it resemble an elephant? (Fig. 376.) A horse? (p. 210.)

Ungulates, as the horse, need no other protection than their great speed, which is due to lengthening the bones of

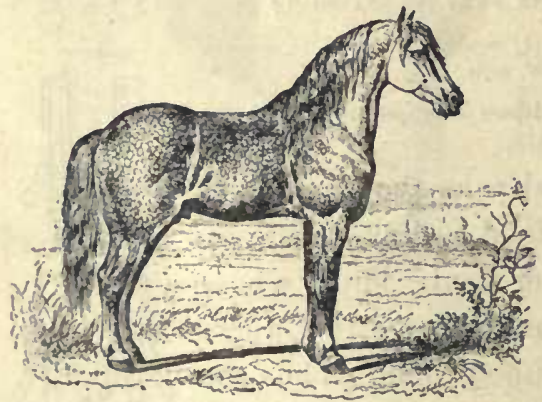

FiG. 385. - HORSE, descended from a small wild species still found in Western Asia. the legs and rising upon the very tip of the largest toe, which, to support the weight, developed an enormous toe-nail called a hoof. The cattle, not having developed such speed as the horse, usually have horns for defense. If a calf or cow bellows with distress, all the cattle in the neighborhood rush to the rescue. This unselfish instinct to help others was an aid to the survival of wild cattle living in regions infested with beasts of prey. Which of Æsop's fables is based upon this instinct? The habit of rapid grazing and the correlated habit of chewing the cud were also of great value, as it enabled cattle to obtain grass hur- 
riedly and retire to a safe place to chew it. Rudiments of the upper incisors are present in the jaw of the calf, showing the descent from animals which had a complete set of teeth. The rudiments are absorbed and $t$ e upper jaw of the cow lacks incisors entirely, as they would be useless because of the cow's habit of seizing the grass with her rough tongue and cutting it with the lower incisors as the head is jerked forward. This is a more rapid way of eating than by biting. Which leaves the grass shorter

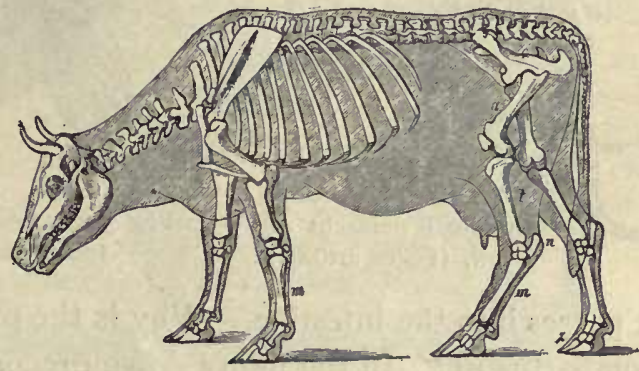

Fig. 386.-Skeleton of Cow. Compare with horse (Fig. 395) as to legs, toes, tail, mane, dewlap, ears, body.

after grazing, a cow or a horse? Why? Grass is very slow of digestion, and the ungulates have an alimentary canal twenty to thirty times the length of the body. Thorough chewing is necessary for such coarse food, and the ungulates which chew the cud (ruminants) are able, by leisurely and thorough chewing, to make the best use of the woody fiber (cellulose) which is the chief substance in their food.

Ruminants have four divisions to the stomach. Their food is first swallowed into the roomy paunch in which, as in the crop of a bird, the bulky food is temporarily stored. It is not digested at all in the paunch, but after being moistened, portions of it pass successively into the honeycomb, which forms it into balls to be belched up and ground by the large molars as the animal lies with eyes half closed under the shade of a tree. It is then swal- 
lowed a second time and is acted upon in the third division (or manyplies) and the fourth division (or reed). Next

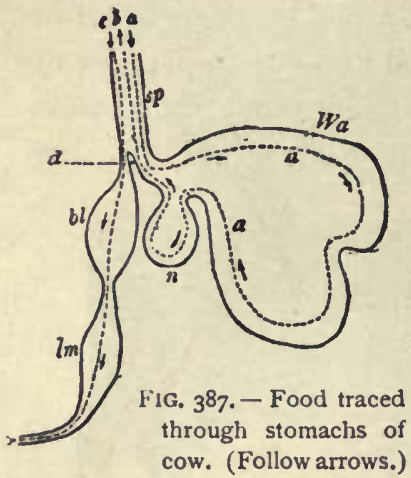

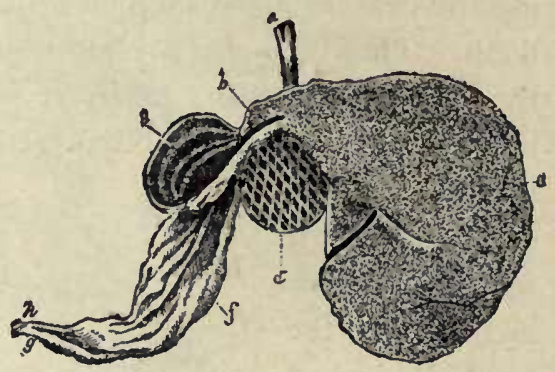

FIG. 388. - Section of cow's stomachs. Identify each. (See text.)

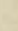

it passes into the intestine. Why is the paunch the largest compartment? In the figure do you recognize the paunch by its size? The honeycomb by its lining? Why is it

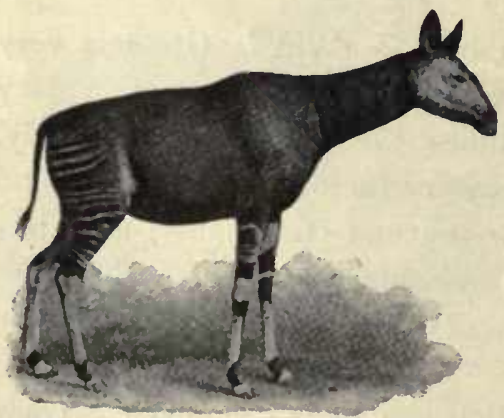

FIG. 389. - OKAP1. This will probably prove to be the last large mammal to be discovered by civilized man. It was found in the forests of the Kongo in 1900.

Questions: It shows affinities (find them) with giraffe, deer, and zebra. It is a ruminant ungulate (explain meaning - see text).

ignorant people make the absurd mistake of calling the ball of hair the cud. This ball accumulates in the paunch of the four divisions may be known by their direct connection with the intestine.

The true gastric juice is secreted only in the fourth stomach. Since the cud or unchewed food is belched up in balls from the round "honeycomb," and since a ball of hair is sometimes found in the stomach of ruminants, some

round? The last two cow. (Follow arrows.) 
because of the friendly custom cows have of combing each other's hair with their rough tongues, the hair sometimes

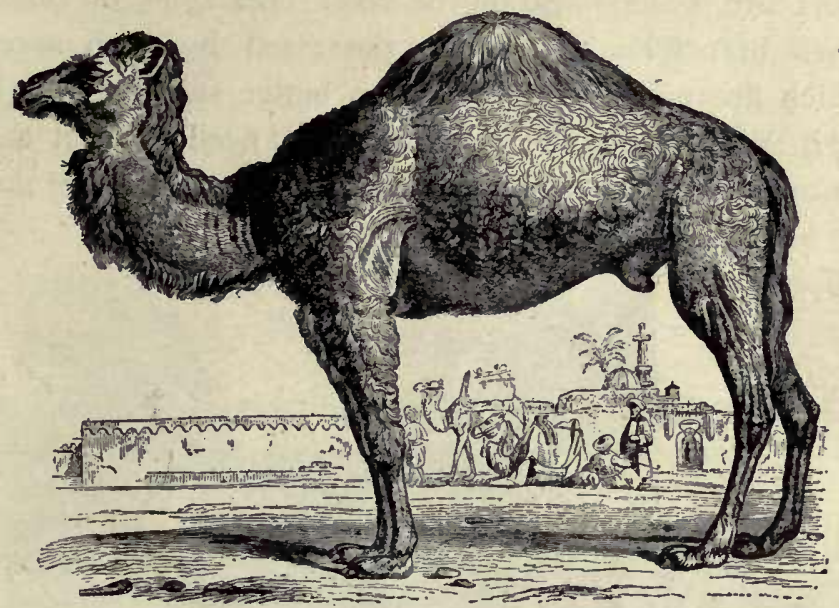

FIG. 390.-AFRICAN CAMEL (Camelus dromedarius).

being swallowed. Explain the saying that if a cow stops chewing the cud she will die.

Does a cow's lower jaw move sidewise or back and forth? Do the ridges on the molars run sidewise or lengthwise? Is a cow's horn hollow? Does it have a bony core? (Fig. 344.)

The permanent hollow horns of the cow and the solid deciduous horns of the deer are typical of the two kinds of horns possessed by ruminants. The prong-horned antelope (Fig. 39I) of

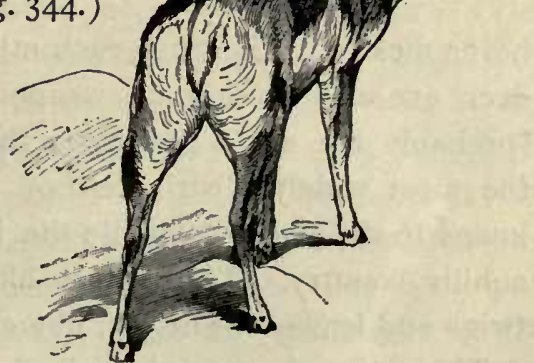

FIG. 391. - PRONG-HORNED ANTELOPE (Antelocarpa Americana). Western states. 
the United States, however, is an intermediate form, as its horns are hollow, but are shed each year. The hollow horns are a modification of hair. Do solid or hollow bones branch? Which are possessed by both sexes? Which are pointed? Which are better suited for fighting? Why would the deer have less need to fight than the cattle? Deer are polygamous, and the males use their

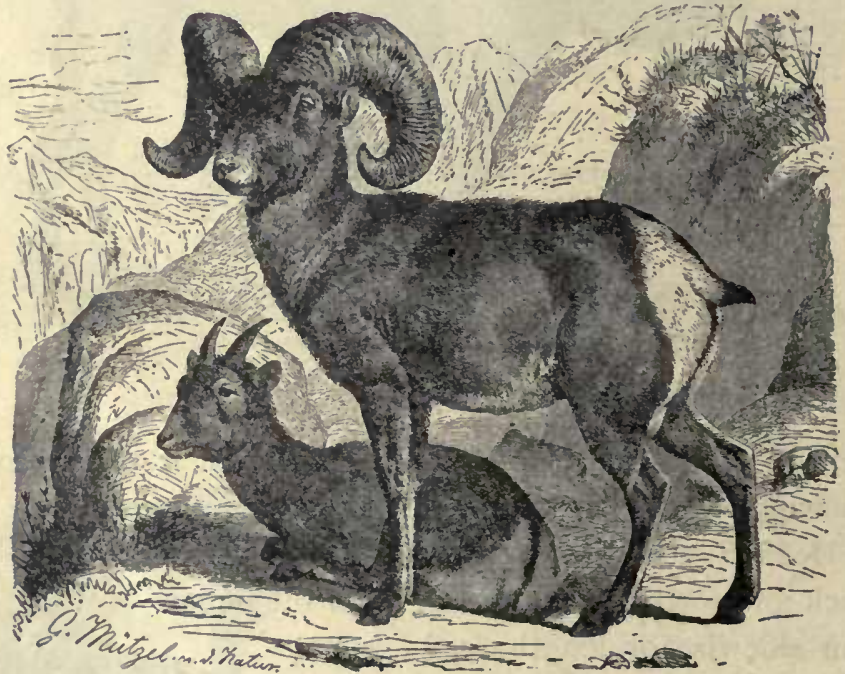

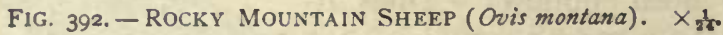

horns mostly for fighting each other. The sharp hoofs of deer are also dangerous weapons. The white-tail deer (probably the same species as the Virginian red deer) is the most widely distributed of the American deer. It keeps to the lowlands, while the black-tailed deer prefers a hilly country. The moose, like the deer, browses on twigs and leaves. The elk, like cattle, eats grass.

The native sheep of America is the big horn, or Rocky Mountain sheep (Fig. 392). The belief is false that they 
alight upon their horns when jumping down precipices. They post sentinels and are very wary. There is also a native goat, a white species, living high on the Rocky Mountains near the snow. They are rather stupid animals. The bison once roamed in herds of countless thousands, but, with the exception of a few protected in parks, it is now extinct. Its shaggy hide was useful to man in winter, so it has been well-nigh destroyed. For gain man is led to exterminate elephants, seals, rodents, armadillos, whales, birds, deer, mussels, lobsters, forests, etc.

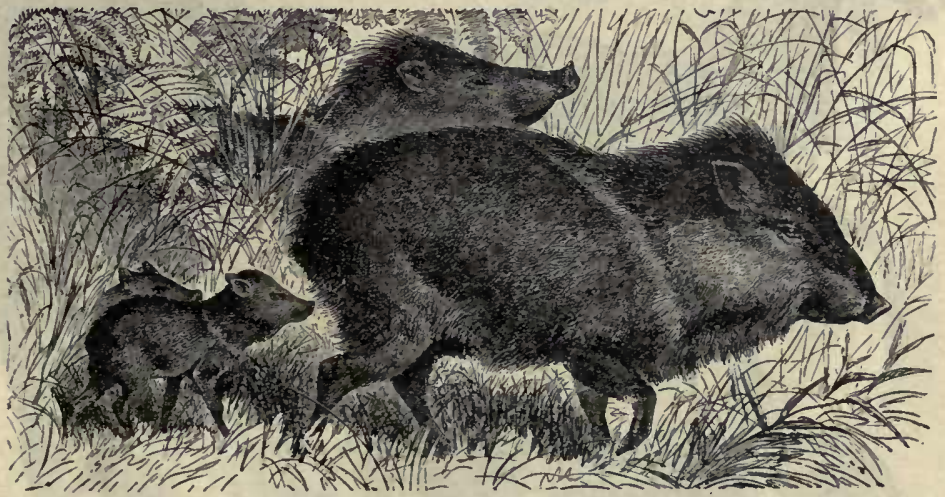

FIG. 393. - PECCARY (Dicotyles torquatus) of Texas and Mexico. $\times \frac{1}{12}$

Our only native hog is the peccary, found in Texas (Fig. 393). In contrast with the heavy domestic hog, it is slender and active. It is fearless, and its great tusks are dangerous weapons. The swine are the only ungulates that are not strictly vegetable feeders. The habit of fattening in summer was useful to wild hogs, since snow hid most of their food in winter. The habit has been preserved under domestication. Are the small toes of the hog useless? Are the "dew claws" of cattle useless? Will they probably become larger or smaller? Order? 


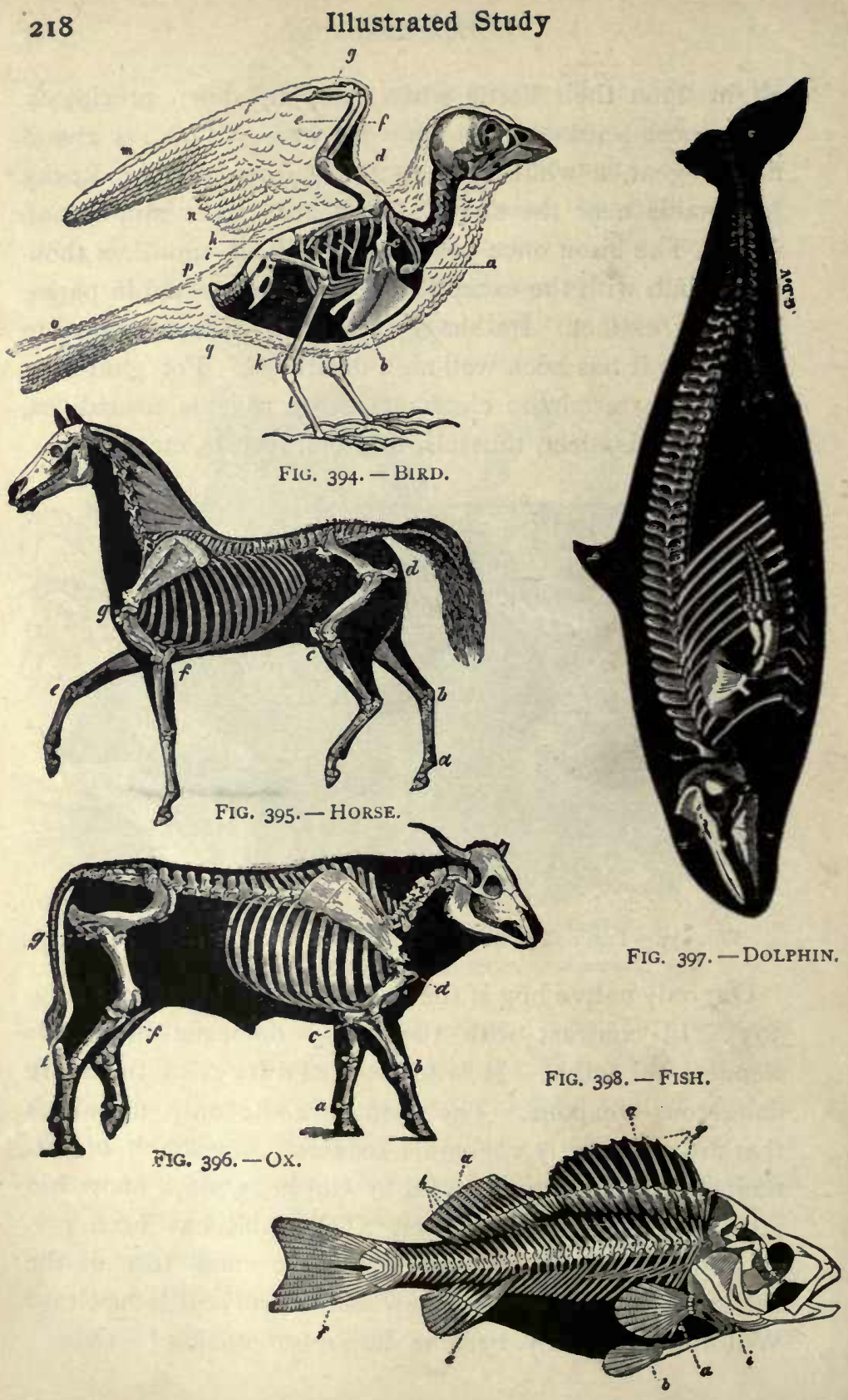




\section{Illustrated Study}
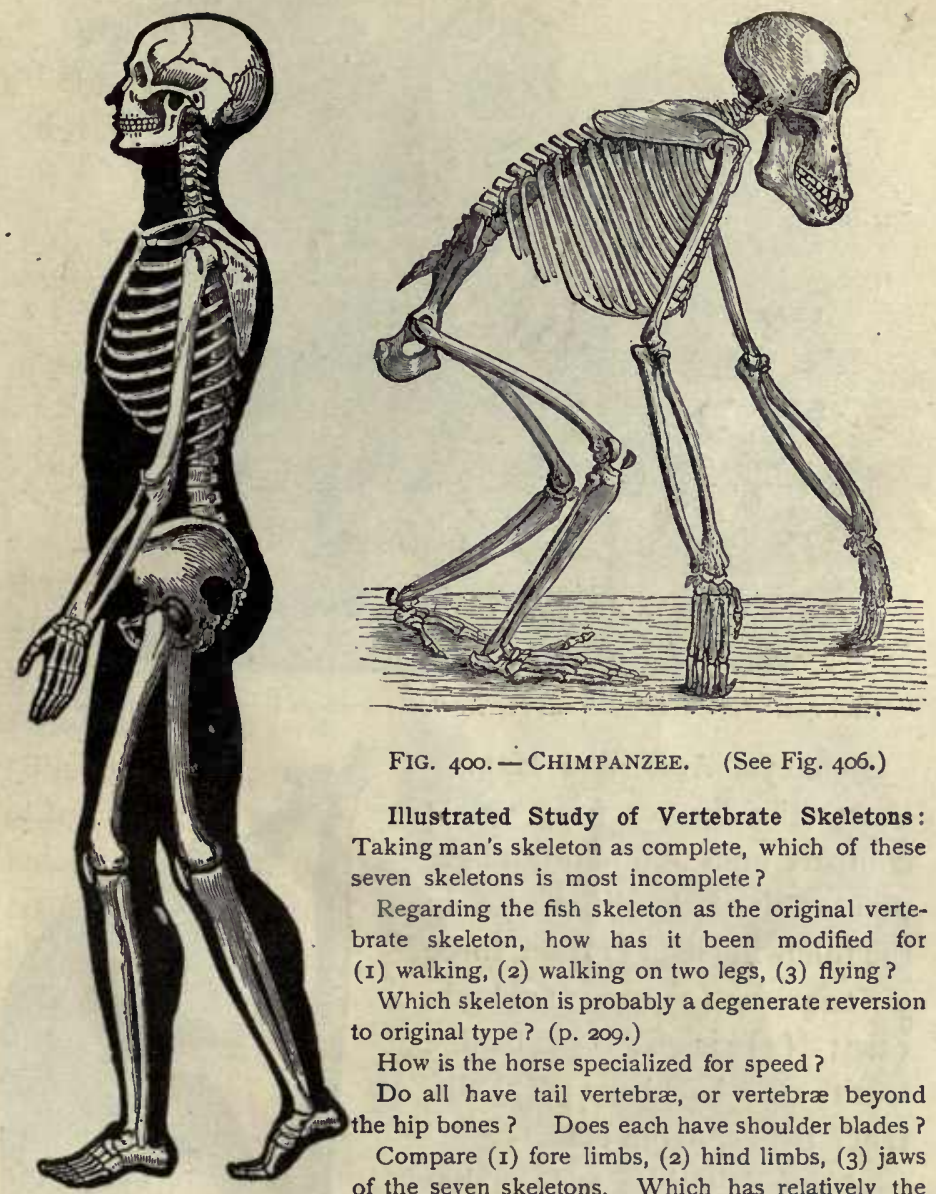

FIG. 400.-ChIMPANZEE. (See Fig. 406.)

Illustrated Study of Vertebrate Skeletons: Taking man's skeleton as complete, which of these seven skeletons is most incomplete?

Regarding the fish skeleton as the original vertebrate skeleton, how has it been modified for (I) walking, (2) walking on two legs, (3) flying ?

Which skeleton is probably a degenerate reversion to original type? (p. 209.)

How is the horse specialized for speed?

Do all have tail vertebræ, or vertebræ beyond the hip bones? Does each have shoulder blades?

Compare (I) fore limbs, (2) hind limbs, (3) jaws of the seven skeletons. Which has relatively the

FIG. 399. - MAN. shortest jaws? Why? What seems to be the typical number of ribs? limbs? digits ?

Does flipper of a dolphin have same bones as arm of a man?

How many thumbs has chimpanzee? Which is more specialized, the foot of a man or a chimpanzee? Is the foot of a man or a chimpanzee better suited for supporting weight? How does its construction fit it for this?

Which has a better hand, a man or a chimpanzee? What is the difference in their arms? Does difference in structure correspond to difference in use?

Which of the seven skeletons bears the most complex breastbone?

Which skeleton bears no neck (or cervical) vertebræ? Which bears only one ? Are all the classes of vertebrates represented in this chart? (p. 125.) 


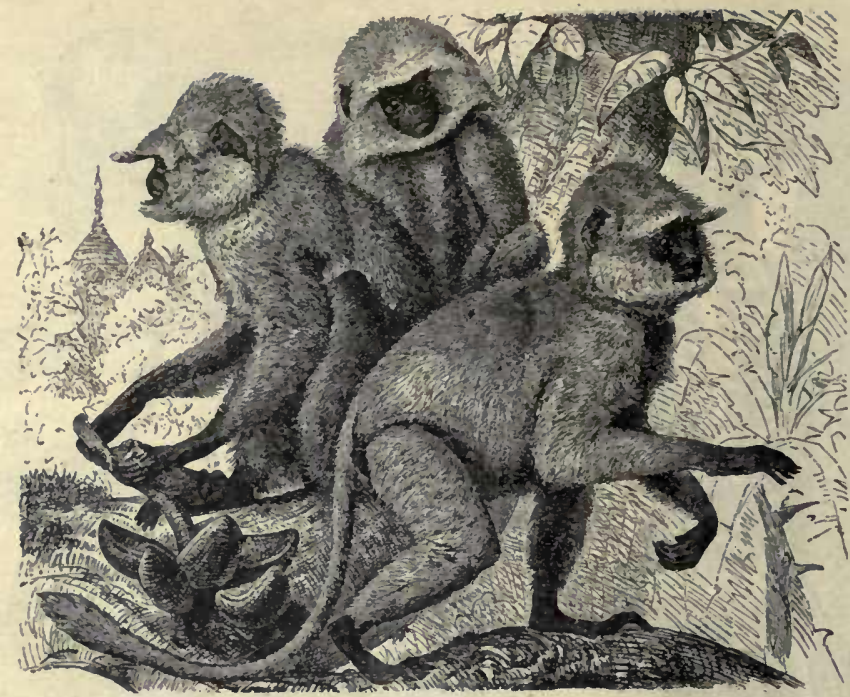

FIG, 4OI. - SACRED MONKEY OF INIDIA (Semnopithecus entellus). $x_{2}$ t.

Monkeys, Apes, and Man.Study the figures $(399,400)$; compare apes and man and explain each of the differences in the following list : ( 1 ) feet, three differences; (2) arms; (3) brain case; (4) jaws; (5) canine teeth ; (6) backbone ; (7) distance between the eyes.

$A$ hand, unlike a foot, has one of the digits, called a thumb, placed opposite the other four digits that it may be used in grasping. Two-handed man and four-handed apes and monkeys are usually placed in one order, the Primates, or

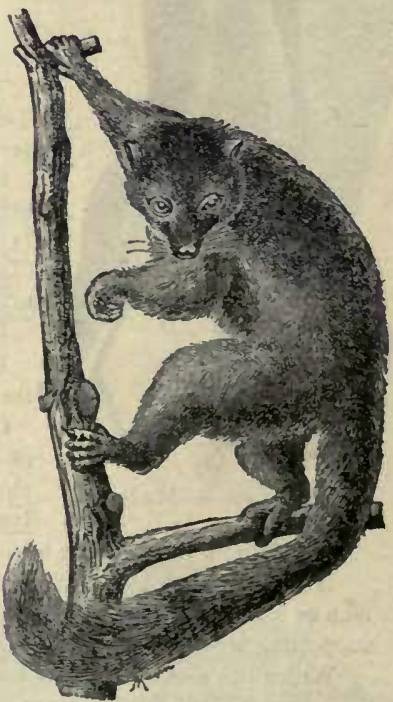

FIG. 402. - LEMUR (Lemur Mongoz). $x$ is. Which digit bears a claw ? 
in two orders (see table, page 193). The lowest members of this order are the lemurs of the old world. Because of

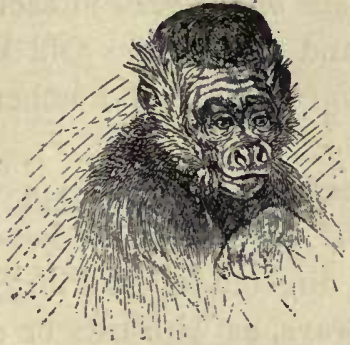

FIG. 403. - BROAD-NOSED MONKEY. $\times \frac{1}{10}$. America.

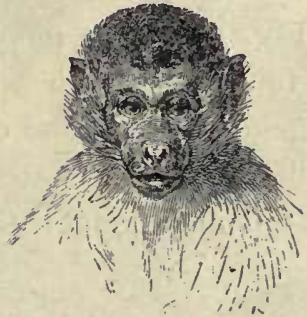

FIG. 404. - NARROW-NOSED MONKEY. $\times \frac{1}{12}$. Old World.

their hands and feet being true grasping organs, they are placed among the primates, notwithstanding the long muzzle and expressionless, foxlike face. (Fig. 402.) Next in order are the tailed monkeys, while the tailless apes are the highest next to man.

The primates of the New World are all monkeys with long tails and broad noses. They are found from Paraguay to Mexico. The monkeys and apes. of the Old World have a thin partition between the nostrils, and are thus distinguished from the

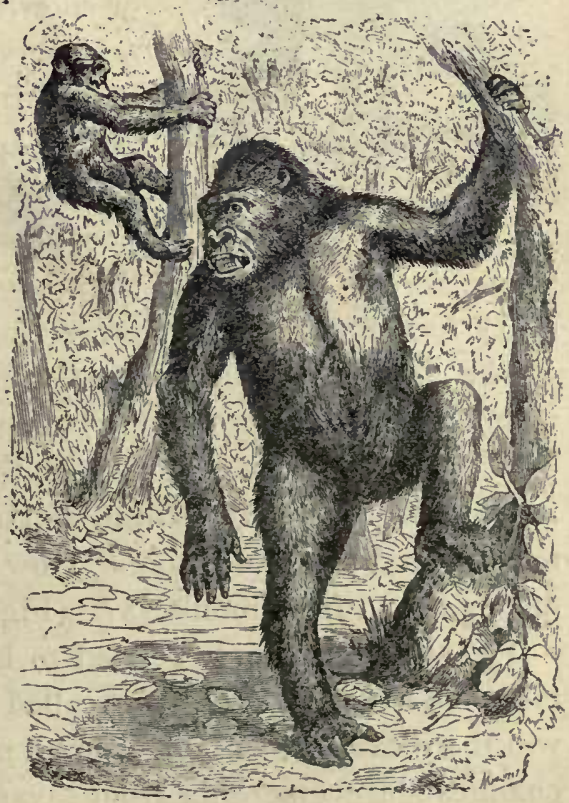

Fig. 405.-Gorilla. (Size of a man.) 
monkeys of the New World, which have a thicker partition and have a broader nose. (Figs. 403, 404.) The monkeys of America all have six molar teeth in each half jaw (Fig. 352); the monkeys and apes of the Old World have thirty-two teeth which agree both in number and arrangement with those of man.

Which of the primates figured in this book appear to have the arm longer than the leg? Which have the

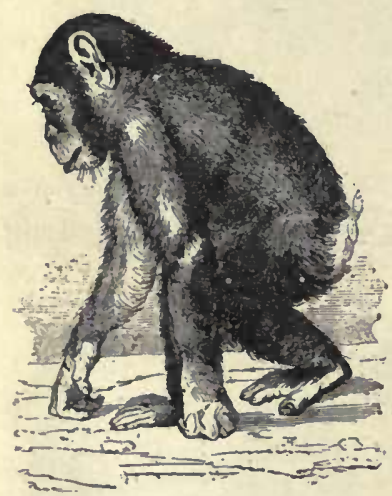

Fig. 406. - ChimpanzeE. eyes directed forward instead of sideways, as with cats or dogs?

Nearly all the primates are forest dwellers, and inhabit warm countries, where the boughs of trees are never covered with ice or snow. Their ability in climb. ing serves greatly to protect them from beasts of prey. Many apes and monkeys are able to assume the upright position in walking, but they touch the ground with their knuckles every few steps to aid in preserving the balance.

The Simians are the highest family of primates below man, and include the gorilla, chimpanzee, orang, and gibbon. Some of the simians weave together branches in the treetops to form a rude nest, and all are very affectionate and devoted to their young. How are apes most readily distinguished from monkeys? (Figs: 40I, 406.)

The study of man as related to his environment will be taken up in detail in the part called Human Biology. We will there examine the effect upon man's body of the rapid changes since emerging from savagery that he has made in food eaten, air breathed, clothing, and habits of life. 
Fig. 407.-Anatomy OF RABBit.

$a$, incisor teeth;

$b, b^{\prime}, b^{\prime \prime}$, salivary glands:

$k$, larynx;

h, windpipe;

$c$, gullet;

$d$, di a phragm (possessed only by mammals);

e, stomach;

$g$, small intestine;

$h, h^{\prime}$, large intestine;

$f$, junction of small and large intestine;

$g, g^{\prime}$, cæcum, or blind sac from $f \quad b$, cerebrum: (corresponds to $c$, midbrain;

the shrunken $d$, cerebellum. rudimentary vermiform appendix in man); $m$, carotid arteries:

$n$, heart;

0 , aorta;

$p$, lungs;

$q$, end of sternum;

$r$, spleen;

$s$, kidney:

$t$, ureters (from kidney to blad. der $v$ ).

2 brain of rabbit:

$a$, olfactory

nerves;

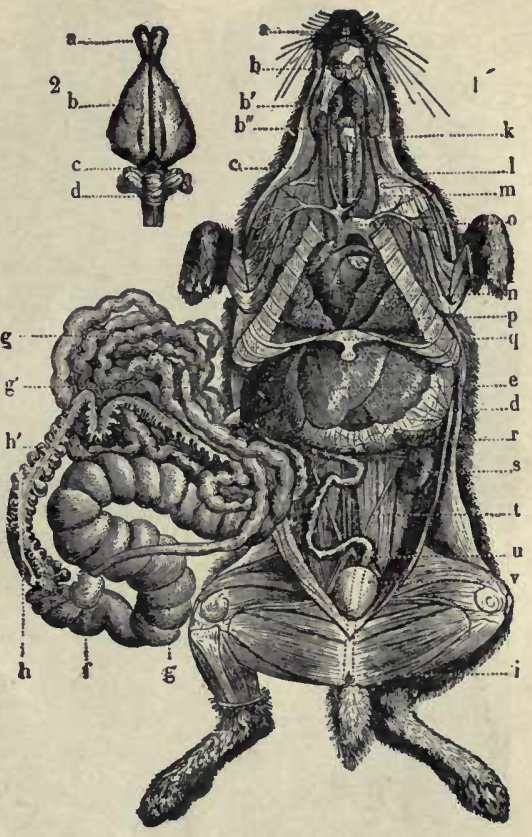

Table for Review

\begin{tabular}{|c|c|c|c|c|c|c|c|}
\hline & FisH & Frog & Turtle & BIRD & CAT & HORSE & MAN \\
\hline \multicolumn{8}{|l|}{ Names of limbs } \\
\hline \multicolumn{8}{|l|}{ Acutest sense } \\
\hline \multicolumn{8}{|l|}{$\begin{array}{l}\text { Digits on fore } \\
\text { and hind limb }\end{array}$} \\
\hline \multicolumn{8}{|l|}{ Locomotion } \\
\hline \multicolumn{8}{|l|}{ Kind of food } \\
\hline Care of young & & & & & & & \\
\hline
\end{tabular}




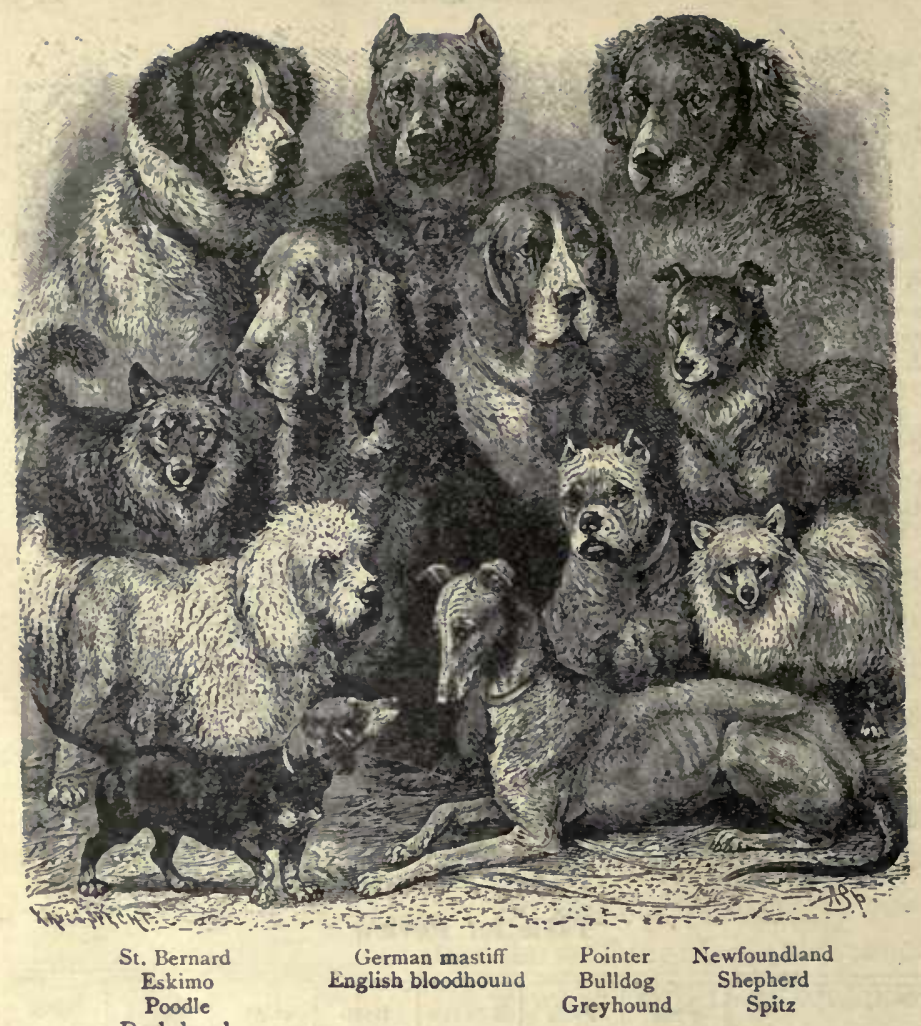

FIG. 408. - ARTIFICIAL SELECTION. Its effects in causing varieties in one species. Which of the dogs is specialized for speed ? Driving cattle? Stopping cattle? Trailing by scent? Finding game? Drawing vehicles? Going into holes? House pet? Cold weather? In Mexico there is a hairless dog specialized for hot climates. The widely differing environments under various forms of domestication cause "sports " which breeders are quick to take advantage of when wishing to develop new varieties. Professor $\mathrm{De}$ Vries by cultivating American evening primroses in Europe has shown that a sudden change of environment may cause not only varieties but new species to arise. 


\section{HUMAN BIOLOGY}

\section{CHAPTER I \\ INTRODUCTION}

To which branch of animals does man belong? To which class and order in that branch? (Animal Biology, pages $125,193$.$) There is no other animal species in the$ same genus or order with man. This shows a wide physical difference between man and other animals, but man's mind isolates him among the other animals still more.

The human species is divided into five varieties or races: I. Caucasian (Fig. I).

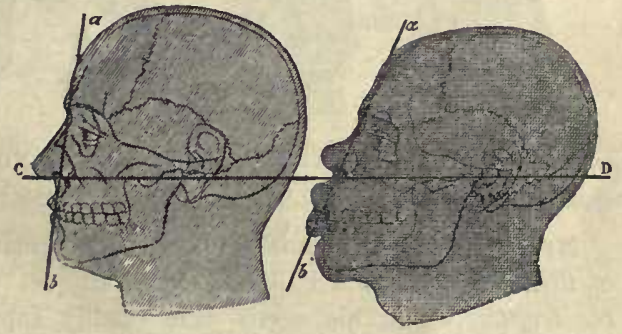

Fig. I. - Facial ANGles of Caucasian (nearly $90^{\circ}$ ) and Ethiopian $\left(\right.$ about $70^{\circ}$ ). The angle between lines crossing at front of upper jaw near base of nose, one line drawn from most prominent part of forehead, the other through hole of ear.

Skin fair, hair wavy, eyes oval. (Europe except Finns and Lapps, Western Asia, America.) 2. Mongolian. Skin yellow, hair straight and black, face flat, nose blunt, almond eyes. (Central Asia, China, Japan, Lapps and Finns of Europe, Eskimos of North America.) 3. Americans. Skin copper red, hair straight, nose straight or arched. (North and South America.) 4. Malay. Skin brown, face flat, hair black. (Australia and Islands of Pacific.) 5. Ethi- 
opian (Fig. I). Skin dark, hair woolly, nose broad, lips thick, jaws and teeth prominent, forehead retreating, great toe shorter than next toe and separate. (Africa, America.)

There is a struggle between the races for the possession of different lands. The Caucasian is gaining in Australia, Africa, and America. With difficulty the Mongolians are kept from the western shores of America. The Ethiopian in America shows a lessened rate of increase every decade; this may be due to the tendency of the race to crowd into cities and the strain of suddenly changing from jungle life in less than two centuries. Civilization is a strain upon any race. It is destroying the American Indian. The Mongolian and Caucasian survive civilization best, but insanity is increasing rapidly among the latter.
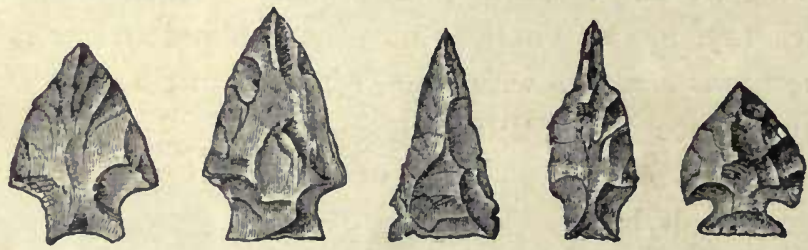

Fig. 2. - INDIAN WEAPONS: LANCE AND ARROW HeADS.

From a bank of mussel shells (remains of savage feast) at Keyport, N.J.

Man's Original Environment. - Primitive man lived without the use of fire or weapons other than sticks or stones. His first home was in the tropics, where his needs were readily supplied, and probably in Asia. Many nations have a tradition of a home in a garden (Greek, paradisos). His food was chiefly tree fruits and nuts. When because

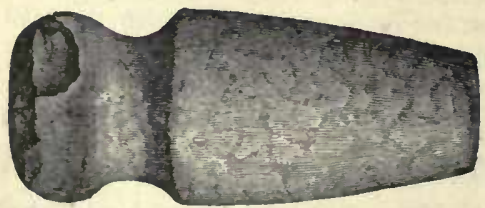

Fig. 3. - Indian Tomahawk. Polished Stone. Keyport, N.J. of crowding he left nature's garden, he acquired skill in hunting and fishing and the use of fire that flesh might supplement the meager fruits of colder climates. His weapons were of rough (chipped) stone at first - in the old stone age. In this age the mammoth lived. He learned to polish implements in the new stone age. The Indians were in that stage when Columbus came to America (Figs. 2, 3). The cultivation of grain and the domestication of animals probably began in this age. The bronze and iron ages followed the stone age. 
The Reaction between Man and his Environment. - The estimates by various geologists of the time man has existed as a species vary from 20,000 to 200,000 years. The active life out of doors which man led for ages (Fig. 4) has thoroughly adapted his body only for such a life. Now steam and other forces work for him, and his muscles dwindle; his lungs are seldom fully expanded, and the unused portions become unsound; he lives in tight houses, and the impure air makes his blooa impure and his skin delicate; he eats soft concentrated food, and his teeth decay and his too roomy food tube becomes sluggish. His nerves and brain are fully active and they become unsound from overwork and impure blood. ${ }^{1}$

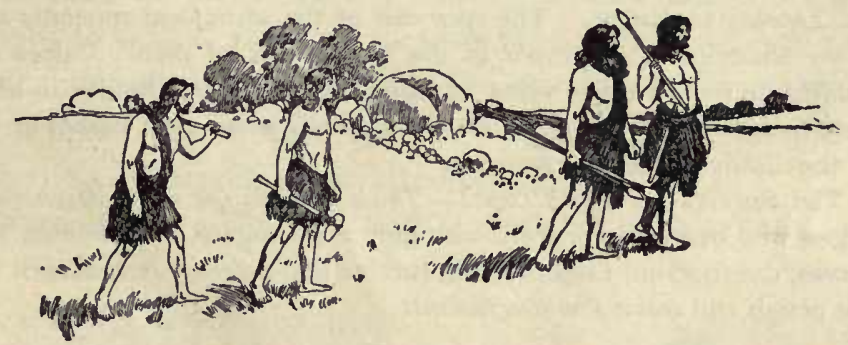

FIG. 4. - PrIMITIVE MAN, showing clothing and weapons of chase and war.

Degeneration of Unused Parts. - Several facts just stated illustrate the biological law that disuse causes degeneration.

Man's Modification of his Environment. - The energy of the world, whether of coal, waterfall, oil, forest, or rich soil, has the sun as its source. All of these are being destroyed by man, often with recklessness and wantonness. The promised land which "flowed with milk and honey" is now almost a desert. Other examples are Italy, Carthage, Spain. The destruction of forests causes floods which wash away the soil. It is estimated that there are only one fourth as many song birds in the United States as there were fifteen years ago. Insects and weeds or deserts replace rich soil, noble quadrupeds, singing birds, and stately trees. Many farmers, however, preserve the fertility of the soil.

To the erect posture is due man's free use of his hands and the coöperation of hands and senses. This has given man his intellectual

1 It has been prophesied that the future man will be a brownie-like creature with near-sighted eyes, shrunken body, slim little legs and arms, large hairless head, toothless gums, a stomach using only predigested food, muscles suited only to push an electric button or pull a lever, and mind very active. But this disregards the indispensable need of a sound mind for a sound body. There cannot even be a play of emotion without a change in the circulation. 
development. The erect position has given greater freedom to the chest. Man uses fewer organs of locomotion than any other animal. The opossum has two hands, but they are on the hind limbs. The ape has four hands, but must use them all in locomotion. (What is a hand ?) The erect position, however, makes spinal deformity easier to acquire, and the whole weight being upon one hip at each step man is liable to hip-joint diseases. In the horizontal trunk the organs lie one behind another; in man they lie one upon another, and are more liable to crowding and displacement. The prone position in sickness helps to restore them. Large blood vessels at neck, armpits, and groins, which occupy protected positions in quadrupeds, are held to the front and exposed to danger. The open end of the vermiform appendix and of the windpipe are upward in the erect trunk of "man. Valves are lacking in some vertical veins and present where little needed in horizontal veins. But the freedom of the hands more than makes up for all the disadvantages of erectness.

The Survival of the Fittest. - Those who do not work degenerate. Those who overwork, or work with only a few organs, as the brain and nerves, degenerate. The workers survive and increase in numbers, the idle perish and leave few descendants.

What rate of adjustment to new environment is possible for man? This has not been ascertained; it is probably much slower than has been generally imagincd. The natives of Tasmania, New Zealand, and many of the Pacific Islands became extinct in less than a century after adopting clothing and copying other habits from Europeans. Life in the country in civilized lands differs less from the environment of primitive man than does life in cities. Cities have been likened to the lion's cave in the fable, to which many tracks led, but from which none led. The care of health in cities is now making rapid strides along the biological basis of purer air, more open space, less noise, simple food, and pure water. Biology, by supplying as a standard the conditions which molded man's body for ages, furnishes a simple and sure basis for hygiene. To mention one instance among many, man blundered for centuries in attempting the cure of consumption, and well- 
nigh gave up in despair. Yet it has recently been shown that if the sufferer returns only in a measure to the open. air habits of his remote ancestors, tuberculosis is one of the most preventable of diseases. The biological guide to health is surer and simpler than tinkering with drugs, fussing with dietetics, and avoiding exposure. Man is of all animals least thoroughly adjusted to his environment, because of his continual and rapid progress. Disease may be defined as the process by which the body adapts, or attempts to adapt, itself to so sudden a change of environment that some organ has failed to work in harmony with the others. By disease the body comes into adjustment with the new condition, or attempts to do so.

Protoplasm. - The life and growth of man's body, as the life and growth of all animals and plants, depend upon the activity of the living substance called protoplasm, as manifested in minute bodies called cells. In fact, protoplasm cannot exist outside of cells. The cells of the human body and their relation to the body as a whole will next be considered.

The Ameba. - Of all the animal kingdom, the minute

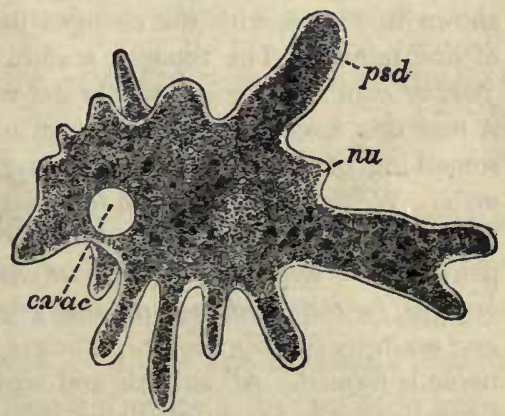

FIG. 5. - AN AMEBA, highly magnified. $n u$, nucleus; $\not p d$, false foot. creatures that can be seen only with a microscope are most different from man. One of the most interesting of these is the $a-m e^{\prime} b a$ (Fig. 5 ; spelled also amaba, see Animal Biology, Chap. II). A thousand of them placed in a row would hardly reach an inch. Some may doubt whether the ameba is a complete animal. Study the figures of it, and no head, or arms, or legs, or mouth can be found. It appears, when still, to be merely a lump of jelly. But the ameba can push out any part of its body as a foot, and move slowly by rolling its body into the 
foot. It can put out any part of its body as an arm, and take in a speck of food; or, if the food happens to be near, the ameba can make a mouth in any part of its body, and swallow the food by closing around it (Animal Biology, Fig. 12). The ameba has no lungs, but breathes with all the surface of its body. Any part of its body can do anything that another part can do. When the ameba grows to a certain size, it multiplies by squeezing together near the middle (Animal Biology, Fig. 13) and dividing into two parts. Amebas have not been observed to die of old age; starvation and accident aside, they are immortal.

The Ameba and Man Compared. - The microscope shows us that the skin, the muscles, the blood, - in fact, all parts of the body, - contain
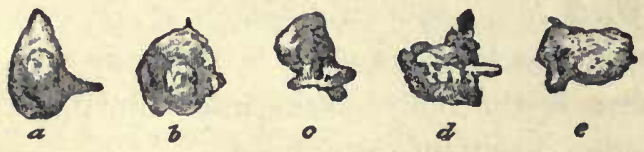

Fig. 6. - A White Blood Cell, magnified; forms noticed at intervals of one minute.

numberless small parts called cells. These cells are continually changing with the activities of the body. One of the most interesting kinds of cells we shall find to be the ruhite blood cells, or corpuscles. One is shown in Fig. 6, with the changes that it had undergone at intervals of one minute. The thought readily occurs that these cells, although part of man's body, resemble the ameba that lives an independent life. A man or a horse or a fish - in fact any animal not a protozoan - has something of the nature of a colony, or collection, of one-celled animals. We are now prepared to understand a little as to how the body grows, and how a cut in the skin is repaired. The cells take the nourishment brought by the blood, use it, and grow and multiply like the ameba. Thus new tissue is formed. All animals and vegetables - that is to say, all living things - are made of cells.

A living cell always contains a still smaller body called a nucleus (Fig. 7). There is sometimes a small dot in the nucleus, called the nuclcolus. The main body of

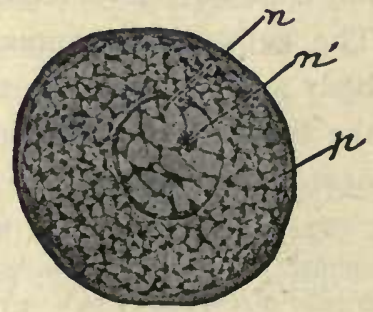

FIG. 7. - DIAGRAM OF A CELL.

P, protoplasm; $n$, nucleus; $n^{\prime}$, nucleolus. the cell consists of the living substance called protoplasm, containing nitrogen. Usually, but not always, there is a wall 
surrounding the cell, called the cell wall. Workers with the microscope found long ago that animals and plants are constructed of little chambers which they called cells. It was found later that the soft contents in the little chambers is of more importance than the walls which the protoplasm builds around itself. A living cell is not like a cell in a honeycomb or a prison. In biology we define a cell as a bit of protoplasm containing a nucleus. No smaller part of living matter can live alone. The protoplasm of the nucleus is called nucleoplasm; the rest of the protoplasm is called cytoplasm.

A fiber is threadlike, and is either a slender cell (Fig. 8), a slender row of cells (Fig. IO), or a branch of a cell. A

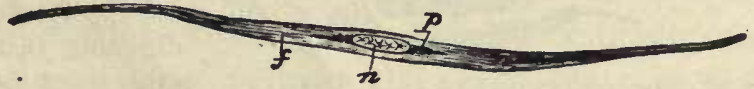

FTG. 8. - A CELL (from involuntary muscle), so slender that it is called a fiber.

tissue is defined as a network of fibers or a mass of similar cells serving the same purpose, or doing the same work. A membrane is a thin sheetlike tissue.

The Nature of the Human Body. - The human body is $a$ community of cells, and may be compared to a community of people. It is a crowded community, for all the citizens live side by side as they work. They are so small that it takes several hundred of them to make a line an inch long. We should never have suspected the existence of cells had it not been for the microscope; but now we know that they eat and breathe and work and divide into young cells which take the place of the old ones.

A child that is born in a community of people may become a railroad man and carry food and other freight from place to place; so, in the great community of cells (see Fig. 9) making up the human body, the red blood cells, like the railroad man, are employed in carrying material from place to place. But the community is old-fashioned, for the 
citizens build canals instead of railroads for their commerce (see Fig. 84). Just as a child may grow up to be a farmer and aid in the conversion of crude soil into things suitable for the use of man, so the digestive cells take the food we eat and change it into material with which the cells can build tissue. Some of the citizens of a community must, at times, take the part of soldiers and policemen, and protect the

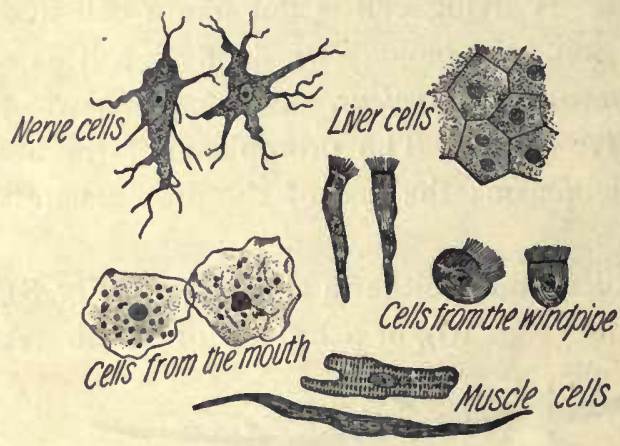

Fig. 9. - Various Cells of the body. (Jegi.) Tiny citizens of the bodily community. community against the attacks of enemies. The white blood cells, already referred to, may be called the soldiers; for they go to any part attacked by injurious germs, a particle of poison, or other enemy, and try to destroy the enemies by devouring or digesting them. At other times they help to repair a break in the skin. If a splin-

ter gets into the skin, the white blood cells form a white pus around the splinter and remove it. In fact, the white blood cell has been referred to as a kind of Jack-at-all-trades. In the human community there are certain persons who reach the positions of teachers, lawmakers, and governors; they instruct and direct the other members of the community. Just so, in the community of cells, there are certain cells called nerve cells (see Fig. II) that have the duty of governing and directing the other cells. The nerve cells are most abundant in the brain. Large cities must have scavengers. Likewise in the human body, a community composed of millions of cells, there are certain cells in the skin and the kidneys which have this duty. They are continually removing impurities from the body. ${ }^{1}$

Division of Labor. - There is a great advantage in each cell of the human body having its special work, instead of having to do everything for itself, as each ameba cell must do. Under this system each cell can do its own work better than a cell of any other kind can do it. Among wild tribes

'From Coleman's "Hygienic Physiology," The Macmillan Co., N.Y. 
there is very little division of labor. Each man makes his own weapons, each knows how to weave coarse cloth, how to cook, how to farm, etc. Savages do not have as good weapons as do people who leave the making of weapons to certain men whose special business it is. What kind of pocketknives or pencils do you think the boys of this country would have if each boy had to make his own pocketknife or pencil? What kind of scissors and thread would the girls have if each girl had to make them herself? Our muscle cells can contract better than the ameba; the cells in the lungs can absorb oxygen better than the ameba. We have just as great an advantage in digestion, feeling, and other processes; for the ameba eats without a mouth, digests without a stomach, feels without nerves, breathes without lungs, and moves without muscles. Division of labor between the sexes also occurs among the higher animals. Those who desire that man and woman should have the same education and work would violate the biological law of "progress by specialization," which could only cause race degeneration.

A part of the body which is somewhat distinct from surrounding parts, and has special work to do, is called an organ; the special work which the organ does is called its function. The eye is the organ of sight. The skin is an organ; its function is to protect the body. This book will treat of (I) the structure, appearance, and position of each organ, or anatomy; (2) the function of each organ, or physiology; (3) the conditions of health for each organ, or hygiene; (4) the conditions under which each organ worked in the primitive life of the race; (5) the effects of change of environment ; 6 ) the anatomy of man compared with the lower animals. (5) belongs to the science of Ecology. These sciences are parts of the science of Biology. 


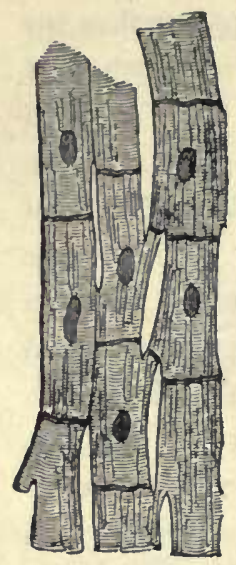

FIG. IO. - THREE MUSCLE FIBERS from the heart (showing the nuclei of six cells).

The Tissues. - As the organs have dif. ferent functions, they must have differens structures that they may be adapted to their work. Just as a house must have brick for the chimney, shingles for the roof, and nails to hold the timbers and other parts together, so the body has various tissues to serve different purposes. The bones must not be constructed like the muscles, and the muscles cannot be like the skin. The chief work of the cells is to construct the tissues and repair them. During life changes are constantly going on. Careful little workmen are keeping watch over every part of the body; thrifty little builders are busy in repairing and restoring. No sooner is one particle removed than another takes its place. In one direction the cells, acting as undertakers, are hurrying away matter which is dead; in the other direction the unseen builders are filling the vacant places with matter that is living.

The Seven Tissues. - There are seven kinds of tissues. Two of them, the muscular and nervous tissues, are called the master tissues, since they control and expend the energies of the body. The other five tissues are called the supporting tissues, since they supply the energy to the master tissues, support them in place, nourish and protect them.

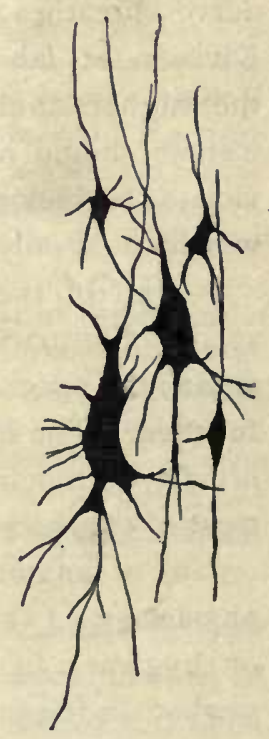

FIG. xx. - NERVE CELLS, showing their branches interlacing. 
The Master Tissues. - The muscular tissue consists chiefly of rows of cells placed end to end (Fig. IO). These cells have the remarkable property of becoming broader and shorter when stimulated by impulses from nerve cells

The nerve tissue consists of cells with long, spiderlike branches (Fig. II). Some nerve cells have branches several feet long, so long that they go from the backbone to the foot. The branches are called nerve fibers (Fig. 142). Nerve fibers which carry impulses to the nerve

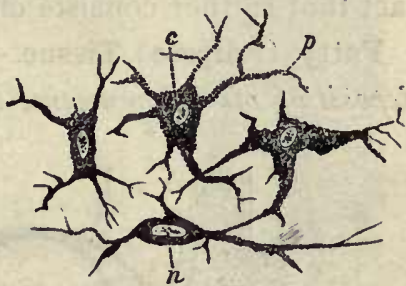

Fig. I2,- Connective Tissue Cells, removed from among the fibers of Fig. I3. cells are called sensory fibcrs. The nerve fibers which carry impulses from the nerve cells are called motor fibers. The organs are set to work by impulses through the motor fibers. Besides these two master tissues there are five supporting tissues.

Connective tissue, like all other tissues, contains cells (see Fig. I2), but it consists chiefly of fine fibers. These fibers are of two kinds, very fine white fibers which $n, c$, nucleus; $p$, branches;

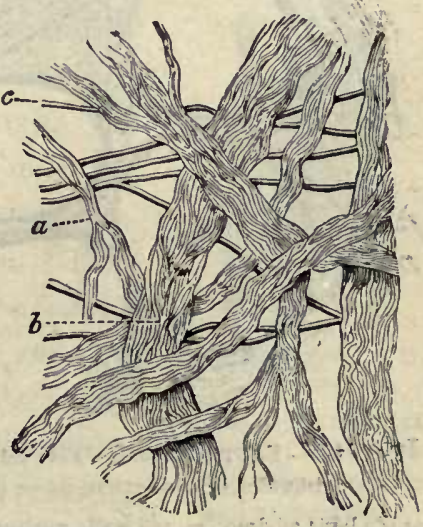

Fig. I3. - Connective Tissue FIBERS.

$a, b$, bundles of white fibers; $c$, a yellow fiber. are inelastic, and larger yellow fibers which are very elastic (see Fig. 13). Connective tissue is found in every organ, binding together the other tissues and cells. It is interwoven among the muscle cells, and the tendons at the 
ends of the muscles are composed almost wholly of it. If every other tissue were removed, the connective tissue would still give a perfect model of all the organs. How abundant this tissue is in the skin may be known from the fact that leather consists entirely of it.

Fatty (Adipose) Tissue. - Fatty tissue is formed by the deposit of oil in connective tissue cells (see Fig. 14). Fat is

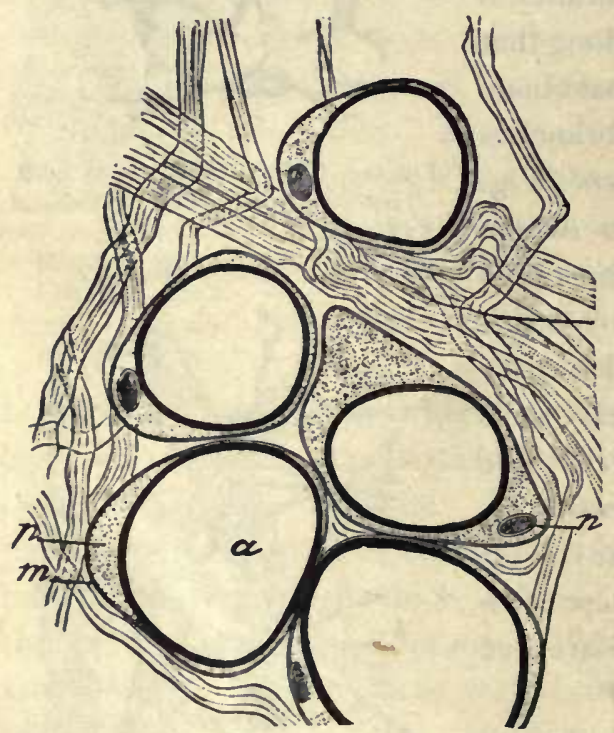

Fig. I4. - FATTY Tissue. Five fat cells, held in bundles of connective tissue fibers.

$a$ is a large oil drop; $m$, cell wall; nucleus $(x)$ and protoplasm $(\beta)$ have been pushed aside by oil drop $(\alpha)$. held in meshes of connective tissue fibers. That fatty tissue consists not alone of fat, but of fibers also, is shown when hog fat is rendered into lard, certain tough parts called "cracklings" being left. What is the difference between beef fat and tallow?

Epithelial tissue consists of one or more layers of distinct cells packed close together (see Fig. I 5). It contains no connective tissue or other fibers, and is the simplest of the tissues. Epithelial tissue forms the outer layer of the skin, called the epidermis, and the mucous membrane lining the interior of the body. It contains no blood vessels, the epithelial cells obtaining their nourishment from the watery portion of the blood which soaks through the 
underlying tissues. Epithelial cells are usually transparent; for instance, the blood is visible beneath the mucous membrane of the lips. The finger nails are made of epithelial cells, and they are nearly transparent.

There are two classes of epithelial cells; one class forms protective coverings (Fig. I 5); the other class forms the lining of glands (Fig. 16). Glands are cavities whose lining of epithelial cells (Fig. I7) form either useful fluids called secretions to aid the body in its work, or harmful fluids called excretions to be cast out, or excreted. Most glands empty their fluids through tubes called ducts.

Cartilag'inous tissue is tough, yet elastic. Cartilage or gristle may be readily felt in the ears, the windpipe, and the lower half of the nose. This tissue consists of cartilage cells embedded in an intercellular substance through which run connective tissue fibers (see Fig. I8). If yellow fibers predominate, the cartilage is yellow and very elastic, as in the ear; "if white fibers predominate, it is white and less elastic, as in the pads of gristle between the bones of the spinal column. Cartilage is to prevent jars, and, in movable joints, to lessen friction.

Bony (Osseous) Tissue. - Solid bone is seen under the microscope to contain

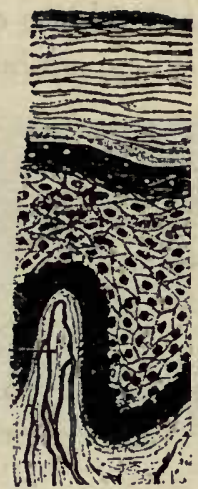

FIG. 15.- EPITHELIAL Tissue (epidermis of skin, magnified).

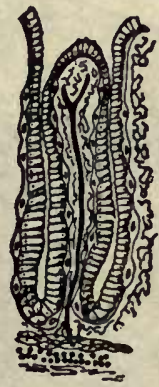

FIG. I6. - EPITHELIAI Tissue; cells forming two glands in wall of stomach.

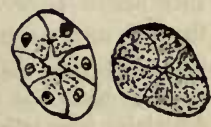

FIG. 17.-SIX GLAND Celus: at left, shrunken after activity ; at right, rested, full of granules: 
many minute cavities (Fig. 19). In these cavities the bonc cells lie self-imprisoned in walls of stone; for these cells

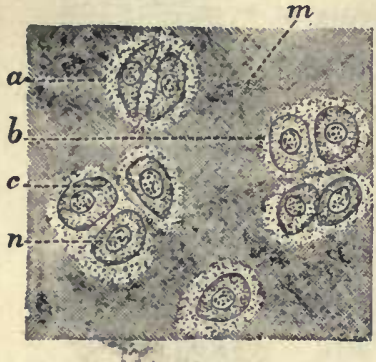

Fig. 18. - CARTILAGINOUS

Tissue. A thin slice highly magnified.

$a, b, c$, groups of cells; $m$, inter. cellular substance.

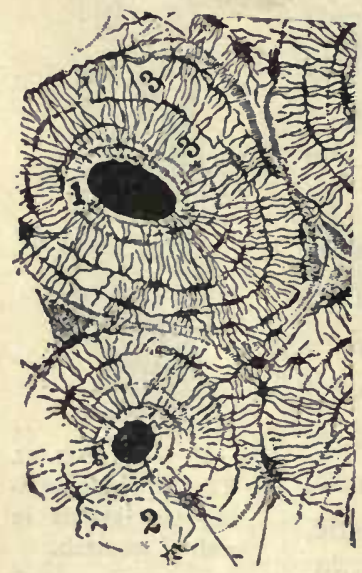

Fig. 19. - Bony TISsue. Thin slice across bone, as viewed through microscope.

Larger blood tubes pass through the large holes $(\mathrm{x})$; the cavities containing bone cells lie in circles, and are connected by fine tubes ( 3 ) with the larger tubes.

work without oxygen. have formed the bone by depositing limestone and phosphate of lime around themselves. There are minute canals (3, Fig. 19), however, through which nourishment comes to the cells. The watery portion of the blood passes - through these small canals from the blood vessels that flow through the larger canals (I, Fig. I9). Bone cells may live for years, although some of the other cells of the body live only a few hours.

New cells to repair the tissues are formed by subdivision of the cells, as with the ameba. Unlike protozcans, many-celled animals are mortal because the outer cells prevent the deeper cells from purifying themselves perfectly and obtaining pure food and oxygen. Even the arteries of an old man become hardened by the deposit of mineral matter which the body has been unable to excrete.

The body is kept alive ani warm by burning, or oxidaticn. One fifth of the air is oxygen gas. We breathe it during every minute of our existence. It is carried by the blood to all the tissues. Not one of the cells could Without it the body would soon be cold and dead, for oxygen keeps the body alive and warm 
by uniting in the cells with sugar, fat, and all other substances in the body except water and salt. Oxygen burns or consumes the substances with which it unites, and the process is called oxidation. Hence the cells have to be continually growing and multiplying to repair the tissue and replace the material used up by oxidation. Sugar and flour and fat oxidize, or burn, outside of the body, as well as in it, as can be proved by throwing them into a fire. Water and salt are two foods that do not burn. Hence they can furnish no heat or energy to the body. Water puts out a fire instead of helping it, and so does salt. Throw salt into a fire or on a stove; it will pop like sand, but will not burn.

The cells need the oxygen of fresh air; they need food for the oxygen to unite with, but they are injured by many substances called poisons. Arsenic destroys the red blood cells. Strychnine attacks the nerve cells in the spinal cord. Alcohol attacks the epithelial cells lining the stomach and, when it is absorbed, attacks the nerve cells and other cells. Morphine attacks the nerve cells.

WritTEN EXERCISES. - Draw a series of seven pictures to show the seven tissues (Figs. 10, 14, 15, 18, 19). Write the "Autobiography" of a White Blood Cell (see also pages 59 and 68). The Rewards of Caring for the Health. Health and the Disposition. Which is more important, a Thorough Knowledge of Geography or of Physiology? Five Things which people Value above Health (and lose health to obtain). The Blessings that follow Good Health. The Tissues Com pared (function, proportion of cells, intercellular material and fibers, activity, rate of change).

See also pages 50, i16. Pupils should choose their own subjects. 


\section{CHAPTER II}

\section{THE SKIN}

Note TO TEACHER. - The experiments should be assigned in turn to the pupils as each chapter is reached: e.g. this set of 13 will leave 3 pupils in a class of 39 to stand responsible for each experiment. Each pupil should do the work separately and credit may be given for the best results. Encourage (or require) each pupil to try every experiment and record them in a note book.

Experiment 1. (At home or in class.) Albinism. - Study a white rabbit as an example of albinism. Does albinism affect only the skin? What evidence that its blood is of normal color?

Experiment 2. Use of Hairs on the Skin. - Let one pupil rest his hand upon the desk behind him while another touches a hair on his hand with a pencil. He should speak at the moment, if it is felt. Do the hairs increase the sensitiveness of the skin? What was their use with primitive man? Are the hands of all your acquaintances equally hairy? Are the hairs to be classed as rudimentary? Will they disappear? Will the race become baldheaded?

Experiment 3. (Home or school.) Invisible Perspiration. - Hold a piece of cold glass near the hand or place the cheek near a cold window pane and notice for evidence of moisture. Its source?

Experiment 4. - Effect of Evaporation on Temperature. - Read a thermometer and cover its bulb with a moist cloth. Read again after twenty minutes. Repeat experiment in breeze.

Experiment 5. Moisten one hand and allow it to dry. Touch the other hand with it. Explain result.

Experiment 6. Absorbing Power of Fabrics. - Wet the hands and dry them upon a piece of cotton cloth. Repeat with woolen, linen, and silk. Arrange in list according to readiness in absorbing water.

Experiment 7. Rates of Drying. - Immerse the cloths in water and hang them up to dry. Test their rates of drying with dry powder or by touch.

Experiment 8. Test Looseness of Weave of above cloths by measuring the distance pieces of equal length will stretch.

Experiment 9. Does Cotton or Wool protect better from Radiant Beat? - Lay a thermometer in the sun for ten minutes, first covering 



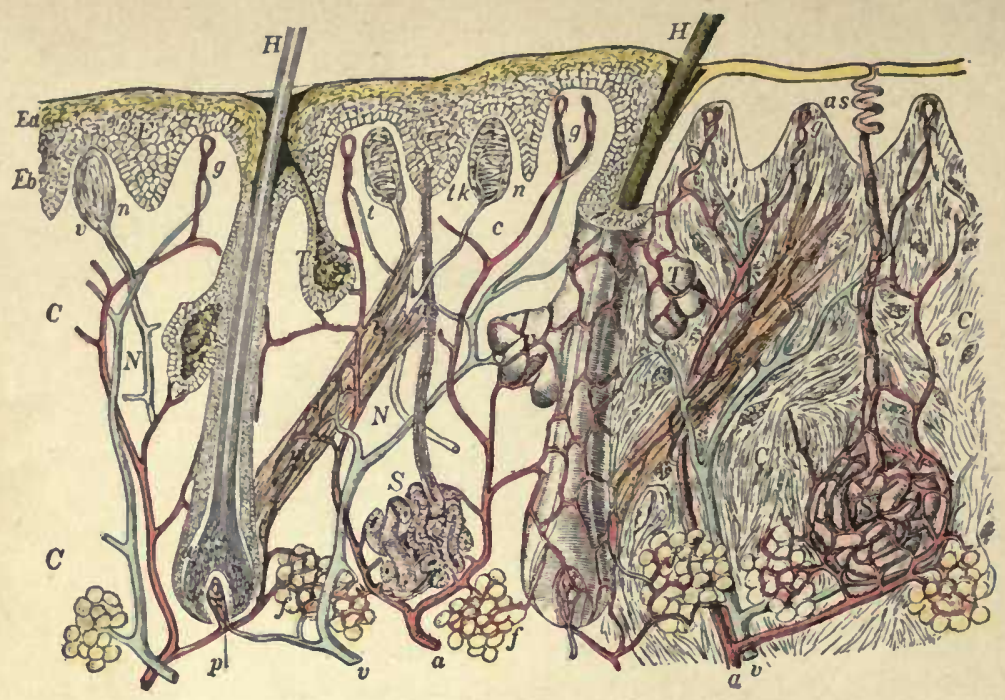

Colored Figure I. - SECTion of Skin. (diagram, enlarged 25 times). On the left the connective tissue fibers of the true skin are shown.

In cutis (c), or dermis, find capillaries, nerve fibers, fat cells, two sweat glands and ducts, four oil glands (two in section), two hairs, three nerve papilla, fize papilla containing capillaries, two muscles for erecting hairs. In epidermis find flat cells, round cells, and pigment cells.

FIG. 2.- WHERE

THE FOOD IS ABSORBED (villus of intestine).

FIC. 3. - WHERE

THE FOOD IS

USE.D (cells with lymph spaces).

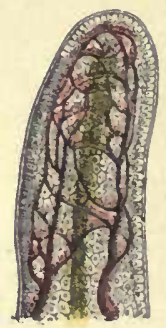

FIG. 2.

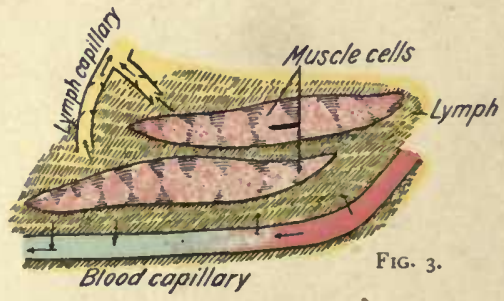

$i, j$, jaws ; ol, nerve of smell;

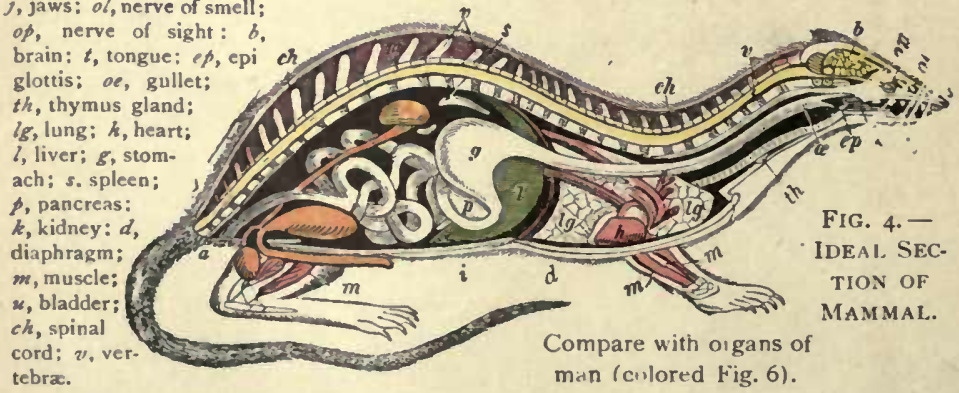


it with a woolen cloth. Note change in reading. After it regains first reading, repeat, covering it with a cotton cloth of same weight and texture? Conclusion? Expose wrists or arms to sun for five minutes, one protected by the cotton, the other by the wool. Result ? Conclusion?

Experiment 10. Rates of Heat Absorption and Radiation by Different Colors. - Expose thermometer to sunlight, covered successively by pieces of cloth of same thickness, material, and texture. Use black, blue, red, yellow, and white cloth. Note rise of temperature for equal times in each case; also the fall of temperature for equal times after removal to shade.

Experiment 11. Effects of Dry Powders. - Prepare two squares from the same piece of leather (e.g. an old shoe). Moisten them both, and apply face powder to one. Which dries more quickly? Repeat after oiling them. Powder a portion of the face or arm daily for a week and compare with the clean portion.

Experiment 12. Dissect the kidney of an ox or sheep, making out the parts mentioned in the text, p. 26.

Experiment 13. (In class.) Emergency Drill. - Have one pupil wet an imaginary burn on the arm of another, treat it with flour or soda, and bandage. (See text.)

The Skin has Two Layers. - The outer layer is called the epidermis; it is thinner, more transparent, and less elastic than the inner layer, or dermis. The epidermis is composed of epithelial cells packed close together (see colored Fig. I).

The dermis, or inner layer, is a closely woven sheet of connective tissue (colored Fig. I) containing a great number of sweat and oil glands, roots of hairs, blood vessels, absorbent vessels (lymphatics), and nerves (colored Fig. I). The dermis is sometimes called the true skin because it is of greater importance than the epidermis. It is united loosely to the underlying organs by a layer of connective tissue. It is in this layer that fat is stored. The upper surface of the dermis rises into a multitude of projections (see colored Fig. I) called papil'la (singular, papilla). The epidermis fits closely over them and completely levels up the spaces between them except on the palms and the soles. Here the papillæ are in rows, and there is a fine 
ridge in the skin above each row of papillæ (Fig. 24). In the papillæ are small loops of blood vessels and sometimes a nerve fiber (colored Fig. I).

The epidermis is composed of a mass of cells held together by a cement resembling the white of an egg. The cells near the surface are hard and flattened; those deeper down near the dermis are round and soft (see Fig. 2I).

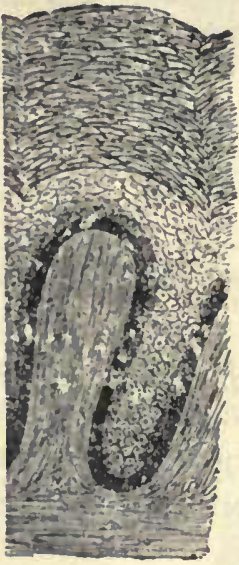

FIG. 20.- EPIDERMIS OF ETHIOPIAN.

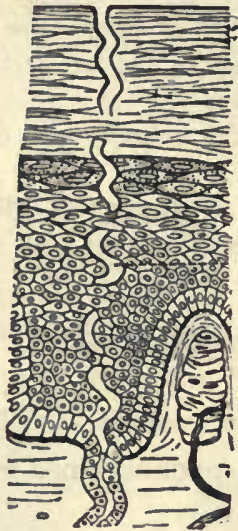

FIG, 2I, -EPIDERMIS of CaUCASIAN.

These cells are living cells. They are kept alive by the nourishment in the watery portion of the blood which soaks through from the blood tubes in the neighboring papillæ. Hence these cells are growing cells; they subdivide when they reach a certain size, and replace those wearing away at the surface, thus constantly repairing the epidermis. The dry outer cells wear away rapidly. They have no nuclei and are dead cells. The new cells forming beneath push them so far away from the dermis that nourishment no longer reaches them, and they die.

Pigment. - The cells in the lower layers of the epidermis contain grains of coloring matter, or pigment. All other cells of the epidermis are transparent; the pigment has the function of absorbing and arresting light. Albinos or animals entirely without pigment have pallid skins and pink eyes (Exp. I). 
Immigrants from a Cloudy to a Sunny Climate. Adaptation. - The cells of the deeper tissues can readily be exhausted by the stimulation of too much light. The sunnier the climate, the greater the need of pigment; hence the dark skin of the negro and the blonde skin and hair of the Norwegian. European immigrants to sunny America will grow darker. The Indian's skin is better suited to our climate than is a fair skin. Brunettes have a better chance for adaptation than blondes. The American type when developed will doubtless be brunette.

The hair grows from a pit or follicle (Fig. 22). Blood vessels and a nerve fiber go to the root or bulb from which a hair grows. The hair will grow until this papilla, or bulb, is destroyed (Exp. 2).

Adaptation of the scalp to a tight warm covering is accomplished through the shedding of the hair rendered useless by the covering. It is impossible to stop the growth of superfluous hair unless the hair papillæ are destroyed with an electric needle, such is the vitality of hair; yet many men, by overheating the head and cutting off the circulation with tight hats, destroy much of the hair before reaching middle age. The health of the hair can be restored and its loss be stopped by going bareheaded except in the

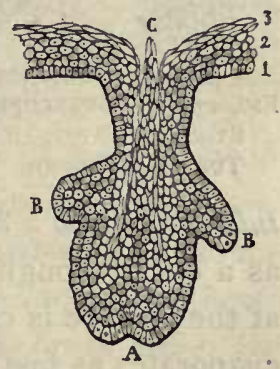

Fig. 22. - Develop. MENT OF A HAIR AND TwO OIL GLANDS. hot sun or in extremely cold weather. This frees the circulation; cold air and light stimulate the cells of the scalp. Some men wear hats, even at night in summer. The brain needs the protection of the hair. Beard protects the larynx or voice box, which is large and exposed in man. It was also a protection in hunting wild beasts and in war. Compare mane of lion, not possessed by lioness. "Goose-flesh" after a cold bath is caused by the contraction of small muscles (colored Fig. I), raising the now tiny hairs in an absurdly useless effort to keep the body warm.

The nails are dense, thick plates of epidermis growing from a number of papillæ situated in a groove, or fold, of the skin; there are many fine papillæ along the bed from which the nail grows. Since it grows from its under side as well as from the little fold of skin at its root, the nail is thicker at the end than near the root. 
The oil glands empty into the hair follicles (colored Fig. I). They form an oil from the blood that keeps the hair glossy

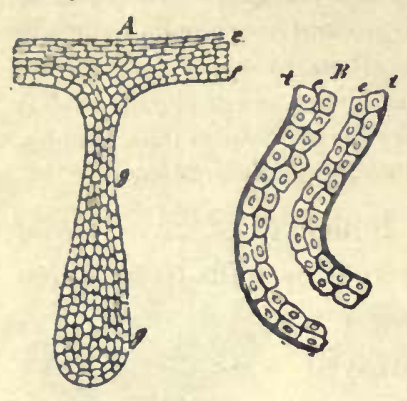

and the surface of the skin soft and flexible by preventing excessive drying. Hair oil should never be used upon the hair, as the oil soon becomes rancid, and besides causes dust and dirt to stick to the hair.

The sweat glands (Fig. 23), FIG. 23. $-A$, DEVELOPMENT OF SWEAT GLAND; $B$, SWEAT TUBE Developed. like the hair bulbs, are deep in the lowest part of the dermis. A sweat gland has the form of a tube coiled into a ball (colored Fig. I). This tube continues as a duct through the two layers of skin, and its opening at the surface is called a pore (Fig. 24). The perspiration evaporates as fast as it flows out through the pores, if the secretion is slow; but if poured out rapidly, it gathers into drops (Exp. 3). The perspiration is chiefly water, containing in solution several salts, including common salt and a trace of a white, crystalline substance called urea. The material for the perspiration is furnished by the blood flowing around the gland in a network of fine tubes. The amount of the perspiration is controlled in two ways: by nerves that regulate the activity of the epithelial cells lining the gland, and by nerves that regulate the size of the blood vessels supplying the gland (Fig. 25).

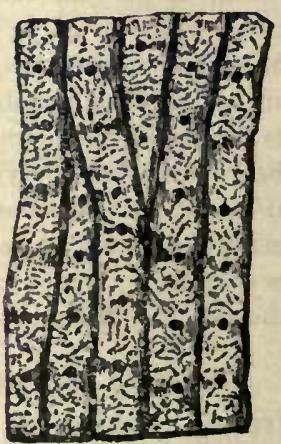

FIG. 24. - PORES on ridges in palm of hand.

Thought Questions. - Freckles, Warts, Moles, Scars, Proud Flesh, Pimples, Blackheads. Use these names in the proper places below :- 
A rough prominerce formed by several papillæ growing through the epidermis at a weak spot and enlarging is called a west Small patches of pigment developing on the hands and face from much exposure to the sun are called 1 . The growth of exposed dermis sprouting through an opening in the epidermis due to accident is called (This should be scraped off and cauterized to aid the epidermis to grow over it again.) Sometimes a cut heals in such a way that no epidermis and therefore no pigment cells cover the place of injury, which is occupied only by white fibrous tissue (cicatricial tissue) of the true skin. In this case the mark left is called a cicatrice or sear. If pores or the openings of oil glands become clogged, but not enlarged, little swellings called may result. An enlarged pore filled with oil and dirt is called a the A spot present since birth, dark with pigment, and often containing hairs and blood vessels, is called a

Regulation of Temperature. - As is well known, rapid running or violent exercise of any. kind causes profuse perspiration. The sweat glands are connected with the brain by means of nerves, and when the body has too much heat, a nerve impulse from the lowest part of the brain causes the sweat glands to form sweat more rapidly. Heat and exercise may cause the activity of the sweat glands to increase to forty times the usual rate. The evaporation of the sweat cools the body, for a large amount of heat is required to evaporate a small amount of water (Exp. 4 and 5). This is shown by the cooling effect of sprinkling water on the floor on a warm day. By fanning we hasten the cooling of the body (Exp. 4).

Exercise tends to heat the body, but it also causes us to breathe faster and causes much blood to flow through the skin. Both of these effects aid in cooling the body, for the cool air is drawn into the lungs, becomes-warm, and takes away heat when it leaves; and the warm blood flowing in the skin loses some of its heat to the cool air in contact with the skin.

Effects of Alcohol upon the Skin. - The more blood goes to the skin, the more blood is cooled. The body 
as a whole may be cooler, but we fecl warmer when there is more blood in the skin bicanse of the effect of the warm blood upon the nerves of temperature. There are no nerves for perceiving temperature except in the skin and mucous membrane, and the body has practically no sensation of heat or cold except from the skin or mucous membrane. That alcoholic drinks make the skin red is commonly noticed. Often the skin is flushed by one drink; the bloodshot eyes and purple nose of the toper are the results of habitual use. Can you explain why alcohol brings a deceptive feeling of warmth? Why does alcohol increase the danger of freezing during exposure in very cold weather? During the chill which precedes a fever, the body (except the skin) is really warmer than usual.

Exercise will relieve internal congestion and send the blood to the skin better than alcohol. This is the effect sought by sedentary people who use it to replace exercise. The long and sad experience of the race with alcohol proves that the attempt to adapt the body to its use should be given up.

Thought QUestions. The Functions of the Skin. - 1. State a fact which shows that the skin is a protection; gives off offensive substances; regulates the temperature. 2. What is lacking in the skin when it cracks or chaps? Why does this occur more often in cold weather? When the hands are bathed with great frequency?

Effects of Indoor and Outdoor Life. - Those who live much out of doors, exposed to sunlight and pure, cold air, are robust and hardy; while those whose occupations keep them constantly indoors, especially if no physical labor is necessary, show by their pale skins, their fat and flabby, or their thin and emaciated bodies, the weakening effect of such a life. We are descended from ancestors who lived in the open air, and it is impossible for a human being to live much indoors without degeneration of the body and shortening of life.

A Well-trained Skin. - We hear a great deal about training the muscles, the brain, the eye, the hand; yet we may fail to realize that 
the skin also can be trained and its powers developed, or it can be allowed to become weak and powerless. Soundness of the skin is as essential to health as soundness of any other organ. A rosy color indicates good health because of a well-balanced circulation. Paleness often means internal congestion and great liability to indigestion, colds, etc. Hence we think a rosy skin beautiful and a pale skin ugly. With the skin in a healthy condition, the danger of taking most diseases is removed.

Characteristics of a Vigorous Skin. - A person who readily takes cold, who is fearful of drafts of air at all times, has a weak skin. To one who has a healthy skin drafts are dangerous only when the skin is moist with perspiration, and the body is inactive; cold drafts may then do harm. Cold air and cold water are the best means of toughening a tender skin. A bath is to the skin what gymnastic exercises are to the muscles. The muscle fibers in the walls of the blood vessels and the nerves controlling them need exercise as well as the rest of the body (Fig. 25).

Importance of Bathing. - If we

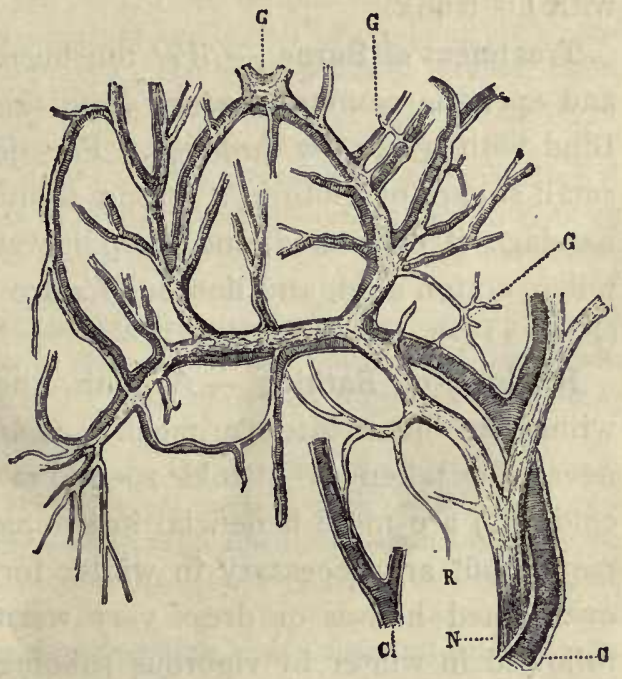
followed the outdoor life and wore

F1G. 25. - BLOON VESSELS, with the VASO-MOTOR NERVES which accompany and control them.

the scanty clothing of savage races, the rains, the cool air, and the sunlight would keep our skins vigorous and sound. But want of exercise to induce perspiration allows the sweat glands to become stopped up. The wearing of clothes is a very uncleanly custom. Clothes make the skin inactive, yet confine the impurities which the weakened skin may still be able to excrete. Thick and 
heavy clothing and overheated rooms prevent the nerves from being stimulated by cold air and sunlight. The best way to counteract these weakening conditions is by frequent cool or cold baths. An air bath, which consists of exposing the bare skin to the air for half an hour or more before dressing in the morning, may take the place of a cold bath. Even the lower animals bathe: birds, dogs, and many lower animals bathe in the rivers. An elephant sometimes takes a bath by showering water over his back with his trunk.

Treatment of Burns. - Wet the burn with a little water and sprinkle common baking soda or flour thickly on it. Bind with a narrow bandage. For deeper burns soak a small square of cloth in a strong solution of baking soda, bandage it on wound, and keep it wet with the solution. Olive, cotton seed, and linseed oils are excellent for burns (Exp. 13).

Hygiene of Bathing. - A bath should not be taken within an hour after a meal. Cold baths (I) should never be taken in a cold room nor when the skin is cold; (2) are more beneficial in summer and in warm climates, but are necessary in winter for those who live in overheated houses or dress very warmly; (3) should be followed in winter by vigorous rubbing and a glowing reaction; (4) should usually not last longer than one minute in winter. Warm baths (I) are more cleansing than cold baths; (2) should not be used alone but should always be followed by a dash of cold water; (3) are better than cold baths if the body is greatly fatigued; (4) are more beneficial when going to bed than upon rising.

Cold baths and very hot baths are both stimulants to the nervous system and cause an expenditure of nervous energy. For one whose nervous energy is at a very low 
ebb cold baths may be weakening if prolonged beyond a few seconds. For one with skin relaxed and body sluggish from indoor life, cool baths arouse activity, tone up the body, and may be as beneficial as outdoor exercise in restoring vigorous health. As with every hygienic measure, each person must find out by experience what suits him best.

Clothing was first employed for ornament. In cold climates it aids in maintaining the uniform temperature of the body; to it man owes his distinction of being the most widely distributed of animal species. Clothing prevents rapid escape of bodily heat by confining air, a nonconductor of heat, in its meshes. Hence, the effect of clothing varies with the weave; likewise with the tendency of its fibers to keep dry, for if water replaces air in the meshes, the body loses heat rapidly. For cool clothing the weave should be hard and tight, for warm clothing it should be soft and loose. The warmth of clothing is affected more by its weave than by its weight. The weave may be tested by stretching; the fabric with softest weave will stretch the most (Exp. 8). Linien makes the coolest of all clothing because it weaves hard with small meshes; silk ranks next in coolness. When warmth is desired, linen or cotton garments should be made of fabrics woven like stockings. Linen and cotton both absorb water rapidly and dry rapidly (Exp. 6); if woolen did also, it would make the warmest of all clothing, but it dries so slowly (Exp. 7) that it cools the body after the activity is over instead of drying rapidly and, as with linen and cotton, keeping the body cool during the exertion (Exp. o). Woolen weaves with the largest air meshes of all materials; hence its warmth increases perspiration, but woolen removes perspiration most slowly and tends to relax the skin if the wearer has an active skin or makes active exertion. Woolen is best for underclothing during extreme cold only or for persons who never make such vigorous muscular exertion as to perspire. In general, cotton or linen is best for underwear. They possess the added advantages of less cost and of not shrinking out of size and shape when washed. A mixture of cotton and silk or of cotton and wool is more durable than either alone. Cotton and linen, unlike woolen, are not attacked by insect pests.

It is better to depend more upon outer clothing than underclothing for warmth. In the Gulf states the wearing of woolen outer clothing indoors during warm weather (which lasts eight months) is unhealthful and uncleanly because of the perspiration absorbed; this is as 
absurd as to wear cotton outer clothing in Northern states during the eight cold months.

Black clothing absorbs twice, blue almost twice, red and yellow almost one and a half times, as much heat as white clothing (Exp. 10). Which material protects best from radiant heat? (Exp. 9.) Because large blood vessels are near the surface at the neck, wrists, and ankles very thin or no covering at those points aids greatly in keeping the body cool. High collars, long sleeves, and high shoes are unhealthful in warm climates and in summer. What objection to black shoes in summer? Patent leather? Show how women dress more sensibly in hot weather than men.

The kidneys are located on each side of the spinal column in the "small of the back" and extend slightly above

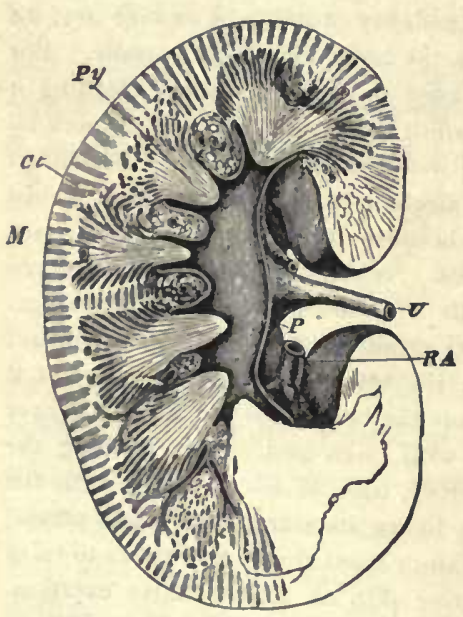

FiG. 26. - SECTION OF KIDNEY.

$R A$, renal artery: $P y$, pyramids surrounding hollow space from which the ureter $(U)$ leads the secretion to the bladder. the level of the waist. They are bean-shaped organs about four inches long (Fig. 26). The kidneys of a sheep or ox closely resemble those of man. They are outside of the peritoneum (Fig. 99) and attached to the rear wall of the abdomen. A large artery (12, colored Fig. 5) goes to each kidney and divides into many capillaries which surround tubules in the kidneys (Fig. 27). The secretion, containing nitrogenous impurities of the blood, is continually being deposited in the tubules, which take it to a funnel-shaped cavity at the inner edge of the kidney (Fig. 26). From this cavity a white tube called the ureter leads down to a storage organ in the pelvis called the bladder. 
Changes in Blood in the Kidneys. The water holding the nitrogenous waste varies in amount with the amount of water drunk and with the activity of the skin, being less in summer when the perspiration is great. The lungs aid the skin and kidneys in disposing of superfluous moisture. The kidneys have almost the entire. responsibility of relieving the body of certain mineral salts and a white crystalline solid called urea. This is very

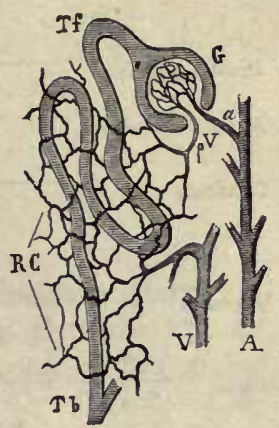

F1G. 27. - PLAN OF A URINARY TUBULE, $T b$, with artery $A$, and $V$ in $p V$.

injurious if retained, causing headaches, rheumatism, and other troubles.

Thought Questions. Hygiene of the Skin. -1 . What kind of a scar is not affected by freckles or tan? 2. Can a scar on a negro be white? 3. Does a scar on a child grow in size? 4. Why is heat most oppressive in moist weather? 5. How do you account for the shape and location of the usua! bald spot? 6. How does the wearing away of the outer cells of the epidermis contribute to the cleanliness of the body? 7. Why does the palm of the hand absorb water more rapidly than the back of the hand? $\mathbf{8}$. Is it more necessary for mental workers to bathe often or change their clothes often? For physical workers? 9. Is cotton or woolen clothing more liable to stretch or shrink out of shape or size? To. catch fire? To make the skin clammy with moisture? To cost nore? To be eaten by moths? 


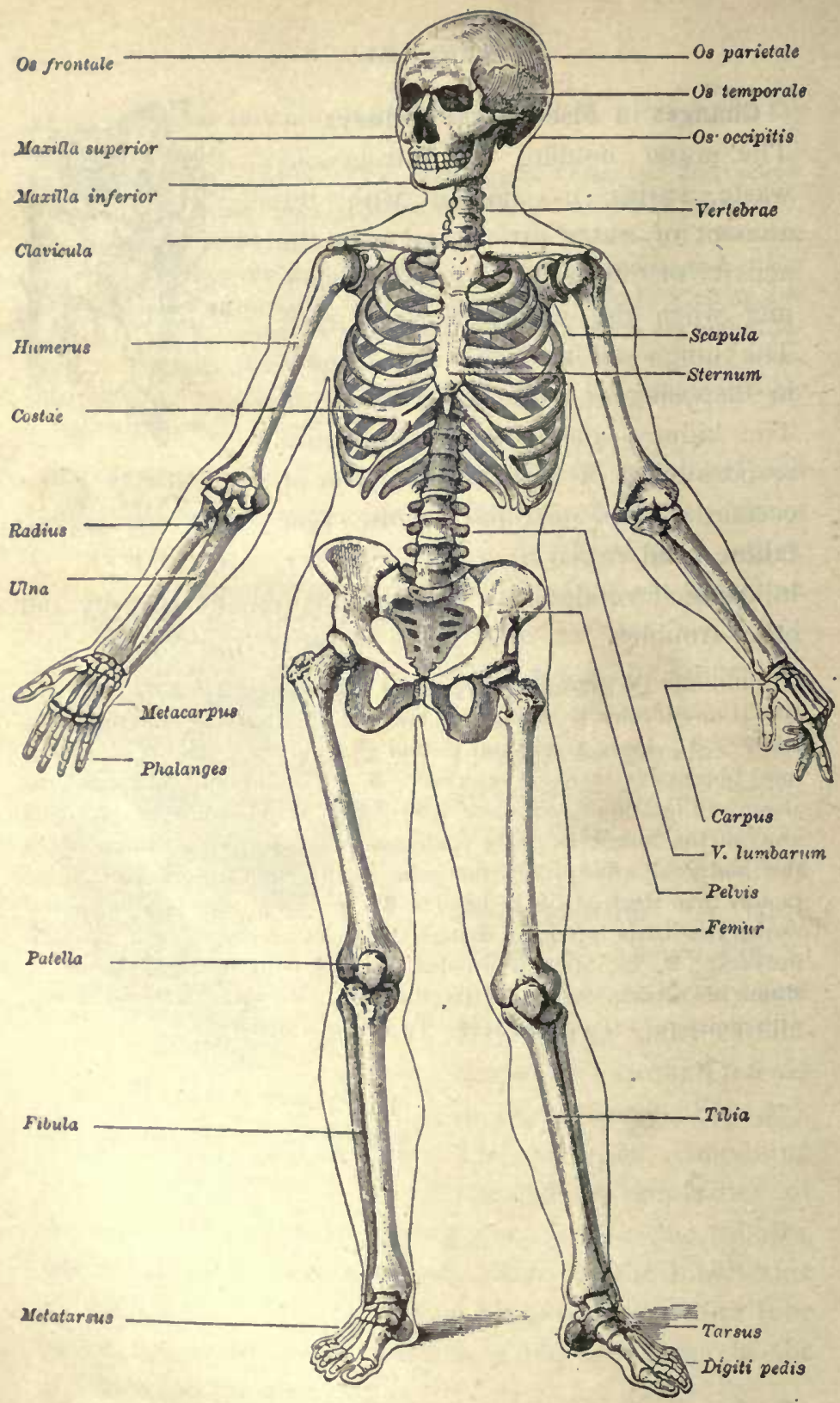

FIG. 28. - THE SKELETON. 


\section{CHAPTER III}

\section{THE SKELETON}

Experiment I. (At home.) Is the Arch of the Foot Elastic?Wet the foot in a basin of water and, while sitting, place the foot flat upon a piece of paper. Draw the outline of the track. Repeat, but stand with your whole weight upon the foot. Draw track. Conclusion? (Take sketches to school. Which sketch shows the flattest foot?) Devise a method for measuring the length of the foot with and without the weight of the body upon it. What difference? Conclusion?

Experiment 2. Composition of Bone. - Place a bone in a hot fire and let it remain for three or four hours. It will keep its shape however long you burn it; but unless you handle it carefully when you take it out, it will crumble to pieces. If not thoroughly burned, the bone will be black from the carbon of the animal matter still left in it. Experiment 3 . Obtain a slender bone like the rib of a hog or the leg bone of a fowl, and put the raw bone into a vessel containing strong vinegar or two ounces of muriatic acid and a pint of water. Leave it there for four days. When the bone is taken out, it can be tied into a knot. The acid may be washed off, and the bone preserved in a bottle of alcohol or glycerine.

Experiment 4. The Forms of Joints. - Obtain the disjointed bones of a fowl or small mammal and place them one at a time in their sockets and study the fit and motion of the joints.

Experiment 5. Pivot Joints. - Through what fraction of a circle do the pivot joints in the forearm and neck allow the hand and head to rotate?

Review Questions. - Where are the bone cells? How does nourishment reach them? How has the mineral part of the bones been deposited? How long may boie cells live? Name animals with outside skeletons. Inside skeletons. No skeleton.

Forms and Uses of Bones. - The three chief uses of bones are protection, motion, and support. In order to fulfill these purposes, the bones must have different sizes, shapes, and positions. The bones are classed by shape, as long, 
fat, and irregular. Those whose chief use is to protect are broad and flat. The bones which furnish support are thick

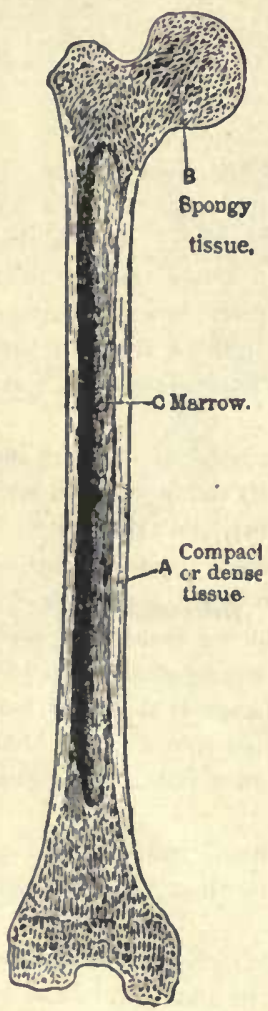

FIG. 29. - FEMUR, sawed lengthwise. The red blood cells are formed in the red marrow of the spongy part. and solid; those designed to aid in motion are long and straight. Including six small bones in the ear, there are two hundred and six bones in the adult skeleton.

Gross Structure of Bones. - The structure of a long bone is shown in Fig. 29. It has a long, hollow shaft of hard, compact bone, and enlarged ends composed of spongy bone. The hollow in the shaft is filled with yellow marrow, which is composed of blood vessels and fat, and aids in nourishing the bone. The long bones are found in the limbs (Fig. 28). The ribs and other flat bones and the irregular bones contain no yellow marrow; they are spongy inside, and hard and compact near

the surface. There is a red marrow in the FroNT VIEW OF cavities in the spongy parts of bones (Fig. 29).

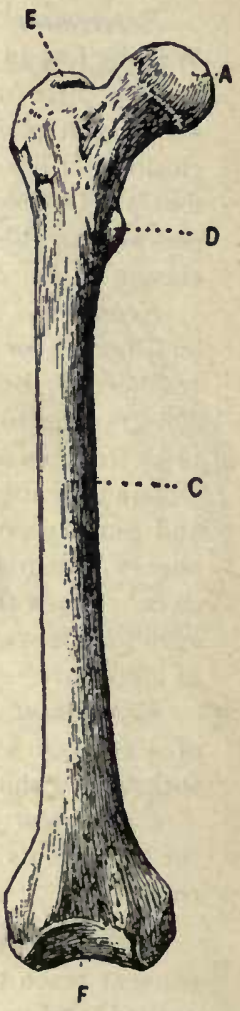
RIGHT FEMUR. New red blood cells are formed in this marrow. The bones have a close-clinging, fibrous covering composed of connective tissue and blood vessels. It is called periosteum. 
Chemical Composition of Bone. - Experiments (2 and 3) show that the bones contain a mineral or earthy substance, which makes them hard and stiff, and a certain amount of animal matter, called gelatine, which binds the mineral matter together and makes the bones tough and somewhat elastic. The fire burned out the animal matter of the first bone, and the acid dissolved out the mineral matter of the second bone. The mineral matter is chiefly lime, and makes up about two thirds of the weight of the bone. (Why is more mineral than animal matter needed?) The animal gelatine is a gristly substance. As the body grows old, the animal matter of the bones decreases, and they become lighter. They are more easily broken and do not heal so readily as the bones of young persons.

The skeleton is subdivided into the bones of the head, trunk, and limbs. The bones of the trunk are those of the spine, the chest, the shoulder blades, collar bone, and hip bones.

The spinal or vertebral column is made up of twenty-six bones (Fig. 31). It is the axis of the human skeleton, to which all other bones are directly or indirectly attached. Animals with inside skeletons have this column, and

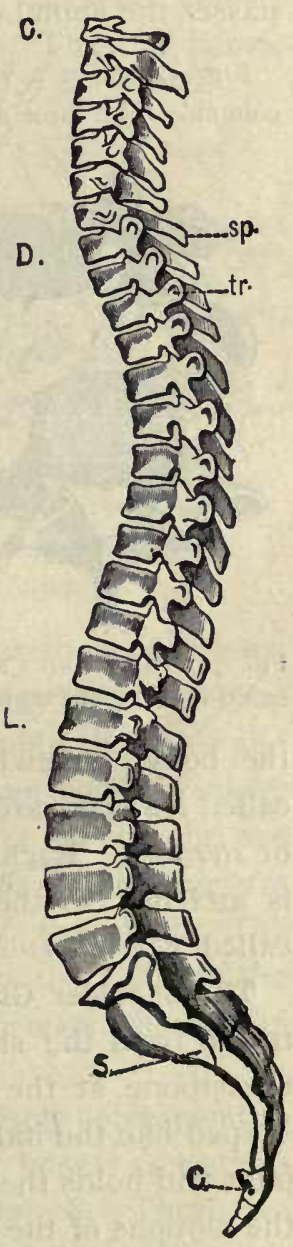

FIG. 3 T. - VERTEBRAL Column, Side view. are called vertebrates. Fish, reptiles, birds, beasts, apes, and man are vertebrates. The spine, as this column is some. 
times called, is not only the main connecting structure and support of the body, but it forms a channel through which passes the spinal cord.

Fig. 32 shows a vertebra, or one of the bones that compose the column. The three projecting points or processes are for the attachment

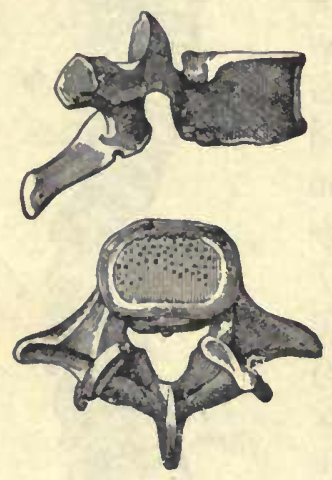

FIG. 32. - SIDE AND UNDER

VIEW OF A VERTEBRA. of ligaments and muscles. The main body of each vertebra is for supporting the weight transmitted by the column above. Just behind this thick body is a half ring (Fig. 32), which with the half rings on the other vertebræ form the channel for the spinal cord. Between the vertebræ are thick pads of gristle, or cartilage, which act as cushions to prevent jars, and by compression allow bending of the spinal column in all directions.

The Chest (see Fig. 75). - The twelve pairs of ribs are attached to the spinal column behind, and extend around toward the front of the body, somewhat like hoops. The first seven pairs, called true ribs, are attached directly to the flat breastbone, or sternum. Each of the next three pairs, called false ribs, is attached to the pair above it. The last two pairs, called floating ribs, are free in front.

The Shoulder Girdle. - The collar bones (Fig. 28) can be traced from the shoulders until they nearly meet on the breastbone at the top of the chest. The collar bone is shaped like the italic letter $f$; it helps to form the shoulder joint and holds the shoulder blade out from the chest that the motions of the arm may be free.

The flat, triangular shoulder blade (Fig. 75) can be felt by reaching with the right hand over the left shoulder. It spreads over the ribs like a fan. Its edges can be made out, especially if the shoulder is moved while it is being 
felt. The high ridge which runs across the bone can be felt extending to the top of the shoulder.

The Pelvic Girdle. - The edges of the hip bones can be felt at the sides of the hips (Fig. 28). The hip bones, with the base of the spine, form a kind of basin called the pelvis.

The skull (Fig. 33) rocks, or nods, on the top vertebra. It consists of the cranium, or brain case, and the bones of the face. The shapes and names of the bones of the skull are shown in Fig. 33.

Adaptations of the Skull for Protection. - Its arched

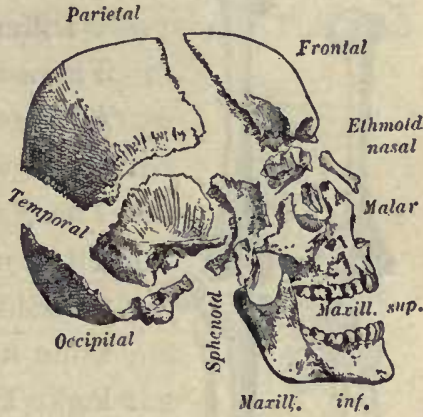

Fig. 33. - Human SKulL, disjointed.

form is best for resisting pressure and turning aside blows. Like all flat bones, the skull has a spongy layer of bone between the layers of compact bone forming the outer and inner surfaces; hence it is elastic and not easily cracked. The nose, brow, and cheek bones project around the eye for its protection. The delicate portions of the ear are embedded in the strongest portion of the skull. The branches of the nerves of smell end in the lining of the bony nasal chambers. The spinal cord rests securely in the spinal canal.

The arms and legs have bones that closely correspond to each other. The Latin names of these bones, as well as of all the other bones, are given in Fig. 28. There are 30 bones in each arm and 30 in each leg (Fig. 34). Here is a list of the bones of the arm, followed by the names in brackets of the corresponding leg bones: upper arm bone [thigh bone], 2 forearm bones [shin bone and 
splint bone], 8 wrist bones [ 7 ankle bones], 5 palm bones [ 5 bones of instep], I4 finger bones [ 14 toe bones]. The shin bone is the larger bone between knee and ankle.

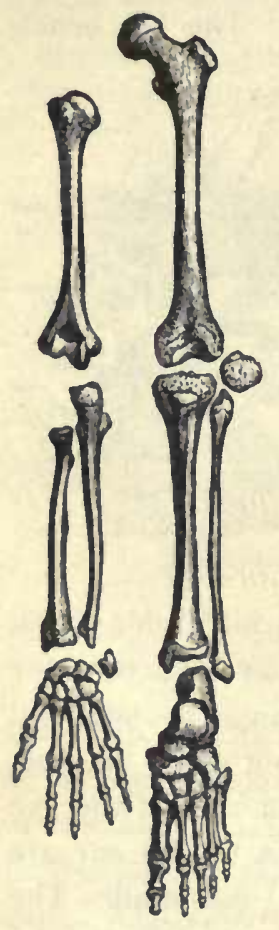

FIC. 34. - BONES OF ARM AND LEG. The long, slender splint bone and the shin bone are bound side by side.

Differences between Arm and Leg. There is a saucer-like bone, called the kneecap, embedded in the large ligament which passes over each knee. There is no such bone in the elbow. There is one less bone in the ankle than in the wrist, hence there are the same number of bones in the arm and leg. The shoulder joint is more freely movable than the hip joint. The fingers are longer and more movable than the toes; the thumb moves far more freely than the big toe. The instep is much stronger than the palm; for each instep must support, unaided, the weight of the whole body at each step, with any other weight that the person may be carrying. The palm is nearly flat, but the instep is arched to prevent jars. When the weight of the body is thrown on the foot at each step, the top of the arch is pressed downward, making the foot longer than before. The arch springs up when the weight is removed (Exp. I).

Illustrated Study. The Shapes of Bones. - Write $L, F$, or 1 after these names (see Fig. 28, etc.), according as the bones are long, flat, or irregular: face, cranium, vertebra, hip, rib, breastbone. collar bone, shoulder blade, upper arm bone, lower arm bones, wrist, palm, fingers, thigh bone, shin bone, splint bone, ankle, instep, toes, kneecap. 
Structure of Joints. - The meeting of two bones forms a joint (Exp. 4). Some of the joints are immovable. The skull bones join in zigzag lines called sutures, formed by the interlocking of sawlike projections (Fig. 35). These immovable joints are necessary for the protection of the brain, which is the most delicate of the organs. The brain attains almost its full size by the seventh year of life; its bony case needs to grow very little after that. The joints of the pelvis are also immovable. All movable joints have two cartilages, and as the bones turn, one cartilage slips over the other. There is an intermediate class of joints found between the vertebræ and where the ribs join the breastbone. These joints depend for their motion upon the flexibility

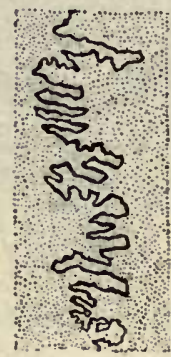
and compressibility of their cartilages. They are called mixed, or elastic. joints, and allow slight motion. Such a joint has only one cartilage.

Kinds of Movable Joints. - The movable joints are found chiefly in the limbs. When one end of the bone is rounded and fits into a cuplike hollow, the joint allows motion in all directions, and is known as a ball-and-socket joint. The hip joints and shoulder joints are examples. A hinge joint allows motion in only two (opposite) directions; for example, the to-and-fro motion of the elbow. A pivot joint allows a rotary motion; examples, the first vertebra on the second, one bone of forearm upon the other. A gliding joint consists of several bones that slide upon one another, as at the wrists and ankles.

The Four Features presented by a Movable Joint (Fig. 36). - If not held in place, the bones would slip out of their sockets, hence there are ligaments, or tough bands, 
to bind the bones together. Sudden jolts would jar the bones and injure them; shocks are prevented by a layer

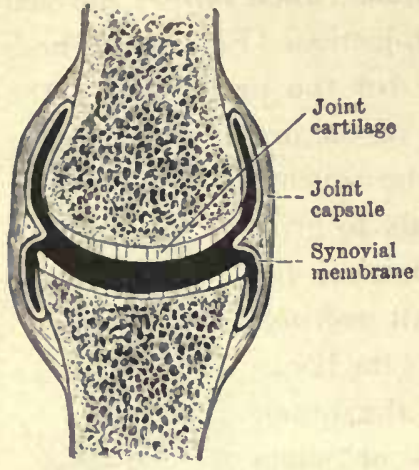

FiG. 36. - DIAGRAM OF A JOINT.

of elastic cartilage over the end of each bone. The moving of one bone over another in bending a joint would wear the bone with friction unless the cartilages were very smooth and lubricated with a fluid called the synovial fluid. The synovial fluid would be constantly escaping into the surrounding tissues except for the collarlike ligament called the capsule, which surrounds the joint and is attached to each bone entirely around the joint (Fig. 36).

Thought Questions. The Kinds of Joints. - Write $B, H, G, E$, $P$, or $I$ after these names according to the kind of joint (ball-and-socket, hinge, gliding, elastic, pivot, immovable) : between bones of skull, head nodding, head turning, vertebræ, lower jaw, ribs to breastbone (Fig. 75), shoulder, elbow, wrist, fingers, hip, knee, ankle, toes.

Growth of Bones. - The blood vessels pass into the bones from the periosteum. If the periosteum is removed, the larger blood vessels are taken away and the bone beneath it perishes. If the underlying bone is removed and the periosteum left, the bone will be replaced. A curious proof of the active circulation in the bone is furnished when madder is mixed with the food of pigs. In a few hours the bones become a darker pink than usual; and if the madder is fed to the pigs. for a few days, their bones become red. A child grows in height chiefly during three or four months in spring and summer; but its body broadens and becomes heavier during autumn.

Health of the Bones. - It is plain that a strong and free circulation of pure blood contributes to the health and strength of the bones; good food and pure air make pure blood. Cases of "delayed union," or slow mending of broken bones, occur more often with intemperate than with sober people. This is because the vitality of the bone cells has 
been weakened by the use of alcohol. Many surgeons dislike to operate on an old drunkard.

Posterior Curvature of the Spine. - The spine (see Figs. 28, 31) has two backward curves (opposite chest and hips) and two forward curves (at loins and neck). The deformity called posterior curvature is chiefly an exaggeration of the upper posterior curve. Round shoulders is the slightest, and hunchback the most marked, degree of this deformity. Causes: I, bending over the work while either standing or sitting; 2, slipping down in the seat, as in Figure $5 \mathrm{I} ; 3$, working habitually with the work low in front, as reading and writing at too low a desk (Fig. 49), or bending over while hoeing, sitting on the floor (Japanese and Chinese); 4, weak muscles in the back; 5, wearing shoes with high heels; 6 , binding the ribs down with tight clothing; 7, walking with the head drooped forward or the chest flat; 8, wearing suspenders without a pulley, or lever, at the back; 9, carrying the hands in the pockets. (Swing the arms to keep the hands out of the pockets and break the habit); Io, wearing a coat or vest that is tight at the back of the neck. This deformity is brought about by stretching the ligaments at the back side of the spine, and by compressing the cartilages until they become wedgeshaped, with the thin part of the wedge in front. The flexibility of the spine is a great advantage, but it increases the risk of deformity. One of the most serious evils of posterior curvature is a flat chest and restricted breathing.

Lateral Curvature of the Spine. - A perfect spine curves to neither side (Fig. 47), but is perfectly erect. The least habitual lateral curvature is deformity. Causes: $\mathrm{I}$, writing at a desk that is too high; 2, habitually carrying a book, satchel, or other weight in the same hand; 3, carrying the head on one side (Fig. 46); 4, habitually standing with the weight on the same foot; 5 , a certain defect of vision (astigmatism, Chap. IX).

To overcome Spinal Deformities. - The work, or the manner of doing the work, should be so changed as to give extra labor to the neglected muscles. Avoid the habits mentioned above as causing deformity. Sit and stand in the manner described in the next paragraph. Sleeping on the back upon a hard mattress without a pillow tends to cure posterior curvature and flat chest.

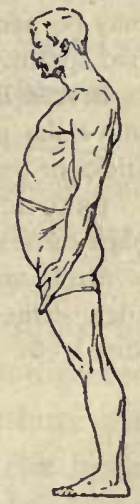

FIG. $37 .-$

INCORRECT

POSTURE.

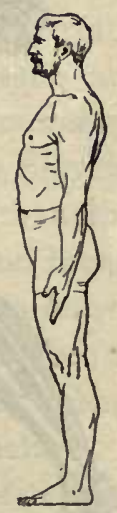

FIG, 38. CORRECT POSTURE, but strained and stiff. 
The correct position in standing is : chest forward, chin in, hips back (Figs. 38, 39). To sit correctly, sit far back in the chair (Figs. 60, $61,62)$ with the body erect and balanced. In youth the bones are soft and growing; they will readily grow into perfect shape, and will almost as readily grow deformed.

Sprains. - Immerse the part in hot water for half an hour, then bandage to keep the part at rest. Use the limb as little as possible. It may be necessary for a physician to apply a plaster dressing to a very bad sprain where the ligament is torn from the bone.

Broken Bones. - To prevent bone from cutting flesh and skin, do not move the person until a temporary splint has been provided by tying sticks or umbrellas around the limb with handkerchiefs.

PRACTICAL Questions. The Skeleton.-1. What kind of a chair back causes one to slide forward in the seat? 2. What fault in sitting is made necessary by using a chair with so large a seat that the front edge strikes the occupant behind the knee? 3. Why is the shoulder more

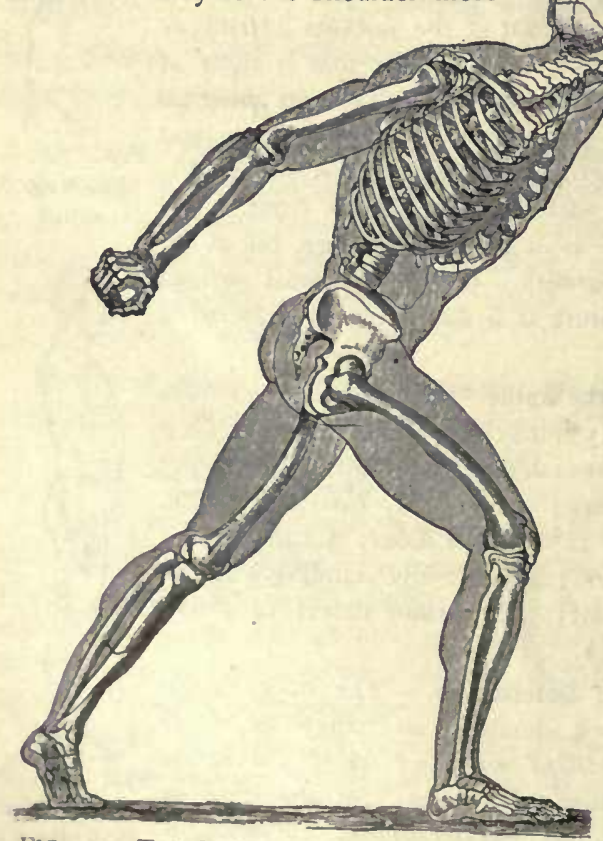

Fig. 39- - The Human Skeleton in Action. often dislocated than the hip? 4. High pillows may cause what deformity? 5. Find three bones in the body not attached to other bones. Find twenty-five bones attached to other bones by one end only (Figs. 28 and 39). 6. What deformities may result from urging a young child to stand or walk? 7. Which bone is most often broken by falling upon the shoulder? 8. Where in bones is fat stored for future use? 9. Ligaments grow very slowly. Why is recovery from a sprain often tedious? 


\section{CHAPTER IV}

\section{THE MUSCLES}

IT has already been stated that there are at least two muscles attached to a bone to move it in opposite directions. Since there are two hundred and six bones, you are not surprised to learn that to move the bones and accomplish the various purposes just stated, there are five hundred and twenty-six (526) skeletal muscles.

Two Kinds of Muscles. - All muscles are controlled by means of the nervous system. Some of them are directed by parts of the brain that work consciously; others are controlled by the spinal cord and the parts of the brain that work unconsciously. Those of the first kind are usually controlled by the will, but they sometimes act involuntarily. They are called voluntary muscles. They move the bones and are located in the limbs and near the surface of the trunk (Fig. 44). The other kind of muscles are never controlled by the will, and are called involuntary muscles. We cannot cause them to act, nor can we prevent them from acting. They contract more slowly than the voluntary muscles. Most of them are tubular and found in the cavity of the trunk. The involuntary muscles belong to the internal organs, and relieve the will of the responsibility and trouble of the activity of these organs; otherwise, the mind would have no time for voluntary actions.

Gross Structure of Voluntary Muscles. - A beefsteak is seen to be chiefly red, although parts of it are white or yellowish. The white or yellowish flesh is fat; the red, 


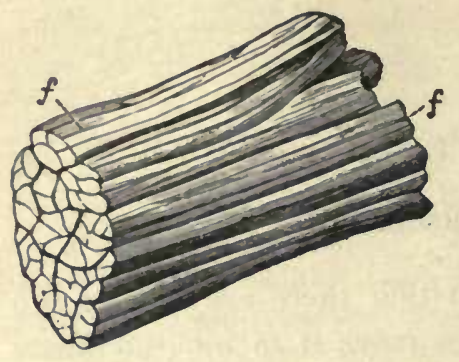

Fig. 40. - Muscle Bunders bound to gether by connective tissue sheaths. lean flesh is voluntary muscle. If a piece of beef is thoroughly boiled, it may be easily separated into bundles the size of large cords. These bundles may, by the use of needles, be picked apart and separated into threadlike fihers (Fig. 40).

Microscopic Structure of Muscles. - These threadlike fibers may, under a magnifying glass, be separated into fine strands called fibrils. These last are the true muscle cells; they are shown by the microscope to be crossed by many dark lines (Fig. 48). Hence voluntary muscles are called striated or striped muscles. Prolonged boiling and patient picking with a needle are needed to dissect muscle, because the bundles are held together by thin, glistening sheets of connective tissue by which they are surrounded. This connective tissue surrounds and

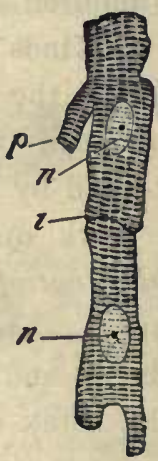

FIG. 4I, - Two MUsClE FIBERS OF HEART. holds in place the separate fibers of each bundle (Fig. 40).

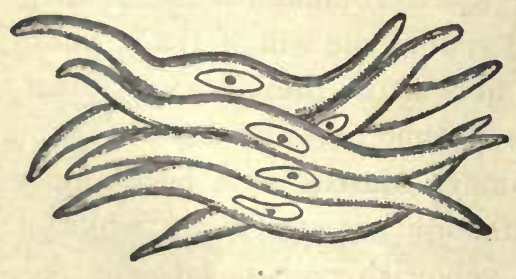

Fig. 42. - Involuntary Muscle Cells (or fibers).
The fibrils of involuntary muscles are spindle-shaped (see Fig. 42). There are no cross lines on the fibrils; hence involuntary muscles are called smooth or unstriped muscles. 
The heart fibers are exceptional; they are the only involuntary muscle fibers that are striped (Fig. 4I).

Thought QUeSTions. Classification of Some of the Muscles.Copy the following list and mark $I$ for involuntary and $V$ for voluntary after the appropriate muscles.

Muscles for chewing. Muscles of gullet. Muscles of the heart. Muscles that move arms. Muscles for breathing. Muscles in the skin that cause the hair to stand on end. Muscles that move eyelids. Muscles that contract pupil of eye. Muscles for talking. Muscles . that contract and expand the arteries (in blushing and turning pale). Muscles that move eyeball. Muscles that give expression to the face.

Tendons. - The connective tissue which binds the fibers of muscles into bundles, and forms sheaths for the bundles, extends beyond the ends of the muscles and unites to form tough, inelastic white cords called tendons. Some muscles are without tendons, and are attached directly to bones. Study the figures and find examples of this (see Figs. $44,75)$. To realize the toughness of tendons, feel the tendons under the bent knee or elbow, where they feel almost as hard as wires. The tendons save space in places where there is not room enough for the muscles, and permit the bulky muscles to be located where they are out of the way. Wherever the tendons would rise out of position when a joint is bent, as at the wrist and ankle, they are bound down by a ligament.

Arrangement of Voluntary Muscles. - Circular muscles, called sphincter muscles, are found around the mouth and eyes. Muscles that

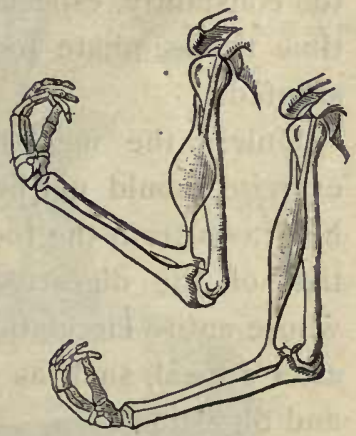
FIG. 43. - (For blackboard.) BICEPS relaxed and contracted. extend straight along the limb either bend it and are called flexors, or straighten it and are called extensors. Most of 
the voluntary muscles are arranged in pairs and cause motion in opposite directions; they are said to be antagonists. The biceps (Fig. 43) bends the arm. Its antagonist is the triceps on the back of the arm. By feeling them swell and harden as they shorten, locate on your own body the muscles mentioned in Fig. 44.

How a Muscle grows Stronger; its Blood Supply.Nature has provided that any part of the body shall receive more blood when it is working than when it is resting. When it works the hardest, the blood tubes expand the most and its blood supply is greatest. So whenever a muscle is used a great deal, an unusual amount of material is carried to it by the blood, the cells enlarge and multiply, and the muscle grows. The walls of the capillaries are so thin that the food which is in the blood readily passes from them to the muscle. Because of the oxidation taking place, a working muscle is warmer than one at rest. By use a muscle grows large, firm, and of a darker red; by disuse, it becomes small, flabby, and pale. But if muscles are worked too constantly, especially in youth, their cells do not have time to assimilate food and oxygen, and their growth is stunted.

Unless the meal has been a very light one, vigorous exercise should not be taken after eating, as the blood will be drawn from the food tube to the muscles and the secretion of the digestive fluids will be hindered. Persons whose entire circulation is weak may find that light exercise after a meal, such as walking slowly, may help circulation and digestion.

Why the Muscles work in Harmony. - When a boy throws a stone, almost every part of the body is concerned in the action. His arms, his legs, his eyes, the breathing, the beating of the heart, are all modified to assist in the effort. 


\section{Illustrated Study of Muscular Function}

Draw a dotted line from each function mentioned on margin to the muscle or muscles having that function.

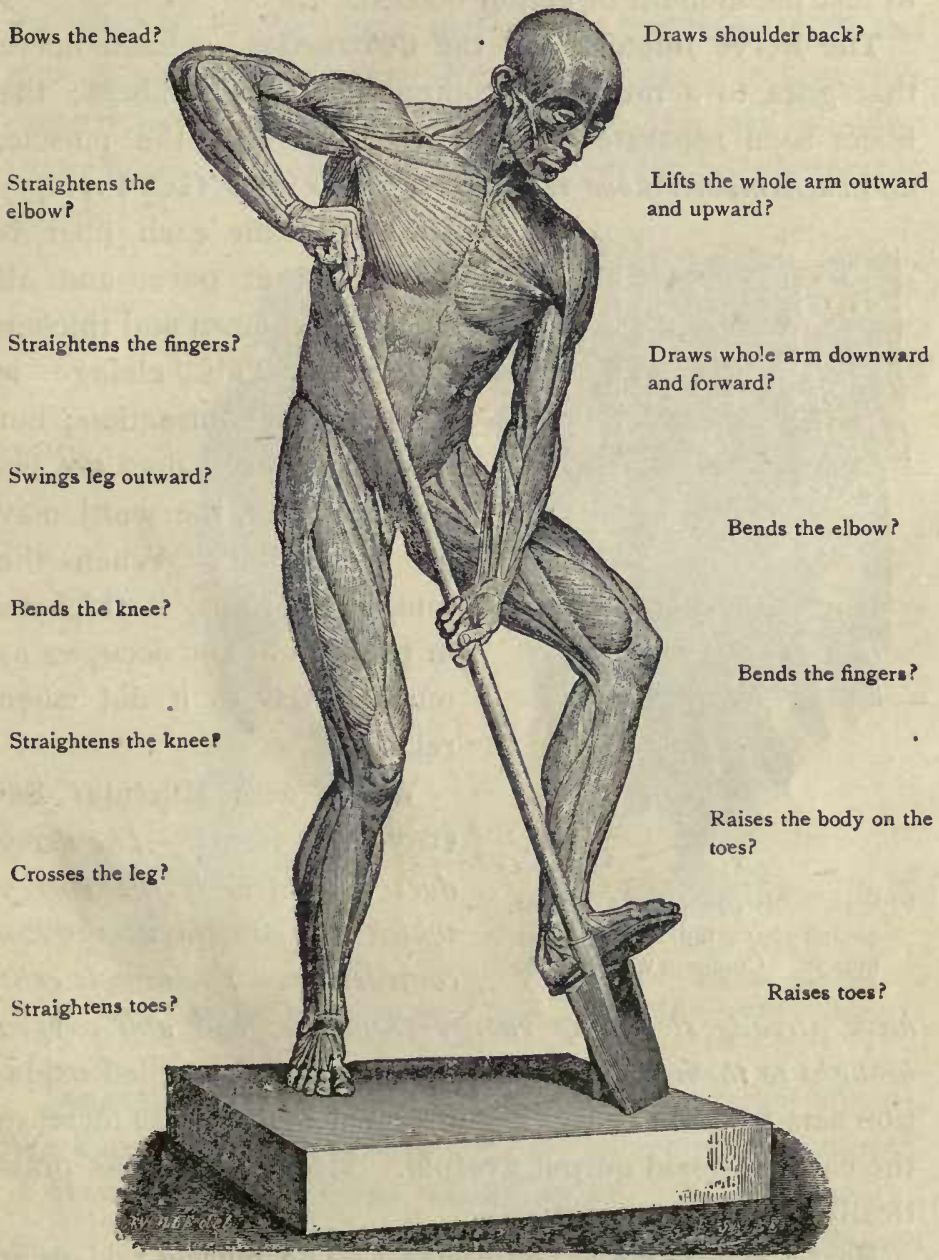

Fig. 44.-Superficial Muscles after the Statue of "The Digger" (Lami). 
As the boy wills to throw the stone, nerve impulses are sent to all the organs that can assist, and they are excited to just the amount of action needed.

The Nerve Impulse and the Contraction. - Each nerve that goes to a muscle is composed of many fibers; the fibers soon separate and go to all parts of the muscle, and each muscle fiber receives its nerve fiber (see Fig. 45).

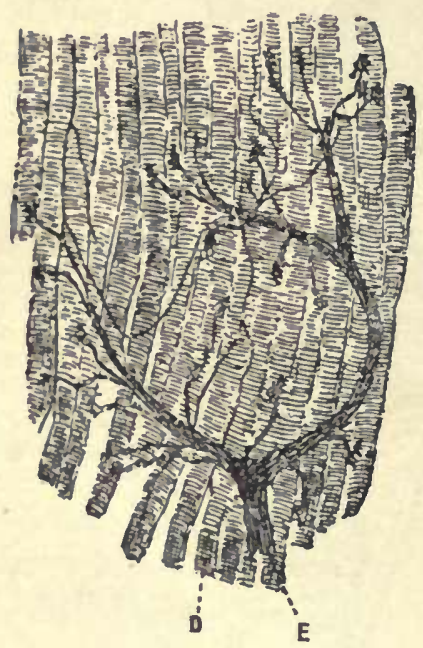

Fig. 45. - MOTOR Nerve Fibers, ending among fibrils of voluntary muscle. Compare with Fig. 48.

In the brain each fiber is stimulated at once, and all the fibers shorten and thicken together. This change is spoken of as contraction; but since the muscle does not become smaller, the word may be misleading. When the muscle shortens, it thickens in proportion and occupies as much space as it did when relaxed.

Where does Muscular Energy come from? - The nerve does not furnish the energy which the muscle uses when contracting. The muscle cells have already stored up energy from the food and oxygen brought to them by the blood, and the process called oxidation sets free the energy. Activity of muscle may increase the carbon dioxid output fivefold. Mental work has practically no effect upon it.

How a Muscle stays Contracted. - The muscle relaxes at once after contraction; and in order to keep it contracted, nerve impulses must be sent in quick succession, causing in fact many contractions; the effect of this is sometimes 
visible, as the trembling of the muscle. Figure 47 shows an easy standing posture.

What causes Fatigue. - Fatigue or exhaustion is due to the using up of the living material in the nerve cells and muscle cells by oxidation. Rest is necessary to give cells opportunity to repair themselves. Why is it less fatiguing to walk for an hour than to stand perfectly still for ten minutes?

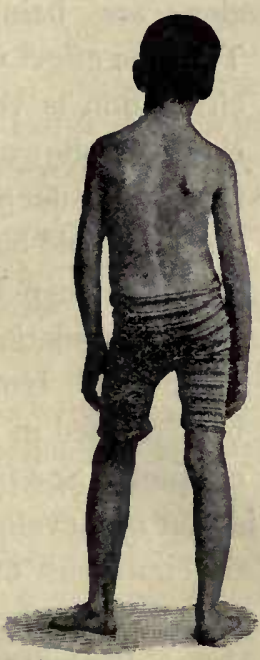

FIG. 46.- IMPROPER POSITION; causes spine to curve to side: raises one hip and shoulder above the other.

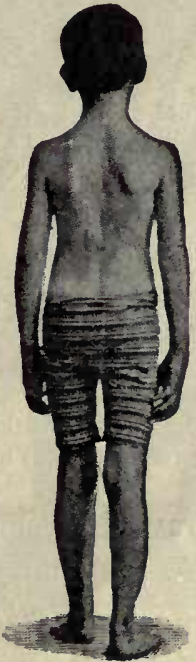

FIG. 47.- BEST POSITION ; chest is free to expand, and weight is easily shifted from one foot to other.

Degeneration of Muscles begins with habitual disuse. We dare not furnish a substitute for the work of a muscle, if we wish the muscle to remain sound. A belt or a stay at the waist will cause the muscles of the trunk to become flabby and the abdomen to relax and protrude.

How Muscular Activity helps the Health. - Life is change, stagnation is death. Muscular activity uses up the 
food, gives a good appetite, and sets the digestive organs to work; it uses up the oxygen and sets the lungs to work; but most of all, every contraction of a muscle helps the blood to flow. As a muscle contracts, it presses upon the veins and lymphatics, and, by this pressure, forces the blood

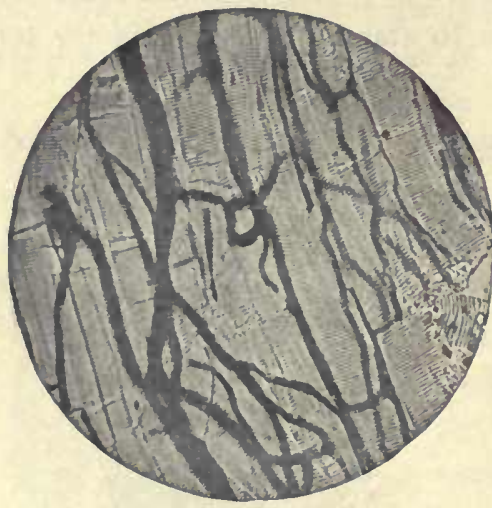

FIG. 48. - CAPILLARIES among fibers of voluntary (cross striped) muscle. (Peabody.) and lymph along (Fig. 48). In any ordinary activity, dozens of muscles are being used. That the effect upon the circulation is very powerful, is shown by the rosy skin, deep breathing, and rapid heart beat. The many benefits of an active circulation of the blood and lymph will be discussed in the next chapter. See page 67 .

A grave danger from athletics is that of developing the muscles, including the heart, to an enormous extent by training; then when training ceases the muscles undergo fatty degeneration from disuse. Heart disease and other diseases may follow. Many athletes die young, killed by trying to turn their bodies into mere machines for running, boxing, or rowing, instead of living complete lives. The athletic ideal is not the highest ideal of health; general activity, resembling the occupations of hunting and farming by which the early race supported itself, is best for health. Many kinds of factory work use only one set of muscles. The savage did not lead a monotonous life, and monotony is bad for both muscles and nerves. 
Advantages of Work and Play over Gymnastic Exercises. - The interest that comes from doing something useful, makes muscular exertion doubly beneficial to the health. The lifting of dumbbells, Indian clubs, and pulley weights, and letting them down again, tends to become very irksome, even though done with the knowledge that the exercise will benefit the health. Useful labor and games place definite objects in view and do not require so great an effort of the will nor exhaust the nerves so much as mere exercise. The interest in the work or the game serves to arouse all the nerves and muscles to work in harmony.

An Advantage of Gymnastics over Work and Play.Gymnastics can furnish any required variety of exercises and can develop exactly the muscles that need development and leave those idle that have become overdeveloped by doing constantly one kind of work or playing continually the same game. The deformity of a flat chest (and round shoulders which always accompany it) does not so often indicate a weak chest or small lungs as it indicates weak or relaxed muscles of the back and the habit of sitting in a relaxed position at work (Figs. 49, 50, 51). Gymnas-

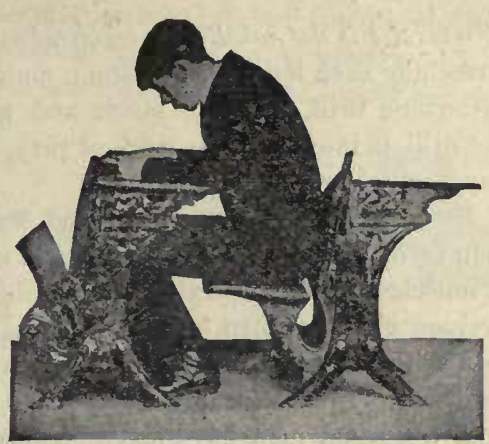

FIG. 49. - DESK TOO LOW. (Jegi.)

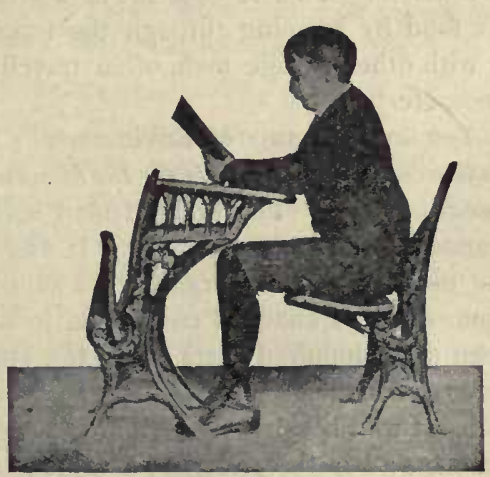

FIG. 50. - CORRECT POSITION.

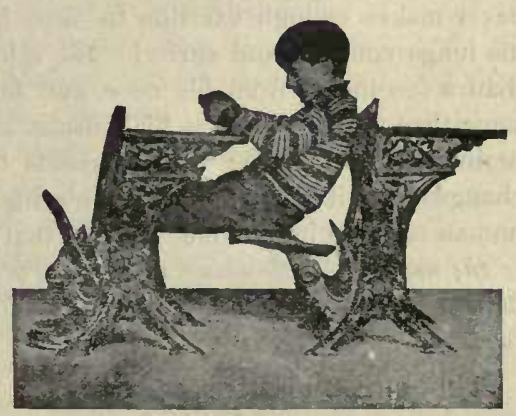

Fig. 51.-SLIPPING DOWN IN SEAT. 
tic exercise is not wholly an artificial custom. Cats stretch themselves, stretching each leg in succession; many animals gambol and play. A gymnastic drill, taken to music and with large numbers of pupils in the drill, is interesting as work or play, and should not be neglected for any study, however important.

Environment of Early Man and Modern Man.-A well-developed man of one hundred and fifty pounds weight should have sixty pounds of muscles. The proportion is often different in the puny bodies of the average civilized men, such as clerks, merchants, lawyers, and other men with sedentary occupations; their bodies are as likely to be lean and scrawny or fat and flabby as to be correctly proportioned. Why does a normal man have sixty pounds of muscles instead of twenty pounds of puny strings such as would have sufficed for a clerk, stuclent, or a writer? This is because, in his native condition, he had to seek his food by roaming through the forest, contending with wild beasts or with other savage men, often traveling many miles a day, climbing trees, etc.

Too Rapid Change of Environment; Destructive Tendencies of Civilization. - It is impossible for the human body to change greatly in a few hundred years. The body of man served hin for many ages for the manner of life outlined above. It was suited for these conditions, and the muscles and the organs that support them cannot accommodate themselves to changed conditions in a few generations. It has only been a few hundred years since the ancestors of the Britons and Germans, for instance, were running wild in the German forests, clad in the skins of wild beasts. Yet civilized man lets his muscles fall into disuse, he takes a trolley car or horse vehicle to go half a mile, an elevator to climb to the height of thirty feet. He neglects all his muscles except those that move the tongue and the fingers of the right hand. $\mathrm{He}$ never makes enough exertion to cause him to draw a deep breath, and his lungs contract and shrivel. He seldom looks at anything farther than a few inches from his nose, and his eyes become weak. At the same time that he neglects his muscles and his lungs, he overworks his brain and his stomach; yet he expects his body to undergo the rapid changes to suit the demands of his life. Such rapid changes in the human race are impossible. A man that does not see that sound health is the most valuable thing in the world, except a clear conscience, is in danger both of wrecking his own happiness and of failing in his duty to others.

Thought QUESTIONS. Shoes. -1 . What the faults of shoes may be in size; shape; sole; heel; toe; instep. 2. Name deformities resulting to skin of foot; nails; joints; arch; ankle; spine. 3. State effects 
of uncomfortable shoes on muscular activity; mind and disposition. 4. State effect of aversion to walking on muscles; circulation. 5. If a shoe is too loose, it slips up and down at the heel and chafes the skin there; if too tight, there is pressure on the toes, which causes a corn or ingrowing nail. Have your shoes been correct, or have they been too loose or too tight? According to this test, what proportion of people wear shoes that are too tight? 6. How many

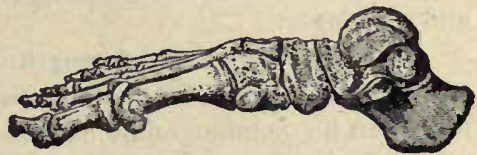

F1G. 52. - ARCH OF FoOT. It forms an elastic spring.

sprained ankles have you known among boys; girls? 7. Why is it that people who grow up in warm climates have high, arched insteps, and short, broad, elastic feet, but people of the same race who pass their childhood in cold climates often have long narrow feet with low arches and sometimes have the deformity called "flat foot"?

Instinct as a Guide for using the Muscles. - The instinctive feeling called fatigue tells us when to rest. There is also a restless, uneasy feeling that comes over a normal human being when confinement and restraint of the muscles have reached an unhealthy limit. This feeling should not be repressed for long at a time. Many, ruled by avarice, ambition, interest in sedentary work, a silly notion of respectability, or a false conception of duty, have repressed this feeling and have lost it. There is then a feeling of languror, and a disinclination to the very activity which health demands. An unheeded instinct is as useless as an alarm clock that has been habitually disregarded.

Exercise and Climate. - In our warmest states and in the tropics, one hour's vigorous physical labor a day, combined with the ordinary activities of life, will keep a person in good condition. In the colder states, muscular exertion for several hours is needed daily.

Complete Living. - Numberless people have devoted themselves to an intellectual occupation, and planned to keep their bodies sound by gymnastics and special exercises. Because of the monotony of exercises, they are soon given up in nearly every instance. The safest way is never to allow all the energies to be devoted to a one-sided occupation, but so to plan one's life and work that a part of the time is devoted to some physical work, whether it be in a garden, workshop, or orchard: in walking a long distance to the office; at bookbinding, cooking, wood carving, or any one of various other useful occupations. The result of manual training shows that not only strength of body, but strength of mind, is promoted by physical labor. Problems of war and of the chase kept active both the body and mind of the savage. Hence he led 
a more nearly complete life than his civilized descendants, and his body was strong accordingly. We should admit the hopelessness of having permanent good health without muscular activity and should determine that muscular exertion shall be as much a habit and pleasure as eating and sleeping.

Alcohol and Muscular Strength. - Benjamin Franklin, one of the wisest and greatest of Americans, was a printer when he was a young man. In his autobiography he gives an account of his experience as a printer in London. He says: "I drank only water; the other workmen, fifteen in number, were great drinkers of beer. On occasion I carried up and down stairs a large form of types in each hand, when others carried but one in both hands. They wondered to see, from this and several instances, that the Water-American, as they called me, was stronger than themselves, who drank strong beer. My companion at the press drank every day a pint before breakfast, a pint at breakfast with his bread and cheese, a pint between breakfast and dinner, a pint at dinner, a pint in the afternoon about $60^{\circ}$ clock, and another when he had done his day's work. I thought it a detestable custom, but it was necessary, he supposed, to drink strong beer that he might be strong to labor."

Exercises in Writing. - The Right and the Wrong Way to ride a Bicycle. Pay Day at a Factory. A Graceful Form: how Acquired; how Lost. A Drinking Engineer and a Railway Wreck.

PRACTICAL QUestions. - 1. Can we always control the voluntary muscles? Do we shiver with the voluntary or involuntary muscles? 2. If a man had absolute control over his muscles of respiration, what might he do that he cannot now do? 3. Why is one who uses alcoholic drinks not likely to be a good marksman? 4. Why should a youth who wishes to excel in athletic contests abstain from the use of tobacco? 5. Is there any relation between the amount of bodily exertion necessary for a person's health and the amount of wealth or the amount of intelligence he possesses? 6. Can you relax the chewing muscles so that the lower jaw will swing loosely when the head is shaken? Can you relax your arm so that it falls like a rope if another person raises it and lets it fall? 7. The average man has sixty pounds of muscle and two pounds of brain; one half of the blood goes through the muscles and less than one fifth goes through the brain. What inference may you draw as to the kind of life we should lead? 8. Why is a slow walk of little value as exercise? 9. How can we best prove that we have admiration and respect for our wonderful bodies? 10. Why is the ability to relax the muscles thoroughly of great benefit to the health? How is this ability tested? (Question 6.) 11. Why is it as correct to say that the muscles support the skeleton as the reverse? 
1. Head arteries (carotid)

2. Nameless arteries (innominate).

3. Collar bone (subclavian) artery.

4. Great bend of the aorta.
18. Ascending vena cava.

rg. Vein from liver (hepatic).

20. Vein from stomtach (gastric).

21. Vein from spleen.
5. Pulmonary arteries.

6 Thoracic aorta.

7, 10. Abdominal aorta

8. Artery to liver (hepatic).

9. Artery to spleen (splenic).

x1. Artery to intestine

(mesenteric).

12. Artery io kidney (renal).

13. Descending vena cava,

84. Nameless vein (innominate, I5 and 16 befnre branching).

15. Collar bone vein (subclavian)

เ6. Jugular vein.

x. Pulnonary vein.

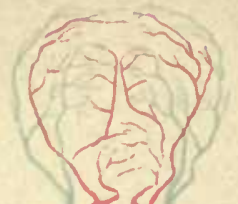




\section{CHAPTER V}

\section{THE CIRCULATION}

Experiment 1. Anatomy of Mammalian Heart.-Get a sheep's or beef's heart from the butcher. Get the whole heart, not simply the ventricles (as usually sold). Note the blood vessels, four chambers, thickness of different walls, valves, cords, openings.

Experiment 2. Does Gravity affect the Blood Flow?-Hold the right hand above the head for a few minutes. At the same time let the left hand hang straight down. Then bring the hands together and see which is of a darker red because of containing more blood. Now reverse the position of the hands for a few minutes, and find whether the effect is reversed. (Entire class.)

Experiment 3. Study of Human Blood. - Examine a drop of blood under the microscope, first diluting it with a little saliva. See Fig. 6o.

Experiment 4. The Circulation in a Frog. - Wrap a small frog in a moist cloth, lay on a slip of glass, place under the microscope, and study the circulation in the web of its foot.

Experiment 5. (Entire class.) Effect of Exercise upon the Pulse. Tap a bell as the second hand of a watch begins a minute and let the pupils count the pulse at the radial artery on the wrist above base of thumb. Repeat standing, or after gymnastics or recess. Result?

Experiment 6. The Action of the Valves in the Veins. - Place the tip of the middle finger on one of the large veins of the wrist; with the forefinger then stroke the vein toward the elbow so as to push the blood from a portion of it, keeping both fingers in place. The vein remains empty between the fingers. Lift the finger nearer the heart and no blood enters the vein; there is a valve above which holds it back. Lift the other finger and the vein fills instantly. Stroke a vein toward the hand, and notice that the the veins swell up into little knots where the valves are. Stroke in the reverse direction. Result?

Experiment 7. Finding the Capillary Pressure. This is found by pressing a glass plate or tumbler upon a red part of the skin. When the skin becomes pale the capillary pressure is counterbalanced.

Experiment 8. Emergency Drill. - Let one pupil come forward, mark with blue chalk or pencil the position on his arm of a supposedly cut vein. Let another pupil use means to stop the imagined blood flow. 
Experiment 9. Let another pupil stop the flow from an imaginary cut artery marked red. See text. Experiment 10. In a case of nose bleed do not let pupil lean over a bowl. (Why?) Cause him to stand rather than lie. (Why? See Exp. 2.) Apply cold water to contract arteries to nose, also have pupil hold a small roll of paper or a coin under upper lip (to make muscular pressure on arteries to nose). Experiment 11. Let one pupil treat another for a bruise (see p. 62). Experiment 12. Emergency drill, restoration from fainting (see p. 57).

The Cells have a Liquid Home. - The cells in the body of man, like the ameba, live in a watery liquid. This liquid is called $l y m p h$. The cells cannot move about as the ameba does to obtain food, so the blood brings the food near them and it soaks through the blood tubes into the lymph spaces next to the cells (see colored Fig. 3). The ameba gives off waste material into the water; the cells of the body give it off into the lymph to be carried off by the circulation. The blood, then, has two functions: (1) to take nourishment to the tissues; (2) to take away waste material from them.

The Organs of Circulation. - These are the heart, which propels the blood; the arteries, which take blood away

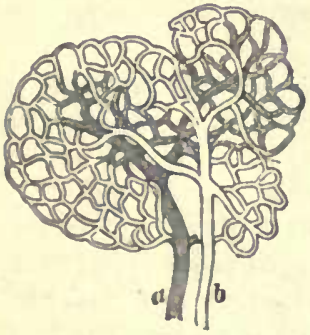

Hic. 53. - CAPIILARIES, connecting artery (b) with vein $(a)$. from the heart; the veins, which take the blood back to the heart; and the capillaries (Fig. 53), which take the blood from the arteries to the veins.

The heart is a cone-shaped organ about the size of its owner's fist. It lies in a diagonal position behind the breastbone, with the small end of the cone extending toward the left. The smaller end (Exp. I) taps or beats against the chest wall at a point between the fifth and sixth ribs on the left side. The breastbone and ribs protect it from blows. An inclosing membrane called the pericardium secretes a serous fluid and lessens the friction from its beating.

Why the Heart is Double. - There must be a pump to move the impure blood from the body to the lungs to get oxygen 
from the air, and there must be another pump to send the pure blood from the lungs back to the body. Hence there are two pumps bound together into one heart, beating at the same time like two men keeping step, or like two carpenters keeping time with their hammers. There are valves in the heart, as in other pumps. These valves are so arranged that when any part of the heart contracts and forces the blood onward, the blood cannot return after that part of the heart relaxes. Are the pumps placed one behind the other? Or is one above the other? Neither; they are side by side, with a fleshy partition between them (Fig. 54). The pump on the $\frac{a}{3}$ right moves the impure blood from the body to the lungs, and the one on the left moves the pure blood from the lungs to the body. There is no direct connection between the right and left sides of the heart.

To trace one complete circuit of the blood (Fig. 54), let us begin with the blood in the capillaries of the outer tissues, such as the skin or muscles. The blood goes through small veins which unite into two large veins, through which it

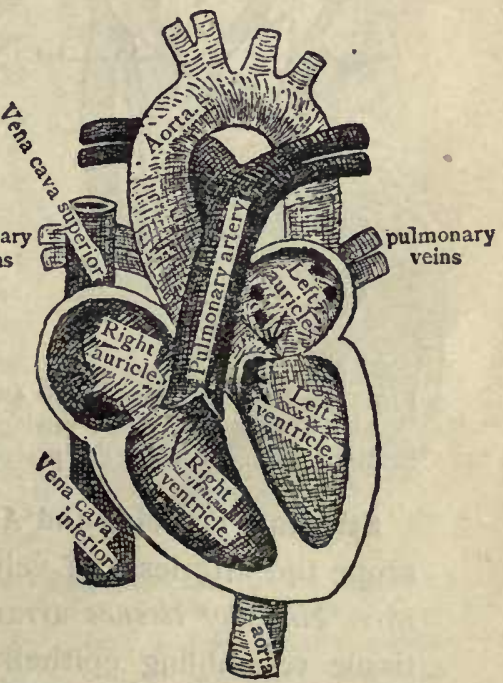

Fig. 54. - DIAgram OF HEart.

Notice the two dark spots in the right auricle, and four dark spots in left auricle, where the veins enter. Does the aorta pass in front of, or behind, the pulmonary artery?

enters the receiving chamber, or right auricle, goes through the tricuspid valve into the expelling chamber, or right ventricle, then through a semilunar valve into the pulmonary artery leading to the lungs. Becoming purified while 
passing through the capillaries of the lungs, the blood goes through the pulmonary veins to the left auricle (Fig. 54), then through the bicuspid or mitral valve, to the left ventricle, whence it is forced through a scmilunar valve into the largest artery of the body, called the great aorta (Fig. 54). Thence it goes to the smaller arteries, and then to the capiliaries of the tissues in general, thus completing the circuit.
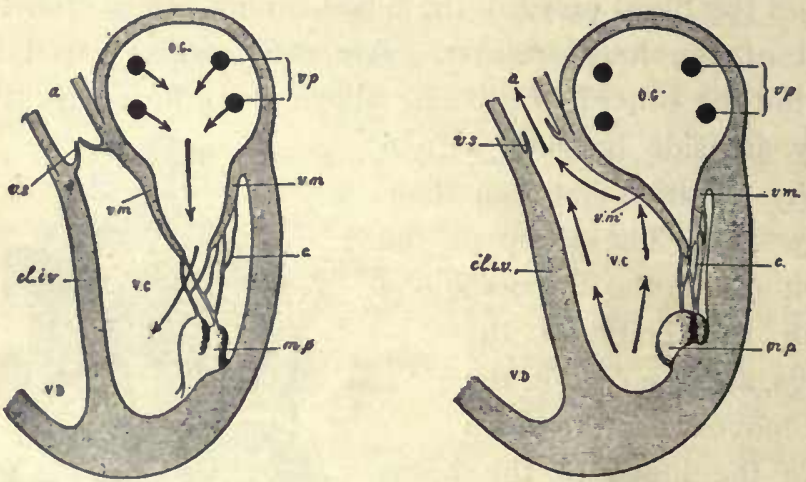

FIG. 55. - THE LEFT SIDE OF HEART (plan), showing the left ventricle at the moment when relaxing and receiving the blood from the auricle; and the same at the beginning of contraction to send blood into aorta. Notice action of the valve.

Structure of Veins and Arteries. - Seen under the microscope the arteries and veins show that they are made of three kinds of tissues arranged in three coats (Fig. 56): a tissue resembling epithelial tissue (Chap. I), as a lining to lessen friction; an outer connective tissue (Chap. I), to give elasticity; and a middle coat of muscular tissue to enable the vessels to change in size. Let us see why blood vessels must have these three properties?

Why the Blood Vessels must be Elastic. - The aorta and its branches are always full of blood. When the left ventricle with its strong, muscular walls contracts, the blood in the aorta and small blood tubes cannot move forward fast enough to make room for the new supply so suddenly sent out of the ventricle. Where can this blood go? If a 
cup is full, it cannot become more full; not so with an artery. The elastic connective tissue allows it to expand as a rubber hose does under pressure. The first part of the aorta having expanded to receive the incoming blood, the stretched walls contract because of the elasticity of the outer connective tissue coat and force blood into the portion of the aorta just ahead, forcing it to expand in turn. Thus a wave of expansion travels along the arteries. This wave is called the pulse.

The Pulse may be most easily felt in the wrists and neck. As the artery stretches and springs back, one beat of the pulse is felt. In men there are about seventy heart beats or pulse beats a minute. In women the rate is about eighty a minute. It is slowest when one is lying down, faster while sitting, still faster when standing, and fastest of all during running or violent exercise. (Exp. 5.) It should not be thought that the muscular or middle layer of the artery actively contracts and helps to send along the pulse wave; for this wave is simply the passive stretching and contracting of the outer connective coat, and travels like a wave crossing a pond when a stone is dropped into the water. The force of the pulse is furnished, not by the muscle fibers in the artery, but by the beat of the heart; the outer, or connective tissue, coat enables the pulse to travel. Why must there be a middle, or muscular, coat for variation in size?

Use of the Middle Coat; Quantity of Blood and its Distribution. - The body of an adult contains about five quarts

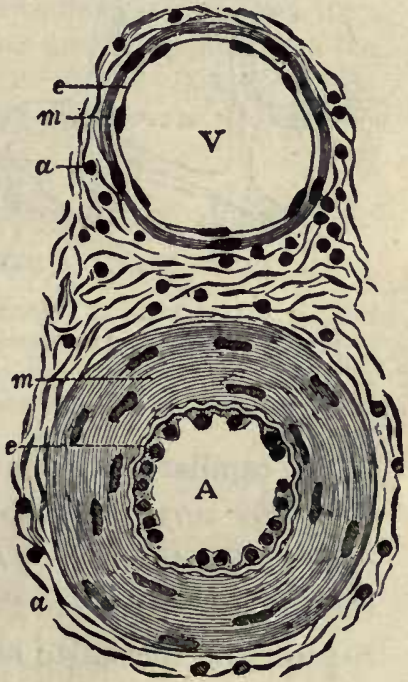

Fig. 56.- SECTION OF ARTERY, $A$, AND VEIN, $V$, showing inner coat, e (endothelial); middle coat, $m$ (muscular); and third coat, $a$ (connective tissue). of blood. The blood furnishes the nourishment needed for the activity of each organ. The more vigorous the work of any organ, the greater is the amount of blood needed. The whole amount of blood in the body cannot be suddenly increased, but the muscular coat of the arteries going to the working organ relaxes, and allows the arteries to become enlarged by the pressure from the heart. Consequently, more blood goes to the active organ, and the other organs get along with less blood for the time. When we are studying, our brains get more blood; when running, the 
leg muscles get more; after a hearty dinner, the stomach and intestines get more than any other part of the body. Why is it difficult to do the

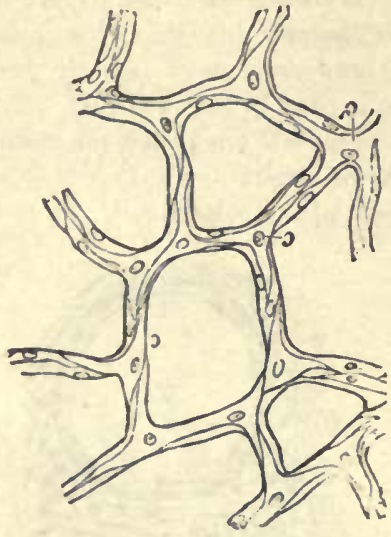

Fjg. 57. - Capillaries MagniFIED, SHOWING CELLS forming their walls. Notice that each cell has a nucleus and three branches. best studying and digest a meal at the same time? We see that the muscular coat of the arteries is a very useful coat, for it enables the supply of blood to be increased in any organ which is in temporary need of it.

Why the Blood Vessels must be Smooth. - The inner coat of the heart and other blood vessels is made of tissue like the epithelial tissue which forms the epidermis and the smooth lining of the mouth and other organs. The purpose of this lining is to lessen friction, and thus save the work of the heart. The friction is greatest in the capillaries because of their small size. The inner coat of smooth cells is the only coat that is prolonged to form the capillaries (see Fig. 57).

The capillaries are small, thin, short, and very numerous. They are wery small so that they may go in between the cells of the tissues. The capillaries are very thin so that the nourishment from the blood may pass readily into the tissues, and the waste material pass readily into the blood. They are very short so that the friction may be less; and they are iery numerous so that all parts of the tissues may be supplied with blood, and that the blood may flow very slowly through them. Because of the number of the capillaries, their total volume is several hundred times larger than the volume of the arteries that empty into them, or of the veins that flow from them. Hence the blood flows slowly through the capillaries, as water flows slowly through a lake along the course of a river. All the changes between the blood and the lungs, and between the blood and the tissues, take place in the capillaries, and 
the object of the other parts of the circulation is merely to move the blood continually through the capillaries.

The effect of gravity is to retard the flow in certain parts of the body and aid the flow in other parts, according to the position of the body (Exp. 2).

Fainting is usually due to lack of blood in the brain, which in turn results from a weakening of the heart beat. Since the brain cannot work without fresh blood, fainting is accompanied by unconsciousness. Recovery from fainting is aided by loosening the clothing at the neck and by placing the head of the patient a little lower than the body so that the weight of the blood may aid the flow to the brain. Dashing a little cold water in the face shocks the nerves and arouses the heart to stronger beats.

The veins have valves placed frequently along their course (Fig. 58). These valves are pockets made by a fold in the inner coat of the wall of the vein. When a boy places his hand in his pocket, the pocket swells out; but if he rubs his hand on the outside of the pocket from the bottom toward the top, it flattens down. So with the action of the blood upon the valves in the veins. (Repeat Exp. 6 in class.)
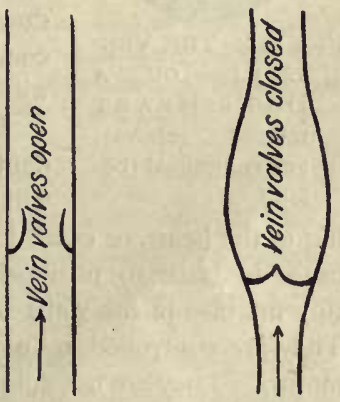

How Muscular Exercise aids the Heart. -When a muscle contracts, it hardens and presses upon a vein which goes through Fig. 58. - VAlves in Veins. (Jegi.) the muscle, and the blood is pressed out of the vein (see Fig. 5.8). The blood cannot go toward the capillaries, for the valves fill and close when it starts that way; so it must all go out toward the heart. When the muscle relaxes, the blood that has been pressed forward cannot go back because of the valves, but the valves nearer the capillaries open, and the veins are filled from the capillaries (Fig. 53). When the muscle contracts again, the same effect on the blood movement is repeated. We see, therefore, that every contracting muscle converts into a pump the vein running through it, and when a person works or exercises, many little pumps are working all over the body, aiding the heart in its function. 
This aid makes the blood flow faster and relieves the heart of part of its work, so that it beats faster, just as a horse might trot faster if another horse helped to draw the load (Exp. 3). The pressure of a contracting muscle upon an artery does not aid the blood flow in the artery because the latter is destitute of valves.

How Breathing aids the Heart. - Breathing is a blood-pumping process as well as an air-renewing process. When the chest expands,
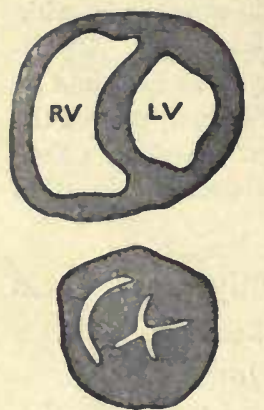

FIG. 59. - THE VENTRICLES OF A DOG'S HEART relaxed (above), and contracted (below).

blood is drawn into it. When the chest contracts, the flow of blood away from it is aided. As the chest expands, the downward pressure of a great, broad muscle, the diaphragm (Fig. 74) compresses the liver, stomach, and other abdominal organs, and forces the venous biood upward into the expanding chest, thus helping it on its way to the heart. But if the abdominal wall is weakened by tight lacing or by the pressure of belts and bands which support the clothing, the weak abdominal wall yields to the downward pressure of the diaphragm, and no compression of the liver or aid to the circulation will result.

How the Blood Vessels are Controlled. - Evidently the biood vessels are not regulated by the will. We cannot voluntarily increase the beating of the heart, or cause it to slacken its action. Even an actor cannot cause his face to turn pale or to blush at will. This is because the tiny muscles in the walls of the blood vessels are involuntary muscles. They are controlled by nerves of the sympathetic system called vasomotors. They are not subject to the will (see Fig. 25). The nerve center which controls the blood vessels is located in the top of the spinal cord at the base of the brain. When cold air strikes the skin the nerves near the arteries are stimulated, the arteries in the skin contract, and the skin turns white. When the heat from a hot fire strikes the skin, the nerves are soothed, the arteries relax, and the face becomes red. When the stomach is filled with food, the heart beats faster and sends more blood to aid in digestion. When we run fast, the heart beats fast to supply more blood to the muscles, but it slows down as sleep comes on, that the body and brain may rest.

Parts of the Blood. - The blood which flows from a cut finger seems to be a bright red throughout. When a drop of it is looked at through a microscope, however, the 
liquid itself is seen to be almost as clear as water. This liquid is called the plasma. Floating in it are millions of biconcave disks containing a pigment (hemoglobin) which gives the red color to the blood. The disks are called red corpuscles (Fig. 60). A few irregularly shaped bodies, nucleated and almost transparent, and called white corpuscles, are also found in the blood. The red corpuscles go only where the plasma carries them (Exps. 3, 4). The white

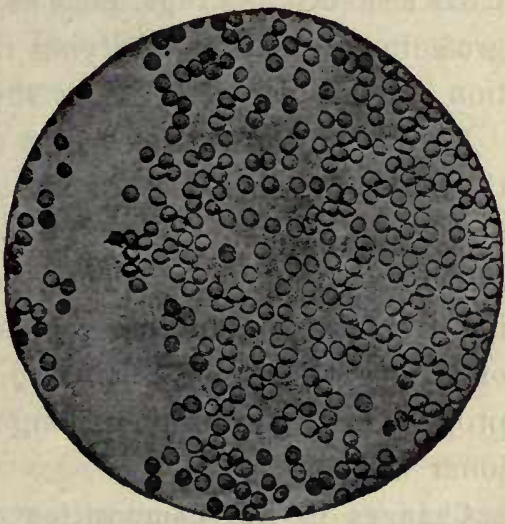

Fig. 60. - Human Blood Cells (magnified 40,000 areas), showing many red cells and a single white blood cell on left, larger than red cells. (Peabody.) corpuscles sometimes leave the blood vessels entirely.

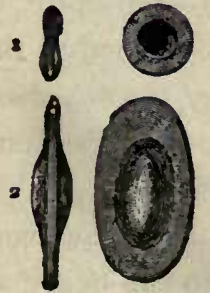

FIG. 6I.-SIDE AND FRONT VIEWS OF FROG'S ANDMAN'S RED CORPUSCLES, drawn to same scale. Compare outline, concavity, diameters.

At times one may be seen shaped like a dumb-bell, half of it through the wall of the blood vessel and half still in the blood vessel. After the corpuscle is out, no hole can be found to account for its mysterious passage. The white corpuscles consist of protoplasm. The red corpuscles contain no protoplasm. Hence the latter are not really alive.

The Use of Each Part of the Blood.The plasma keeps the blood in a liquid state, so that it may flow readily; the plasma also transports the food that has been eaten and digested, and carries carbon dioxid to the lungs and other waste material to the kidneys. The red 
corpuscles transport the oxygen from the lungs to the tissues. The white corpuscles devour and destroy irritating particles, such as drugs, poisons, and germs. They are of great importance in purifying the blood and as a protection against disease. One is shown in Fig. 60.

The sounds of the heart beat may be heard by applying the ear to the chest. They are two, a long, dull sound and a short, clear one. The first comes from the vibration of the bicuspid valve together with an unexplained tone arising from large contracting muscles, in this case the walls of the ventricles. The second, or short, clear sound, is produced by the sudden closing and vibration of the semilunar valves.

Changes in the Composition of the Blood as it passes through the Various Organs. - When the blood is forced out by the heart, part of it goes to the stomach and intestines through arteries which divide into capillaries. These capillaries absorb all kinds of food from the alimentary canal except the fats (see p. 64), and unite to form the portal vein, which takes the absorbed food to the liver. In the liver some of the impurities of the blood are burned up and changed into bile. The blood, purified and laden with food, is carried from the liver to the heart, where it reënters the general blood stream. The blood flow from the food tube through portal vein and liver to the heart, as just described, is called the Portal circulation.

Renal circulation. Two branches from the aorta carry blood to the kidneys. There the urea and a large amount of water are taken out, and the purified blood is emptied into the large vein that leads up to the heart.

Pulmonary circulation (Fig. 67). This is the circulation through the lungs. During this circulation carbon dioxid gas is removed from the blood and oxygen is added to it. 
Some impurities and a large amount of water escape from the blood as it passes through the skin.

Coagulation. - So long as blood is in an uninjured blood vessel it remains a liquid. In a few minutes after it flows from a blood vessel, it forms into a stiff, jellylike mass called a clot (Fig. 62). The process of forming the clot is called coagulation, and it is brought about by the albuminous substance called fibrin, which is always in the plasma of healthy blood. On exposure to air the fibrin forms into a net- FIG. 62.-BLood CLot work of fine threads throughout the separated from serum. mass (Fig. 63) and the corpuscles become entangled in the meshes. The clot consists of the fibrin of the plasma and corpuscles; the watery portion of the plasma, called the serum, separates from the clot (Fig. 62). The property of

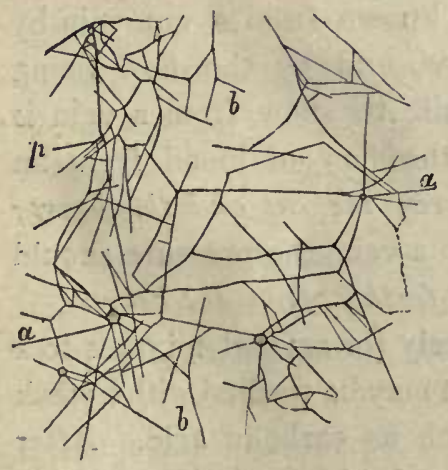

FIG. 63. - NETWORK OF FIBRIN IN HUMAN BLOOD (enlarged). coagulating is a great safeguard, as a clot often plugs up a cut blood vessel. What is the difference between serum and plasma?

Veins and Arteries compared. - The veins have thin, soft walls and the arteries have thick, tough, elastic walls. When a vein is cut, it may usually be closed by pinching the walls of the end together. If an artery is cut, the walls will not readily stick together, but often stand open until the end of the artery is tied. For this reason, and because an artery is subject to the direct pressure of the heart, a cut artery is more dangerous 
to life than a cut vein. Because of the toughness of the arteries, and because they are located close to the bones, they are less likely to be cut than the veins, which are softer and nearer the surface. The veins begin in capillaries and empty into the auricles; the arteries begin at the ventricles and empty into capillaries; and there is a semilunar valve at the origin of each artery.

Cuts and Bruises. - I. Wash a cut under minning water. 2. Stop the blecding. The washing in cold water may do this. Elevating an injured arm or leg will aid the blood greatly in forming a clot at the opening. 3. Bandage firmly with a strip of cloth and sew the end. Keep wet the part of the bandage where the cut is; this lowers the temperature of the wound. It may be necessary to hold a gaping wound closed with strips of surgeon's plaster placed across the cut. A handkerchief folded first into a triangle and then into a narrow bandage is often useful. A cut artery may be known from a cut vein by the brighter color of the blood, and by the flow being stronger at each heart beat, while the flow from a vein is uniform. Pressure to stop the flow of blood from an artery should be applied between the cut and the heart; but when the blood comes from a vein, the pressure should be applied to the side of the cut farthest from the heart.

Apply hot water immediately for several minutes to a bruise. Either a bruise or a cut may be washed with a weak solution of some antiseptic such as carbolic acid. After washing a bruise it may be bound with a cloth soaked in witch hazel or arnica.

\section{The Lymphatic System}

This system contains and conveys a liquid called the lymph. It consists of lymph spaces, lymph tubes, 
(lymphatics), and lymphatic glands. Lymph corresponds nearly to the blood without the red corpuscles. It is the familiar liquid seen in a blister, or oozing out where the skin has been grazed without breaking a blood vessel.

Necessity for Lymph and Lymph Spaces. - The body cannot be nourished with the albumin, sugar, oxygen, and other digested food in the blood, until this food passes out of the blood vessels. The food leaves the blood through the thir walls of the capillaries. Many of the cells do not touch the capillaries, and the lymph penetrates the spaces between the cells to reach them (see colored Fig. 3). If there were no lymph spaces, these cells could not get any food. The lymph bathes the cells, and the cells absorb what they want from the nourishing fluid. The red corpuscles bearing the oxygen cannot pass through the capillary walls. Oxygen, being a gas, readily passes through the walls and reaches the cells through the lymph in the lymph spaces. The waste materials must go back into the blood; carbon dioxid passes back through the capillary walls and is taken to the lungs; how the other waste materials formed in the cells pass back will soon be explained.

Need of Lymphatics. - The plasma continually passes into the tissues, but it cannot return directly into the blood. The lymph contains waste material which must be removed, and also much unused food which nature, like an economical housekeeper, will offer to the tissues again. There are vessels called lymphatics that take the lymph back into the blood (see Fig. 64).

The Lymphatic Circulation (Fig. 64). - The blood flow does not begin nor end, but makes a never ending circle. The countless lymphatics begin, with open ends, in the lymph spaces between the cells (colored Fig. 3). The smaller lymphatics unite into larger ones until finally they all unite into two large ones that empty into the large veins 
under the collar bones, near the neck. The one that empties under the left collar bone (3, Fig. 66) is called the thoracic duct because it goes

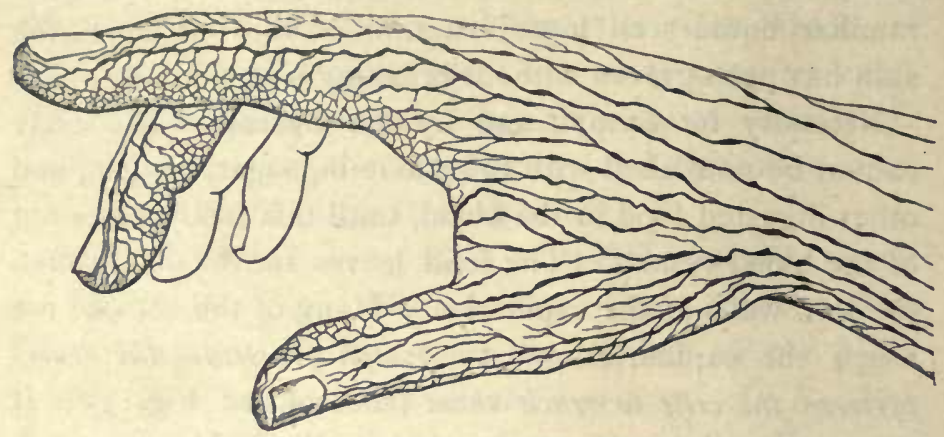

FIG. 64.-SURFACE LYMPHATICS OF HAND.

up through the thorax just in front of the spinal column (1. Fig. 66). The other at the right side of the neck is called the right lymphatic duct (see Figs. 64, 65).

In persons with the dropsy, the lymph accumulates in the lymph spaces and is not drained away by the lymph flow. Dropsy usually

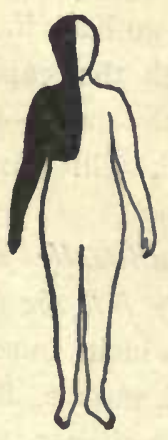

FIG. 65. - DIAGRAM TO SHOW THE TWO PARTS OF THE BODY DRAINED BY THE TWO LYMPH DUCTS. is drawn into the chest; and it is forced out of the chest at every contraction. Deep breathing is as great a benefit to the body in moving stagnant lymph as it is in purifying the blood. 
The lymphatic glands are kernel-like enlargements along the lymphatics, and they contain a great many lymph cells which purify the lymph as it passes through

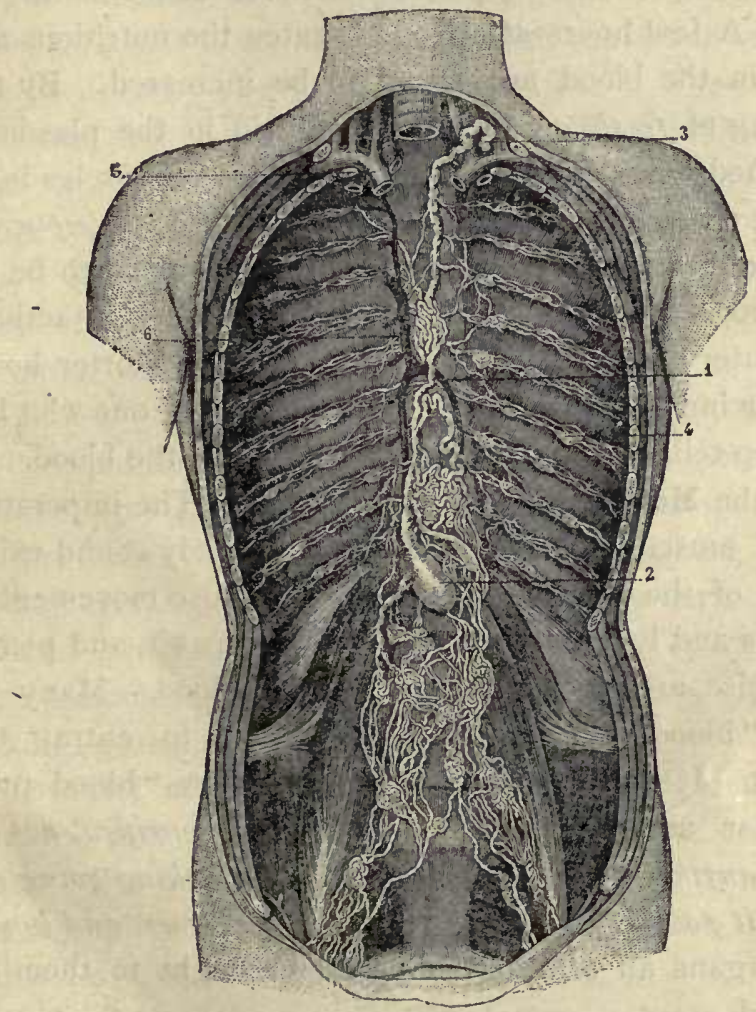

Fig. 66. - ChIEF LyMPHATIC VesSELS AND GLANDS of trunk.

1, 3, Thoracic duct (emptying at 3); 2, receptacle for chyle (lacteals below it).

them. The lymphatic glands are numerous in the armpits and the groins. The cells in the lymph glands multiply, and some of them are carried by the lymph into the blood to became those remarkable little bodies, the white corpuscles. 


\section{Hygiene of the Circulation}

Effects of Work, Fresh Air, and Rest on Corpuscles and Plasma. - Work uses up the nutritious elements in the blood. A few hours after food is eaten the nutritious materials in the blood are found to be increased. By the breathing of fresh air the carbon dioxid in the plasma is diminished and the oxygen in the colored corpuscles is increased, changing the blood to a brighter red. Sleep gives time for the exhausted cells and depleted blood to be replenished. Loss of sleep means longer hours of activity and greater consumption of nutriment with shorter hours for replacing the nutriment. The pale skin of one who has lost sleep tells of the exhausted condition of the blood.

How the Muscles help the Circulation. - The imperative need of muscular exercise to keep the body sound exists because of the lack of other means to cause movement in the veins and lymphatics. Good food, pure air, and plenty of exercise are necessary for healthy blood. Many socalled "blood purifiers" are advertised to entrap the ignorant. It is impossible to imagine how "blood purifiers" can aid the blood. The blood is purified, not by putting anything into the blood, but by something going out of it as it passes through the skin, kidneys, liver, and lungs. These organs all send out impurities brought to them by the blood.

The one great hygienic effect of muscular exercise is an active circulation, and from an active circulation nine chief effects may be traced. The effects upon the body will be given in order, beginning with the surface-skin, fat, muscles, bones; and the effects upon the internal organs are given in order of position, beginning with the highest - brain, lungs, heart, digestive organs. 
Effects of Exercise and Improved Circulation. - I. The skin is made fresh, pink, and smooth from the flushing of the capillaries; it is purified by the perspiration and the renewal of cells. 2. If the fat is too great in amount, it is burned up; if it is too small in amount, the better nourishment brought by the blood increases it. 3. The muscles are better fed (see Fig. 48) and grow firm, strong, and large. 4. The skeleton is held in proper position by the stronger muscles, and deformity is prevented. 5. The brain. The pure, fresh blood, loaded with oxygen from expanded lungs, flushes every capillary of the brain, clears the mind, and doubles or trebles its power to work. 6. The lungs are expanded by deep breathing if the exercise be rapid and vigorous. A slow stroll or saunter is not of value. 7. The circulation. Every contracting muscle aids the heart in its work. The deep breathing moves stagnant lymph. 8. The stomach. Exercise burns up the food and increases the appetite. 9. General effects. Exercise promotes good humor, decreases loafing, cigarette smoking, gossiping, and other vices.

The effect of tobacco on the heart, if cigarettes or cigars are used, is sometimes to cause attacks of irregular beating; the heart flutters faintly for a while, then palpitates strongly, then flutters again. This condition is called tobacco heart, or trotting heart.

Effect of Alcohol upon the Circulation. - After a person has taken an alcoholic drink his face and skin are likely to become flushed, and perhaps his heart beats faster. Most investigators have found that the alcohol itself does not directly increase or strengthen the action of the heart. Hence it is probably wrong to call alcohol a heart stimulant. The flushing of the skin is believed to be due to the relaxing effect of alcohol. It relaxes, it paralyzes, the 
vasomotor nerves which control the little muscle fibers: in the walls of the blood vessels. The relaxing and: enlarging of the blood vessels decreases the resistance to the blood flow, and the heart beats faster under its lighter load. The narcotic effect of alcohol is much more power-ful than its irritating or stimulating effect. The effect. of alcohol in causing fatty degeneration of the muscles: often weakens the heart and other blood vessels.

Climate and Brain Work. - In going to sleep the vessels in the skin dilate and blood is drawn from the brain to the skin. It is difficult to go to sleep when cold, for cold sends the blood to the brain and keeps the mind active. On the same principle, mental work is difficult in very warm weather because of the enlarged capillaries in the skin and the withdrawal of blood from the brain to the skin. This increases the perspiration and keeps the temperature of the body down to normal, but it deprives the brain of blood needed for good mental work. Mental workers in warm weather and in warm climates should seek eviery condition favoring coolness. Benjamin Franklin was accustomed to strip himself almost entirely of clothing when he was writing and wanted his brain to work at its best. The wearing of barefoot sandals and the thinnest cotton clothing, light in color, helps to prevent mental inertia in hot weather. In the Gulf states in summer and in our tropical islands the best mental work can be done by rising at dawn and working before the hot part of the day begins. Some of the greatest thinkers in the world have lived in warm climates (Greece and India), but they wore very few clothes and ate moderately of the simplest food (see p. 44).

Congestion is a swelling of the blood vessels of some part, with the accumulation of blood therein. Congestion is active when a rapid flow of blood distends the capillaries. Example, flushing of face when running. Congestion is passive when there is a narrowing of the outlet of the capillaries, the blood moves slowly and partly stagnates in the swollen vessels. Example, when the nose feels stopped up during a cold. If a syringe is worked so fast that the rubber tube swells, this is like active congestion; if the end of the tube is pinched together so that moderate pumping causes it to swell, this is like passive congestion.

Inflammation is congestion where the vessels of any part are strained and injured. White corpuscles collect there to repair the vessels and devour the blood that escapes and stagnates there. They also destroy germs that have usually found lodgment and begun to multiply. The 
serum of the blood also destroys the germs by the antitoxins in it. Inflammatory troubles are: colds, rheumatism, diarrhœa, and all diseases with name ending "itis." An inflamed part is red, swollen, hot, and painful.

Prevention and Care of Colds. $-A$ cold is an inflammation of a mucous membrane. Colds are prevented by so living as to encourage a free, vigrorous circulation, and especially by not coddling the body so tenderly that the circulation becomes deranged by the least exposure. The circulation may be deranged by overheating as well as by chilling the body; usually it would be more appropriate to say that the person caught "a hot" than "a cold." At the first sign of a cold vigorous exercise, a cold bath, or going outdoors into cold air may aid in sending fresh blood to remove the stagnation and stop the inflammation. A warm foot bath and hot drinks may relieve by drawing blood from the congested mucous membrane. After the cold has become fixed such measures will not help, but the cure is aided by helping the skin to keep its full share of blood. The cold must run its course. The cells will be given every chance to repair the injury and destroy the germs (if any) by avoiding hard work, eating moderately of digestible food, avoiding drugs, especially infallible drugs advertised in newspapers, even if recommended by otherwise intelligent people. Repeated colds tend to become a disgusting disease called chronic catarrh. Constricting the blood vessels of the skin causes congestion of the (internal) mucous membranes. A skin tenderly protected constricts more readily than one accustomed to cold. Cold is the best preventive of cold. Cold baths, pure air, light clothing, free breathing, moderate eating, ward off colds. Fussing with sprays, gargles, and drugs will not; for the main factor in bringing on a cold is not germs, nor temperature, but the state of the system itself. Persons who have suffered much with colds have found that after substituting cotton underwear for woolen, colds became very rare. Linen will have a similar effect, but it is not as durable, soft, or heat-retaining as cotton (see p. 16).

Practical Questions. - 1 . Through what kind of skin do the blue veins in the wrist show most plainly? 2. Which is more compressible, a vein or an artery? 3. Why are those who take little exercise likely to have cold feet? (p. 57.) 4. Where does the so-called venous blood flow through an artery? 5 . What vein begins and ends in capillaries? (The portal vein, colored Fig. 5.) 6. To what purifying organ, after leaving the lungs, does the heart send part of the blood for further purification. (Colored Fig. 5.) 7. What keeps the blood moving between the beats of the heart? 


\section{CHAPTER VI}

\section{THE RESPIRATION}

Experiment 1. (Home.) Study of the Throat. - Sit with the back to the light. Study the open mouth and throat with a mirror and make out the uvula, tonsils, and other parts shown in Fig. 68.

Experiment 2. Anatomy of Lungs. - Study fresh lungs of sheep, hog, fowl, or frog. Will they float? Will they contract when expanded by air blown in through a quill or other tube? What is the structure of the windpipe? Can you distinguish the arteries from the veins by the stiffness of their walls? Which contain pure b'ood? Study branching of air tubes. Make a sketch.

Experiment 3. Tests of Expired Air.-Breathe upon a mirror, bright knife blade, or cold window pane. Result? State your conclusion? Experiment 4. - Carbon dioxid added to limewater will cause a white cloud consisting of particles of limestone. Breathe through a tube or straw or the hollow stem of a reed into clear limewater. Result? Conclusion? (Limewater may be had at druggist's or made by pouring water upon a lump of unslackened lime and draining it off when lime has settled.) Experiment 5. Breathe for several minutes upon the bulb of a thermometer. Result? Conclusion? Experiment 6 . Breathe a few times into a large, carefully cleaned pickle jar, or a bottle. Cork it tightly, and set it in a warm place for several days. Then uncork and smell the air in it. Result? Conclusion? Experiment 7. Pierce a small hole in a card, place card over a wide-mouthed bottle, and breathe into bottle through a tube, lemonade straw, or hollow reed. Pull out straw. Place bottle, mouth downward, on table, and slip out card. Slide bottle to edge of table and lift lighted candle into bottle. Result? Experiment 8. Place bottle of fresh air over lighted candle. Result? Conclusion? (See Animal Biology, p. 14.)

Experiment 9. (School.) Testing the Air of a Room. - Fill a fruit jar or large bottle with water, and take it into a room containing many people. Pour out the water. (This insures that all the air now in the jar is air obtained in the room to be tested.) Seal the jar if test is not to be made at once. Test by pouring in two tablespoonfuls of clear limewater and shake. If the limewater turns milky, the ventilation is bad.

Experiment 10. (Home and school.) Homemade Current Detector.Dangle a bit of paper by means of a spider web or thread from the 
end of a walking stick or ruler. (Or test with the flame of a candle.) Hold it near cracks of window, above and below doors, and especially before openings intended for entry and exit of air, and test if air moves as desired.

Experiment II. Ventilation of the Schoolroom. - Let the whole class rise, and with the fingers test cracks around doors and windows. Wherever the air feels cold to the hand the air is entering.

Experiment 12. Dust. - With a mirror cause a sunbeam to play like a search light into a closed room several hours after it has been swept. Result? Do the same in a room where every window and door were open during sweeping and left open afterwards. Result? Conclusion? Note also the amount of dust on the furniture of each room.

Experiment 13. Study of Habitual Quiet Breathing. - Without any more disturbance of the breathing than can be helped, direct your attention to your breathing while sitting quietly. Record motions of any parts of chest and abdominal walls that may be noticeable. If necessary, lay the hands successively against different parts of the wall to test for motion. Think of another subject, and later repeat observations.

Experiment 14. Study of Deep Breathing. - Place your hands successively upon the front and sides of your chest, waist, and abdomen, while drawing in and sending out deep breaths. What motions of the several parts are observed at each stage?

Experiment 15. Study of Elasticity as a Factor in Breathing. (I) Notice whether in quiet breathing there is an elastic rebound as the breath goes either in or out. If so, it is due to the elasticity of the cartilages or air cells of lungs, or both. (2) Breathe by inflating the lungs strongly at each breath. Is the air then forced out without effort? (3) Breathe by flattening the chest and abdomen as much as possible at each breath. Does the air then rush in without effort?

Experiment 16. Chest Breathing. - Try to breathe wholly by deep expansions and contractions of chest wall. What motions, if any, are noticed in abdominal wall as breath goes in? As it goes out? (Test motions with hand.)

Experiment I7. Abdominal Breathing. - Try to hold the chest walls still and breathe by strong contraction and expansion of abdomen. Do the chest walls move at all? Neither "chest breathing" nor "abdominal breathing" is the normal way. See text.

Experiment 18. Full Breathing. - Try breathing by outward and inward movement of walls of chest, waist, and abdomen. Do you succeed? This is normal breathing. Is the motion greater at the front or the sides of the waist? Put a belt around the waist tight enough to stay in place and repeat. Is the waist motion interfered with? 
Experiment 19. How the Ribs are Lifted. - Make a model like sketch to represent backbone, breastbone, and two ribs, using pins to

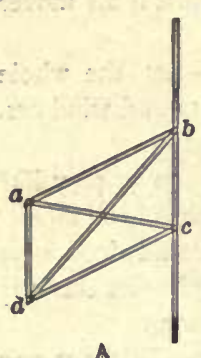

A make joints loose at corners. Use cords for diagonals. What happens when cord $a c$ is pulled? When cord $b d$ is pulled? The cords correspond to the two sets of muscles between the ribs.

Experiment 20. Study of Laughing. - Place the hands upon the waist and abdomen when laughing. What motion occurs at each sound of laugh? Draw in the abdominal wall with a jerk. What is the effect upon the breath?

Experiment 21. Modifications of the Breath. Write I, E, or IE after each word in this list, according as inspiration, expiration, or both, are involved in the action. (Test with sham acts if possible.) Sighing, sobbing, crying (of a child), coughing, laughing, yawning, sneezing, hiccoughing, snoring.

Experiment 22. Effects of Exercise. - Count and record the rates of breathing before and after vigorous exercise.

Experiment 23. Comparative Study. - Observe and record the rate and manner of breathing of cow, horse, dog, cat, etc. Is the air drawn in or sent out more quickly? Is there a pause? If so, after which stage of breathing?

Experiment 24. Emergency Drill. - Resuscitation from drowning: etc. See Coleman's “Elements of Physiology," page 356.

Necessity for Breathing and for Specialized Organs of Breathing. - The body is a self-regulating machine which possesses energy. This energy, like that of steam engines, arises from oxidation which takes place continually, but at a varying rate. Food for fuel is taken at intervals, but oxygen must be taken in continually. Man breathes about eighteen times per minute. The blood in the tissues soon becomes dark because of loss of oxygen and absorption of carbon dioxid. It is then pumped through the heart to the organ which has the function of absorbing oxygen and giving off carbon dioxid (Fig. 67). In some animals, as the ameba and the earthworm, the surface of the body suffices for breathing. This cell breathing is the true essential respiration; it is universal among living things, 
both plants and annimals. To supply the deeper cells large animals require a breathing surface greater than the area of the skin. This is supplied by having the oxygen-absorbing surface folded inward to form folds, tubes; and cavities of great complexity. If the lungs of a man were unfolded and all their tubes and cavities spread upon one surface, an area of more than one hundred square feet (or ten feet square) would be covered.

Each respiration, or breath, consists of the passing in of the air, or inspiration, sending it out, or expiration, and a pause after one but not after both of the other stages.

\section{The Air Passages.}

- The air usually passes in at the nose and returns by the same way, except during talking or singing. Observe your mouth with a mirror (Fig. $68)$; at the back part, an arch is seen which is the rear boundary line of the mouth (Exp. I). Just above the

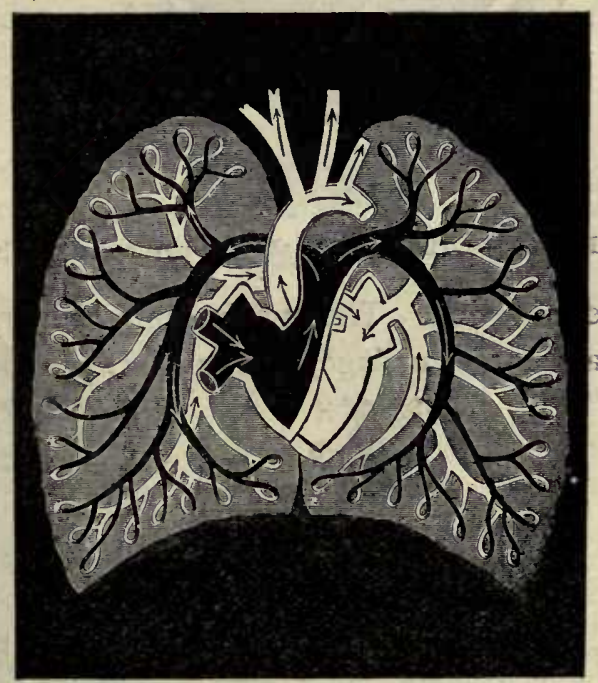

Fig. 67.-Circulation through Lungs (schematic): "venous" blood (in pulmonary artery) black; "arterial" blood (in pulmonary veins) white.

arch is likewise the rear boundary line of the nasal passages. The funnel-shaped cavity beyond, into which both the mouth and nasal passages open, is called the pharynx (far'inks), or throat (see Fig. 68, also Fig. 83). Below, 


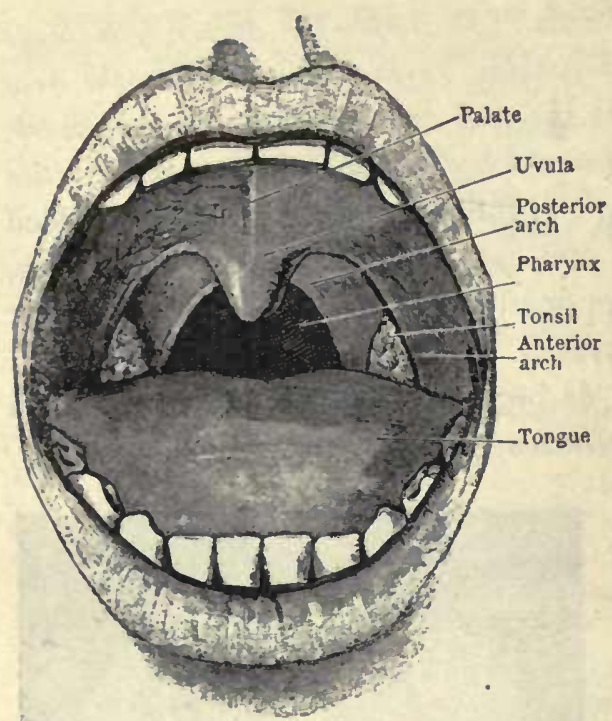

FIG. 68.- OPEN MOUTH, showing palate and tonsils. two tubes open from the pharynx. One is the trachea (trā'kea) or windpipe, the other is the esophagus or gullet. At the top of the trachea is the cartilaginous lar$y n x$, or voice box. If the finger is placed upon the larynx or Adam's apple, it is plainly felt to move up and down when swallowing. The opening into the larynx is provided with a lid of cartilage, the epiglottis. Inside the larynx, the

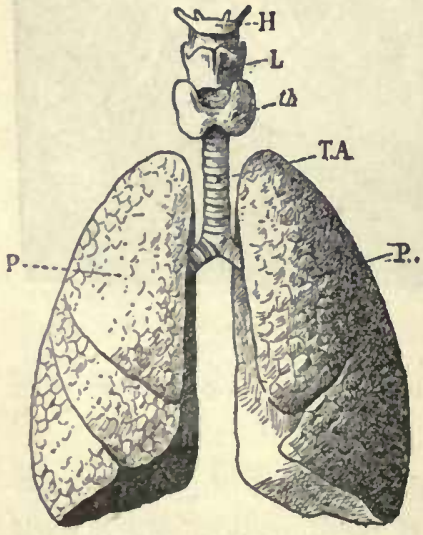

FıG. 69. - LUNGS, $P$; with trachea, $T A$; thyroid gland, th; larynx, $L$; and hyoid bone, $H$. vocal cords are stretched from front to back. Just below the larynx comes the trachea proper, which is a tube about three fourths of an inch in diameter and about four inches long (Fig. 69). It consists of hoops of cartilage (Fig. 69) which are not complete circles, but are shaped somewhat like the letter $\mathrm{C}$, being completed at the rear by involuntary muscular tissue, whose function 
is to draw the ends together at times (for instance, during coughing) and reduce the size of the tube. The function of the hoops of cartilage is to keep the windpipe open at all times. If it should be closed by pressure, life might be lost. These rings of cartilage may be felt in the neck.

The lower end of the trachea is just behind the upper end of the breastbone; there it divides into two large. tubes. These subdivide into a great number of smaller branches called bronchial tubes. Cartilage is found in the walls of all but the smallest of the tubes. The subdivision continues, somewhat like the branching of a tree, until the whole lung is penetrated by bronchial tubes. Each tiny tube finally ends in a wider funnel-shaped chamber called a lobule (Fig. 70), into which so many dilated

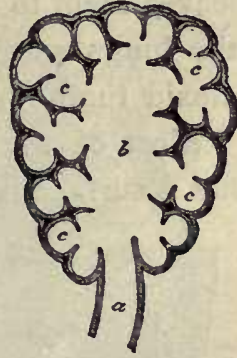

Fig. 70. - LOBULE OF LUNG. sacs, called air cells, open, that the walls of the terminal chamber or lobule may be said to consist of tiny cups, or

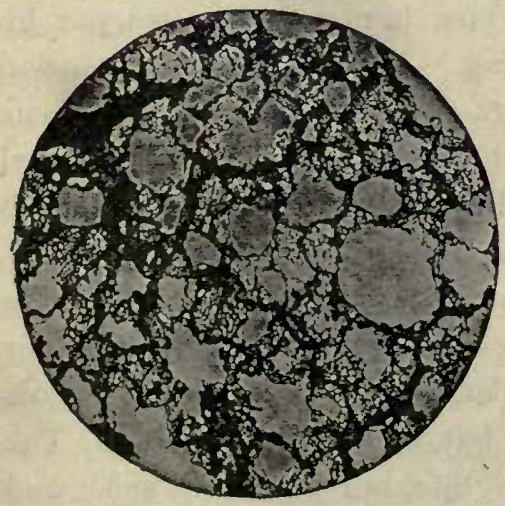

Fig. 7I. - CAPILla Ries around Air Sacs of LuNGS (enlarged 30 diameters). Air sacs in white spaces. Dark lines are capillaries. (Peabody.) air cells, placed side by side. The lobules, or clusters of air cells, are chiefly near the surface of the lung. (The word "cell" is here used in its original sense to denote a cavity or chamber, and not in the sense of a protoplasmic cell.)

The aircells are elastic and enlarge by stretching as the chest expands; hence, the cells 
must have many of the yellow elastic fibers of connective tissue in their walls. They are lined with an exceedingly thin membrane of epithelial cells through which oxygen and carbon dioxid are exchanged. In the walls of the air cells there is a network of capillaries (Fig. 7I). The dark red blood comes into these capillaries from the pulmonary arteries, and is changed to a bright red by the time it leaves them to enter the pulmonary veins. The air leaves the lungs warmer, moister, and containing more carbon dioxid than when it entered.

Most of the mucous membrane lining the air passages has a surface layer of ciliated cells. Cilia are tiny thread-

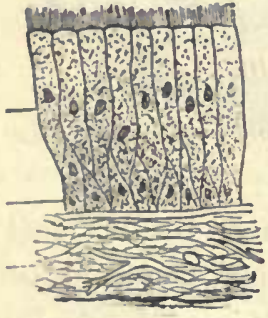

Fig. 72. - CiLIATED

CELLS, lining the air passages. like projections (Fig. 72) which continually wave to and fro, the quicker stroke always being outward; for their function is to remove particles of dust and germs that may find entrance to the air passages. When the mucus containing the dust is raised nearly to the larynx, it may be thrown out by coughing. Near the opening of the nos. trils are placed many hairs, hundreds of times larger than cilia, through which the air is strained as it enters the nose. Hairs are multicellular; cilia are parts of cells. See Animal Biology, Fig. I4.

The Lungs. - The entire chest cavity is occupied by the lungs except the space occupied by the heart, the larger blood vessels, and the gullet. The right lung has three lobes, or divisions, and the left lung has two lobes. The lungs are light pink in early life, but become grayish and darker as age advances. This change is more marked in those who dwell in cities, or wherever the atmosphere is smoky and dusty. The lungs are covered and inclosed by 
a smooth membrane called the pleura. This membrane turns back and lines the chest wall, so that when the chest expands, the two sleek membranes glide over each other with far less friction than would be the case if the lungs and chest wall were touching (Exp. 2).

The Respiratory Muscles. - (Repeat Exps. 13, I4, I5.) The chief breathing muscles are the diaphragm (see Figs. 73 and 74), the muscles forming the abdominal walls (see Fig. 44), and two sets of short muscles (an internal and an external set), between the ribs. They are called intercostals. (They are the flesh eaten when eating pork ribs.) The diaphragm, which is shaped like a bowl turned upside down, rounds up under the base of the lungs somewhat like a dome and separates the chest from the abdomen. Its hollow side is toward the abdomen and its edges are attached to the lowest ribs and the vertebra of the loins. Inspiration is brought about by the rising of the ribs and the descent of the diaphragm. Expiration takes place when the ribs descend, the abdominal walls draw in,

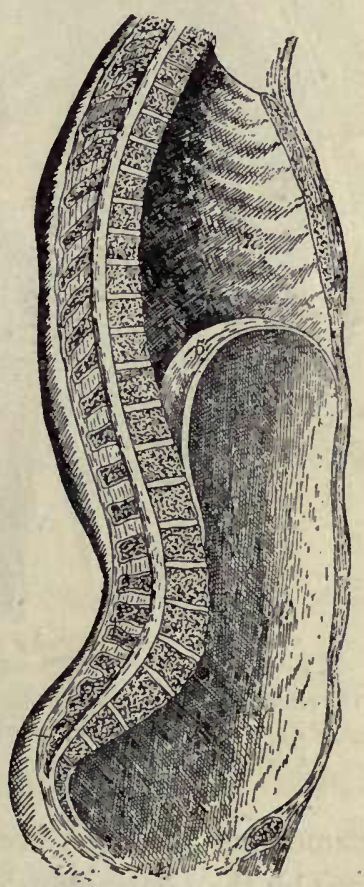

Fig. 73. - Vertical SECtion OF TRUNK, showing diaphragm, cavities of thorax and abdomen. and the transmitted pressure lifts the relaxed diaphragm.

Inspiration. - To cause inspiration the diaphragm contracts, it flattens and descends, since its edges are attached 
lower than its middle (Fig. 73); the lungs descend with it, thus lengthening the chest from top to bottom; at the

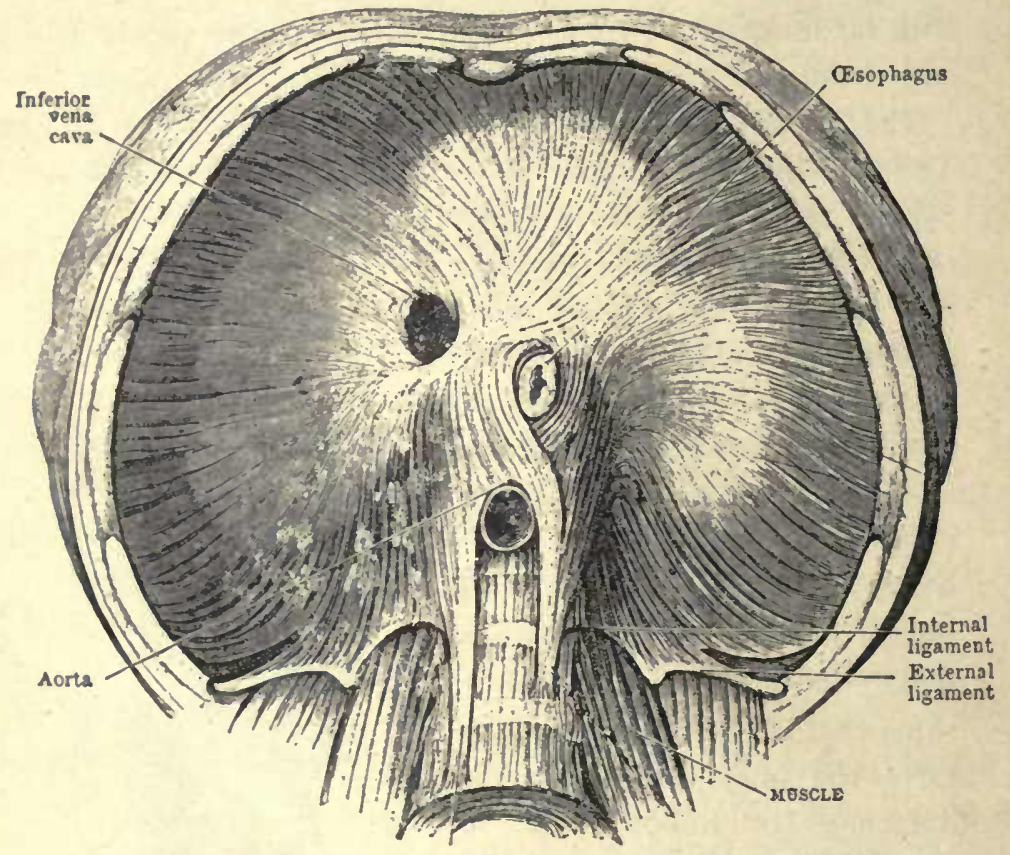

FIG. 74.- DiApHRAGM (or midriff), seen from below. (Cunningham.)

The central portion (light) is tendinous. As the diaphragm descends, it acts like the piston of a great pump and the blood is forced up through the vena cava, and the ly mph through the thoracic duct (Fig. 66).

same time the ribs are raised upward and outward (Fig. 76) by the contraction of the outer set of muscles between the ribs. Thus the chest is made longer, broader, and deeper from front to back. The lungs expand when the chest expands, and the air rushes in. Why is this? The lungs contain no muscles and cannot expand themselves; the air cannot be pulled in, for its parts do not stick together. The true reason is that the air has weight. The 
atmosphere has a height of many miles, and the air above is pressing on that below. When the chest walls are raised there would be an empty space or vacuum between these walls and the lungs, did not the pressure of the outside air push air through the windpipe into the lungs and expand them (Exp. 19).

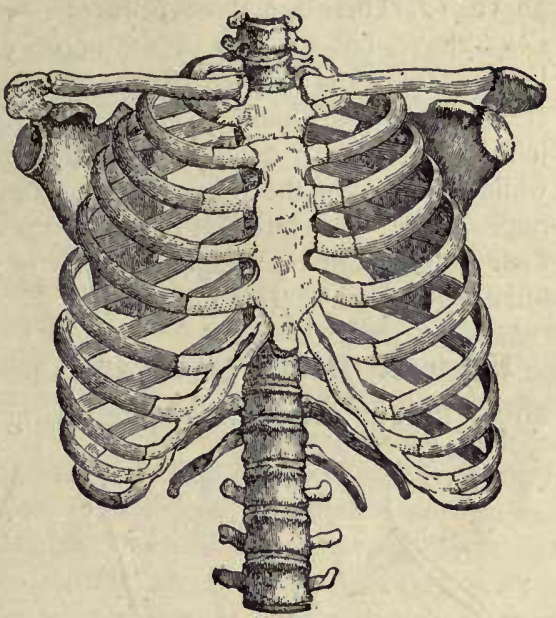

FIG. 75. - Framework of Chest.

Expiration. - In very active breathing the abdominal

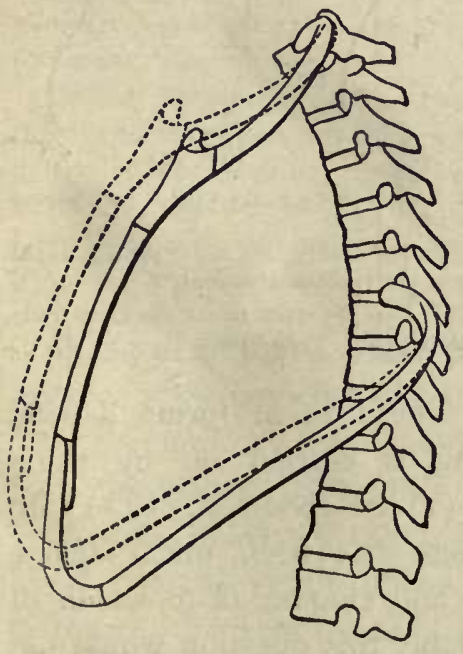

FIG. 76. - BlackBoARD SKetch, to show how the chest is expanded when the ribs move upward and outward. walls actively contract so that they press strongly upon the digestive organs, which in turn press the diaphragm up. The ribs are also drazen down and in. Thus the chest becomes smaller and forces the air to flow out through the windpipe (Exps. 20 and $2 \mathrm{I}$ ).

Thought Questions. - Why breathing with the waist is easier than breathing with the upper chest. Effects of confining the waist.

I. There are two pairs of ribs below, while there are none 
above. 2. There are three pairs of $\longrightarrow$ ribs below, while there are none above, but all ribs of the upper chest are - ribs. 3. The lower of the joints between the seven pairs of true ribs and the sternum are more flexible than the upper joints because - - (Observe the joints in Fig. 75.) 4. The walls of the waist swing - and while the walls of the upper chest must move — and — 5. The bones of the rest upon the upper chest. In upper chest breathing their weight, and the weight of both of the — must, therefore, be lifted. (Fig. 28.) Test by trying it.

Hygienic Habits of Breathing. - Chest breathing uses chest chiefly, abdominal breathing uses abdomen chiefly,

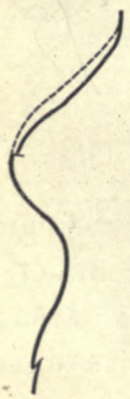

FIG. 77.

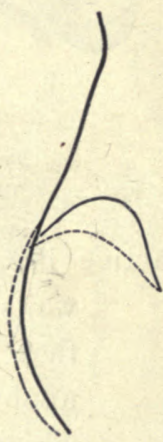

FIG. 78 .

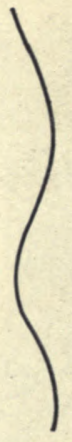

Fig. 77. - Female Figure encased in Corset. Expansion at the waist is here impossible and the breathing is called "collar-bone breathing."

Fig. 78. - Male Figure. Here, owing to pressure of clothing and faulty position, expansion of chest is hindered and breath is taken by the " abdominal method."

Fig. 79. - Figure Properly Poised and Free. Here the entire thorax can move freely, and natural breathing is the result. (For blackboard.) From Latson.

full breathing uses both. These three forms depend upon whether the breathing is carried on by using the muscles of (I) the chest, (2) the abdomen, or (3) both (see Figs. 77, 78, 79). There has been much debate among physicians, surgeons, and singers as to which of these methods is best. Probably this question would not have been raised but for the confining and deforming effect of clothing upon the waist. Full breathing is used 
by children of all races, by both men and women of wild tribes, and by men of civilized countries. It is undoubtedly the natural way, as well as the easiest and most effective way (Exps. I6, I7, I8).

Breathing with the upper chest is exhausting because of the stiffness of the upper part of the bony cage (see Fig. 75); for it is inclosed by true ribs fixed to the breastbone by short cartilages. The ribs in the waist (Fig. 75) are either floating in front or fixed by long cartilages to the ribs above. In pure abdominal breathing the diaphragm must contract more than in full breathing in order to descend, because its edges have been drawn together and fixed by binding the ribs at the waist. In full breathing the floating and false ribs at the waist (five pairs in all) float in and out as nature provided. As they move out, this broadens and deepens the chest, and aids the flattening of the diaphragm by moving its edges firther apart. Those persons, perhaps one in a thousand, who voluntarily deform the body with tight clothing are beneath contempt. But so uniform is the pressure of tight clothes and shoes that the wearer soon becomes unconscious of them, and so powerful are the effects that not one person in a thousand escapes deformity and injury. Children's clothing should be supported by the shoulders, and adults' clothing by both shoulders and hips, but by the waist, never.

Cellular Respiration. - The chemical activities within the cells and their need of oxygen, not the amount of oxygen in the lungs or blood, determine how much oxygen the cells absorb from the blood. Oxygen cannot be forced even into the blood beyond the required amount. Deep breathing movements, however, help the flow of the blood and lymph. Carried to excess, they tire the will and exhaust the nerves.

Changes in Blood while in the Lungs. - The coloring matter (or hemoglobin) of the corpuscles absorbs oxygen (and becomes oxy-hemoglobin). Carbon dioxid is given off from the plasma. The blood becomes a brighter red.

Changes in Air in the Lungs. - The air entering the lungs consists of about one fifth oxygen and four fifths nitrogen. This nitrogen is of no use to the body, and is exhaled unchanged. A part of the oxygen inspired is taken up by the blood, and carbon dioxid is sent out in its place. 
About half a pint of water is given off through the lungs in a day. Minute quantities of injurious animal matter are also given off in the breath from even the soundest person. The air leaves the lungs warmer, damper, and with more carbon dioxid than when it entered (Exps. 3 to 9).

Persons with decayed teeth, catarrh, indigestion, diseased lungs, or other unsoundness give off still more of this material. When many people are assembled in a badly ventilated room, the amount of injurious animal matter in the air is much increased, and is called "crowd poison." Its odor is strong and repulsive to one who just enters the room, but the sense of smell becomes dull to it in a few minutes. It would seem that nature gives a fair warning against harm; but if we disregard the warning it soon ceases.

People who are really Unclean. - Nature's plan seems to be for us to live out of doors. Air once breathed is impure. It is just as unfit to enter our bodies as muddy water or decayed food. Yet many who call

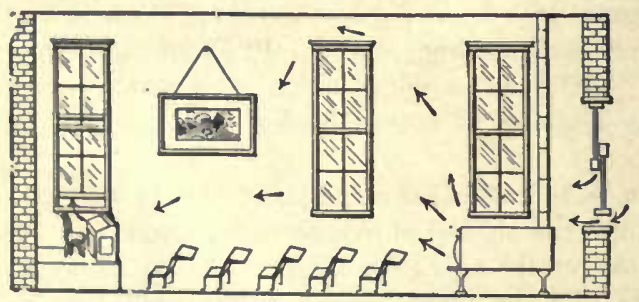

Fig. 80. - Ventilation of STOVE-heated Room. ${ }^{1}$

How are the inlet and outlet situated with reference to the stove ? themselves cleanly and refined, and will not allow a speck of dirt to remain on their clothes, nor use a spoon just used by another, do not object to breathing into their lungs, over and over again, the cast-off air from the lungs of others. If a window is opened for ventilation, they are horror-stricken for fear of drafts. Drafts are injurious only to persons perspiring, or to those who have coddled the skin by continually overheating it. There are thousands of schools, churches, and theaters all over the land, which reek daily with the malodorous particles from the lungs of their occupants. Although the air in them is odorless to those who occupy them, it is disgusting to any one who enters from the fresh air. Figure 80 shows the correct ventilation of a stove-heated schoolroom.

Dust causes catarrh of the bronchial tubes and chronic ${ }^{1}$ From Coleman's Elements of Physiology (400 pp.). The Macmillan Co., N.Y. 
inflammation of the lungs; it prepares for consumption, by gradually weakening the lungs of those who breathe it. Intelligence and common sense are necessary to prevent it from accumulating in the house. The chief' purpose of the house cleaning should be not only to remove bits of paper from the floor, which do no harm even to the shoes, but to remove impurities from the air. It does no good to stir up the dust and allow it to settle down again (Exp. 12). In many houses dust is thus allowed to accumulate for months. Experiments show that dust and germs floating in the air are not diminished to a great extent by a gentle draft through the room. The windows must be open and sweeping done in the direction of the air currents; the windows should be left open for a long while after the sweeping. A windy day is best for sweeping.

The habit some housekeepers have of buying furnishings and brica-brac for the home until it looks like a retail store or junk shop, makes it almost impossible to clean their houses. A few articles, carefully selected, adorn a home more than many bought at random, and they do not litter the house and serve as traps for dust. With all precautions some dust may settle down. This should not simply be stirred up again with a feather duster, but the dusting should be done with a damp cloth. Ashes should be sprinkled before they are moved. Carpet sweepers, but never brooms, should be used upon carpets. Carpets and lace curtains are truly dust traps, in which dust will accumulate without limit. Those who value the health will not use such uncleanly abominations, at least in bedrooms. Though linoleum, bare floors with movable rugs, oiled and painted floors, may not look so comfortable as a fixed carpet, they bring far more comfort in the end. The weakening effect of ordinary dust is one of the chief causes of lung diseases, and prepares a fertile soil for the consumptive germ. The sputum coughed up by consumptives falls upon the floor or street, soon dries, and the germs are driven about by the wind. In many cities there is a law against spitting in public places, and the streets are flushed with water before they are swept.

Ventilation presents no difficulties in the summer time or in warm climates. The reason that it is a difficult 
question in cold weather is because the air furnished must be not only pure, but warm. To keep cold air out often means to keep foul air in. Heating with hot air, by which

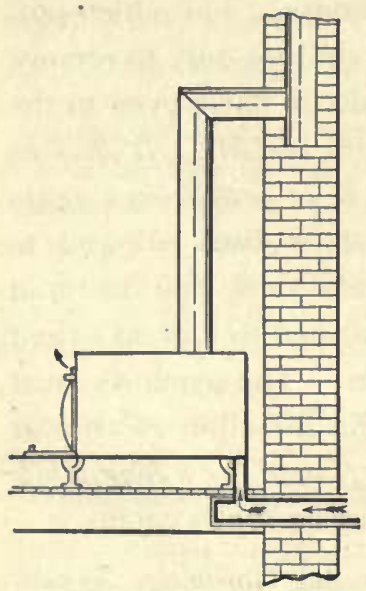

FIG. 8r. - The air enters through a special inlet and is warmed as it passes through hood surrounding the stove. system pure air is passed over a furnace, and fresh air constantly admitted, may be a good method (Figs. 80, 81), but is often a dismal failure because it dries out the air, which in turn dries out the skin. To prevent this, wide vessels of water should be set at the inlets. Dry air is cooling. Why? Dr. Barnes proved that moist air at $65^{\circ}$ is as comfortable as dry air at $71^{\circ}$. Air saturated with vapor at $60^{\circ}$ will only be 50 per cent saturated at $80^{\circ}$. Such air dries out the mucous membrane of eyes, nose, and throat. Heating by hot water circulating in pipes, or by steam, gives no means of introducing fresh air, and is likely to cause worse ventilation than any other method. The radiators should stand close to windows or other fresh-air inlet, that the air may be heated as it enters, and the outlet for air should be farthest

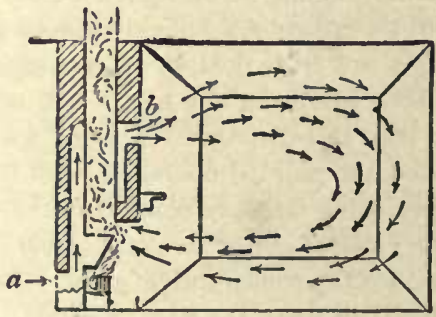

Fig. 82, - Chimney with a passage behind fireplace, or grate, in which the air is warmed as it enters. from the radiators. The same rules apply to heating by stoves. An oil stove for heating is an inconceivable 
iniquity to any but a person densely ignorant of hygiene. Heating by fireplaces (Fig. 82) is the most healthful of all methods, for there is a constant removal of air through the chimney, and this air will be replaced; even if all doors and windows are closed, it will come in through tiny cracks. Radiant heat travels in straight lines from a fireplace and warms solid objects, but not the air passed through. Hence an open fire will keep the body warm with the room at a low temperature. Fireplaces, however, do not afford sufficient heat in severe climates.

Stoves are not as healthful as fireplaces, for there is not so much air removed through the pipe as through the chimney. Carbon monoxid, unlike carbon dioxid, is an $a c$ tive poison causing the blood corpuscles to shrivel. It passes through red-hot iron or a cracked stove or furnace.

Reasons for Breathing through the Nose (Fig. 83). - (I) The many blood vessels in the mucuous membrane lining the nasal passages so

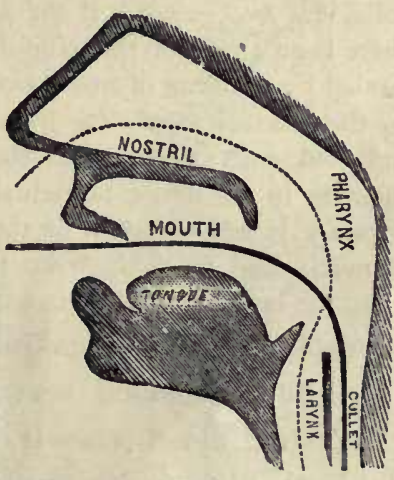

Fig. 83. - BLACKBOARD SKETCH. heat the air that it does not irritate the bronchial tubes. (2) The hairs
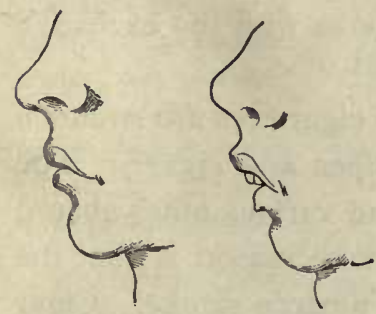

FlG. 84. - Facial expression in mouth breathing, and breathing through the nose. in the nostrils strain the air and catch dust; the cilia of the nasal passages also do this. (3) A mouth-breather often swallows food before chewing it sufficiently, because he cannot hold his breath longer. (4) The nasal inucous membrane of an habitual mouthbreather dries and shrinks and obstructs the circulation, bringing on catarrh of the nose. (5) Mouth breathing causes an unpleasant expression of countenance (see Fig. 84). (6) The 
breath does not come througl the nose as quickly as through the mouth; the lungs are kept more expanded, and one does not get "out of breath" so quickly. (7) The voice of the mouth breather has a hard twang, not a full, resonant tone as when the nostrils are open. (8) Flavors and odors are better appreciated. Sometimes the sense of smell is almost lost by mouth breathers. If one cannot breathe through the nose, even for a short time, there is probably an adenoid, or tonsil-like, growth in nose or pharynx, and a physician should be consulted. "Adenoids" are glandular or grapelike in form.

Diseases of the Respiratory Organs. - A cold or catarr h is an inflammation of a mucous membrane. If the inflammation is in the nasal passages, it is called a cold in the head; if it is in the pharynx, it is called a sore throat; if it is in the larynx or voice box, there is hoarseness; if it is in the bronchial tubes, it is bronchitis; finally, if it is in the air cells, it is pneumonia. If the air is cut off from access to the air cells, there is an attack of the painful disease called asthma, which is accompanied by a feeling of suffocation. Some believe that asthma is caused by the mucous membrane lining the finest bronchial tubes becoming inflamed and swollen, and closing the tubes; others think that the muscles in the large bronchial tubes contract and close the tubes. Pleurisy is inflammation of the pleura and makes breathing painful. If much fluid forms between the pleuras, the inner pleura may press upon the lungs and interfere with breathing.

Alcohol not only weakens the blood vessels near the surface, but the blood vessels in general. Weakened and congested blood vessels in the lungs make them more liable to pneumonia and other congestive diseases. Continual congestion causes an abnormal growth of connective tissue fiber in the walls of the cells. This diminishes the capacity of the lungs and interferes with the exchange of carbon dioxid and oxygen.

Tobacco. - It is often asked why cigarettes are so much more injurious to the health than pipes and cigars. The nature of the paper of cigarettes and various other absurd reasons have been assigned. The true reason is that the cigarette smoker usually inhales the tobacco smoke. Cigar smoke, if drawn into the lungs, would usually be coughed up at once. Cigarette smoke is weaker - it is so weak 
that the smoker is not content simply to absorb the nicotine through the mucous membrane of the mouth; he draws it into the lungs. The very mildness of the smoke leads to inhalation. Hence, as the surface of the lungs is a hundred times greater than the surface of the mouth, and its lining much thinner, cigarette smoking is far more injurious than cigar smoking.

The poison accumulates in the bowl of a pipe; hence an old pipe is very injurious. The irritation of tobacco smoke often sets up a chronic dry catarrh of the air passages; rarely it causes cancer of lips or tongue. Sir Henry Thompson says: "The only persons who enjoy smoking and find it tranquillizing at times are those who smoke in great moderation. Men who are rarely seen without a cigar between the lips, have long ceased to enjoy smoking. They are confirmed in a habit, and are merely miserable when the cigar is absent." They do not smoke for pleasure, but to escape misery which wiser men escape by avoiding tobacco altogether.

Practical QuesTions.-- 1. State

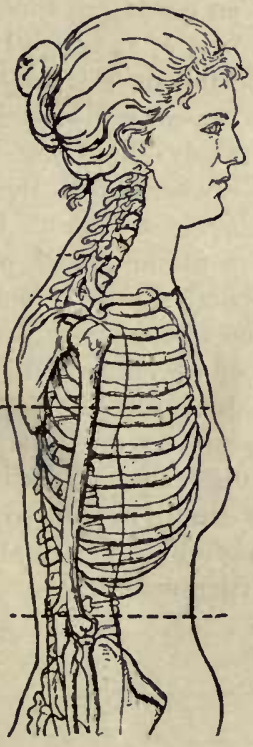

FIG. 85 .

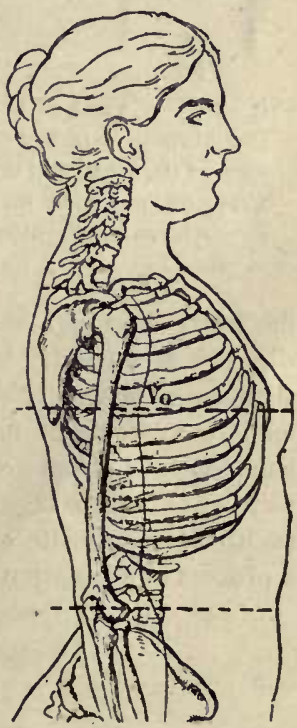

FIG. 86.

Fig. 85.-Flattened Chest and waist organs sunken from wearing tight clothing since the age of fourteen. Such women often walk with bodies bent forward to hide the prominent abdomen.

Fig. 86. - A Natural, WOMaN.

how in the case of a person with round shoulders a gradual remolding of cartilages (which ones?), the strengthening of the muscles (which ones?), and the practice of deep breathing may each contribute toward 
acquiring an erect and perfect figure. 2. Should a hat be well ventilated? (A punch for making the holes costs a dime.) Should a hat

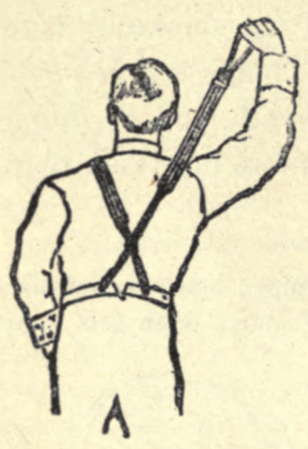

FIG. 87. - Suspenders should have a pulley or lever at the back, that the strap on one side may loosen when one shoulder is raised. be stiff or soft? 3. Name habits that impair the power of the lungs. 4. How could you convince a person that a bedroom should be open while and after it is swept ? That it should be ventilated at night? 5. Which is the more injurious to others, tobacco chewing which causes the ground to be unclean, or smoking which renders the air impure? 6 . Why do those who stand straight up to hoe not get tired half so quickly as those who bend or "hump" over? (Chap. VI.) 7. Why do students who sit in rocking chairs, or from other causes lean the head forward when they study, often find that they recover from drowsiness if they sit erect, or sit in a straight chair? 8. How are high collars a fruitful source of bad colds ? 9. If the draft up the chimney of the fireplace, when the fire is burning, takes up a volume of air sufficient for many people, why is it unnecessary to open a window? 10. Why does cold impure air make a person colder than cold pure air? (p. I4.) 11. Do the modern customs of uniformity in dress for all classes and climates, shipping foods from great distances, one section or nation imitating the ways of another section or nation, lead toward health or disease? Do such customs violate or conform to the great biological law that life is a process of adaptation to environment? 



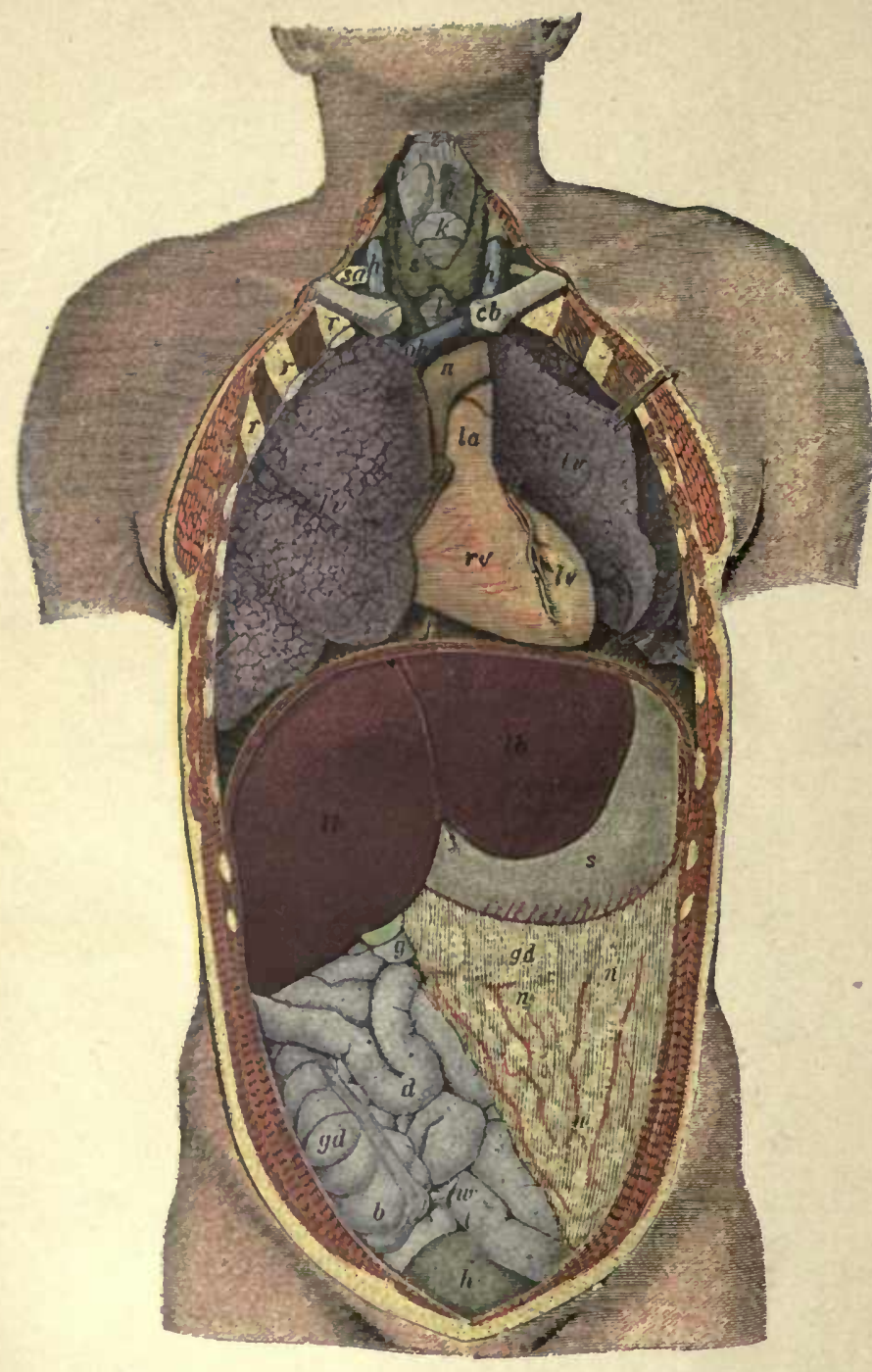

Colored Figure 6. - Organs of the Trunk.

$e b$, collar bone: $r$, ribs: $z$, tongue bone (hyoid) $; k, k$, cartilages of larynx; $l$, windpipe: s, thyroid gland; $r v$, right ventricle; $l v$, left ventricle; $r u$, right auricle; $l u$, left auricle: $a$, arta: ka, artery to head (carotid); sa, subclavian artery; la, pulmonary artery: oh, superior vena cava; $h v$, jugular vein; $l u$, lungs; $f$, diaphragm: $I b$, liver; $g$, gall badder: s, stomach: $x$, spleen; $n$. mesentery with vessels; $d$, small intestine: $g d$, large intestine: $b$, cxcum; $w$, vermiform appendix; $h$, bladder. 


\section{CHAPTER VII}

\section{FOOD AND DIGESTION}

Experiment 1. Tests for Acid, Alkaline, and Neutral Substances... Repeat tests described in General Introduction. ${ }^{1}$

Experiment 2. Test for Starch. - See General Introduction.

Experiment 3. Test for Grape Sugar. - See General Introduction.

Experiment 4. Test for Proteid. - See General Introduction.

Experiment 5. Test for Fats. - See General Introduction.

Experiment 6. Human Teeth. - Study the form of teeth from every part of the mouth. Get a handful from a dentist. Break some of the teeth to make out their structure. Classify them. Draw section, enlarged.

Experiment 7. Study of the Teeth. (At home.) - Sit with the back to the light and look into a mirror, with the mouth wide open. Do you see the four kinds of teeth named in text? Which are fitted for cutting? Which for grinding? Are any suited for tearing? Are any of the teeth pointed? What is the difference in the bicuspids and molars? Are there any decayed places? Are the teeth clean? Are the so-called canine teeth so long that they project beyond the line of the other teeth, as they do in a dog? Do the edges of the upper and lower incisors meet when the mouth is closed, or do they miss each other like the blades of scissors? How many roots has each lower tooth? (See Fig. 92.) Which tooth has the longest root?

Experiment 8. Structure of Mammalian Stomach. - Get a piece of tripe from the market. Study its several coats. The velvety inner coat is covered with mucous membrane. (Photomicrograph, Fig. 95.)

Experiment 9. Model of Human Food Tube. - Make a model of the food tube out of yellow cambric, giving to each organ its correct size. Follow the dimensions given in text.

Necessity for Foods. - Growing plants and growing animals need new material to enable them to increase in size or grow. Plants never cease to grow while they live; most mammals attain their full size in one fifth of the time

I See also Peabody's “Laboratory Exercises in Physiology," Holt, N.Y. 
occupied by their whole lives. (By this rule how long ought man to live?) Animals, moreover, move from place. to place, and work with their muscles. The energy for this comes from the food they eat. Plants do not use food for this purpose. Another need for food comes from the necessity for heat in all living things. The activities of animals cause the tissues to wear out, or break down, and food furnishes material with which new living matter is built up by the cells and the tissues repaircd. We have already stated the rôle of oxygen in setting free energy in the living substance of the cell by oxidizing it. There is no furnace in the body as in an engine, but the oxidation occurs in the cells themselves and the fuel is built up into living matter by the cells before it is oxidized. Plants must lift mineral from the inorganic to the organic world before it can be food for animals. Plants can assimilate minerals; animals cannot. The body cannot make bone out of limewater. The iron in iron tonics cannot be used. Iron makes the grain brown, and the peach red. There is ten times as much iron in our food as the body needs.

State four reasons why animals need food. Which of these reasons is very powerful with plants? Least powerful? Absent altogether? Why is constant breathing necessary for life? When is breathing more rapid? Why? People who lead what kind of lives usually have poor appetites? Good appetites? Why? What was the first distinct organ evolved by animals? (Animal Biology, Chap. IV.)

The Body is a Machine for transferring Energy. - Energy cannot be destroyed, but it can be transferred and changed in form. When a coin is rubbed on the table, muscular energy, supplied by oxidation in the muscle, produces the motion. Friction may change motion into heat, and the coin will become very hot. The uniting of food and 
oxygen in the cells of the body gives the heat and motion (energy) of the body. Only substances which will oxidize, or burn, are true foods. Water, salt, and carbon dioxid will not burn; hence, they cannot give rise to energy in the body. But the sun energy, acting in the green leaf, tears apart the carbon from the oxygen (Plant Biology, Chap. XIII), sets free the oxygen, and the carbon is stored in starch for future burning. Sunshine is energy (light and heat). The sun sustains the life of plants and through them the life of animals. The oxidation in the body is so slow that it can hardly be called a burning, but it is faster than the oxidation of iron in rusting or of wood in rotting, and is about equal to the continual burning of two candles.

The Four Kinds of Nutrients, or Food Stuffs. - The kinds of food which we eat seem to be numberless, but they contain only four kinds of food stuffs, - starches, fats, proteids, and minerals. Many foods contain all four classes of food stuffs. Milk contains sugar (a changed form of starch), cream (a fat), curd (a proteid), and water (a mineral). Oatmeal contains starch, oil, gluten, and water.

\section{Uses of the Nutrients, oR Foon StufFs}

I. Proteids. The tissue-building foods (also of value as fuel).

2. Starches (and sugars) $\}$ Energy and heat (fuel) and

3. Fats (and oils) fat producing foods.

4. Minerals (water, salt). Important aids in using other foods.

Relative Fuel Value. - A pound of fat produces as much heat in the body as $2.3 \mathrm{lb}$. of proteid or $2.3 \mathrm{lb}$. of starch, the last two having equal fuel value in the body.

Starch and the sugars are closely related; starch readily changes into sugar. They contain much carbon and are called carbohydrates. Starch is especially abundant in grains, seeds, and fleshy roots (Fig. 88). The sugar in ripe fruit and in honey is called fruit sugar. Milk sugar 
is found in sweet milk. Grape sugar is found in grapes and honey; the small grains seen in raisins consist of

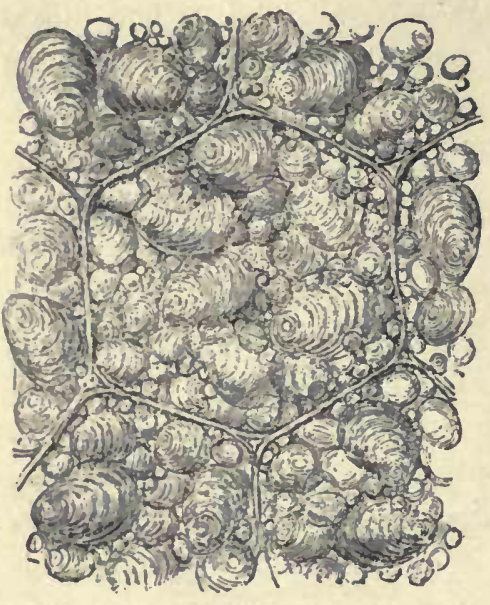

Fig. 88. - A TINy BI' of Potato, highly magnified, showing cells filled with grains of starch. Cooking bursts these cells. grape sugar; it can also be prepared artificially from starch. Cane sugar is found in cane, in sap of the maple, and in the sugar beet (Exps. 2, 3).

Fats include the fats and oils found in milk, flesh, and plants. A fat, such as tallow, is solid at the ordinary temperature; while an oil, such as olive oil, is liquid at the same temperature. Tallow was oil while it was in the warm body of the ox. Sugar is transformed into fatty tissue as readily as is fatty food itself.

Proteids are the only foods that contain the tissuebuilding nitrogen. Protoplasm cannot be formed without nitrogen. We do not often see a pure proteid food, for this food stuff is not so readily separated from foods containing it as are starch, sugar, and fat. Albumen, or white-of-egg, is proteid united with four times its weight of water. Pure proteid is also called albumin. Coagulation by heat is one test for proteid (Exp. 4). These are the names of proteids, or albumins, found in several common foods: casein, the curd or cheesy part of milk; myosin of lean meat; fibrin in blood; legumin in beans and peas; gluten, or the sticky part of wet flour; gelatin in bones. Proteid is valuable to the body as fuel 
as well as a tissue builder. We could burn beans and peas as well as the strictly fuel foods, starch and fat, in an engine, and get heat to move the engine. If one takes up athletics or hard physical labor, he should increase the amount of fats and carbohydrates eaten, but not of proteid. Muscular activity increases the carbon waste but not the nitrogen waste of the body.

Minerals. - The iron of the blood and the mineral salts in bone (carbonate and phosphate of lime) must enter the body in organic form in order to be used. Water and salt are mineral focds. The body is about two thirds water. The cells must do their work under water. They cannot live when dried. Water enables the blood to flow; and the blood is not only the feeder, but also the washer and cleanser of the tissues. Some persons get out of the habit of drinking plenty of water, and their health suffers thereby. In such a case drinking plenty of water will be safer and more effective than taking poisonous drugs to restore health.

Adulteration of Food. - Sometimes cheaper materials, of little or no value as food but of no great injury to health, are added to foods. Examples: water added to milk, sawdust to ground spices, chicory to coffee, glucose to maple syrup. Other forms of adulteration not only cheat the purse but tend to destroy health, or actually do so. Examples: Boracic acid or formalin added to milk to prevent souring, copper to canned peas, etc., to give a bright green color ; salicylic acid or borax used in minute quantities as a preservative with canned corn, tomatoes, etc.; acids added to " apple" vinegar; dried fruit treated with sulphur to prevent a dull color. Pure food laws tend to repress these evils. It is best to buy foods in their original form. For instance, lemons are more reliable than vinegar. A bit of lemon at each plate, in house- 
holds that can afford it, is far preferable to vinegar. We should always buy from neighbors when possible. Farmers and gardeners should do their own drying and canning. For purity of water, see Chap. X.

The Daily Ration. - A quarter of a pound (4 oz.) of proteid foods and one pound ( $16 \mathrm{oz}$.) of fuel foods (total $20 \mathrm{oz}$. of water-free foods) are needed to replace the daily waste of the body. Hence a balanced ration has proteid and fuel food in the ratio of 4 to 16 , or 1 to 4 . But recent experiments at Yale University indicate that $2 \mathrm{oz}$. of proteid daily are more strengthening than four.

Appetite is a perfect guide for those who lead an active life and eat slowly of simple food. Highly seasoned food and complex mixtures deprave the appetite; it then leads astray, instead of guiding safely. Of course the appetite cannot guide one to eat the right kind and quantity of food at a table where the food lacks any of the four necessary food stuffs, or where innutritious or indigestible food is provided. It is well to select one food for a meal because it is rich in proteids, another because it is rich in fat, and the third because it is rich in starch or sugar. (See table, p. 95.) Intelligence in regard to diet enables a housekeeper to provide nourishing food for less money than an ignorant housekeeper often pays for food deficient in nourishing qualities.

A Balanced Ration. - A deficiency of starch may be supplied by an excess of fat or sugar. It is most essential to provide proteid as it cannot be replaced by any other food stuff. An excess of proteid is most harmful. An excess of starch or fat is oxidized into water and carbon dioxid, which are harmless waste products; an excess of proteid is changed into urea which may become harmful by overworking the liver and kidneys which excrete it. 
Composition OF ONE OUNCE OF VARIOUS FoODS in Fractions of AN OUNCE

\begin{tabular}{|c|c|c|c|c|c|c|c|c|c|c|c|}
\hline \multirow{2}{*}{\multicolumn{4}{|c|}{ Daily Ration }} & & & $\begin{array}{l}\text { PRO- } \\
\text { TEIDS }\end{array}$ & FATS & $\begin{array}{l}\text { CARBOHY } \\
\text { DRATES }\end{array}$ & WATER & $\begin{array}{l}\text { Mineral } \\
\text { Salts }\end{array}$ & $\begin{array}{l}\text { WOODY } \\
\text { FIBER }\end{array}$ \\
\hline & & & & & & $4 \mathrm{oz}$ & $20 z$. & I4 oz. & 2 qt. & & 0 \\
\hline I. & Nuts. & & & & & & & & & & \\
\hline & Pecan . & • & . & • & . &. $\mathrm{IO} 3$ & .708 & .143 & .03 & .017 & \\
\hline & Walnut & - & - & - & - & $.15^{8}$ & .574 & .16 & .03 & .014 & \\
\hline & Almonds & - & - & . & - & .235 & .53 & .12 & .078 & & \\
\hline & Cocoanut & - & - & - & - & .056 & .51 & & .35 & & .04 \\
\hline & Chestnut & - & • & - & - & .037 & .02 & .38 & .54 & .009 & .02 \\
\hline II. & Fruits. & & & & & & & Sugar & & & \\
\hline & Peach . & - & - & . & . & .007 & & .045 & .85 & .007 & .04 \\
\hline & Apple . & & - & • & - & .004 & & .072 & .84 & .005 & .05 \\
\hline & Blackberr & & - & - & - & .005 & & .040 & .86 & .004 & $.0 \mathrm{I}$ \\
\hline & Cherry . & & - & - & - & .005 & & . 10 & .84 & .007 & .02 \\
\hline & Grape : & & - & - & • & .125 & & .15 & .70 & .005 & \\
\hline & Fig (dried & & , & - & - & .040 & .014 & .50 & & & \\
\hline & Banana & - & • & - & - & .050 & & .20 & .75 & & \\
\hline III. & ANIMAL Fo & OI & & & & & & & & & 2 \\
\hline & Lean beef & & - & - & - & .20 & .035 & .009 & .75 & .016 & \\
\hline & Fat pork & & • & - & . & .098 & .489 & & .390 & .023 & \\
\hline & Smoked h & an & & • & - & .25 & .365 & & .278 & .IOI & \\
\hline & Whitefish & . & . & • & - & .181 & .029 & & .780 & .010 & \\
\hline & Poultry & . & . & . & . & .210 & .038 & & .740 & .012 & \\
\hline & Oysters & & - & • & - & .175 & .005 & & .800 & .015 & \\
\hline & Cow's mil & & - & - & - & .035 & .040 & .040 & .870 & .007 & \\
\hline & Eggs • & - & - & . & - & .125 & .120 & & .735 & .010 & \\
\hline & Cheese & - & - & • & - & .335 & .243 & & .368 & .054 & \\
\hline & Butter . & . & & - & - & .003 & .910 & & .060 & .021 & \\
\hline IV. & PoDs OR L & EG & & ES. & & & & Starch & & & \\
\hline & Beans . & & - & . & - & .25 & .020 & .52 & .125 & .035 & .060 \\
\hline & Peas & - & - & . & . & .217 & .019 & .577 & .12 & .028 & .032 \\
\hline & Peanuts & - & • & . & - & .2947 & .465 & .162 & .02 & .028 & .043 \\
\hline V. & GRAINS. & & & & & & & & & & \\
\hline & Wheat flo & ur & $(n$ & . & e) & .110 & .020 & .703 & .150 & .017 & .003 \\
\hline & Wheat br & ea & & - & - & .080 & .015 & .490 & .400 & .012 & .003 \\
\hline & Oatmeal & - & & - & - & .126 & .056 & .630 & .150 & .030 & .016 \\
\hline & Maize (co & $r n$ & & - & - & .100 & .067 & .706 & .135 & .014 & .015 \\
\hline & Rice & - & - & - & - & .050 & .008 & .832 & .100 & .005 & .040 \\
\hline VI. & VEGETABLE & & & & & & & & & & \\
\hline & Potatoes & - & . & - & - & .012 & .001 & .205 & .767 & .009 & .006 \\
\hline & Cabbage & - & - & - & - & .02 & .030 & .058 & .910 & .007 & .015 \\
\hline
\end{tabular}


Studies based on Table. - What nuts are rich in proteids? What fruits? What animal foods? What legumes? What grains? What foods are rich in fats? What are rich in carbohydrates? Which grains have much starch? Which nut? Which fruits have nuch sugar? A family was living chiefly on corn bread, potatoes, syrup, cakes, and sweetmeats : what two of the four food stuffs were deficient in their diet? Another family lived chiefly on fat pork, bread, rice, vegetables, and fruit : which food stuff was deficient? A dozen eggs weigh $1 \frac{1}{2} \mathrm{lb}$. Which give cheaper nourishment, eggs at 15 cents a dozen or beef at 15 cents a pound? Which is cheapest among the foods abounding in proteid? Fat? Carbohydrates? Which is cheaper food, a pound of beef at 20 cents or a pound of pecans at the same price? (Fig. 10I.) What food contains most water? Least water? Which of the foods abounding in proteid is costliest? Cheapest? Notice that nearly all foods containing much proteid are costly. Water and woody fiber are not counted as nutriment. What weight of nutriment in $1 \mathrm{oz}$. of cow's milk? If a quart of whole milk costs 12 cts., what is a quart of skimmed milk worth?

How the Right Proportions of Fuel Foods and Proteid are reached by Different Nations. - Milk has an excess of nitrogen, and oatmeal an excess of carbon; oatmeal and milk form a popular food with the Scotch. Potatoes are mostly starch and water, and an Irishman who tried to live on potatoes alone would have to eat seven pounds a day to get enough proteid. The Irish peasant keeps a cow and chickens; by eating milk and eggs he gets along on half the amount of potatoes named above. The Mexicans eat bread made of corn meal, and supply the proteid by using beans as a constant article of diet. Hundreds of millions of people in Asia (the Hindus, Chinese, and others) subsist mainly on rice, which contains only five per cent of proteid and no fat; the chief addition they make is butter, or other fat, and beans, which contain vegetable proteid.

Outline of Digestion. - The food is made soluble in the alimentary canal and is absorbed by the blood vessels and lymphatics in its walls. This canal is about thirty feet long (Figs. 89, 90) and consists of -

(I) The mouth, where the food remains about a minute, while it is chewed and mixed with the saliva; the saliva changes a portion of the starch to malt sugar.

(2) The gullet, a tube nine inches long, running from 
mouth to stomach and lying in front of the spinal column.

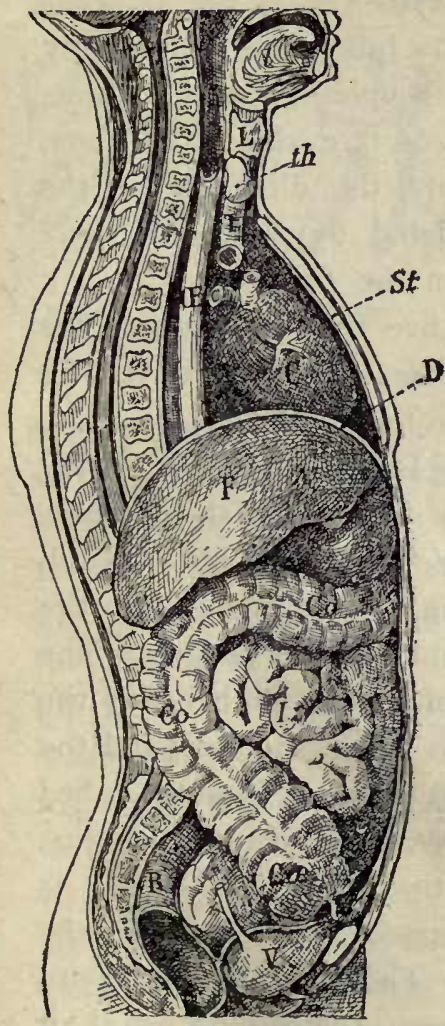

FIG. 89. - ORGANS OF TRUNK from the side.

$L$, larynx; th, thy roid gland; $T$, trachea ; St, breastbone ; $C$, heart ; $D$, diaphragm : $F$, liver ; $E$, stomach ; $I$, intestine: $\mathrm{Co}$, colon; $R$, rectum ; $V$, bladder.

Question: Parts of which organs are farther back than spinal column? Compare this figure with colored Fig. 6.
Illustrated Study of Food Tract.

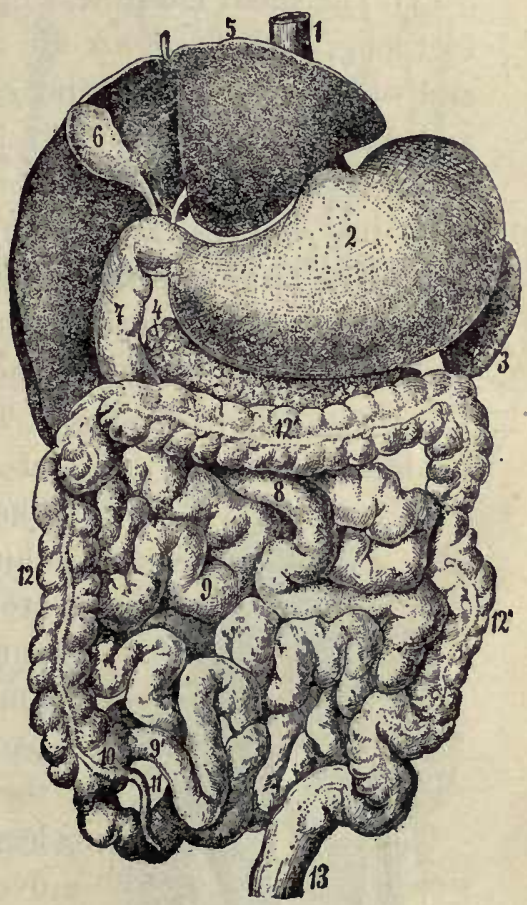

Fig. 90. - Digestive ORGans, from the front (liver turned up).

x, gullet : 2 , stomach ; 3 , spleen ; 4 , pancreas : 5 , liver (turned upward); 6 , gall bladder; $7,8,9$, small intestine; $9^{\prime}$, junction of small with large intestine; го, caecum (blind sac); II, vermiform appendix; I2, I2', I2" , ascending, transverse, and descending colon; $1_{3}$, rectum (straight) just below S-shaped flexure of colon.

Question: Compare with Fig. 89, and colored Fig. 6.

(3) The stomach, a large pouch where the food is stored, and from which it passes in the course of several hours, 
having become semi-liquid, and the proteids having been partly digested by the gastric juice, an acid secretion from the small glands in the stomach walls.

(4) The small intestine, a narrow tube more than twenty feet long, where the fats are acted upon for the first time, and where the starches and proteids are also acted upon, and where, after about ten hours, the digestion of the three classes of foods is completed by pancreatic juice from the pancreas, and bile from the liver.

(5) The large intestine, about five feet long, where the last remnant of nutriment is absorbed, and the indigestible matcrials in the food are gathered together (Exp. 9).

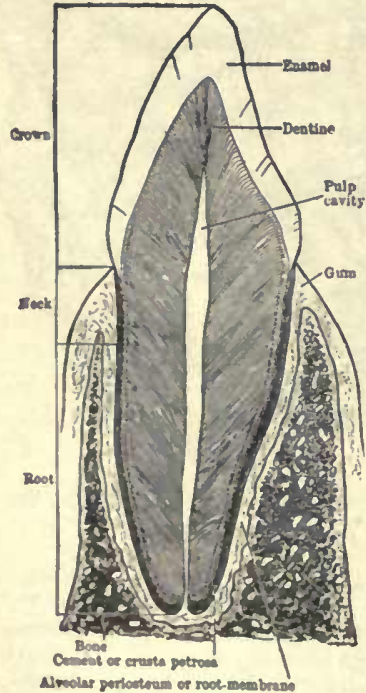

Fig. 91.-CANiNe ToOTh CUT LENGTHWISE.

The Teeth. - The main body of the tooth consists of bonelike dentine, or ivory. Hard, shining enamel protects the crown, or visible portion. The part of the tooth beneath the gum is called the neck, and the part in the bony socket is called the root. The enamel ends just beneath the gum, where it is overlapped by cement of the root. There is a pulp cavity in every tooth (Fig. 9I); it contains pulp made up of connective tissue, with nerves and blood vessels which enter at the tip of the root (Exp. 6).

The temporary set of teeth is completed at about two years of age and consists of twenty teeth. The teeth cannot grow as the jaw grows, and soon a larger and permanent set starts to growing deeper in the 
jaw. At the age of twelve or thirteen years all the permanent set have appeared except the four wisdom teeth, which appear between the ages of seventeen and

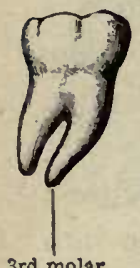

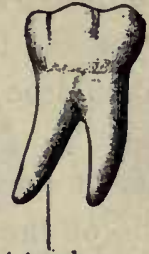

Ist molar 2nd molar

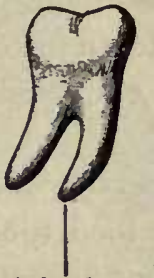

FIG. 92. -

2nd premolat

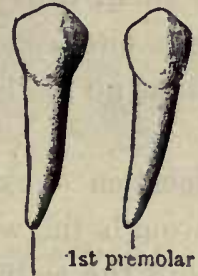

Canme

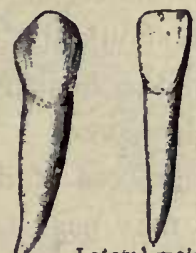

Lateral meisor

Central incisor

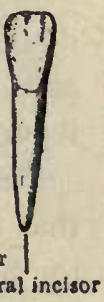

twenty-five. The second set not only replaces the twenty of the first set, but to fill the larger jaws twelve molars are added, three at the back in each half jaw, making thirtytwo teeth in the second set (Exp.

7). The teeth in each quarter of the mouth, named in order from the front, are: two incisors, one canine, two premolars, three molars.

Care of the Teeth. - The best way to care for the teeth is to keep the digestion perfect. Perfect digestion tends to preserve the teeth, and sound teeth tend to

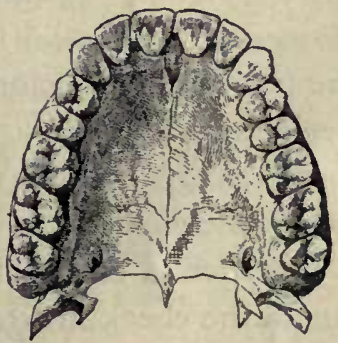

FIG. 93.-UPPER JAW WITH TEETH. keep the digestion perfect. The teeth should be washed regularly. Prepared chalk is the best dentifrice. Do not rub across, but from gums to teeth, to prevent rubbing the gums loose from the teeth. An unclean brush may harbor germs. Toothpicks and dental floss are useful. If one eats only soft food, in which the mill and the cooking stove have left no work for the teeth, the teeth will decay; for it seems to be a law of nature that useless organs are removed. The pressure from cheiving 
hard food is an aid to the teeth by helping the circulation and nerves in the pulp. To take a very hot or very cold drink into the mouth may cause the enamel to crack. If a tooth aches, or a small decayed place is found in it, a dentist should be consulted at once. A tooth is so valuable to the health that no tooth should be extracted when it can be saved.

The process of digestion consists in liquefying the food that it may pass through the walls of the food tube into the blood, and through the walls of the blood vessels into the tissues. It is accomplished: (I) by mechanical means, including the chewing muscles, the teeth, and three layers of muscles in the walls of the food tube; (2) by chemical means, or the action of alkalies and acids upon the food; (3) by organic agency, or the action of ferments. A ferment (or enzyme) is a vegetable substance which has the power of producing a chemical change in large quantities of substance brought in contact with it, without being itself changed. There is one ferment secreted in the mouth, two in the stomach, and three in the small intestine.

Digestion in the Mouth. - Saliva is formed by six glands : one in the cheek in front of each ear, one at the angle of each lower jaw, and one pair is beneath the tongue. Each gland opens into the mouth by a duct. Saliva is ropy because it is mixed with mucus formed by the mucous membrane lining the mouth; it usually contains air bubbles. There is a ferment in the saliva called ptyalin, which has the power of changing starch to malt sugar. If a bit of bread is chewed for a long time, it becomes sweet, because some of the starch is changed to sugar. The flow of saliva is caused by chewing, or by the sight, or even the thought, of agreeable food. Dryness of food is by far more powerful than anything else in causing the saliva to 
flow. Saliva is secreted only one fourth as fast when eating oatmeal and milk as when eating dry toast (Fig. 94).
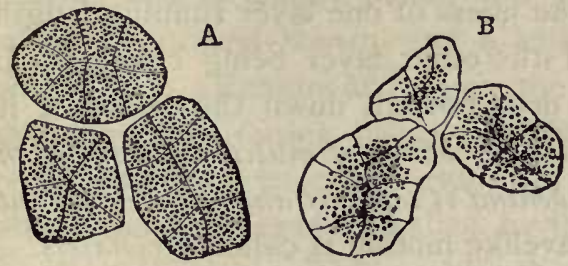

C

\section{Fig. 94. - Cells of a Salivary Gland}

$A$, after rest, full of granules ; $B$, after short activity ; $C$, after prolonged activity, cells shriveled and granules lost.

Starchy grains and fruits were eaten by early man without cooking, and required more chewing than sweet, ripe fruits or oils or proteids. Hence the saliva was given the power of acting upon the starch, for it must remain in the mouth longer. The saliva is alkaline; and if the food is not thoroughly mixed with it, the stomach digestion will also be imperfect, for the alkaline saliva is necessary to excite an abundant flow of gastric juice in the stomach (Exp. I).

Eating slowly is difficult because of the grinding and cooking of food; hence the common practice of overeating. To eat slowly (I) do not take large mouthfuls; (2) do not take a second morsel until the first has been swallowed; (3) sit erect or lean back after putting food into the mouth; (4) the hands should lie idle most of the time. To lean forward and keep food traveling to the mouth like coal into a chute means overeating with all its bad effects.

Chewing gum is a coarse and impolite habit, and wastes the saliva, besides weakening the glands and irritating the stomach by the saliva that is continually swallowed. Cherving tobacco has several of these disadvantages, besides allowing the poison in the tobacco to be absorbed by the mucous lining of the mouth.

The pharynx (far'inks), or throat, is a muscular bag suspended behind the nose and mouth. (See Fig. 89, also Fig. 83.) There are seven openings into the pharynx: two from the nostrils, two from the ears, one each from the mouth, larynx, and gullet. Which of these openings are downward? Forward? Lateral?

The gullet (or esophagus) is a muscular tube about nine 
inches long. (See Fig. 89.) Like the rest of the food tube, it is lined with mucous membrane. It has two layers of muscles in its walls, the fibers of one layer running lengthwise, and the fibers of the other layer being circular. In swallowing, the food does not fall down the gullet of its own weight, but the circular bands of muscle in front of the food relax, and those behind it contract and push it on into the stomach. This wavelike motion is called peristalsis.

The stomach, the greatest enlargement of the food tube, is like a large bag lying sideways. It lies to the left side of the abdomen. The

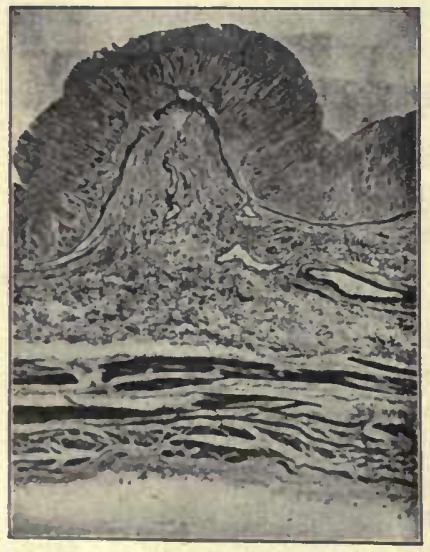

Fig. 95. - MUSCUlar AND OTHER LAYERS IN WALL OF STOMaCh.

1, mucous lining; 2, layer of blood vessels and connective tissue: 3 , muscular layers (involuntary muscies); 4, connective-tissue fibers. (Peabody.) walls of the stomach consist chiefly of muscular fibers which nun lengthwise, - crosswise, and slantzise, making three coats (Exp. 7, also Fig. 95). As soon as the food reaches the stomach, the layers of muscles begin to contract, changing the size of the stomach, first in length, then in breadth, thus churning the food to and fro, and mixing it with the gastric juice, a fluid more active than the saliva. For as the food enters the stomach, the mucous membrane lining. it turns a bright red, and many little gastric glands in the lining begin to secrete gastric juice.

Digestion in the Stomach. - The stomach churns the food from two to four hours after the meal, according to 
the kind of food eaten, the way it has been cooked, and the thoroughness with which it has been chewed. The gastric juice is chiefly water, and contains two ferments called pepsin and rennin, and a small quantity of hydrochloric acid. Rennin acts upon the curd of milk, and is abundant only during infancy. Hydrochloric acid kills germs that may enter the stomach, and changes the food which has been made alkaline by the saliva into an acid condition (Exp. I). This enables the pepsin to act upon the proteid part of the food, for pepsin will not act while the food is alkaline. Gastric juice digests lean meat, which is a proteid food, by first dissolving the connective tissue that holds the fibers in place, and they fall apart; it then acts upon the fibers separately and makes them soluble. Like human fatty tissue (Fig. 14), fat meat consists of cells filled with fat and held together by threads of connective tissue. The cell walls and the threads, both being proteid, are soon dissolved by the gastric juice, and the free fat is melted into oil, but still undigested. The food is reduced in the stomach to a creamy, half-fluid mass called chyme. Where the stomach opens into the small intestine, there is a folding in or narrowing of the tube so as to form a kind of valve called the pylorus. After the food has been changed to chyme, this fold relaxes every minute or two, and allows some of the chyme to escape into the intestine.

The small intestine is about one inch in diameter and twenty feet long, with many coils and turns in its course (Fig. 90). Its mucous lining is wrinkled into

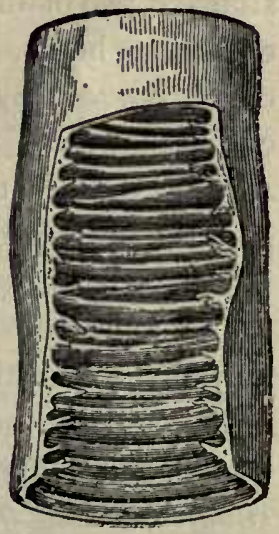

FIG. 96.-A PORTION of SMall INTESTINE cut open to show the folds in its lining. 
numerous folds in order to increase the secreting and absorbing surface (Fig. 96). On and between the folds

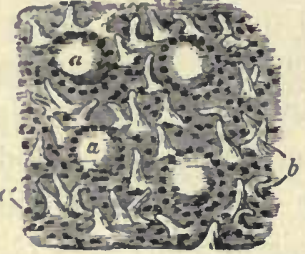

FIG. 97. - LINING OF SMALI, INTESTINE, magnified, showing villi and mouths of intestinal glands. are thousands of little threadlike projections called villi (Fig. 97). In each villus are found fine capillaries and a small lymphatic called a lacteal (colored Fig. 2). The villi are so thick that they make the lining of the intestine like velvet, and enormously increase the absorbing surface.

Digestion in the Small Intestine. -

This is by far the most active and important of the digestive organs. The mouth digests a small part of the starch, and the stomach digests a small part of the proteid; the small intestine digests most of the starch, most of the proteid, and all of the fats. The food is in the mouth a few minutes, and in the stomach two or three hours; it is in the small intestine ten or twelve hours. There are thousands of small glands called intestinal glands that open between the villi (Fig. 97) and secrete the intestinal juice, which digests cane sugar. Besides these, there are two very large and active glands, the pancreas and liver, which empty into the intestine by ducts.

The Pancreas. - The small intestine is the most important of the digestive organs, chiefly because it receives the secretion from the pancreas, the most important of digestive glands. The pancreas is a long, flat, pinkish gland situated behind the stomach (see Fig. 90). The pancreatic juice contains three powerful ferments, one of which (amylopsin) digests the starches, another (trypsin) digests proteids, and the third (steapsin), with the aid of the bile, 
breaks up the fats into tiny globules. Fat in small globules floating in a liquid is called an emulsion; fresh milk is an emulsion of cream (Fig. 98). Fat is not changed to another substance by digestion, but it is emulsified, and in this condition it readily passes through the walls of the intestines and is absorbed by the lymphatics called lacteals (colored Fig. 5) found in the villi. It then ascends through the thoracic duct to a large vein at the left side of the neck (Fig. 100). The

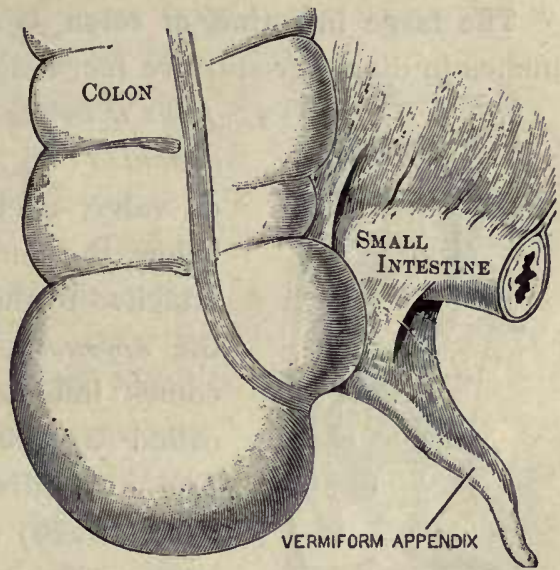

FIG. 98. - JUNCTION OF LARGE ANL SMALL INTESTINE. digested proteid, starch, and sugar pass into the capillaries of the portal vein, and go to the liver on their way to the general circulation (Fig. IOO). The portal circulation empties into the large ascending vein leading to the right auricle (Fig. IOO).

The Liver. - This large, chocolate-colored gland is located just beneath the diaphragm on the right side (Fig. 9o, colored Fig. 6). It is on a level with the stomach, which it partly overlaps in front. The liver has three important functions: (I) It is a storeroom; digested sugar and starch are stored in it as a substance called liver starch (or glÿ'cogen). (2) It is a guardian, and destroys poisonous substances which may be swallowed, and which would otherwise enter the blood. Twice as much morphine or other poison is necessary to kill a man when it is taken by the mouth and passes through the liver as when it is injected through the skin. Alcohol, morphine, coffee, and drugs are partly burned up in the liver. (3) It is a gland, and secretes bile. The bile is made chiefly from waste products and impurities in the 
blood; it is an excretion. Although an excretion, it is of use on its way out of the body. It is alkaline and helps to neutralize the acid in the chyme; it excites the peristalsis, or wavelike motion, of the intestines, and it aids the pancreatic juice to emulsify the fats.

The large intestine, or colon, is about two and one half inches in diameter and five feet long. The small intestine

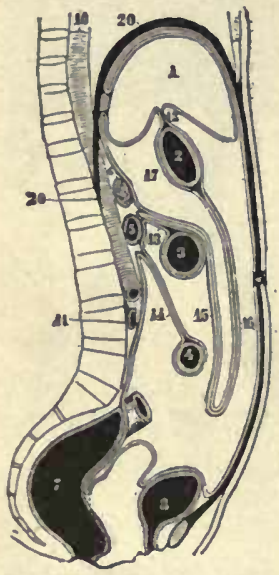

Fig. 99. - Diagram OF

TRUNk to show the many folds of the PERITONEUM supporting the liver, stomach, and intestines.

joins it in the lozver right side of the abdomen (Fig. 90). There is a fold, or valve, at the juncture, and just below the juncture there is a tube attached to the large intestine, called the appendix, which sometimes becomes inflamed, causing a disease called appendicitis (Figs. 90, 98). The appendix is a vestigial (vestigium, trace) or rudimentary organ, long since useless. Absorption of the watery part of the food continues in the colon, but the colon secretes no digestive fluid. The undigested and innutritious parts of the food are regularly cast out of the colon. ${ }^{1}$ The peritone' $u m$ is a membrane with many folds that supports the food tube (Fig. 99). Absorption. - The way in which the various digested foods are absorbed has been stated in several preceding topics. What is the name of the organs of absorption in the small intestine? Which of the following pass into the lacteals, and which into the capillaries of the portal vein : sugar, digested proteid, emulsified fats? Water and salt need no digestion, and are absorbed all along the food

${ }^{1}$ No truly refined person will allow business, pleasure, haste, or neglect to interfere with regular attention to emptying the colon. This is more necessary for real cleanliness than regular baths. 
tube, the absorption beginning even in the mouth. What reasons can you give for the absorption of food being many times greater in the small intestine than in the stomach? Through what large tube is the fat carried in passing from the lacteals to the veins? Into what large vein do all the capillaries that take part in absorption empty? (Colored Fig. 5.) What is the provision for storing the sugar so that it will not pass suddenly into the blood after a meal, but may be given to the blood gradually? Food is assimilated, or changed into living matter (protoplasm), in the cells. Blood and lymph (except the white corpuscles) are not living matter. (Fig. 100.)

Thought Questions. The Digestive Organs. - 1. In which of the digestive organs is only one kind of secretion furnished by glands? 2. In which organ are three kinds of secretions furnished by glands? 3. Which class of food goes

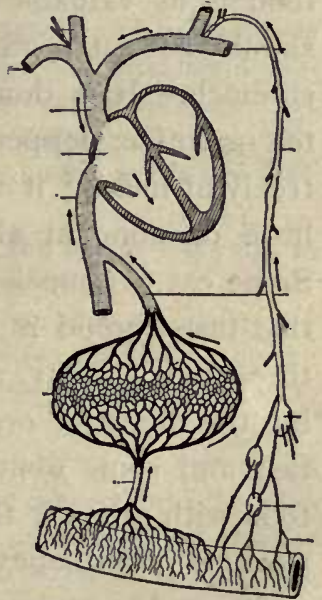

FIG. IOO. - THE TWO PATHS OF FOOD ABSORPTION. Thoracic duct (for fats): through the portal vein and liver (for all other foods). through the lymphatics? 4. Which classes of foods go through the liver? 5. Which classes of foods are digested in only one organ ? 6. Which classes of foods are digested in two organs? 7. Which division of the food tube is longest ? Broadest? Least active ? Most active? 8. Soup is absorbed quickly; why does eating it at the beginning of a meal tend to prevent overeating?

Hygienic Habits of Eating. - In hot weather much blood goes to the skin and little to the food tube, and digestion is less vigorous. Hearty eaters suffer from heat in summer because of much fuel, and because the blood is kept away from the skin where it would become cool and then cool the whole body. Some persons believe that the 
stomach should be humored and given nothing that it digests with difficulty; others believe that it should be gradually trained to digest any nutritious food. Some believe that no animal food should be eaten; others believe that animal food is as valuable as any. Some believe that all food should be eaten raw, but this would irritate a delicate stomach. It is doubtless best to use no stimulant, either tea or coffee, pepper or alcohol. Some eat fast and drink freely at meals; it is better to eat slowly and drink very little or none at all while eating, nor soon afterwards. Some eat five meals a day, and between meals if anything that tastes good is offered them; others eat only two or three meals a day, and never between meals, thus allowing the digestive organs time to rest. Some onit breakfast and some omit supper. Some prepare most of the food with grease; this is a tax upon digestion. Physical workers often believe in eating the peelings and seeds of fruits, and partaking freely of weedy vegetables, such as cabbage, turnip tops, string beans. Mental workers usually try to reject all woody fiber and indigestible pulp from the food before swallowing it. Some eat large quantities of food and digest a small portion; others eat little but digest nearly all.

The Power of Adaptation of the Digestive Organs. - Of course some liabits of eating are better for the health than others, yet the undesirable ways often bring so little injury that they are not discontinued. This shows that the food tube has great powers of adaptation to different conditions. But there are limits to this adaptation; there is an old saying that what is one man's meat is another man's poison. A brain worker cannot follow the same diet as a field hand without working at a disadvantage. An irritable stomach may be injured by coarse food that would furnish only a healthful stimulus to a less sensitive one. A business man who has little leisure at noon should take the heaviest meal after business hours. In general, it may be said that it does not make so much difference what is eaten as how it is eaten, and how 
much is eaten. There is a common tendency to exaggerate the importance of dietetics.

Thought Questions. Indigestion. - I. A Fctid Breath. 1. Name three causes of bad breath. 2. Let us investigate whether indigestion could cause a bad breath. In what kind (two qualities) of weather does meat spoil the quickest? 3. Suppose that meat or other food is put into a stomach with its gastric glands exhausted and its muscular walls tired out, what will be the rate of digestion, and what might happen to the food? 4. Odorous contents of the stomach (e.g. onion) can be taken by the blood to the lungs where it will taint the breath.

After answering the above questions, write in a few words how indigestion may cause a bad breath.

II. A Coated or Foul Tongue. 1. When the doctor visits you, at what does he first look? 2. What sometimes forms on old bread? (p. I58.) 3. Do you think such a growth possible on undigested bread in the stomach? 4. The microscope shows the coating on the bread to be a growth of mold. If it forms on the walls of the stomach, it may extend to what?

III. Stomach Ache. 1. How can you tell whether fruit preserved in a sealed glass jar is fermenting? 2. What connection is there between belching after eating too freely of sweet or starchy food, and the observation above? 3. A muscle gives pain when it is stretched. Why does belching sometimes give relief to an uneasy stomach? 4. Can you, by using these facts, explain a cause of stomach ache?

For what Kind of Man were the Human Digestive Organs created ?That food is best to which the food tube has been longest accustomed. It would be of the greatest value as a guide to diet if we knew the food eaten by early man during the many ages when he led a wild life in the open air. The organs of early man were doubtless perfectly adapted to the life he led. The food tube is adapted to the needs of those long ages, for a few centuries of civilization cannot change the nature of the digestive organs; yet some people disregard natural appetites and try to force the digestive organs to undergo greater changes in a few months than centuries could bring about.

To test whether an Article of Food belonged to Man's Original Diet. - Scientists agree that the human race began in a warm country; that early man was without gristmil's, stoves, or fire, and ate his food raw. If an article of food is pleasant to the taste in its raw, pure state, there is little doubt that it, or a similar food, was eaten by primitive man before he knew the use of fire in preparing his food. Apply this test to the following foods, underlining those foods that pass the test : apples, bananas, lettuce, turnip greens, turnips, fruits, nuts, beef, fowls, 


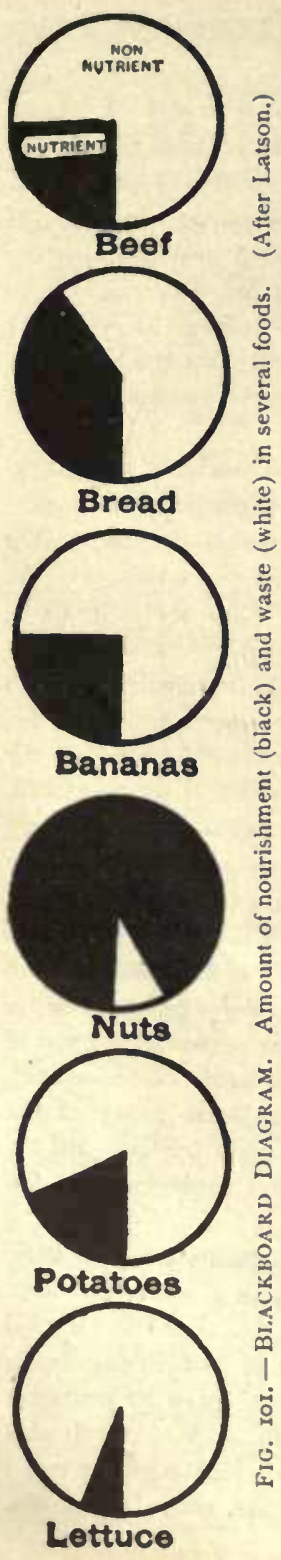

eggs, oysters, green corn, cabbage, pork, watermelons, grains, crabs, fish, white or Irish potatoes, yams, tomatoes.

The Order in which Man increased his Bill of Fare. - Flesh-eating animals have a short food tube, as their food is digested quickly; they have long, pointed teeth for tearing, sharp claws for holding, and a rough tongue for rasping meat from the bones. Man's even teeth, long food tube, soft and smooth tongue, and flattened nails, indicate that he is suited for a diet largely vegetable (see Table, p. IIr). The race at first probably ate tree fruits, ${ }^{1}$ both nuts and fleshy fruits (Fig. IOI). Because of famine, or after migration to colder climates, and after learning the use of fire, the race probably began to use flesh for food. Afterward the hunters became farmers and learned to cultivate grain, which formed a most important addition to the food supply, and made possible a dense population. Coarse, woody foods, like the leaves and stems of herbs, were probably added last of all. Woody fiber (cellulose) can be digested by cattle, but it cannot be digested by man.

The Natural Guide in Eating is Taste. Man should preserve his taste uncorrupted as, next to his conscience, his wisest counselor and friend. It has been developed and transmitted through countless ages as a precious heritage. Simple food is more delicious to people with natural tastes than the most artificial concoctions are to those with perverted taste.

Animal Food. - The flesh of animals furnishes proteid and fat (Fig. IO2). As cooking coagulates and hardens

1 See Genesis i. 29. Some raw food should be eaten daily. Pecans are the most digestible of all nuts. A half dozen or more eaten regularly for breakfast will prevent constipation or cure it in ten days or less. 
albumin, raw or half-cooked meat is said to be more digestible than cooked meat; but meat that is not thoroughly

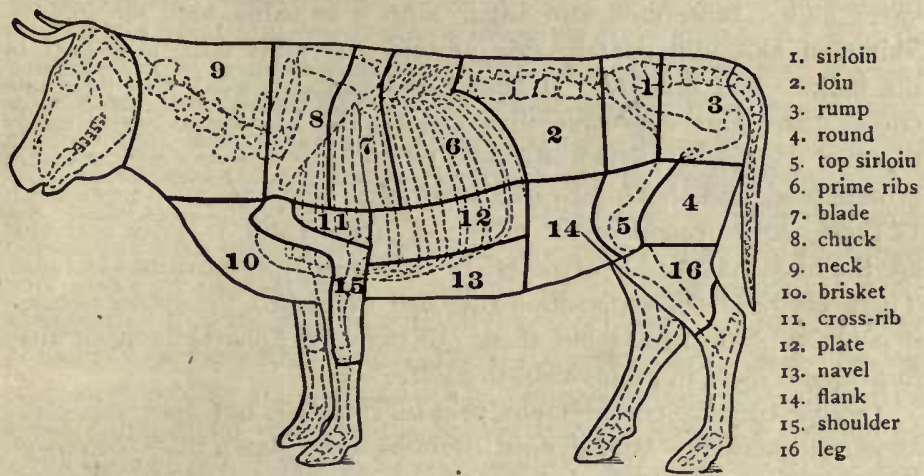

Fig. 102. - DiAgram Showing CuTS of BeEF.

cooked is dangerous because it may contain trichinæ ("Animal Biology," p. 50) and other parasites. Lean meats contain much proteid. Some persons who cannot easily digest starch and sugar because of fermentation eat fat for a fuel food. Beef tea and beef extracts contain but a small part of the proteid in meat and all of the waste matter, including urea.

\begin{tabular}{|c|c|c|c|c|}
\hline $\begin{array}{l}\text { MAMMALS } \\
\text { COMPARED }\end{array}$ & $\begin{array}{l}\text { CARNIVORA, OR } \\
\text { FLESH-EATERS }\end{array}$ & $\begin{array}{l}\text { HERBIYORA, OR } \\
\text { HERB-EATERS }\end{array}$ & $\begin{array}{l}\text { OMNIVORA, OR } \\
\text { ALL-EATERS }\end{array}$ & $\begin{array}{l}\text { FRUGIVORA, OR } \\
\text { FRUIT-EATERS }\end{array}$ \\
\hline Examples. & Cat, dog, lion. & Cow, horse. & Hog, peccary. & Man, monkey. \\
\hline $\begin{array}{l}\text { Length of } \\
\text { food tube. }\end{array}$ & $\begin{array}{l}3 \text { times length } \\
\text { of body. }\end{array}$ & $\begin{array}{l}30 \text { times length } \\
\text { of body. }\end{array}$ & $\begin{array}{l}\text { Io times length } \\
\text { of body. }\end{array}$ & $\begin{array}{l}12 \text { times length } \\
\text { of head-trunk. }\end{array}$ \\
\hline Teeth. & $\begin{array}{l}\text { Pointed for } \\
\text { tearing flesh. } \\
\text { Canine teeth } \\
\text { long. }\end{array}$ & $\begin{array}{l}\text { Layers of } \\
\text { enamel and } \\
\text { dentine form- } \\
\text { ing ridges. }\end{array}$ & $\begin{array}{l}\text { Cutting teeth } \\
\text { project. Ca- } \\
\text { nines form } \\
\text { tusks. }\end{array}$ & $\begin{array}{l}\text { Teeth even, } \\
\text { close together. } \\
\text { Canines not } \\
\text { projecting. }\end{array}$ \\
\hline Digits. & Sharp claws. & Hoofs. & Hoofs. & Flattened nails. \\
\hline Colon. & Smooth. & Sacculated. & Smooth. & acculated. \\
\hline
\end{tabular}


Wilk of cows is improperly called a perfect food by some writers. Although it contains the four classes of food stuffs, the proteid is in excess, the fuel food being deficient. Buttermilk is more digestible than sweet milk. Buttermilk and sugar form a valuable food for infants. Skimmed milk still contains the proteid, the most nutritious part of the milk. Sour milk, or "clabber," and curds pressed into "cottage cheese" are more digestible than sweet milk. Cream is more easily digested than butter, which is a solid fat. Cheese is a very concentrated proteid food, and should be eaten sparingly. Eggs are a valuable food. Is there more proteid or fat in eggs? (See Table.) Pork and veal are the most indigestible of meats. Fish is nearly as nutritious as meat. There used to be a supposition that fish nourished the brain because it contains phosphates; but there are more phosphates in meat than in fish, and more in grains than in meat.

Grains contain considerable proteid (gluten), but they especially abound in starch. Wheat flour contains more gluten than corn meal, hence it is more sticky, and retains the bubbles of gas so that the dough rises well in bread making. Eggs are sometimes added to corn meal to make it sticky and cause it to rise well. Which grain has the largest percentage of oil? (See Table.) Of starch? Of gluten? Which is poorest in gluten? Grains may be made to resemble fruit by long cooking at a high temperature $\left(300^{\circ} \mathrm{Fahr}\right.$.), for their starch is thus changed to dextrin, a substance resembling sugar. You learned that the starch of fruit is turned into sugar as the sun ripens it. Dextrin is yellow and gives the dark color to toasted bread. It is changed to sugar almost instantly when brought in contact with saliva. It is used as a paste on postage stamps.

Vegetables contain much water and woody fiber. White potatoes are underground stems and are one fifth starch. Yams, or sweet potatoes, resemble roots, and contain both starch and sugar. Beans and peas are very nutritious. They have been called "the lean meat of the vegetable kingdom." They require boiling for several hours. If the skins are removed by pressing them through a colander, they are very easy of digestion. This purée of beans makes delicious soup. "Hullless beans" and "split peas" are also sold by grocers.

Practical Questions. -1 . Clothing and shelter for man or beast economize what kind of food? 2. Why should bread remain longer in the mouth than meat? 3. In snowballing, what is the appearance of the hands when they itch from cold? Extreme cold irritates and congests the stomach more quickly than it does the hands. Why is it that ice water does not satisfy the thirst, but often produces a craving to drink more water? 4. Should biscuits having a yellow 
tint or dark spots due to soda be eaten or thrown away? 5. Why, during an epidemic, are those who have used alcohol as a beverage usually the first to be attacked? 6. Do you buy more wood (cellulose) when you buy beans or when you buy nuts? (p.95.) 7. Do you buy more water when you buy bread or when you buy meat? 8. Why do people who live in overheated rooms often have poor appetites? (p.90.) 9. Explain how the stomach may be weakened by the eating of predigested foods. 10. Why are deep breathing and exercises that strengthen weak abdominal walls better for the liver than are drugs? (See p. 58.) 11. Sixty students at the University of Missouri found by doing without supper that their power to work was greater, their health better, and many of them gained in weight. So they ate only two meals thereafter. If sixty plowboys tried the experiment, would the result probably have been the same? 12. If a person began to eat less at each meal, or only ate one meal a day, yet gained in weight, should he agree with a friend who told him he was starving himself? Should he agree if. instead of gaining, he last weight? 13. Why is half-raw or soggy bread harder to digest than the raw grain itself? Which would be thoroughly chewed and cause a great flow of saliva? 14. Ask a fat person whether he drinks much water. A lean person. 15. Why is one whose waist measures more than his chest a bad life insurance risk? 16. What changes in habits tend to make a rheumatic middle-aged person more youthful? 17. How is the ingenious "fireless cooker" constructed?

Atwater's Experiments with Alcohol. - A few years ago Professor Atwater proved that if alcohol is taken in small quantities, it is so completely burned in the body that not over two per cent is excreted. He inferred that it is a food, since it gives heat to the body and possibly gives energy also. His experiments did not show whether any organ was weakened or injured by its use. As alcohol is chiefly burned in the liver, it probably cannot supply energy as is the case with food burned in nerve cell and muscle cell. The heat supplied by its burning is largely lost by the rush of blood to the skin usually caused by drinking the alcohol. Dr. Beebe, unlike Professor Atwater, experimented upon persons who had never taken alcohol, and whose bodies had not had time to become trained to resist its evil effects. He found that it caused an increased 
excretion of nitrogen. When the body became used to it, this decreased, but the proteid excreted by the kidneys contained an abnormal amount of a harmful material called uric acid. Uric acid, a substance which is present in rheumatism and other diseases, is usually destroyed by the liver. As the burden of destroying the alcohol falls chiefly upon the liver, it is not surprising to find that it is so weakened and injured by alcoholic drink that it cannot fully perform its important functions. Bright's disease and other diseases accompanied by uric acid are more frequent among persons who use alcoholic drinks.

Definition of Food. - A food is anything which, after being absorbed by the body, nourishes the body without injuring it. Does alcohol or tobacco come within this definition?

Advantages of Good Cooking. - Taste and flavor may be developed; parasites are killed; taste may be improved by combining foods; starch grains are burst and the food softened. Thus digestion is aided.

Disadvantages of Bad Cooking. - Proteid foods are hardened; flavors may be driven off; too many kinds of food may be mixed; cooked vegetables are more likely to ferment than raw vegetables; palatable food may be made tasteless or soggy or greasy ; soda and other indigestible ingredients may be added; food may be so highly seasoned as to cause catarrh of the stomach; it may so stimulate the appetite that so much is eaten as to overload the stomach. Food may be made so soft that it cannot be chewed and is eaten too rapidly; for instance, bread shortened with much grease.

The Five Modes of Cooking. - Food may be cooked (I) by heat radiating from glowing coals or a flame, as in broiling; (2) by hot air, as baking in a hot oven; (3) by boiling in hot water or grease, as frying; (4) by hot water, not boiling, as in stewing; (5) by steaming.

Radiant Heat. - Toasting bread and broiling meat are examples. The meat should be turned over every ten seconds to send its juices back and forth, thus preventing their escape, and broiling the meat in the heat of its own juices. Roasting is an example of this method combined with the second method. The fire should be hot at first in order to sear the outside of the meat and prevent the escape of its juices. If the piece roasted is small, the hot fire may be kept up; but if it is large, a longer time is required, and the fire should be decreased, otherwise the outside will be scorched before the central part 
becomes heated. White, or Irish, potatoes roasted with their skins on best retain their flavor as well as valuable mineral salts (potash, etc.).

Cooking by hot air can only be used with moist foods. Baking is an example. Foods only slightly moist are made hard, dry, and unpalatable if cooked by this method.

Cooking by Boiling. - To boil potatoes so as to make them mealy instead of soggy, the water should be boiling when they are put in, and after they are cooked the water should be poured off and the pot set on the back of the stove for the potatoes to dry. Boiling onions drives off the acrid, irritating oil. Rapid boiling of vegetables gives less time for the water to dissolve out the nutrients. (See Steaming.) Raw cabbage is treated by the stomach as a foreign substance, and sent promptly to the intestine; cabbage boiled with fat may remain in the stomach for five hours. Instead, it should be boiled in clear water for twenty minutes. Beans and peas require several hours' boiling.

Cooking in hot liquid below the boiling point is better than boiling. In frying meat, it should be put in hot grease that a crust may be formed to prevent the grease from soaking in. Grease much above boiling point becomes decomposed into fatty acids and other indigestible products. Hence butter is more digestible than cooked fats. In whatever way meat is cooked, it should never be salted until the cooking is finished or the salt will draw out the juices which flavor it. Eggs may be cooked by placing them in boiling water and setting the kettle off the stove at once to cool. A finely minced hard-boiled egg is as digestible as a soft-boiled egg. Since boiling for more than a very few minutes coagulates and hardens albumin, there is no such thing as boiling meat without making it tough and leathery throughout. It may be stewed, a process which belongs to the next method.

In stewing meat, it may be plunged into boiling water for a few minutes; this coagulates the albumin on the surface. The fire should then be reduced, or the vessel set on the cooler part of the stove, or a metal plate should be placed beneath it, that the water may barely simmer. The water should show a temperature of $185^{\circ}$ or $190^{\circ}$ if tested with a thermometer. A piece of meat cooked in this way is tender and juicy.

Cooking by steam requires a double vessel or a vessel with a perforated second bottom above the water, through which the steam may rise to the food that is to be steamed. Steamed vegetables have a better flavor and are more nutritious than those cooked in any other way. A steamer is different from a double boiler. Oatmeal should be cooked for at least forty minutes, and it is more digestible if steamed for several hours until it is a jelly. To do this, it may be cooked during the preparation of two meals. Cooking that leaves it lumpy and sticky is a dis. advantage, and makes it more likely to ferment than if eaten raw. 
Thought Questrons. Cooking. - Meat. 1. In making soup, why should the meat be put in while the water is cold? 2. In roasting meat, why should the oven be hot at first, and more moderate afterward? How should you regulate the temperature in boiling or stewing meat? 3. What happens to salt or anything salty on a cloudy, damp day? This is because the salt attracts - This shows that meat should not be salted until after it has been cooked, because if salted before - - 4. Very tough meat should be b-ed or st-ed. 5. Meat may be prevented from becoming grease-soaked when frying by having the grease very —, use very —, simply greasing the

6. Bread. Bread crust causes the - to be used more and cleans them. It will not - together in the stomach like the crumb. It increases the quantity of the - and is more digestible than the crumb, since the - has been changed by slow heat to 112). Therefore loaves or biscuit should be (large or small?) and they should (touch or be sèparated?) in a pan. 7. How can you tell whether the oven has been too hot while the bread was baking? 8 . Why can you tell best about the digestibility of bread when you are slicing it? 9. Regulating the heat is the greatest art of the cook. How may the temperature of the oven be lowered by means of the damper? The draft? The fuel?

Exercises IN Writing. - Story of a Savage who went to dwell in a City (his trouble with artificial ways). Is it easier to learn Physiology or to practice it? How to make Bread. Describe People seen in an Audience (tell what their appearance suggests). A Scene at a Dinner Table. Thoughts of a Physician on his Round of Visits. A Good Cook. A Bad Cook. Is Cooking a Greater Accomplishnent than Piano Playing? Common Causes of Illness. The Influence of Imperfect Digestion upon the Other Organs. Effect of Lack of Muscular Activity. The Way of the Transgressor is Hard. What Fools we Mortals be! Health Fads. Temperance in all Things. The Right Way the Easiest. Looking Back. Looking Forward. Hygiene of the Schoolroom. Patent Medicines. Microbes. Mind Cure. Nervous Women. Dissipated Men. How a Friend of mine lost his Health. Why a Friend of mine is Sound and Strong. Tobacco. It never pays to neglect the Health. Which does more Harm, an Ignorant Cook or an Ignorant Janitor? A Visit to a Sick Room. Alcohol and Crime. Natural Instincts and Appetites; how preserved, how lost. A Lesson about Alcohol based upon the Morning News. Effects of Alcohol upon the Greatness of our Country (workmen, voters, soldiers, children). Adam's Apothecary Shop. Adam's Ale (water). 


\section{CHAPTER VIII}

\section{THE NERVOUS SYSTEM}

Review Questions introducing this Subject. - What is a cell? What are the five supporting tissues? What are the two master tissues? Why are they so called? What kind of cells have many branches? Does the food ever come in contact with the salivary glands? When you look at a basket of apples, the sight "makes your mouth water." Is there a connection between the eye and the mouth? What two tissues enable the skin to blanch and to blush? Do the different organs share the blood in the same proportions at all times? How can this proportion be changed? How is the brain protected from injury? How is the spinal cord protected? Is the hole for the spinal cord through the main body of the vertebra, or behind the main body?

Harmonious Activity. - Strike suddenly at the eye of another, and the lids fall to protect it, and the hands rise 'to ward off the blow. If a grain of dust gets into the eye, the tear glands form tears to wash it out. If you touch the hand unexpectedly to a hot iron, the muscles of the arm jerk the hand away. If the foot of a sleeping person is tickled, the muscles of the leg pull it away. Many muscles coöperate in the act of running. If the human being were merely an assemblage of working organs, the organs might act independently, and there would be such confusion that the body would be powerless, and life could not be maintained. The nervous system enables the organs to work together for the common good. Why does an ameba not need a nervous system?

The Need of Nerve Centers as well as Nerves. - If there were no central office in a telephone system of one thousand subscribers, then every subscriber, in order to com- 


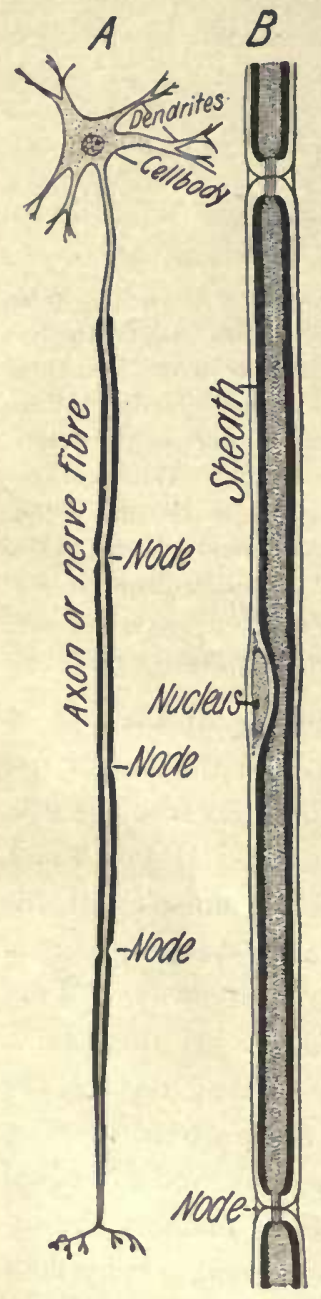

FIG, 103. - Showing a NEURON, .4, or nerve cell with all its parts - dendrites, cell body, and axon; $B$, a portion of a white fiber highly magnificd. (Jegi.)

municate with every other subscriber, would need one thousand wires running into his house; all together, there would have to be several hundred thousand (to be exact, 499,500) wires. With a central office only one thousand are needed. As a telephone system has central offices, so the nervous system has nerve centers. Nerve centers contain nerve cells. Although there are some subordinate nerve centers in the spinal cord, the greatest collection of nerve centers in our bodies is in the skull, and is called the brain. Fishes were the lowest animals studied in animal biology found to possess a true brain.

The nervous system, unlike a telephone system, has other duties besides allowing communication. It enables us to think, and, after reflection, to will and to act by controlling the various organs.

The Units of which the Nervous System is Constructed. - A nerve cell with all its branches, or fibers, is called a neuron (see Fig. 103); some neuron branches are several feet long. Neurons are the units that compose the nervous system. The living substance in cells is 
called protoplasm. The protoplasm in nerve cells possesses the most marvelous and varied powers of any known substance, for the nerve cells are the seat of the mind.

Nerve Cells and Fibers. The many branches of nerve cells make them the most remarkable of all cells for irregularity in shape. Since the protoplasm of the cell contimues into the fibcrs, it is plainly wrong to consider the nerve cell as something apart from its fibers. It is not a complete cell without them. A cell usually has many short branches called dendrons or

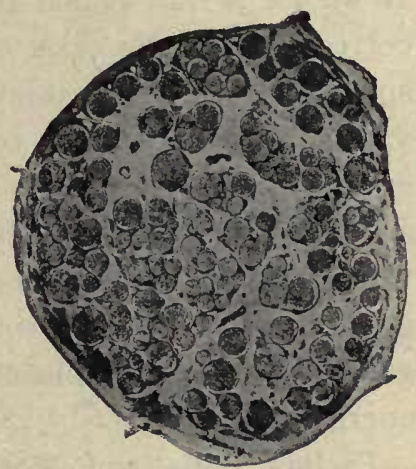

Fig. I04. - LARGE NeRVE TRUNK, such as supplies the muscles. Cross-section (magnified 6 diameters), showing bundles of nerve fibers. (Peabody.)

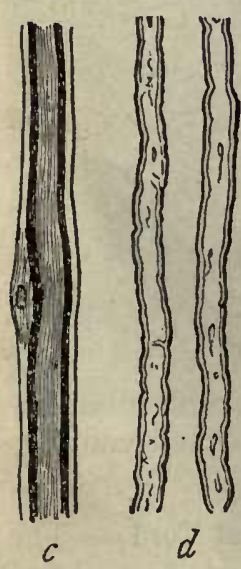

FIG. 105. $-c$, a white fiber with its fatty sheath (dark); $d$, two gray fibers (without sheath). dendrites (see Fig. IO3) for communicating with near-by cells, and one long branch called an axōn (Fig. 103) for communicating with distant parts. The axons form the fibers that go to the skin, muscles, and other organs.

A Nerve. - These long branches, or axons, of nerve cells go all over the body and are often bound together into visible cords called nerves, or nerve trunks (Fig. I04).

White and Gray Fibers (Fig. I05).Some fibers have a fatty covering surrounding the thread of protoplasm; they are white and glistening, and are called white fibers. Others are without this fatty 
covering, and are called gray fibers. Both kinds of fibers have conncctive tissue on the outside to strengthen them. If we let a lead pencil represent a white fiber, the lead corresponds to the axis of protoplasm; the wood corresponds to the white, shiny fat that surrounds it; and the varnish corresponds to connective tissue on the surface of the fiber. A number of white fibers together makes a white mass that is called white matter. The axis of a white fiber, of course, is not white. A mass of cells or of gray fibers is called gray matter. The oxidation of the gray matter, or protoplasm, in neurons gives rise to nerve energy.

Feeling Cells and Working Cells. - Nerve cells are divided into two classes: sensory cells, which feel or receive impressions; and motor cells, which send out impressions to the working organs. Those fibers which carry impressions to the receiving cells are called sensory fibcrs; those which carry impulses from the cells to the working organs are called motor fibers.

Ganglia and Nerve Centers. - Nerve cells are not scattered uniformly in nervous tissue, but are gathered into

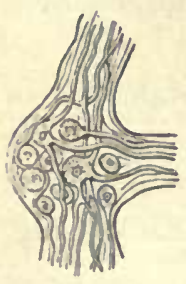

FIG, 106, - A Ganglion. groups. A group of nerve cells is called a ganglion (Fig. 106). One or more ganglia having a single function, such as to control the muscles of breathing, form what is called a nerve center. The brain consists of a number of nerve centers with their connecting fibers.

Gross Structure of the Spinal Cord. - The nerve fivers from nearly all over the body lead to cells situated in a large cord in the spinal column called the spinal cord. The spinal cord is scparated by a dcep fissure almost into halves (Fig. 107). The cells 
are situated in the central portion of each half, and the two masses of gray matter thus formed are connected by a narrow isthmus of gray matter. The outer part of the cord consists chiefly of white fibers. The white matter is thus on the outside of the cord (Fig. IO7). The brain, unlike the cord, has the gray matter on the outside and the white matter on the inside. For microscopic study of the spinal cord, see Fig. I08.

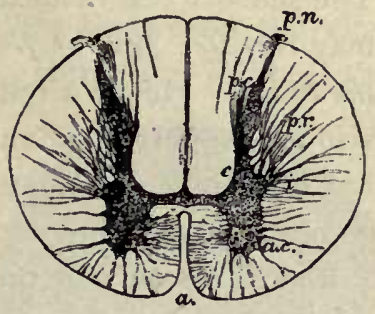

FIG. I07.-CROSS-SECTION OF SPINAL CORD, showing area of gray matter (dark).

The Work of the Spinal Cord. - There are two functions of the cord: reflex action and transmission of impulses

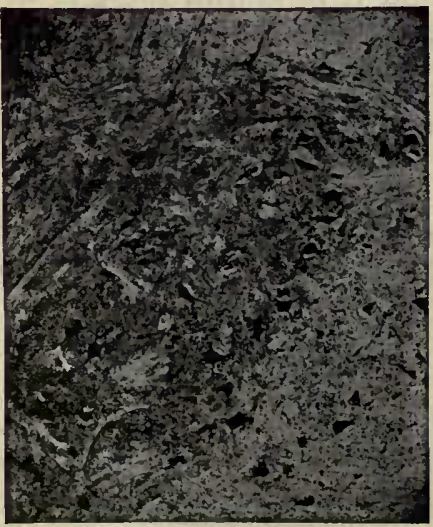

Fig. I08. - SECTION OF SPINAL CORD, showing nerve cells (large black spots) with their branches (black dots and lines). Five bundles of nerve fibers are shown near upper margin. (Peabody.) from the body to the brain. Reflex action is action that takes place without the aid of the will.

Reflex action never begins in the cord, but at the outer end of a sensory fiber, usually located in the skin. The impression goes to the cord along a sensory fiber. It is received in a sensory cell and transferred by dendrons to a motor cell which sends back an impulse along a motor fiber to a muscle; the muscle contracts and the action is complete. At least two nerve cells are necessary for reflex action. The actions of the lowest animals are almost entirely reflex. 
Reflex Action, Consciousness, and Will. - Usually not all of the force of the impulse is transferred to the motor cell. The sensory cell by means of another of its many branches may transfer part of the impulse to a cell which sends it to the brain. Hence a reflex act is not necessarily an unconscious one. If you unintentionally touch the hand to a hot stove pipe, you may be conscious of the pain and the involuntary jerking away of the hand at the same time.

Reflex Action and the Will. - The will may inhibit, or prevent, an expected reflex act. Yet many reflex acts occur in spite of the effort of the will to

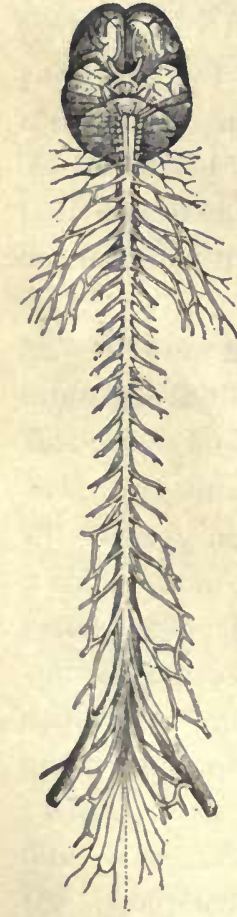

FIG. IO9. - BRAIN AND SPINAL CoRd. prevent them. One cannot always keep from closing the eyes before a threatened blow even if from the other side of a plate glass window, and it is known there is no danger. Sneezing is a reflex act and cannot always be prevented. The forming of saliva and other secretions are reflex acts. Reflex acts are quicker than voluntary acts. An eighth of a second is about the time required for a person to press an electric button after seeing a signal; a reflex act may occur in a shorter time.

The Brain consists of Three Chief Parts. - (I) There is an enlargement at the top of the spinal cord called the medulla, or the medulla oblongata. It may be regarded as the part of the spinal cord within the skull (see Figs. I09, I IO, I I4). (2) Above the medulla is the cerebellum, or little brain. (3) The cerebrum, or large brain, fills all the skull except the small part occupied by the medulla and cere- 
bellum. The cerebrum covers the cerebellum. (Fig. IIO.) Is this true of the monkey's brain? (See Fig. II3.)

The work of the medulla is chiefly to control the vital functions (see Figs. IIO, II4). Here are located the centers for regulating the breathing, the heart beat, the size of the blood vessels (thus regulating nutrition), and also the less important centers that control swallowing, secretion of saliva, and vomiting. The center for breathing is sometimes called the vital knot, because although the

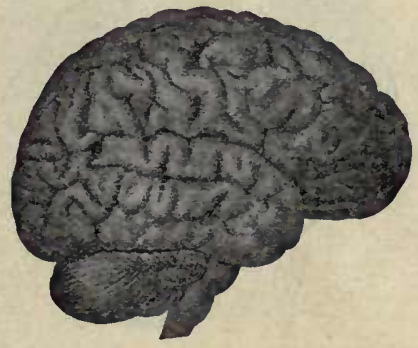

FIG. IIO. - THE BRAIN (cerebrum, cerebellum, medulla). cerebrum and cerebellum may be removed from an animal without causing immediate death, the slightest injury to the vital knot kills the animal at once. In cases of

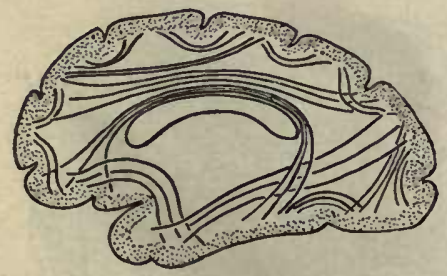

FIG. III. - Association FIBERS, connecting cells within the cerebrum. (Jegi.) hanging, death is caused by injury to this center.

Automatic Action. - The center called the vital knot is said to regulate the breathing automatically, not reflexly. Reflex acts start in the skin; automatic acts start in the interior of the body. The condition of the blood regulates the breathing automatically during sleep, and partly regulates it during waking. If too much carbon dioxid accumulates in the blood this excites the vital knot, which sends out stronger impulses to the respiratory muscles. Deeper breathing follows, which purifies the blood, and the breathing is then 
shallow or slow until carbon dioxid accumulates again.

The Four Kinds of Nerve Action and the Centers that control them. - The cord controls chiefly reflex action; the medulla controls chiefly automatic action; the cerebellum

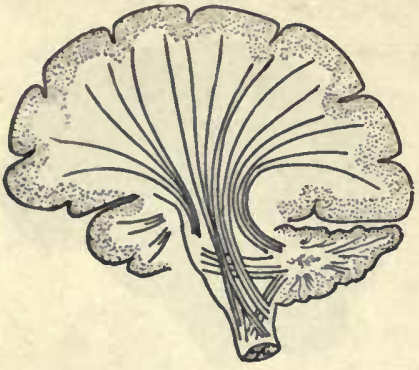

FIG. II2. - SENSORY ANI MOTOR FIBERS. (Jegi.) controls chiefly coördinate, or harmonizing, action; the cerebrum controls the purely vol. untary acts, for it is the seat of conscionsness and thought. The medulla, like the cord, has the gray matter on the inside (Fig. IO9).

Structure of the Cerebellum. - The cerebellum, like the cerebrum, has the gray matter or cells on the outside. The gray matter is folded into furrows that are not nearly so winding as the folds in the cerebrum (see Fig. I I 5). The fibers going to the surface cells have a branched arrangement called the arbor vita, or tree of life, which is shown where the cerebellum is cut. The cerebellum, like the cerebrum, is deeply

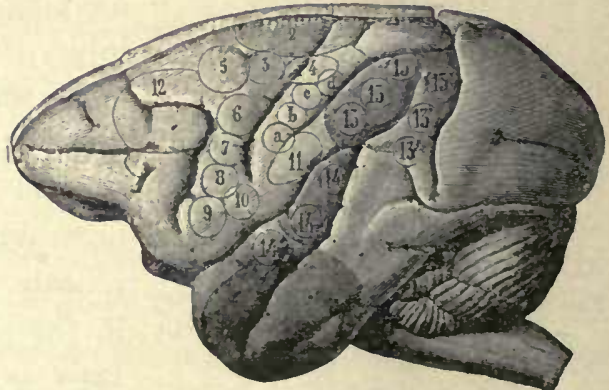

FIG. II3.-BRAIN OF A MONKEY. Numerals show location of motor centers. (See Fig. 115.) cleft and thus divided into halves, called hemispheres, connected by a band of white matter.

The work of the cerebellum is to aid the cerebrum in controlling the muscles. It coördinates the muscular move. 
ments; that is, it makes the muscles act at the right time and with due force in complex acts, such as standing, walking, talking. A man could strike just as hard without the action of the cerebellum, but he would not be likely to hit what he aimed at. A drunken man staggers and fails to control the muscles in walking because the alcohol has caused the blood to collect and congest around the cerebellum and press upon

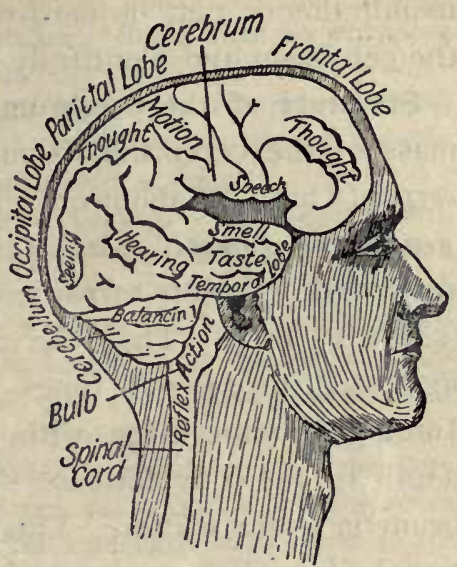

FIG. I14. - THE LOBES OF THE RIGHT SIDE OF BRAIN and their functions. (Jegi.)

The speech center is true only for left-handed persons. Medulla is marked "Bulb."

it. One whose cerebellum

has been injured by accident staggers like a drunken man.

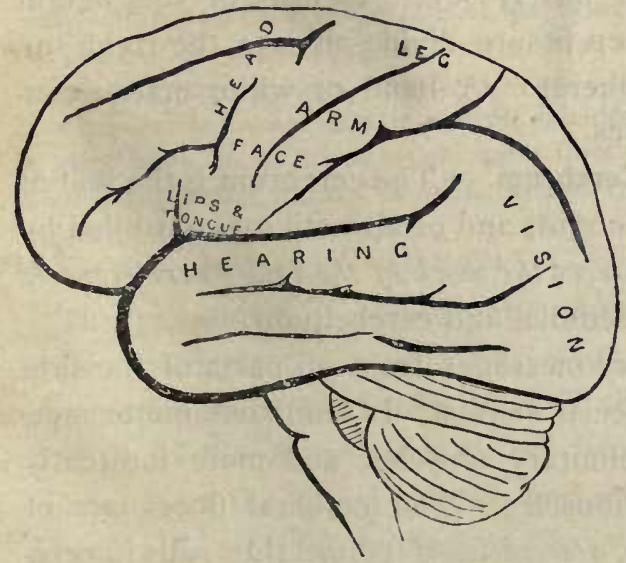

FIG. II5.-MOTOR AND SENSORY AREAS OF LEFT HEMISPHERE, Speech center marked "Lips."

In what region are the motor centers? The sensory centers?
Coverings of the Brain. - Lining the skull and covering the cerebrum are found two membranes which inclose a lymph-like fluid. Thus a kind of water led is made which surrounds the soft and delicate cerebrum and protects it from jars. A 
membraneous net, or meshwork, of blood vessels covers the cerebrum and plentifully supplies it with blood.

Structure of the Cerebrum. - The gray matter, or cell mass of the cerebrum, forms a surface layer, called the cortex ("bark"), about one eighth of an inch thick. This gray layer is deeply folded, the folds, or convolutions, being scparated by deep furrows, some of them an inch deep (see Fig. I IO). Thus the area of the surface layer is increased to several times what it would be if smooth. Intelligence increases with increase in the number and depth of the convolutions. The greater part of the cerebrum is white matter. This consists largely of associational fibers (Fig. I I I) which connect the cells in the gray matter with each other and with important interior ganglia at the base of the cerebrum (Fig. II2). These basal ganglia are the largest parts of the brains of the lower vertebrates (Animal Biology, Figs. 222, 259). Why do these animals not need large cerebrums? The human cerebrum comprises nearly seven eighths of the weight of the brain. A deep fissure divides it into the right and left cerebral hemispheres. A band of white matter connects the hemispheres.

Functions of the Cerebrum. - The cerebrum is the seat of consciousness and thought, and of all activity controlled by the will. It also dircts the work of the lower nerve centers in the spinal cord, medulla, and cerebellum.

It receives sensory messages from all parts of the skin and through the special senses. It sends out motor messages to all the voluntary muscles, and more indirectly to the involuntary muscles. The cerebral fibers are of three kinds: sensory, associational (connecting cells in cerebrum), and motor (Figs. I I I, I I2). It is estimated that the cerebrum alone contains $9,200,000,000$ cells. 
Spinal and Cranial Nerves. - The nerves from the spinal cord go out through notches between the vertebræ. Since there are thirty-one pairs of spinal nerves (Fig. 109) and only twenty-four vertebræ, some of the nerves go out through holes in the sacrum. The cranial nerves (to eyes, ears, tongue, nose, face, etc.) leave the brain through holes in the cranium, or skull. There are twelve pairs of them.

Relation of the Cerebrum to the Lower Centers. - As already stated, nerve activities are of four kinds, - reflex, automatic, coördinate, and voluntary. A manufactory has more complex work than a shop. A man with a shop may enlarge it into a factory and leave trained assistants in charge of the different shops, keeping only the general management for himself. If he should cease to control his assistants entirely, the work of the factory would soon be in disorder. If the manager should try to direct everything, he would become exhausted. So the cerebrum, the seat of the will and the reason, leaves the reflex centers in the spinal cord, medulla, and cerebellum to do most of the work. If the mind wishes the hand to move and grasp the hand of a friend, the motor center in the cerebrum sends a message to the cerebellum; and if the cerebellum has been well trained, the act is accurately performed.

A less imperfect wisdom than that of the mind is in the lower nerve centers. The reason and will control the lower centers through the cerebrum, but the control is very limited. It is well that this is so, not only for the relief of the cerebrum, but for the safety of the body. Can you change the rate of the heart beat by the exercise of the will? Can you blush at will, or prevent the flushing of the capillaries when you are embarrassed, or when you go close to a hot fire? It is impossible for a person to commit suicide by holding the breath. What change in the blood would soon force a breath to be taken? Repeat the two examples of reflex action triumphing over the will which have already been given. We shall next take up a system of nerves almost independent of the will.

The ganglionic or sympathetic portion of the nervous system controls the viscera (vis'se-ra), or internal organs, $\epsilon . g$. peristalsis of food tube, tone of arteries. The nerves that go to the viscera branch off from the spinal nerves not far from the spinal column, and enter a row of ganglia on each side of the spine (see Fig. I I5). Each ganglion is connected by nerves with the one above and below it, so that they appear like two knotted cords suspended one 
on each side of the spinal column and tied together below; for both chains of ganglia end in the same ganglion in the pelvis. Some of the fibers from the spinal cord pass through these ganglia on their way to the viscera, losing their white sheaths in the ganglia and emerging as gray fibers. The spinal cord and brain with the fibers which do not pass through the double chain of ganglia are called

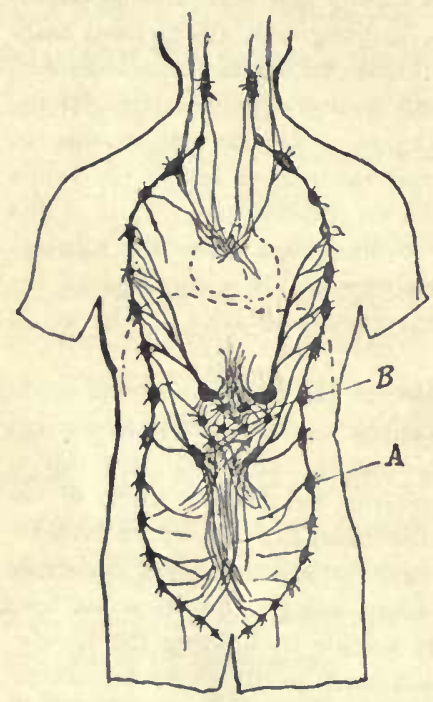

Fig. 116. - DIAGRaM OF SYMPATHETIC SYSTEM showing double chain of ganglia; also plexus at heart and solar plexus. the cerebro-spinal system. The double chain of ganglia and the fibers which go through them are called the ganglionic or sympathetic system.

Why these Nerves are called the Sympathetic System. - These nerves, after leaving the double chain of ganglia, form many intricate networks of ganglia and fibers. Each network is called a plexus (Fig. I 16). The largest of the plexuses is just back of the stomach, and is called the solar plexus. A blow upon the stomach may paralyze this plexus and cause sudden death. The plexuses and fibers connect the viscera so perfectly that one organ cannot suffer without the others changing their activity, or sympathizing with it. An overloaded stomach causes the heart to beat faster and send it more blood; a loss of appetite usually accompanies illness and allows the stomach to rest. This sympathy is necessary, for if one organ is 
diseased, the others do not continue to work and tax the strength of the ailing organ.

How the Sympathetic and Cerebro-spinal Nerves Differ.The ganglionic nerves (I) contain mostly gray fibers; (2) pass through ganglia after leaving the spinal cord; (3) control the unconsious activities of the body; (4) pass to organs which contain slow-acting involuntary muscles, not to sense organs and quick-acting voluntary muscles; (5) transmit impulses slowly (about $20 \mathrm{ft}$. instead of 100 ft. per second). Crawfish and insects have hardly more than the ganglionic system of nerves (Animal Biology, Figs. 92, 132, 197).

Examples of the Supervisory Functions of the Sympathetic System. - Regulation of the heart beat and of the size of the blood vessels; secretion of sweat glands; contraction of pupils of eyes in a bright light; peristalsis.

Examples of Sympathetic Nerve Impulses reaching Consciousness. - Pain in colic and cramps; "heartburn" (pain in stomach from indigestion); backache (from nerves in organs prolapsed by tight clothing pulling upon their attachments at spine); hunger; thirst.

The Mind and Health. - A contented or peaceful mind is indispensable to soundest health. Worry causes difficult breathing with bated breath. Happiness brings full, easy breathing. Biological study of physiology shows the futility of making health a care or anxiety, and teaches "no meddling" with the body, whether by stimulating it, drugging it, deforming it, overheating it, half smothering it in close rooms, cultivating artificial instincts, etc. If the body degenerates through wrong living, and disease ensues, a new way of living is needed, not some quick and wonderful remedy. The new life will renew the body and nothing else can.

Hygiene of the Nervous System

Necessity of Food, Fresh Air, and Rest for Sound Nerves. - The health of the nerves depends upon a free supply of 
pure, nutritious blood. Nearly one fifth of the blood goes to the brain. It is clear that the brain cannot give out energy until it has first received it; the blood supplies energy to the brain. The blood in turn receives the nour-

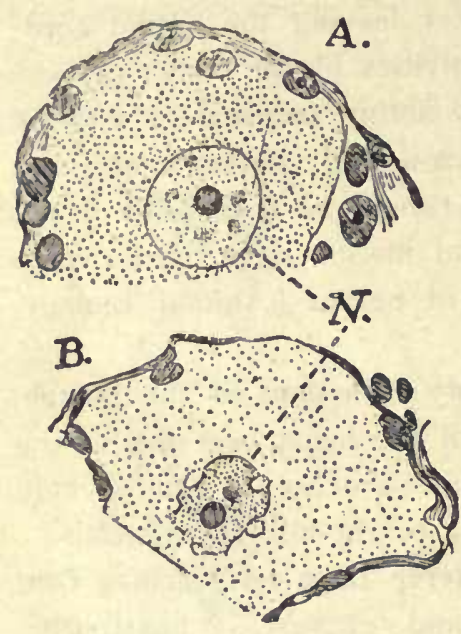

Fig. II7. - EFFects of Fatigue on Nerve Cells.

$A$, resting cell, $B$, fatigued cell, with its body and nucleus shrunken. ishment from food and pure air. A rested cell is full of nourishment; a tired cell is shriveled (see Fig. I 17).

Sleep. - During waking hours energy is used up faster than it is stored in the cells, and protoplasm is oxidized faster than the cells can replace it. During sleep the opposite is true; repair is more rapid than waste. During sleep the muscles are strengthened, the breathing is less, the heart beats more slowly, less heat is produced, digestion is slower, less blood goes to the brain. Why is it necessary to be more warmly protected by clothing or bed covering when asleep than when awake? Above all, the nervous system has an opportunity to recuperate from the constant activity of waking hours. The eye and the ear are rested by darkness and silence. Sleep caused by morphine or other drug is not normal sleep and brings little refreshment.

Practical Suggestions. - Sleep is deepest during the second hour after going to sleep, and a greater shock is given to the nervous system by waking a sleeper during that hour than at another time. An alarm clock is a very unhealthful device. One who cannot trust to nature 
even to awaken has great presumption. If one does not rise promptly upon waking naturally, the instinct to awake when enough sleep has been taken will be lost, and the habit of sleeping too much will be formed, and the brain, like the muscles, will become weak from inactivity. Infants sleep most of the time, and it is injurious to them to be waked. Adults usually require about eight hours of sleep. There is a risk in going to sleep in a warm room, for the bed covering which is comfortable then may not be enough to prevent taking cold when the fire goes out. Sleep usually comes more promptly to one who goes to bed at the same hour each night. The muscles are relaxed in sleep, and relaxing them perfectly upon lying down and breathing slowly, tends to bring sleep. One who is sleepless usually finds that he is breathing fast and is holding the head stiff on the shoulders, the teeth clenched, and the muscles contracted, even though he is lying down. Excitement and worry during the day, but especially just before retiring, tend to produce sleeplessness. One who overworks his mind by too great attention to business is inviting ruin. A student who loses sleep while preparing for an examination will probably. fail. Rested brain cęlls and pure blood are needed for good work.

Rules for Preventing Sleepiness. - (1) Do not sit close to stove or especially a fireplace or in very warm room, and do not wear very warm clothing in the house. (2) Let in fresh air freely. (3) Do not sit in rocking chair nor with chest flattened. (4) Make the last meal a very light one.

Habits. - Our habits of doing and thinking and feeling really constitute our characters. This shows the importance of right habits. By gradually changing our habits we can strengthen our characters and form them somewhat as we wish. When a muscle contracts in a certain way, this act makes it easier for the muscle to contract in that way the next time; thus great muscular strength may be developed. When a nerve cell acts, the circulation around the cell is increased, the fibers develop by use, and the act is easier the next time. We cannot entirely get rid of our habits, because we cannot get rid of our brains.

Healthy fatigue is caused by the accumulation of waste products resulting from the oxidation of substances in nerve, muscle, and gland cells. The presence of waste in 
the tissues affects the nerves. We are rested and strong when these wastes are removed and the tissues are supplied with fresh food and oxygen. Work causes the accumulation of carbon dioxid, which is nature's narcotic. ${ }^{1}$ The drowsy feeling that ensues is more pleasant than the drowsy feeling from alcohol or opium. Those who do not employ nature's narcotic but free themselves of it by hurried, anxious breathing become restless and crave artificial narcotics.

Fatigue without work occurs with people who are idle. The oxidation in their cells is not complete, and poisonous products of the incomplete burning result. This is known as self-poisoning (auto-toxemia). The poisons are taken by the blood to the nerves and brain, and give a tired feeling as effectually as does hard work; or the food may fer-

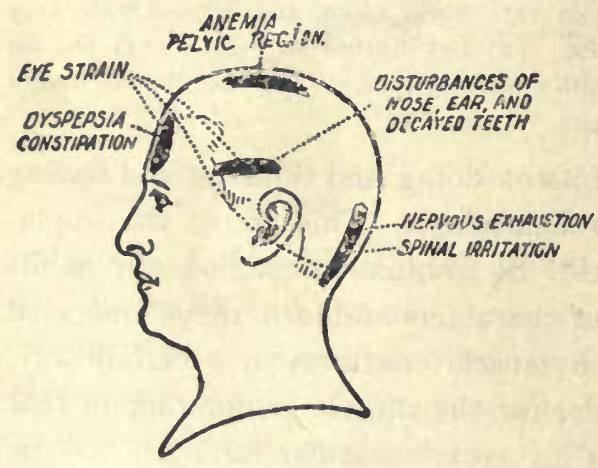

Fig. I18. - THE Situation of HEADACHES with reference to their causes. ment in the food tube and form poisons which increase the tired feeling. Such persons are usually irritable, while persons who are fatigued by use. ful labor are likely to be dull and drowsy.

Headaches are caused by poisons in the blood or by pressure of blood congested in the head. Like all other pains they should be a source of benefit in

${ }^{1}$ It has been found that it is injurious to rebreathe expired air containing one per cent of carbon dioxid, but a far greater percentage is harmless if introduced into fresh air, thus indicating that the injury from poor ventilation comes chiefly from the "crowd poison," or organic particles thrown off. 
that they show us ways of living to be shunned in the future. Many persons, however, not only derive no profit from a headache, but by unwise efforts to cure the pain, bring permanent injury to themselves in addition to the suffering of the headache.

Bromides, opium, and other poisons deaden and weaken the nervous system while preventing the headache from being felt. Headache poruders, phenacetin, acetanelid, antikamnia, and other vile poisons made from coal tar, shock and weaken the heart and reduce the vital activities so that the headache is no longer felt. In consequence of shocks from repeated doses of such drugs, the heart will not work so well, and may give way some time in the future when an effort or strain makes unusual demands upon it. Their use has made heart disease more prevalent. The liver and kidney cells and the white corpuscles have to destroy and remove the drugs. Many people are foolish enough to injure their bodies and risk death rather than suffer pain or avoid pain by prudent living.

Sick headaches are foretold by a dull feeling, sleepiness after eating, a coated tongue, and constipation. It would be better to remove the undigested, spoiled food from the stomach (four glasses of water will cause vomiting) than to take a drug. At the first indication of trouble, abstain from eating, or use a fruit diet for twenty-four hours, and drink water freely. This will enable the body to dispose of the excess of waste matter.

The Highest Living Medical Authority on Drugs.-Dr. Osler, formerly of Johns Hopkins University and now of Oxford University, says :

"But the new school does not feel itself under obligation to give any medicines whatever, while a generation ago not only could few physicians have held their practice unless they did, but few would have 
thought it safe or scientific. Of course there are still many cases where the patient or the patient's friends must be humored by administering medicine, or alleged medicine, where it is not really needed, and indeed often where the buoyancy of mind, which is the real curative agent, can only be created by making him wait hopefully for the expected action of medicine; and some physicians still cannot unlearn their old training. But the change is great. The modern treatment of disease relies very greatly on the old so-called natural methods, diet and exercise, bathing and massage, in other words giving the natural forces the fullest scope by easy and thorough nutrition, increased flow of blood, and removal of obstructions to the excretory systems or the circulation in the tissues. One notable example is typhoid fever. At the outset of the nineteenth century it was treated with " remedies" of the extremest violence, - bleeding and blistering, vomiting and purging, antimony and calomel, and other heroic remedies. Now the patient is bathed and nursed and carefully tended, but rarely given medicine. This is the result partly of the remarkable experiments of the Paris and Vienna schools into the action of drugs which have shaken the stoutest faiths; and partly of the constant and reproachful object lesson of homeopathy. No regular physician would ever admit that the homeopathic "infinitesimals" could do any good as direct curative agents; and yet it was perfectly certain that homeopaths lost no more of their patients than others. There was but one conclusion to draw, that most drugs had no effect whatever on the diseases for which they were administered." - "Encyclopædia Americana," Vol. X. (Munn \& Co., New York.)

Applying Hygienic Tests Systematically. - The cause of ill health (e.g. a headache) should be sought with system and thoroughness, applying the tests in rotation to every function of the body: Lungs. Is the air habitually breathed fresh and free from dust? Is the body held up, and is the chest or waist cramped by clothing? Muscles. Is enough physical exertion made to cause deep breaths to be drawn? Food. Is it simple, digestible, and eaten properly? Drink. Is the water pure? Cleanliness, Work and Rest, Clothing, Ventilation, and Mental State may be inquired into until the source of trouble is found and the cause of ill health removed. To give drugs and leave the cause of ill health untouched, is to fail. There are signs of coming weakness or illness which, if heeded and the ways of living improved, will usually prevent illness. Among these signs are headaches, paleness, sensitiveness to cold, heavy feeling or pain after meals, constipation. Huxley says that young people should so learn physiology and so understand their bodies that they will heed the first sign of nature's displeasure, and not wait for a box on the ear. 
Nervous Children. - A report on the health of the school children in one of our large cities shows that one third of the children in those schools have some disorder of the nerves. Nervousness (weakened control of the nerves) may show itself by sluggishness of mind, great irritability of temper, frequent spells of the "blues," or by involuntary movements of a jerky or fidgety kind. Sound development of city children's nerves is hindered because of the constant noise in cities both day and night; by shortening of the hours of sleep; by excessive use of sugar for food; by living much among people with no chance to be alone and let the nerves rest, and among boys by the use of cigarettes.

How to Prevent the School from injuring Children. (I) Ventilation is of first importance. Breathing the breath of fifty other children does far more harm than overstudy. (2) The time devoted to work should not be long, especially in the lower grades (no study out of school). (3) The work should be diversified; not only printed words, but pictures, natural objects, and the outdoor world should be studied. (4) The teacher and parent should see that the habitual poise of the child is favorable to health. (5) The children should be encouraged to play. Running games at recess are of the greatest value, and are as indispensable to the health of a boy or girl as of a colt. (6) Physical exercise should be provided at short intervals between lessons, especially stretching exercises and movements that straighten the spine and hips and elevate the chest.

The Effect of Alcohol upon Nerve Function. - In attacking the nerve centers, alcohol begins with the cerebrum, the highest, and proceeds toward the lowest. Hence as a man becomes drunk he first talks foolishly (cerebrum affected), then he staggers (cerebellum affected), and he finally goes to sleep and breathes very hard (medulla affected) in a drunken stupor. It rarely happens that the breathing center is completely disabled and the man dies from the strong poison. The greatest evil of alcohol is 
seen in the case of steady drinking. This gradually de troys the soundness of the nervous system and weakens self-control. The tendency with nearly all drinkers is to increase the amount taken.

Not Total Abstainers, but the Advocates of Universal Moderation are the Visionaries. - The evil results from alcohol are so great as to be almost incredible. The plainest statements of its effects are sometimes denounced as unscientific by persons prejudiced in its favor. A part of the two billion dollars annually paid for liquors is used in influencing public opinion through the press.

Practical QUeSTIONS. - 1. Why does travel often cure a sick person when all else fails? 2. Why is working more healthful than "taking exercise"? (p. 47.) 3. Is it better for children to play or to take exercise? 4. Why can one walk and carry on a conversation at the same time? (p. 127.) 5. How does indigestion cause a headache? (p. 133.) 6. Does perfectly comfortable clothing from head to foot help to make one at ease in company ? Does uncomfortable clothing tend to make one awkward? 7. Why is it as important to have the shoes and clothes perfectly comfortable when going out as when staying at home? 8. When one's finger is cut, where is the pain? 9. In what two ways may opening a window when a student is becoming dull and drowsy at his books enable him to wake up and study with ease? 10. What kinds of cells shrivel like a baked apple when they become fatigued? (Fig. 117.) 11. A nerve or nerve fiber can hardly become tired or fatigued, for the nerve cell supplies the energy. What do we mean when we say the nerves are worn out? (Fig. 117.) 12. Why do you throw cold water upon a fainting person? 13. Why does constant, moderate drinking undermine the health more than occasional intoxication? 14. Why does stoppage of the circulation cause one to faint? (See Chap. VI.) 15. Why is grazing the skin often more painful than cutting it? (Colored Fig. 1.) 16. Why do the lower animals always act upon sudden impulse? What part of the brain enables man to retain sensations and not act upon them until later? 17. Does "nervousness" more probably indicate a bright mind or a high temper? 18. What is the effect of a cold bath upon the nerves? (Chap. II.) 19. Did you ever know a cigarette smoker whose hand trembled? 20. Need there be any fear of a sobbing child holding its breath until it dies? 21. Why is muscle tone greater in cold weather ? 
The True Function of Stimulants. - One whose heart has nearly given out because of exposure to severe weather may be temporarily revived by alcohol. It will not be wise to do so unless it is certain that a warm fire and protection zeill be reached before the reaction comes. Much less would be necessary to revive an abstainer than a drunkard. Habitually disturbing the body with stimulants makes them ineffective in a time of emergency. A cup of coffee will not keep a watcher awake if he is used to coffee.

Definitions : Stimulant, Narcotic, Poison. - A stimulant is anything that excites the body to activily, but is of no help or of insignificant lutp, in replacing the strength used up.

A narcotic is anything that deadens or dulls the nervous system. It comes from a word meaning "to benumb."

Poisons are active substances, which, taken in quantities, as man takes food, destroy life; in smaller quantities they injure the body and may destroy life. Alcohol is a poison. Wine, beer, whisky, contain varying quantities of it.

The Narcotic and Stimulant Effects of Poisons. - Examples of poisons are alcohol, nicotin, opium, arsenic, strychnin. Poisons excite the body when taken in small doses, while in large doses they produce paralysis and death. The irritating or stimulating effect is due to derangement of the functions or to the efforts of the cells to free the body of the destructive substance. The narcotic effect is due to the poison having so benumbed the nerves and injured the cells that their activities cease, or become less for a time. You readily see how the same poison can be both a stimulant and a narcotic: the stimulating effect always comes first, followed by the stupefying effect. If the dose is very small, the stimulating effect will last longer; if it is large, the narcotic effect is greater and felt more quickly. A habit of using stimulants is an invariable sign 
of weakness. The first dose of morphine or cocaine may be the first step in a lifelong blight of strength and happiness. If physicians whose treatment of a case results in leaving a patient with a drug or alcohol habit were sued for malpractice, they would be less reckless. The annual consumption of morphine is estimated at twenty-seven grains per capita in China, and fifty grains in the United States.

Reaction. - This is the depressed and exhausted condition that comes on after a period of unnatural activity. It follows the exciting effects of a stimulant.

Natural Stimulants. - If there were nothing to arouse activity, life would be impossible. A cold wind is a natural stimulant. The activity aroused by a cold wind is just enough to help the body withstand the cold; artificial stimulants cause an expenditure having no relation to the needs of the body. Hence there is a great waste of energy. Feelings may stimulate, as love for his family may stimulate a man to labor. The desire for knowledge may stimulate a boy to study. Hunger may stimulate a man to eat. Hunger is a natural stimulant, and is not likely to make him eat to excess; tea, coffee, pepper, etc., arouse a false appetite. These things are used chiefly for their stimu. lant effect, for they contain little or no nourishment. We will now study about artificial stimulants. Such stimulants always cause an unregulated and unhealthy action, and are always followed by reaction.

How much Strength is stored in the Body? - Dr. Tanner of Minnesota believed that most people eat too much. Another physician said that no human being could go forty days withont food. Dr. Tanner made the experiment. He lost thirty-six pounds in weight, but he weighed $12 I_{2}^{1}$ pounds and had considerable strength at the end of the 
forty days. The first thing he ate at the close of his fast was the juice of a ripe watermelon.

Once some miners were shut in by the caving of a part of a mine. But, unlike the case just described, they were without water as well as food. When, by digging, the rescuers reached them seven days after, several were still found alive, although most of them had died. The miners, no doubt, had nourishment in their bodies for some weeks more of life, but the body lacked water to dissolve it and bring it within the reach of the cells most needing it.

A Stupendous Fact. - These incidents show how wisely the body is made, and prove that the cells store up nourishment for weeks ahead. The large amount of nourishment stored in the human body is one of the most striking and important facts with which the science of physiology has to deal, and it should be borne in mind, or we may make great mistakes about some very simple matters and especially in regard to the effects of stimulants.

Foolish Rashness. - Did you ever get so tired that you had to give up and stop, however much you would have liked to continue at work or play?. To rest was the wise thing to do. Because you know there is much energy stored in the body, this need not tempt you to go on until you almost break down. Probably you know people who are conceited about their bodies and say they are "made of cast iron"; that nothing can hurt them. Such conceit will be almost sure to get its possessor into trouble.

How a Safeguard may be broken down. - It is a very wise arrangement that, under ordinary conditions, we cannot get at the surplus energy we have. Carbon dioxid and other wastes accumulate in the tissues and paralyze the nerves. Fatigue and other feelings compel us to be provident, as it were; yet stimulants and narcotics, by irritating 
the nerve cells, arouse them and cause us to expend some of this reserve energy. Thus man is enabled to get at this precious store which he should save for emergencies, when he is sick and cannot digest food, or when he is making some mighty effort. A weak, ill man who has eaten very little for weeks, when delirious is sometimes so powerful that it takes several strong men to hold him in bed. But the delirious mania often uses up the little energy left, and costs the man his life.

The only source of energy for man's body is the union of food and oxygen; he must get his energy from the same source that the engine does; and this is from his food, which serves as fuel, and the oxygen which burns it. If one has been working hard preparing for examinations, or gathering hay, or in attending to some important business, or has been under the excitement of some pleasure trip, and feels "blue" and worn out, then let him bear the result like a man, or like a true boy or girl, as the case may be. Giving up for a while, or "toughing it out" with the blues, or losing a little time from business, will not hurt, but will restore strength, while a stimulant will leave him less of a man than before.

Nervousness. - The attempt to divide the race into brain workers, muscle workers, and loafers, whether men or women, is a powerful factor in race degeneration. Leonard Hill says: "Hysteria and nervous exhaustion are the fruits not of overwork, but of lack of varied and interesting employment. The absurd opinion that hard work is menial and low, leads to most pernicious consequences. The girl who, turning from brain work to manual labor, can cook, scrub, wash, and garden, invites the bloom of health to her cheeks; while the fine do-nothing lady loses her good looks, suffers from the blues, and is a nuisance to her friends and a misery to herself." A Japanese lady holds views similar to those of Dr. Hill. Read footnote. ${ }^{1}$

1 Statement by Madame Toyi Niku of Yeddo, Japan, after a six months' visit to the United States. - "Worry and inactivity, it seems to me, sharply 
Subjects For Debate. - (1) Does the Chinese woman deform her body less than the Caucasian woman and suffer less from it? (2) Does as much disease originate in the dining room as the barroom ? (3) Are drugs a necessary evil ? (4) Does pride cause as much illness as ignorance? (5) Is it ever right to neglect the health ? (6) Does the mind or the way of living have more effect upon the health ?

Disuse and Degeneration. - Many persons in civilized countries cherish a vain hope of having sound muscles without habitual use of them, pure blood without deep breathing, a strong circulation in an inactive body, a fresh skin without keeping the body sound, a hearty appetite without enough physical labor to use the food already eaten, steady nerves with a part of the body overworked and a part stagnating from disuse. Their flabby muscles, pale skins, highly seasoned food to arouse appetite, narcotics to deaden irritable nerves, and the wide use of drugs as a fancied substitute for right living all show the attempt to be a miserable failure. If the parents leading such a life escape with fairly good health and average length of life, they leave a few unhealthy children in whom physical degeneration is plain. Complete, balanced living only prevents degeneration. Although there are cases of illness which are not necessarily a disgrace, disease usually originates in weakness of character or lack of common sense. The snob who thinks himself above physical labor, the dupes who at the bidding of avaricious fashion mongers think more of clothes than of a free body, the narrow, unbalanced man, who concentrates all his energies on one ambition, the short-sighted one who worries, all grow into a diseased state.

mark the women of your middle classes. I did not attempt to study your leaders of society, for they are much alike the world over - the same fuss, the same display of jewels and finery, the same scandals, the same uselessness. Your women do not diversify enough. If they are good cooks, they stop there; perbaps another is a good housekeeper, another can sew finely; but doing one thing makes narrow-mindedness. In Japan we strive to do many things. The worry troubles of your women, it seems to me, come largely from improper eating and overeating. I have sat at many of your tables and there is too much food on them and too much variety. First, women overeat, then they doctor, then they starve, and then they become nervous. A woman's diet, especially a mother's, should always be simple. Cut down eating and increase variety of labor and exercise. My own people live that way with a result that we have better feminine bodies, better skins, and better tempers than your women. I like the brightness of your young women. Perhaps you will take the hideous hats off them some day, find a substitute for the bad corset, and let them wear clothes that are loose, yet are soft and clinging. They are bound up in their clothes too much now and their judgment of colors and combinations is not good. Their clothing is either garish or very dull in hue. The simplest girl in Japan knows how to harmonize color with herself. - Mother's Magazine, November, 1907. 


\section{CHAPTER IX}

\section{THE SENSES}

Experiment 1. Where are the Nerves of Touch most Abundant?Open a pair of scissors so that the points are one eighth of an inch apart, and touch both points to the tip of the finger. Are they felt as one or as two points? Find how far they must be separated to be felt as two points when applied to the back of the neck. Record results. Caution: The person should be blindfolded, or should look away while the tests are being made. Two pins stuck in a cork will be more convenient to use than scissors.

Experiment 2. Nerves of Temperature, or Thermic Nerves. - Draw the end of a cold wire along the skin. Does the wire feel cold all the

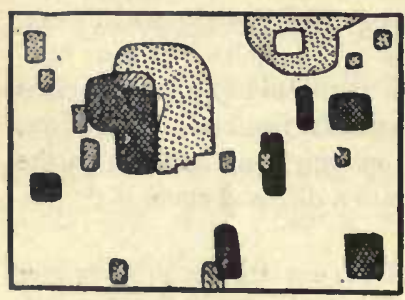

FIG. II9.- "COLD" SPUTS (light shading). "Нот" Srots (dark), skin of thigh. time? Repeat with a hot wire. Do you conclude that temperature is felt only in spots?

Muscular Sense. - Experiment 3 . Make tests of the ability to distinguish the weight of objects weighing nearly the same, when laid by another in outstretched hand; also by laying them in the hand while it rests upon a table. Which test showed more delicate distinctions? In which were muscles brought into use? Experiment 4 . Close the eyes and let some one move your left arm to a new position; then see if you can with the forefinger of the right hand touch the forefinger of the left hand in its new position at the first attempt.

Experiment 5. Functions of the Several Parts of the Tongue. Test the tip, edges, and back of the tongue with sugar, vinegar, quinine, and salt. Where is the taste of each most acute? Record results. Flavors. - Experiment 6. Blindfold a member of the class, and while he holds his nostrils firmly closed by pinching them, have him place successively upon his tongue a bit of potato and of onion. Can he distinguish them? Experiment 7. Mark $F$ after each of the following 
foods that have a flavor (see text): vanilla, apple, lemon, beef, peaches, grapes, coffee, onion, potato, cinnamon.

Experiment 8. A Smelling Contest. - Place the following and other things having taste in vials around which paper has been pasted to conceal their contents : pepper sauce, vinegar, kerosene, flavoring extracts (diluted), several perfumes, iodine, bits of banana, lemon, apple, etc. Number the vials and have pupils test and write results in a list. Correct the lists and announce pupil having keenest sense of smell.

Experiment 9. A tasting contest may be arranged in a similar way. Smelling and tasting tests should be made quickly as these senses are soon dulled by repeating a sensation.

Experiment 10. Advantage of Two Eyes over One. - Try to touch forefinger to something held by another at arm's length from you, bringing the finger in from the side: (I) with one eye closed; (2) with both eyes open. Result? Conclusion? We tell the distance of an object by the amount of convergence of the eyeballs needed to look at it.

Experiment II. Duration of Impression. - Whirl a stick with a glowing coal on one end (see Fig. 123).

Experiment 12. Color Blindness. - Provide a number of yarns of different tints, and the same tints. Test color blindness by having each pupil match tints and assort the yarns.

Experiment 13. Fatigue of Optic Nerve. - Gaze long and steadily at a moderately bright object, then close the eyes. Result ? Conclusion?

Experiment 14. Dissection of Eye. - The eye of an ox is an interesting subject for dissection. The lens is like a clear crystal. Make out all parts named in the text (see Fig. 122).

Experiment I5. Image formed by a Convex Lens. - For a few cents obtain from a jeweler a convex lens, or use a strong pair of spectacles worn by an old person. Hold the lens a few feet from a window (darken any other windows near). A little beyond the lens hold a white card or book open at a blank page to catch the image. Have some one walk before the window.

Experiment 16. Work of Iris. - Notice the size of the pupils. Cover one eye with the hand for a few minutes. Uncover and look in a mirror. Gaze at bright window and look again in the mirror. Conclusion? Do the two pupils still keep the same size when one eye is shaded?

Experiment 17. Accommodation. - By holding your finger or a pencil in line with writing on the blackboard, you find that you cannot see both finger and blackboard distinctly at the same time - first one and then the other is distinct. Explain (see text). 
Experiment 18. Astigmatism (effect of unequal curvature of cornea or lens along certain lines). With end of crayon draw about twelve straight, even lines crossing at one point on the blackboard. Have the lines of equal distinctness. How many pupils report that the lines in certain directions are blurred? Inquire whether these pupils have frequent headaches from eye strain.

Experiment 19. Can Sound reach the Ear through the Bones?Hold a watch between the lips and notice its ticking. Close the teeth down upon it and notice any change in the sound. Cover one, then both ears, and note the result.

Experiment 20. Test keenness of hearing by having pupils walk away from a ticking watch until it becomes inaudible. Test each ear. A "stop" watch is preferable.

Experiment 21. Advantage of Two Ears over One. - Have the class stand in a circle. Blindfold some one and place him in the middle of the circle. Let various pupils clap the hands as the teacher points to each. Can the blindfolded one point in the direction whence the sound comes? Stop one ear with a handkerchief and repeat. Result? Conclusion? From what two points in the circle does the sound fall upon both ears alike?

Experiment 22. The Cause of Nasal Tones. - Let a pupil go to the back of the room and read a paragraph, and hold his nose until partly through the reading. Or the teacher may read with his face and hand hidden by a large book. Let the other pupils raise their hands when they notice a change in the quality of the reader's voice. Does the experiment show that a "nasal" tone comes partly through the nose or through the mouth only? Does stoppage of the nostrils by catarrh cause a nasal tone?

Five Differences between Special and General Sensation. - First, the nerves of special sense all end in special organs at the surface; for instance, the touch corpuscles are for touch, the eye is for sight, etc. There are many nerves in the body that do not end in special organs; these nerves give what is called general sensation. A second difference is that general sensation tells of the condition of the interior of the body, while special sensations tell us of the condition of the surface of the body and of the outside world. Third, general sensations are not so exact as the reports of the special senses. One can locate a point on the skin that has been touched much more accurately than he can locate an internal pain. A fourth difference is that the meaning of each special sensation must be learned (usually in infancy); but the meaning of general sensations is inherited. This inherited knowledge of what general sensations mean is also called instinct. Fifth, the sympathetic nerves 
usually bring general sensations; the spinal and cranial nerves usually bring special sensations.

Examples of general sensations are hunger, thirst, satiety, nausea, faintness, giddiness, fatigue, weight, aching, shuddering, restlessness, blues, creepy feeling, tingling, sleepiness, pain, illness. Any nerve can convey the general sensation of pain, if injured along its course. If a nerve of touch is cut, there is no sensation of touch, but of pain. Touch sensations come only from the ends of the nerves. General sensations are of many kinds. We are only half conscious of some of them; many of them are hard even to describe.

Hygiene of the General Sensations. - General sensation is an invaluable aid to the health. Without it as a guide, the body could not remain alive a single day. Pain should be heeded as our best friend, and not killed with poisonous drugs as if it were our worst enemy. We should not deaden the stomach ache with an after-dinner cigar. If we do not go to bed when sleepy, the desire for sleep may leave us, and we will undergo untold suffering from sleeplessness. Thirst should be satisfied with cool water, which quenches it the best; he who makes his teeth ache with ice water will inflame his stomach and be continually thirsty. He who does not stop eating when his hunger is satisfied, will distend his stomach with food, and the stretched organ will be harder to satisfy thereafter; in fact, eating after a feeling of satiety may cause indigestion so that the cells will not get the food. A dyspeptic is always hungry, for the cells are starving. Fatigue of body or mind gives us wise counsel; but this feeling may be deadened by alcohol or tobacco, and work continued until the body is injured. We should heed the warning of pain or fatigue or restlessness as promptly as an engineer heeds a red flag on the railway track. One who uses narcotics acts like a reckless engineer who removes the danger signal and goes ahead, hoping by good luck to escape an accident.

Most of the nerves of touch end in papilla of the dermis as microscopic, egg-shaped bodies (Fig. I20). There are also many in the interior of the mouth, especially on the tongue. On the palms they are arranged in curved lines, and on the tips of the fingers they are in circular lines, with one papilla in the center. The delicacy of the sense of touch varies very much in different parts of the skin. This delicacy refers to two things: the ability to feel the slightest pressure and the ability to tell the exact point of 
the skin that is touched. A lighter pressure can be felt on the forehead and temples than with any part of the
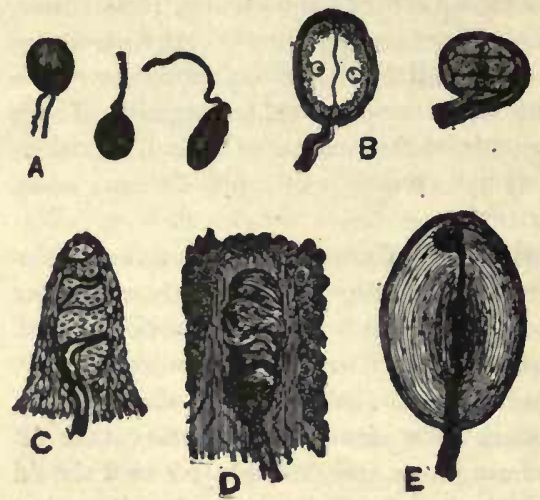

FIG. 120. - DIFFERENT KINDS OF TOUCH BODIES AT ENDS OF NERVES.

$A$, from cornea of the eye: $B$, from the tongue of a duck: $C, D, E$, from the skin of the fingers. (Jegi.) body. (Why is it best for this to be the case?) The greatest delicacy in locating the point of the skin touched is found to be located in the tip of the tongue, the lips, and the ends of the fingers (Exp. I). (Why is it best that this is so?) This delicacy is least in the middle of the back. The delicacy varies with the number of touch corpuscles in different parts of the skin. The sense of touch is capable of great cultivation, as in the case of the blind.

The temperature sense is given by special nerves called the thermic nerves (Exp. 2). That the thermic nerves are easily fatigued is noticed soon after entering a bath of hot water; it is also shown by the fact that in cold countries the nose or ears of a person may freeze without his feeling it.

The Muscular Sense. - The special sense of touch gives some sense of weight. A weight upon the skin must be increased by one third before it feels heavier, but by lifting an object so as to bring into action the muscular sense residing in nerves ending in the muscles an increase of only one seventeenth of the original weight can be noticed (Exp. 3). This sense gives us a continual account of the position of the limbs (Exp. 4).

The end organs of taste are located in the papillæ of the tongue. The tongue has a fuzzy look because of the numerous papillæ. 
The principal tastes are only four ; namely, sweet (tasted chiefly by tip of tongue), sour and saline (sides of tongue), bitter (tasted on the back of tongue) (Exp. .5).

The nerves of smell end in the mucous membrane of the upper half of the two nasal chambers; the fibers are spread over the upper proportion of the walls. The direct current of air does not pass as high as these nerve endings; hence sniffing aids the perception of odors. This sense is able to bring up the associations of early life more powerfully than any of the senses. The odor of a flower like one that grew in an old garden can almost restore the consciousness of the past. We smell gases only;-solids and liquids cannot affect this pair of nerves (Exp. 8).

Flavors. - The tastes that we call flavors are really smells. We confuse them with taste, because they accompany food that is in the mouth. Name some foods that seem "tasteless" when one has a severe cold in the head. Why is this? Some of the most repulsive drugs can be easily swallowed if the nose is held (Exp. 6 and 7).

Hygiene of the Senses of Taste and Smell. - A savage or a beast uses the senses of taste and smell to find out whether things are good to eat or not. If a civilized man's senses are not perverted, and he eats only simple foods that have a pleasant taste, they will not injure him or cause him sickness. Things that are poisonous usually have unpleasant tastes and often have unpleasant odors. These senses are naturally of wonderful delicacy. They can be cultivated to a still more remarkable degree, or they can be blunted and almost destroyed. Chronic catarrh dulls or destroys the sense of smell. The loss or even the weakening of the perception of flavors is an injury to the working of the closely related sense of taste. When a person loses the enjoyment of delicate flavors, he wants food to have strong seasoning and more decided taste to prevent it from being insipid. Everything must be either very greasy or very sweet or very salty or very sour, to please his degenerate senses. Wheat, corn, and other grains have each its own pleasant taste, yet such persons must have lard in their bread because they are not capable of appreciating anything with a delicate taste. In 
England, butter is not salted and its delicate taste is enjoyed; in America, salt is added to preserve it, and most people have come to prefer the strong taste of salty butter to the delicate taste of pure butter, and do not like it unless its true taste is partly hidden by the taste of salt (Exp. 9).

Deceiving the Sense of Taste. - The habit of using narcotics like tea and coffee is usually begun by concealing the repulsive bitter taste of the substance by mixing sugar, cream, and other agreeable things with it. Licorice is sometimes mixed with tobacco to weaken its biting taste. Pure alcohol would never be drunk by any one who had the least respect for the sense of taste, but the agreeable flavor of grapes, apples, and other fruit which still remains in wine, cider, and brandy, conceals the repulsive taste of the alcohol. Beer has the insipid taste of grain which has undergone decomposition or partial rotting, and hops are added because the strong bitter taste of hops is needed to hide the stale, rancid taste of the rotted grain. Eggnog is made of eggs, a nourishing food; sugar, which has an agreeable taste; water, a refreshing drink, and alcohol, a fiery poison. A very good eggnog is often made without alcohol, but a good one could hardly be made with any of the pleasant ingredients left out. The best eggnog is made by using the fresh juice of lemon, orange, or grape, instead of alcoho!.

Effect of Narcotics. - Tobacco, alcohol, opium, and other narcotics dull the senses of taste and smell and prevent the enjoyment of delicate Havors. They accomplish this as much by their effect upon the brain as upon the nerves themselves.

It is Wrong to eat Food that is not Relished. - Unpalatable food is not likely to be well digested. It is a law of the body that the food which is enjoyed the most is digested the best. This applies to a hungry person eating food with its own honest taste, not to food disguised by the taste of something else. The rule does not apply to a taste perverted by having been forced to become accustomed to poisonous things. People who munch their food slowly enjoy the pleasures of taste the most, and digest their food the best. The nerves of taste and smell easily become fatigued. The first whiff from a cologne bottle is the strongest. Highly flavored foods should be eaten moderately, if we would obtain the greatest enjoyment from them.

Thought QUestions. - 1. Interfering with the Body. What is the natural direction of growth of the big toe? 2. Think of six evil results, direct or indirect, which will follow from displacing it by tight shoes (p. 48). 3. Which part of the spinal column, designed in infinite wisdom to be most flexible, do some people try to make the most inflexible? 4. The mobility of the false and floating ribs was 
intended as a blessing. Some people interpret the blessing as an opportunity to do what? 5. Name six articles which warn us to avoid them by their bitter, burning, or nauseating tastes, yet which are used by man. 6. Name six feelings which are intended as warnings for our guidance, but which are commonly disregarded.

The eyes on the rays of the starfish are mere spots of pigment. Insects have lenses in their eyes. The eyes of vertebrates are all formed on the same general plan as the human eye.

The eyeballs are globes about an inch in diameter. They are placed in deep, bony sockets, called orbits, in the front part of the skull. The optic nerve, other nerves, and several large blood vessels pass to the eye through a hole in the back of the orbit. A soft cushion of fat is in the orbit behind the eyeball. A pressure upon the eyeball causes the eye to sink in to the socket, for the fat yields to the pressure. This is a protection to the eye.

The eyelids protect the eyes from dust, and at times from the light. They are aided in this by the eyelashes.

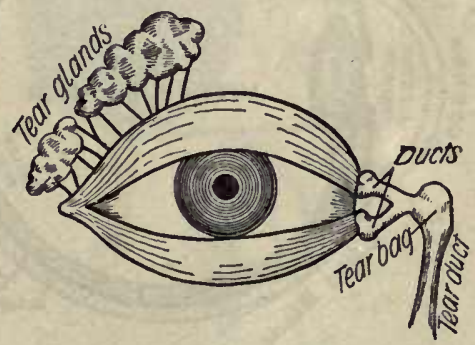

FIG. I21. - TEAR GLANUS AND Ducts of right eye. (Jegi.)

The tears are formed by tear glands situated above the eyeball in the portion of the orbit farthest from the nose, just beneath the bony brow where it feels the sharpest (Fig. 121). They are about the size of almonds. A saltish liquid is continually oozing from the tear glands and passing over the eyeball; it is carried into the nose through the nasal duct (Fig. I2I). The tears reach this duct through tie'o small canals, which open into the eye in the little fleshy elevation at the inner corners of the 
eye (Fig. 121). The opening of one of the canals may be seen by looking into a mirror. Sometimes these canals are stopped up, and what is called a "weeping eye" results. A temporary stoppage may occur during a cold in the head.

Tears prevent friction between eye and lid. Winking applies the tears to the ball. Small glands along the edges of the lids form a kind of oil which usually prevents the tears from flowing over the lids. Sometimes this oily secretion is so abundant, especially during sleep, as to cause the lids to stick together. The mucous membrane

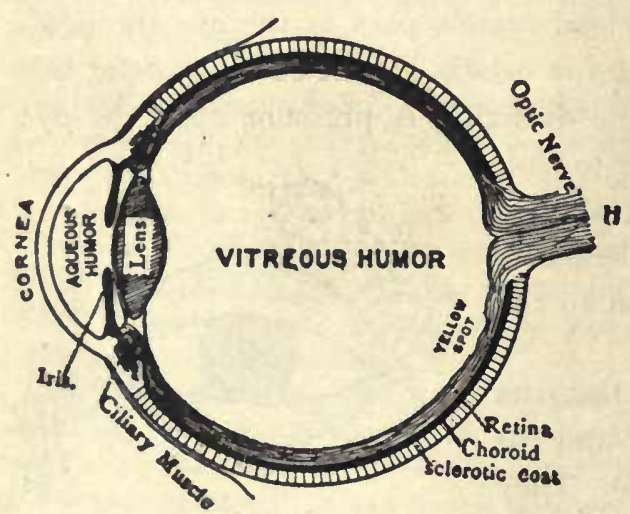

Fig. 122. - THE ANATOMY OF THE EyE. of the eyelids continues as a transparent membrane (the conjunctiva) which passes over the front of the ball.

The globe of the eye consists of its outer wall and the soft contents (Fig. 122).

The wall has three layers or coats. The outer coat is the tough sclerotic (Greek, skleros, hard), composed of dense connective tissue (Exp. 14). It gives strength and firmness to the eyeball. It shows between the lids as the "white of the eye." It is white and opaque except in front; there it bulges out to form the transparent cornea. This clear portion of the wall may be seen by looking at the eye of another from the side.

The second coat, called the choroid, consists of blood 
vessels and a loose connective tissue containing many dark brown or black pigment granules. The choroid absorbs superfluous light. Cats' eyes shine at night because this coat in their eyes reflects some light. The choroid separates from the sclerotic toward the front of the eye and forms the colored iris. The iris makes the eyes beautiful, and it also serves the useful purpose of regulating the amount of light. The hole in the iris is called the pupil (Exp. 15).

The third and innermost coat, the sensitive pinkish layer called the ret'in- $a$, is the most important and characteristic tissue in the eye. It receives the light rays, and retains the image for a fraction of a second (Exp. I1). Hence the pictures in a kinetoscope (Fig. I23) appear as one moving picture. The retina is made chiefly of the fibers of the optic nerve. This nerve contains about five hundred thousand fibers, and enters at the back of the ball. The spot where it enters contains no nerve endings and is not sensitive to light. It is called the

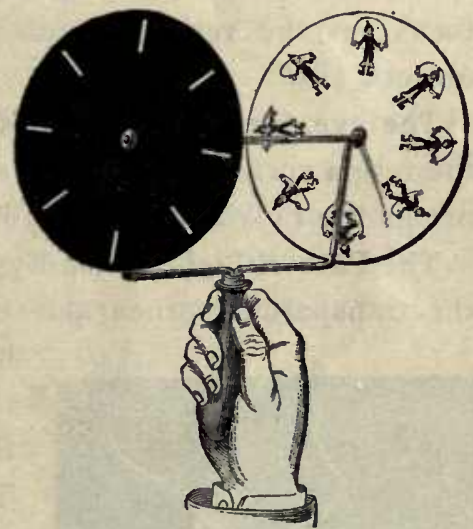

FIG. 123. - STROBOSCOPE, the original of the kinetoscope. The observer looks through the slits of a rapidly revolving disk and a new image falls on the retina before the last image has faded. Compare the pictures in the figure.

blind spot. The spot where the light most often falls is most sensitive to light. It is the yellow spot (Fig. 122).

Test for the Blind Spot. - In this experiment shut the right eye and be careful not to let the left eye waver. 
* Read this line slowly. Can you see the star all the time? (If so, hold the book farther or closer and repeat.)

Within the coats of the ball, like the pulp within the rind of an orange, are the soft contents, divided into three parts. The first is a watery liquid in front, which serves to keep the cornea bulged out (Fig. I22). It is called the a'que-ous humor. The main cavity of the ball is occupied by a clear, jellylike substance called the vit're-ous humor, which serves to keep the ball distended. Back of the iris, and separating the two humors just named, is the crys'talline lens, a beautiful clear lens, convex or rounded out on both sides (Exp. I4). It serves to bring the light to a focus on the retina, thereby forming images of outside objects.

The eye, like a camera, has a dark lining, the choroid; the retina corresponds to the sensitive plate, and the lens brings the rays to a focus on it and forms the image.

The Path of Light in the Eye. - The light enters through the transparent cornea and passes through the aqueous

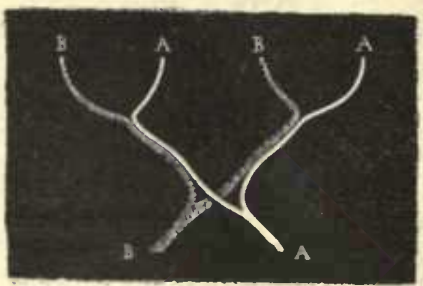

Fig. 124. - Crossing OF OPTIC NERVES showing that one nerve reaches same half of both eyes. humor. As it goes through the pupil, the iris shuts off all the light that is not needed. The crystalline lens receives the light that has been allowed to pass, and so bends the rays that by the time they have passed through the vitreous humor they fall upon the retina in just the right way to form a tiny image of anything outside (Exp. I I). The choroid absorbs any light that passes the retina. The iris and choroid of albinos have no pigment; hence albinos squint their eyes to shut out some of the light. 
Accommodation. - In order to focus the light upon the retina, the lens must change shape for cvery change in the distance of the object looked at (see Fig. I25). The shape of the lens can be readily changed, for it is elastic and has muscular fibers around its edges (Exp. I 7).

Defects in the Eye. - Some

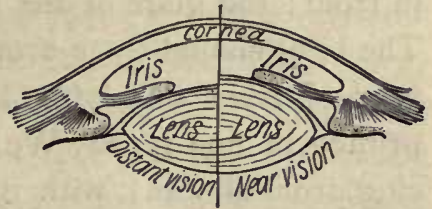

FIG. I25. - Change of lens in accommodation. (Jegi.)

-eyeballs are too long, and the lens brings the rays to a focus before they reach the retina. Such eyes are nearsighted (Fig. 126) and require

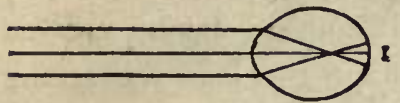
glasses that round inward (concave). Some eyeballs are too flat, and the rays are not brought

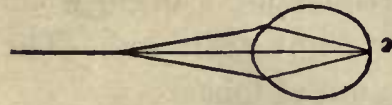
to a focus soon enough. Such eyes are farsighted and require

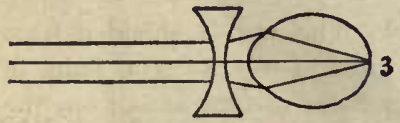

Fig. I26. - (I) NEARSIGHTED EYE (ball too long), which only focuses rays for near objects (2) when concave glasses are used (3). glasses that round outward (convex). See Fig. 127. (Repeat Exp. I 5.)

Care of the Eyes. - Because the eyes can do a large amount of work without giving pain, they are often abused. When reading or doing intricate work, turn the eyes from the

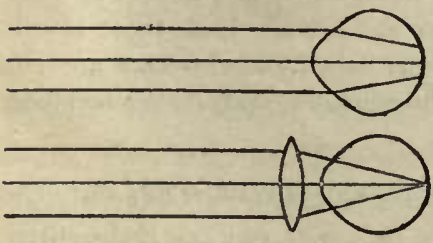

FIG. I27. - FARSIGHTED EYE (ball too short) which needs convex lens to focus rays upon retina. work occasionally and look at some distant object; stop work before the eyes are tired. Twilight of early evening has ruined many good eyes. You should always stop work before the twilight begins, for the 
light fades so gradually that you will surely be straining the eyes before you know it. Do not work with the light in front; the glare of the light makes objects appear dim. The light should come from above, and (for right-handed people) from the left. Do not read papers or books printed in fine type. We should not read when convalescing from illness; with the head bent down; when the eyes are sore; in jolting cars. Heating the eyes by a burner, or drying the eyeballs in a dry, stove-heated atmosphere, using a light without a shade, cause trouble with students' eyes. Of what are blood-shot eyes often a sign? Our eyes are best suited for seeing at a distance because primitive man had no houses, books, sewed clothes. Effort is required to shape the lens for seeing near objects. Most cases of nearsightedness begin when children are taught to read under eight years old. The eyes are sometimes injured by the use of tobacco.

Thought Questions. The Eye. - 1. The eye is shielded from blows by bony projections of,$- \ldots$, and -2 . The hairs of the eyebrows lie inclined toward - in order to turn - from the - 3. I find by trying it that I (can or cannot?) see the position of a window with my eyes closed. 4. The pupil appears to be black, because no - is - from the interior wall of the eye. I know that the iris is partly muscle, because it — the size of the

Sound. - Anything that is sending off sound does so by vibrating, or shaking to and fro, very rapidly. For instance, a vibrating violin string sets every particle of air near it swinging to and fro. The nearest particles of air strike the next ones and bounce back, these in turn strike against others, and thus vibrations called sound waves are sent through space in all directions from the sounding body. We feel these waves with the ear.

The ear consists of three portions : the external ear, the middle ear (or drum), and the internal ear (or labyrinth, see Fig. 128). The cranial nerve connecting the ear with the brain is called the auditory nerve. The outer and 
middle ear pass on the vibrations of air to the ends of the fibers of the auditory nerve in the internal ear.

The external ear consists of a large wrinkled cartilage on the exterior of the head and a canal leading from it, called the meatus. This passage is closed at its inner end by the drum membrane or drum skin. It is often called the drum, but this name is properly applied to the whole middle ear. A trial will show that the drum skin cannot

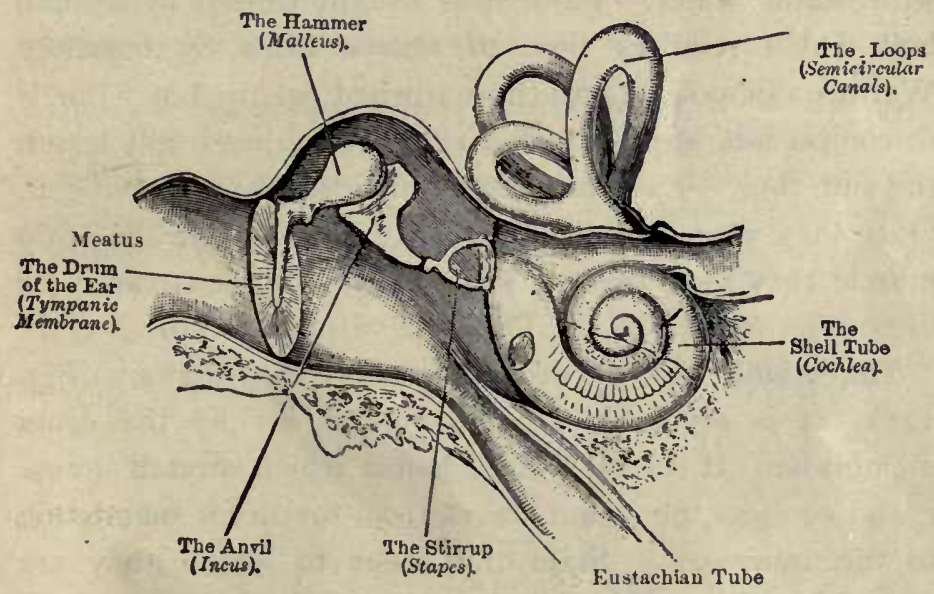

FIG. I28. - MIDDLE AND INTERNAL EAR (greatly enlarged).

be seen even with the aid of a bright light, for the passage is slightly curved (see Fig. 128). Hence a missile or a flying insect cannot go straight against the ear drum. The skin ining this passage contains wax glands, which secrete a bitter sticky wax, which helps to keep the passage flexible. This wax catches dust and usually stops insects that may enter. If an insect enters the ear, it may often be coaxed out by a bright light held close to the ear. The ear wax in a healthy ear dries with dust and scales of epidermis and falls out in flakes, thus cleansing the ear. It 
is unwise to probe into the ear with a hard object or even with the corner of a towel. It is not necessary to insert the finger in the meatus to cleanse it; it is one inch long, but only about one fourth inch across. (How large is the little finger?) The cartilaginous ears on the sides of the head should be carefully washed because of their many crevices. If ear wax is deposited too fast, it will cause temporary deafness and earache. It may be syringed out with warm water. Earache is usually caused by a small boil which requires time to relieve itself by bursting. Warm water poured into the upturned ear, or hot flannels or compresses applied to the side of the head will lessen the suffering. Each ear has three muscles for moving it. Once they were doubtless useful to all, but like the scalp muscle they have become so weakened by disuse as to be useless to most people. They are vestigial organs.

The middle ear, or drum chamber, contains air (Fig. 128). It is separated from the outer ear by the drum membrane. It contains three bones which stretch across it and conduct the sound waves from the drum membrane to the inner ear. State the order in which they are placed (see Fig. I28). The middle ear is connected with the pharynx by a tube (the Eustaclian tube; pronounced yoo-stake'e-an, see Fig. 128). This tube is opened every time we swallow. It allows the air from the throat to enter the middle ear and keep the air pressure equal on each side of the drum skin. This tube and the middle ear are lined with mucous membrane.

A cold in the head or a sore throat may extend through this tube to the middle ear and affect the hearing. This occurs because the tube is closed by congestion of its lining; the air of the middle ear may be partly absorbed, and the pressure of the outside air may cause the drum 
membrane to bulge inward, and to be stretched so tight that it cannot vibrate freely.

The inner ear is called the labyrinth, because of its winding passages. There is a spiral passage called the snail shell and three simpler passages called the loops (Fig. 128). The inner ear is filled with a limpid liquid which conveys the vibrations to the ends of the auditory nerve found in the snail shell. If the auditory nerve or labyrinth becomes diseased, the deafness is probably incurable. Quinine and other drugs may cause deafness.

Sense of Equilibrium. - Some fibers of the auditory nerve end in the loops and are not believed to be used in hearing. It is believed that each loop acts like a carpenter's level, and the varying pressure of the fluid upon the nerves in the loops tells us the position of the body and constitutes the sense of equilibrium. There are how many of these loops in each ear? (Fig. 128.) 


\section{CHAPTER X}

\section{BACTERIA AND SANITATION}

Experiment I. Yeast Plants. - With a microscope examine a drop from a glass of water in which you have washed grapes or apples (Fig. 129).

Experiment 2. Fermentation. - Put a tablespoonful of sugar into this water and set the glass in a warm place for a day or two. Do

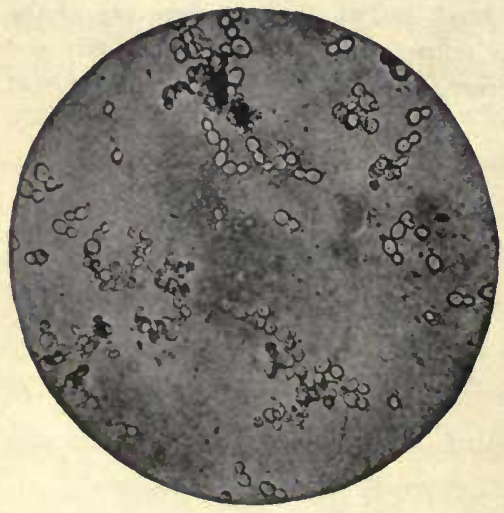

FIG. 129. - YEAST CELLS magnified 200 diameters, or 40,000 areas). Yeast plants multiply by budding. Notice small cells growing on larger and older ones. you see any bubbles of gas? Have the odor and taste changed? Does the microscope show that the yeast plants are now more abundant? By fermentation, or the growth of yeast in sugar, sugar is changed into carbon dioxid, a gas, and alcohol, a liquid.

Experiment 3. A Sanitary Map. - Construct a sanitary map of the community. Indicate houses where consumption, typhoid fever, or other transmissible diseases have occurred, with number of cases. Mark location of stagnant waters where mosquitoes breed, mark garbage dumps, unclean streets. Suggest where improvements may be made in drainage, dust, noises, sunshine, shade, etc.

Bacteria, or microbes, the smallest living things, are visible only under a microscope of high power. (See "Plant Biology," p. I82.) They obtain food either from dead tissue or from degenerate tissue of living plants and 
animals. The green plants and the animals now upon the earth have proved their fitness to survive by successfully resisting these one-celled vegetable germs, or bacteria. Microbe diseases attack only the weaker individuals of the human species, or those who have gone to regions where there are microbes which their bodies have not yet acquired the power of resisting.

Usefulness of Bacteria. - Their chief work is to destroy dead tissue and return it to the soil and air for the use of green plants again, otherwise the earth would be filled with carcasses, etc. They are indispensable in soil formation. They give the agreeable flavors to butter and cheese, and cause milk to sour. A rod-shaped bacterium is called a bacillas (Fig. I 30); a spherical one is a coccus.

Multiplication of Bacteria. - This is by division or fis. sion. Sometimes, instead of dividing, a little rounded mass known as a spore appears. The spore breaks out and the bacterium itself perishes. Species which do not produce spores are readily destroyed, but spores have a hard, tough shell, and they may be dried or heated even to boiling without being killed. Spores float through the air and start new colonies. Most common bacteria grow best between $70^{\circ}$ and $95^{\circ} \mathrm{F}$. They render it difficult to preserve foods, especially proteid foods (cheese, lean meat, eggs, etc.). Food decays slowly if at all below $70^{\circ}$ and above $125^{\circ}$. Direct sunlight, or the temperature of boiling water $\left(212^{\circ} \mathrm{F}\right.$.) kills bacteria but not spores. Pantries, kitchen, and sickrooms should have bright walls and all the light possible. Boiling water should be poured into the sink, and dish cloths should be thoroughly washed in boiling water.

Diseases due to Bacteria. - A germ disease is usually due partly or wholly to substances called toxins produced by the bacteria. Most disease germs attack a single organ 
of the body. Diphtheria is caused by a species (Fig. I 30) that grows on the mucous membrane of the throat; this

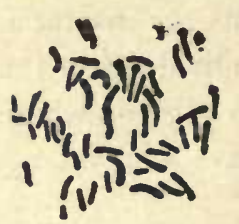

FIG. $130 .-B \Lambda$ CILLUS UF DIPHTHERIA. germ produces a powerful toxin. The germs of typhoid fever (Fig. I3I) and Asiatic cholera multiply in the small intestine. In both these diseases the source of infection is the diarrhœal discharges from the alimentary canal. Flies may carry the germs on their feet from the discharge to food. Sometimes typhoid fever cases occur throughout a town because the water supply has become contaminated by sewage. Cases may occur only in families that buy milk from a certain dairy, because the milk cans have been washed in contaminated water. In caring for a typhoid patient all suspicious material should be disinfected or burned. Germs of tuberculosis (called consumption if the disease is in the

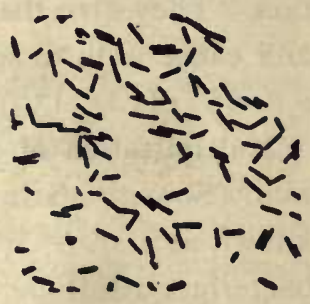

FIG. I3I. - BACILLUS UF TYPHOID FEVER. lungs) may float through the air. Recent investigations indicate, however, that infection usually occurs through the alimentary canal, the germs being swallowed, then absorbed and taken to the lungs in the blood or lymph. To prevent a patient from reinfecting himself in new parts of the lungs or elsewhere, he should carefully cleanse his teeth, mouth, and throat (by gargling with formal or lysol) before eating.

Mosquito Fevers. - Malaria, yellow fever, and probably dengue are transmitted each by a different genus of mosquito (Fig. 132). A mosquito of the malarial genus may bite a patient and suck into its body blood-corpuscles containing spores of the malarial parasite (a protozoan 
animal, see "Animal Biology," p. 7). Afterwards a spore (in another stage) may be transmitted by this mosquito when it bites another person. The germ enters a red corpuscle, grows, and finally divides into many little spores. At this moment the corpuscle itself breaks up, setting free in the blood the spores and toxin formed. This causes the chill and fever. This development usually takes forty-eight hours, hence the fever occurs every other day. These mosquitoes begin to fly at dusk. How are they recognized? (Fig. 132.)

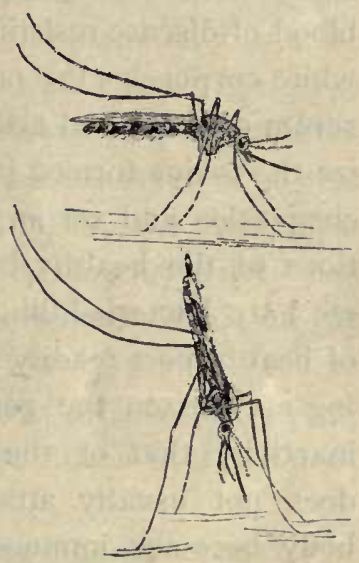
They should be kept out of houses by screens or from the beds by netting. Kerosene should be poured on breeding places at the rate of one ounce for fifteen square feet of standing water. This should be repeated twice a month.

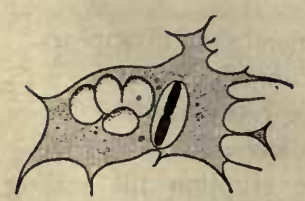

FIG. I33. - ProteCtIVE WHIIE CORPUSCLE (phagocyte) digesting a microbe.

Cactus macerated in water

FIS. I32. - CULEX OR COMMON MosquiTo, above (possibly carries dengue fever). ANOPHELES OR MALARIAL MOSQUITO, below (not always infected). Body of malarial mosquito is never held parallel to the supporting surface (unless a leg is missing); it has five long appendages to the head, the culex (above) has only three. (Draw.) may be used, and forms a permanent film on the water. Stagnant pools may be filled or drained (Exp. 4). Malarial patients should themselves be screened, as the chief source of danger to others; for only mosquitoes who suck the blood of malarial patients will transmit the disease. Even then it is only transmitted to those whose white blood corpuscles are unable to protect them (Fig. 133). 


\section{Further Means of Protection against Disease Germs. -} The best protection is physical vigor. There are certain substances called opsonins which exist in the plasma of the blood of disease-resisting persons; these opsonins give the white corpuscles the power to devour disease germs. The serum of the blood also develops antitoxins which neutralize the toxins formed in disease. Not only can the white corpuscles and serum kill bacteria, but most of the secretions of the healthy body (gastric juice, nasal secretions, etc.) are bacteria-killing as well. Persons in a low state of health most readily succumb to disease. Excess in eating may lessen the germicidal power of gastric juice and inactivity that of the lymph. The same germ disease does not usually attack the same person twice, as the body becomes immune; that is, an opsonin, or an antitoxin, is developed which cures the first attack and remains to protect the body in future.

The periods of quarantine or isolation for several common germ diseases are given in the following table:-

\begin{tabular}{|c|c|c|}
\hline $\begin{array}{l}\text { NAME OF } \\
\text { DISEASE }\end{array}$ & $\begin{array}{c}\text { From EXPosure } \\
\text { TILL. FIRSt } \\
\text { SYMPTOMS }\end{array}$ & $\begin{array}{c}\text { Patient is Infrectious } \\
\text { to Others }\end{array}$ \\
\hline Diphtheria & 2 days & I4 days after membrane disappears. \\
\hline Mumps & $10-22$ days & I 4 days from commencement. \\
\hline Scarlet fever & 4 days & Until all scaling has ceased. \\
\hline Smallpox & $12-17$ days & Until all scabs have fallen. \\
\hline Measles & I4 days & $\begin{array}{l}3 \text { days before eruption till scaling } \\
\text { and cough cease. }\end{array}$ \\
\hline Typhoid fever & I I days & Until diarrhœea ceases. \\
\hline Whooping cough & I 4 days & $\begin{array}{l}3 \text { weeks before until } 3 \text { weeks after } \\
\text { beginning to whoop. }\end{array}$ \\
\hline
\end{tabular}

Water Supply. - Bacteria are more abundant in flowing streams than in water standing in lakes or reservoirs (con- 
trary to the usual belief). They are most abundant in rivers that flow through populous regions. They are comparatively scarce in dry, sandy soils, and very numerous in moist, loamy soils. The water of cities should never be taken from a stream or lake into which sewerage flows unless it is thoroughly filtered. Filters are constructed thus : first a layer of small stones, next a layer of coarse sand, lastly a layer of very fine sand on top, the total thickness being four or five feet. Beneficial microbes live upon the grains of sand and destroy all, or nearly all, of the dangerous microbes as the water slowly soaks through. The construction of such waterworks is left to sanitary engineers, of course, and the average citizen does not need to know the details.

The department of street cleaning should receive the willing coöperation of all citizens. Banana peelings, paper, etc., should not be thrown upon the street or school grounds. Garbage, ashes, and rubbish should be placed in separate cans, as the rules provide. Garbage cans, if not thoroughly cleaned, acquire unpleasant odors and breed flies and bacteria. They should be thoroughly washed with very hot water and sal soda and scalded with boiling water and scrubbed with an old broom. ${ }^{1}$

The chief duties of the Health Department are: quarantine isolation and disinfection, with the purpose of preventing or controlling contagious and infectious diseases;

1 The chief Disinfectants are : fresh air, sunshine, heat, formaldehyde, etc. Airing and sunning will destroy some germs in bedding and clothing as effectually as chemicals. Boiling and steaming are the best ways of applying heat. Formaldehyde is a volatile liquid. After room is sealed and strips of paper pasted all over cracks, a specially constructed generator is applied to keyhole, and room kept closed for 12 hours. Mercuric chloride (corrosive sublimate) is used I part to 1000 parts of water for disinfecting soiled clothing, towels, utensils, surgeon's instruments, and wounds. In place of this, carbolic acid, 5 per cent solution, may be used, but it is not so good a germicide. 
inspection of dairies, slaughterhouses, and other sanitary work; inspection of milk $^{1}$ and other food stuffs ; the department gathers vital statistics; it enforces the rules for disinfection of public buildings.

Importance of Coöperation with the Health Department. Only an ignorant and short-sighted person would fail to coöperate promptly and cheerfully with local or state health officers. It is for the benefit and protection of every one that the truth concerning contagious diseases be reported promptly. Only in this way may outbreaks of disease be prevented and many lives saved. $\mathrm{He}$ is a bad citizen and a public enemy who will conceal a case of disease dangerous to the community. Outbreaks of fatal diseases may be easily prevented or stamped out if the health officer is sustained and his directions carried out.

${ }^{1}$ Milk may be sterilized by boiling, but boiled milk is not digestible nor nutritious. Milk may be Pasteurized by immersing bottles of milk in water which is kept nearly (but not quite) at boiling point $\left(160^{\circ} \mathrm{F}\right.$.) for five minutes. But this makes the milk less valuable than fresh milk, and destroys beneficent microbes. Buttermilk has many such microbes, which kill injurious microbes and purify the stomach. Cleanliness, or an aseptic condition, is far preferable to antiseptics. 


\section{INDEX}

$\mathrm{I}, \mathrm{V}, \mathrm{X}$, etc. $=$ Introduction : $\mathrm{P}=$ Plant Biology : $\mathrm{A}=$ Animal Biology : $\mathrm{H}=$ Human Biology.

Aboral surface, A 35 .

Aborted seeds, $\mathrm{P}$ x 66 .

Absorption, H 106 .

Abutilon, P 156.

Accessory fruit, $\mathrm{P} \times 64,169$.

Accommodation in eye, $\mathrm{H}$ I43, I53.

Acephala, A 107.

Acid, ix.

Adaptation to environment, P 6, A I 48, I85, 20I, 205, 207, H I9, I08, I09, II 0 .

Adenoid growths, н 86.

Adipose tissue, H $\mathrm{I} 2$.

Adulteration of food, $\mathrm{H} 93$.

Adventitious roots, P 36 ; buds, $P$ II4.

Aerial roots, $\mathrm{P} 34$.

Aggregate fruit, P 168 .

Air cells, H 75 .

Air plants, $\mathrm{P} 35$.

Akenes, P 165.

Albinism, H 16, I8.

Albumen, H 92 .

Albumin, H 92 .

Alcohol and circulation, $\mathrm{H} 67 ;$ and fermentation, $\mathrm{H} \mathrm{I}_{58} 8$; and food, $\mathrm{H}$ II 3 ; and muscles, $\mathrm{H} 55^{\circ}$; and nerves, $\mathrm{H}$ I 35 ; and skin, $\mathrm{H} 20$.

Algae, P I79, 183,195 .

Alkaline, ix.

Alternation of generation, P I 79, A 30 , 31.

Ambulacral, A 36 .

Ameba, A Io.

Americans, H I.

Anadon, A 98 .

Anatomy, $\mathbf{H} 9$.

Anemophilous, P 149.

Animal food, H 95, I 10.

Annual plant, $\mathrm{P}$ I 7 .

Antelope, A 2 I 5 .

Antennæ, A 68,87 .

Anther, P I35, I44, I80.

Antheridium, P I 78, I86, I98, 200, 202, 203.

Ant-eater, giant, A I99; spiny, A I96.
Ant-lion, A 9I.

Ape, A 220.

Apical dehiscence, P I66.

Appendicitis, H 106.

Appendix, vermiform, " $\mathrm{H}$ I06.

Appetite, H 94, IIO.

Aptera, A 82.

Apteryx, A 174.

Aquarium, A I 7 .

Archegonium, P I78, I98, 200, 202,

203.

Argonaut, paper, A I07.

Arm, ㅍ 33 .

Armadillo, A 200.

Arrowhead, H 2.

Arteries, Н 5 I, 53, 54, 6r .

Arthropoda, A 9, 125.

Arum family, P I 40.

Ash, $P 92$.

Asiatic cholera, Н I 60 .

Assimilation, $\mathrm{P} 97, \mathrm{H} 90$.

Association fibers, H $123,126$.

Asthma, ㅍ 86.

Astigmatism, H I44.

Athletics, В 46,47 .

Atwater's experiments, H II3.

Auricle, H 53 .

Automatic action, H I23.

Axil, P I 2.

Axis, plant, $P$ I5.

Axon, H IIg.

Bacillus, H I $_{5} 8$, I 59 .

Bacteria, P 39, 109, I82, स 158, I59, I60, 161 .

Bandage, н 62 .

Barberry, P $157,193$.

Bark, P 54, 66, 67 .

Bark-bound trees, $P$ 54.

Bast, P 6r, 66.

Bat, A 202.

Baths, H 23, 24.

Batrachia, A 126.

Bean, P 20, 28, 39, I 94, ㅍ 95, 96, I I 2 .

Beaver, A 204. 
Bedbug, A 92, 93.

Bee, bumble, A 89; honey, A 88 .

Beebe's experiments, Dr., H I 13 .

Beef, 표 111 ; tea, H 111 .

Beetle, A 90, 91 .

Berry, P 167.

Biennial plant, $P \mathbf{1 7}$.

Big-headed turtle, A 149.

Bilateral, A $34,49,98$.

Bile, 8 105.

Bill of bird, A 151 .

Biology defined, A r, 49 .

Birds, A 150.

Blind spot, H 151 .

Blood, H 58 ; quantity of, $\mathrm{H} 55$; of insects, $\mathbf{A} 78$.

Blood vessels, मі 52 ; control of, н 58 .

Board of Health, H 163.

Boll weevil, A 95, 96 .

Boll worm, A 95, 96 .

Bones, H 29 ; composition of, $\mathrm{H} 3 \mathrm{r}$; growth of, 4 14, 36; forms of, $\mathrm{H} 28$, 29, 34; structure of, $\mathbf{H} 30$.

Bony tissue, $\mathbf{H} 13$.

Borax, H 93.

Brace cells, P 67 .

Bracts, $P$ 134.

Brain, H 122; coverings of, $\mathrm{B} 125$; of fish, $A 118$.

Branch, P 111, A 9 .

Breathing, forms of, $\mathrm{H} 80$; of bird, A $16 \mathrm{r}$; of insect, A 76; through mouth, H 85 .

Breeding, plant, $P 7,8$.

Bronchial tubes, В 75 .

Bruises, $\mathbf{H} 62$.

Bryophytes, P I8I.

Bud propagation, P 121 .

Budding, P $127,128$.

Buds, P 72, 82, 87, 111 ; flower, P 115 ; fruit, $P$ I 15 .

Bureau of entomology, A 95.

Burns, मा 24.

Burs, P 172,174 .

Bushes, P I91, A 171 .

Butterfly, A 83 .

Cabbage, P I13, в 95.

Cabbage butterfly, A $84,86,87$.

Callus, P 56.

Calyx, P 133 .

Cambium, P 63, 65.

Camel, A 214.

Candle, xv, A 5 .

Cane sugar, н 92, то4.

Capillaries, B 52, 53, 56 .
Capsule, P 165.

Carbohydrate, P 95, HI 91, 95.

Carbon, vii, xviii, $\mathbf{P} 92$.

Carbon, dioxid, A 24, P 22, 93, 106, H $60,76,81,132$; monoxid, \& 85 .

Carnivorous, P 99, स III.

Carp, A I 12, I17, 123.

Carpel, P 136.

Cartilage, $\mathrm{B} 13,35$.

Castor bean, $\mathbf{P} 24$.

Cat, A 184 .

Caterpillar, tent, A 84 .

Catkin, P 158.

Caucasian, H I, 2.

Caulicle, $P$ 20, 22, 25 .

Cedar apple, P r 94 .

Cell, $P 42,63,145,176$, A 6,7, ㅍ 5,6 .

Celom, A 46.

Cephalopod, A 106.

Cerebellum, स 122, I24.

Cerebro-spinal system, H 128, 129.

Cerebrum, H 122, $125,126$.

Chelonia, A 143 .

Chemistry, xv.

Chemical symbols, $x v$.

Chest, स 32.

Chewing, $\mathbf{H}$ 99, ro 1 .

Chimpanzee, A $219,221$.

Chirping, A 66 .

Chitin, A 77 .

Chlorophyll, P 86,94, 101, $183,186$.

Cholera, in 160 .

Choroid, H $150,152$.

Chyme, H ro3.

Cigarettes, н $67,86$.

Cilia, A 14, 20, I01, 103, I 76 .

Ciliated chamber, A $I \%$.

Cion, $P$ I 25.

Circulation, $\mathrm{H} 5 \mathrm{I}$; and breathing, $\mathrm{H} 58$; and exercise, म 67 ; hygiene of, म 68 ; in ameba, A 12 ; in insect, $A 77$; in fish, A 117; portal, в 60 , 105; pulmonary, н 60 ; renal, $\mathbf{H} 60$.

City, $\mathbf{H} 4$.

Cladophylla, P roo.

Clam, hardshell, A 104; softshell, A 104.

Class, 19 .

Classification, of animals, A 8, 125 ; of birds, A 177; insects, $A$ 82; mammals, A 193 .

Cleft graft, P 126.

Cleft leaf, $P 75$.

Cleistogamous, P 151 .

Click-beetle, A 9 I. 
Climate, and clothing, स 25 ; and brain work, H 68; and early man, ㅍ 2 .

Climbing plants, $\mathrm{P} 129$.

Clitellum, A 43, 47 .

Cloaca, A 18.

Clot, ㅍ 6 I.

Clothes moth, A 84, 92, 93 .

Clothing, $\mathrm{H} \mathbf{r 6}, 25$.

Clover, P 39.

Club mosses, P 203.

Cluster, flower, $\mathbf{P}$ I55, 159 ; centrifugal, P 156, 159; centripetal, P 156 ; indeterminate, P 156 .

Coagulation, H 6 r.

Cockroach, A $7 \mathbf{r}$.

Cocoon, A 84.

Codling moth, A $84,86,87,95$.

Coelenterata, A 28.

Colds, care of, н 69,86 .

Coleoptera, A 82.

Collecting insects, A 72.

Colon, E ro6, rrr.

Colonies, plant, P Ir.

Colorado beetle, A 9o, $9 \mathrm{r}$.

Coloration, warning, A 84,146 ; protective, A $34,37,49$.

Colors of flowers, A 85 .

Comparative study, A 85, I08, I 22, 223 ; moth and butterfly, A 85 .

Composite flowers, P 140.

Compositions, subjects for, H $15,5^{\circ}$, Ir6, 141 .

Compound substance, vii.

Congestion, Н 68.

Conjugation, $\mathbf{P} 185$.

Conjunctiva, $\mathrm{H}$ I50.

Connective tissue, H II, 54, 220 .

Consumption, H 159 .

Convolution, स 126 .

Cooking, HI I 4 .

Coördination, H I 24.

Copper head, A $\mathbf{r} 45$.

Coral, A 3 I.

Coralline, A $3 \mathbf{I}$.

Coral snake, A $145,146$.

Cork, P 66, 67.

Corn, P 3, 25, 26.

Cornea, H $\mathrm{r} 5 \mathrm{O}$.

Corolla, P $\mathrm{r}_{33}$; funnel form, $P$ I 38 ; labiate, $\mathbf{P} \mathrm{I}_{3} 8$; personate, $\mathbf{P}$ I 39 ; rotate, $\mathbf{P} \times \mathrm{x}_{3} 8$; salver form, $\mathbf{P}$ I 38 .

Corpuscles, origin of, н $3 \circ$; red, н 59 ; white, H 59, 60, 65, 68 .

Corset, स $58,80,87$.

Cortex, $\mathbf{P} 44$.

Corymb, P 159 .
Cotton plant, P 7, A 95.

Cotyledon, $\mathbf{P} 20$.

Cricket, A 7 I.

Cross-fertilization, A 25.

Crowd poison, ㅍ 82 .

Cryptogam, P r 76, r80, r83-204.

Cuckoo, A 179 .

Currant, P 157.

Cuttings, P I $21,123,124$.

Cuttlefish, A ro\%.

Cyme, P r 59, 160.

Cypraa, a ro4.

Cysts, A 13.

Cytoplasm, $\mathrm{H} 6$.

Darwin, A 48, 148

Debates, subjects for, ㅍ I4I.

Deciduous, P 82.

Decumbent, $P 50$.

Degeneration, H 3, 4, I4 I.

Dehiscence, P 144,164 .

Deliquescent, P 5 r.

Dendron, H Ixg.

Dependent plants, P ro6.

Dermis, H 17 .

Devil's horse, A $7 \mathrm{I}$.

De Vries, A r48, 224.

Dextrin, $\mathrm{t}$ Ir 2 .

Diaphragm, н 77,78 .

Dichogamy, P 144.

Dicotyledon, P 20.

Dicotyledonous stems, P 6r.

Digestion, P 95, н 89, 96, roo.

Digitate, $\mathrm{P} 74$.

Digits, A 222, H Irr.

Dimorphous, P 144 .

Diœcious, P $138, \mathrm{r} 70$.

Diphtheria, स 160 .

Diptera, A 82.

Disease, defined, н 5 .

Disinfection, $\mathrm{H}_{\mathrm{I}} \mathrm{6}_{3}$.

Dispersal of seeds, $\mathbf{P}$ r 72 .

Dissection, $\mathbf{P} 30$.

Division of labor, A 27, 29, स 8 .

Dodder, P 35, ro6.

Dog, 224.

Dolphin, A 209.

Doodle bug, A 9r.

Dorsal, A 43.

Dove, A 179 .

Dragon fly, A 93.

Drainage, स 158 , I6r.

Dropsy, $\mathrm{H} 64$.

Drugs, H 60, r30, 133 .

Drupe, P 168.

Drupelet, P 168. 
Duckbill, A 196.

Dust, H 82, 158.

Ear, of bird, A 151; of frog, A 131; of fish, A 112; of man, H 154 .

Earthworm, A 42.

Echinoderms, A 9, 34, 125 .

Ecology, P I 4, H 9.

Economic importance of birds, A 167 ; insects, A 93; mollusks, A 105;

- rodents, A 206.

Ectoderm, A 26, 87.

Ectoplasm, A I I, 14 .

Egg, of insect, A 81 ; of hen, H 95, 96, I I 2 .

Filaters, $\mathrm{P} 198$.

Element, viii.

Embryo, p 26, 180.

Embryo sac, P I 80.

Enamel, н 98.

Endoderm, A 26, 27, 37 .

Endodermis, P 44.

Endoplasm, A II, 14.

Endosperm, P 21, 24.

Energy, н 96, 140; in ameba, A 12 ; organic, A 2, 3; plant, A 2, 3, 5 .

Entomophilous, P 148.

Environment, P 6, А 148, H 2, 3, 4, 48 .

Enzyme, н 100 .

Epicotyl, P 23, 25.

Epidermis, of leaf, P 86,87 ; of man, H I 7; of mussel, A 98 .

Epigeal, $\mathrm{P} 23$.

Epiphyte, P 35, I 10.

Epithelial, H 12, 54 .

Equisetums, $\mathbf{P} 201$.

Erect posture, H 3 .

Esophagus, $\mathrm{B}$ 74, 101.

Fssays, subjects for, II 15, 25, 50, 116 .

Essential organs, P 135 .

Ethiopian, H 12, 18.

Evaporation, viii.

Excretion, A 12.

Excurrent, P 51 .

Exercise; н 45, 48, 49, 57, 67.

Expiration, $\mathrm{H} 79$.

Explosive seeds, P 172.

Eye, I 149; of bird, A 150; of frog, A 30; of grasshopper, A 67, 79; of fish, A III.

Fainting, $\mathbf{H} 57$.

Family, a 8.

Fangs, venomous, A 145 .

Farmers' bulletins, A 95 .

Fatigue, of muscles, $\mathrm{H} 45$; of nerves, H $130,131,136$.
Fats, test for, xi.

Fatty tissue, $\mathrm{F} \mathrm{I2,} \mathrm{IO3.}$

Feather, A 155.

Fehling's solution, $x i$.

Ferment, H 100, $103,104,158$.

Fermentation, P 190 , H 158 .

Fern, $P$ I 76 .

Fertilization, P I 44; cross, P 144, 146 A 85 ; self, P $145,147,188$.

Fiber, $\mathrm{H} 2$.

Fibrin, H 6 I.

Fibro-vascular bundles, p 61, 90 .

Field study, P $3,6,8,14,19,27,46$ $57,71,84,91$, 101, $110,118,128$, $132,143,152,162,170,174,181$, A $10,22,42,71,72,97,127,165$ $166,167,184$.

Filament, P $\mathbf{I} 35$.

Filter, $\mathrm{H}_{163}$.

Fins, A 110,113 .

Flagellum, A $21,27$.

Flatworm, A 49.

Flavors, $\mathrm{H} 142,147$.

Flea, A 92, 93.

Flight, of bird, A 157, 175; of moth, A 84.

Floral envelopes, $\mathrm{P} 133$.

Florets, P 140.

Flower, P I33, 180, A 85; apetalous, P 136; clusters, P 155; complete, P 136; diclinous, P 137; double, P I42; imperfect, $P$ I 37; incomplete, P I36; lateral, P I 36 ; naked, P 136; perfect, P 137; pistillate, P I37; regular, $P$ I38; staminate, P I37; sterile, P 137 ; solitary, P I 56; terminal, $P$ I 56.

Fly, horse, A 81; house, A 92, 93 .

Foliage, P 16.

Follicle, $\mathrm{P} \mathrm{I}^{6} 5$.

Food, H 88; defined, H 114 ; of birds, A 177 .

Food stuffs, H 91 .

Food tube, of bird, A I 63 ; of fish, A I I6; of insect, $A$ 76; of man, $\mathrm{H} 97$; of mussel, A 102.

Foot, म 29 .

Foraminifera, A $15,18$.

Forestry, P 68.

Formaldehyde, $\mathrm{H}_{16} 6_{3}$.

Formalin, $\mathbf{E} 93$.

Framework of plant, $P$ I5.

Frog, A 128.

Frond, $P$ 176, I78, I 81 .

Fruit, $P 163$, $\mathrm{F} 95$.

Fucus, $P$ I 86. 
Funaria, P 201.

Function, A I, H 9.

Fungi, $P$ I 87.

Fungus, $P$ 107, 108, 184, 187, 195.

Gametophyte, P 179.

Gamopetalous, P I 34 .

Gamosepalous, P I 34 .

Ganglion, A 45, H 120 .

Ganglionic system, H 127 .

Garbage, H 163 .

Gasteropod, A 108.

Gastric juice, $\mathrm{H} \mathrm{IO}_{3}$.

Gastrula, A 7 .

General sensation, H $144, \mathbf{1 4 5}$.

Generation of plants, $P$ 16.

Genus, A 8.

Geographical barriers, A 148 .

Geotropism, P 44, 47 .

Germination, $\mathbf{P}$ 22, 23, 27 .

Gila monster, A 147 .

Gills, of mussel, A 100; of tish, A I 5 .

Glands, lymphatic, н 65 .

Gland tissue, $\mathbf{H}$ I 3 .

Glomerule, P I6o.

Gnawing mammals, A 203.

Gopher, pouched, A 204.

Gorilla, A 221.

Grafting, P 125 .

Grain, H 95, I 12 .

Grantia, A I8.

Grape sugar, x, H 88, 92 .

Grasshopper, A 70 .

Grit cells, P 67 .

Guard cells, P 88 .

Gullet, H 74, 94, IOI.

Gymnastics, H 47 .

Gymnosperm, P 26, 170.

Gypsy moth, A 95.

\section{Habit, H 13 I.}

Hairs, Р 87, н 19.

Hands, H.4; defined, A 220.

Headaches, H 132, 133 .

Heart, human, H $5 \mathrm{I}, 52$; insect, A 77 ; sound of, $\mathrm{H} 60$.

Heating, $\mathbf{H} 84$.

Hemiptera, A 82 .

Hemoglobin, H 59, 8r.

Herb, $P$ I 7 .

Heredity, A I 47, I 53, H 4 .

Hessian fly, A 95 .

Hill, Dr. L. H., quoted, H 1 fo.

Hilum, P $21,26$.

Hip, H 4, P 168 .
Hollyhock, P I+7.

Homology, P I35.

Horned toad, A I 40.

Host, P 107.

House fly, A 92, 93.

Houstonia, P 107.

Human species, H I, A 220.

Hydra, A 22.

Hydranth, A 29.

Hydrochloric acid, $\mathrm{H}_{\mathrm{IO}}$.

Hydroid, A 28, 29, 30 .

Hygiene, н 49, 66, 80, 107, I 29, 14 r.

Hymenoptera, A 82.

Hyphæ, P 107, 188.

Hypocotyl, P 22.

Hypogeal, P 23.

Hypostome, A 23.

Ichneumon fly, A 89 .

Imago, A 8I.

Immunity, H I58, I60.

Indehiscent, $\mathrm{P}$ I64.

Indian, H 2.

Indusium, $\mathbf{P}$ I77.

Inflammation, H $68,86$.

Inflorescence, P I 55, 160 .

Infusoria, A 16 .

Inhibit, $\mathbf{H} 68$.

Inorganic, A $\mathbf{I}$.

Insecticides, A 95 .

Insects, A 73, 75; biting, A 82 ; classi fied, A 82; sucking, A 82 .

Inspiration, स 77 .

Instinct, A 80, 121 ; H 49 .

Intercostal, H 77 .

Internode, P 52.

Intestinal gland, $\mathrm{H} \mathrm{IO}_{4}$.

Intestine, $\mathrm{H}$ 98, 103 , 106.

Involucre, P $34,141,163,164$.

Iodine test for starch, $\mathbf{x}$.

Iris, $\mathrm{H} 143,15 \mathrm{I}$.

Iron, vii, P 39 .

Iron tonics, $\mathbf{H} 90$.

Isoëtes, P 203.

Ivory, H 98 .

Jacana, Mexican, A I 78 .

Jay, blue, A I $8 \mathbf{r}$.

Jelly fish, A 29,30 .

Joints, H 29, 35, 36 .

Kangaroo, A 198.

Key fruit, P 164.

Kidneys, of fish, A 117 ; of insects, A 76 ; of man, H 26,27 ; of nuussel. A IO2; of worm, A 45 . 
Kinetoscope, H I5J.

Labial palpi, ^ 68,74 , ror.

Labium, A 68, 74.

Laboratory, $\mathrm{P} 3$.

Labrum, A 68, 74.

Labyrinth, II 157 .

Lacteal, if 64, 65, 104, 105 .

Lady bug, A 9 I.

Lamellibranch, A 107.

Landscape, $\boldsymbol{P} \mathbf{I}_{3}$.

Lark, meadow, A I82; sky, A I79.

Larkspur, P 148, 149.

Larva, A 81 .

Larynx, H 72.

Lasso cell, $\mathbf{\wedge} 34$.

Lateral spinal curvature, $\mathbf{H} 37$.

Latex tubes, P 67.

Leaf, apex of, $P$ 80; base of, $P$ 80; function of, $P$ 92; margin of, $P 80$; structure, $P 86$.

Leaf scar, $\mathbf{P}$ go.

Leaves, arrangement of, $P$ 82; shapes of, $P 78,85$.

Leg, of bird, A I52; of horse, A 210; of insect, A 74; of man, $\mathrm{H} 33$.

Legume, P $165,1 \mathrm{H} 95$.

Legume family, $\boldsymbol{y} 35,169$.

Lemur, A 220.

Lenticel, P 89 .

Lepidoptera, A 82, 87 .

Lichens, P 195.

Ligneous, $\mathbf{P} 17$.

Lime water, $\mathbf{x x}, \mathbf{H} 70$.

Liver, $\mathrm{H}$ 105.

Liverworts, P 196.

Lobes of leaf, $P 75$.

Lobule of lung, it 75 .

Locule, $P{ }_{13} 6,163,166$.

Loculicidal dehiscence, P 166.

Louse, $A$ 92, 93.

Lumber, $\mathrm{P} 68$.

Lungs, of bird, A 165 ; of man, स 76 .

Lycopodium, $\mathrm{P}_{204}$.

Lymph, H $52,62,63$.

Lymphatics, H 62, $6_{3}$.

Lymph spaces, H 63 .

Macrospore, P 203, 204.

Madreporite, A 35.

Malaria, II 160 .

Malay, H I.

Mammal, A 184, н III; classified, A I93; defined, A 189 .

Manatee, A 200.

Mandibles, A 68, 74 .
Mantis, praying, A 3 .

Mantle, A 99.

Marchantia, P 196.

Maxilla, A 68, 74.

Maxillary palpi, A 68, 74 .

May beetle, A 90, 91 .

May fly, A 83 .

Measuring worm, A $8 \mathrm{r}, 84$.

Medulla, H 122, 123.

Medullary ray, 84 .

Medusa, A 3 I.

Mesoglea, ^ 26.

Mesophyll, P 86.

Metamorphosis of insect, A 80, 8I 82.

Metazoan, A I.

Micropyle, P 21, 26.

Microscope, P $21,26$.

Microspore, $\mathrm{P} 2 \mathrm{O}_{3}$.

Midrib, $\mathbf{P} 77$.

Migration of birds, A I7 I, 173 .

Milk, H 91, 95, 96, II2.

Mimicry, A 146.

Mind and health, $\mathbf{H} \mathbf{2 9}$.

Minerals, xiv, H 90, $91,93,95$.

Mint family, P 139.

Mistletoe, P 109.

Moccasin, A 145.

Mold, P 188.

Mole, A 201.

Mollusk, A 9, 97, 125.

Molting, A 69, 174 .

Mongolian, H $\mathrm{I}$.

Monkey, A 220.

Monocotyledons, P 20, 25,63 .

Moncecious, P 138, 150, 170 .

Morphine, H 105 .

Morula, A 7 .

Mosquito, A 92, 93, 96, н I60, 16 I.

Mosses, P 199.

Moss, Spanish, P 1 ro.

Moth, A 83.

Mother-of-pearl, A 99.

Motor, cell, H I20; fiber, H I20.

Mullein, $\mathrm{P} 87$.

Municipal sanitation, H 162,163 .

Muscadine, P 36.

Muscles, H 39; arrangement of, H $4 \mathrm{I}$; control of, II 39,44 ; function of, H 39, 43; growth, $\mathbf{H} 42$; kinds of, н 39 ; structure of, स 39 .

Muscles and health, $\mathbf{H} 45$.

Muscular sense, H I42, 146 .

Muscular tissue, H Ir.

Mushroom, P 107, 194.

Mussel, A 96, 103. 
Mycelium, P 107, 108, I88.

Mychorrhiza, p 108.

Nails, 표 I9:

Narcotic, H I37, I48.

Nasal tone, H I44.

Natural selection, P 8, A I48.

Nautilus, chambered, A 107.

Nectar, A 8, P I48.

Nephridium, A 45.

Nerve, H II9; spinal, H 127 ; cranial, H 127.

Nerve cell, 프 II9; fatigue of, स I 30 .

Nerve center, H II7, 120.

Nerve fiber, H I I g.

Nerve tissue, 표 II.

Nerves, vaso-motor, H 23 .

Nervous children, H 135 .

Nervous system, of bee, A 78 ; of man, H II7; of mussel, A IO2.

Nest building, a I66, I82.

Neuron, H 1 I 8 .

Neuroptera, A 82.

Neutral substances, ix.

Nitella, P 187.

Nitric acid test for proteid, xi.

Nitrogen, viii, P 39,40 , н 8 I.

Nitrogenous compounds, xi.

Nodes, P $20,52$.

Nodules, $P$ 39, 40.

Nose bleed, H 52 .

Nostoc, P I 84 .

Nostril, of bird, A I $_{5}$; of fish, A II 2.

Notebooks, P 3 .

Nucleolus, A 6, ㅍ 6.

Nucleoplasm, H 7 .

Nucleus, P I44, I85, A 6, I I, I4, H 6,18 .

Nutrients, स 9 I.

Nuts, P I64, H 95 .

Octopus, A 106.

Oil gland, H 20.

Oils, test for, xi.

Okapi, A 214.

Oleander, $\mathbf{p} 86$.

Omnivorous, A 47, H III.

One-celled animals, A 7 .

Oögonia, P I 86.

Opossum, A I97; H 4 .

Opsonin, H 162 .

Optic nerve, H I5I, I52.

Oral surface, A 35 .

Orang, A 227.

Orbit, H 149 .

Orchid, P 35 , I 10.
Order, A 9.

Organ, A $\mathbf{1}, \mathrm{H} 9$.

Organic, xiv, A I.

Organism, A r.

Orthoptera, A 82.

Oscillatoria, P 184 .

Osculum, A r8.

Osler, Dr. William, quoted, ㅍ $\mathbf{3} 33$.

Osmosis, P 42, 48 .

Outdoor life, ㅍ 5, 22.

Ovary, P I35, I44, I63, I 70, A 25 , 37, I 7 .

Overgrowth, P I2.

Oviduct, A 46.

Ovule, P I44, I 86 .

Oxidation, xii, A $3,4,5$, H I4, 90 , $91,120$.

Oxygen, viii, A 4, 5, В 4, 76, 81, 140

Oyster, A I04.

Palisade cells, P 86.

Palmate, P 74.

Pancreas, H 104.

Panicle, P 158.

Papilla, ㅍ I7.

Pappus, P I4I.

Paramecium, A I3.

Parasites, P 107, A 49, 93.

Parenchyma, P 60, 86.

Partridge, A 178.

Pearls, A 105.

Peccary, A 217.

Pedicel, P I62.

Peduncle, $\mathbf{P} 62$.

Peltate, $\mathrm{P} 77$.

Pelvis, H 33 .

Pepsin, H I03.

Perch, A rog, Iro, 123.

Perennial, P I7.

Pericarp, P I64, I65, I69.

Peristalsis, H 102, 106, 127.

Peritoneum, ㅍ 106.

Pests, insect, A 93.

Petals, P I34.

Petiole, P 76

Phagocyte, H I6I.

Pharynx, H 73,85 , Iox.

Pheasant, A 174 .

Phenogam, P I 77, 180 .

Phosphorus, vi.

Photo-synthesis, P 94, ror.

Phyllotaxy, P 84 .

Physics, xiv.

Physiology, H 9.

Pigment, H 18.

Pine cone, $\mathbf{P} 27,170$. 
Pinna, $\mathrm{P}$ 18r.

Pinnate, $P$ 74.

Pinnatifid, P 76.

Pistil, P 135.

Plantain, P I 57.

Plant societies, $\mathbf{P} 9$.

Plants, unlikeness of, P 9 .

Plastron, A $14 \mathrm{I}$.

Pleura, н 76 .

Plexus, H 128.

Plumule, P 20, 23, 25.

Plur-annual, $\mathbf{P}$ I 8.

Pod, P I 64 .

Poison, $\mathbf{H} 137$.

Pollen, P I 35, 144, I80, A 85.

Pollen basket, A 88 .

Pollination, P 144, 145; artificial, P 153.

Polyp, A 9, 22, 125.

Polypetalous, P 134 .

Polysepalous, P 134.

Polytrichum, P 199.

Pome, P 169.

Portal vein, H 105.

Portuguese man-o'-war, A 28.

Posterior curvature of spine, $\mathrm{H} 37$.

Potato, H 92, 95, I12; bug, A 90.

Practical questions, H $50,69,87$, I I 2, 136.

Primates, A 220.

Primitive man, H 3 .

Primrose, P 149.

Proboscis, of butterfly, ^ 83,87 ; elephant, A 207.

Prolegs, A 84,87 .

Propagation by buds, P 121 .

Prop-roots, P 36.

Protection of birds, A $17 \mathrm{I}$.

Protective resemblance, A $34,146$.

Proteid, xi, н 88, 91, 92, 94, 95, 96, 104.

Proterandrous, $P$ 146.

Proterogynous, P 146.

Prothallus, P I 78, 202.

Protoplasm, xiv, P 42, 94, 97, 185 , A $6,11, \mathrm{H} 5,6,59,106,113$.

Protozoa, A 7, 9, 11, 125.

Pruning, P 105.

Pseud-annual, P 17.

Pseudoneuroptera, A 82.

Pseudopod, A II.

Pteridophytes, P I8I, 20I, 203.

Ptyalin, H 100.

Puffball, P I94.

Pulse, H 55 .

Pure food law, y 93.

Pylorus, H 103.

Pyxis, P 166.
Quarantine, H 163.

Quarter-sawed, 870.

Quill, A 156.

Rabbit, A 205, 223.

Radial symmetry, A 34, 125 .

Ration, daily, H 94, 96.

Rattlesnake, A 145 .

Reaction, H I5I, 152.

Receptacle, P 134, 163 .

Rectum, A I 34, H 97.

Reflex action, H I2I.

Regeneration of lost parts, A 37 .

Rennin, 표으.

Reproduction, A I 2, I 5, 20, 25, 37, $46,120$.

Reptiles, A 139.

Respiration, cellular, H $8 \mathbf{I}$; human, H 70; hygiene of, $\mathrm{H} \mathrm{So;} \mathrm{in} \mathrm{plants,}$ P 97,103 .

Resting spore, P I84, 185, 189, I9I, 192.

Retína, H $151,152$.

Rhizome, P 52, 202.

Rhizopoda, A 16.

Road runner, A 169.

Robin, A 18 .

Root cap, $\mathbf{P} 44$.

Root climber, P 129.

Root hairs, P 4I, 42, 46 .

Rootlet, P 4I.

Root pressure, $\mathrm{P}$ 99, 104.

Roots, and air, P 4I ; forms of, $P$ 32; function, P 38 ; structure, P 38,43 ; systems, P 32 .

Rotifer, A 49.

Round worm, A 49.

Ruminant, A 213.

Rust, P 192.

Salamander, A I $34,138,139$.

Saliva, н 96, 100, 112.

Salt, $x$, ㅍ 93 .

Samara, P 164 .

Sand, xiii.

Sandworm, A 49.

Sanitary map, H 158 .

San José scale, A 95 .

Sap, $\mathrm{P} 67$.

Saprophyte, P 107, 108.

Scab in sheep, A 95 .

Scales, of bird, A I6r; fish, A r1o; moth, A 89 .

Scallops, A 104.

Scape, P I61.

Scarab, A 9o, 9 I. 
School and health, $\mathrm{H}$ I 35 .

Sclerotic, H 150.

Scouring rush, $\mathrm{P} 203$.

Scramblers, P I 29.

Sea anemone, A 33 .

Sea fan, A 32.

Sea horse, A 124.

Sea urchin, A 38 .

Seed, $\mathrm{P} 20, \mathrm{I} 63$, I80; coat, P 21 .

Selaginella, P 204.

Selection, natural, $\mathrm{P} 8$; artificial, p 8.

Sense, muscular, H 143 ; thermic, H 142 .

Senses of insects, A 76 .

Sensory, cell, H I20; fiber, H 120 , I21.

Sepal, P $133,169$.

Septicidal capsule, P 166.

Serum, н 6 г.

Sessile, P 77.

Setæ, A 43,48 .

Sexual selection, A I74.

Shark, A I2I.

Shelf fungus, $\mathrm{P}$ r 94 .

Shoes, $\mathrm{H} 48$.

Shoulder, ㅍ 32 .

Shrub, P 19.

Sick headache, $\mathbf{H} \times 33$.

Sieve tubes, P 66.

Silicle, P 167.

Silique, P 167.

Silkworm, A 84, 86, 95 .

Silver scale, A 83 .

Siphon, A I0I.

Siphonoptera, A 82 .

Skeleton, of bird, A 152 ; cat, A I88; frog, A ${ }^{3}{ }^{\mathrm{I}}$; of fish, A II 3 ; man, स 28 ; chart of, A 218.

Skin, $\mathrm{H}$ I6.

Skull, H 63; mammalian, A I94.

Sleep, is r 3 o.

Slipper animalcule, A I 3 .

Sloth, A 199.

Slug, A 105.

Smell, н 147 .

Snail, A ro5.

Societies, P 9 .

- Soil, P 40, 47, A 48.

Soredia, P 196.

Sori, P $177,192$.

Souring of milk, H 158 .

Spadix, P 140.

Sparrow, A 182 ; English, A 170.

Spathe, P $138,140$.

Specialization, A $20,27,66,210$, II 8.
Species, A 8.

Spermary, A 25, 27.

Spermatophytes, P 180.

Spicule, A 18.

Spider, A 94 .

Spike, P 157.

Spinal cord, н I 20, I 2 I.

Spinal deformities, н 37 .

Spine, н $3 \mathbf{r}$.

Spiracle, A 77, 87 .

Spirogyra, P 184 .

Sponges, A 17, I 25; glass, A 19; horny, A $19 ;$ limy, A 19 .

Spontaneous combustion, xiii.

Sporangium, P $177,186,188,201$, 203, 204.

Spore, P 176, I 78 , I 81, I 84 , म 159 .

Sporophyll, P I80, 201 .

Sporophyte, P 177.

Sports, A $148,224$.

Sprain, H 38 .

Squash bug, A 93, 95 .

Squid, A 106.

Stamen, P 135 .

Starch, x, P 95, гог, н 88, 91 .

Starvation, $\mathrm{H}_{1} 8$.

Stem, P 49; endogenous, P 59; exogenous, $\mathrm{P} 6 \mathrm{I}$; kinds of, $\mathrm{P} 49$.

Sterilizing wounds, н 163 .

Stickleback, A II 9 .

Stigma, P I 35, I44, 145 .

Stimulant defined, н 137 .

Stipule, P 76, 84 .

Stock, P I25.

Stomate, $\mathbf{P} 87$.

Stone age, H 2.

Stone fruit, P 168.

Storage of food, P 99.

Street cleaning, ㅍ ${ }^{6} 63$

Struggle to live, P 4,6, A $_{147}$, н 4 .

Study, comparative, A $82,149,223$.

Style, P $135,{ }_{3} 63$.

Sugar, H 9I, 100.

Sulphur, vii.

Summer-spore, $p$ ig $x$.

Sun energy, P 95, А 2, H 9 I.

Sunlight, A 2 , म 18.

Survival of fittest, P 7, A 147 , H 4 , I4I.

Sutures, 표 35 .

Swarm-spores, P I 86.

Sweat gland, $\mathrm{H} 20$.

Symbiosis, P 196.

Sympathetic system, H I 27, 129.

Syngenesious, P $14 \mathrm{x}$.

Synovial fluid, н 36 . 
Tadpole, A 126, 134 .

Tanner, Dr., H 138 .

Tapeworm, A 49.

Tarantula, A 94 .

Taste, H IIO, $143,146$.

Tear gland, H 149 .

Teeth, म $88,98,99$, III; of frog, A 130.

Teleutospores, P $\mathbf{I 9 2 .}$

Temperature, H 21 ; nerves of, H 142 , 146.

Tendon, $\mathbf{H} 4 \mathrm{I}$.

Tendril, $P$ ror.

Terrapin, A 143, 144.

Thallophyte, P I8I, 184 .

Thallus, P 184,197 .

Thompson, Sir Henry, on smoking, H 87 .

Thoracic duct, E 64,65, 105 .

Thorns, $\mathbf{P}$ Ior.

Thought questions, II 20, 27, 79, 107, Iog, I I6.

Thyrse, P 160 .

Thyroid gland, $\mathbf{B} 97$.

Tillandsia, $P$ i 10.

Timber, decay of, P 195.

Tissue, H 7, 10, P 60, 62 .

Toad, A 137 .

Toadstool, P 194 .

Tobacco, and heart, $\mathrm{E} 67$; and lungs, H 86; and taste, H 148; when enjoyable, $\mathbf{I} 87$.

Tortoise, A 140, 143, 144 .

Torus, P 134, 169 .

Touch, в I45, A 119.

Toxin, ㅍ 160, 161.

Toyi Niku, Madame, quoted, H 14 I.

Trachea, I 74 .

Tracheid, P 65.

Transpiration, $P$ 98, ro3.

Trap-door spider, $A 94$.

Tube feet, A 35 .

Tuberculosis, स 5,160 .

Tumble bug, A 90, 91 .

Turtle, A 140, 143,144 .

Twiners, P 129, 131.

Typhoid fever, E ${ }_{5} 5$.

Umbel, P 159.

Umbo, $A 98$.

Undergrowth, P 12.

Ungulate, A 2 I 2.

Urea, $\mathbf{I}$ 94.

Uric acid, H II4.

Urinary tubule, $\mathbf{\text { H }} 27$.
Vacuole, A I I, I2, I4.

Valve, P I 64, H $5 \mathrm{I}, 53,57$.

Vampire, A 203.

Variation, A 147, P 2.

Variety, A 8.

Vaso-motor nerves, स $23,68$.

Vaucheria, P 186.

Vegetables, H 95, I 12.

Venomous snakes, $A x_{43}$.

Vent, A 42.

Ventilation, ㅍ $71,82,83$.

Ventral, A 43.

Ventricle, ㅍ 53 .

Vermes, A 9, 125 .

Vermiform appendix, $\mathbf{B}$ 4, ro6.

Vertebra, ㅍ 71, 82, 83.

Vertebrates, A 9, 125 .

Vertebrate skeletons, A 2 I8.

Verticellate, P 84 .

Vestigial organs, В 106.

Villi, H 104 .

Vinegar, स 94.

Viscera, I I 27 ; of bird, A r63.

Vitreous humor, II 152 .

Voluntary act, H I22, 124 .

Warning sound, A 147 .

Wasps, digging, A 89 .

Water-pore, $\mathbf{P} 88$.

Waterworks, $\mathrm{H} 16_{3}$.

Weevil, A 90, 91, 96.

Whale, A 208.

Wheat rust, P 192.

White corpuscles, $\mathbf{H} 59$; origin of, H $6 \mathrm{I}$; work of, $1 \mathrm{H} 60,161, \mathrm{I} 62$.

White weed, or ox-eye daisy, P 155.

Whorled, $P 84$.

Willow mildew, $P$ rgo.

Wind travelers, $P$ I 73.

Wings, of grasshopper, A 67; of bird, A $153,158$.

Woodpecker, A I 80 .

Woody fiber, $\mathbf{P}$ I 7 .

Worms, A 42.

Wounds of plants, $P 56$.

Written exercises, म I 5,50, II 6 .

Yeast plants, $P$ I9o, H I 58 .

Yellow fever, Н 160 .

Yellow spot, H $\mathbf{5}$ I.

Zoology defined, A I.

Zoophytes, A 33 .

Zygnema, P I 85 .

Zygospore, P I 85, I89, I81, I89. 


\section{LESSONS IN HYGIENIC PHYSIOLOGY}

By W. M. Coleman. $x+271$ pages. 198 illustrations ( 16 colored, 13 full-page plates). 60 cents net.

In Lessons in Hygienic Physiology the study of physiology is simplified without weakening the presentation of its three essential principles - the biological principle of environment, the chemical principle of oxidation, and the physical principle of energy. The subject is approached throughout from the standpoint of health, because this is the most useful as well as the most interesting point of view. The question of temperance is treated fully, but at the same time in a conservative manner. The book is fully illustrated, one hundred and ninetyeight figures being furnished, sixteen of which are colored. The Lessons is suited to the needs of teachers who may find the Elements somewhat too advanced for their classes.

\section{ELEMENTS OF PHYSIOLOGY}

By W. M. Coleman. xii +364 pages. A very full course in Physiology and Hygiene. Profusely illustrated in black and white and in colors. 90 cents net.

This book has an exceptionally large number of illustrations - two hundred and forty-eight, of which eight are full-page colored plates. The need for a compound microscope is largely obviated by sixty microscopic views of cells and tissues. The Elements is provided with a Colored Manikin arranged to show every important organ in its natural position with reference to the organs before it, behind it, and around it. Since every pupil has the manikin while studying each lesson, it is really more serviceable than the manikins usually fornd in schools. This book contains twenty-five Thought Lessons of about ten questions each, logically developing different lines of thought; also three hundred questions in Applied Physiology.

\section{THE MACMILLAN COMPANY}

Sixty-four and Sixty-six Fifth Avenue, New York 


\section{BOTANY}

An Elementary Text for Schools. By L. H. BAILEY, Director of the Col. lege of Agriculture, and Professor of Rural Economy in Cornell University. Revised and enlarged. Illustrated. 12mo. Half leather. xiv +355 pages. \$1.10 net.

The subjects treated are four in number: the nature of the plant itself, the relation of the plant to its surroundings, the minute structures of plants, and the determination of the kinds of plants. Each of these subjects is practically distinct, so that the teacher may begin where he will.

The five hundred illustrations in the book are an important as well as an attractive feature. They are not pictures merely - they are illustrations of the subject-matter; many of them are reproductions of photographs.

A flora containing descriptions of more than six hundred common wild and cultivated plants, with keys to the natural orders, completes the book.

\section{LESSONS WITH PLANTS}

Suggestions for Seeing and Interpreting Some of the Common Forms of Vegetation. By Professoo L. II. BAlL.ey. Illustrated. $12 \mathrm{mo.}$ Half leather. xxxi +491 pages. \$1.ro net.

The book is based upon the idea that the proper way to begin the study of plants is by means of plants, instead of formal ideas or definitions. Instead of a definition as a model telling the pupil what he is to see, the plant shows him what there is to be seen, and the definition follows. In this way the pupil soon begins to generalize, and the conclusion reached is the true definition.

\section{THE MACMILLAN COMPANY}

Sixty-four and Sixty-8ix Fifth Avenue, New York 









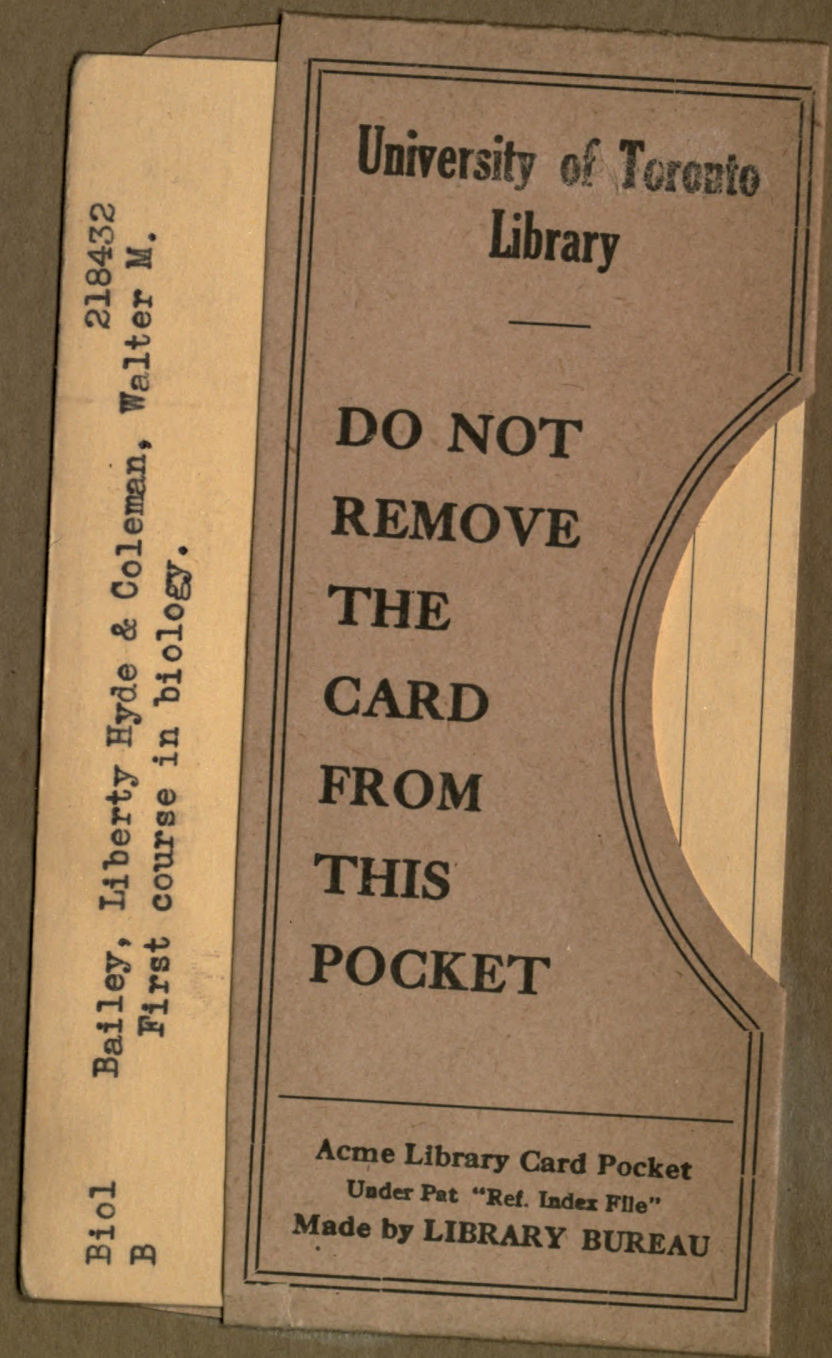




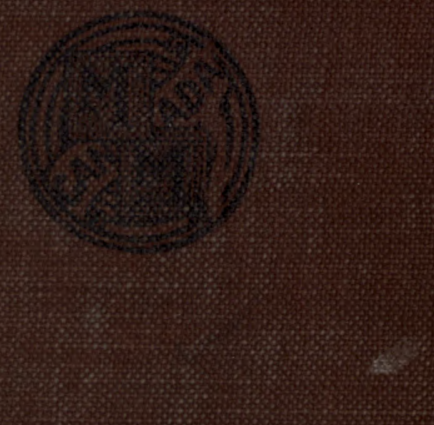

